\title{
EL VERDE URBANO DE LAS CIUDADES DE SALAMANCA, VALLADOLID Y ZAMORA: DELIMITACIÓN, LOCALIZACIÓN Y UTILIZACIÓN
}

Memoria presentada por el Licenciado en Geografía Alejandro Gómez Gonçalves para optar al grado de Doctor en Geografía por la Universidad de Salamanca. 



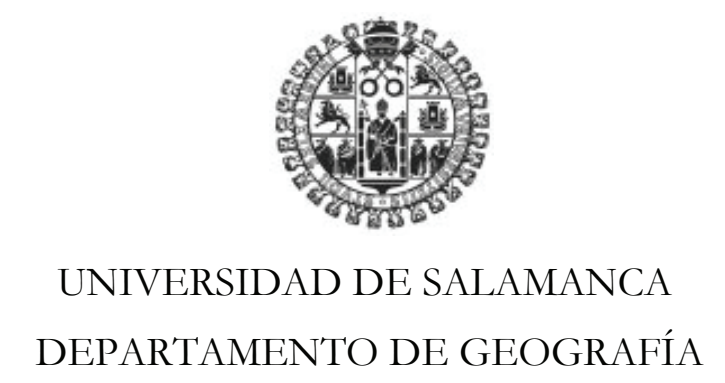

D. JOSÉ LUIS SÁNCHEZ HERNÁNDEZ, Profesor Titular de Geografía Humana de la Universidad de Salamanca, y D. ANTONIO CEBALLOS BARBANCHO, Profesor Titular de Geografía Física de la Universidad de Salamanca, autorizan la presentación de la memoria titulada “EL VERDE URBANO DE LAS CIUDADES DE SALAMANCA, VALLADOLID Y ZAMORA: DELIMITACIÓN, LOCALIZACIÓN Y UTILIZACIÓN", realizada bajo su dirección por el Licenciado en Geografía D. ALEJANDRO GÓMEZ GONÇALVES para optar al grado de Doctor en Geografía.

En Salamanca a 7 de mayo de 2013

José Luis Sánchez Hernández y Antonio Ceballos Barbancho 



\section{AGRADECIMIENTOS}

Quisiera agradecer la colaboración de aquellas personas que han contribuido a que este trabajo vea la luz. Sin ellos hubiera sido muy difícil superar los numerosos obstáculos con los que me he encontrado a lo largo de este periodo de investigación.

En el plano académico me gustaría expresar un profundo agradecimiento a mis directores, D. José Luis Sánchez Hernández y D. Antonio Ceballos Barbancho, que desde un primer momento me dieron su apoyo y su confianza para realizar un estudio novedoso, con la incertidumbre que ello conlleva. También me gustaría reconocer el trato afectuoso con el que me recibió Dña. Paula Santana al llegar a la Universidad de Coimbra y que ha continuado durante el período en el que hemos seguido colaborando activamente. No puedo olvidarme de Dña. Cláudia Costa, a quien quiero dar las gracias por todo lo que me ha ayudado en estos últimos años.

Tengo que reconocer el exquisito trato recibido por parte del Departamento de Geografía de la Universidad de Salamanca, al que siempre estaré agradecido por mi formación como geógrafo y como persona. Me gustaría mencionar especialmente las atenciones recibidas tanto por D. José Manuel Llorente Pinto como por D. Julio Villar Castro, ya que siempre se mostraron dispuestos a escuchar las dudas y preguntas que les plantee acerca de mi trabajo e, incluso, me permitieron acudir a alguna de sus clases. También quería dar las gracias a D. Basilio Calderón Calderón, del Departamento de Geografía de la Universidad de Valladolid, por la paciencia que demostró cada vez que hablé con él sobre los parques y la evolución de las ciudades de Valladolid y de Zamora.

No querría olvidarme del apoyo recibido por mis compañeros de despacho, especialmente por parte de Valeriano Rodero González, que fue quien diseñó la portada de la Tesis, y de Rubén Fernández Álvarez, puesto que durante todo este tiempo me han ayudado a superar los problemas diarios.

Me gustaría agradecer tanto a D. Sicilio Barrios Frechilla como a D. Fernando Lombardía Morcillo, del Servicio de Planeamiento del Ayuntamiento de Salamanca, la gran ayuda que me prestaron a la hora de acceder a la fotografía aérea y a la ortofotografía de los diferentes Planes Generales de Ordenación Urbana.

También quiero transmitir mis más sinceros agradecimientos a D. J. Francisco Fernández Martín, Jefe de la Sección de Parques y Jardines del Ayuntamiento de Salamanca, por haber contribuido a mejorar este trabajo con sus explicaciones acerca de la gestión de los espacios verdes de Salamanca, y a D. Ángel María Asensio Paunero y a D. Nuño Arroyo Martínez, del Servicio de Parques y Jardines de Valladolid, por la amabilidad con la que me atendieron y por toda la información que me facilitaron.

Querría hacer una mención especial al trato y a la comprensión recibidos por parte de los habitantes de Salamanca, Valladolid y Zamora, porque en la mayor parte de los casos respondieron amablemente a las preguntas que les fui planteando, permitiendo así la realización de una Tesis Doctoral en la que la opinión de las personas es un componente muy destacado. No me puedo olvidar de la gran ayuda prestada por Diego Jiménez García, que contribuyó a que la labor de encuestado se hiciera mucho más leve.

$\mathrm{Y}$ finalmente, quería darles las gracias a mi familia y amigos. A mi hermano Carlos, a mis padres Alejandro y María Teresa, a Eloísa, a Álvaro, a Roy y a Leticia, ya que ellos son los que me han animado y apoyado en los momentos más difíciles. Gracias otra vez por haber estado a mi lado durante todo este tiempo. 



\section{ÍNDICE TESIS DOCTORAL}

1. ¿Por qué un estudio del verde urbano desde la Geografía? ....................................... 5

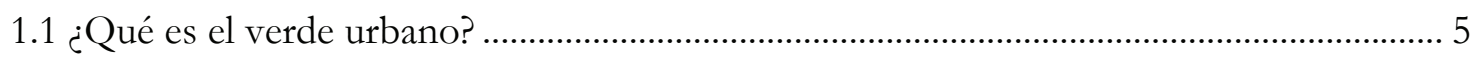

1.2 ¿Por qué se realiza un análisis del verde urbano desde la Geografía? ................................. 8

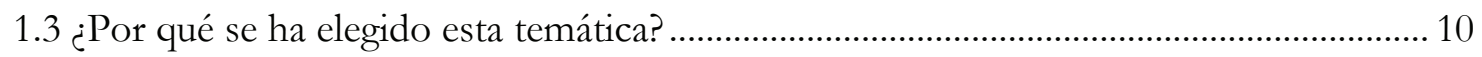

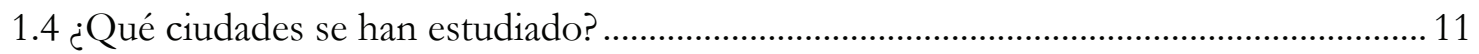

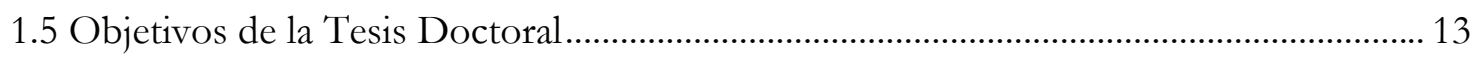

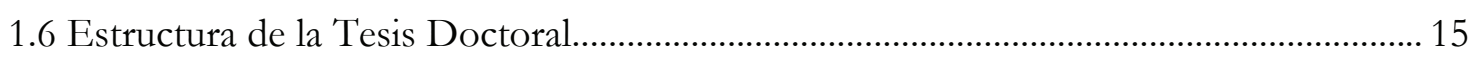

2. Aspectos metodológicos del estudio del verde urbano en Salamanca, Valladolid y

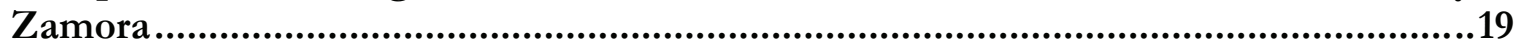

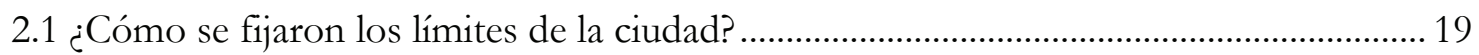

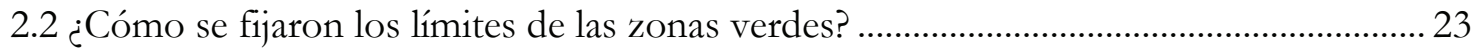

2.2.1 Los parques y jardines gestionados por los ayuntamientos ....................................... 24

2.2.2 Superficies fijas para delimitar el verde urbano....................................................... 27

2.2.3 Superficie del verde urbano dependiente del tamaño de la ciudad ............................ 28

2.3 ¿Cómo se definió el verde urbano y el verde urbano disponible? ..................................... 30

2.4 ¿Cómo se identificó el verde urbano en las ciudades objeto de estudio?................................ 30

2.5 ¿Cómo se analizó el origen y la evolución del verde urbano? ................................................ 39

2.6 ¿Cómo se estudió verde urbano disponible desde una perspectiva social?.............................. 40

2.6.1 Características y equipamientos........................................................................................ 41

2.6.2 Valoración del uso del verde urbano por los habitantes de la ciudad........................... 44

2.6.3 Análisis de las visitas de los usuarios del verde urbano disponible................................... 50

2.6.4 Estimación de la calidad del verde urbano disponible.......................................................... 51

2.6.5 Cálculo del índice de atracción del verde urbano disponible .............................................. 51

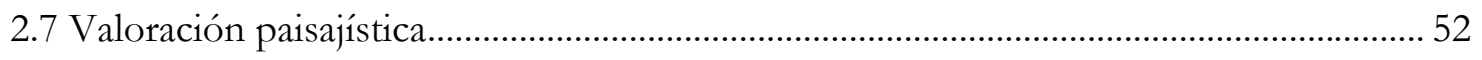

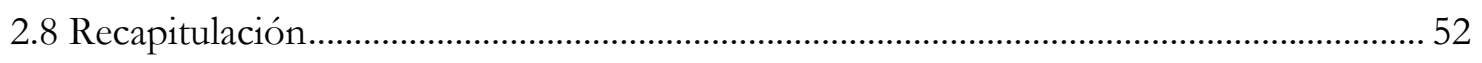

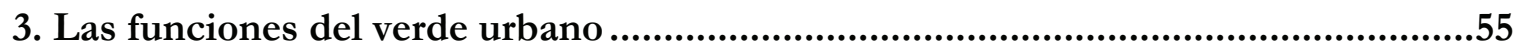

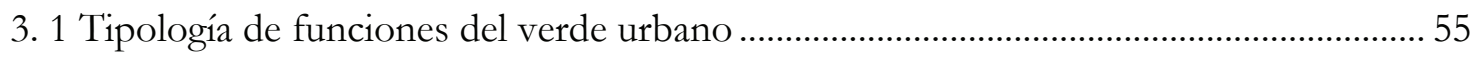

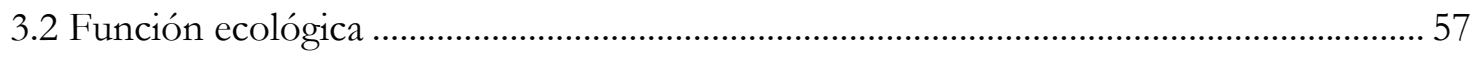

3.2.1 Variaciones en la composición atmosférica................................................................... 57

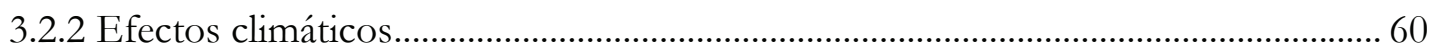

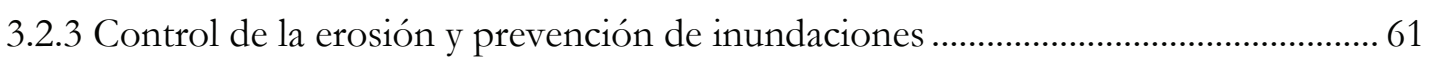

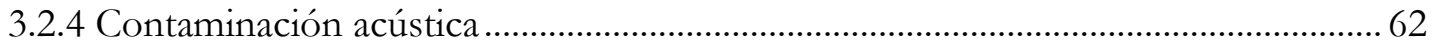

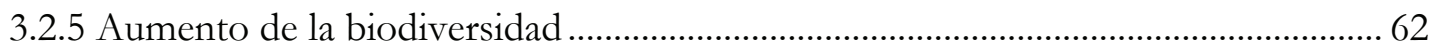

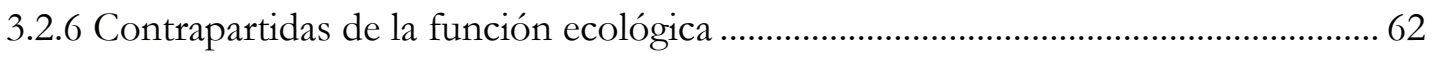

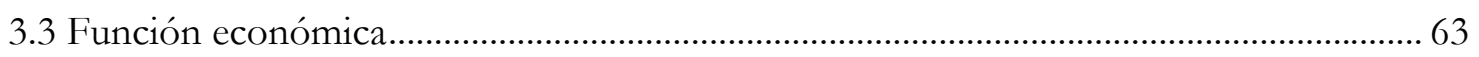

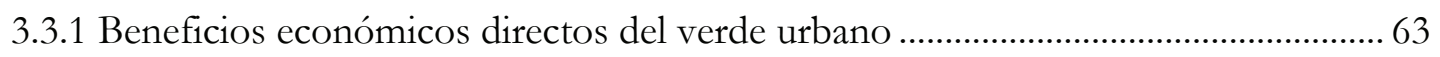


3.3.2 Beneficios económicos indirectos del verde urbano.

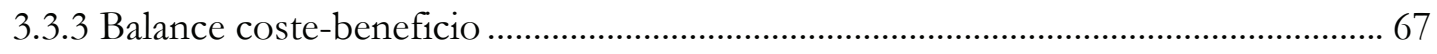

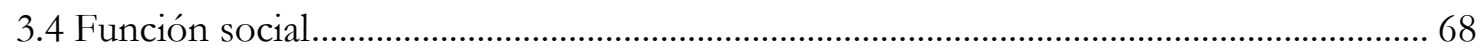

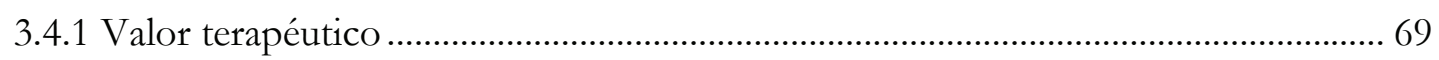

3.4.2 Beneficios en el desarrollo social y personal .......................................................... 71

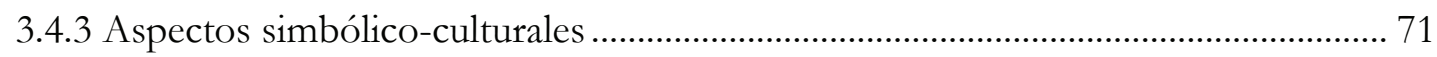

3.4.4 Miedo, discriminación y actividades ilícitas en los espacios verdes .......................... 71

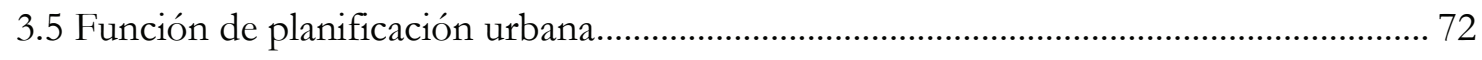

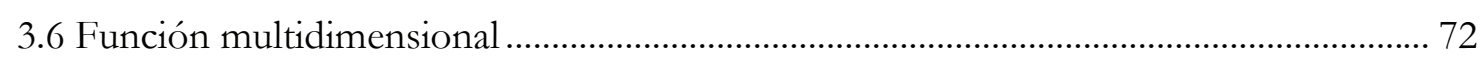

3.6.1 Consecuencias estético-paisajísticas........................................................................ 73

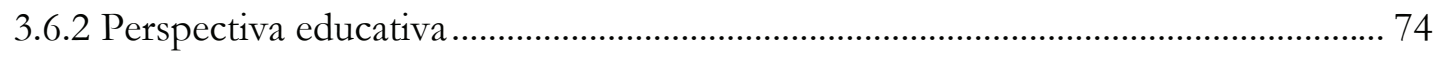

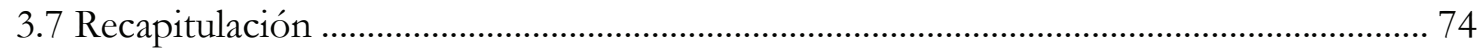

4. Evolución histórica de las ciudades de Salamanca, Valladolid y Zamora...............77

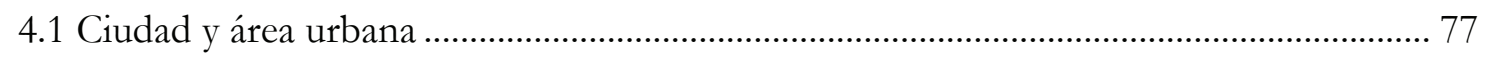

4.2 Origen y evolución del verde urbano de la ciudad de Salamanca ......................................... 80

4.2.1 Evolución urbana de Salamanca hasta 1956 ............................................................... 80

4.2.2 Evolución urbana hasta la aprobación del PGOU de 1984 ......................................... 88

4.2.3 La ampliación de la trama verde con el PGOU de 1984 .............................................. 93

4.2.4 Síntesis de la evolución histórica del verde urbano en Salamanca ............................. 98

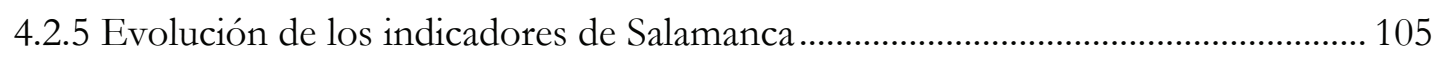

4.3 Origen y evolución del verde urbano de la ciudad de Valladolid........................................ 108

4.3.1 Evolución urbana de Valladolid hasta 1956 ................................................................... 113

4.3.2 Crecimiento de la ciudad hasta la aprobación del PGOU de 1984 .......................... 117

4.3.3 Evolución urbana en democracia: PGOU 1984, 1997 y 2003.................................. 123

4.3.4 Síntesis de la evolución histórica del verde urbano en Valladolid................................ 132

4.3.5 Evolución de los indicadores de Valladolid ............................................................. 139

4.4 Origen y evolución del verde urbano de la ciudad de Zamora............................................ 141

4.4.1 Evolución urbana de Zamora hasta 1956 _.................................................................... 141

4.4.2 Crecimiento de la ciudad hasta la aprobación del PGOU de 1986 ......................... 149

4.4.3 Evolución de la ciudad durante el periodo de aplicación del PGOU de 1986..... 153

4.4.4 Síntesis de la evolución histórica del verde urbano en Zamora.................................... 158

4.4.5 Evolución de los indicadores de Zamora ................................................................... 164

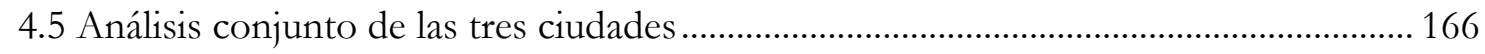

4.5.1 El caso singular de los huertos urbanos................................................................... 169

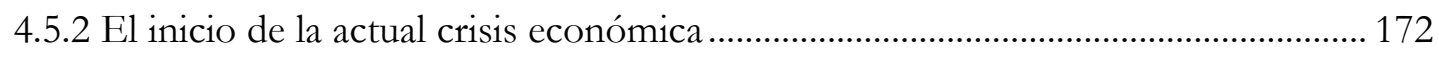


5. Estudio del verde urbano desde una perspectiva social........................................ 177

5.1 Características de los usuarios del verde urbano disponible ...................................................... 177

5.1.1 Distribución por edades, sexo y ocupación .................................................................. 177

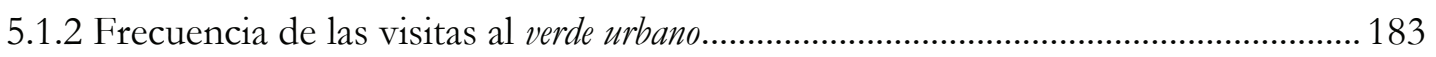

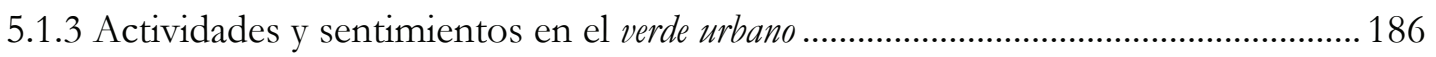

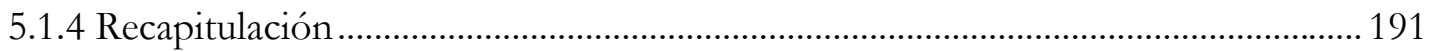

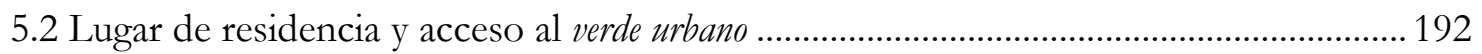

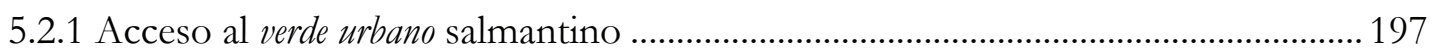

5.2.2 Acceso al verde urbano vallisoletano ............................................................................. 202

5.2.3 Acceso al verde urbano zamorano ................................................................................... 208

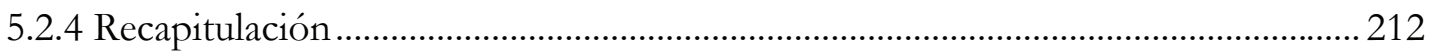

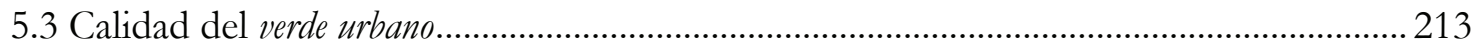

5.4 Técnica para estimar la calidad del verde urbano en las tres ciudades estudiadas ............ 224

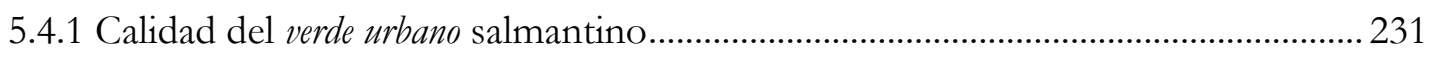

5.4.2 Calidad del verde urbano vallisoletano ........................................................................... 234

5.4.3 Calidad del verde urbano zamorano ..................................................................................2 237

5.4.4 Reflexiones sobre la calidad del verde urbano............................................................239

5.5 Espacios verdes más frecuentados: síntesis de la calidad y de la distancia desde el lu-

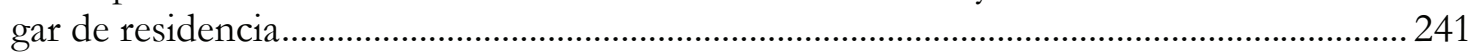

5.5.1 Índice de atracción en el verde urbano salmantino ...................................................... 242

5.5.2 Índice de atracción en el verde urbano vallisoletano....................................................... 246

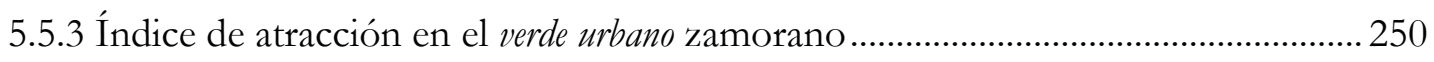

5.5.4 Recapitulación: espacios verdes más visitados en tres ciudades castellano-leone-

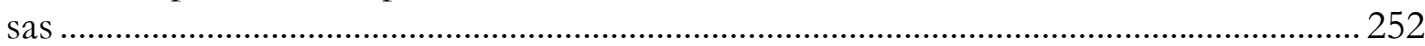

5.6 Reflexiones sobre el uso y la creación del verde urbano ……………………....................25

6. Conclusiones .........................................................................................................259

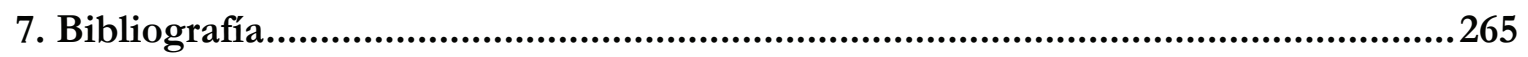

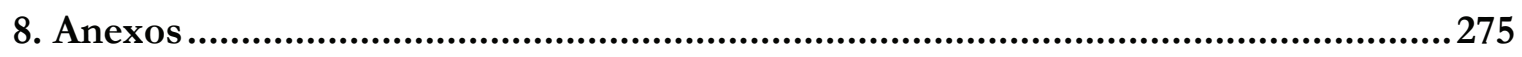

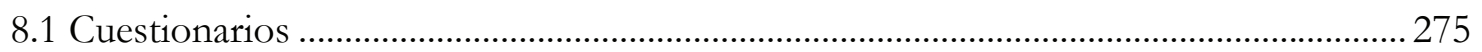

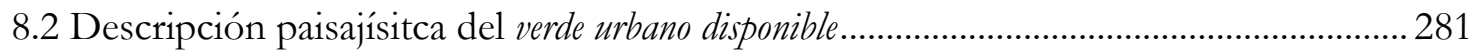




\section{1. ¿POR QUÉ UN ESTUDIO DEL VERDE URBANO DESDE LA GEOGRAFÍA?}

El verde urbano, entendido como el conjunto de zonas verdes de una ciudad, está compuesto en su mayor parte por espacios públicos cuya construcción y mantenimiento corren a cargo de las administraciones locales. No se trata de un elemento que surge espontáneamente en el interior del tejido urbano, sino que su presencia está determinada por la normativa urbanística y por el planeamiento. Por ejemplo, un ayuntamiento como el de Valladolid tenía previsto para el año 2012 un gasto en parques y jardines de 9,4 millones de euros, esto es, el 3,7\% del gasto total del consistorio para ese ejercicio. Parecería una cifra menor si no fuera porque ocupa el décimo lugar en importancia, dentro del ranking de cuarenta y un programas en los que se dividió el capítulo de gastos de ese municipio. La pregunta es obligada: ¿por qué se realiza semejante gasto? ¿A qué necesidades responde?

La incorporación de los espacios verdes al planeamiento urbano se ha convertido en un derecho de los ciudadanos (Sanesi y Chiarello, 2006) porque su construcción está vinculada al cumplimiento de objetivos sociales, aunque su desarrollo responda a leyes biológicas (Corona, 2001). Las funciones o los beneficios que las zonas verdes proporcionan a las personas motivan su construcción en las ciudades, aunque son pocos los estudios dirigidos a identificar las necesidades de la población en relación a estos espacios, es decir, sobre qué buscan los ciudadanos cuando visitan los parques y jardines, qué hacen en ellos o por qué visitan unas áreas verdes y no otras. Esta Tesis Doctoral pretende averiguar qué uso hacen las personas de estos espacios a los que se destinan tantos recursos municipales, mostrando una realidad compleja que hasta la fecha no ha sido suficientemente estudiada. Para explicar en qué consiste esta investigación y cómo se va a llevar a cabo, se han planteado una serie de cuestiones que serán respondidas en este capítulo introductorio. Son las siguientes: ¿qué es el verde urbano?, ¿por qué se realiza un análisis de los espacios verdes desde la Geografía?, ¿por qué se ha elegido esta temática?, ¿qué ciudades se han estudiado? y por último, ¿cuáles son los objetivos y la estructura de esta investigación?

\section{1 ¿Qué es el verde urbano?}

Uno de los desafíos más notables a los que se tiene que enfrentar esta investigación es la elaboración de una definición del verde urbano desde un punto de vista científico. Este concepto, con todas sus variantes (áreas verdes, jardines, espacios verdes, parques urbanos, zonas verdes...), es utilizado con mucha frecuencia en contextos sociales muy diversos, pero no existe una definición comúnmente aceptada. Por lo tanto, será necesario delimitar semántica y territorialmente el objeto sobre el que se quiere desarrollar un análisis geográfico.

Tomando como referencia algunas publicaciones orientadas al estudio de diversos aspectos de las áreas verdes urbanas, se ha observado que cada una de ellas utiliza criterios distintos para seleccionar estos espacios. Por ejemplo, en determinados artículos se incluyen las zonas forestales situadas en las afueras de la ciudad (Salvo y García-Verdugo, 1993; McPherson et al., 1994; Levent et al., 2009) y en otros solo los espacios verdes que se encuentran en el interior de la trama urbana y que además tuvieran un perímetro definido (Rodríguez y Díaz, 2003). En algunos se fijó un tamaño mínimo de los parques y se excluyeron los espacios ajardinados que no contasen con una determinada superficie mínima (Van Herzele y Wiedemann, 2003; Canosa et al., 2003; Gámez, 2005), mientras que en otros casos se prestó cierta importancia a la titularidad de las zonas verdes (Muga, 1980; Rodríguez y Díaz, 2003), aunque para la inmensa mayoría la propiedad de los terrenos era un tema 
secundario. En resumen, una búsqueda bibliográfica no muy profunda muestra que existe cierta dificultad a la hora de concretar este concepto, como se puede comprobar en la Tabla 1.1, en la que aparecen los principales términos utilizados para tratar estos espacios, así como su definición, ordenando alfabéticamente la información obtenida en función del apellido de los diversos autores.

En cada trabajo se utiliza un término diferente a la hora de calificar los espacios verdes en la ciudad, cuyos límites territoriales estarán más o menos definidos en función del objetivo perseguido. No obstante, se identifica una base conceptual común en la literatura consultada, ya que por verde urbano se entiende, de forma general, aquel espacio abierto de la ciudad cuyo elemento característico es el desarrollo de cualquier tipo de vegetación. Algo más difuminado aparece el cumplimiento de diversas funciones, que sería otro rasgo definitorio de estos espacios, y que justificaría su presencia en el interior del continuo urbano. Aparte de los aspectos citados, los puntos de encuentro entre los autores son más bien escasos al tratar el tema desde distintos campos científicos. Por lo tanto, las ideas que articulan la definición del concepto de verde urbano, atendiendo a las definiciones consultadas, son su ubicación dentro del tejido urbano, su finalidad social y, sobre todo, su configuración a partir de elementos vegetales.

Más allá del ámbito académico, el verde urbano ha sido definido de forma precisa en la legislación urbanística. En España las competencias en materia de urbanismo fueron transferidas a las Comunidades Autónomas por la Constitución de 1978. Las tres ciudades analizadas en esta Tesis Doctoral están situadas en Castilla y León, donde se encuentra en vigor la Ley de Urbanismo de 1999 y su Reglamento de Urbanismo (RUCYL) en la versión revisada de 2009. Este último define las zonas verdes como superficies dentro de los espacios libres públicos, específicamente destinadas a la plantación de especies vegetales. Pese a la ambigüedad de dicha definición, la normativa urbanística posee un valor operacional indiscutible para la reserva de espacios libres públicos en los núcleos urbanos, determinando el mínimo legal de un municipio a través de la imposición de dos requisitos:

1. La superficie minima del sistema general de espacios libres públicos se obtiene aplicando un módulo de 5 metros cuadrados por habitante sin incluir en el cómputo los espacios libres públicos del sistema local ni los Espacios Naturales Protegidos (Artículo 83 del RUCYL).

2. La reserva de suelo para el sistema local de espacios libres públicos debe alcanzar al menos: en suelo urbano no consolidado, 15 metros cuadrados de suelo por cada 100 metros cuadrados construibles, y en suelo urbanizable 20 metros cuadrados de suelo por cada 100 metros cuadrados construibles (Artículo 105 del RUCYL). Asimismo la reserva debe cumplir las signientes condiciones:

a. Debe garantizarse el adecuado soleamiento, y su indice de permeabilidad, o porcentaje de superficie destinado a la plantación de especies vegetales, no debe ser inferior al 50 por ciento.

b. En los sectores con uso predominantemente residencial, debe distribuirse en áreas adecuadas para su uso, evitando las zonas residuales, con una superficie unitaria minima de 500 metros cuadrados y de forma que pueda inscribirse en su interior una circunferencia de 20 metros de diámetro. En su interior deben preverse áreas especiales reservadas para juego infantil, de superficie no inferior a 200 metros cuadrados y equipadas adecuadamente para su función. 
Tabla 1.1 Principales definiciones del concepto de espacio verde urbano o términos similares.

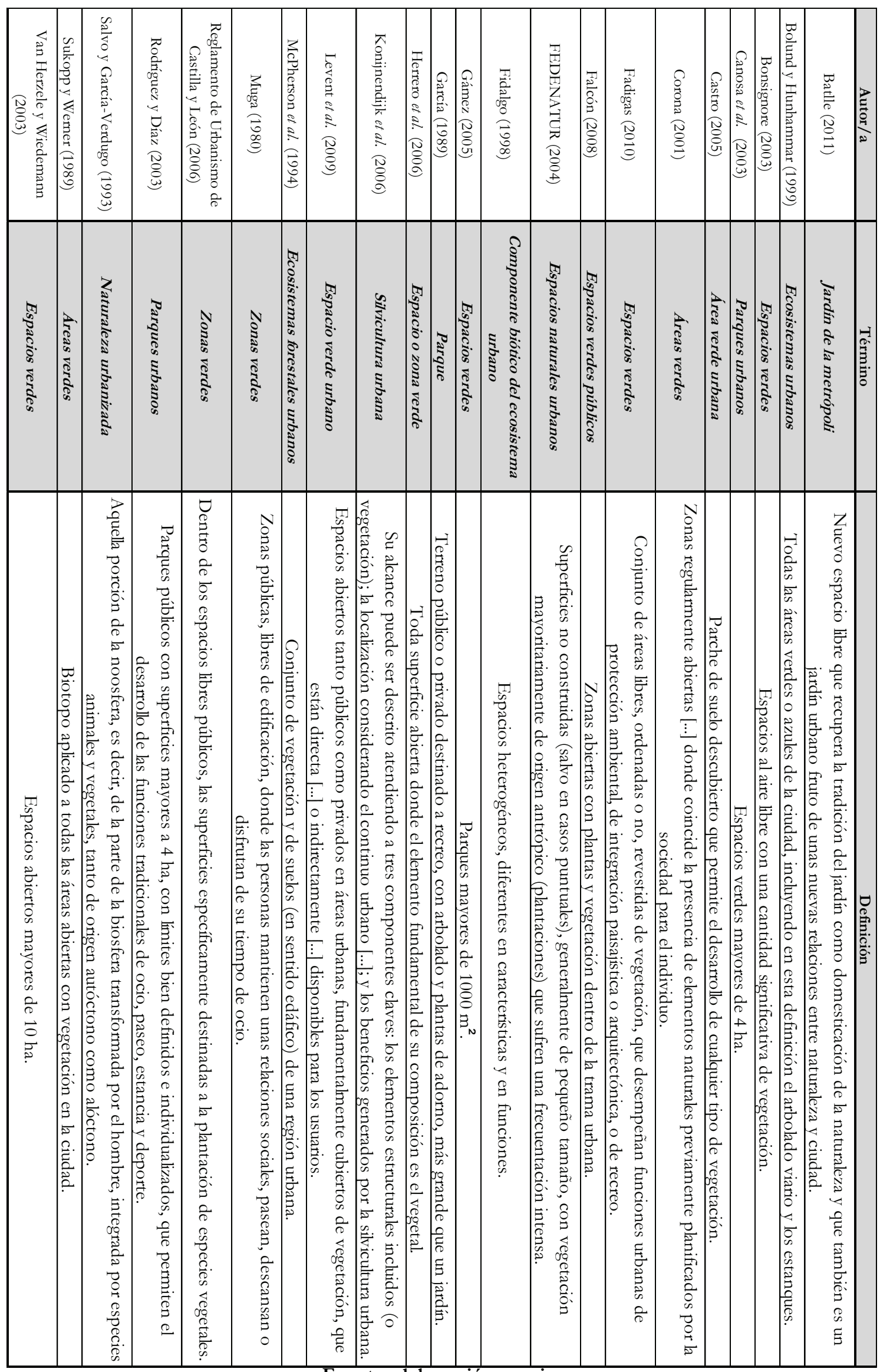

Fuente: elaboración propia. 
c. En los sectores con uso predominantemente industrial o de servicios, debe destinarse de forma preferente a arbolado en bandas lineales con un ancho minimo de 5 metros, que favorezca la transición con el medio ambiente circundante, así como la salvaguarda de los espacios arbolados y de los cances naturales y de las vías pecuarias afectados.

Una vez consultadas las diferentes definiciones, conviene señalar que no todo lo que comúnmente se considera como zonas verdes forma parte de la categoría de verde urbano. La presencia de vegetación es un elemento común en todos los textos consultados, por lo que parece adecuado incluir esta característica en una futura definición de estos espacios. Pero antes conviene reflexionar sobre la importancia del suelo, entendido como el sustrato sobre el que se asienta la vegetación. Se trata de uno de los elementos fundamentales de cualquier formación vegetal, por ser un espacio capaz de proporcionar vida a plantas y animales (Sukopp y Werner, 1989). En las ciudades el suelo está vinculado con la edificabilidad y el negocio inmobiliario, y pocas veces se piensa en él como germen para la vida. Físicamente es percibido en muchas ocasiones como algo engorroso que conviene eliminar, incluso dentro de los parques y jardines públicos, al provocar molestias a los transeúntes y a ciertos usuarios, por lo que en no pocas ocasiones se sustituye por elementos de construcción, como cemento o materiales plásticos (ver Figura 1.1).

Las áreas verdes son concebidas habitualmente como una superficie de dos dimensiones y podría pensarse en fijar un determinado porcentaje de suelo entre las características para incluirlas dentro de la categoría de verde urbano. Sin embargo, el estrato arbóreo otorga a estas zonas el tercer eje, el vertical, permitiendo así que sean consideradas como espacios tridimensionales. De esta manera, los parques y jardines dejarían de estar asociados únicamente a superficies, convirtiéndose en una forma cúbica donde se encontraría gran parte de la naturaleza urbana y donde los humanos, como bípedos, interactuarían con el resto de seres vivos presentes en estos espacios. Por consiguiente, cuando se hable de verde urbano, se hará siempre referencia a espacios tridimensionales y no solo a superficies.

Dentro de esta categoría también estarían incluidas las zonas verdes en las que el suelo haya sido cubierto o eliminado y aquellas porciones de arbolado viario que cumplan con el resto de condicionantes para ser englobadas dentro de la categoría de verde urbano. Pese a todo, es necesario destacar la importancia del suelo como elemento que desempeña una labor esencial en la absorción de agua y de nutrientes, además de ser un soporte fundamental para la vida.

Volviendo a las características de las zonas verdes, conviene mencionar que actualmente las funciones perseguidas mayoritariamente con la construcción de estos espacios son las sociales, concretamente las terapéuticas y recreativas. Recientemente se han ido demostrando diversos aspectos positivos asociados a la existencia de parques y jardines en el interior de la ciudad y su presencia está actualmente reglamentada por las leyes de urbanismo de la mayor parte de países europeos. Por tanto, puede aceptarse entonces que el desempeño de determinadas funciones justifica la voluntad de la sociedad por integrar las áreas verdes en las ciudades.

\section{2 ¿Por qué se realiza un análisis del verde urbano desde la Geografía?}

La rama de la Geografía que estudia los aspectos formales o morfológicos de la ciudad, las relaciones entre los distintos espacios de la misma y la población que reside en estos últimos, es la Geografía Urbana. Esta Tesis Doctoral se ha centrado en el uso de las zonas verdes por parte de la población, un aspecto que parecería más vinculado al Urbanismo que a la Geografía Urbana, pero sobre el que los geógrafos vienen trabajando desde hace algunos años. Cabe esperar que una vez terminada esta investigación, sea posible 
Figura 1.1 Sustitución del suelo por materiales de construcción. En la parte superior: Jardines de la Vaguada (Zamora, Z-10). En la parte inferior: Parque de la Alamedilla (Salamanca, S-10).
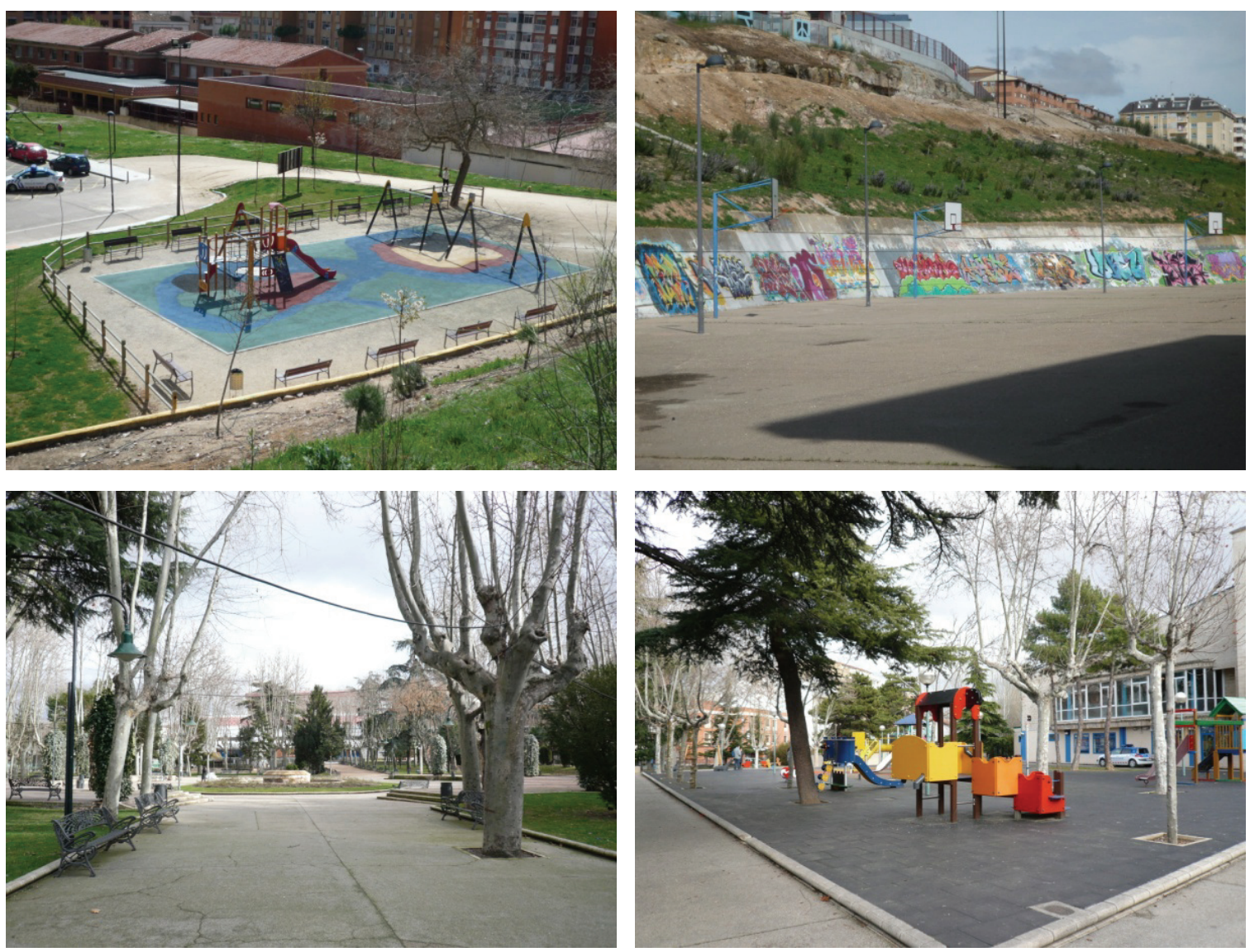

Fuente: Gómez, A. (31/03/2011) y Borrallo, E. (31/01/2009).

extraer alguna recomendación o principio que pueda emplearse en el planeamiento urbano, por lo que, de una manera u otra, se estaría desarrollando una vertiente aplicada de la Geografía Urbana.

Desde hace algunos años, esta disciplina se viene interesando por la presencia de los espacios verdes en el interior de las ciudades y, en concreto, por el acceso y la posibilidad de uso por parte de los ciudadanos. Sin embargo, no es un ámbito exclusivo de los geógrafos, sino que se trata de una materia sobre la que tienen mucho que decir otras disciplinas, como la arquitectura, la ecología, la sociología o el urbanismo.

De entre las publicaciones más destacadas y que más han influido en esta Tesis Doctoral, es necesario mencionar el estudio de Chiesura (2004) sobre un parque de Ámsterdam, que ha servido de modelo para afrontar el reto de obtener información sobre temas tan diversos como son las actividades que realizan los usuarios en las zonas verdes o los sentimientos que les inspiran estos lugares. En España se publicó un estudio sobre la relación existente entre el diseño de los espacios abiertos urbanos de la ciudad de Alicante y el colectivo de usuarios mayores de sesenta y cinco años, que justifica la realización de investigaciones sobre esta temática al confirmar que en nuestro país existe una falta de información sistematizada sobre las opiniones de los usuarios del verde urbano (Puyuelo et al., 2005). Otro trabajo relevante fue el desarrollado por Muga (1980) en las áreas verdes de la ciudad de Logroño, en el que se reconoce la enorme dificultad para definir estos espacios de una manera clara y precisa. Por otra parte, Segovia y Neira (2005) aportaron algunos datos muy reveladores sobre la utilización de los espacios verdes en su estudio sobre Santiago de Chile, en la medida en que identificaron una disminución de la frecuentación de los mismos 
después de la puesta de sol. Van Herzele y Wiedemann (2003) publicaron un trabajo clarificador sobre los factores que determinan la accesibilidad de los ciudadanos a las áreas verdes, estableciendo una relación entre su tamaño y su capacidad de atracción. En la ciudad de Bari (Italia), Sanesi y Chiarello (2006), además de estudiar el uso que la población hace de los espacios verdes, identificaron tres partes diferenciadas de la ciudad mediterránea atendiendo a la presencia o ausencia de parques en su interior. En Portugal actualmente hay varios autores centrados en el estudio del verde urbano desde una perspectiva social: Madureira (2011 y 2012) ha estudiado la disponibilidad de espacios verdes en la ciudad de Oporto, Fonseca et al. (2010) realizaron un exhaustivo análisis del uso de los parques y jardines urbanos de la ciudad de Bragança por parte de los ciudadanos, mientras que el grupo de geógrafas dirigido por Paula Santana (Santana et al., 2007a; 2007b; 2010; 2011) centró su análisis en la ciudad portuguesa de Amadora, en la periferia de Lisboa. Estas últimas vinculan la presencia de zonas verdes con una mejora en la salud física y mental de la población, relacionando de este modo el planeamiento urbano con la salud.

Por tanto, la presencia de geógrafos entre los principales referentes en este campo demuestra que la Geografía es una disciplina con una amplia trayectoria en el estudio de los espacios urbanos. En concreto, durante los últimos años ha comenzado a prestar atención a las zonas verdes situadas en el interior de la ciudad, tanto desde el punto de vista de su localización espacial como del uso que de ellos hacen las personas.

\section{3 ¿Por qué se ha elegido esta temática?}

España es un país eminentemente urbano, donde el 79\% de la población vive en ciudades (INE, 2011). Concretamente, más de la mitad de los habitantes censados reside en las dieciocho áreas metropolitanas de mayor tamaño y un tercio lo hace en las cinco más importantes: Madrid, Barcelona, Valencia, Sevilla y Bilbao (Gómez, 2005). Este es un fenómeno global que afecta a todo el planeta, como constató el Fondo de Población de las Naciones Unidas (UNFPA, por sus siglas en inglés), al estimar que entre 2008 y 2009 la población urbana habría superado a la rural por primera vez en la historia, lo que supondría que más del $50 \%$ de los seres humanos se concentrarían en tan solo el 3\% del territorio. Sin embargo, este fenómeno no es homogéneo y en algunas regiones muy pobladas, y con fuerte tradición industrial, se ha detectado un proceso de declive urbano o shrinkage, como ocurre en determinadas ciudades europeas o norteamericanas, de entre las cuales el ejemplo paradigmático es la aglomeración urbana de Detroit (Martínez-Fernández et al., 2012). Se entiende así la previsión de la UNFAPA (2007), que sugiere la posibilidad de que la mayor parte del crecimiento de la población urbana a nivel mundial se produzca en ciudades medias y pequeñas.

El verde urbano se encuentra en un medio antropizado llamado ciudad, donde podría producirse una situación de dotación no óptima de estos equipamientos desde un punto de vista social, si únicamente actuasen las fuerzas y los intereses económicos (Frutos, 2004), pero afortunadamente también intervienen agentes sociales y políticos (Polése, 1994) a través del planeamiento urbano. Durante los últimos años se ha generado un interés creciente por el análisis de las zonas verdes en el interior de las ciudades, especialmente desde la aparición de las Agendas 21 locales, con las que se pretendía integrar el desarrollo sostenible en las políticas locales. En concreto, entre los indicadores que maneja la Comisión Europea para medir las interacciones de los aspectos medioambientales, sociales y económicos a nivel municipal, aparecen incluidas las zonas verdes públicas. La Primera Generación de Indicadores Comunes Europeos propone la valoración de las zonas verdes mediante un análisis de la accesibilidad de la población ya que, como apunta Harvey (1989), la ciudad es un sistema gigantesco de recursos localizado territorialmente, donde la disponibilidad de estos depende de la accesibilidad y de la proximidad. 
El origen de los actuales espacios verdes hay que buscarlo en el siglo XIX, durante la segunda revolución urbana, cuando fueron apareciendo parques de gran tamaño en las principales ciudades de los países industrializados. En un contexto caracterizado por un potente crecimiento demográfico y por un deterioro paralelo de las condiciones ambientales y sociales en las que vivía la población, fueron surgiendo nuevas concepciones urbanas como la Ciudad Lineal de Arturo Soria, la Ciudad Jardín de Ebenezer Howard, las propuestas funcionalistas de Le Corbusier o la Broadcare City de Frank Lloyd Wright, por citar únicamente los ejemplos más destacados. Por su posterior influencia en la creación de espacios verdes urbanos, destaca la Ciudad Jardín, que pretendía ser un híbrido entre la ciudad y el campo, donde la sociedad humana y la belleza de la naturaleza pudieran estar unidas (Howard, 1965).

El origen de los fuertes desequilibrios registrados en las áreas urbanas, tanto económicos, como sociales o territoriales, se debe a que el mercado no contabiliza correctamente los costes sociales y ambientales de la expansión de las ciudades, ni es capaz de resolver por sí solo los problemas de higiene e insalubridad generados durante el proceso de urbanización (Polése, 1994). Por este motivo los distintos gobiernos tuvieron que asumir responsabilidades en la configuración de la ciudad para mejorar las condiciones de vida de sus habitantes (Naredo, 2000). Actualmente, en la mayor parte de los países europeos, el funcionamiento del llamado Estado del bienestar, es decir, un estado que provee ciertos servicios para la población, ha contribuido a estructurar las ciudades a medida que los poderes públicos actuaban cada vez más directamente en el urbanismo, creando procedimientos para la planificación racional, de acuerdo con las necesidades de la población (Ascher, 2010). Sin embargo, a la hora de construir las zonas verdes, existe muy poca información en cuanto a quiénes son los usuarios y a los problemas que pudieran afectarles. En el diseño de estos espacios se utilizan con frecuencia patrones subjetivos, muy influenciados por valores estéticos y por modas de una determinada época, que pueden llegar a provocar un desfase entre los usuarios últimos y los equipamientos proyectados (Puyuelo et al., 2005). Frente a esta situación se contrapone la voluntad de algunos sociólogos como Bauman (2007), que ve los espacios públicos como una oportunidad para reconciliar a los habitantes de las ciudades, o Ascher (2010), que propone construir una nueva gobernanza urbana en la que la toma de decisiones sea flexible, enriqueciendo así la democracia representativa con nuevos procedimientos con los que consultar a los habitantes, a los usuarios y a todos aquellos que tuvieran algo que decir sobre los espacios públicos.

En definitiva, la utilización del verde urbano es un ámbito todavía poco estudiado, pese a que la creación de estos espacios esté ligada al urbanismo desde finales del siglo XIX. Actualmente, en un contexto de crisis económica y de mudanza de los valores sociales, es necesario retomar esta temática desde el convencimiento de que deben ser áreas destinadas a cubrir las exigencias de las personas, puesto que su creación está íntimamente relacionada con la satisfacción de necesidades sociales. Las funciones del verde urbano serán analizadas más adelante, dedicando un capítulo entero a su análisis detallado.

\section{4 ¿Qué ciudades se han estudiado?}

Las áreas verdes se encuentran en el interior del tejido urbano, pero ¿cuáles son los límites de la ciudad? Es necesario clarificar cómo se pretende delimitar esta entidad territorial, desde la perspectiva de que conceptualmente no es posible obtener una definición universal de ciudad y, por consiguiente, al abordar el medio urbano habrá que tener claro que la realidad que se estudie no será la ciudad, sino lo que se quiera entender por ella en función de los intereses de cada investigación. Esta idea es expresada por Nel·lo y Muñoz (2004: 292) en los siguientes términos: 
"[... La discusión sobre los límites urbanos es hoy una cuestión irresoluble de forma univoca desde una perspectiva cientifica. Podríamos, claro está, circunscribir normativamente el problema y delimitar el espacio a través de criterios parciales como se han descrito. Con ello tendremos ámbitos operativos y útiles, quizás, para el tratamiento de determinadas cuestiones [...]. Pero estos ámbitos no responderán a lo que la ciudad es, sino a aquello que, de acuerdo con nuestros intereses y objetivos, queremos que la ciudad sea".

Los distintos actores que se han visto en la tesitura de acotar espacialmente las ciudades para poder trabajar sobre ellas han fijado distintos límites en función de los objetivos perseguidos. El caso de los términos municipales es paradigmático al tratarse de límites político-territoriales que han sido, en muchos casos, superados por el crecimiento de la ciudad sobre el territorio. La expansión del proceso de urbanización ha dejado inservibles las viejas definiciones de ciudad, provocando que la distinción entre mundo rural y mundo urbano deje de ser operativa desde un punto de vista científico (Nel·lo y Muñoz, 2004). Esto es debido a que el crecimiento ha acabado con el tradicional concepto de delimitación de las ciudades, basado en los aspectos que enfrentaban el campo a la ciudad: grandes núcleos donde se concentraban actividades industriales y de servicios en el caso del medio urbano frente a actividades primarias y pequeños núcleos de población en el caso del medio rural.

El crecimiento urbano ha generado durante los últimos años una serie de procesos de expansión sobre el territorio que han provocado que las principales ciudades españolas hayan superado los límites administrativos establecidos. Al igual que ocurrió en su día con las barreras espaciales que suponían las murallas y las cercas, las ciudades han saltado estos límites incorporando al proceso de urbanización a los núcleos rurales más próximos. Las entidades territoriales resultantes se han ido expandiendo al tiempo que absorbían espacios que históricamente habían pertenecido a otros municipios, convirtiéndolos así en parte de las urbes tanto desde un punto de vista funcional como desde un punto de vista económico y laboral, aunque en muchos casos sigan manteniendo su independencia administrativa.

El proceso de urbanización en las ciudades medias españolas se ha caracterizado por una concentración de población en los núcleos tradicionales hasta finales de los años setenta y principios de los ochenta del siglo pasado, cuando arrancó la periurbanización y comenzó una paulatina modificación de las relaciones históricas mantenidas entre estas ciudades y su entorno más cercano, debido a que dicho proceso provocó la difuminación de los límites y las distancias espaciales (Mallarach y Vilagrasa, 2002). Se produjo de esta manera lo que autores como Roca (2003) interpretan como una transformación significativa de la ciudad: la entidad estática se convertiría en una red de flujos cada vez más extensa que conectaría personas, bienes e información.

La extensión de la urbanización y de las formas de vida urbanas por espacios cada vez más alejados de las ciudades centrales ha dado lugar a lo que algunos autores han denominado campo urbano o urban field. Así, pequeñas concentraciones de población estarían conectadas por una red de flujos en cuyo interior podrían aparecer grandes espacios vinculados con actividades primarias, tanto agrícolas como ganaderas o forestales. Esta situación ha sido motivada por la mejora de las redes de transporte, tanto público como privado, y por la dispersión de los puestos de trabajo y de las residencias desde los centros tradicionales hacia la periferia. Surgen de esta manera conceptos como ciudad de la información o ciudad difusa, este último utilizado para referirse al momento de la evolución humana en que las formas urbanas se extienden por el territorio, integrando la mayor parte del espacio mediante redes cada vez más complejas (Nel·lo y Muñoz, 2004). Esto supondría el fin del modelo de crecimiento urbano basado en anillos concéntricos y su sustitución por una urbanización difusa conectada por una red de relaciones (Salom y Casado, 2007).

Por tanto, en muchos casos, hablar de ciudad ha dejado de ser operativo, ya que se alude únicamente a una parte de una entidad o área urbana que comparte unas características y problemáticas comunes. Sin embargo, en el interior de las aglomeraciones se puede 
distinguir el lugar central donde se concentran la mayor parte de las residencias y de los puestos de trabajo, que será por tanto el espacio en el que se encuentre el verde urbano. Roca (2003:30) expresa esta idea de la siguiente manera:

"[...] Parece evidente que la "ciudad de la información" no ha sustituido todavía, ni es seguro que lo baga en el futuro, a la "ciudad físico-funcional" en la que hasta abora hemos habitado. La actividad bumana, si bien se extiende por todo el planeta, se concentra en el lugar físico donde se reside y trabaja de forma habitual".

Desde el convencimiento de que la "ciudad físico-funcional" es hasta la fecha, la parte de la ciudad que concentra la mayor parte de las residencias y de los puestos de trabajos en las áreas urbanas españolas, se ha tratado de analizar únicamente las áreas verdes localizadas en su interior. En concreto, las ciudades seleccionadas en esta Tesis Doctoral son Salamanca, Valladolid y Zamora, situadas en la submeseta norte de la Península Ibérica, dentro de la Comunidad Autónoma de Castilla y León (ver Figura 1.2). La elección de dichas urbes estuvo motivada por su proximidad espacial y por la oportunidad que tres ciudades de distinto volumen demográfico y extensión territorial brindan para contrastar un modelo de análisis de los espacios verdes urbanos. Valladolid es el municipio que cuenta con un término de mayores dimensiones, 79.635 ha, seguido de Zamora, 14.936 ha y de Salamanca 3.936 ha. En lo que a demografía se refiere, Salamanca contaba en 2011 con 153.472 habitantes, mientras que Valladolid poseía aproximadamente el doble de población, 313.437 censados, y Zamora aproximadamente la mitad, 65.525. Las tres ciudades comparten el hecho de ser capitales provinciales y de albergar la mayor parte de los órganos de gobierno provincial, y Valladolid es además sede de las principales instituciones de Castilla y León.

Cuentan con un clima mediterráneo con un invierno moderado sin estacionalidad pluvial marcada y un verano relativamente largo (Csa, en la clasificación de Köppen). Además, se encuentran en un territorio bioclimático similar, ya que se incluyen en el piso supramediterráneo con temperaturas medias anuales comprendidas entre 8 y $13^{\circ} \mathrm{C}\left(11,8^{\circ} \mathrm{C}\right.$ en Salamanca; $12,2^{\circ} \mathrm{C}$ en Valladolid y $12,8^{\circ} \mathrm{C}$ en Zamora) y presentan un ombroclima seco (350-600 $\mathrm{mm}$ anuales) con precipitaciones anuales medias iguales a $380 \mathrm{~mm}$ en Salamanca, $457 \mathrm{~mm}$ en Valladolid y $387 \mathrm{~mm}$ en Zamora. Esto implica que la climatología influirá de manera similar en la estacionalidad y en el horario de las visitas a los espacios verdes de las tres ciudades, dado que no hay diferencias significativas entre ellas.

Comparten también el hecho de ser atravesadas por diferentes ríos de notable dimensión: Salamanca se erigió a orillas del Tormes y Valladolid entre el Pisuerga y su afluente el Esgueva, hoy canalizado. Estos ríos son a su vez tributarios del Duero, que a su paso por Zamora ya ha recogido las aguas del Pisuerga y en la frontera con Portugal hace lo propio con las del Tormes.

Estas ciudades fueron elegidas por presentar unas características muy similares tanto en lo climático (días de lluvia, estaciones cálidas, horas de luz...), como en su configuración histórica, cuyo reflejo en el plano muestra un centro histórico fácilmente reconocible y un área de crecimiento que responde a una expansión territorial relativamente reciente. De esta manera, se trabajó con tres casos con características similares, reduciendo así la posible influencia de otro tipo de factores diferenciadores, con el valor añadido que aporta una diferencia demográfica y territorial significativa.

\subsection{Objetivos de la Tesis Doctoral}

De forma muy sintética, el fundamento de la presente Tesis Doctoral puede resumirse en los siguientes tres objetivos recogidos en el título del trabajo: i) definir y delimitar el concepto de verde urbano a través de una reflexión y una propuesta teórico-me- 
Figura 1.2 Localización espacial de los municipios de Salamanca, Valladolid y Zamora.

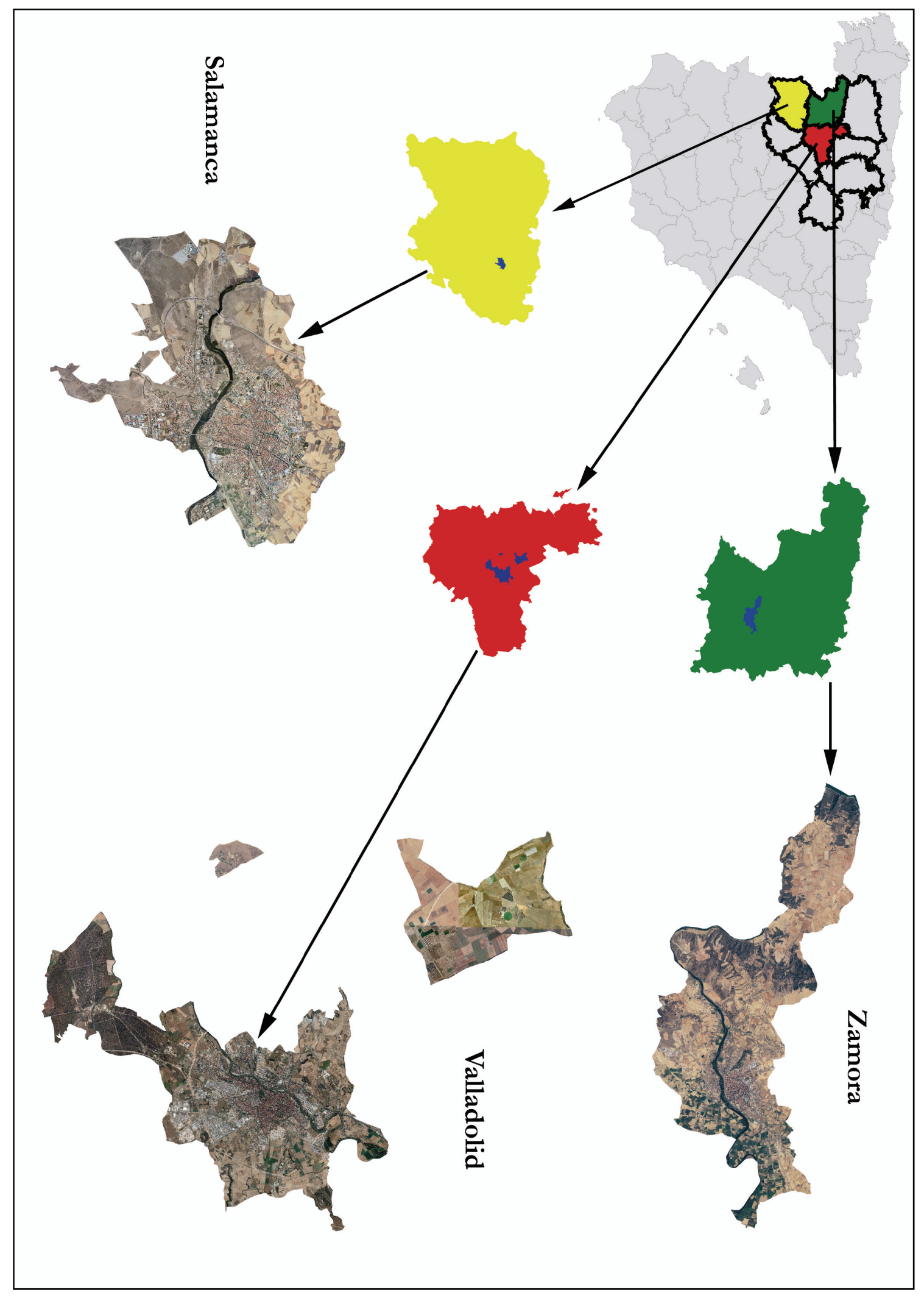

Fuente: IGN. 
todológica, ii) localizar estos espacios dentro del perímetro de las tres ciudades seleccionadas, iii) analizar tanto el uso como la valoración que las personas usuarias hacen de los mismos.

De acuerdo con lo anterior, en primer lugar se abordará una definición del verde urbano de forma clara y concisa, que pueda ser aplicada a ciudades de un ámbito territorial concreto como es la Comunidad Autónoma de Castilla y León.

Posteriormente, en segundo lugar, se estudiarán las pautas de localización espacial de las áreas verdes en Salamanca, Valladolid y Zamora, atendiendo a una serie de objetivos específicos como son:

- Analizar la evolución histórica reciente de las zonas verdes en las tres ciudades seleccionadas, identificando los procesos comunes que explican la presencia o la ausencia de este tipo de espacios en el interior del tejido urbano, delimitado éste conforme a la metodología derivada del primer objetivo.

- Examinar la evolución temporal de la producción y localización del verde urbano mediante el cálculo de índices que ponen en relación la superficie verde con la población residente y con la extensión del espacio urbanizado, a fin de identificar los períodos de mayor y menor crecimiento relativo de la trama verde en las tres ciudades.

- Estudiar la distribución espacial de las áreas verdes en los diferentes sectores urbanos para identificar patrones comunes en su localización, determinar su grado de accesibilidad e identificar los posibles desequilibrios que afectan a la población en razón de la disponibilidad de zonas verdes en las proximidades de su lugar de residencia.

Finalmente, en tercer lugar, se analizará el uso que los habitantes de cada ciudad hacen de los espacios verdes, atendiendo al tipo de usuarios y a los factores determinantes de las visitas, así como la valoración de los mismos por parte de la ciudadanía. Para ello, se fijaron los siguientes cuatro objetivos específicos:

- Identificar qué motivos tienen las personas para visitar, o no, cada parque, tratando de valorar la incidencia de la distancia desde el lugar de residencia y de la calidad del verde urbano, entendida como el conjunto de condiciones que hacen que las zonas verdes satisfagan las demandas y las necesidades de los ciudadanos.

- Determinar qué áreas verdes son las más visitadas, elaborando un índice que permita distinguir las menos atrayentes de las más atractivas.

- Definir el perfil tipo del usuario de los espacios verdes, tratando de identificar los principales puntos comunes entre las tres urbes.

- Conocer cómo valoran las personas el verde urbano de cada ciudad, analizando las principales actividades que los usuarios desarrollan en estos espacios, así como los sentimientos que experimentan en su interior.

\subsection{Estructura de la Tesis Doctoral}

La estructura de la Tesis Doctoral está compuesta por seis capítulos, cuya distribución puede consultarse en la Figura 1.3. La descripción de cada uno de ellos aparece 
brevemente resumida a continuación:

- 1. ¿Por qué un estudio del verde urbano desde la Geografía? Se trata del punto de partida en el que se sitúa conceptual y territorialmente la investigación. Se ha realizado una aproximación al concepto de verde urbano, explicando por qué se plantea un trabajo de este tipo desde la ciencia geográfica.

2. Aspectos metodológicos del estudio del verde urbano en Salamanca, Valladolid y Zamora. En este capítulo se fijarán los límites de lo que se entiende por ciudad y se definirá de manera clara y concisa el verde urbano. Posteriormente se cartografiarán los espacios verdes en cada una de las ciudades, delimitando así el ámbito en el que se analizará el uso que los ciudadanos hacen de estos espacios. Además, en este capítulo aparecerán explicados los procesos metodológicos e instrumentales empleados en esta investigación para llevar a cabo un estudio de las áreas verdes desde una perspectiva social, detallando cómo se va a analizar el verde urbano sin personas y el verde urbano con personas, y cómo se realizará la valoración paisajística de cada espacio seleccionado.

- 3. Las funciones del verde urbano. Se analizará el estado de la cuestión acerca de los principales beneficios que las zonas verdes generan tanto para los ciudadanos como para el medio ambiente urbano, tratando de justificar la presencia de estos espacios en el interior de las ciudades, así como la realización de un estudio como el aquí propuesto.

- 4. Evolución histórica de las ciudades de Salamanca, Valladolid y Zamora. Se realizará un estudio de la evolución urbana de los tres casos seleccionados atendiendo especialmente a los acontecimientos que han influido en la creación de los espacios verdes. El análisis estará centrado en los últimos cincuenta años y se prestará especial atención a los procesos comunes que hayan supuesto un estancamiento o una aceleración en la construcción de las zonas verdes urbanas. Se aplicarán algunos de los índices más utilizados, como es el que pone en relación el número de habitantes con la superficie verde de una ciudad, para determinar la influencia de los factores locales en la creación de los parques y jardines.

- 5. Estudio del verde urbano desde una perspectiva social. Utilizando las técnicas y métodos descritos en el capítulo segundo, se intentará obtener información sobre qué está sucediendo actualmente en los espacios verdes de las ciudades seleccionadas, cuáles son las preferencias de los usuarios, por qué visitan una zona verde y no otra, etc. Se prestará especial atención a la influencia que tiene la distancia desde el lugar de residencia a la hora de visitar el verde urbano, puesto que este es uno de los indicadores que actualmente maneja la Unión Europea. Será sin duda el capítulo más original de esta Tesis Doctoral y permitirá obtener una imagen de conjunto de los usuarios del verde urbano de tres ciudades castellano-leonesas de distinto tamaño, lo cual servirá para identificar comportamientos comunes y, quizás, alguna particularidad de cada lugar.

- 6. Conclusiones. Por último se comentarán los aspectos más relevantes de la investigación, haciendo balance del trabajo realizado y de los objetivos inicialmente marcados. 
Figura 1.3 Distribución de los capítulos de la Tesis Doctoral.

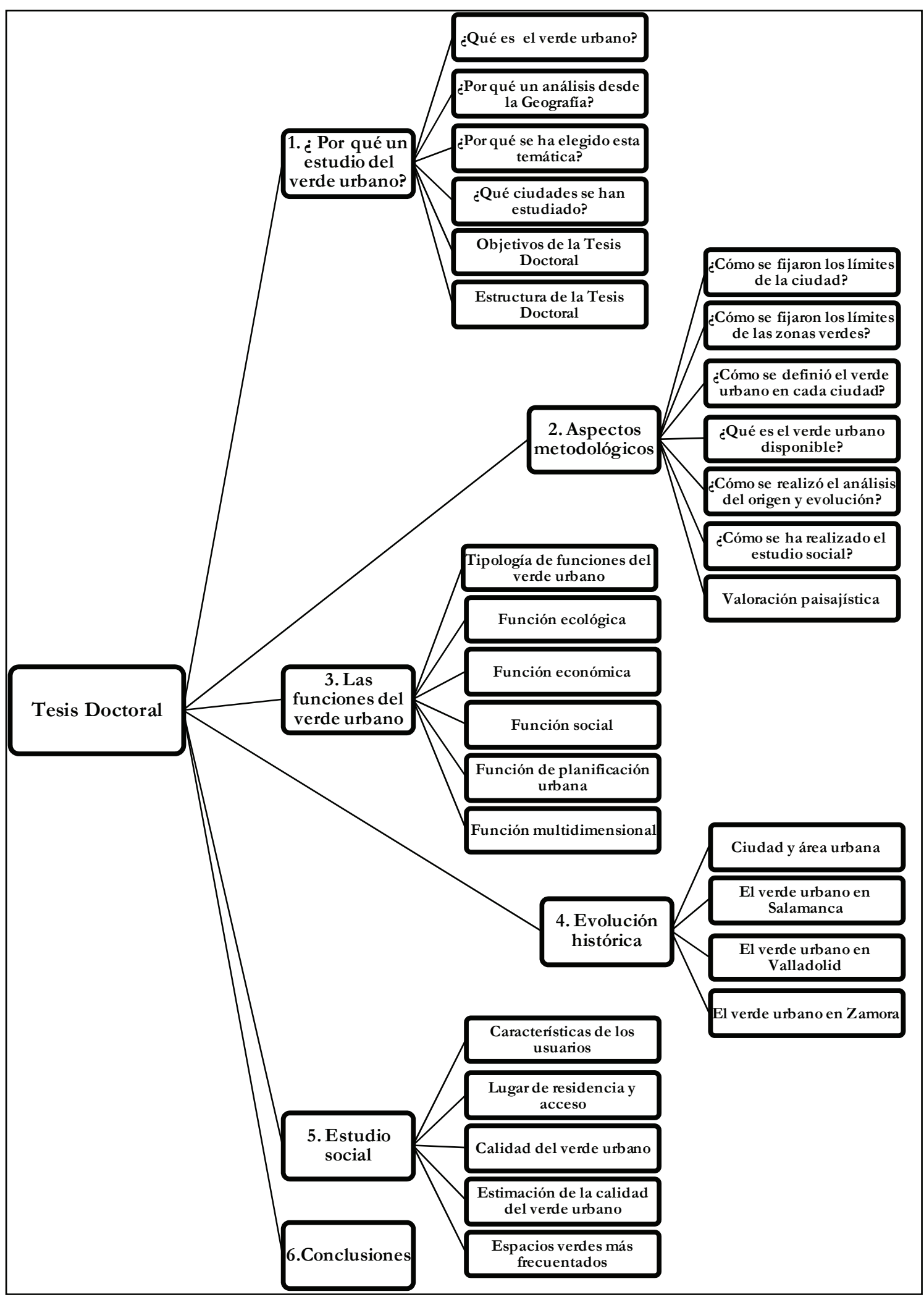

Fuente: elaboración propia. 


\section{ASPECTOS METODOLÓGICOS DEL ESTUDIO DEL VERDE URBANO EN SALAMANCA, VALLADOLID Y ZAMORA}

En este segundo capítulo se ha definido la metodología utilizada en la Tesis Doctoral, entendiendo por método la sucesión de pasos para la obtención de una serie de objetivos con los que se pretenden lograr nuevos conocimientos. A continuación aparecen planteados los principales problemas y desafíos a los que se ha tenido que enfrentar esta investigación, así como las técnicas que han permitido cumplir los objetivos anteriormente planteados. El orden en que aparecen expuestas las ciudades seleccionadas se debe al desarrollo progresivo del trabajo, ya que en primer lugar se comenzó a estudiar en el año 2008 la ciudad de Salamanca y se continuó posteriormente con Valladolid y Zamora. De aquí en adelante, se asociará un color a cada ciudad a la hora de elaborar tablas o gráficos conjuntos, concretamente el amarillo a Salamanca, el rojo a Valladolid y el verde a Zamora.

\section{1 ¿Cómo se fijaron los límites de la ciudad?}

Durante las últimas décadas, el proceso urbanizador ha superado los límites administrativos de las principales ciudades de nuestro país afectando a núcleos de población relativamente alejados e históricamente vinculados con actividades agrarias.

En el capítulo anterior se explicó que no existe un consenso para fijar los límites de las entidades urbanas. Algunos autores utilizan el concepto de área urbana para referirse al conjunto del territorio constituido por uno o varios municipios en los que se produce un proceso de difusión de la urbanización en torno a la ciudad tradicional (Mallarach y Vilagrasa, 2002; Serrano, 2006). En el caso de esta investigación, que tiene entre sus objetivos el analizar el uso que los ciudadanos hacen de los espacios verdes urbanos, se optó por un criterio demográfico-administrativo para definir claramente el núcleo o ciudad central de cada área urbana. En la Tabla 2.1 aparecen los principales criterios metodológicos utilizados por Nel·lo y Muñoz (2004) para delimitar las entidades urbanas de distinto tipo.

Quedarían excluidos de la ciudad los espacios agrícolas y forestales que forman parte del urban field o campo urbano, habitualmente localizados entre los límites de la ciudad tradicional y el resto de núcleos de población que forman parte del área urbana. Surgiría pues, una distinción entre el verde urbano y el verde periurbano, incluyendose en este último una gran variedad de espacios vegetados situados en el interior del área urbana pero fuera de lo que en esta investigación ha sido considerado como ciudad.

Junto al administrativo, se empleó también un criterio morfológico citado por $\mathrm{Nel} \cdot \mathrm{lo}$ y Muñoz (2004), utilizado con éxito para delimitar las ciudades europeas en el Atlas of agglomerations in the European Union publicado por la Network for Urban Research in the European Community. Consiste en integrar, en una misma aglomeración de espacio construido, a las parcelas urbanas que presenten discontinuidades espaciales inferiores a $200 \mathrm{~m}$ de suelo no urbano. La citada publicación demostró que la variable espacial de integración de parcelas en la ciudad no se encuentra en relación con su volumen demográfico, sino que se trata de una variable que no depende de la escala. Para comprender esto pueden compararse, como ejemplo, ciudades como París o Londres, que albergan varios millones de ciudadanos, con otras como Salamanca, que se sitúa en el intervalo de entre 100.000 y 200.000 habitantes. Esto demuestra que, en efecto, la discontinuidad espacial no es dependiente del total de efectivos demográficos de cada entidad urbana y por tanto, se empleará la misma distancia de 200 metros al estudiar ciudades de menos de 100.000 habitantes. 
Tabla 2.1 Variables para delimitar la ciudad.

\begin{tabular}{|c|c|c|c|}
\hline Criterios & Características & Ventajas & Inconvenientes \\
\hline Demográficos & \begin{tabular}{|c|} 
Delimitación \\
administrativa existente y \\
utilización de un umbral \\
demográfico
\end{tabular} & $\begin{array}{c}\text { Utilidad para } \\
\text { identificación de la ciudad } \\
\text { central }\end{array}$ & $\begin{array}{c}\text { Disociación entre el } \\
\text { concepto de ciudad y el de } \\
\text { municipio }\end{array}$ \\
\hline Continuidad espacial & $\begin{array}{c}\text { Delimitación a partir de la } \\
\text { cartografía del continuo } \\
\text { de espacio construido }\end{array}$ & $\begin{array}{l}\text { Fácil de generalizar. } \\
\text { Supera el ordenamiento } \\
\text { administrativo }\end{array}$ & $\begin{array}{l}\text { Incapacidad para integrar } \\
\text { espacios que no tienen } \\
\text { continuidad física entre } \\
\text { ellos }\end{array}$ \\
\hline Áreas funcionales & $\begin{array}{c}\text { Delimitación de espacios } \\
\text { urbanos a partir de las } \\
\text { redes de relación }\end{array}$ & $\begin{array}{l}\text { Interés para el estudio de } \\
\text { las estructuras territoriales }\end{array}$ & Delimitación problemática \\
\hline $\begin{array}{c}\text { Estructura económica y } \\
\text { forma de vida }\end{array}$ & $\begin{array}{l}\text { Delimitación en función } \\
\text { de la estructura } \\
\text { económica y condiciones } \\
\text { de vida de la población }\end{array}$ & $\begin{array}{l}\text { Complemento de otras } \\
\text { variables de tipo físico y } \\
\text { funcional }\end{array}$ & $\begin{array}{c}\text { Dificultad de uso por la } \\
\text { homogeneización } \\
\text { económica }\end{array}$ \\
\hline Servicios y jerarquía & $\begin{array}{l}\text { Delimitación a partir de la } \\
\text { jerarquía de las funciones } \\
\text { radicadas en un territorio }\end{array}$ & $\begin{array}{c}\text { Interés para el estudio de } \\
\text { las áreas funcionales de } \\
\text { movilidad }\end{array}$ & Delimitación problemática \\
\hline
\end{tabular}

Fuente: Nel·lo y Muñoz (2004).

Para llevar a cabo esta investigación se han empleado las ortofotos de Salamanca, Valladolid y Zamora, disponibles en la web del IGN (htttp://www.ign.es). El Instituto Geográfico Nacional de España proporciona actualmente los vuelos fotogramétricos, la ortofotografía aérea y los modelos digitales del terreno, en el marco del Plan Nacional de Ortofotografía Aérea (PNOA). Mediante la utilización de un Sistema de Información Geográfica (SIG), en este caso el programa ArcView 3.2, se delimitaron las ciudades objeto de estudio empleando las ortofotos que fuesen necesarias para cubrir toda la superficie urbana, descargándolas de la citada web a través del número de hoja del mapa topográfico nacional (MTN) 1: 50.000. Los documentos utilizados pertenecían a la cobertura del PNOA de 2007 en el caso de Salamanca, mientras que para Valladolid y Zamora se emplearon las ortofotografías más recientes de 2008 y 2009 respectivamente. Todas ellas tenían una resolución de $50 \mathrm{~cm}$, una combinación de bandas de color verdadero y un sistema que toma como referencia el dátum ETRS89. En la Figura 2.1 aparece la parte central del área urbana de Salamanca sin los límites político-administrativos y la descripción de la ortofoto utilizada aparece en la Tabla 2.2. En cambio, en la Figura 2.2 se han aplicado los criterios mencionados para la delimitación espacial de la ciudad, cuyo resumen es el siguiente:

1. Demográfico: a partir de los límites administrativos existentes, se selecciona el municipio más poblado de la aglomeración objeto de estudio, independientemente de si alcanza o no los 100.000 habitantes.

2. Morfológico: para quedar integrado en la ciudad, el espacio construido no debe presentar discontinuidades espaciales superiores a $200 \mathrm{~m}$. Los espacios abiertos (el verde urbano, los cursos fluviales, etc.) son considerados como elementos estructurantes del tejido urbano y por ello, siempre que se encuentren a menos de $200 \mathrm{~m}$ del continuo urbano, serán considerados como una parte más de la aglomeración. 
Figura 2.1 Área urbana de Salamanca sin límites político-administrativos.

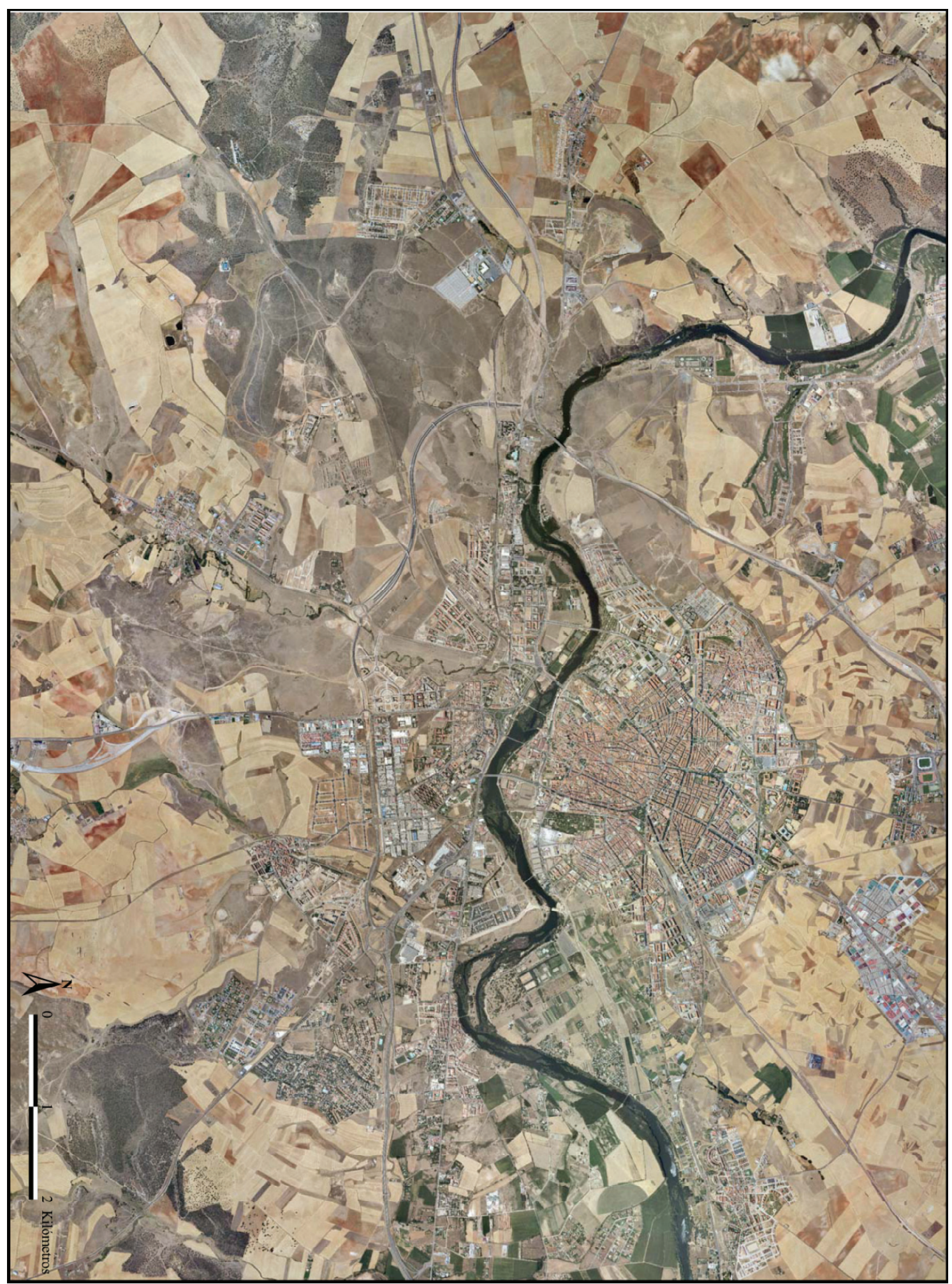

Fuente: elaboración propia a partir de la ortofotografía de 2007 del IGN. 
Figura 2.2 Límites municipal y morfológico de Salamanca.

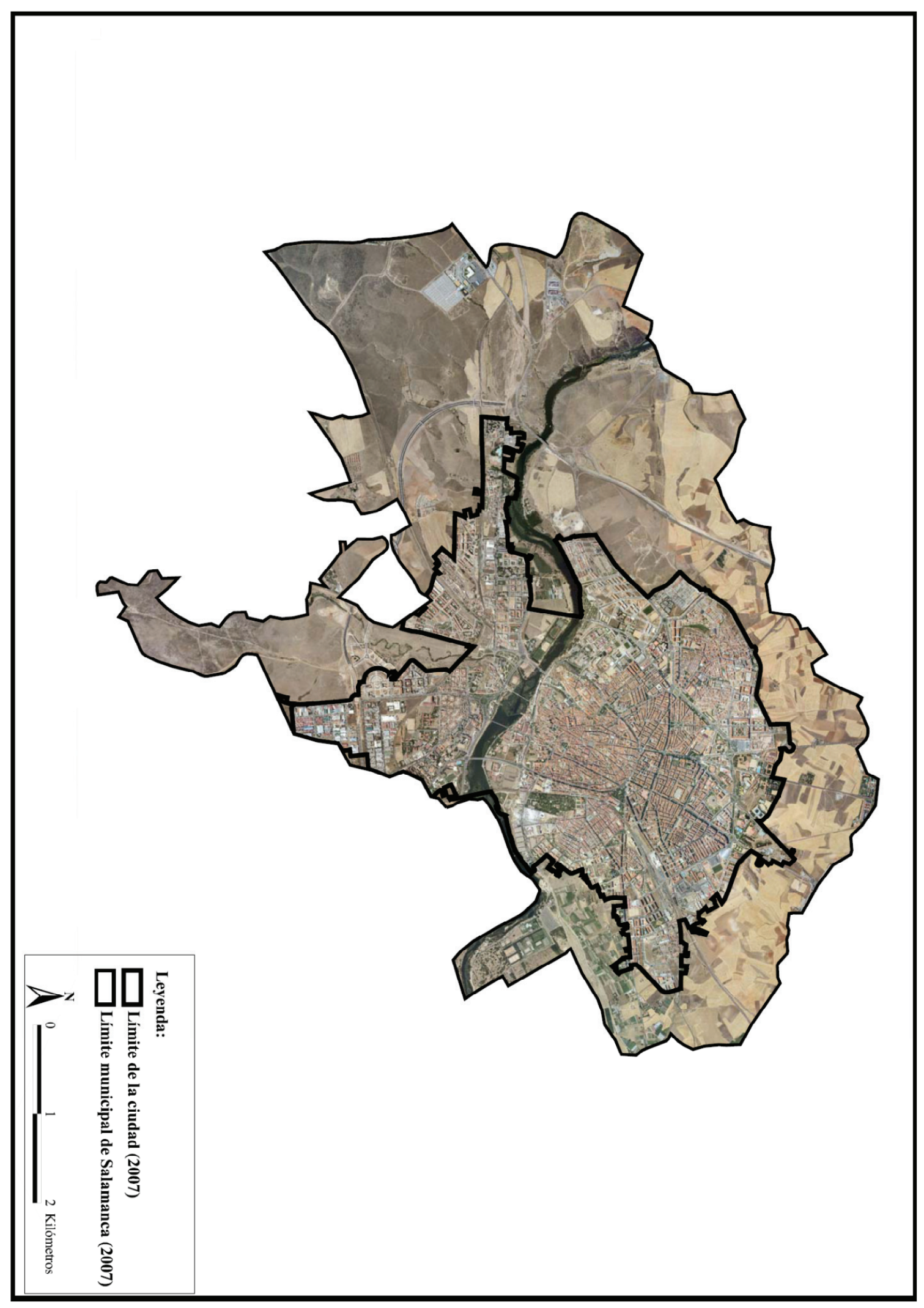

Fuente: elaboración propia a partir de la ortofotografía de 2007 del IGN. 
Tabla 2.2 Descripción de la ortofoto utilizada para delimitar la ciudad de Salamanca.

\begin{tabular}{|c|c|}
\hline \multicolumn{2}{|l|}{ Ortofoto utilizada: } \\
\hline \multicolumn{2}{|c|}{ PNOA_MR_OF_ETRS89_HU30_h50_0478.ecw } \\
\hline \multicolumn{2}{|c|}{ Descripción de la misma: } \\
\hline PNOA & Plan Nacional de Ortofotografía Aérea \\
\hline MR & Máxima resolución \\
\hline OF_ETRS89 & Sistema de referencia \\
\hline HU30 & Huso al que corresponde \\
\hline h50 & Escala 1:50.000 \\
\hline 0478 & $\mathrm{~N}^{\circ}$ de la hoja del Mapa Topográfico Nacional \\
\hline ecw & Sistema de compresión \\
\hline
\end{tabular}

\section{2 ¿Cómo se fijaron los límites de las zonas verdes?}

El reto más complejo al que se enfrentó esta investigación fue la obtención de una definición de verde urbano, al tratarse de la piedra maestra sobre la que se asienta esta Tesis Doctoral. Se ha optado por construir una categoría en la que se incluirán aquellas áreas verdes de mayores dimensiones, por ser las que teóricamente recibirían más visitas. En general, los grandes espacios verdes tienen capacidad de satisfacer una mayor variedad de necesidades humanas debido a que el tamaño de los mismos guarda relación con la cantidad de equipamientos que poseen (Van Herzele y Wiedemann, 2003). Se han excluido los jardines de pequeño tamaño, a los que no acuden las personas, tratando con ello de limitar la investigación a las zonas verdes con un tamaño suficiente para desempeñar las funciones tradicionales como son el ocio, el deporte o el paseo (Canosa et al., 2003).

$\mathrm{Al}$ trabajar con los parques de mayor tamaño se estaría analizando un porcentaje muy elevado del total de la trama verde de cada ciudad, a la vez que se excluirían otros espacios que no son utilizados por los usuarios debido a su pequeño tamaño, como es el caso de los parterres de césped, jardineras e incluso vegetación espontánea en tejados y solares aislados, o a su especial localización, como ocurre con las rotondas. El fundamento de excluir los espacios verdes de menores dimensiones se encuentra en la evidencia de que las zonas verdes de tamaño minúsculo no son capaces de atraer potenciales usuarios. Lo difícil, por tanto, sería estimar la superficie mínima por debajo de la cual un parque perdería parte de su capacidad para contener determinadas características y equipamientos, capaces de atraer a los flujos de visitantes. Para demostrar que no todas las zonas verdes son utilizadas por los usuarios se ha recurrido a dos casos extremos representativos de las áreas verdes que gestiona el Servicio de Parques y Jardines del Ayuntamiento de Salamanca (SPYJAS). En primer lugar se ha fotografiado el espacio verde de menores dimensiones de Salamanca, esto es, la Plaza de Juan XIII (ver Figura 2.3), situada en el centro de la ciudad entre el Palacio del Arzobispo y la Catedral, donde son mantenidos tres parterres que suman 13,3 $\mathrm{m}^{2}$ y que obviamente no pueden ser utilizados por los habitantes de la ciudad. Y en segundo lugar se ha seleccionado la Glorieta de Vetones y Vacceos, situada en el barrio salmantino del Arrabal, con una extensión de 1,8 ha y donde tampoco se pueden llevar a cabo las funciones citadas anteriormente.

Una zona verde no es capaz de albergar un determinado tipo de actividades como la práctica deportiva, el paseo o determinados juegos para niños, cuando no alcanza un tamaño mínimo, perdiendo así una parte importante de su funcionalidad. Sin embargo, esto no significa que los pequeños parques y jardines no posean valor, sino que como apuntan Van 
Figuras 2.3 Espacios verdes no utilizados por los ciudadanos. Arriba: Plaza de Juan XIII (Salamanca). Abajo: Glorieta de Vetones y Vacceos (Salamanca).
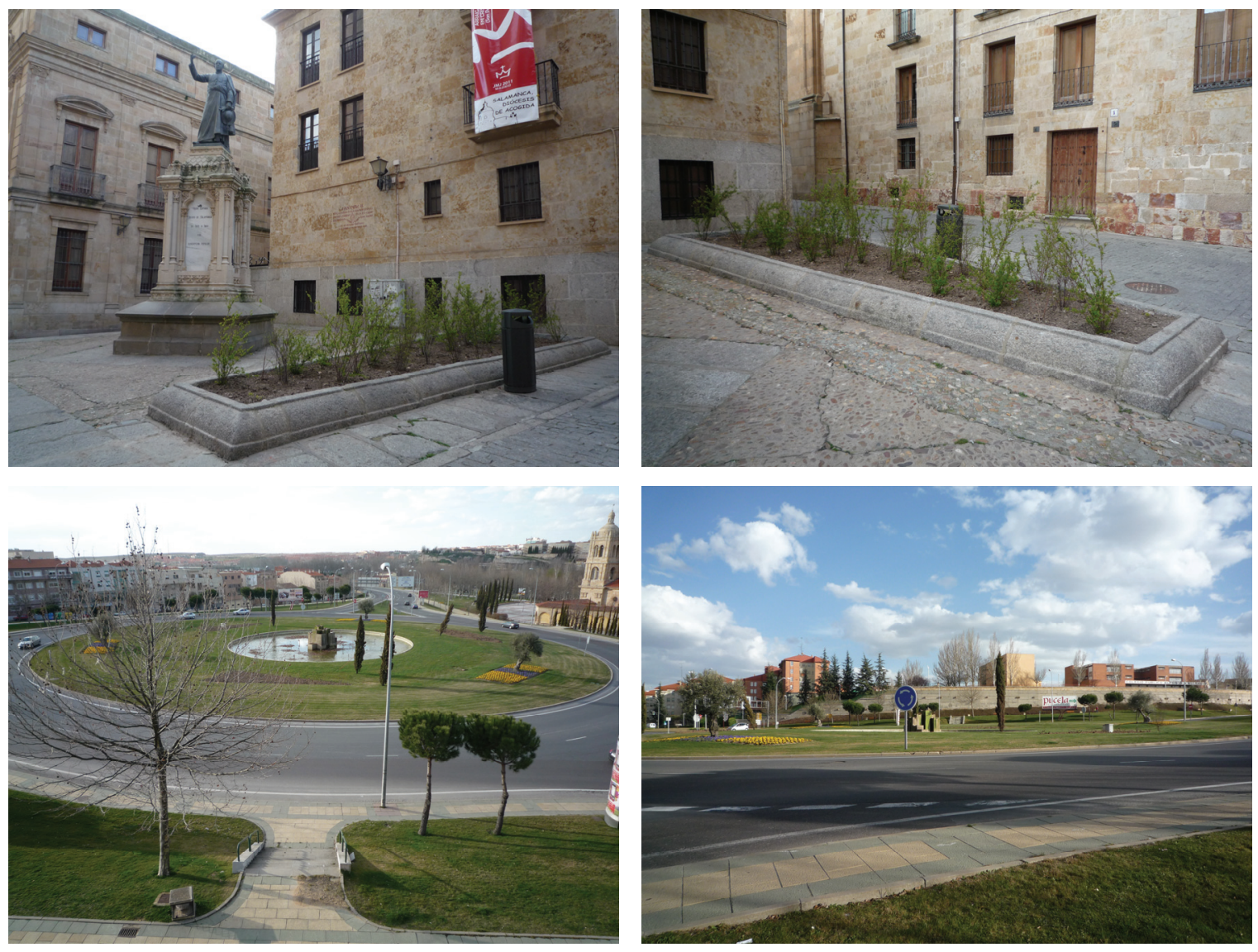

Fuente: Gómez, A. (07/03/2011).

Herzele y Wiedemann (2003), forman parte junto con plazas, bancos, zonas de juego, etc., del conjunto de espacios públicos de la ciudad, con un innegable valor recreativo. Aunque no hayan sido incluidos en esta investigación, dichos autores destacan su importancia en las proximidades del lugar de residencia, especialmente para las personas con movilidad reducida y para los niños de menor edad.

Para determinar el tamaño mínimo del verde urbano se utilizó una técnica considerada como la más adecuada de entre todas las testadas. Para llegar hasta ella se fueron descartando otras que, como se verá a continuación, se mostraron menos operativas al ser aplicadas en las ciudades elegidas.

\subsubsection{Los parques y jardines gestionados por los ayuntamientos}

Las ciudades españolas cuentan con un servicio encargado de la gestión y del mantenimiento de los espacios verdes, dependiente en la mayoría de los casos de la concejalía o del área de medio ambiente. Por lo tanto, parecería sensato utilizar los censos de parques y jardines que poseen estos organismos, ya que son los encargados de su cuidado y del gasto monetario vinculado al mismo. La técnica planteada es la siguiente: a través de los datos proporcionados por dichas instituciones, fueron seleccionadas las áreas verdes de mayores dimensiones, tratando con ello de trabajar con un número reducido de las mismas pero suficientemente representativo sobre el total de la superficie verde total gestionada por los municipios. 
Para ello se solicitaron los censos de espacios verdes a los servicios encargados de su mantenimiento en los tres municipios donde se desarrolló esta investigación, apareciendo ya un obstáculo insalvable como fue la imposibilidad de obtener datos del municipio de Zamora. Este hándicap impediría la utilización de esta técnica, pero se continuó analizando su validez en Salamanca y Valladolid para tratar de obtener aspectos claves en la búsqueda de una definición del verde urbano. Empleando únicamente los censos facilitados por el SPYJAS y por el SPYJAV (Servicio de Parques y Jardines del Ayuntamiento de Valladolid), se ordenaron las zonas verdes de mayor a menor tamaño y se representaron en la Figura 2.4, donde en el eje de abscisas aparece el número de parques y jardines, y en el de ordenadas, el porcentaje acumulado de la superficie verde total mantenida por los distintos ayuntamientos.

Figura 2.4 Porcentaje acumulado de la superficie verde total en los municipios de Salamanca y de Valladolid.

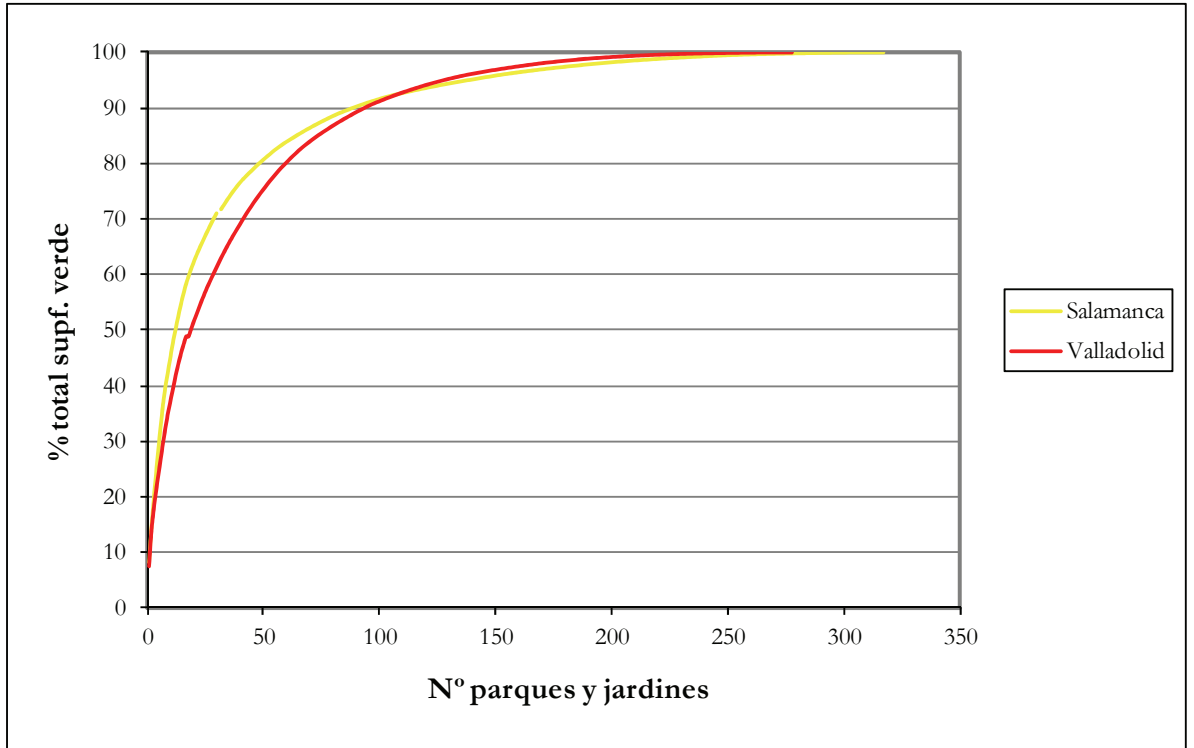

Fuente: Servicio de Parques y Jardines del Ayuntamiento de Salamanca (SPYJAS) y Servicio de Parques y Jardines del Ayuntamiento de Valladolid (SPYJAV).

El análisis de dicho gráfico confirma que con un número reducido de las áreas verdes de mayor tamaño, se obtienen cifras porcentualmente muy significativas respecto del total de parques y jardines gestionados por los distintos ayuntamientos. En el caso de Salamanca, el conjunto de los trece espacios de mayor tamaño representa más del 50\% de la trama verde mantenida por el gobierno local y los treinta mayores un $71 \%$, lo que supone una superficie de 100,1 ha y de 158,9 ha respectivamente. Por su parte, en Valladolid se necesitan diecinueve espacios verdes para superar el $50 \%$ de la superficie verde total de la ciudad y la suma de los treinta parques y jardines de mayores dimensiones representa un $61,2 \%$ de la superficie gestionada por el SPYJAV, lo que equivale respectivamente a cifras de 177,4 ha y de 217,1 ha.

Se observa pues, que con las treinta mayores áreas verdes se estarían manejando cifras porcentuales significativas de la trama verde de cada municipio. Por tanto, para analizar la validez de este procedimiento se han examinado, a modo de ejemplo, los treinta espacios de mayores dimensiones del censo del SPYJAS (ver Tabla 2.3). Estos son los principales inconvenientes identificados al analizar estos datos, extensibles al resto de zonas verdes de Salamanca:

1. El censo incluye espacios verdes situados fuera de lo que en esta investigación se ha considerado como ciudad. Este es el caso de las cinco áreas verdes de mayores dimensiones mantenidas por el SPYJAS (Ciudad deportiva de la Aldehuela, Monte de 
utilidad pública de la Aldehuela, Parque paisajista del Baldío, Chopera de la Aldehuela y Paseo de las Dehesas) que comprenden una extensión de 64,1 ha, equivalente al $28,6 \%$ de la superficie verde total gestionada por dicho organismo.

Tabla 2.3 Listado de los espacios verdes de mayores dimensiones gestionados por la Sección de Parques y Jardines del Ayuntamiento de Salamanca (SPYJAS).

\begin{tabular}{|c|c|c|c|c|c|}
\hline $\mathbf{N}^{\mathbf{o}}$ & Nombre & Barrio & Superficie (ha) & $\begin{array}{c}\text { Superficie }(\% \\
\text { total) }\end{array}$ & $\begin{array}{c}\text { Superficie (\% } \\
\text { acumulado) }\end{array}$ \\
\hline 1 & ALDEHUELA, CIUDAD DEPORTIVA & ALDEHUELA & 18,4 & 8,25 & 8,25 \\
\hline 2 & ALDEHUELA, MONTE U. PUBLICA & ALDEHUELA & 13,7 & 6,15 & 14,39 \\
\hline 3 & PARQUE PAISAJISTA (Baldio) & ALDEHUELA & 11,5 & 5,15 & 19,55 \\
\hline 4 & ALDEHUELA, CHOPERA DE LA & ALDEHUELA & 10,3 & 4,61 & 24,15 \\
\hline 5 & PASEO DE LAS DEHESAS & ZURGUEN & 10,0 & 4,48 & 28,64 \\
\hline 6 & JESUITAS, PARQUE DE LOS & PROSPERIDAD & 9,2 & 4,13 & 32,77 \\
\hline 7 & JARDIN BOTANICO HUERTA OTEA & HOSPITAL & 8,7 & 3,90 & 36,67 \\
\hline 8 & MIGUEL DELIBES, PARQUE DE & ARRABAL & 6,9 & 3,10 & 39,77 \\
\hline 9 & SECTOR $59 \mathrm{~B}$ & TEJARES & 5,6 & 2,51 & 42,28 \\
\hline 10 & TESO DEL PARADOR & ARRABAL & 5,5 & 2,46 & 44,74 \\
\hline 11 & SALAMANCA, AVDA. DE & AVDA. SALAMANCA & 5,5 & 2,46 & 47,20 \\
\hline 12 & URBANIZACION LA PLATA S. 61 & LA PLATINA & 4,8 & 2,16 & 49,36 \\
\hline 13 & JERONIMOS, PARQUE DE LOS & LA PROSPERIDAD & 4,6 & 2,07 & 51,43 \\
\hline 14 & WURBURG, PARQUE DE & GARRIDO NORTE & 4,3 & 1,92 & 53,35 \\
\hline 15 & EL MONTALVO II, SECTOR & POL. EL MONTALVO II & 4,2 & 1,88 & 55,23 \\
\hline 16 & ALDEHUELA, VIVERO MUNICIPAL & ALDEHUELA & 3,8 & 1,68 & 56,91 \\
\hline 17 & BARRIO DE SAN JOSE & SAN JOSE & 3,4 & 1,54 & 58,46 \\
\hline 18 & PUENTE ROMANO (ambas zonas) & ARRABAL & 2,9 & 1,28 & 59,74 \\
\hline 19 & BARRIO EL TORMES & EL TORMES & 2,7 & 1,21 & 60,94 \\
\hline 20 & LAZARILLO, PARQUE DEL & TEJARES & 2,5 & 1,10 & 62,04 \\
\hline 21 & BURGOS, PLAZA DE & CAPUCHINOS & 2,4 & 1,08 & 63,12 \\
\hline 22 & VALHONDO, PARQUE DE & PIZARRALES* & 2,2 & 0,99 & 64,12 \\
\hline 23 & MAYOR DE CHAMBERI-CORDEL DE MERINAS & ALAMBRES & 2,1 & 0,93 & 65,05 \\
\hline 24 & MIROBRIGA 2, PARQUE DE & PUENTE LADRILLO & 2,0 & 0,91 & 65,96 \\
\hline 25 & VILLAR Y MACIAS, PARQUE DE & SAN BERNARDO & 2,0 & 0,90 & 66,86 \\
\hline 26 & FLUVIAL, PASEO (zona 2) & LA FONTANA & 2,0 & 0,90 & 67,76 \\
\hline 27 & ALAMEDILLA, PARQUE DE & ALAMEDILLA & 1,9 & 0,85 & 68,60 \\
\hline 28 & VISTAHERMOSA, 2 S. 35-C & VISTAHERMOSA & 1,9 & 0,84 & 69,44 \\
\hline 29 & CHINCHIBARRA, PARQUE DE LA & CHINCHIBARRA & 1,8 & 0,82 & 70,27 \\
\hline 30 & BETONES Y VACCEOS, GLORIETA DE & EL TORMES & 1,8 & 0,78 & 71,05 \\
\hline
\end{tabular}

Fuente: Servicio de Parques y Jardines del Ayuntamiento de Salamanca.

2. Algunas zonas verdes que forman un continuo espacial han sido divididas en varios sectores por motivos ligados a la optimización en la gestión del patrimonio vegetal. En esta investigación, el verde urbano se concibe como un conjunto único, no restringido por la delimitación impuesta por la parcelación urbana sino por su accesibilidad y por la continuidad de elementos vegetales de cierta envergadura, lo que implica que en no pocas situaciones se ha considerado que un espacio verde con o sin cerramiento, tiene continuidad en otra zona urbana vegetada. Un ejemplo de ello es el Teso del Parador ( ${ }^{\circ} 10$ en la Tabla 2.3), incluido en esta investigación dentro del Parque de El Zurguén ( $\mathrm{n}^{\circ}$ 8, aquí nombrado como Parque de Miguel Delibes), por constituir un continuo verde sin ruptura. 
3. Varios jardines de reducidas dimensiones, en ocasiones sin ningún equipamiento, aparecen concentrados en una categoría denominada "barrio": Barrio de San José (no 17) o Barrio El Tormes (n 19).

4. Obviamente, no aparece el verde urbano no gestionado por el ayuntamiento, por lo que numerosos espacios quedarían excluidos de la trama verde de la ciudad al utilizar este procedimiento. Por ejemplo, no se contemplan otras áreas abiertas que según Van Herzele y Wiedemann (2003), citando los trabajos de Harrison y Burgess, son frecuentemente consideradas como positivas por parte de los ciudadanos: los cementerios, los campos de golf, los descampados o baldíos, los huertos urbanos, etc. En el caso de Salamanca son llamativas las ausencias del Complejo deportivo de Salas Bajas, debido a que se trata de una zona verde cuya gestión depende de la Universidad de Salamanca, y del conjunto de huertos urbanos presentes en la ciudad.

5. En cambio, aparecen incluidas áreas verdes no visitadas como las glorietas $\left(\mathrm{n}^{\circ} 30\right)$, que alterarían el propósito de una investigación en la que se analice el uso del verde urbano por parte de los ciudadanos.

6. Estos datos no siempre están al alcance de un investigador, como se evidenció al solicitar el censo de espacios verdes al Ayuntamiento de Zamora.

Por estos motivos se rechazó el uso de los censos de parques y jardines municipales para delimitar el verde urbano. Sin embargo, este análisis permitió confirmar que un pequeño número de zonas verdes puede representar un porcentaje muy elevado de la superficie total de la trama verde de una ciudad, lo que justifica en parte el propósito de trabajar con las áreas verdes de mayores dimensiones.

\subsubsection{Superficies fijas para delimitar el verde urbano}

Algunos autores fijan una superficie mínima para incluir una parcela con vegetación dentro de las diferentes tipologías utilizadas al referirse a las zonas verdes urbanas. Para valorar la idoneidad de este método o técnica, se han tomado como referencia cuatro investigaciones. Por un lado se han analizado dos trabajos españoles que fijan en 4 ha el límite de los parques urbanos, tanto en la ciudad de Madrid (Rodríguez y Díaz, 2003), como en el conjunto de núcleos urbanos de la Comunidad de Madrid (Canosa et al., 2003). Por otro lado Gámez (2005) fijó en $1.000 \mathrm{~m}^{2}$ la superficie mínima para que un espacio vegetado fuera considerado como verde en Santiago de Chile, mientras que Van Herzele y Wiedemann (2003), en sus estudios en varias ciudades de Flandes (Bélgica), clasificaron estas áreas en función del tamaño creando distintas categorías. Estos autores se centraron en los espacios más extensos, concretamente en los que superaban las 10 ha, por su elevada capacidad de atracción.

Si se comparan entre sí las distintas ciudades en las que se han desarrollado los trabajos citados, se observa que existe una sensible diferencia en cuanto al tamaño demográfico de las mismas: Canosa et al. (2003) trabajaron con municipios de más de 10.000 habitantes de la Comunidad de Madrid, Rodríguez y Díaz (2003) analizaron la situación del municipio capitalino con 3.265.038 habitantes en 2011 (INE), Gámez (2005) realizó su investigación en la ciudad de Santiago de Chile, donde estaban censados 200.792 habitantes en el año 2002 (INE Chile, 2011) y las cuatro ciudades incluidas en la investigación de Van Herzele y Wiedemann (2003) oscilaban entre los 499.499 habitantes de Amberes y los 72.273 de Cortrique (DGIP, 2011). 
Para incluir un espacio vegetado dentro de la categoría de verde en Santiago de Chile, Gámez (2005) utilizó algunos criterios del planeamiento francés que fijaban en $1.000 \mathrm{~m}^{2}$ la superficie mínima de los mismos. Como se señalará en el cuarto capítulo de la presente investigación, este criterio estuvo vigente en el planeamiento español durante un periodo de tiempo considerable: desde que se publicó el reglamento de la segunda Ley del Suelo de 1976 hasta que una vez transferido el urbanismo a las Comunidades Autónomas, estas fueron publicando sus propias leyes. Concretamente, en Castilla y León la Ley de Urbanismo fue aprobada en 1999 y el actual Reglamento de 2009 cifra en $500 \mathrm{~m}^{2}$ la superficie unitaria mínima para el sistema local de espacios verdes públicos, lo que supone una reducción del 50\% (Artículo 105 del RUCYL).

De las cuatro investigaciones anteriormente citadas, únicamente Canosa et al. (2003) y Van Herzele y Wiedemann (2003) trabajaron con municipios o comunnes de tamaño variable, lo que les obligó a buscar un tamaño mínimo de espacio verde que fuera válido en ciudades de diverso tamaño. Sin entrar a valorar las distintas categorías creadas, la tipología propuesta por Van Herzele y Wiedemann (2003) comparte algunas de las ideas que se encuentran detrás del planeamiento vigente en Castilla y León. Por ejemplo, se realiza una distinción entre las áreas verdes que teóricamente serían de mayor tamaño, diseñadas mediante el planeamiento general y destinadas a dar servicio a buena parte de los habitantes de la ciudad (Artículo 83 del RUCYL), y los espacios verdes de dimensión reducida, mayoritariamente vinculados al planeamiento local, cuya función sería dar servicio a los residentes en las nuevas piezas urbanas (Artículo 105 del RUCYL).

Por su parte, Canosa et al. (2003) utilizaron un valor fijo de 4 hectáreas como límite para incluir un espacio verde dentro de la categoría de parque urbano. Llama la atención el empleo del mismo criterio tanto para el municipio de Madrid, como para el de Tres Cantos, que contaba en 2011 con 41.065 habitantes (INE). De esta manera se igualan los tamaños mínimos del verde entre diferentes entidades urbanas, sin tener en cuenta que actualmente las legislaciones autonómicas vinculan la reserva de suelo para espacios libres públicos de un municipio a dos criterios, como se explicó en el capítulo anterior: por un lado al total de habitantes del mismo, en el caso del planeamiento general, y por otro a la superficie de suelo construible, que en el caso de Castilla y León oscila entre un 15\% y un $20 \%$ de la extensión del planeamiento local. Para valorar la operatividad de este método se empleó el concepto de parque urbano, tal y como fue concebido por Canosa et al. (2003), en las tres ciudades castellano-leonesas seleccionadas para esta investigación. El resultado reflejaba un notable contraste entre Zamora, que contaría solo con cuatro espacios con las características anteriormente señaladas, frente a los veinticuatro de Valladolid. Una simplificación tan fuerte del número y de la extensión de la trama urbana alteraría sustancialmente los resultados, especialmente en el análisis territorial, al excluir del estudio a una parte importante de las áreas verdes.

Por lo tanto, si lo que se pretende es determinar una cifra a partir de la cual una superficie pasa a formar parte, de manera general, del verde urbano, habría que relacionar de algún modo el tamaño de la entidad urbana dentro de la cual aparecen situados los espacios verdes con la cifra umbral que se debería aplicar en cada uno de los casos.

\subsubsection{Superficie del verde urbano dependiente del tamaño de la ciudad}

De entre todas las testadas, la técnica de los coeficientes fijos se muestra como la más funcional de las conocidas hasta el momento, ya que resuelve el problema de la superficie mínima del verde urbano desde una perspectiva geográfica basada en la diferencia de escala. Se trata de un criterio novedoso que persigue la optimización de las propuestas citadas anteriormente para determinar si una superficie con vegetación se debe incluir o no dentro de la categoría mencionada. La reducción del elevado número de parques y jardines que 
gestionan los ayuntamientos, permitiría trabajar únicamente con las zonas verdes de mayor tamaño, que serán las que cuentan con una entidad suficiente para desarrollar las funciones tradicionales de estos espacios, donde además se concentrarán la mayor parte de las visitas a las áreas verdes de una ciudad. Aquí se retoma uno de los argumentos más repetidos a lo largo de esta investigación: la relación entre los seres humanos y el verde urbano. Conviene recordar que se pretende analizar el uso que las personas hacen de estos espacios y por eso se han excluido las zonas verdes minúsculas o inaccesibles. Experiencias como la de Van Herzele y Wiedemann (2003) en las ciudades flamencas apuntan a que existe una relación directa entre el tamaño de un área verde y su capacidad de atracción, vinculada a la satisfacción de una mayor variedad de las necesidades humanas, y consecuentemente las áreas de menor tamaño serían menos atractivas.

Por lo tanto, se ha puesto en relación el tamaño de las ciudades analizadas con la superficie mínima del verde urbano. En primer lugar, y para determinar la escala de la ciudad, se hicieron coincidir los límites de la urbe con los bordes verticales u horizontales de un A-4 utilizando un layout de un programa de SIG, en este caso el ArcView 3.2. De este modo se consiguió hacer extensible este procedimiento a urbes de muy distinto tamaño, obteniendo como resultado diversas imágenes con escalas mayores o menores en función de su dimensión. Después se multiplicó la escala de la ciudad por un coeficiente fijo con el que se obtuvo un tamaño mínimo del verde urbano diferente en función de la dimensión de la misma. Se fueron probando varios factores de multiplicación y finalmente se optó por un coeficiente de $0,3 \mathrm{~m}^{2}$, por considerarlo como el más adecuado después de analizar los resultados obtenidos en Salamanca, Valladolid y Zamora. En la Tabla 2.5 aparecen las escalas obtenidas en las tres ciudades objeto de estudio mediante la técnica anteriormente señalada. Una vez multiplicadas por el coeficiente fijo de $0,3 \mathrm{~m}^{2}$ se obtuvieron las cifras mínimas del verde urbano: 1,26 ha para la ciudad de Valladolid, 0,9 ha para Salamanca y 0,66 ha para Zamora.

Tabla 2.4 Tamaño mínimo del verde urbano utilizando un coeficiente de $0,3 \mathrm{~m}^{2}$.

\begin{tabular}{|l|c|c|c|}
\hline & $\begin{array}{c}\text { Escala de la imagen } \\
\text { de la ciudad }\end{array}$ & Coeficiente fijo $\mathbf{( m}^{\mathbf{2}} \mathbf{)}$ & $\begin{array}{c}\text { Superficie mínima del } \\
\text { verde urbano }\left(\mathbf{m}^{\mathbf{2}}\right)\end{array}$ \\
\hline Salamanca & $1 / 30.000$ & 0,3 & 9.000 \\
\hline Valladolid & $1 / 42.000$ & 0,3 & 12.600 \\
\hline Zamora & $1 / 22.000$ & 0,3 & 6.600 \\
\hline
\end{tabular}

Fuente: elaboración propia.

Las principales ventajas de utilizar una técnica basada en coeficientes fijos para definir el tamaño mínimo del verde urbano en una determinada ciudad son las siguientes:

1. Permite una cierta autonomía de trabajo al no depender de los datos facilitados por los ayuntamientos, ya que en ocasiones la obtención de los mismos puede ser problemática.

2. Supera los inconvenientes generados por la fijación de un tamaño mínimo común de las áreas verdes para trabajar en ciudades con unos valores demográficos y territoriales muy diversos, poniendo en relación el límite del tamaño de los espacios verdes con el de la urbe en el que están ubicados.

3. Dentro de la categoría de verde urbano se incluyen todas las zonas verdes de la ciudad, independientemente de la entidad encargada de su mantenimiento. 
4. Prescinde de espacios no visitados o no accesibles, como son las glorietas o las medianas de las vías de circulación, así como de las pequeñas áreas verdes que por su tamaño no son capaces de desempeñar las funciones tradicionales del verde urbano.

5. Concibe cada zona verde como un todo, con independencia de que catastralmente se trate de más de una parcela o de que posean nombres o una gestión diferente.

6. No incluye áreas verdes periurbanas, con las ventajas e inconvenientes que ello conlleva.

\section{3 ¿Cómo se definió el verde urbano y el verde urbano disponible?}

A partir de las reflexiones anteriormente expuestas, se ha elaborado una definición de verde urbano de acuerdo con los requisitos enunciados por Pardinas (1969). Según este autor toda definición debe cumplir con tres características: ha de ser empirica, es decir, verificable por la experiencia, operativa, tener la cualidad de expresar la operación por cuyo medio llega a determinarse empíricamente el objeto del que estamos hablando, y ser fidedigna, esto es, estar formulada de tal manera que cualquier investigador pueda distinguir el objeto definido de los demás objetos.

Por verde urbano se entiende aquel espacio tridimensional dominado por la vegetación y caracterizado por el desarrollo de diversas funciones sociales, con una superficie mínima de 0,9 ha en el caso de la ciudad de Salamanca en 2007, de 1,26 ha en el caso de la ciudad de Valladolid en 2008 y de 0,66 ha en el caso de la ciudad en Zamora de 2009.

Como se apuntó anteriormente, el orden de las ciudades está determinado por la fecha de realización de cada análisis, motivando así una diferenciación cronológica entre las imágenes utilizadas en los tres casos.

De ahora en adelante se utilizará la cursiva para referirse a esta definición de verde urbano; en cambio, al mencionar lo que comúnmente se denominan áreas verdes o verde urbano, se continuará manteniendo el formato habitual. En el estudio de los espacios verdes desde una perspectiva social solo se ha utilizado el verde urbano disponible, definido como el verde urbano que puede ser visitado por la mayor parte de los ciudadanos al no presentar un carácter privado ni una configuración inaccesible. Se ha utilizado este concepto y no el de verde urbano accesible, reservando este último término para analizar si los espacios verdes estaban ubicados en las proximidades de las residencias de los ciudadanos. De esta nueva categoría estarían excluidos los huertos urbanos, por no estar disponibles para ser visitados por los ciudadanos, así como el resto del verde urbano cuya visita se encontrase restringida, bien por su carácter privado, bien por una topografía que dificultase su acceso. Los huertos, son espacios orientados a la obtención particular de beneficios económicos, su titularidad es privada y su acceso está vedado a los habitantes de la ciudad. Sin embargo fueron estudiados por desempeñar funciones beneficiosas para los seres humanos. El origen del verde urbano no disponible ha sido analizado en el capítulo cuarto, pero no ha sido incluido en el estudio desde una perspectiva social, puesto que los espacios no conocidos no podrían ser valorados correctamente.

\section{4 ¿Cómo se identificó el verde urbano en las ciudades objeto de estudio?}

Una vez definido el tamaño mínimo del verde urbano, fueron seleccionados los espacios con una superficie igual o mayor a la obtenida mediante la operación anteriormente referida y se procedió a su digitalización utilizando las imágenes de la ciudad con composición infrarroja, en las que los espacios verdes aparecen en tonos rojos más o menos intensos. Para ello se recurrió a las ortofotos anteriormente utilizadas para delimitar las urbes, 
es decir, aquellas proporcionadas por el IGN, con la particularidad de que esta vez se utilizó la composición del infrarrojo, que es una combinación de bandas llamada de falso color (IrRG), del canal infrarrojo, el rojo y el azul. Esta composición permite una fácil localización de los parques y jardines, gracias a la característica signatura espectral de la vegetación. Así, en la imagen final obtenida, las plantas aparecen representadas en rojo con más o menos intensidad en función de su vigor.

El resultado obtenido de aplicar el método de los coeficientes a los espacios verdes de Salamanca, Valladolid y Zamora, aparece representado en las figuras comprendidas entre la 2.5 y la 2.10, ambas incluidas. Para cada ciudad se han elaborado dos imágenes: en la primera se han destacado las áreas verdes sobre la ortofoto, presentando los huertos urbanos en color amarillento, mientras que en la segunda los espacios verdes están numerados y en rojo aparece el verde urbano no disponible. La información de cada uno de estos espacios aparece en su tabla correspondiente en la que se recoge el nombre y la superficie de cada verde urbano (ver Tablas 2.5, 2.6 y 2.7). En total, Zamora cuenta con veintinueve verdes urbanos, Salamanca con treinta y cuatro y Valladolid con cincuenta y seis, datos que presentan cierta lógica si se tiene en cuenta que la normativa urbanística vigente vincula la creación de espacios verdes públicos al número de habitantes de la ciudad y a la superficie construible de los nuevos sectores urbanos.

La superficie total del verde urbano de Salamanca es de 124 ha y la de Valladolid de 331 ha, lo que equivale respectivamente al 55,4\% de la superficie total gestionada por el SPYJAS (223,7 ha) y al 93,3\% de la mantenida por el SPYJAV (354,6 ha). La baja representatividad de los espacios seleccionados en Salamanca es debida a que las cinco zonas verdes de mayor tamaño gestionadas por el SPYJAS (ver Tabla 2.3) estaban situadas fuera de los límites de lo que se ha considerado como ciudad, y su superficie conjunta era de 64,1 ha, es decir, un $28,6 \%$ del total de la gestionada por dicho organismo. Si estos cinco espacios fueran eliminados del total de los parques y jardines de Salamanca, el verde urbano seleccionado para esta ciudad tendría una representatividad del $77,7 \%$, una cifra más cercana a la obtenida en Valladolid.

Anteriormente se citó el trabajo de Rodríguez y Díaz (2003) sobre los parques urbanos de la ciudad de Madrid, donde estas autoras afirman que el conjunto de los 51 parques con más de 4 ha representaban el 61\% de la superficie verde pública del municipio. Estos espacios poseen una serie de características que los asemejan a lo que en la presente investigación se ha denominado como verde urbano disponible, por lo que en la Tabla 2.8 se han comparado esos datos con los obtenidos en las tres ciudades estudiadas. En ella aparecen reflejadas la superficie mínima del verde urbano tomada como límite, el número de verdes urbanos disponibles en cada ciudad, el porcentaje que la superficie total de los mismos representa sobre el total de la superficie de parques y jardines gestionada por los distintos ayuntamientos, la escala de la representación gráfica de las urbes si se ajustasen al tamaño de un A-4 según la técnica utilizada en esta investigación y la población municipal en el año 2010.

Estos datos muestran una relación directa entre la escala de la ciudad y el tamaño de los espacios verdes, observándose también una vinculación del volumen demográfico al tamaño de la ciudad debido a que en nuestro país, el modelo de crecimiento urbano es bastante similar entre los territorios del interior. La superficie total del verde urbano disponible de cada ciudad representa una cifra porcentual significativa, lo que termina por confirmar una de las hipótesis planteadas anteriormente: al trabajar con un número reducido de los espacios verdes de mayores dimensiones, se obtiene un porcentaje elevado de la superficie verde total de una ciudad. Además, en los cuatro casos seleccionados se observa que al reducirse el tamaño mínimo del verde urbano se produce un progresivo descenso del número de espacios verdes, siendo muy llamativo el ejemplo de Zamora, donde la superficie mínima es de 0,66 ha y solamente hay 18 áreas vegetadas que la superan o la igualan. 
Figura 2.5 Localización espacial del verde urbano en la ciudad de Salamanca.

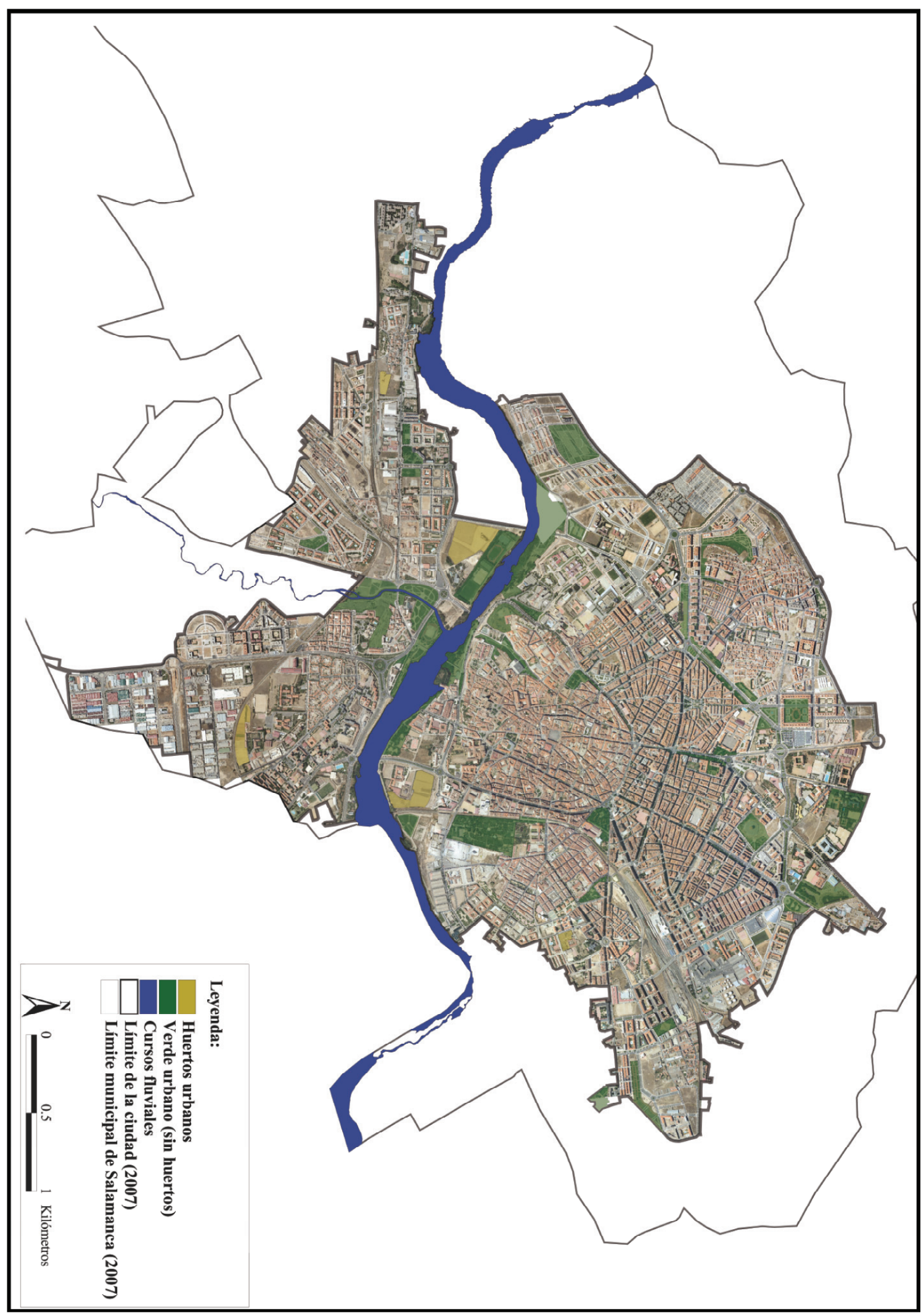

Fuente: elaboración propia a partir de la ortofoto de 2007 del IGN. 
Figura 2.6 Localización espacial del verde urbano disponible en la ciudad de Salamanca.

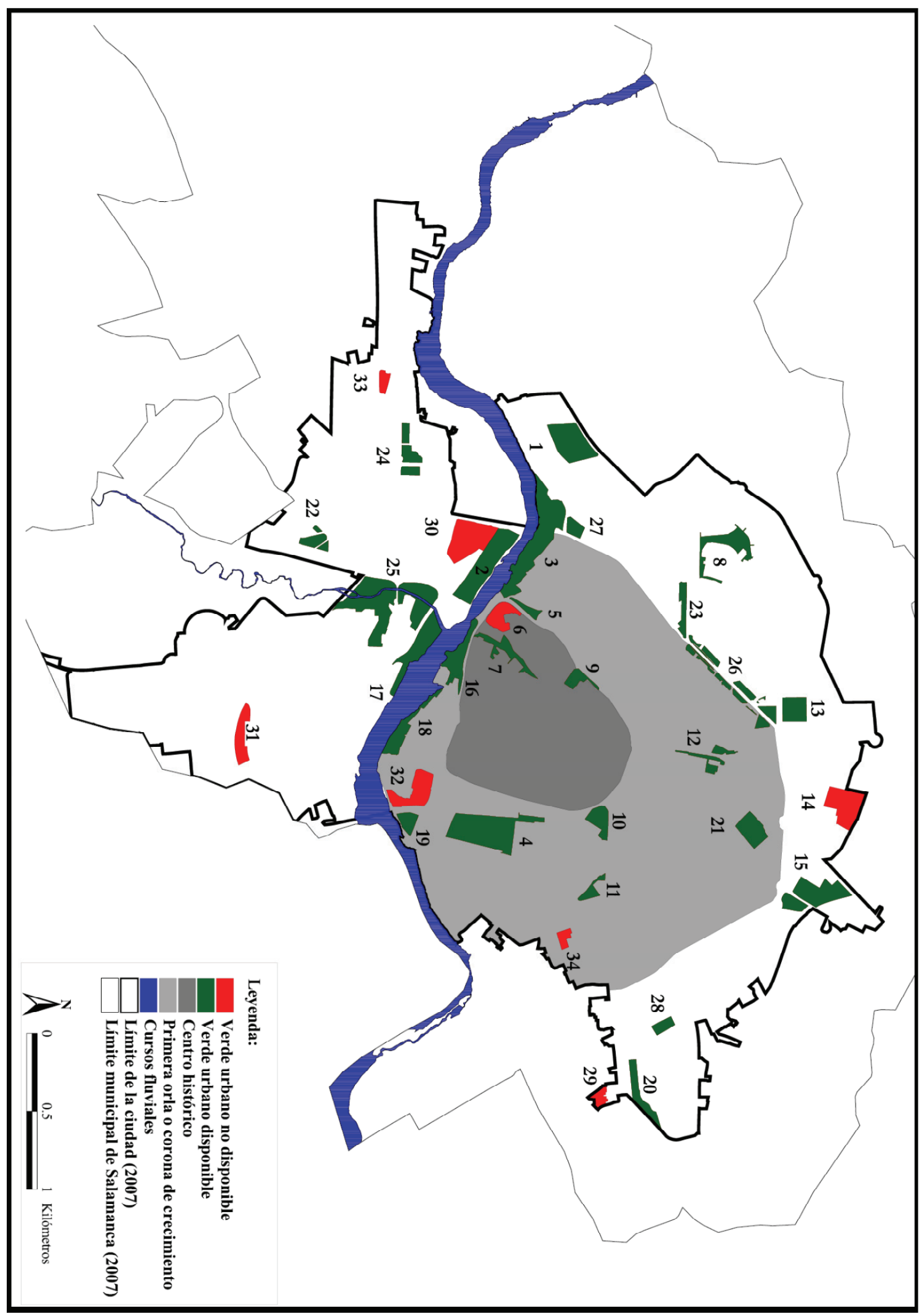

Fuente: elaboración propia a partir de la ortofoto de 2007 del IGN. 
Figura 2.7 Localización espacial del verde urbano en la ciudad de Valladolid.

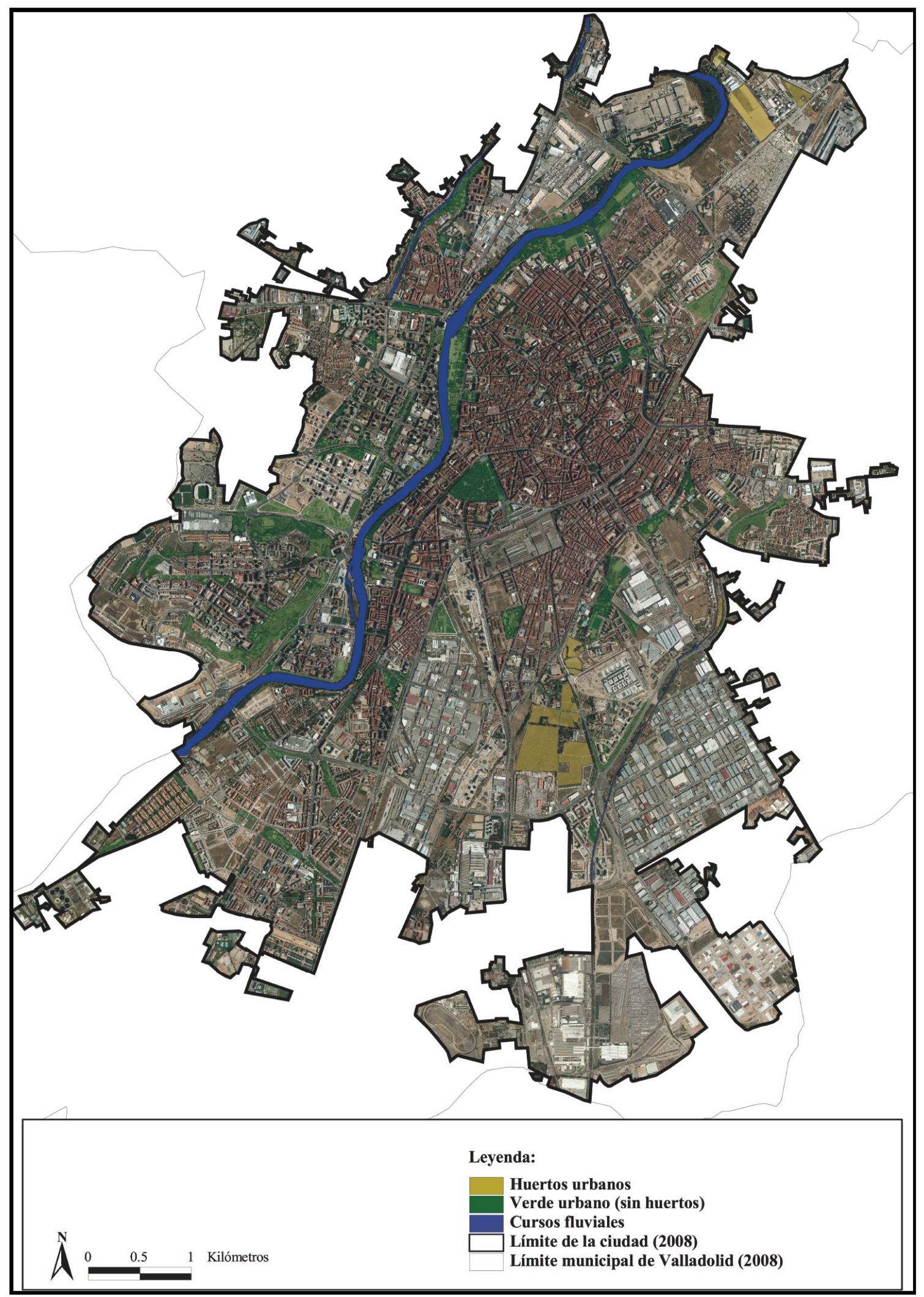

Fuente: elaboración propia a partir de la ortofoto de 2008 del IGN. 
Figura 2.8 Localización espacial del verde urbano disponible en la ciudad de Valladolid.

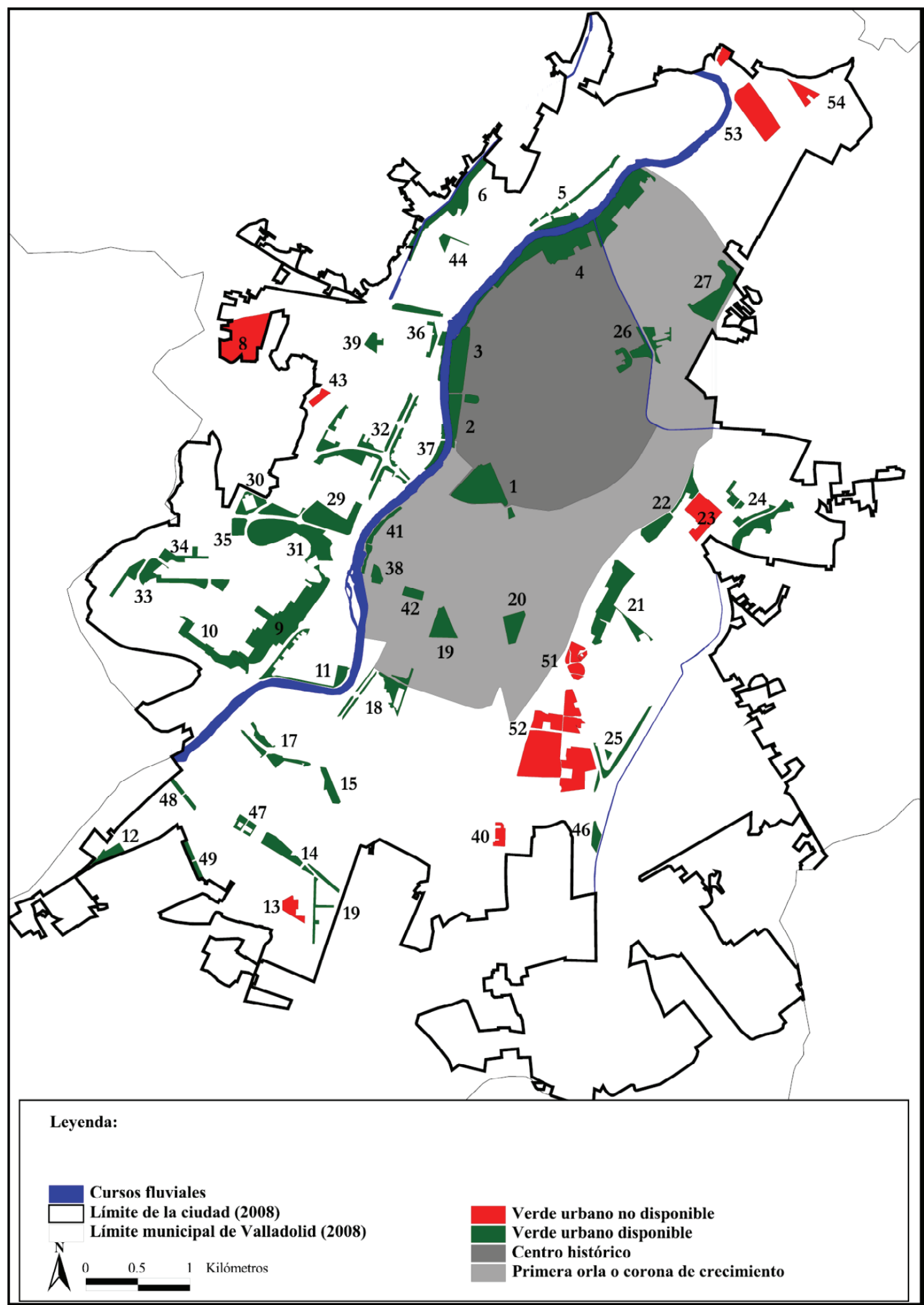

Fuente: elaboración propia a partir de la ortofoto de 2008 del IGN. 
Figura 2.9 Localización espacial del verde urbano en la ciudad de Zamora.

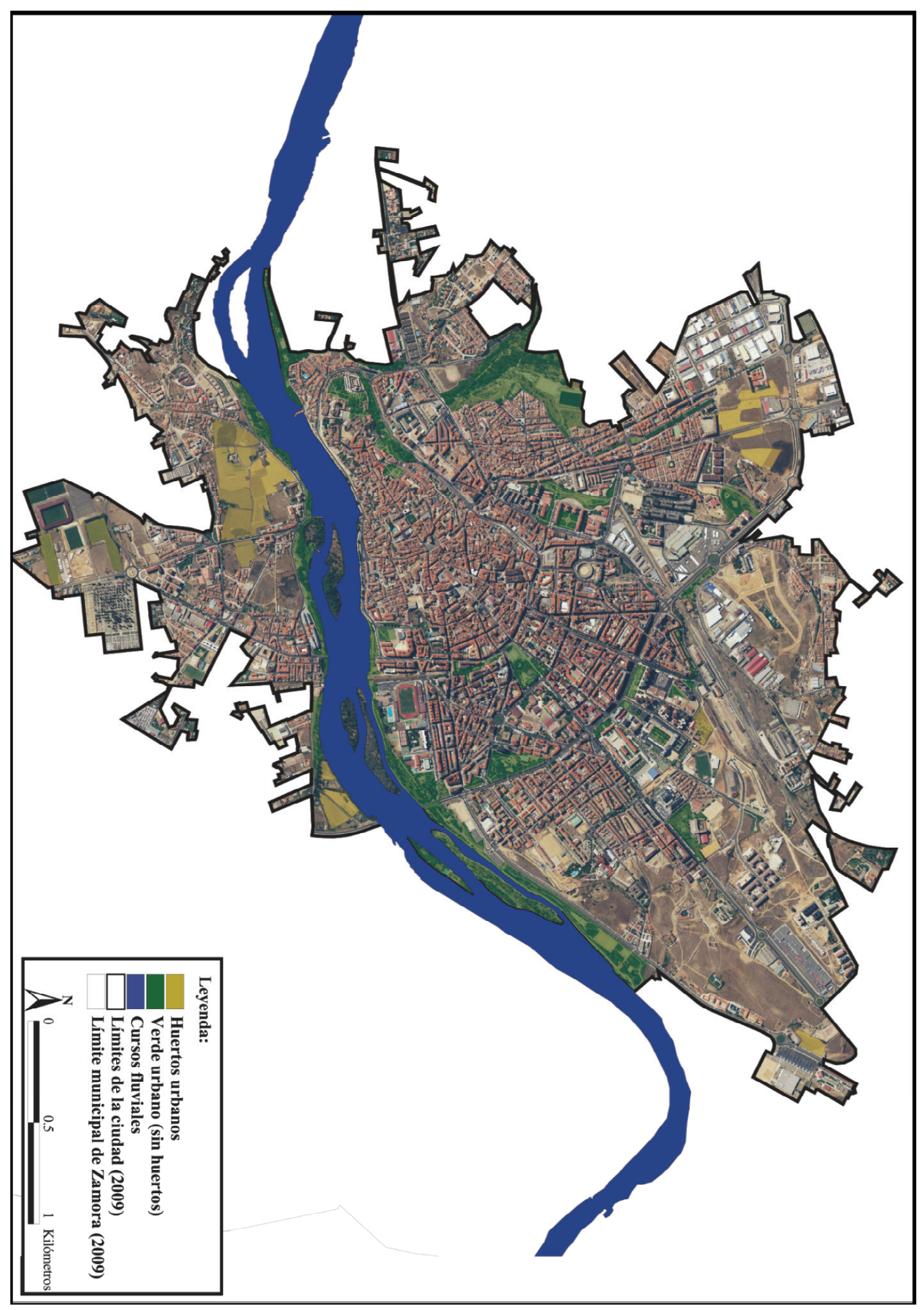

Fuente: elaboración propia a partir de la ortofoto de 2009 del IGN. 
Figura 2.10 Localización espacial del verde urbano disponible en la ciudad de Zamora.

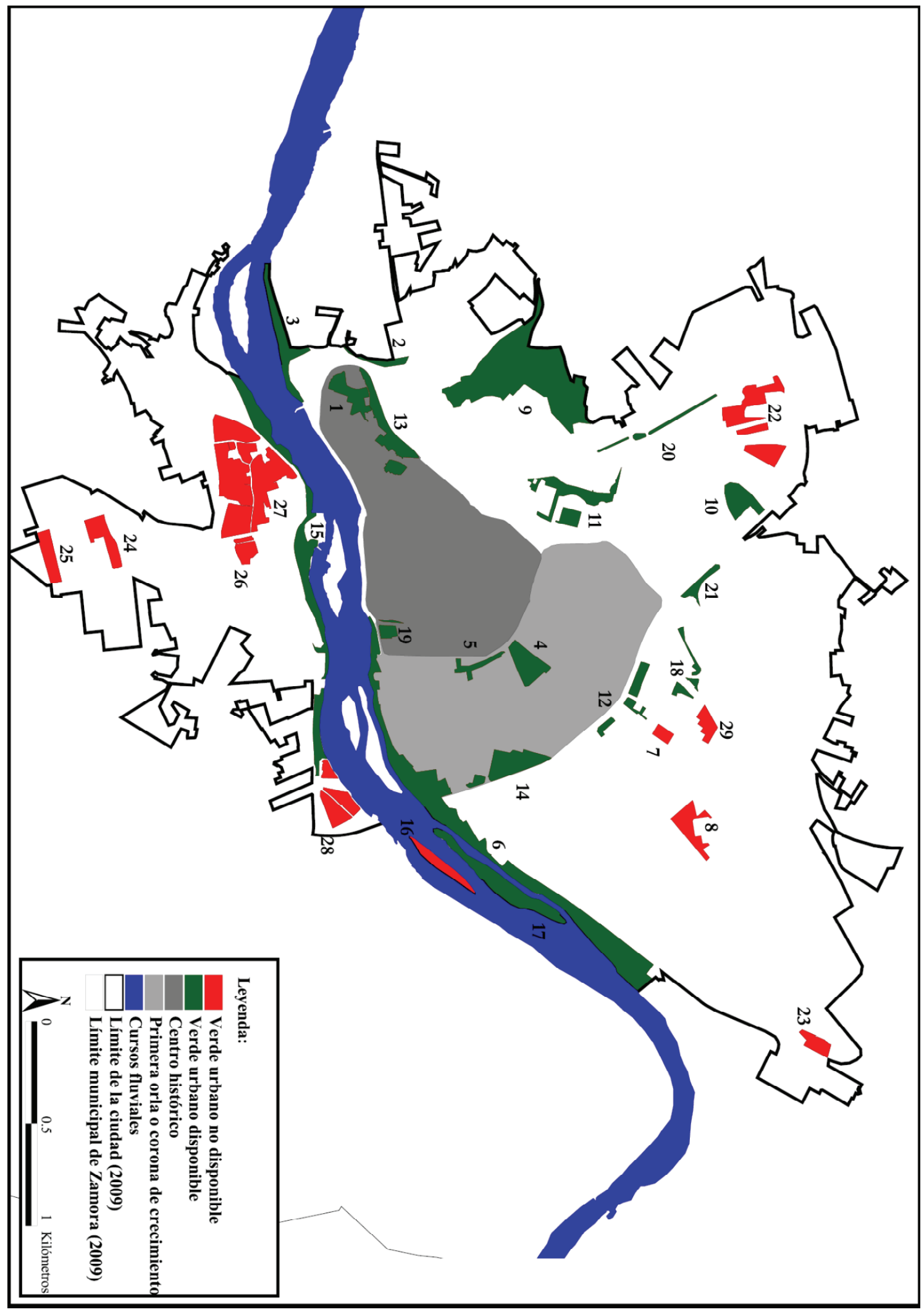

Fuente: elaboración propia a partir de la ortofoto de 2009 del IGN. 
Tabla 2.5 El verde urbano de la ciudad de Salamanca.

\begin{tabular}{|c|c|c|c|c|c|}
\hline $\mathbf{N}^{\mathbf{o}}$ & ha & Nombre & $\mathbf{N}^{\circ}$ & ha & Nombre \\
\hline S-1 & 5,8 & Parque de Don Juan Tenorio & S-18 & 3,1 & Parque Fluvial \\
\hline $\mathrm{S}-2$ & 7,4 & Complejo deportivo Salas Bajas & S-19 & 1,4 & Verde urbano del entorno de Mirat \\
\hline S-3 & 10,8 & Jardín botánico de Huerta Otea & S-20 & 2,7 & Parque de Ciudad Rodrigo \\
\hline S-4 & 10,1 & Parque de los Jesuitas & S-21 & 3,0 & Parque de la Chinchibarra \\
\hline S-5 & 0,8 & Jardines del Hospital Clínico & S-22 & 1,6 & Parque de Vistahermosa \\
\hline S-6 & 2,5 & Verde urbano del cerro de San Vicente & S-23 & 1,6 & Parque de Villar y Macías \\
\hline S-7 & 2,3 & Verde urbano de la Vaguada de La Palma & S-24 & 1,9 & Verde urbano de La Salle \\
\hline S-8 & 4,0 & Parque de Valhondo & S-25 & 13,5 & Parque de El Zurguén \\
\hline S-9 & 1,3 & Campo de San Francisco & S-26 & 4,3 & Verde urbano Av. Salamanca \\
\hline S-10 & 2,2 & Parque de la Alamedilla & S-27 & 1,2 & Verde urbano Facultad de Comunicación \\
\hline S-11 & 1,0 & Parque Picasso & S-28 & 1,0 & Parque de Bretón \\
\hline S-12 & 1,7 & Verde urbano de las Salesas & S-29 & 1,2 & Verde urbano residencia San J. de Sahagún \\
\hline S-13 & 2,7 & Plaza de Burgos & S-30 & 6,3 & Huerto en Salas Bajas \\
\hline S-14 & 5,1 & Seminario de Legionarios de Cristo & S-31 & 2,8 & Huerto en el Montalvo \\
\hline S-15 & 6,0 & Parque de Würzburg & S-32 & 4,1 & Huerto de la Fundación Rodríguez Fabrés \\
\hline \multirow{2}{*}{ S-16 } & \multirow{2}{*}{3,6} & \multirow{2}{*}{$\begin{array}{l}\text { Verde urbano de la margen derecha del } \\
\text { Puente Romano }\end{array}$} & S-33 & 0,9 & Huerto en Tejares \\
\hline & & & S-34 & 0,9 & Huerto de las Misioneras Seculares \\
\hline \multirow{2}{*}{ S-17 } & \multirow{2}{*}{5,2} & \multirow{2}{*}{$\begin{array}{l}\text { Verde urbano de la margen izquierda del } \\
\text { Puente Romano }\end{array}$} & Total & 124,0 & \\
\hline & & & & & \\
\hline
\end{tabular}

Fuente: elaboración propia.

Tabla 2.6 E1 verde urbano de la ciudad de Valladolid.

\begin{tabular}{|c|c|c|c|c|c|}
\hline $\mathbf{N}^{\circ}$ & ha & Nombre & $\mathrm{N}^{\circ}$ & ha & Nombre \\
\hline $\mathrm{V}-1$ & 12,7 & Campo Grande & V-29 & 9,0 & Verde urbano Cortes de Castilla y León \\
\hline \multirow{2}{*}{$\mathrm{V}-2$} & \multirow{2}{*}{4,6} & \multirow{2}{*}{$\begin{array}{l}\text { Parque Rosaleda Francisco Sabadell y Parque } \\
\text { de Poniente }\end{array}$} & $\mathrm{V}-30$ & 4,8 & Verde urbano Auditorio Miguel Delibes \\
\hline & & & $\mathrm{V}-31$ & 15,4 & Verde urbano Mirador Parquesol \\
\hline $\mathrm{V}-3$ & 9,5 & Parque de las Moreras & $\mathrm{V}-32$ & 13,8 & Verde urbano Huerta del Rey \\
\hline V-4 & 26,7 & Parque Ribera de Castilla & $\mathrm{V}-33$ & 8,8 & Verde urbano Parquesol Calle Morelia \\
\hline V-5 & 5,5 & Verde urbano Camino del Cabildo & \multirow{2}{*}{$\mathrm{V}-34$} & \multirow{2}{*}{2,5} & \multirow{2}{*}{$\begin{array}{l}\text { Verde urbano Parquesol Calle Juan de } \\
\text { Valladolid }\end{array}$} \\
\hline V-6 & 7,0 & Jardín Botánico & & & \\
\hline V-7 & 1,2 & Darsenas del Canal Castilla & $\mathrm{V}-35$ & 2,0 & Parque del Reloj de Sol \\
\hline $\mathrm{V}-8$ & 14,7 & Cementerio de las Contiendas & $\mathrm{V}-36$ & 5,0 & Verde urbano Palacio de la Ribera \\
\hline V-9 & 21,0 & Parque del Mediodía & $\mathrm{V}-37$ & 1,6 & Ribera de Huerta del Rey \\
\hline V-10 & 6,6 & Ladera sur Parquesol - Fuente de Dios & V-38 & 1,4 & Verde urbano Plaza Juan de Austria \\
\hline $\mathrm{V}-11$ & 4,7 & Arturo Eyries & V-39 & 1,7 & Verde urbano Calle Morena - Feria Muestras \\
\hline $\mathrm{V}-12$ & 2,4 & Verde urbano Centro de acústica (Santa Ana) & $\mathrm{V}-40$ & 1,8 & Verde urbano Colegio San Agustín \\
\hline V-13 & 2,4 & Jardines Presindencia Junta Castilla y León & \multirow{2}{*}{ V-41 } & \multirow{2}{*}{2,4} & \multirow{2}{*}{$\begin{array}{l}\text { Ribera Pisuerga entre Puente Colgante y } \\
\text { Puente Juan de Austria }\end{array}$} \\
\hline V-14 & 5,3 & Parque de Covaresa & & & \\
\hline $\mathrm{V}-15$ & 2,4 & Parque de la Alameda & $\mathrm{V}-42$ & 1,6 & Plaza del Ejército \\
\hline $\mathrm{V}-16$ & 1,8 & Verde urbano Avenida de los Castaños & $\mathrm{V}-43$ & 1,3 & Residencia de ancianos Cardenal Marcelo \\
\hline V-17 & 4,3 & Verde urbano Valparaíso - Ronda Sur & V-44 & 1,2 & Jardines de La Victoria \\
\hline V-18 & 3,9 & Parque Arturo León & V-45 & 1,6 & Verde urbano Barrio de la Esperanza \\
\hline $\mathrm{V}-19$ & 4,4 & Parque de las Norias de Santa Victoria & V-46 & 1,6 & Verde urbano Pinar de Jalón \\
\hline $\mathrm{V}-20$ & 3,9 & Parque de la Paz & \multirow{2}{*}{ V-47 } & \multirow{2}{*}{1,5} & \multirow{2}{*}{$\begin{array}{l}\text { Verde urbano Calle de la Vega de } \\
\text { Valdetronco - Villas Sur }\end{array}$} \\
\hline $\mathrm{V}-21$ & 12,2 & Parque de Canterac & & & \\
\hline $\mathrm{V}-22$ & 5,9 & Parque San Isidro - Fuente de la Salud & $\mathrm{V}-48$ & 1,2 & Verde urbano Escuela Deportiva Niara \\
\hline V-23 & 7,3 & Club Militar San Isidro & V-49 & 1,8 & Verde urbano Calle Alcaparra \\
\hline $\mathrm{V}-24$ & 7,4 & Verde urbano Ronda Este & $\mathrm{V}-50$ & 1,4 & Huerto urbano Norte \\
\hline V-25 & 4,0 & Verde urbano Calle Arribes del Duero & V-51 & 4,1 & Huertos en Zambrana \\
\hline V-26 & 6,1 & Campus Esgueva & V-52 & 32,6 & Huertos urbanos Sur \\
\hline V-27 & 8,8 & Campus Miguel Delibes & V-53 & 10,5 & Huertos Soto de la Medinilla \\
\hline \multirow[t]{2}{*}{ V-28 } & 1,6 & Paseo Zorrilla Sur & V-54 & 2,5 & Huerto urbano ACOR \\
\hline & & & Total & 331,0 & \\
\hline
\end{tabular}

Fuente: elaboración propia. 
Tabla 2.7 E1 verde urbano de la ciudad de Zamora.

\begin{tabular}{|c|c|c|c|c|c|}
\hline $\mathrm{N}^{\mathrm{o}}$ & ha & Nombre & $\mathrm{N}^{\mathrm{o}}$ & ha & Nombre \\
\hline $\mathrm{Z}-1$ & 1,9 & Parque del Castillo y de la Catedral & Z-16 & 1,8 & Club naútico \\
\hline $\mathrm{Z}-2$ & 0,8 & Verde urbano Calle de los Caballeros & Z-17 & 5,0 & Isla de las Pallas \\
\hline $\mathrm{Z}-3$ & 3,4 & Parque de Olivares & Z-18 & 0,9 & Jardin Carretera de la Estación \\
\hline $\mathrm{Z}-4$ & 2,2 & Parque de la Marina & Z-19 & 0,6 & Verde urbano Puerta Nueva \\
\hline $\mathrm{Z}-5$ & 0,8 & Verde urbano Candelaria Ruiz del Árbol & Z-20 & 0,9 & Verde urbano Calle Ntra Sra. de las Mercedes \\
\hline Z-6 & 16,5 & Margen derecha del Duero & $\mathrm{Z}-21$ & 0,8 & Verde urbano Av. Cardenal Cisneros (Eroski) \\
\hline $\mathrm{Z}-7$ & 0,5 & Jardin de los Salesianos & $\mathrm{Z}-22$ & 4,4 & Huertos Norte ciudad \\
\hline $\mathrm{Z}-8$ & 2,0 & Jardines del CFIE & $\mathrm{Z}-23$ & 1,0 & Huerto Este \\
\hline Z-9 & 16,5 & Bosque de Valorio (parte urbana) & $\mathrm{Z}-24$ & 1,8 & Huerto Norte estadio de fútbol \\
\hline Z-10 & 1,9 & Parque de Peña Trevinca & $\mathrm{Z}-25$ & 1,5 & Huerto Sur estadio de fútbol \\
\hline $\mathrm{Z}-11$ & 3,3 & Jardines de la Vaguada & Z-26 & 1,1 & Huertos Cabañales \\
\hline $\mathrm{Z}-12$ & 1,4 & Verde urbano Avda. Cardenal Cisneros & $\mathrm{Z}-27$ & 12,3 & Huertos San Frontis \\
\hline $\mathrm{Z}-13$ & 3,7 & Parque de San Martín & Z-28 & 2,6 & Huertos Sureste \\
\hline Z-14 & 3,0 & Parque de León Felipe & Z-29 & 1,0 & Huerto Calle Antón de Centenera \\
\hline $\mathrm{Z}-15$ & 8,3 & Margen izquierda del Duero & Total & 101,6 & \\
\hline
\end{tabular}

Fuente: elaboración propia.

Tabla 2.8 Datos referentes a los espacios verdes de las cuatro ciudades de referencia.

\begin{tabular}{|l|c|c|c|c|c|} 
& $\begin{array}{c}\text { Tamaño } \\
\text { verde } \\
\text { urbano (ha) }\end{array}$ & $\begin{array}{c}\mathbf{N}^{\mathbf{0}} \text { verdes } \\
\text { urbanos } \\
\text { disponibles }\end{array}$ & $\begin{array}{c}\text { \% Servicio } \\
\text { Parques y } \\
\text { Jardines }\end{array}$ & $\begin{array}{c}\text { Escala de } \\
\text { la ciudad }\end{array}$ & $\begin{array}{c}\text { Habitantes } \\
\text { (INE, 2010) }\end{array}$ \\
\hline Madrid & 4 & 51 & 61 & $1 / 100.000$ & 3.273 .049 \\
\hline Valladolid & 1,26 & 44 & 71 & $1 / 42.000$ & 315.522 \\
\hline Salamanca & 0,9 & 26 & 44,7 & $1 / 30.000$ & 154.462 \\
\hline Zamora & 0,66 & 18 & Sin datos & $1 / 22.000$ & 65.998 \\
\hline
\end{tabular}

Fuente: elaboración propia.

\section{5 ¿Cómo se analizó el origen y la evolución del verde urbano?}

Se ha estudiado la evolución urbana y la progresiva aparición de áreas verdes en el interior de las ciudades hasta la fecha de la ortofoto más reciente al comenzar esta investigación. Debido a la cronología del trabajo, existe una sensible diferencia entre el año de la ortofoto de Salamanca, 2007, y el de Zamora, con fecha de 2009. El desfase existente entre ambas y la actualidad es inevitable, pero no provocará una merma significativa en el trabajo ya que se pretende analizar la historia de las ciudades en las últimas décadas, prestando especial atención a la aparición de las zonas verdes. No obstante, es necesario incidir en la temprana caducidad de casi cualquier documento que aborde temáticas relacionadas con la ciudad, puesto que la escala temporal reinante en los procesos urbanos no es ni siquiera anual, pudiéndose desarrollar grandes modificaciones del tejido urbano en periodos de tiempo muy cortos.

Especialmente se ha prestado atención al último medio siglo, es decir, al periodo comprendido entre la actualidad y el año 1956, fecha de la primera fotografía aérea del territorio peninsular, destacando algunos hechos anteriores, pero sin revisar en profundidad la historia de cada una de las ciudades. Las herramientas utilizadas permitieron desarrollar una valoración real y con gran exactitud de la expansión territorial de cada una de ellas. De entre la variedad de documentos cartográficos existentes, los que recogen más fielmente la realidad urbana en cada momento son las fotografías aéreas y las ortofotografías, debido a que ofrecen una imagen puntual del tejido urbano, permitiendo obtener de una manera más o menos exacta la delimitación de la ciudad. Es necesario señalar que la fotografía aérea tiene numerosos inconvenientes (no así la ortofoto, cuyo visionado se realiza de manera clara y nítida). Por ejemplo, dependiendo de la iluminación en el momento de la realización del 
vuelo, pueden aparecer sombras que al trabajar con grandes escalas compliquen la limitación precisa tanto del entramado urbano como de los espacios verdes. Asimismo la resolución de la fotografía aérea impide, en ocasiones, apreciar con claridad determinados elementos de la ciudad. Pese a todo, parece el método más exacto para realizar estimaciones del crecimiento espacial, al tratarse de una imagen real que recoge no solo las características morfológicas de las construcciones, sino que además muestra el estado de los terrenos próximos a las ciudades y los cambios en el tiempo, tanto en el interior como en la periferia.

Los documentos empleados para realizar este análisis han sido muy similares en las tres ciudades: tres fotografías aéreas y dos ortofotografías. La primera es la de 1956, del llamado vuelo americano, es decir, el vuelo realizado por el ejército de los Estados Unidos que posteriormente fue cedido al Servicio Geográfico del Ejército (SGE). Por otra parte, las fotografías aéreas de 1971 y de 1984 las proporciona directamente el Instituto Geográfico Nacional (IGN), al igual que las ortofotos de 2000-2001 y las de la actualidad, que varían entre 2007 y 2009, con la particularidad de que se inscriben dentro del Plan Nacional de Ortofotografía Aérea (PNOA), cuyo objetivo es proporcionar ortofotografías de todo el territorio estatal con cierta periodicidad. Son pues, documentos de distintas épocas, que componen la base del estudio territorial de las ciudades de Salamanca, Valladolid y Zamora, y de sus espacios verdes. Con este material se han generado distintos productos cartográficos a partir del trazado de los límites de las ciudades de 1956, de 1971, de 1984, de 2001 y de 2009, dentro de los cuales se han identificado los espacios verdes más significativos para la consecución del objetivo de explicar la actual configuración de la trama verde. A través de las cinco imágenes de referencia, se ha reconstruido la evolución histórica de cada una de las ciudades estudiadas y de sus principales hitos urbanísticos, utilizando como apoyo fundamental la literatura especializada en esta cuestión.

Para el análisis de la evolución urbana se ha optado por utilizar el barrio como la unidad administrativa de referencia debido a su tamaño intermedio, porque no son tan extensos como los distritos, ni tan reducidos como las manzanas o las circunscripciones electorales, a su carácter más o menos estable en el tiempo, ya que otras unidades administrativas varían en función del crecimiento de la población, y a su fácil identificación por parte de los ciudadanos. Al igual que el verde urbano, los barrios se encuentran delimitados espacialmente en el mapa de cada una de las ciudades, y este documento aparecerá acompañado de una tabla en la que se especifique el nombre de cada uno de ellos.

\section{6 ¿Cómo se estudió verde urbano disponible desde una perspectiva social?}

Para analizar desde un punto de vista geográfico, el uso que los ciudadanos hacen de estos espacios, se estudió por un lado "el verde urbano sin personas", es decir, el conjunto de características estructurales, cuyo análisis se realizó mediante la evaluación de sus componentes, y por otro, "el verde urbano con personas", prestando especial atención al comportamiento de los ciudadanos en las áreas verdes de la ciudad, a sus impresiones, a sus necesidades y a sus opiniones. Posteriormente se estudiaron las relaciones que existen entre ambos aspectos empleando un concepto novedoso como es la calidad de las zonas verdes, que permite estimar la influencia en la valoración que hacen los ciudadanos, tanto de los equipamientos de los propios parques como de algunos comportamientos sociales que pueden llegar a ser percibidos como negativos.

El uso que los ciudadanos hacen de las áreas verdes se ha estudiado a través de entrevistas personales, combinadas con inventarios mediante los cuales se identificaron las características fundamentales de cada uno de los espacios estudiados. La obtención de estos resultados puede llegar a ser de utilidad a la hora de planificar nuevas áreas verdes ya que su aparición en el interior de la ciudad está motivada por una serie necesidades sociales y para su planificación y correcta gestión deberían tenerse en cuenta los usos que los ciudadanos vayan 
a hacer de las mismas. La paradoja que se plantea es que los gobiernos locales, o los técnicos encargados de diseñar estos espacios, han planificado los parques y jardines en función de lo que ellos han interpretado como más conveniente para la sociedad, produciéndose un distanciamiento notorio entre la voluntad de los usuarios y la planificación de estas áreas. Este hecho queda nítidamente reflejado en las siguiente cita de Puyuelo et al. (2005:15):

"[...] Existe una falta de información sistematizada sobre las opiniones que las distintas tipologías de usuarios, directos e indirectos, tienen de los espacios destinados al uso colectivo y ello redunda en un comportamiento desarraigado, poco estimulado y participativo hacia el cuidado de los elementos comunes".

El verde urbano tiene la particularidad de ser un espacio en contacto continuo con las personas y su desarrollo, e incluso su misma existencia dependerá de que los planificadores prevean qué condiciones perjudiciales, tanto para las instalaciones como para la vegetación, pudieran llegar a darse en las distintas zonas de las ciudades, tratando así de actuar en consecuencia al elegir los equipamientos más adecuados y su óptimo emplazamiento dentro de los espacios verdes.

\subsubsection{Características y equipamientos}

En primer lugar se evaluaron los componentes estructurales de estos espacios, es decir, lo que se ha llamado "verde urbano sin personas". Este concepto refleja lo que comúnmente se denomina equipamientos o infraestructuras de las áreas verdes, que son los elementos materiales, tanto vivos como inertes, que conforman estos espacios. Dentro del mismo se incluye la vegetación, aunque su tratamiento se realizó de forma descriptiva. Los objetivos fueron, en primer lugar, inventariar cada espacio para conocer las principales características de cada uno de ellos y, en segundo, poner en relación los datos obtenidos a través de las encuestas con los elementos estructurales de la trama verde.

Con un inventario estandarizado de equipamientos se recogieron los componentes principales de cada zona verde, elaborando una imagen propia de cada una de ellas. Está compuesto por veintinueve ítems, con respuestas cerradas que se fueron rellenando en las sucesivas visitas sobre el terreno a cada uno de los verdes urbanos disponibles. La información obtenida fue complementada con un trabajo de gabinete en el que se observó, sobre el plano o sobre la ortofoto, la ubicación de los diferentes espacios en la ciudad, y con una segunda visita en la que se completó la información obtenida. Los inventarios se realizaron a comienzos de la primavera, ya que durante las estaciones cálidas, algunas variables relacionadas con la vegetación se observan con mayor precisión. Tal es el caso de la sombra o los estratos de vegetación, más difíciles de apreciar durante la estación fría en espacios donde predominen las caducifolias, o la presencia de fuentes o láminas de aguas, cuyo funcionamiento pudiera verse perturbado durante el invierno tanto por cortes programados del flujo durante periodos en los que se considera que los espacios verdes son poco visitados, como por condiciones meteorológicas habituales, tales como heladas o precipitaciones en forma de nieve.

A continuación se describe cada uno de los ítems que componen el inventario propuesto para la evaluación de los equipamientos del verde urbano, que han sido agrupados en cuatro grandes categorías para facilitar su manejo:

\section{i) Emplazamiento:}

1. Posición en la ciudad: se trata de la localización del espacio verde en la ciudad. Se han establecido tres grandes divisiones basadas en los conceptos clásicos de ciudad mediterránea para reducir al máximo la subjetividad a la hora elegir una opción. Se 
trata de "centro", es decir, la parte de la ciudad antigua que en el caso de las ciudades mediterráneas se corresponde con el espacio interior de las murallas medievales, "ensanche", que se corresponde mayoritariamente con el "ensanchamiento" de la ciudad, esto es, el crecimiento no planificado de la ciudad comprendida entre las murallas y las sucesivas ampliaciones hasta el último cuarto del siglo $\mathrm{XX}, \mathrm{y}$ "periferia", aquellos lugares dentro de la ciudad que se corresponden con la expansión urbana propia de finales del siglo XX y principios del siglo XXI, o aquellas que por su localización espacial hayan quedado en los límites de la ciudad, pese a que su construcción no coincida con este periodo histórico concreto.

\section{ii) Uso y usuarios:}

2. Tipo de uso mayoritario: se valoraron las actividades mayoritariamente realizadas por los usuarios en cada parque. Por un lado aparecen áreas de "estancia", es decir, lugares en los que las personas se reúnen y pasan periodos de tiempo relativamente largos en ellos, de "actividad física", donde la actividad dominante entre los usuarios es la práctica deportiva o el ejercicio físico, de "actividad física y estancia", que sería una mezcla de ambas, y en último lugar la categoría de "zona de tránsito", referida a los espacios que solo son utilizados como sitios de paso.

3. Acceso: se observó la existencia de algún tipo de restricción en lo referido al uso del verde urbano. Acceso "restringido", será el condicionado por alguna barrera, ya sea monetaria, de seguridad o de otro tipo. "Abierto", englobaría aquellos espacios cuyo acceso es público, mientras que "privado" lo haría con los que la titularidad del espacio pertenezca a un particular.

4. Cerramiento: valora si la entrada al verde urbano se encuentra restringida a los visitantes un número determinado de horas. Los espacios deberían estar totalmente cercados, y por lo tanto, poseer un número determinado de accesos.

5. Accesibilidad para sillas de ruedas y coches de niños: este ítem identifica la presencia de posibles elementos arquitectónicos que faciliten la entrada y el disfrute del espacio verde a personas con movilidad reducida.

\section{iii) Vegetación y sustrato:}

6. Estratos de vegetación: valora la presencia o no de los tres principales estratos verticales de la vegetación: "arbóreo", "arbustivo" y "herbáceo". Como este apartado es meramente descriptivo, no se analizará el porcentaje de cobertura de cada estrato, certificando únicamente la existencia de cada uno de ellos.

7. Origen de la vegetación: con este ítem se analizó de forma general el origen mayoritario de la vegetación, diferenciando entre especies exóticas o "alóctonas", y especies de origen "autóctono", es decir, originarias del espacio que se estudia. Existiría una categoría intermedia llamada "mixta", en la que habiendo presencia de ambos tipos de vegetación, no se produciría un dominio claro por parte de ninguna de ellas.

8. Tipo de vegetación: se realizó una clasificación de la vegetación mayoritaria de cada espacio en función de la pérdida anual de la hoja, diferenciando entre "caducifolias", que pierden la hoja anualmente, "perennifolias", que mantienen la mayor parte de las 
hojas durante la estación fría, y "mixta", en las que no domina ninguna de las dos anteriormente citadas.

9. Materiales artificiales: con este ítem se examinó la presencia de materiales artificiales en la configuración de las zonas verdes. Las categorías recogidas son "hormigón o asfalto" como componentes superficiales del verde urbano, "materiales de construcción", cuya presencia se produce en la construcción de elementos arquitectónicos, "sintéticos", mayoritariamente presentes como pavimento de las zonas de juegos infantiles sustituyendo tanto al suelo como al hormigón o al asfalto, mientras que "no hay", refleja la ausencia total de materiales artificiales.

10. Zonas de sombra: se valoró la presencia o ausencia de zonas de sombra habilitadas para el paseo o para el descanso que pudieran ser utilizadas por los usuarios y que en las áreas verdes, mayoritariamente son producidas por los árboles. Dicho análisis permitió explicar el uso de determinados espacios durante las estaciones cálidas, la presencia o no de lugares con sombra en los que poder descansar o pasear condiciona de manera decisiva el uso del verde urbano.

11. Especies alergénicas: se realizó una valoración de las especies que componen los espacios verdes, señalando la presencia de las principales especies arbóreas alergénicas presentes en las ciudades españolas, debido a que estas podrían llegar a resultar repulsivas para una parte de los ciudadanos. En los países de Europa occidental, un porcentaje nada desdeñable de la población sufre alergias de algún tipo, destacando de entre ellas las vinculadas con elementos vegetales. Hungría (2003) menciona el olivo (Olea europaea), los cipreses, especialmente Cupressus arizonica, y el plátano de sombra (Platanus hispanica) como las principales especies arbóreas alergénicas presentes en las ciudades españolas, a los que habría que añadir también el chopo híbrido (Populus $\times$ canadensis), mientras de entre las herbáceas, destacan las gramíneas por su gran efecto alergénico.

12. Suelo: este ítem examinó si la presencia de suelo, entendido como espacio vivo que sirve de nutriente a las plantas y animales, era mayor al $50 \%$ de la superficie del espacio verde.

13. Corredores verdes: analizó si la zona verde objeto de estudio se encontraba conectada a otros espacios verdes de dentro o de fuera de la ciudad, por medio de corredores de vegetación

14. Vegetación colindante: se observó si en las proximidades del área objeto de estudio existían zonas verdes que pudieran llegar a considerarse como una prolongación del espacio objeto de estudio.

15. Zona de césped: se certificó la presencia de zonas con césped, independientemente de que estuvieran o no pensadas para su uso como espacio de esparcimiento.

\section{iv) Actividades económicas:}

16. Establecimientos comerciales: se valoró si dentro del espacio verde existía algún tipo de establecimiento comercial, desde quioscos hasta tiendas de otro tipo. 
17. Establecimientos de hostelería: se prestó atención a si dentro del área verde había algún tipo de establecimiento hostelero, desde bares hasta restaurantes.

18. Actividades económicas esporádicas: este indicador refleja si el espacio verde en cuestión era utilizado esporádicamente para albergar eventos que llevasen aparejadas actividades económicas, como ferias, verbenas, mercadillos, etc.

19. Espectáculos culturales y/o musicales: expresa la presencia fija o esporádica de infraestructuras adecuadas en el verde urbano para la realización de actividades culturales o musicales.

\section{v) Equipamientos e infraestructuras:}

20. Bancos: se observó la presencia de bancos para sentarse en los distintos espacios analizados.

21. Zonas de juego infantil: se constató la presencia o la ausencia de zonas específicas para el recreo infantil con infraestructuras propias para esa franja de edad.

22. Zonas deportivas: se valoró la existencia de campos de deportes, independientemente de la superficie sobre la que se instalasen y de su tamaño.

23. Áreas para perros: este ítem recoge la existencia de áreas especiales para estos animales, acondicionadas para la deposición de excrementos caninos.

24. Zona de actividad física para mayores: refleja la presencia de una zona concreta dentro de los espacios verdes para el desarrollo de actividades físicas para personas de avanzada edad.

25. Láminas de agua: se verificó la existencia de láminas de agua en el interior de la zona verde, y comprende desde estanques a grandes fuentes.

26. Fuentes: se observó la presencia de fuentes o grifos de agua potable.

27. Zonas de cocina o merenderos: se valoró la presencia o no de zonas de cocina, de merenderos, de parrillas, de barbacoas, etc., en las cuales poder organizar una comida, con o sin presencia de fuego.

28. Paneles informativos: refleja la existencia o no de paneles en los que se informase de las características del área verde en cuestión.

29. Recogida selectiva de basuras: se certificó la existencia de contenedores especiales para cada tipo de basura o residuo en el espacio verde o en su periferia inmediata.

\subsubsection{Valoración del uso del verde urbano por los habitantes de la ciudad}

Tras analizar los equipamientos se estudió “el verde urbano con personas". Para obtener datos sobre el comportamiento de los ciudadanos en los espacios verdes se optó por utilizar una técnica cualitativa como es la encuesta. Se trata de uno de los métodos de recogida de datos más utilizados en Geografía, pero que no pertenece propiamente a ninguna disciplina. Su ventaja principal es que permite obtener datos originales sobre individuos que 
forman parte de una población o de una muestra representativa de la misma y además favorece la comunicación directa con los sujetos del estudio, permitiendo obtener datos tanto objetivos como subjetivos (Gumuchian y Marois, 2000). Se trata de un método útil porque se adapta fácilmente a las exigencias de la investigación, permitiendo obtener, en este caso, una imagen aproximada de las actividades que las personas realizan en las zonas verdes, de la frecuencia de las visitas y de toda una serie de aspectos que influyen en la realización de estas últimas, así como una valoración de los espacios verdes y de la percepción de los ciudadanos sobre los beneficios que generan.

Para llevar a cabo la encuesta se elaboró un cuestionario, es decir, un instrumento normalizado en el que la estructura y el contenido fueron construidos en función de los objetivos de esta investigación. En concreto, se optó por la encuesta por muestreo, esto es, interrogar a individuos que forman parte de una población objetivo. Se consideró conveniente llevar a cabo los cuestionarios en el interior del verde urbano disponible para tener la certeza de que siempre se trata de usuarios de estos espacios, excluyendo otras zonas verdes como huertos urbanos, así como todos aquellos que por su carácter privado o por su inaccesible configuración dificultasen la presencia potencial de usuarios. Es importante destacar que este trabajo se centró exclusivamente en los usuarios de las áreas verdes, dejando de lado a la parte de la población no usuaria de las mismas.

Inicialmente se plantearon las encuestas personales siguiendo el método utilizado por Chiesura (2004) en su trabajo sobre el Vondelpark de Ámsterdam. En dicha investigación se seleccionaron individuos al azar de entre los visitantes del parque, sin efectuar discriminación por su edad, sexo, posición social o sus características profesionales, y se entregó un sobre franqueado con el cuestionario a las personas que aceptaron participar, que una vez completado deberían devolver vía postal.

Para valorar la efectividad de esta técnica en el ámbito de estudio de la presente investigación, se elaboró el cuestionario y se realizó un test entre los usuarios del verde urbano disponible de Salamanca. Los resultados obtenidos demostraron que el procedimiento no fue bien acogido y la tasa de respuestas fue muy reducida. Finalmente se recurrió a la encuesta por entrevista directa debido a la gran cantidad de ventajas que presentan, tales como la alta tasa de respuestas motivadas por la interacción entre entrevistador y entrevistado, la posibilidad de explicar la pregunta si la persona encuestada no comprende alguna cosa o la capacidad, incluso, de plantear cuestiones más delicadas o personales, a la vez que se reduce el sesgo en las respuestas al no poder leer las cuestiones por adelantado y aumenta la información de las respuestas al ser más completas y más elaboradas, especialmente en las cuestiones abiertas (Gumuchian y Marois, 2000). Estos mismos autores señalan también algunas desventajas de este procedimiento tales como la posible influencia del entrevistador en el encuestado en determinadas aspectos y, sobre todo, la variabilidad en la tasa de respuesta debida especialmente a posibles problemas para encontrar personas en determinados lugares y a la desconfianza de los encuestados.

El resto de condiciones citadas en el trabajo desarrollado en Ámsterdam se mantuvieron, informando también a los encuestados sobre los objetivos de la investigación y sobre el procedimiento de la encuesta. A la hora de determinar el tamaño de la muestra de población, es decir, el tamaño del grupo que represente más fielmente posible a una población (Savard, 1978), esta investigación se enfrentó al hecho de que no existe un censo del número de visitantes del verde urbano. Por tanto, para establecer una cifra mínima se volvió a tomar como referencia el estudio de Chiesura (2004), en el que dicha autora realizó 750 encuestas en el parque citado anteriormente y donde tuvo una aceptación muy positiva por parte de los usuarios. Esta técnica se volvió a testar en la ciudad de Salamanca, estableciendo una relación entre el número de encuestas y el volumen demográfico de las ciudades.

En Ámsterdam fueron encuestados 750 usuarios y la población del núcleo central de la aglomeración urbana era de aproximadamente 740.000 habitantes en 2009, lo que implica 
que se realizó alrededor de una encuesta por cada casi mil habitantes. Como en la presente investigación se iba a trabajar con ciudades de pequeña dimensión como Zamora o Salamanca, además del ratio empleado en la capital de los Países Bajos, se consideró conveniente incrementar la cifra final de encuestasen en al menos otras cien más, con el fin de reforzar los resultados y asegurar la representatividad entre el total de usuarios de los espacios verdes. Por ejemplo: el número de encuestas a realizar en Salamanca, una ciudad que en 2009 contaba con 155.619 habitantes, sería la suma de 156 encuestas y de las cien extra mencionadas.

Gumuchian y Marois (2000) señalan que el muestreo probabilístico, aquel en el que los sujetos son elegidos de forma aleatoria, debe respetar dos reglas: que la base del muestreo incluya todas las entidades a partir de las cuales está hecha la selección y que los sujetos sean seleccionados por un procedimiento de muestreo independiente y aleatorio. Por tanto, siguiendo con el ejemplo de Salamanca donde ya se conoce la cifra mínima de encuestas a realizar, se planteó una distribución teórica de las mismas entre todos y cada uno de los verdes urbanos disponibles de la ciudad. Para ello se utilizó un criterio de igualdad basado en la superficie, que implica realizar un mayor número de encuestas en los espacios verdes más extensos. En primer lugar, se obtuvo el número de encuestas por hectárea realizando una sencilla división, lo que permitirá multiplicar posteriormente el resultado por el número de hectáreas de cada espacio verde. La operación es la siguiente:

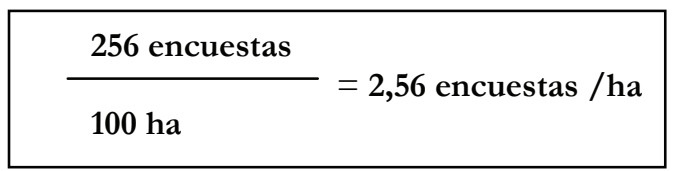

Una vez determinado el cociente de 2,56 encuestas por hectárea, se multiplicó por el tamaño de cada zona verde, obteniéndose los resultados que aparecen en la Tabla 2.9. En ella se observa cómo en Salamanca el espacio en el que se deberían realizar un mayor número de entrevistas era el Parque de El Zurguén (S-25), mientras que en los Jardines del Hospital Clínico (S-5) tan solo se tendría que encuestar a dos personas.

En el año 2010, se testó esta técnica en el conjunto de la trama verde de Salamanca, obteniéndose un número de encuestas superior al planteado. Considerando adecuada la proporción de encuestas por hectárea de verde urbano disponible utilizada en Salamanca, se aplicó a los espacios verdes de las otras dos ciudades manteniendo así el número de entrevistados por hectárea. El resultado fue de 646 encuestas para la trama verde de Valladolid, distribuidas entre las 252,5 ha de sus 44 verdes urbanos disponibles, mientras que en Zamora, que solo posee 71,7 ha, se debería realizar un mínimo de 183 encuestas en sus 18 espacios verdes (ver Tablas 2.10 y 2.11).

Después de definir el tamaño de la encuesta fue necesario decidir el periodo para llevarla a cabo. Tratándose de un número de cuestionarios conocido, no fue preciso realizar una distribución anual de los mismos, ya que no se pretendía obtener el número total de visitantes del verde urbano ni su distribución espacial. Esta información se suplió con la realización de un número reducido de preguntas, obteniendo con ello una imagen a grandes rasgos de la distribución horaria y de las épocas del año en las que los ciudadanos visitan estos espacios con mayor frecuencia.

Como referencia al respecto se tomó el trabajo de Ramos (2006) que, pese a no abordar una temática similar, hace frente a un desafío metodológico parecido al aquí planteado debido a que tuvo que elegir una semana del año para el desarrollo de la totalidad del trabajo de campo. De este modo se concentró toda la carga de encuestas en un periodo 
Tabla 2.9 Distribución teórica de las encuestas en el verde urbano disponible de Salamanca.

\begin{tabular}{|c|c|c|c|c|c|}
\hline $\mathbf{N}^{\circ}$ & Id. & ha & $\begin{array}{c}\mathbf{N}^{\circ} \\
\text { encuestas }\end{array}$ & Redondeo & Nombre \\
\hline 1 & S-1 & 5,8 & 14,8 & 15 & Parque de Don Juan Tenorio \\
\hline 2 & S-2 & 7,4 & 18,9 & 19 & Complejo deportivo Salas Bajas \\
\hline 3 & S-3 & 10,8 & 27,6 & 27 & Jardín botánico de Huerta Otea \\
\hline 4 & S-4 & 10,1 & 25,9 & 26 & Parque de los Jesuitas \\
\hline 5 & S-5 & 0,8 & 2,0 & 2 & Jardines del Hospital Clínico \\
\hline 6 & S-7 & 2,3 & 5,9 & 6 & Verde urbano de la Vaguada de La Palma \\
\hline 7 & S-8 & 4 & 10,2 & 10 & Parque de Valhondo \\
\hline 8 & S-9 & 1,3 & 3,3 & 3 & Campo de San Francisco \\
\hline 9 & S-10 & 2,2 & 5,6 & 6 & Parque de la Alamedilla \\
\hline 10 & S-11 & 1 & 2,6 & 3 & Parque Picasso \\
\hline 11 & $\mathrm{~S}-12$ & 1,7 & 4,4 & 4 & Verde urbano de las Salesas \\
\hline 12 & $\mathrm{~S}-13$ & 2,7 & 6,9 & 7 & Plaza de Burgos \\
\hline 13 & S-15 & 6 & 15,4 & 15 & Parque de Würzburg \\
\hline 14 & S-16 & 3,6 & 9,2 & 9 & Verde urbano margen derecha Puente Romano \\
\hline 15 & S-17 & 5,2 & 13,3 & 13 & Verde urbano margen izquierda Puente Romano \\
\hline 16 & S-18 & 3,1 & 7,9 & 8 & Paseo fluvial \\
\hline 17 & S-19 & 1,4 & 3,6 & 4 & Verde urbano del entorno de Mirat \\
\hline 18 & S-20 & 2,7 & 6,9 & 7 & Parque de Ciudad Rodrigo \\
\hline 19 & S-21 & 3 & 7,7 & 7 & Parque de la Chinchibarra \\
\hline 20 & $\mathrm{~S}-22$ & 1,6 & 4,1 & 4 & Parque de Vistahermosa \\
\hline 21 & $\mathrm{~S}-23$ & 1,6 & 4,1 & 4 & Parque de Villar y Macías \\
\hline 22 & S-24 & 1,9 & 4,9 & 5 & Verde urbano de La Salle \\
\hline 23 & $\mathrm{~S}-25$ & 13,5 & 34,6 & 35 & Parque de El Zurguen \\
\hline 24 & S-26 & 4,3 & 11,0 & 11 & Verde urbano Av. Salamanca \\
\hline 25 & S-27 & 1,2 & 3,1 & 3 & Verde urbano de la Fac. de Comunicación \\
\hline 26 & S-28 & 1 & 2,6 & 3 & Parque de Bretón \\
\hline Total & & 100,2 & & 256 & \\
\hline
\end{tabular}

Fuente: elaboración propia

Tabla 2.10 Distribución teórica de las encuestas en el verde urbano disponible de Zamora.

\begin{tabular}{|c|c|c|c|c|l|}
\hline $\mathbf{N}^{\text {o }}$ & Id. & ha & $\begin{array}{c}\mathbf{N}^{\circ} \\
\text { encuestas }\end{array}$ & Redondeo & \multicolumn{1}{|c|}{ Nombre } \\
\hline $\mathbf{1}$ & Z-1 & 1,9 & 4,8 & 5 & Parque del Castillo y de la Catedral \\
\hline $\mathbf{2}$ & Z-2 & 0,8 & 2,0 & 2 & Verde urbano Calle de los Caballeros \\
\hline $\mathbf{3}$ & Z-3 & 3,4 & 8,6 & 9 & Parque de Olivares \\
\hline $\mathbf{4}$ & Z-4 & 2,2 & 5,6 & 6 & Parque de la Marina \\
\hline $\mathbf{5}$ & Z-5 & 0,8 & 2,0 & 2 & Verde urbano Candelaria Ruiz del Árbol \\
\hline $\mathbf{6}$ & Z-6 & 16,5 & 42,2 & 42 & Margen derecha del Duero \\
\hline $\mathbf{7}$ & Z-8 & 16,5 & 42,2 & 42 & Bosque de Valorio (parte urbana) \\
\hline $\mathbf{8}$ & Z-9 & 1,9 & 4,9 & 5 & Parque de Peña Trevinca \\
\hline $\mathbf{9}$ & Z-10 & 3,3 & 8,4 & 8 & Jardines de la Vaguada \\
\hline $\mathbf{1 0}$ & Z-11 & 1,4 & 3,6 & 4 & Verde urbano Avenida. Cardenal Cisneros \\
\hline $\mathbf{1 1}$ & Z-12 & 3,7 & 9,5 & 9 & Parque de San Martín \\
\hline $\mathbf{1 2}$ & Z-13 & 3,0 & 7,6 & 8 & Parque de León Felipe \\
\hline $\mathbf{1 3}$ & Z-14 & 8,3 & 21,3 & 21 & Margen izquierda del Duero \\
\hline $\mathbf{1 4}$ & Z-16 & 5,0 & 12,9 & 13 & Isla de las Pallas \\
\hline $\mathbf{1 5}$ & Z-17 & 0,9 & 2,3 & 2 & Jardin Carretera de la Estación \\
\hline $\mathbf{1 6}$ & Z-18 & 0,6 & 1,5 & 1 & Verde urbano Puerta Nueva \\
\hline $\mathbf{1 7}$ & Z-19 & 0,9 & 2,2 & 2 & Verde urbano Calle Nuestra Señora de las Mercedes \\
\hline $\mathbf{1 8}$ & Z-20 & 0,8 & 1,9 & 2 & Verde urbano Avda. Cardenal Cisneros (Eroski) \\
\hline Total & & 71,7 & & 183 & \\
\hline & & & & Fuente: elaboración propia. \\
\hline
\end{tabular}


Tabla 2.11 Distribución teórica de las encuestas en el verde urbano disponible de Valladolid.

\begin{tabular}{|c|c|c|c|c|c|}
\hline $\mathbf{N}^{\circ}$ & Id. & ha & $\begin{array}{c}\mathbf{N}^{\circ} \\
\text { encuestas } \\
\end{array}$ & Redondeo & Nombre \\
\hline 1 & V-1 & 12,7 & 32,5 & 33 & Campo Grande \\
\hline 2 & $\mathrm{~V}-2$ & 4,6 & 11,8 & 12 & Rosaleda Francisco Sabadell y Parque Poniente \\
\hline 3 & $\mathrm{~V}-3$ & 9,5 & 24,3 & 24 & Parque de las Moreras \\
\hline 4 & V-4 & 26,7 & 68,3 & 68 & Parque Ribera de Castilla \\
\hline 5 & V-5 & 5,5 & 14,0 & 14 & Verde urbano Camino del Cabildo \\
\hline 6 & V-6 & 7,0 & 18,0 & 18 & Jardin Botánico \\
\hline 7 & $\mathrm{~V}-7$ & 1,2 & 3,1 & 3 & Darsenas del Canal Castilla \\
\hline 8 & V-9 & 21,0 & 53,7 & 54 & Parque del Mediodia \\
\hline 9 & $\mathrm{~V}-10$ & 6,6 & 17,0 & 17 & Ladera sur Parquesol - Fuente de Dios \\
\hline 10 & V-11 & 4,7 & 12,0 & 12 & Arturo Eyries \\
\hline 11 & $\mathrm{~V}-12$ & 2,4 & 6,0 & 6 & Verde urbano Centro de acustica (Santa Ana) \\
\hline 12 & V-14 & 5,3 & 13,6 & 14 & Parque de Covaresa \\
\hline 13 & V-15 & 2,4 & 6,3 & 6 & Parque de la Alameda \\
\hline 14 & V-16 & 1,8 & 4,7 & 5 & Verde urbano Avenida de los Castaños \\
\hline 15 & V-17 & 4,3 & 10,9 & 11 & Verde urbano de Valparaiso - Ronda Sur \\
\hline 16 & V-18 & 3,9 & 10,0 & 10 & Parque Arturo León \\
\hline 17 & V-19 & 4,4 & 11,2 & 11 & Parque de las Norias de Santa Victoria \\
\hline 18 & $\mathrm{~V}-20$ & 3,9 & 9,9 & 10 & Parque de la Paz \\
\hline 19 & $\mathrm{~V}-21$ & 12,2 & 31,2 & 31 & Parque de Canterac \\
\hline 20 & $\mathrm{~V}-22$ & 5,9 & 15,0 & 15 & Parque San Isidro - Fuente de la Salud \\
\hline 21 & $\mathrm{~V}-24$ & 7,4 & 18,9 & 19 & Verde urbano Ronda Este \\
\hline 22 & $\mathrm{~V}-25$ & 4,0 & 10,2 & 10 & Verde urbano Calle Arribes del Duero \\
\hline 23 & $\mathrm{~V}-26$ & 6,1 & 15,5 & 16 & Campus Esgueva \\
\hline 24 & $\mathrm{~V}-27$ & 8,8 & 22,5 & 23 & Campus Miguel Delibes \\
\hline 25 & $\mathrm{~V}-28$ & 1,6 & 4,1 & 4 & Paseo Zorrilla Sur \\
\hline 26 & $\mathrm{~V}-29$ & 9,0 & 22,9 & 23 & Verde urbano Cortes de Castilla y León \\
\hline 27 & $\mathrm{~V}-30$ & 4,8 & 12,3 & 12 & Verde urbano Auditorio Miguel Delibes \\
\hline 28 & $\mathrm{~V}-31$ & 15,4 & 39,4 & 39 & Verde urbano Mirador Parquesol \\
\hline 29 & $\mathrm{~V}-32$ & 13,8 & 35,3 & 35 & Verde urbano Huerta del Rey \\
\hline 30 & $\mathrm{~V}-33$ & 8,8 & 22,4 & 22 & Verde urbano Parquesol Calle Morelia \\
\hline 31 & $\mathrm{~V}-34$ & 2,5 & 6,5 & 7 & Verde urbano Parquesol Calle Juan de Valladolid \\
\hline 32 & $\mathrm{~V}-35$ & 2,0 & 5,1 & 5 & Parque del Reloj de Sol \\
\hline 33 & V-36 & 5,0 & 12,8 & 13 & Verde urbano Palacio de la Ribera \\
\hline 34 & V-37 & 1,6 & 4,1 & 4 & Ribera de Huerta del Rey \\
\hline 35 & $\mathrm{~V}-38$ & 1,4 & 1,4 & 3 & Verde urbano Plaza Juan de Austria \\
\hline 36 & V-39 & 1,7 & 4,3 & 4 & Verde urbano Calle Morena - Feria de Muestras \\
\hline 37 & $\mathrm{~V}-41$ & 2,4 & 6,1 & 6 & Ribera Pisuerga entre Pte. Colgante y Pte. Juan Austria \\
\hline 38 & $\mathrm{~V}-42$ & 1,6 & 4,0 & 4 & Plaza del Ejército \\
\hline 39 & $\mathrm{~V}-44$ & 1,2 & 3,1 & 3 & Jardines de La Victoria \\
\hline 40 & V-45 & 1,6 & 4,0 & 4 & Verde urbano Barrio de la Esperanza \\
\hline 41 & $\mathrm{~V}-46$ & 1,6 & 4,1 & 4 & Verde urbano Pinar de Jalón \\
\hline 42 & V-47 & 1,5 & 3,9 & 4 & Verde urbano Calle Vega de Valdetronco - Villas Sur \\
\hline 43 & V-48 & 1,2 & 3,1 & 3 & Verde urbano Escuela Deportiva Niara \\
\hline 44 & $\mathrm{~V}-49$ & 1,8 & 4,6 & 5 & Verde urbano Calle Alcaparra \\
\hline Total & & 252,5 & & 646 & \\
\hline
\end{tabular}

Fuente: elaboración propia.

de tiempo reducido y la obtención de resultados fue moderadamente rápida. Por tanto, para el desarrollo del trabajo de campo, se estimó que una fecha adecuada sería la semana en que se produce el equinoccio de primavera (20 o 21 de marzo según el año), es decir, el comienzo de la primavera, evitando que durante la semana de encuestas tuviera lugar alguna festividad laboral importante que pudiera modificar la percepción de los habitantes sobre el uso del 
verde urbano. Se trató de establecer una semana tipo, por lo que si en esa semana algún día no reuniera las condiciones ideales para desarrollar las encuestas, se elegiría otro de la semana posterior, evitando de este modo los días de invierno. Las fechas en la que se llevaron a cabo los trabajos de campo fueron dos semanas sucesivas del mes de marzo de 2011 en el caso de Valladolid y Zamora, concretamente entre el 21 de marzo y el 3 de abril, mientras que en Salamanca la semana elegida para el desarrollo de la encuesta fue la transcurrida entre el $15 \mathrm{y}$ el 21 de marzo de 2010. Se eligieron estas fechas debido a que durante el mes de marzo el número de visitantes no alcanza las altas cotas del periodo estival o de vacaciones y tampoco presenta reducciones tan fuertes como las que se producen en los meses más crudos del invierno.

El uso de las zonas verdes está influenciado por la hora del día y por la rigurosidad del clima (Cedeño, 2003). Por lo tanto, las encuestas se realizaron durante las horas de sol, al ser el periodo de tiempo en el que menos usuarios estarían posponiendo alguna visita, y durante días en los que no se registraron eventos meteorológicos adversos que pudieran condicionar la presencia de potenciales usuarios. Los cuestionarios fueron repartidos durante los siete días de la semana, intentando realizar una distribución horaria lo más equilibrada posible para recoger las opiniones de una mayor diversidad de ciudadanos.

Arnberger (2006) analizó las frecuencias de uso en dos parques de Viena (Austria) a lo largo de un año, combinando el análisis de vídeos con encuestas personales. Mediante la utilización de grabaciones en las entradas de los parques, estimó con precisión el número de visitantes y su distribución horaria. Sin embargo, la presente investigación no está dirigida únicamente al análisis de la frecuencia de uso, ya que aplicar una metodología como la anteriormente mencionada sería muy costoso en términos monetarios y su desarrollo resultaría muy complicado para el conjunto de espacios verdes de tres ciudades diferentes. El importe económico de un proyecto similar al de Arnberger no podría ser afrontado en el marco de este trabajo y en el hipotético caso de que sí pudiera llevarse a cabo, se generaría un volumen de información tan grande, con miles de imágenes diarias, que sería casi imposible que una única persona pudiera contabilizar el número de visitantes totales.

Podría pensarse que concentrando el análisis en una sola semana se estaría perdiendo fiabilidad en lo referente a la frecuencia de uso del verde urbano, pero los inconvenientes anteriormente señalados motivaron un estudio mediante preguntas directas a los usuarios.

El cuestionario utilizado fue el testado en Salamanca y contiene formatos de respuestas mayoritariamente cerradas, autoexcluyentes o de múltiple respuesta, existiendo también algunas con ranking de respuestas o con respuestas abiertas, aunque se intentó limitar la presencia de estas últimas lo máximo posible. En cuanto al diseño del cuestionario, se ha optado por un modelo muy similar al utilizado por Rodero (2008) en su estudio de comarcas productoras de alimentos de calidad, ya que permite un uso intensivo del espacio en el papel y la presentación de las cuestiones da como resultado un documento claro y bien estructurado. El conjunto de preguntas se distribuye en cinco grandes grupos y abordan diferentes aspectos de la relación entre los encuestados y el verde urbano. El cuestionario utilizado en cada una de las tres ciudades objeto de estudio puede consultarse en los anexos (ver punto 7.1) y los bloques en los que se dividen las preguntas que lo componen son los siguientes:

1. Datos personales: se trata de cuestiones que caracterizan al propio individuo, cuyo objetivo es ubicar el resto de las respuestas dentro de un universo que pretende ser representativo de la población usuaria del verde urbano disponible. Aparecen en primer lugar y comprenden de la pregunta uno hasta la cuatro, ambas incluidas.

2. Frecuencia de uso de los espacios verdes: con estas cuestiones se suple la inmensa labor que supondría realizar un estudio de las frecuencias de las visitas a las 
áreas verdes. Su resultado ofrece una panorámica general de la distribución temporal del uso de estos espacios con un grado moderado de detalle. Engloba las preguntas cinco, seis y siete.

3. Espacios verdes visitados: identifica el verde urbano más veces visitado por el usuario y su posible alternancia entre distintos espacios. Incluye las cuestiones ocho y nueve, así como la veintiuno que aprovecha el apartado de evaluación de las áreas verdes para completar esta información.

4. Motivaciones para la visita: comprende cinco preguntas, de la diez a la catorce, que proporcionan información para entender el porqué de las visitas.

5. Valoración del verde urbano: mediante la realización de seis preguntas, de la quince a la veinte, se cuestiona directamente al usuario acerca de sus impresiones sobre la calidad, entendida como conjunto de condiciones que hacen que las áreas verdes satisfagan las necesidades de los ciudadanos.

6. Funciones de los espacios verdes: se pretende testar las impresiones del usuario sobre los beneficios que el verde urbano puede proporcionar al medio ambiente urbano y a los ciudadanos. Se trata de las últimas seis cuestiones que abordan aspectos desarrollados en el apartado conceptual de esta investigación.

Se ha seguido un orden lógico a la hora de elaborar el cuestionario, colocando en primer lugar los datos personales de los entrevistados, manteniendo una distribución estructurada en la que se pregunta el cuándo, el porqué, el dónde y finalmente la opinión que le merecen las visitas, ya que el quién y el cómo se dan por supuestos a la hora de realizar la encuesta. De esta manera, se cuestiona en primer lugar sobre la frecuencia, es decir, las veces que visitan las zonas verdes, y a continuación sobre el espacio más visitado. Posteriormente se pregunta el porqué de la visita y finalmente se pide una valoración explícita de las experiencias vividas. El último apartado, en el que se cuestiona acerca de las funciones del verde urbano, se ha incluido la valoración a modo de apéndice, ya que de una manera implícita valora la percepción de los habitantes sobre alguno de los beneficios que producen estos espacios. Estas respuestas no corresponderían tanto a una impresión puntual, como a una meditación interior, más vinculada a la ideología de cada uno, fruto de años de reflexiones o experiencias, que acabaría por reflejar lo que las áreas verdes suponen para cada persona.

La utilización de un cuestionario idéntico ha permitido obtener una foto fija del uso que los habitantes realizan del verde urbano disponible y comparar los comportamientos en tres ámbitos urbanos diferentes. La principal ventaja de esta técnica es que se puede emplear en cualquier ciudad, como demostró recientemente el trabajo en el que se analizó el uso del verde urbano de la ciudad portuguesa de Coimbra (Gómez et al., 2013).

\subsubsection{Análisis de las visitas de los usuarios del verde urbano disponible}

Para identificar las motivaciones y la frecuencia de las visitas a los espacios verdes se utilizó la información obtenida en las encuestas. Una vez procesada permitió obtener un perfil tipo del visitante del verde urbano disponible de cada una de las ciudades seleccionadas, incluyendo en él la edad, el sexo y la ocupación. Posteriormente se delimitaron cartográficamente las zonas de la ciudad sin acceso al verde urbano disponible utilizando la distancia desde el lugar de residencia y se estimó el número de personas que no tendrían acceso a estos espacios. En cuanto al análisis de las visitas, se utilizó la información extraída 
de la encuesta para determinar, por ejemplo, las estaciones en las que los usuarios acuden a las zonas verdes con mayor frecuencia o la distribución horaria de las visitas.

\subsubsection{Estimación de la calidad del verde urbano disponible}

Una vez analizados tanto el comportamiento de los ciudadanos como las características y los equipamientos, se estimó la calidad del verde urbano disponible. La calidad permite estimar numéricamente el conjunto de condiciones que hacen que las zonas verdes satisfagan las demandas y las necesidades de los ciudadanos. Para su cálculo se utilizó una técnica basada en la identificación de los factores que influyen en su valoración tanto positiva como negativamente. Este parámetro se cuantificó tomando como referencia una de las preguntas del cuestionario, concretamente la número veinte, en la que a los usuarios se les pidió que valoraran, con una nota del 1 al 10, una serie de espacios elegidos cuidadosamente a la hora de diseñar la encuesta.

A partir de las valoraciones se fueron identificando los factores que contribuirían a satisfacer las principales necesidades, así como los motivos por los que los usuarios acudían a las áreas verdes, para con ello estimar la calidad del resto de espacios por los que no se preguntó. Se empleó la información recogida en los inventarios y la obtenida tanto en las encuestas, como en las visitas realizadas para lograr valorar la calidad de cada espacio. Por último, se cartografiaron los datos obtenidos de calidad estimada y se compararon con el uso mayoritario que los usuarios hacen de las zonas verdes.

\subsubsection{Cálculo del índice de atracción del verde urbano disponible}

Contrastando la información obtenida en la pregunta número nueve del cuestionario, en la que los usuarios identificaron los espacios verdes que visitaban con más frecuencia, con el verde urbano en el que se realizó cada encuesta, se identificó la capacidad de atracción del verde urbano disponible.

Para su cálculo se puso en relación el número de encuestas realizadas en cada zona verde, aunque fuera un número inferior al estimado inicialmente, con el de personas que dijeron que esa era la zona verde que más veces visitaban. Por ejemplo, en Salamanca el Parque de El Zurguén (S-25) fue en el que se planificaron un mayor número de encuestas por ser el más extenso, mientras que en los Jardines del Hospital Clínico (S-5) únicamente se proyectaron dos. Ya se explicó que la distribución teórica de las encuestas está directamente vinculada al tamaño, aunque durante la realización del trabajo de campo no siempre se logró realizar una distribución idéntica a la planificada y los posibles déficits de respuestas se corrigieron aumentando el número de encuestas en aquellos espacios donde sí fue posible entrevistar a alguien.

$\mathrm{Al}$ afirmar que un parque es el que más veces visita, un usuario estaría expresando que existen distintos motivos que le llevan a frecuentar ese espacio verde y no otro. Si solamente se atendiese al número de encuestados en cada área verde, el resultado estaría muy condicionado por el tamaño de cada una de ellas, debido a que es el factor que determinó la distribución teórica de las encuestas. Para comparar los datos obtenidos por estas respuestas no bastará con ordenar de mayor a menor las zonas verdes más veces visitadas por los usuarios, puesto que hay más posibilidades de que un parque aparezca más veces mencionado si en él se han realizado bastantes encuestas y si el número de encuestas de una ciudad es superior al de otra. El índice de atracción permite superar la influencia de la distribución inicial de las encuestas, contabilizando el número de personas que dijeron que un espacio verde era el que más veces visitaban y poniéndolo en relación con el número de encuestas realizadas en ese parque para, en definitiva, saber cuánta gente no entrevistada en una zona verde afirmó que esa en concreto era la que más veces visitaba. El resultado ha sido 
dividido por el número de encuestados en cada una de las ciudades analizadas, consiguiendo comparar el verde urbano disponible de las tres pese a que se hubiese realizado un número de encuestas muy distinto. A continuación aparece detallada la fórmula empleada, acompañada de un ejemplo concreto:

\section{Fórmula empleada:}

$$
\text { Índice de atracción de un parque } X=((a-b) / c) \times 100
$$

a: $\mathrm{n}^{\circ}$ de personas que dijeron que $\mathrm{X}$ era el espacio verde que más visitaban.

b: $\mathrm{n}^{\circ}$ de encuestas realizadas en dicho espacio verde.

c: $\mathrm{n}^{\mathrm{o}}$ de encuestas realizadas en dicha ciudad.

\section{Ejemplo:}

\section{Índice de atracción del Parque de la Marina (Z-4): ( ( 15 - 6 )/ 186 ) x $100=4,84$}

15: $\mathrm{n}^{\mathrm{o}}$ de personas que dijeron que el Parque de la Marina (Z-4) era el espacio verde que más visitaban.

6: $\mathrm{n}^{\mathrm{o}}$ de encuestas realizadas en dicho espacio verde.

186: $\mathrm{n}^{\circ}$ de encuestas realizadas en Zamora.

\subsection{Valoración paisajística}

Además de analizar el comportamiento de los usuarios y los equipamientos presentes en las zonas verdes, se creyó conveniente realizar un breve resumen de las principales características de cada uno de los verdes urbanos disponibles. De esta manera, el lector que no conozca la realidad concreta podrá hacerse una idea de la composición paisajística y de sus características más destacadas con un simple vistazo a su ficha. Como modelo de estas fichas, se emplearon las utilizadas por Ramos (2001) en su estudio de los aeropuertos de Canarias, incluyendo varias fotografías y la ortofotografía utilizada para su delimitación junto al resto de la información.

\subsection{Recapitulación}

Esta metodología ha sido presentada como una sucesión de pasos con los que se fueron alcanzando los objetivos fijados en el capítulo anterior, superando así una serie de dificultades de partida. En los casos en los que no existe una solución clara o un consenso a nivel científico, como fueron por ejemplo los casos de la delimitación espacial de la ciudad o del verde urbano, se optó por una definición que, como se verá a lo largo de esta Tesis Doctoral, ha mostrado cierta operatividad y ha permitido cuantificar fenómenos cercanos que no se había tratado hasta la fecha. 


\section{LAS FUNCIONES DEL VERDE URBANO}

En este capítulo se ha realizado una síntesis bibliográfica de los principales trabajos publicados sobre los espacios verdes urbanos por tratarse de un tema más o menos reciente, que en ocasiones provoca cierta confusión debido a la gran cantidad de disciplinas que los estudian.

Es necesario realizar una breve reflexión acerca de qué se entiende por función desempeñada por el verde urbano. Se trataría de aquellas acciones y efectos de la vegetación que redundan en beneficios directos o indirectos para los ciudadanos o para el medio ambiente urbano. Esta definición, apoyada en los trabajos de Bolund y Hunhammar (1999), no se circunscribe exclusivamente a las personas, sino que en ocasiones llega a suponer un beneficio para el conjunto del ecosistema urbano, como ocurre, por ejemplo, con la mayor parte de las funciones llamadas ecológicas. Las ciudades, como creación humana, han tratado de dar respuesta a las necesidades de la población a lo largo de su historia. Los espacios verdes surgieron para mejorar la calidad de vida en los medios urbanos, respondiendo a requerimientos cambiantes fruto de los valores sociales comunes. Concretamente, en los países del sur de Europa, el aumento del verde urbano comenzó en la segunda mitad del siglo XX debido a razones culturales y sociales (Fadigas, 2010), hasta que en las últimas décadas, la incorporación de las áreas verdes al planeamiento urbano se ha convertido en un derecho de los ciudadanos (Sanesi y Chiarello, 2006) consagrado en la normativa urbanística. Como el objetivo de esta investigación es analizar las zonas verdes de tres ciudades situadas en dicho marco geográfico, este apartado conceptual está centrado principalmente en beneficios generados en ciudades europeas, aunque no por ello se han dejado de citar trabajos significativos desarrollados en otros espacios.

\section{1 Tipología de funciones del verde urbano}

Entre los estudios consultados que abordan problemáticas relacionadas con las funciones o servicios de las áreas verdes, pocos autores se centran en las acciones beneficiosas generadas por estas. La mayoría analiza una única función de acuerdo a su campo de estudio, obviando aspectos que escapan de su dominio conceptual. Sin embargo, los textos que abordan varias funciones del verde urbano lo hacen desde una perspectiva multidisciplinar, apoyándose en investigaciones llevadas a cabo por autores especialistas en diversas materias. Tras revisar la bibliografía, se han identificado más de una docena de funciones entre las que se encontraría la ecológico-ambiental, la social, la económica, la arquitectónica, la paisajística, la urbanística, la multidimensional, la sanitaria, la recreativa, la estética, la educativa, la psicológica, la de satisfacción de las necesidades básicas, la simbólica y la pedagógica. Algunas de estas presentan cierta afinidad y podrían llegar a agruparse, reduciendo así el número total de categorías y facilitando con ello el estudio. Lo cierto es que muchas de ellas podrían incluirse dentro de la categoría denominada como función social, que es citada por los veinte trabajos en los cuales se tratan los distintos aspectos beneficiosos.

De entre los artículos que recogen una categorización de funciones de los espacios verdes, dos han servido como referente a la hora de realizar una tipología sobre este tema. En primer lugar, el de Priego-González (2008) recoge las tres grandes funciones (ecológica, social y económica) mencionadas en la mayor parte de los trabajos consultados. Y en segundo lugar el de Levent et al. (2009), cuya tipología sitúa la función de planificación urbana y la función multidimensional al mismo nivel que las tres anteriormente citadas y ha sido tomada como modelo para la división de las funciones del verde urbano. La inclusión de una categoría multidimensional responde a una necesidad metodológica, puesto que al existir 
ciertas funciones o subfunciones transversales, que afectan a varias de las tres categorías principales, su ubicación en una u otra presentaba cierta dificultad. De esta manera, todas las funciones que han sido identificadas en la literatura consultada se han agrupado en tan solo cinco grandes categorías. El resultado de agrupar las distintas funciones presentes en las publicaciones consultadas que tratan esta temática (ver Tabla 3.1), da como resultado la Figura 3.1 en la que aparece el número de trabajos donde ha sido citada cada función o alguna de las subfunciones que la componen. Es posible observar como la ecológica y la social son las más comunes, aparecen en prácticamente todos los trabajos consultados, mientras que la urbanística y la multidimensional son citadas únicamente por un tercio de los autores que tratan varias funciones del verde urbano.

Tabla 3.1 Autores que recogen varias funciones de los espacios verdes.

\begin{tabular}{|l|c|}
\hline \multicolumn{1}{|c|}{ Autores } & Funciones de los espacios verdes \\
\hline Akbari et al. (1992) & Beneficios ambientales y psicológicos. \\
\hline Bedimo-Rung et al. (2005) & Beneficios físicos y psicológicos para la salud, sociales, económicos y ambientales. \\
\hline Bolund y Hunhammar (1999) & Servicios ambientales y valores recreacionales. \\
\hline Canosa et al. (2003) & Funciones sociales. \\
\hline Corona (2001) & Valor ecológico, paisaje arquitectónico y socioeconómico. \\
\hline Dunnett et al. (2002) & Beneficios sociales, ambientales y económicos. \\
\hline Dwyer et al. (1992) & Dimensión ambiental y dimensión social. \\
\hline Fadigas (2010) & Beneficios ambientales, sociales y económicos. \\
\hline Falcón (2008) & Funciones naturales, sociales y económicas. \\
\hline FEDENATUR (2004) & Función recreativa, ambiental, higiénico-sanitaria, estética, educativa. \\
\hline García (1989) & Beneficios sociales, estéticos, climáticos y físicos, ecológicos y económicos. \\
\hline Konijnendijk et al. (2005) & Beneficios estéticos, ecológicos y de satisfacción de las necesidades básicas. \\
\hline Kuchelmeister y Braatz (2000) & Beneficios ambientales, y beneficios socio-económicos. \\
\hline Levent et al. (2009) & Beneficios sociales, ambientales y urbanísticos. \\
\hline Nowak et al.(1997) & Beneficios ambientales, sociales y económicos. \\
\hline Pérez y Talavera (2008) & Función ambiental, psíquica, social, estética, urbanística. \\
\hline Priego-González (2008) & Beneficios económicos, psicológicos, perceptuales y simbólicos. \\
\hline Sanz (2005) & Beneficios ambientales, materiales y sociales. \\
\hline Smardon (1988) & Ealores ecológicos, económicos, sociales, de planificación urbana y multidimensionales. \\
\hline Sorensen et al. (1998) & ambiental, de integración paisajítica o arqitectón \\
\hline
\end{tabular}
Fuente: elaboración propia.

Pese a que todos los beneficios generados por los espacios verdes urbanos pueden ser calificados como funciones, se restringirá el uso del término función para referirse a las cinco grandes categorías, mientras que para cada uno de los componentes de las mismas se utilizará el término de subfunción. El conjunto de funciones y subfunciones aparece representada en la Figura 3.2, para la que se ha tomado como referencia la categorización de Levent et al. (2009). A continuación se definen las cinco grandes categorías de funciones:

1. Función ecológica: recoge todas aquellas alteraciones en el medio ambiente urbano resultantes de la actividad vegetal en la ciudad, de las que se benefician de una manera directa o indirecta los ciudadanos.

2. Función económica: engloba todo tipo de beneficios económicos, tanto directos como indirectos, generados por la presencia de zonas verdes y por su gestión.

3. Función social: conjunto de efectos generados por la presencia de espacios verdes urbanos, que afectan de manera directa a la vida social en la ciudad.

4. Función de planificación urbana: papel que juegan las áreas verdes en la configuración de la estructura urbana. 
5. Función multidimensional: recoge los beneficios que son comunes a varias funciones y, por lo tanto, no pueden ser incluidos en una sola de las categorías establecidas.

Una vez realizada la tipología de funciones, se desglosará de una manera sucinta las subfunciones que componen dichas categorías, para realizar un estudio de cada una de ellas.

Figura 3.1 Presencia de las funciones de los espacios verdes en los trabajos consultados.

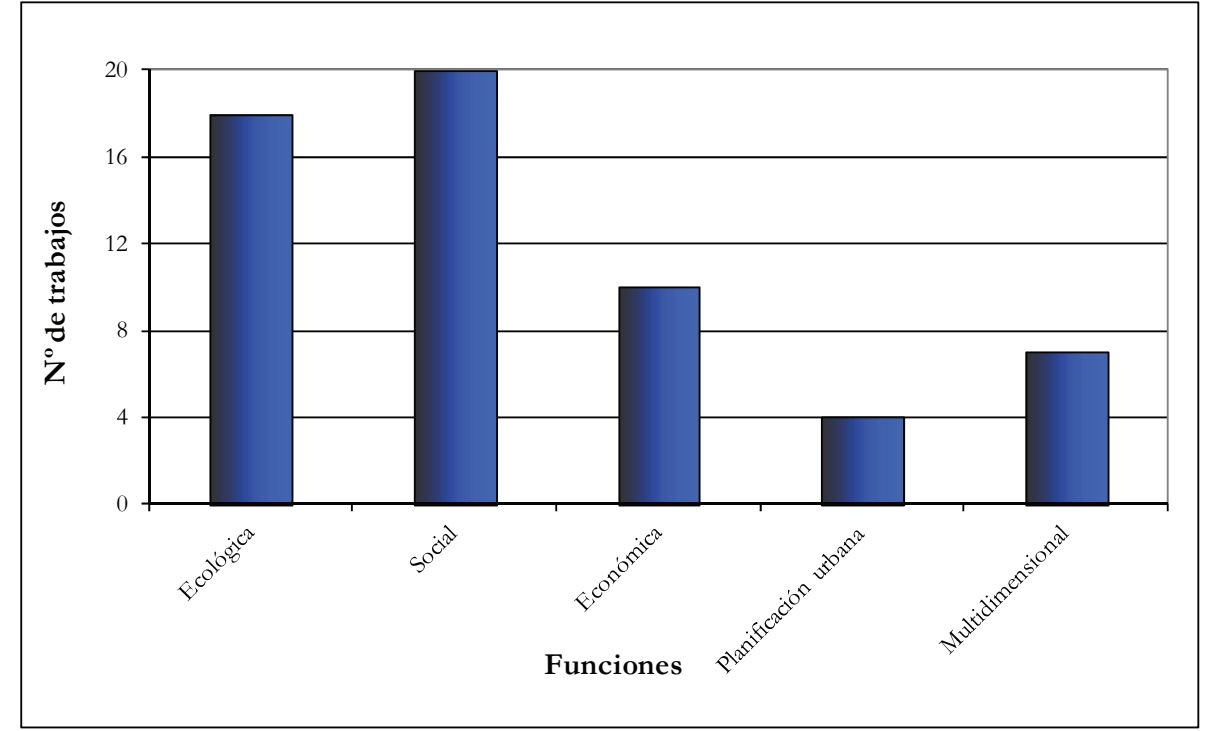

Fuente: elaboración propia.

\subsection{Función ecológica}

Las funciones ecológicas pueden ser definidas como todas aquellas alteraciones en el medio ambiente urbano resultantes de la actividad vegetal, de las que se benefician de una manera directa o indirecta los ciudadanos. Esta función se encuentra en el origen de la creación de los parques y jardines urbanos desde el comienzo de la Revolución Industrial, ya que el urbanismo de mediados del siglo XIX proponía la creación de las zonas verdes para dar respuesta a los problemas higiénico-sanitarios de las ciudades industriales (Gómez, 2005). La aparición sistemática del verde urbano fue un fenómeno inicialmente vinculado al Reino Unido (Fadigas, 2010), ya que en 1845 por primera vez una comisión sugería la necesidad de crear parques públicos para mejorar las condiciones de higiene de las ciudades inglesas (Benevolo, 1987). Los efectos de todas aquellas actuaciones tuvieron su continuación en la corriente ambientalista e higienista y se tradujeron en un incremento de la sensibilidad ambiental en las ciudades, dando lugar a importantes parques y jardines que han quedado integrados en el plano de las principales ciudades de la época.

\subsubsection{Variaciones en la composición atmosférica}

\section{i) Absorción de gases tóxicos}

De entre las características químicas particulares de la atmósfera urbana destaca la elevada concentración de gases contaminantes, cuyo origen se encuentra en el incremento del número de vehículos, de industrias y de otras actividades propias de las ciudades. Es lo que comúnmente se denomina polución atmosférica y en los países industrializados se ha convertido en un problema de salud que cuesta cada vez más dinero a la sanidad pública. Sus componentes principales son el monóxido de carbono (CO), los óxidos de nitrógeno $\left(\mathrm{NO}_{\mathrm{x}}\right)$, 
el ozono $\left(\mathrm{O}_{3}\right)$ formado a través de reacciones químicas ocasionadas principalmente por los óxidos de nitrógeno y por los compuestos orgánicos volátiles (VOC, en sus siglas en inglés), el dióxido de azufre $\left(\mathrm{SO}_{2}\right)$ y las partículas de materia menores de 10 micras (PM10) (McPherson et al., 1994).

Figura 3.2 Tipología de funciones del verde urbano.

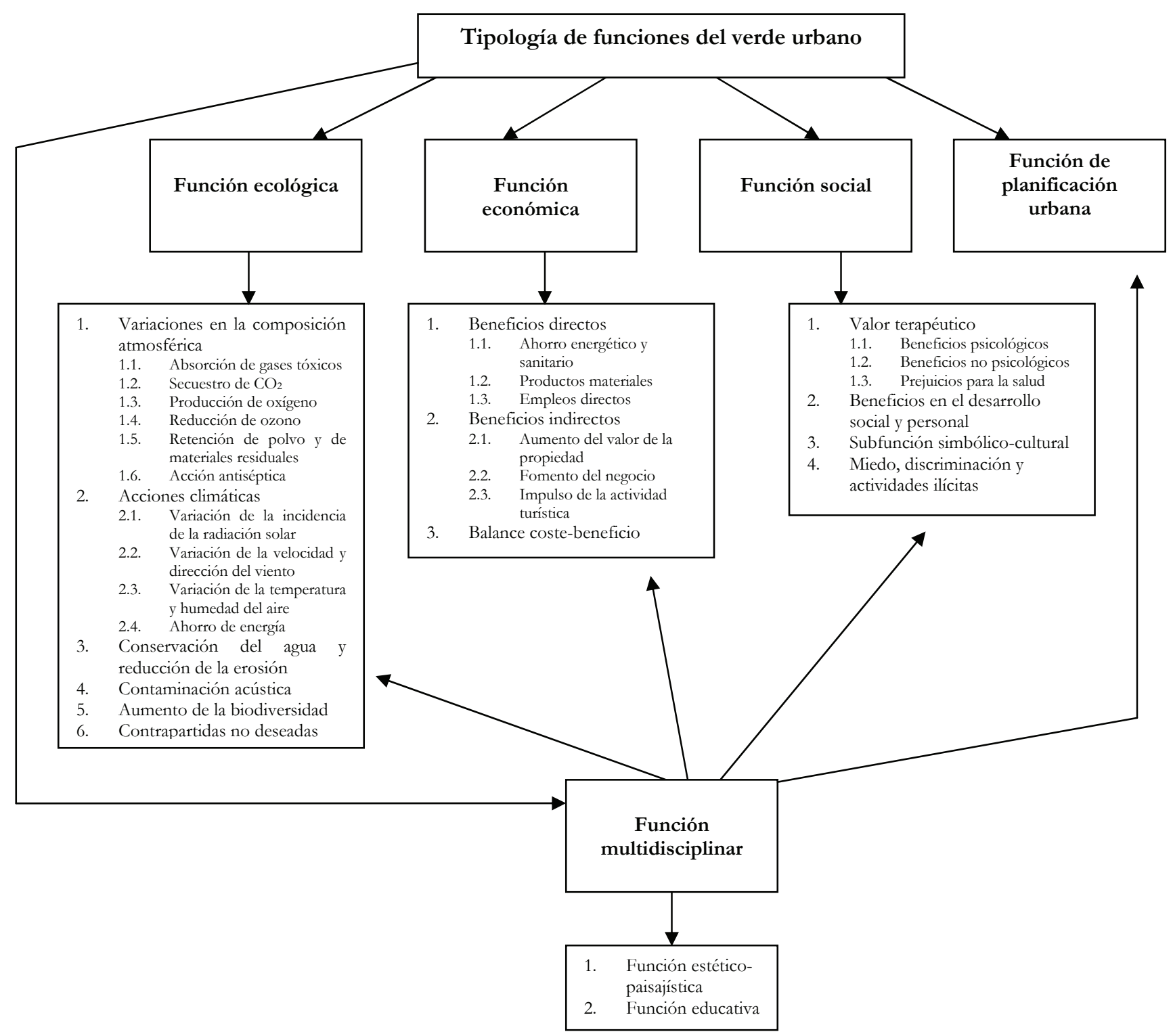

Fuente: elaboración propia a partir de Levent et al. (2004).

Los árboles urbanos actúan como purificadores del aire, absorbiendo y filtrando la polución atmosférica, mayoritariamente a través de los estomas de las hojas (Ochoa, 1999). Mediante la fotosíntesis, la vegetación absorbe $\mathrm{CO}_{2}$ y otros gases contaminantes, transformándolos en distintos subproductos y reduciendo su concentración atmosférica (Priego-González, 2008). La capacidad de filtrado aumenta con la superficie foliar de la vegetación (Bolund y Hunhammar, 1999), variando a lo largo del día y del año en función de la actividad vegetal de la planta. Los seres vegetales podrían contribuir a la mitigación del problema, aunque en ningún caso deberían ser vistos como la solución, ya que es necesario 
que su gestión se integre dentro de una política encaminada a la reducción de las emisiones contaminantes.

\section{ii) Secuestro de $\mathrm{CO}_{2}$}

El $\mathrm{CO}_{2}$ está considerado como el principal causante del efecto invernadero y su aumento en las últimas décadas provocará un incremento de las temperaturas superficiales de entre $1,8{ }^{\circ} \mathrm{C}$ y $4{ }^{\circ} \mathrm{C}$ antes de 2100 según las estimaciones de 2007 del IPCC ${ }^{1}$. La mayor parte de la generación antrópica de $\mathrm{CO}_{2}$ atmosférico es producida por el uso de combustibles fósiles, tanto para la obtención de energía como para el funcionamiento de los medios de transporte, de los que las ciudades son grandes consumidoras.

Los vegetales actúan como sumideros temporales de dióxido de carbono ya que lo absorben mediante la fotosíntesis y almacenan el carbono en sus tejidos. Dentro del proceso global de absorción de este gas, los árboles urbanos juegan un papel importante. No solo lo retiran de la atmósfera, sino que influyen positivamente en las temperaturas urbanas al evitar el uso de energía y propiciar la consiguiente reducción en las emisiones de $\mathrm{CO}_{2}$ gracias a sus efectos climáticos. La actuación como sumidero únicamente tiene validez a corto plazo, ya que los árboles muertos y los restos vegetales en descomposición devuelven el carbono almacenado a la atmósfera. Algunos autores como Nowak y Crane (2002) proponen tratamientos específicos para la madera a fin de conservarla, y con ella una parte del $\mathrm{CO}_{2}$ secuestrado por la vegetación urbana. Estas actuaciones deberían complementarse con una planificación a largo plazo de las zonas verdes para propiciar una sustitución del arbolado maduro por especímenes jóvenes. Sin embargo, la reducción de $\mathrm{CO}_{2}$ y de gases contaminantes por el verde urbano es limitada en comparación con la magnitud total de emisiones producidas en las ciudades.

\section{iii) Producción de oxígeno}

En las áreas urbanas los niveles de $\mathrm{CO}_{2}$ son bastante elevados en comparación con el resto del planeta, reduciéndose con ello el nivel de oxígeno libre. Ochoa (1999) hace referencia a estudios llevados a cabo en Frankfurt, en los que se observó que la concentración de $\mathrm{O}_{2}$ se reduce en un 17-18\% en el interior de la ciudad. A través del proceso fotosintético, la vegetación urbana libera oxígeno a partir de la absorción de moléculas de dióxido de carbono $\left(\mathrm{CO}_{2}\right)$.

\section{iv) Reducción del ozono}

El ozono troposférico, llamado a veces smog fotoquímico (del inglés smoke, humo, fog, niebla), es el ozono situado en la capa más baja de la atmósfera. Hoy en día forma parte de la polución atmosférica de las grandes ciudades, causando importantes daños en los seres vivos. Se origina por reacciones químicas a partir de los óxidos de nitrógeno $\left(\mathrm{NO}_{\mathrm{x}}\right)$ procedentes de la combustión de los vehículos y de los compuestos orgánicos volátiles (VOC) que en una proporción considerable son originados por la vegetación. En la Europa mediterránea, la mayor parte de los VOC son de origen vegetal debido a las características propias de su flora (Priego-González, 2008).

Como se apuntó anteriormente, el aumento de la cobertura arbórea contribuye a reducir los contaminantes atmosféricos. Además, mediante los beneficios climáticos que produce la vegetación se mitigan los efectos del ozono troposférico en la medida en que la

\footnotetext{
1 Panel Intergubernamental del Cambio Climático. Fue creado en 1988 por la Organización Meteorológica Mundial y por el Programa Ambiental de las Naciones Unidas.
} 
incidencia de los días con smog está estrechamente relacionada con el aumento de las temperaturas (Dwyer et al., 1992).

\section{v) Retención de polvo y materiales residuales}

La retención de polvo y de otras sustancias se produce mediante los órganos aéreos de las plantas, fijándose a través de procesos mecánicos que implican el choque de las partículas de polvo contra las hojas de los vegetales, y mediante procesos en los que intervienen partículas electroestáticas (Ochoa, 1999).

\section{vi) Acción antiséptica}

La vegetación urbana desempeña un importante efecto antibiótico a través de la eliminación o el filtrado de agentes patógenos y microorganismos presentes en la atmósfera urbana (Falcón, 2008). Ochoa (1999) hace referencia a diversos estudios que habrían demostrado que los espacios verdes presentan concentraciones de microbios en el aire mucho más bajos que en otras partes de la ciudad.

\subsubsection{Efectos climáticos}

En los últimos doscientos años se ha producido una progresiva modificación climática en los entornos urbanos cuyo efecto más palpable es el incremento de la temperatura del centro respecto de las áreas rurales circundantes. Con la alteración del medio natural al crear espacios urbanos, se han introducido variables que contribuyen decisivamente a este cambio climático. Ejemplo de ello son los espacios construidos, que almacenan calor durante el día y lo irradian por la noche, la alta presencia de gases contaminantes en la atmósfera urbana, el reducido poder mitigador de la evapotranspiración vegetal debido al pequeño tamaño del verde urbano, la impermeabilidad del suelo y la emisión de calor por los automóviles y por la actividad industrial (Priego-González, 2008). El efecto de la isla de calor urbana contribuye también al calentamiento global del planeta, ya que el incremento del consumo energético producido al tratar de reducir la temperatura en el interior de los edificios provoca en ocasiones una mayor cantidad de emisiones de gases contaminantes a la atmósfera. La vegetación urbana puede ayudar a reducir la temperatura de las ciudades y a ahorrar energía, provocando con ello un beneficio para el medio ambiente al disminuir la emisión de gases que contribuyen al calentamiento de las ciudades y del planeta.

\section{i) Variación de la incidencia de radiación solar}

La variación de la radiación solar es el elemento del microclima urbano sobre el que la vegetación urbana tiene mayor influencia (Ochoa, 2009), ya que una correcta forma y densidad del verde urbano puede llegar a propiciar el bloqueo hasta del $95 \%$ de la radiación incidente (Akbari et al., 1992). Cuando los árboles están correctamente emplazados alrededor de un edificio, bloquean la radiación solar indeseada en verano, reduciendo la energía diaria utilizada para su refrigeración. McPherson et al. (1994) proponen el uso de árboles para controlar la temperatura de los edificios en las ciudades, favoreciendo la existencia de especies que combinen tanto una pérdida de la hoja relativamente temprana en la estación fría, como un rebrote temprano en la estación cálida, con la finalidad de aprovechar el máximo de radiación solar en invierno y de evitar un exceso de esta en verano. 


\section{ii) Variación en la velocidad y dirección del viento}

En ciudades con una alta densidad de construcción, el viento a nivel de suelo está condicionado principalmente por la estructura urbana, mientras que la vegetación tiene un efecto poco apreciable. No así en hábitats urbanos con una morfología poco compacta donde los efectos sobre el viento serán más relevantes (Akbari, 2002). En estos escenarios los árboles contribuirán a reducir el viento, generando con ello ciertos beneficios en la medida en que durante los días fríos de invierno impiden que el viento contribuya al descenso de las temperaturas en el interior de las viviendas y edificios. Sin embargo, este hecho presenta ciertas contrapartidas ya que la reducción de la velocidad impediría una renovación de las masas de aire y por tanto, propiciaría un alargamiento de la presencia de gases contaminantes en la atmósfera urbana.

\section{iii) Variación en la temperatura y en la humedad del aire}

Akbari et al. (1992) apuntan a que la temperatura del aire puede reducirse cuando la radiación solar es utilizada por las plantas para la evapotranspiración, impidiendo con ello un excesivo aumento de la temperatura superficial de las mismas. El término evapotranspiración se refiere conjuntamente a dos procesos diferentes: la pérdida de humedad por evaporación directa y la pérdida de agua por la transpiración vegetal. Los vegetales utilizan la energía obtenida a través de la radiación solar $(540 \mathrm{cal} / \mathrm{g})$ para provocar el cambio de estado del agua, que pasa de líquido a gas, reduciendo con este proceso su temperatura superficial. La presencia de aire comparativamente más frío que la temperatura ambiental en la capa de aire más próxima a las hojas, provoca un microclima en las copas que contribuye a reducir de manera sensible la temperatura ambiental en las zonas arboladas de las ciudades.

\section{iv) Ahorro de energía}

La vegetación urbana puede producir ahorros significativos en el consumo de energía gracias a sus efectos atenuantes en la climatología local. A través de una correcta gestión de los beneficios térmicos provocados por el arbolado, podría conseguirse una reducción del consumo realizado en los edificios, tanto en calefacción como en refrigeración, induciendo con ello una disminución en las emisiones de gases contaminantes generados por estas actividades (Honjo y Takakura, 1991). El área de influencia de este efecto estaría en función del tamaño del espacio verde y del intervalo entre este tipo de espacios. McPherson y Simpson (1995), en sus investigaciones desarrolladas en EEUU, confirmaron el ahorro energético producido por la vegetación en ciudades con una importante presencia de viviendas unifamiliares.

\subsubsection{Control de la erosión y prevención de inundaciones}

El desarrollo de las ciudades genera cambios sustanciales en los usos del suelo que provocan la progresiva desaparición de las masas vegetales existentes, la modificación de las propiedades del suelo y la consiguiente alteración de la tasa de infiltración. Una de las consecuencias de estos cambios es que un alto porcentaje de agua de lluvia pasa inmediatamente a formar parte del flujo superficial, provocando un aumento de la erosión y una mayor incidencia de las inundaciones. Los árboles funcionan como estructuras de retención, induciendo una disminución de la velocidad y del volumen de la escorrentía en episodios de tormenta, una reducción de los daños producidos por inundaciones y un ahorro de los costes de tratamiento del agua de lluvia (Bolund y Hunhammar, 1999). 


\subsubsection{Contaminación acústica}

Hoy en día el ruido se considera una forma invisible de contaminación. Los niveles excesivos de ruido procedentes del tráfico y de otras fuentes contribuyen a generar daños fisiológicos y psicológicos a la población, especialmente en las áreas urbanas. Ochoa (2009) señala que el efecto de disminución del ruido por parte de la vegetación es poco significativo. No obstante, parece que podría contribuir a reducir sus efectos psicológicos perniciosos en la medida en que los espacios verdes actúan como pantalla visual entre el emisor y las personas, pudiendo enmascarar ciertos ruidos debido a que la propia vegetación provoca sonidos que son percibidos como agradables por los ciudadanos.

\subsubsection{Aumento de la biodiversidad}

La urbanización lleva aparejada un proceso de eliminación de la mayor parte de los elementos naturales originales de un determinado espacio y la creación de un nuevo hábitat diferente con posibilidades para que distintas especies se instalen allí (Rubio, 1995). En este contexto, las zonas verdes se convierten en espacios singulares en el interior de las ciudades al convertirse en el hábitat principal de numerosos seres vivos (ver Figura 3.3). Algunos de estos espacios acogen diferentes especies animales y vegetales de interés, y dentro de la Unión Europea pueden llegar a forman parte del conjunto de espacios protegidos Red Natura 2000, por contar con valores ambientales que merecen ser conservados.

Hoy en día existe un interés creciente entre la ciudadanía por el medio ambiente, que se demuestra en un aumento de las visitas a los espacios verdes para observar y descubrir la naturaleza (Nowak et al., 1997). No es descabellado pensar que el aumento de la conciencia ambiental y el creciente interés por la calidad de vida provoquen en un futuro no muy lejano un aumento de la importancia de los beneficios ecológicos del verde urbano.

\subsubsection{Contrapartidas de la función ecológica}

Los espacios verdes en la ciudad pueden causar una serie de perjuicios o contrapartidas tanto al medio ambiente urbano como a las personas. Por un lado hay que mencionar que la creación de compuestos orgánicos volátiles por los árboles contribuye a la formación del ozono troposférico, anulando en parte los beneficios que a este respecto proporciona la vegetación urbana. Por otro, es también necesario reparar en que las labores de mantenimiento de la vegetación provocan emisiones de $\mathrm{CO}_{2}$ y de otros gases contaminantes que contribuyen a aumentar el efecto de la isla de calor urbana. La utilización excesiva de fertilizantes y herbicidas en el mantenimiento de los parques y jardines, puede desembocar en una llegada de estos materiales a los ríos y arroyos a través de la escorrentía superficial, provocando un descenso de la calidad del agua en las ciudades y de la vida acuática de los ríos (Boinsignore et al., 2003).

Desde el punto de vista material, la vegetación urbana puede provocar contrapartidas en la medida en que genera daños en el pavimento de las calles y en las conducciones de agua, electricidad o gas, así como molestias a los transeúntes en forma de caída de ramas o de otros materiales, de exudación de resinas o de creación de sombras indeseadas (McPherson et al., 1997). Muchos de los inconvenientes generados por las áreas verdes se deben a un incorrecto mantenimiento y a una mala planificación y elección del arbolado urbano, pudiendo ser evitados en un alto porcentaje. 
Figura 3.3 Fauna adaptada al hábitat urbano en Regent's Park (Londres): garza real (Ardea cinerea), ganso común (Anser anser) y ardilla de las Carolinas (Sciurus carolinensis).
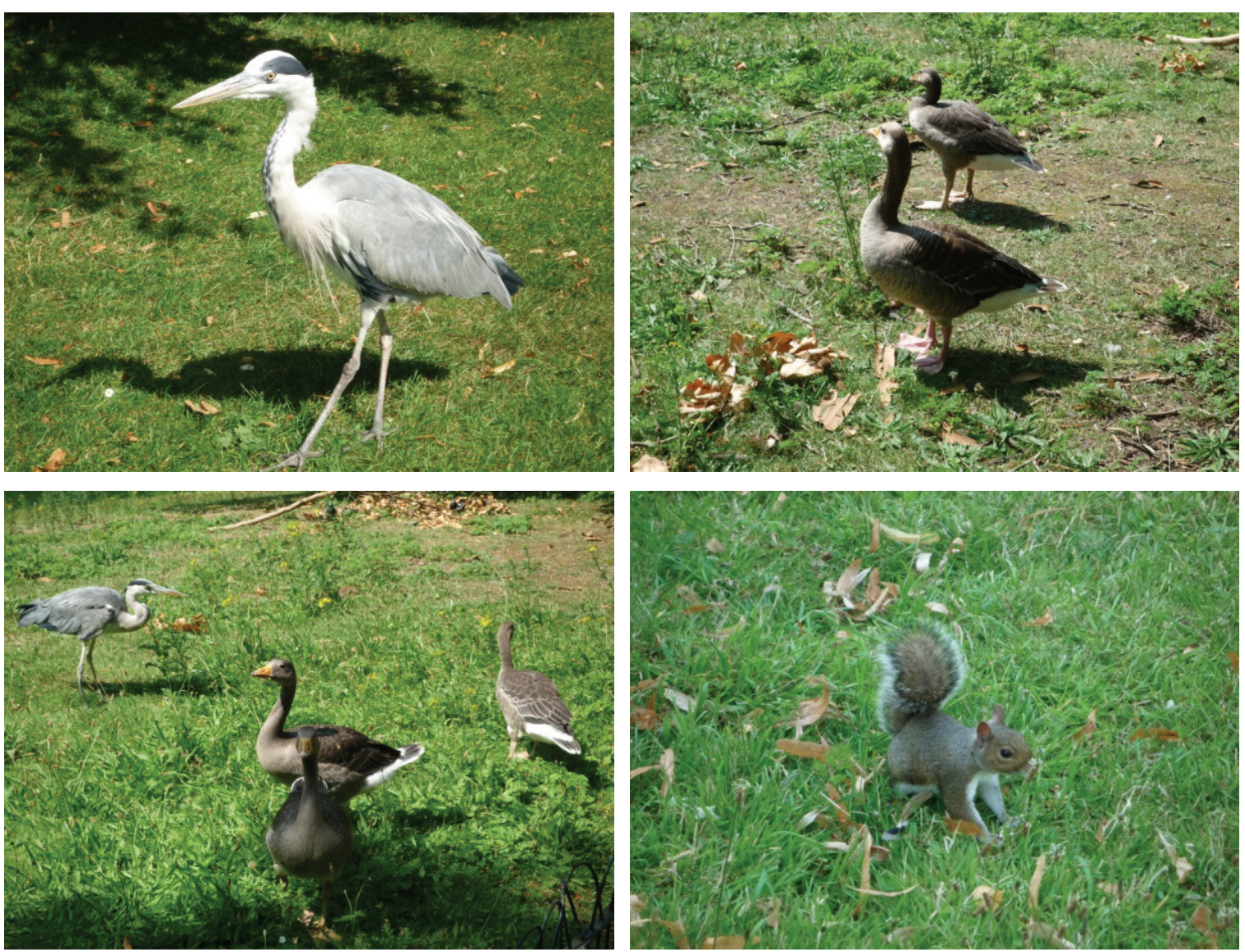

Fuente: Gómez, A. (28/07/2011).

\subsection{Función económica}

Por función económica se entiende todo aquel beneficio monetario, tanto directo como indirecto, generado por la presencia y por la gestión de las zonas verdes en la ciudad. Debido a su carácter abstracto y a la dificultad de transformar los beneficios económicos en dinero real, esta función apenas es percibida por el conjunto de la población. En este apartado se ha realizado un análisis de las principales subfunciones económicas que han sido consideradas por los distintos autores como atribuibles al verde urbano. Se han clasificado en dos grandes grupos: por un lado, los beneficios económicos directos, que son los originados por los elementos que componen la trama verde de la ciudad, como por ejemplo la obtención de materias primas o el ahorro energético provocado por la presencia de la vegetación, y por otro lado los indirectos, que comprenderían todas las actividades económicas beneficiadas por la presencia de las zonas verdes. Dentro de este último grupo se hallarían conceptos tan diversos como el fomento de la actividad económica, la atracción de turistas o el aumento del precio de las viviendas.

\subsubsection{Beneficios económicos directos del verde urbano}

\section{i) Ahorro energético y sanitario}

La energía ahorrada por los espacios verdes gracias a su labor refrigerante (Honjo y Takakura, 1991) y a su acción mitigadora de la velocidad del viento en invierno (McPherson y 
Simpson, 1995), tiene una traducción monetaria y supone un importante ahorro económico para los propietarios de las viviendas próximas a lo largo de las distintas estaciones. Otro beneficio económico que debe tenerse en cuenta es la influencia del verde urbano en la reducción del gasto médico provocado por la elevada contaminación atmosférica de las ciudades. La vegetación provoca una sensible reducción de la cantidad de gases tóxicos, generando una disminución de los problemas de salud derivados y su consiguiente ahorro para los sistemas sanitarios públicos. En definitiva, la mayor parte de las funciones ecológicas desarrolladas por el verde urbano tienen un valor económico, aunque en muchos casos no es percibido ni por los ciudadanos ni por sus gobernantes. Funciones como el filtrado del aire o la retención de la escorrentía superficial son actividades beneficiosas que, aún siendo fáciles de constatar, presentan una notable dificultad a la hora de ser contabilizadas en términos monetarios.

\section{ii) Productos materiales}

Un tema que presenta cierta importancia en países de América Latina y del Caribe es el papel desempeñado por el conjunto de la trama verde como sustento económico de las capas de población más deprimidas. Los estudios de Cobo (1997) desarrollados en la ciudad de Quito (Ecuador) demuestran que estos espacios se convierten en una pieza fundamental en la vida de muchas personas, al ser aprovechados para la obtención de productos de primera necesidad con los que cubrir tanto las necesidades de alimento, recolectando frutos y otros productos forestales, como las de combustible, a través del acopio de madera. Este último aspecto es también recogido por Kuchelmeister y Braatz (2000), quienes apuntan a que cuando las poblaciones marginales tienen dificultades para adquirir combustibles a precio de mercado, utilizan sustitutivos, como leña y carbón, obtenidos en las áreas verdes. Además de las poblaciones con menos recursos, otros muchos ciudadanos recurren al verde urbano con el fin de obtener pequeños ingresos sin coste directo de producción. En los países del ámbito mediterráneo se aprovechan, en determinadas ocasiones, los frutos de algunos árboles de estos espacios como complemento puntual de la dieta de las personas o de los animales, o como artículos para la venta al por menor (ver Figura 3.4). La variedad de frutos dependerá de las especies de árboles y arbustos presentes en las ciudades.

Dentro del conjunto de espacios verdes, los huertos urbanos presentan una clara vocación productiva. Su existencia en el interior de la mayoría de las aglomeraciones urbanas está vinculada, de manera general, con el surgimiento de los asentamientos urbanos junto a terrenos agrícolas muy fértiles que aseguraban su existencia (Mumford, 1956). En los países mediterráneos, la agricultura se ha ido convirtiendo en una actividad residual en el interior de las ciudades, debido a que el proceso de expansión urbano lleva aparejado una progresiva desaparición de este tipo de uso del suelo. Sin embargo, en algunos países europeos esta tendencia ha comenzado a cambiar y cada vez son más los gobiernos locales que contemplan estos espacios como parte del patrimonio natural de la ciudad que ha de ser protegido, animando incluso a los agricultores a que continúen con las actividades tradicionales (ver Figura 3.4). En numerosas ciudades de Asia, América Latina y de África, la agricultura urbana es una práctica frecuente y su desarrollo permite el sustento de una parte importante de la población que habita en zonas urbanas marginales. Esta actividad facilita también el acceso a productos de primera necesidad de las poblaciones más deprimidas, al reducirse los costes de transporte de los alimentos, lo que repercutirá en el precio final.

\section{iii) Empleo directo en el mantenimiento de las zonas verdes}

Otro aspecto que hay que considerar dentro de las funciones económicas del verde urbano es la creación de puestos de trabajo directos. Una parte sustancial del presupuesto de 
Figura 3.4 Beneficios económicos directos. Arriba: recogida de castañas en el verde urbano de la Vaguada de la Palma (Salamanca). Abajo: huerto en el Instituto Politécnico (Bragança, Portugal).
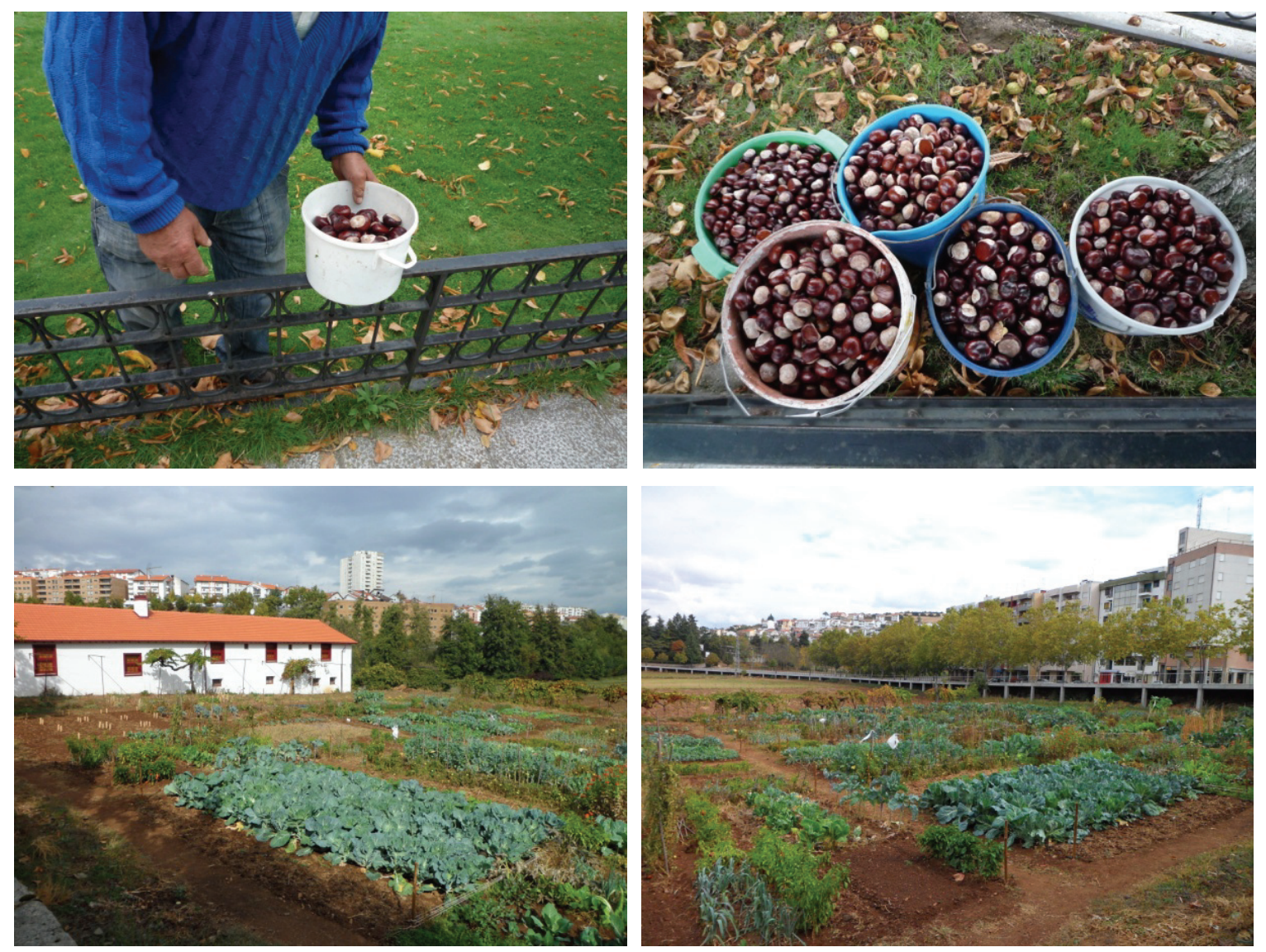

Fuente: Gómez, A. (09/10/2009 y 23/10/2011).

las distintas administraciones públicas destinado al mantenimiento y a la creación de la vegetación en la ciudad, se invierte en la contratación de trabajadores debido a que la jardinería requiere una importante cantidad de mano de obra. Dentro de estas actividades encontraríamos por un lado, el empleo temporal dedicado a la construcción de parques y jardines, el empleo permanente para el mantenimiento de los espacios verdes y el empleo indirecto vinculado con los equipos de suministro y de manutención necesarios para estas labores.

\subsubsection{Beneficios económicos indirectos del verde urbano}

\section{i) Aumento del valor de las propiedades}

La construcción de un espacio verde en el interior de la ciudad provoca en muchas ocasiones una revalorización del suelo urbano próximo. El incremento del valor de terrenos y viviendas repercutirá de una forma positiva en el conjunto de la ciudad, a través de un aumento de la recaudación de impuestos derivados del desarrollo residencial en las proximidades de estos espacios (Dula, 2008). Las personas consideran los barrios con espacios verdes como lugares atractivos para residir o para trabajar (ver Figura 3.5) y eso tiene su traducción económica en el aumento del precio de las propiedades inmobiliarias en la zona (Priego-González, 2008). Dwyer et al. (1992), basándose en estudios previos, valoraron en un $5 \%$ el incremento mínimo del precio de la propiedad debido a la proximidad de espacios verdes urbanos. 
Figura 3.5 Barrios atractivos para vivir o para trabajar. Arriba: Central Park (Nueva York). Abajo: Parc Diagonal Mar (Barcelona).
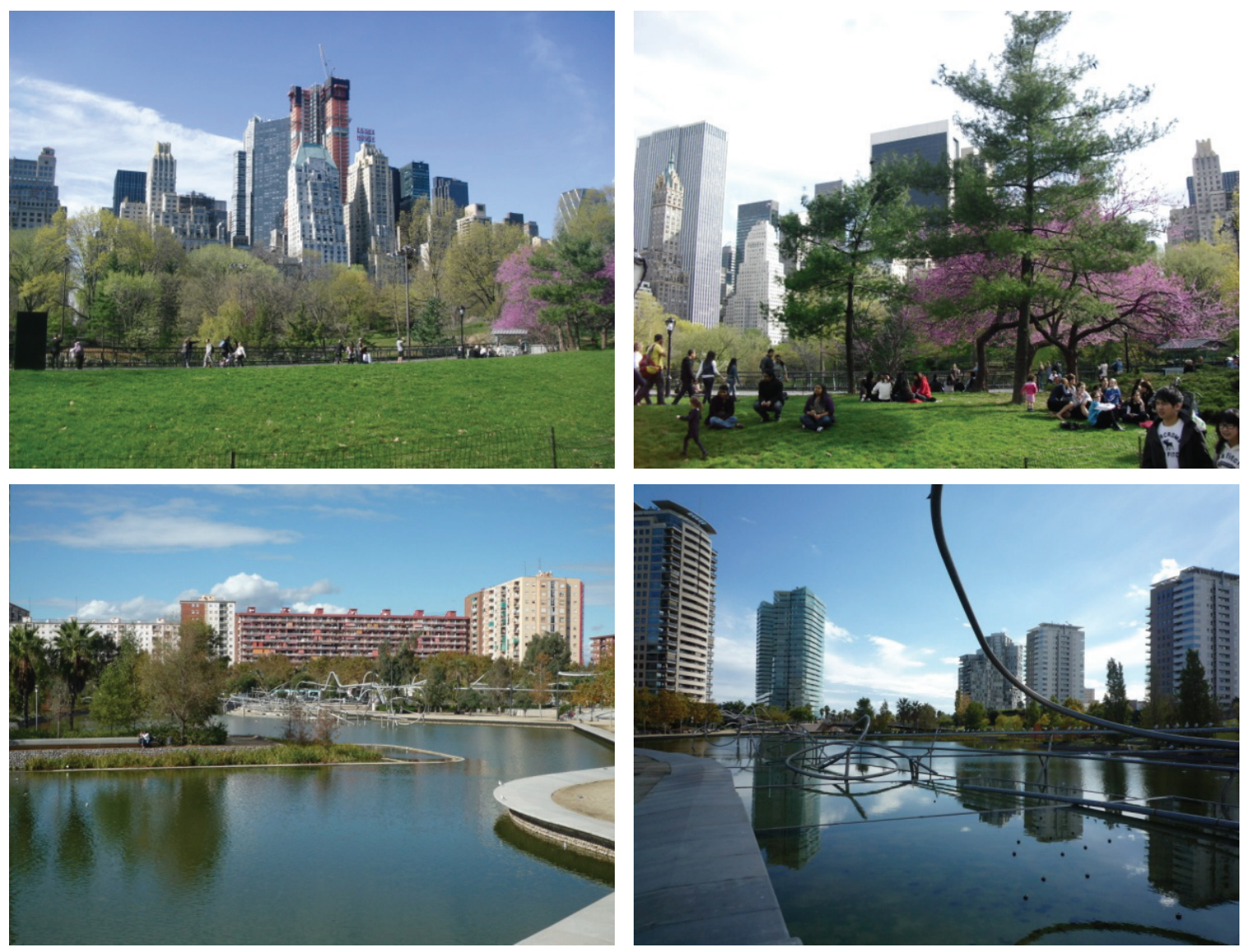

Fuente: Sánchez, J.L. (04/04/2012) y Gómez, A. (31/10/2010).

\section{ii) Fomento del negocio y atracción de empresas}

El verde urbano actúa como un foco de atracción de personas que buscan descansar, relajarse, jugar o sencillamente aislarse de la ciudad, llegando a convertirse en un servicio de interés general con un importante atractivo para el turismo. Algunos autores sostienen que los espacios verdes provocan un sensible crecimiento económico, en la medida en que potencian el crecimiento urbano y el desarrollo económico, debido a que sus componentes vegetales y dotacionales son percibidos como un aliciente por la inmensa mayoría de la población (Dula, 2008). El verde urbano se convierte en una oportunidad de negocio para comerciantes y empresarios, que utilizan su capacidad de atracción para desarrollar actividades económicas. Algunos centros comerciales crean zonas verdes a su alrededor con el fin de generar un ambiente que atraiga clientes e incremente tanto el valor de los negocios, como el atractivo del propio centro comercial (Dwyer et al., 1992).

Los parques y jardines pueden llegar a generar beneficios también para las administraciones públicas a través de la recaudación de tasas impuestas a determinadas actividades desarrolladas en ellos. Estas áreas pueden actuar como herramientas para promover el desarrollo económico en barrios en proceso de revitalización al fortalecer su capacidad de atracción, fomentando la actividad económica a través del consumo (Dula, 2008). Como se indica en el apartado referente a las funciones sociales, los espacios verdes tienen una relevancia notable en la motivación de los trabajadores. En general, los beneficios psicológicos de los espacios verdes tendrán también cierto valor económico, ya que influyen directamente en la capacidad productiva del individuo. La mejora del rendimiento en el 
trabajo, la influencia en el tiempo de recuperación de pacientes en los hospitales tras intervenciones quirúrgicas, pasando por otras muchas situaciones, provocarían un ahorro o una disminución de los costes, tanto para las empresas como para las Administraciones Públicas. Otro tipo de actividades económicas que se desarrollan esporádicamente en los espacios verdes son ferias, verbenas y conciertos. En dichos eventos, los parques públicos actúan como receptores o contenedores, fomentando el desarrollo de actividades económicas en su interior, que al igual que las situaciones anteriormente citadas, generan beneficios tanto a particulares como a los organismos públicos vía impuestos.

\section{iii) Impulso de la actividad turística}

Durante las últimas décadas los espacios verdes más emblemáticos de las principales ciudades europeas y norteamericanas, como es el caso de Central Park en Nueva York, de los Jardines de Luxemburgo o del Campo de Marte en París, de Hyde Park o de Regent's Park en Londres, del Tiertgarten de Berlín, del Vondelpark en Ámsterdam, de El Retiro en Madrid o del Parque Güell en Barcelona, por citar algunos ejemplos, se han convertido en lugares atractivos para los turistas debido a sus componentes artísticos, históricos y ambientales (ver Figura 3.6). Como complemento a estos valores tradicionales, destaca la progresiva relevancia social que ha ido ganando el verde urbano, en la medida en que facilita la relajación, el descanso y la relación entre personas, lo que influye en que los turistas visiten estos espacios y que cada vez lo hagan durante periodos de tiempo más prolongados. A raíz de este auge de las áreas verdes como destino turístico, han surgido una serie de actividades que tratan de aprovechar este flujo de personas para obtener rendimientos económicos. Así, en los alrededores de dichos parques se han ido instalando determinados servicios asociados al turismo de masas, como tiendas de recuerdos, puestos ambulantes, bares y cafeterías, librerías y un amplio abanico de comercios minoristas especializados en la atención de una clientela con un perfil específico.

\subsubsection{Balance coste-beneficio}

A partir de los diferentes estudios sobre este tema, parece evidente que no se podría calificar de gasto innecesario o superfluo el realizado por las entidades locales al crear y mantener los espacios verdes urbanos. Es cierto que existen numerosos aspectos mejorables y recursos cuya utilización dista mucho de ser la óptima pero, en líneas generales, se podría afirmar que los espacios verdes generan importantes beneficios económicos tanto para la población como para las Administraciones Públicas. En su trabajo sobre el verde urbano de la ciudad de Modesto (EEUU), McPherson et al. (1999) llegaron a la conclusión de que los beneficios económicos producidos en un año concreto por los árboles de la ciudad no solo fueron superiores a los costes de creación y mantenimiento de ese año, sino que casi los duplicaron. Es remarcable el hecho de que los beneficios económicos obtenidos en este estudio fueran única y exclusivamente generados por la función ecológica del verde urbano, obviando otras fuentes de ingresos, como el turismo o el aumento del valor de las propiedades. Sin embargo, es necesario tener presente que estudios como el citado se han llevado a cabo en ciudades americanas con morfologías urbanas diferentes a las de los países mediterráneos, por lo que habrá que tener ciertas precauciones a la hora de extrapolar las situaciones.

Al valor económico de las funciones ecológicas se unen trabajos como el de Dula (2008). Pese a no acompañar las afirmaciones con datos empíricos, este autor apunta a que los beneficios derivados del aumento del precio de la propiedad debido a la proximidad de zonas verdes, podrían llegar a superar los gastos generados por estos espacios. Sin embargo, es muy difícil estimar una cifra monetaria precisa con la que valorar los beneficios producidos por las áreas verdes. Hasta la fecha no se conoce ningún estudio que aborde de 
Figura 3.6 Espacios verdes emblemáticos de dos capitales europeas. Arriba: Tiergarten (Berlín). Abajo: Campo de Marte (París).
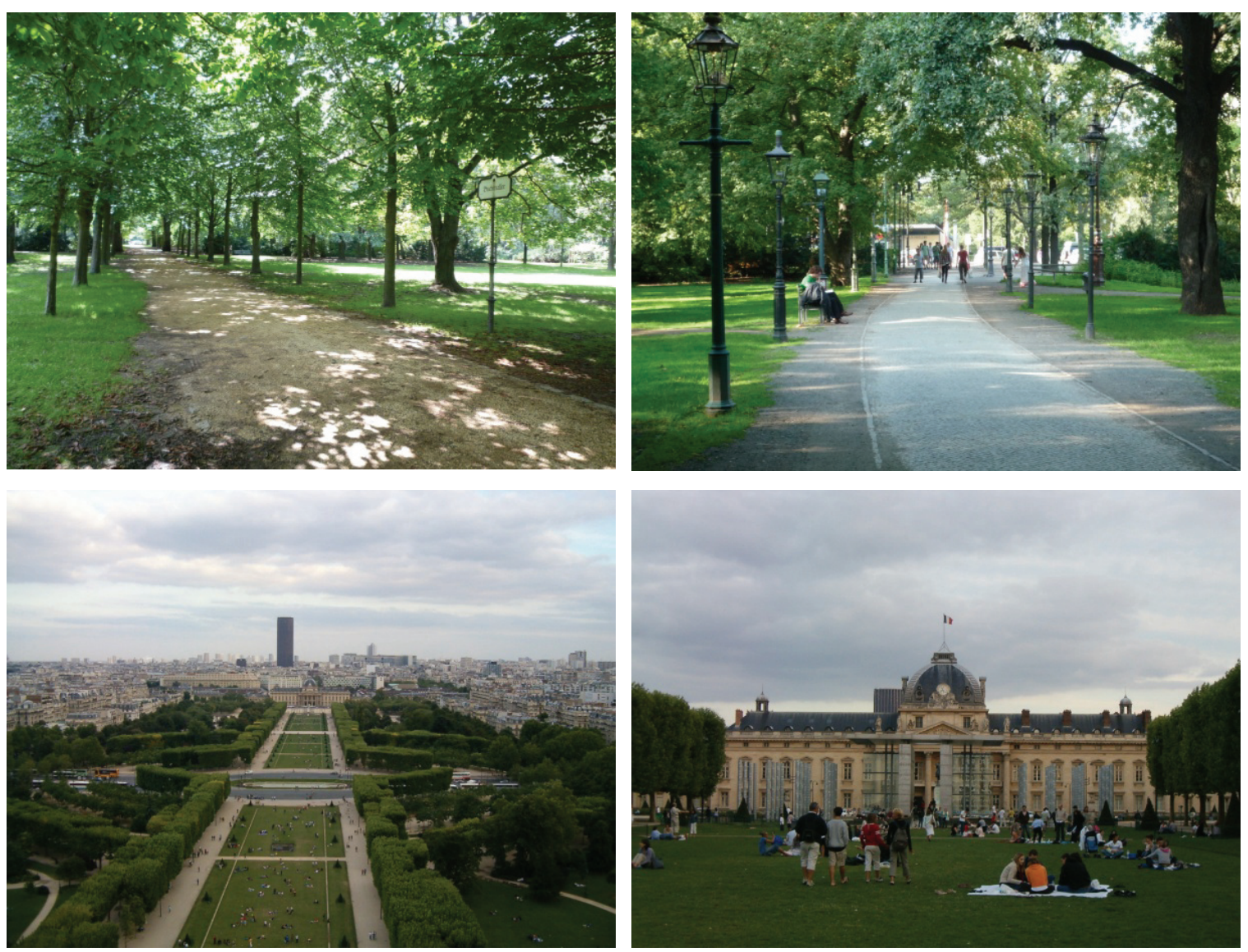

Fuente: Gómez, A. (02/08/2011 y 06/08/2006).

manera pormenorizada el conjunto de beneficios económicos producidos por el verde urbano, ya que cada autor realiza una aproximación al tema mediatizada por los límites de su formación académica o profesional. Por lo tanto, será necesario crear grupos de trabajo interdisciplinares para abordar esta y otras cuestiones referidas a los espacios verdes urbanos, en los que el geógrafo podría desempeñar un papel relevante.

\subsection{Función social}

Hoy en día la creación de zonas verdes en las ciudades se ha convertido en una exigencia social, ya que las personas otorgan un alto valor a estos espacios al ser conscientes de los beneficios que generan. El verde urbano adquiere una notable trascendencia al convertirse en un elemento necesario para la convivencia y el bienestar de los ciudadanos y es el marco de lo que la literatura especializada denomina como funciones sociales. Estas se definen como las acciones generadas por la presencia de espacios verdes que afectan de manera directa a la vida social en la ciudad (Galindo et al., 1997). Han sido excluidas de este apartado las funciones estético-paisajística y educativa, por ser consideradas funciones multidimensionales, es decir, vinculadas con más de una función. 


\subsubsection{Valor terapéutico}

\section{i) Beneficios psicológicos}

El medio urbano es generalmente un entorno estresante para los ciudadanos, en contraposición al contacto con la naturaleza, que promueve la relajación, la tranquilidad y el bienestar psíquico de los individuos (Maller et al., 2005; Tzoulas et al., 2007). La presencia de áreas verdes puede hacer del ambiente urbano un lugar más placentero para vivir al provocar en las personas estados fisiológicos de mayor relajación que los espacios que no cuentan con componentes vegetales (Dwyer et al., 1992). De manera general son consideradas como atractivas, contribuyendo a reforzar la percepción de bienestar entre los ciudadanos (Chiesura, 2004; Tzoulas et al., 2007). En los países desarrollados, la mayoría de los contactos con la naturaleza en la ciudad se realizan en pequeños lapsos de tiempo durante los que se llevan a cabo actividades de relajación y de recreo (Ulrich et al., 1991). A través de los beneficios terapéuticos, los espacios verdes contribuyen a mejorar la calidad de vida de los residentes (Bolund y Hunhammar, 1999), al permitirles escapar de los problemas de las áreas urbanas y entrar en contacto con la naturaleza (Chiesura, 2004; Bendimo-Rung et al., 2005).

Las áreas verdes ayudan al restablecimiento del estrés, entendiendo por este último la respuesta de un individuo ante una situación que perturba su bienestar. A medida que las personas entran en contacto con la vegetación en la ciudad se produce un notable decrecimiento del estrés (Ulrich et al., 1991). Chiesura (2004) cita los estudios de Schroeder en los que se demuestra que los ambientes naturales de la ciudad provocan cierta relajación en los sujetos, contribuyendo a reducir los estados de estrés en mayor medida que las zonas urbanas sin vegetación. Los espacios verdes pueden actuar de barrera o de pantalla, aislando al sujeto de las actividades urbanas cotidianas (Ochoa, 2009) y ayudándolo a recuperarse del estrés diario. Si las visitas se acompañan con la realización de actividad física (ver Figura 3.7), se producirá un mayor restablecimiento del equilibrio psicológico de las personas (Galindo et al., 1997). Esta reducción del estrés tiene también su traducción económica, como demuestra el trabajo de Kaplan (1993), en el que se observa una notable mejora de la productividad de los trabajadores cuando tienen una visión de espacios ajardinados desde sus puestos de trabajo. Los beneficios psicológicos del verde urbano provocan también una notable reducción de las agresiones y de la violencia en la ciudad (Baycan-Levent et al., 2009), así como un descenso de los sentimientos de miedo a la vez que aumentan los afectos positivos (Smardon, 1988). Bendimo-Rung et al. (2005) mencionan un conjunto de investigaciones en las que se afirma que la práctica del ejercicio físico reduce el nivel de la depresión en personas con tendencias depresivas, confirmando que la actividad física y la salud psicológica están asociadas. En su trabajo llevado a cabo con pacientes que se recuperaban de una colecistectomía, Ulrich (1984) demostró que aquellos que podían ver espacios ajardinados a través de sus ventanas, pasaron menos tiempo en el hospital que los pacientes que no tuvieron una visión de los espacios verdes. Por otro lado, Nilsson y Randrup (1998) citan los estudios llevados a cabo por Grahn, en los que se constata el valor medicinal real de los parques y jardines al contribuir a la mejora de los pacientes en los hospitales.

\section{ii) Beneficios no psicológicos}

El verde urbano es el mayor conjunto de espacios abiertos y libres de tráfico de muchas ciudades. De Vries et al. (2003) y Santana et al. (2007b) demostraron la importancia de estos espacios en la práctica de actividades físicas y en la relajación, así como sus impactos 
Figura 3.7 Beneficios psicológicos y no psicológicos derivados de la práctica deportiva, de la relajación y del recreo. Arriba: Parque Ribera de Castilla (Valladolid). Abajo: Vondelpark (Ámsterdam).
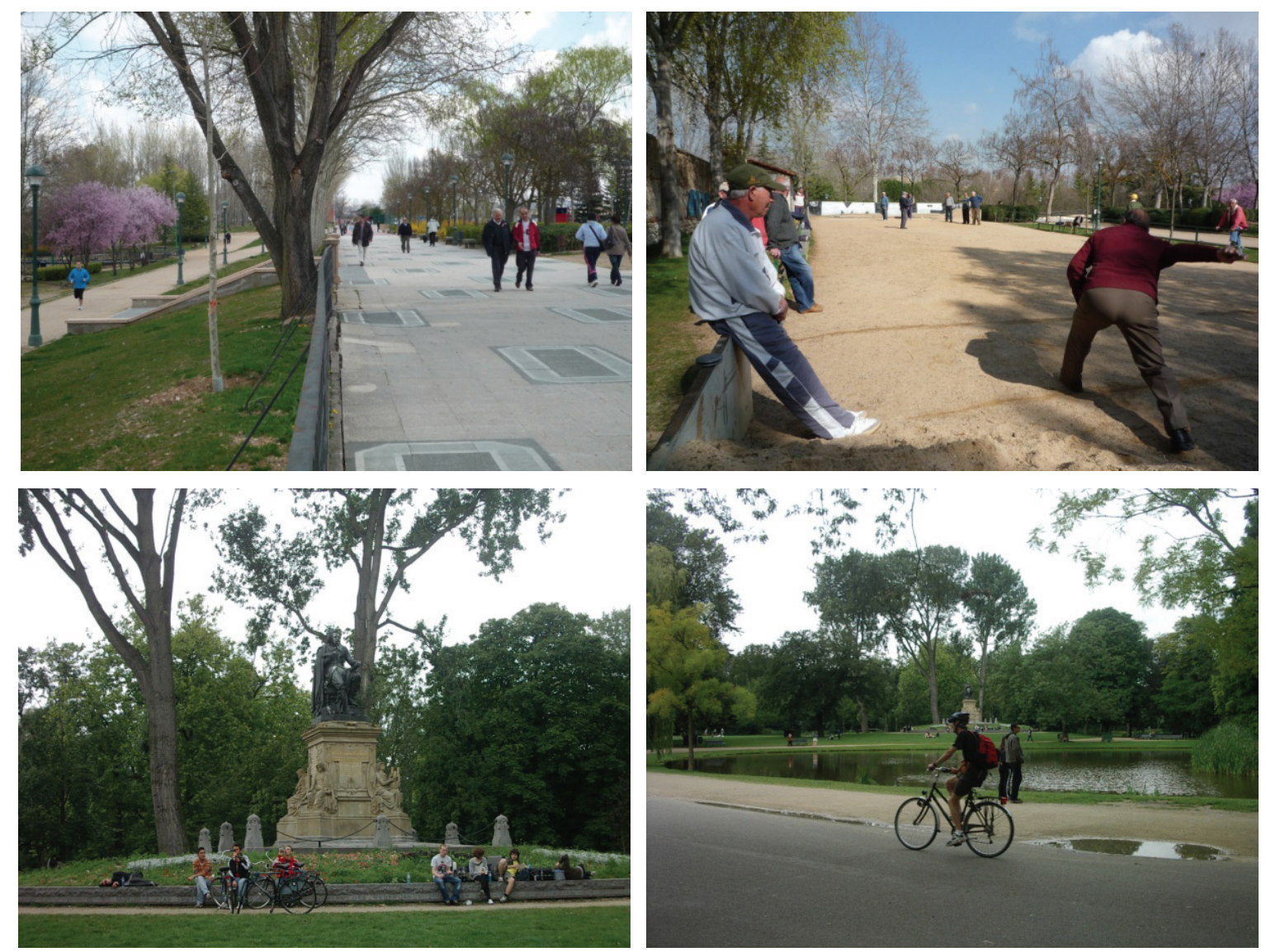

Fuente: Gómez, A. (22/03/2011) y Sánchez, J.L. (25/07/2011).

en el índice de masa corporal, en la percepción de la propia salud y en la longevidad. Además de los beneficios psicológicos que produce la actividad física, hay que añadir otros beneficios para la salud en forma de reducción de la obesidad y de enfermedades coronarias, así como la mitigación del tipo de vida sedentario (ver Figura 3.7) (Byrne y Wolch, 2009). Por otra parte, las funciones ecológicas desarrolladas por la vegetación contribuyen a mejorar la calidad del medio ambiente de las ciudades, reduciendo algunos de los efectos perjudiciales para la salud que provocan los ambientes urbanos. Por tanto, existen evidencias suficientes para concluir que la trama verde de una ciudad tiene repercusiones positivas en la salud pública (Tzoulas et al., 2007; Santana et al., 2007a, 2008, 2010).

\section{iii) Perjuicios para la salud}

Mediante la emisión de pólenes la vegetación urbana puede agravar o provocar determinadas patologías respiratorias o alérgicas, así como ciertos trastornos en la salud (Falcón, 2008). Los compuestos orgánicos volátiles (VOC) también pueden llegar a ser perjudiciales, en la medida en que contribuyen a la generación de ozono troposférico. Por otra parte, la existencia de animales en las áreas verdes puede provocar contrapartidas en forma de ruidos desagradables, de daños en el mobiliario urbano y de contactos con especímenes que pudieran ser portadores de alguna enfermedad (Nowak y Dwyer, 2007). 


\subsubsection{Beneficios en el desarrollo social y personal}

Las áreas verdes públicas desempeñan un rol importante en la mejora de las relaciones humanas, al ofrecer lugares en los que la población puede desarrollar vínculos sociales (Kim y Kaplan, 2004; Bendimo-Rung et al., 2005). Efectivamente, varios estudios han demostrado que estos espacios son lugares de convivencia e interacción social, donde se registra una disminución de la agresividad y de la violencia (Kuo y Sullivan, 2001; Doyle et al., 2006). Son lugares democráticos, en los que no se realiza distinción de ningún tipo, y permiten un restablecimiento del equilibrio social debido a la igualdad que se establece entre los diferentes usuarios (Falcón, 2008). Por lo tanto, las zonas verdes contribuyen tanto a la inclusión social, al permitir el encuentro entre distintas personas (Cobo, 1997), como a la generación de beneficios personales mediante el aumento de la autoestima o de la valoración personal (Galindo et al., 1997). El contacto entre habitantes de un mismo barrio permite mejorar la relación entre los individuos (Falcón, 2008) y fomenta el sentimiento de pertenencia y de identificación con una comunidad (López-Torrecilla, 2009). De esta manera el verde urbano se convierte en un elemento vertebrador de los barrios, mejorando las condiciones de vida y generando en los ciudadanos actitudes de control social.

\subsubsection{Aspectos simbólico-culturales}

En ocasiones los parques y jardines juegan un notable papel en la historia y en la cultura de las ciudades al ser considerados por los habitantes como una parte más de la historia local. Como se mencionó en la función económica, algunos han llegado a convertirse en una parte más de los diferentes itinerarios turísticos de las principales capitales europeas, debido a su importancia histórico-cultural. Representan la parte con mayor visibilidad del medio ambiente urbano y a la hora de promocionar las ciudades, los valores naturales tienen cada vez más peso en la medida en que su existencia se asocia a la imagen o a la marca de una ciudad. De manera general, Freire (2005) apunta a que los espacios verdes están sustituyendo a los antiguos espacios públicos (plazas y calles) como lugares de relación y de encuentros sociales. Por otro lado, el verde urbano también puede convertirse en símbolo de pertenencia a una comunidad, ya que el contacto social entre usuarios genera la aparición de un espíritu de identidad o cultura cívica (Cobo, 1997).

\subsubsection{Miedo, discriminación y actividades ilícitas en los espacios verdes}

Además de los beneficios anteriormente mencionados, el verde urbano puede provocar miedo e inseguridad en buena parte de la población, especialmente durante la noche. La posibilidad de sufrir daños directos en los parques o el sentimiento de amenaza, redunda en la disminución del uso (Segovia y Neira, 2005; Santana et al., 2009). Cuando el sol se pone, algunos de estos espacios se convierten en zonas poco frecuentadas al ser percibidos como lugares peligrosos por parte de los ciudadanos (Cedeño, 2003). Durante el día los usuarios de las zonas verdes están sujetos a cierto control, ya que las reglas sociales tienen validez e influyen en las actitudes y en los comportamientos de los ciudadanos (Flores y González, 2007).

Byrne y Wolch (2009) documentaron que en EEUU las minorías étnicas y raciales, así como determinados grupos sociales como los homosexuales, sufren situaciones de marginación, discriminación y persecución en los parques públicos. La sensación de inseguridad en los espacios verdes es especialmente notoria entre las mujeres, ya que los perciben como menos seguros en comparación con los hombres, lo que provoca un menor uso de los mismos (Segovia y Neira, 2005). El temor de la mujer tendría su origen en la 
socialización femenina, condicionando el uso nocturno de cualquier espacio público (Cedeño, 2003).

Sin embargo, una correcta gestión del verde urbano puede mitigar algunos de los problemas mencionados. Por ejemplo, se ha demostrado que en las áreas verdes bien cuidadas se registran menos situaciones de miedo, menores acciones incivilizadas y comportamientos menos violentos (Westphal, 2003), mientras que en las desatendidas, en las que la maleza y la vegetación crecen libremente, se pueden producir incrementos de los crímenes violentos (Byrne y Wolch, 2009). Algunos estudios apuntan a la posibilidad de que determinados espacios verdes con pocos usuarios o con un mantenimiento deficiente puedan transformarse en potenciales puntos calientes de criminalidad (Newman, 1972; Geason y Wilson, 1989). Por tanto, será necesario que el control de las zonas verdes se lleve a cabo por parte de los mismos usuarios (Segovia y Neira, 2005; Santana et al., 2009), ya que en ellos se fomentan las relaciones sociales y aumentan los niveles de pertenencia a la comunidad, lo que finalmente provoca un incremento de la seguridad.

\subsection{Función de planificación urbana}

Esta función puede ser definida como el papel que juegan los parques y jardines en la configuración de la estructura urbana. Las zonas verdes son utilizadas habitualmente en la ordenación y en la gestión de las ciudades por su valor como elementos que articulan y cohesionan los espacios urbanos. Además influyen positivamente en la percepción que los habitantes tienen de los distintos barrios por el amplio conjunto de beneficios que proporcionan. A la hora de realizar una ordenación del territorio, la trama verde permite tanto la consolidación del tejido urbano (Sanz, 2005) como la obtención de un equilibrio paisajístico, social y ecológico (FEDENATUR, 2004) (ver Figura 3.8). Son utilizados por los técnicos como lugar central en torno al que se orientan los edificios y el tráfico, tanto de personas como de vehículos. Los espacios verdes tienen una utilidad urbanística, en la medida en que son elementos organizadores de la trama urbana, que actúan como hitos y jalones en el interior de la ciudad. Asimismo son empleados como una herramienta muy útil para valorar las políticas urbanas de cada momento histórico, ya que el verde urbano muestra las deficiencias en la expansión urbana (Rodríguez y Díaz, 2003).

Junto a estas labores llevan a cabo también un efecto de ruptura (ver Figura 3.8). Esto permite diversificar el paisaje y crear discontinuidades, ayudando a romper la monotonía a la vez que se limita la extensión urbana (FEDENATUR, 2004). En muchas ciudades, especialmente en las de la Europa occidental, la función de planificación urbana sirvió históricamente para crear una separación física entre el centro y los ensanches decimonónicos, aprovechando el espacio dejado por las murallas para crear bulevares y paseos arbolados, así como para dotar de salubridad a barrios en los que se hacinaban las personas con menos recursos, mediante la construcción de parques públicos. Hoy en día no se concibe la construcción de un barrio sin zonas verdes, en primer lugar porque son solicitadas por los ciudadanos como equipamientos indispensables, y segundo porque contribuyen a transformar estos espacios en lugares atractivos para vivir, convirtiéndose en un activo que hace aumentar la calidad de un barrio frente a otro que no cuente con zonas verdes.

\subsection{Función multidimensional}

Esta función recoge subfunciones cuyos beneficios no pueden ser incluidos en una sola de las categorías establecidas. Se tratará, por tanto, de funciones que afectan a varios de los cuatro grandes grupos anteriormente señalados y que presentan elementos comunes con ellos. En el caso de la subfunción estético-paisajística y de la educativa, generan beneficios 
Figura 3.8 Espacios verdes utilizados para consolidar las nuevas piezas urbanas. Arriba: Parque das Nações (Lisboa). Abajo: elementos de ruptura paisajística, Avenida Sá da Bandeira y Parque da Sereia (Coimbra).
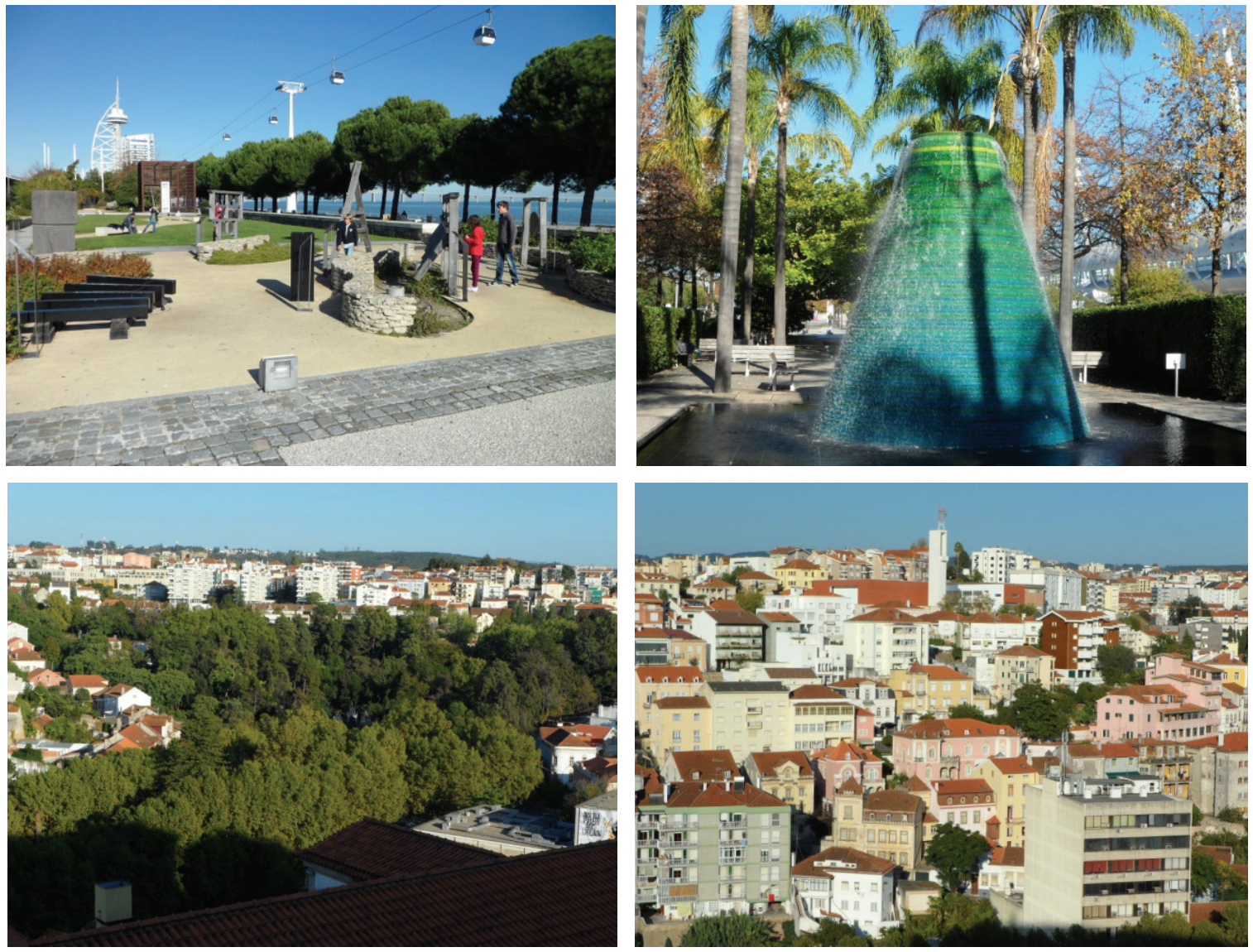

Fuente: Gómez, A. (22/12/2011) y Borrallo, E. (21/10/2011).

tanto ambientales como sociales, incluyendo también en el caso de la primera beneficios pertenecientes a la función económica y de planificación urbana.

\subsubsection{Consecuencias estético-paisajísticas}

Los habitantes de las ciudades prefieren los paisajes que cuenten con elementos vegetales a los paisajes puramente urbanos (Ulrich, 1986). Los espacios verdes permiten el disfrute a través de la contemplación de ciertos componentes paisajísticos y estéticos (Boinsignore et al., 2003), generando cierta satisfacción en los ciudadanos (Galindo et al., 1997) que termina por convertirse en un factor terapéutico en comparación con el resto de paisajes urbanos (Ulrich, 1984). La presencia de vegetación tiene efectos positivos en la preferencia territorial de las personas, favoreciendo el desarrollo de actividades económicas. Galindo et al. (1997) ahondan en los orígenes de los gustos estéticos de los seres humanos, apuntando a que se consideran como bellos los paisajes que cuentan con rasgos que a lo largo de la evolución han supuesto un beneficio para la supervivencia humana.

Como se indicó en la función social, la visión de espacios verdes es necesaria para que los ciudadanos puedan restablecerse del estrés producido por el medio urbano. La mera contemplación de paisajes con elementos vegetales puede reportar importantes beneficios al aumentar la productividad de los trabajadores (Kaplan, 1993), reducir el tiempo de curación de los enfermos (Ulrich, 1984) y ayudar a que las personas se recuperen de situaciones estresantes (Westphal, 2003). Galindo et al. (1997) señalan que posiblemente los seres 
humanos vivan más saludablemente con los beneficios generados por las actividades estéticas que sin ellas.

\subsubsection{Perspectiva educativa}

Las áreas verdes urbanas son también lugares pedagógicos y de aprendizaje, puesto que permiten un contacto directo con la naturaleza. Se trata de espacios donde se puede acceder libremente al medio ambiente y entrar en contacto los procesos naturales (Sorensen et al., 1998), generando entre los individuos sentimientos de aprecio y de respeto por aquello que se conoce (Falcón, 2008). Sánchez-Barbudo (1989) los considera como un elemento importante en la educación, debido a la capacidad que tiene el medio ambiente local tanto para motivar a los niños, como para servir de puente entre el aula y la naturaleza. Para García (2007) la educación ambiental es una herramienta fundamental para la conservación de la naturaleza urbana que permitirá un aumento de la conciencia ecológica.

\subsection{Recapitulación}

Los espacios verdes generan un amplio abanico de beneficios tanto para el medio ambiente urbano como para los ciudadanos. Contribuyen a mejorar la habitabilidad de los núcleos urbanos, actúan como reguladores del microclima local y en general atenúan las descompensaciones existentes en el interior del ecosistema urbano. La trama verde es una herramienta fundamental para la configuración de la ciudad, debido a su destacada capacidad para organizar el espacio urbano y su presencia genera, además, distintos beneficios económicos e importantes ahorros para las administraciones locales. Es también un aliciente para los negocios y el turismo, induce importantes beneficios terapéuticos en los habitantes, al tiempo que permite mejorar las relaciones sociales y personales.

La existencia de estos espacios en el interior de las ciudades presenta una serie de contrapartidas para la vida cotidiana, que podrían acentuarse si no se realizara una correcta gestión de los mismos. Sin embargo, son muchos más los beneficios derivados de las funciones tratadas en este capítulo. Analizando cada uno de ellos se consigue plasmar una realidad que es difícil de percibir en su totalidad y permite justificar plenamente un estudio como el planteado. 


\section{EVOLUCIÓN HISTÓRICA DE LAS CIUDADES DE SALAMANCA, VALLADOLID Y ZAMORA}

En este capítulo se ha analizado la evolución urbana de las tres ciudades seleccionadas atendiendo especialmente a los fenómenos que han influido en la construcción del verde urbano. En la introducción de esta investigación se explicó que la ciudad estudiada no es estrictamente la ciudad real, sino que se limita a una parte de los municipios centrales de las aglomeraciones urbanas para facilitar el análisis de unos espacios verdes concretos. No obstante, conviene mencionar las principales características de estas entidades urbanas de mayor tamaño para contextualizar los procesos identificados en los municipios seleccionados.

\subsection{Ciudad y área urbana}

La expansión del proceso de urbanización ha provocado que durante la segunda mitad del siglo XX Salamanca, Valladolid y Zamora superasen los límites administrativos de sus términos municipales originales, extendiéndose por núcleos de población que históricamente habían tenido una clara vocación agrícola. Este proceso ha convertido progresivamente a estos municipios en parte de la ciudad desde un punto de vista funcional y económico, aunque hayan mantenido su independencia administrativa. Sobre los casos concretos de las tres ciudades analizadas existen algunos trabajos como el citado en el capítulo introductorio de Serrano (2006), que trabajó con datos de población del año 2004, en el que sitúa a Valladolid en el puesto dieciocho de las cuarenta y cinco mayores aglomeraciones urbanas españolas con 390.516 habitantes, mientras que Salamanca ocuparía el puesto treinta con 195.437 habitantes. Sin embargo otros trabajos de carácter más local revelan valores ligeramente diferentes. Por ejemplo, las Directrices de Ordenación del Territorio de Valladolid y Entorno de 2001 incluían veintitrés municipios ${ }^{2}$ en una aglomeración urbana que contaría con una población total de 372.200 habitantes, mientras que un trabajo publicado hace ya algunos años identificó veintisiete municipios ${ }^{3}$ afectados por el proceso de urbanización vinculado a Salamanca (Gómez, 2007), cuya población total se estima en 206.475 residentes en el año 2011. En Zamora fueron seleccionados los diez municipios señalados por Huertos ${ }^{4}$ (2007) en su estudio sobre el espacio periurbano de dicha ciudad y se obtuvo una cifra total de 75.030 residentes en la aglomeración. El método para determinar la extensión del área urbana es diferente en cada uno de los casos citados y consecuentemente, los resultados variarán en función del número de municipios seleccionados. Con independencia del método utilizado, las cifras manejadas permiten identificar un proceso común de difusión del fenómeno urbano por el territorio, intensificado en las últimas décadas y que afecta de una forma evidente a los municipios más próximos a las ciudades tradicionales. En la Figura 4.1.1 aparece representado con un trazo

\footnotetext{
${ }^{2}$ Los municipios recogidos en este documento son Aldeamayor de San Martín, Arroyo de la Encomienda, Boecillo, Cabezón de Pisuerga, Castronuevo de Esgueva, Cigales, Ciguñuela, Cistiérniga, Fuensaldaña, Gería, Laguna de Duero, Mucientes, Pedraja de Portillo, Renedo de Esgueva, Santovenia de Pisuerga, Simancas, Tudela de Duero, Valdestillas, Viana de Cega, Villanuela, Villanueva de Duero y Zaratán.

${ }^{3}$ Los municipios incluidos en dicha investigación son Aldealengua, Aldeatejada, Arapiles, Barbadillo, Cabrerizos, Calvarrasa de Arriba, Calzada de Don Diego, Carbajosa, Carrascal de Barregas, Castellanos de Moriscos, Castellanos de Villiquera, Doñinos de Salamanca, Florida de Liébana, Galindo y Perahuy, Miranda de Azán, Monterrubio de la Armuña, Moriscos, Mozárbez, Parada de Arriba, Pelabravo, San Cristóbal de la Cuesta, San Pedro de Rozados, Santa Marta de Tormes, Valverdón, Villamayor y Villares de la Reina.

${ }^{4}$ Este autor selecciona los municipios de Arcenillas, Casaseca de las Chanas, La Hiniesta, Monfarracinos, Moraleja del Vino, Morales del Vino, Roales, Valcabado y Villaralbo.
} 
fino el volumen demográfico de las tres áreas urbanas de acuerdo con los trabajos anteriormente mencionados y con un trazo más grueso el número de habitantes del municipio central de cada una de ellas. La expansión de las formas de vida urbanas en los núcleos más próximos a Salamanca y Valladolid comenzó a finales de la década de los setenta del siglo pasado, pero se hizo especialmente intensa durante la segunda mitad de la década de los noventa. En estos dos municipios se alcanzó el máximo absoluto de población a lo largo de la década de los ochenta del siglo pasado, experimentando posteriormente un sensible decrecimiento hasta mediados de la década siguiente. A partir de ese momento la población de la ciudad tradicional se ha mantenido más o menos estabilizada, mientras que el resto de municipios de las áreas urbanas han experimentado un notable crecimiento demográfico. Tras el cambio de siglo este proceso se intensificó y en ambos casos supone un incremento de población que supera los veinticinco mil habitantes. Mucho más débil fue la influencia de la periurbanización en Zamora, donde el total de habitantes del área urbana fuera del municipio central es de 9.505 habitantes, frente los 58.763 de Valladolid y a los 53.003 de Salamanca.

Figura 4.1.1 Evolución demográfica de las tres áreas urbanas estudiadas.

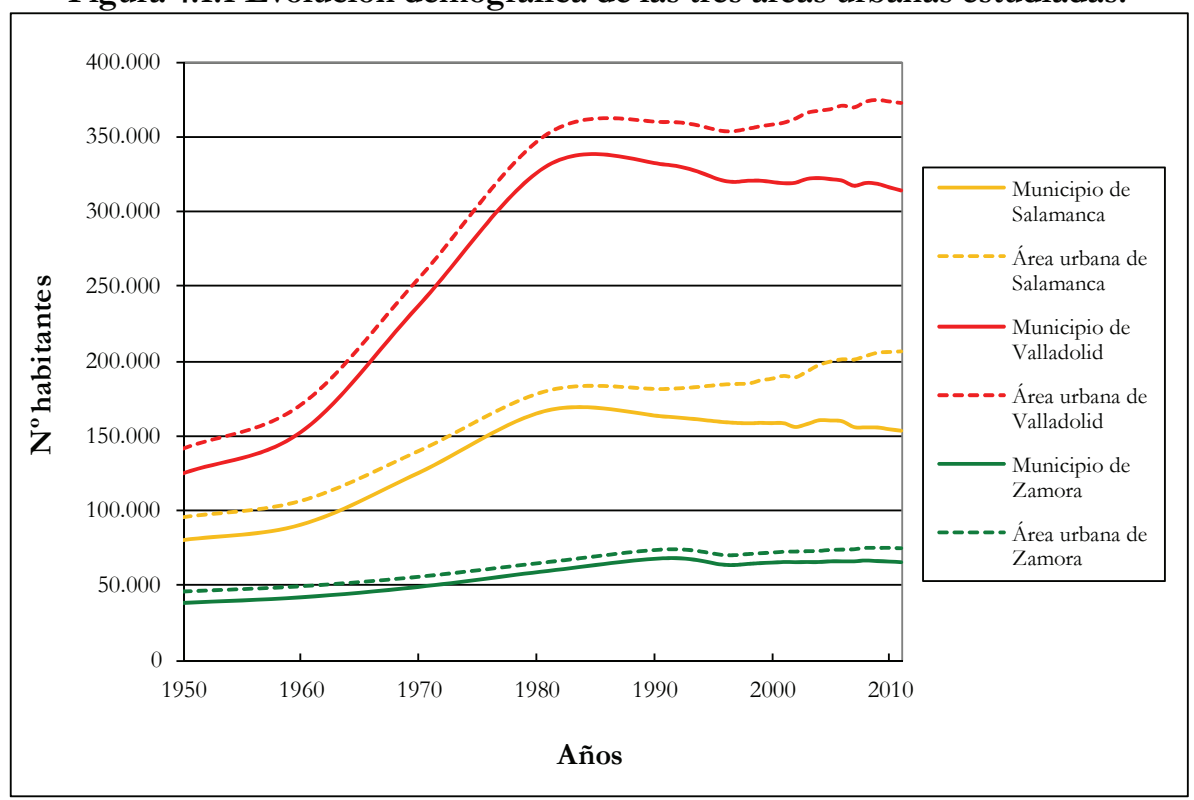

Fuente: INE.

Como el objetivo de esta investigación es analizar la localización y el uso de los espacios verdes en el interior de las tres ciudades, se han excluido de la misma todos los espacios agrícolas o forestales situados entre la urbe tradicional y los nuevos núcleos urbanos, que son denominados urban field o campo urbano en la literatura consultada. Se optó por trabajar únicamente con los municipios centrales de las aglomeraciones urbanas, puesto que todavía puede distinguirse el lugar central donde se concentran la mayor parte de las residencias y de los puestos de trabajo (Roca, 2003). Estos espacios situados fuera de lo que en esta investigación se ha considerado como ciudad podrían ser denominados como buertos, bosques o parques periurbanos, dependiendo de sus características.

A lo largo de este capítulo se ha estudiado de forma individual la evolución urbana de Salamanca, Valladolid y Zamora, y se han identificado una serie de procesos urbanísticos comunes en ellas. Como punto de partida se ha tomado el año 1956, fecha de la primera fotografía aérea, pero se ha retrocedido hasta comienzos de siglo para constatar que en 1900 ninguna de las ciudades alcanzaba los cien mil habitantes. Hasta el estallido de la Guerra Civil vivieron un periodo de ligero crecimiento demográfico gracias al impulso económico generado por la capitalidad provincial y a una incipiente industrialización, que fue muy 
desigual en los tres casos. Tras la contienda comenzarán a recibir un flujo continuo de inmigrantes de origen rural en un periodo de fuertes dificultades económicas, durante el cual el acceso al mercado de la vivienda era muy complicado. Para solucionar este tipo de situaciones, habituales en las principales ciudades del país, el Estado adquirió competencias en la construcción de vivienda social, creando así el Instituto Nacional de la Vivienda mediante la Ley del 19 de abril de 1939. De esta manera fueron surgiendo grandes asentamientos de vivienda pública cuyo modelo se caracteriza por la construcción de un gran polígono, ocupando generalmente suelo no urbanizable, que servirá de aliciente para la actividad urbanística privada (Calderón et al., 1992) y que en las tres ciudades estudiadas no tuvo en cuenta el planeamiento urbano en vigor. Las actuaciones estatales en materia de vivienda se mantuvieron hasta la aprobación del Plan de Estabilización en 1959, con el que se puso fin al periodo autárquico. En concordancia con la nueva política económica, el Estado abandonó la promoción directa de vivienda y fomentó la intervención del sector privado mediante la Ley de Viviendas Subvencionadas y el II Plan Nacional de la Vivienda, finalizado en 1974 (García, 2000). Durante la década de los sesenta se producirá el despegue económico vallisoletano impulsado por una fuerte industrialización que entre 1964 y 1971 fue respaldada por la declaración de Polo de Desarrollo. Por su parte, Salamanca y Zamora mantuvieron una actividad económica basada mayoritariamente en los servicios propios de las capitales provinciales, que en el caso de la primera se vio favorecida por la pujanza de su Universidad. El éxodo rural impulsó el enorme crecimiento de las ciudades durante las décadas de los sesenta y setenta, motivando una considerable expansión territorial del suelo urbano y un progresivo abandono de los centros históricos, donde junto al rico patrimonio histórico artístico proliferaban los edificios viejos o ruinosos.

En 1956 se aprobó la primera Ley del Suelo que, a juicio de Terán (1978), no llegó a ponerse realmente en práctica por su carácter contradictorio y por su falta de adaptación a la nueva política económica liberal. Veinte años más tarde se aprobó la reforma de la Ley de Suelo, también conocida como segunda Ley del Suelo, con la que se trató de racionalizar y controlar el crecimiento de las ciudades. Esta legislación será la que regule los primeros Planes Generales de Ordenación Urbana en democracia, aprobados en las ciudades analizadas a lo largo de la década de los ochenta (Salamanca y Valladolid 1984, Zamora 1986). Este tipo de documento es el instrumento mediante el cual los ayuntamientos realizan una ordenación integral del territorio municipal, clasificando el suelo y definiendo los elementos de los sistemas generales de equipamientos e infraestructuras. Además, se fueron aprobando los Planes Especiales del Casco Histórico (Salamanca, 1984, Valladolid, 1992, Zamora, 2000) con el objetivo de rehabilitar y revitalizar esta parte de la ciudad. Todo este proceso se acompañó de un estancamiento del crecimiento demográfico de los municipios centrales de las aglomeraciones urbanas, ya mencionado con anterioridad, debido a un creciente movimiento de periurbanización, especialmente intenso en Valladolid y Salamanca. En 1997 el Tribunal Constitucional derogó la mayor parte de la Ley del Suelo de 1990, reconociendo al mismo tiempo las competencias de las Comunidades Autónomas en materia de urbanismo y de ordenación del territorio. Actualmente sigue en vigor la Ley de Urbanismo de Castilla y León de 1999 y su Reglamento de Urbanismo revisado en 2009.

El planeamiento permite adecuar la ordenación del espacio urbano a la voluntad de los ciudadanos, favoreciendo por ejemplo, la reserva de suelo para zonas verdes y restringiendo la implantación de determinadas actividades molestas cerca de los núcleos más densamente poblados. Desde la llegada de la democracia se ha cumplido de una manera más o menos estricta con la normativa urbanística, propiciando así un aumento muy considerable del número de verdes urbanos desde la década de los ochenta del siglo pasado. 


\subsection{Origen y evolución del verde urbano de la ciudad de Salamanca}

Salamanca contaba con 153.472 habitantes en 2011, ocupando así un lugar intermedio entre las tres ciudades analizadas. Está dividida en cuarenta y cinco barrios según el Ayuntamiento (ver Tabla 4.2.1), cuya representación cartográfica puede observarse en la Figura 4.2.1, en la que además se han incluido las principales divisiones del tejido urbano de Salamanca. Los barrios del 1 al 8 componen el centro histórico, que se corresponde con el espacio situado en el interior de la cerca medieval. Aparece marcado en un tono gris oscuro y su extensión es de 120,8 ha, bastante superior a la del Plan Especial de Protección y Reforma Interior del Recinto Universitario y Zona Histórico-Artística (PECH) de 1984. Lindando con este espacio aparece la primera ronda en un tono más claro. La separación entre esta y la segunda corona, que comprende los barrios periféricos del norte de la ciudad, comienza en el Puente de la Universidad y sigue en dirección a la Avenida de Portugal, continúa por la Avenida de Salamanca, la Avenida de los Castaños y la Avenida de los Cipreses y en 2007 finalizaba en la Calle Colombia. Los espacios situados al sur del río quedan fuera de esta división, como también lo están en la literatura científica y en los diferentes textos administrativos consultados. Esta percepción de la ciudad otorga un valor secundario a los procesos acaecidos al sur del Tormes, excluyéndolos de la configuración de las orlas de crecimiento de la ciudad. En el capítulo metodológico quedó fijado en 0,9 ha el tamaño mínimo del verde urbano de la ciudad de Salamanca en 2007. La Tabla 4.2.2 es idéntica a la Tabla 2.5 y recoge los treinta y cuatro espacios que pertenecen a dicha categoría, con su tamaño y nombre correspondiente, mientras que en las Figuras 4.2.2 y 4.2.3, que son reproducciones de la 2.5 y de la 2.6, aparecen situados en el interior de la ciudad. En la primera imagen se han destacado las áreas verdes sobre la ortofoto de Salamanca, diferenciando los huertos urbanos en un color amarillento y en la segunda están numerados todos los espacios verdes, apareciendo en rojo los ocho verdes urbanos no disponibles. En total suman 124 ha de zonas verdes, de las que 100 son visitables por la población y 15 ha están dedicadas a la agricultura.

\subsubsection{Evolución urbana de Salamanca hasta 1956}

A mediados del siglo XX la ciudad únicamente contaba con dos parques de tamaño reducido, aunque albergaba en su interior una amplia superficie dedicada a la agricultura urbana. Tras la Guerra Civil la penuria económica obliga a que el Estado asuma competencias en la construcción de vivienda, con el objetivo de proporcionar un hogar digno a una población que aumenta significativamente debido a la llegada de grandes contingentes de emigrantes de origen rural.

\section{i) Transformación urbana}

El siglo XX comienza en Salamanca con un moderado crecimiento demográfico, alcanzando los 32.414 habitantes en 1920. Se trata de un periodo en el que la población provincial se estanca (ver Figura 4.2.4) y la ciudad, en su condición de centro económico, actúa como atractivo para habitantes del campo que ven en la incipiente industria y en la construcción una salida a las penurias de la vida en el medio rural. Los nuevos ciudadanos se encontraron con serias dificultades para conseguir alojamiento en la capital, lo que provocó el surgimiento de la autoconstrucción y el hacinamiento en las viviendas. La mayor parte de las mismas se emplazaron en las proximidades del lugar de trabajo, en terrenos de poco interés agrario o de propiedad pública, sin que mediase ningún tipo de planificación. Resultado de este proceso es la aparición de una serie de barrios como Prosperidad (31), Garrido (23 y 25), Carmelitas (16), Barrio Vidal (20), Alto del Rollo (28) y Pizarrales (18), a 
los que se une el barrio de Chamberí (38), en torno a la feria de ganado del Arrabal del Puente (36) (Miranda, 1985). Si hasta los años veinte el crecimiento demográfico fue moderado, durante el periodo transcurrido entre 1920 y 1950 se produjo un incremento del $150 \%$, estimulando una expansión considerable de los sectores anteriormente mencionados y la creación de nuevos asentamientos como el barrio de Alambres (37), al sur del río Tormes. A finales de la década de los treinta, se instala en Salamanca el cuartel general de las fuerzas sublevadas y antes de finalizar la Guerra Civil se redacta el plan D'Ors-Gamazo que, en opinión de Terán (1978), representa la aproximación más cercana a una formulación sistemática de la teoría de urbanización falangista. Aunque no se llegó a aplicar, tiene cierto interés debido a que junto con los presupuestos ideológicos del Movimiento, heredaba ciertos principios del urbanismo ambientalista plasmados en propuestas tales como la creación de un cinturón verde en torno a la ciudad o de un gran parque en el barrio de San Vicente (7). La situación económica obligó al régimen a ceder y a permitir la intervención privada, acabando de esta forma con la utopía urbanística falangista.

Tabla 4.2.1 Nombre y número de los barrios de Salamanca.

\begin{tabular}{|c|l|c|l|c|l|}
\hline $\mathbf{N}^{\mathbf{0}}$ & Nombre barrio & $\mathbf{N}^{\mathbf{0}}$ & Nombre barrio & $\mathbf{N}^{\mathbf{0}}$ & Nombre barrio \\
\hline 1 & Centro & 16 & Carmelitas - Oeste & 31 & Prosperidad \\
\hline 2 & San Juan & 17 & Carmen & 32 & Tormes \\
\hline 3 & Sancti - Spíritus & 18 & Pizarrales & 33 & San José \\
\hline 4 & San Cristobal - Claras & 19 & Blanco & 34 & La Vega \\
\hline 5 & San Esteban & 20 & Vidal & 35 & Teso de la Feria \\
\hline 6 & Universidad & 21 & Glorieta - Ciudad Jardín & 36 & Arrabal \\
\hline 7 & San Vicente & 22 & Salesas & 37 & Alambres - San Buenaventura \\
\hline 8 & Úrsulas - San Marcos & 23 & Garrido Sur & 38 & Chamberí \\
\hline 9 & Labradores & 24 & Chinchibarra & 39 & Tejares \\
\hline 10 & Alamedilla & 25 & Garrido Norte & 40 & Buenos Aires \\
\hline 11 & Santo Tomás & 26 & Estación & 41 & Zurguén \\
\hline 12 & Fontana & 27 & Puente Ladrillo & 42 & Vistahermosa \\
\hline 13 & Tenerías & 28 & Rollo & 43 & Capuchinos \\
\hline 14 & Hospital & 29 & Delicias & 44 & Platina \\
\hline 15 & San Bernardo & 30 & San Isidro & 45 & Montalvo \\
\hline
\end{tabular}

Fuente: Observatorio Urbano de Salamanca.

Tabla 4.2.2 El verde urbano de la ciudad de Salamanca.

\begin{tabular}{|c|c|l|c|c|l|}
\hline $\mathbf{N}^{\mathbf{0}}$ & ha & \multicolumn{1}{|c|}{ Nombre } & $\mathbf{N}^{\mathbf{0}}$ & ha & \multicolumn{1}{|c|}{ Nombre } \\
\hline S-1 & 5,8 & Parque de Don Juan Tenorio & S-18 & 3,1 & Parque Fluvial \\
\hline S-2 & 7,4 & Complejo deportivo Salas Bajas & S-19 & 1,4 & Verde urbano del entorno de Mirat \\
\hline S-3 & 10,8 & Jardín botánico de Huerta Otea & S-20 & 2,7 & Parque de Ciudad Rodrigo \\
\hline S-4 & 10,1 & Parque de los Jesuitas & S-21 & 3,0 & Parque de la Chinchibarra \\
\hline S-5 & 0,8 & Jardines del Hospital Clínico & S-22 & 1,6 & Parque de Vistahermosa \\
\hline S-6 & 2,5 & Verde urbano del cerro de San Vicente & S-23 & 1,6 & Parque de Villar y Macías \\
\hline S-7 & 2,3 & Verde urbano de la Vaguada de La Palma & S-24 & 1,9 & Verde urbano de La Salle \\
\hline S-8 & 4,0 & Parque de Valhondo & S-25 & 13,5 & Parque de El Zurguén \\
\hline S-9 & 1,3 & Campo de San Francisco & S-26 & 4,3 & Verde urbano Av. Salamanca \\
\hline S-10 & 2,2 & Parque de la Alamedilla & S-27 & 1,2 & Verde urbano Facultad de Comunicación \\
\hline S-11 & 1,0 & Parque Picasso & S-28 & 1,0 & Parque de Bretón \\
\hline S-12 & 1,7 & Verde urbano de las Salesas & S-29 & 1,2 & Verde urbano residencia San J. de Sahagún \\
\hline S-13 & 2,7 & Plaza de Burgos & S-30 & 6,3 & Huerto en Salas Bajas \\
\hline S-14 & 5,1 & Seminario de Legionarios de Cristo & S-31 & 2,8 & Huerto en el Montalvo \\
\hline S-15 & 6,0 & Parque de Würzburg & S-32 & 4,1 & Huerto de la Fundación Rodríguez Fabrés \\
\hline \multirow{2}{*}{ S-16 } & \multirow{2}{*}{3,6} & Verde urbano de la margen derecha del & S-33 & 0,9 & Huerto en Tejares \\
\cline { 3 - 6 } & & Puente Romano & S-34 & 0,9 & Huerto de las Misioneras Seculares \\
\hline \multirow{2}{*}{ S-17 } & \multirow{2}{*}{5,2} & Verde urbano de la margen izquierda del & Total & $\mathbf{1 2 4 , 0}$ & \\
\cline { 4 - 6 } & & & & \\
\hline
\end{tabular}

Fuente: elaboración propia. 
Figura 4.2.1 División en barrios de la ciudad de Salamanca.

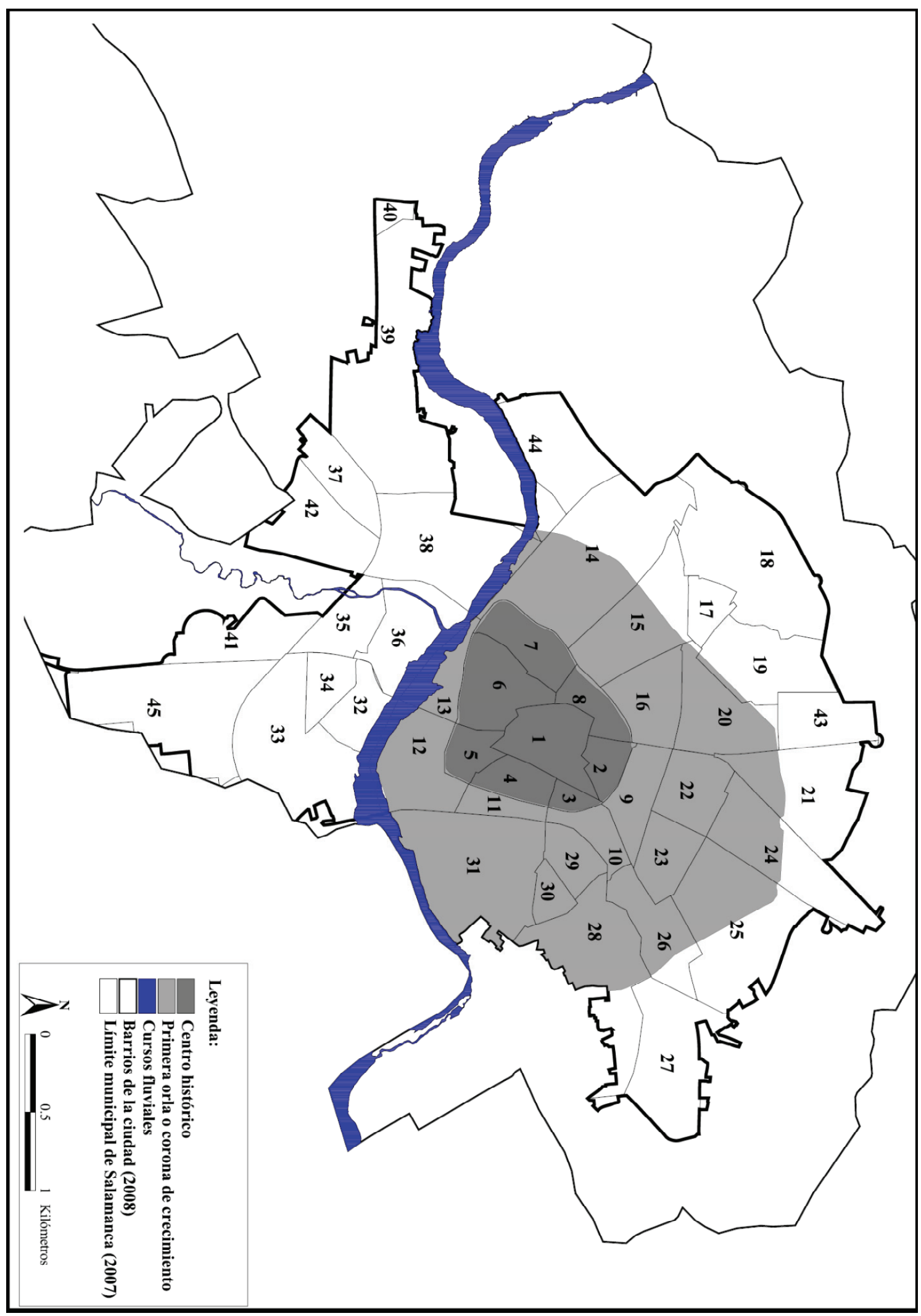

Fuente: elaboración propia a partir de la ortofoto de 2007 del IGN y del Observatorio Urbano de Salamanca. 
Figura 4.2.2 Localización espacial del verde urbano en la ciudad de Salamanca.

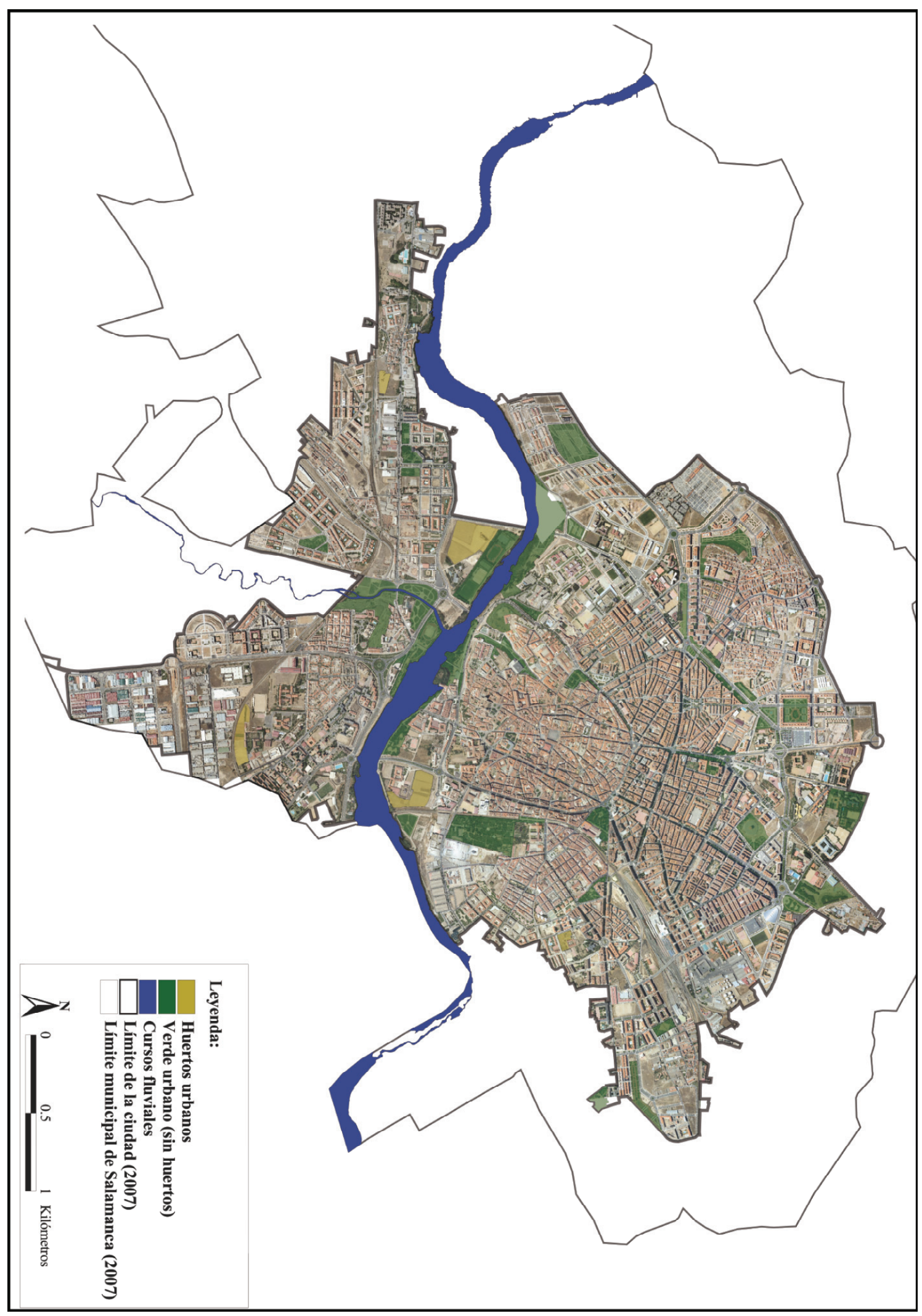

Fuente: elaboración propia a partir de la ortofoto de 2007 del IGN. 
Figura 4.2.3 Localización espacial del verde urbano disponible en la ciudad de Salamanca.

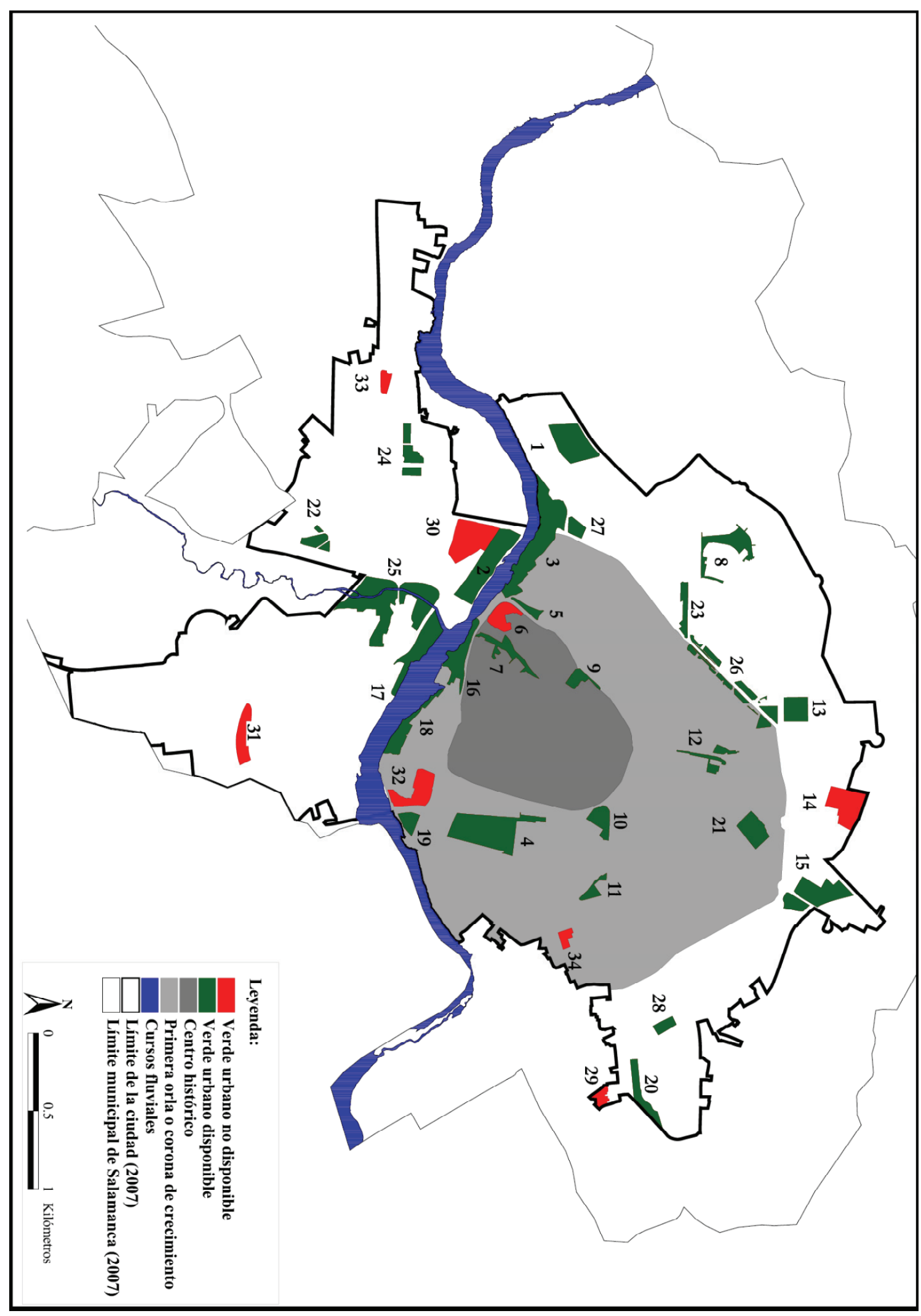

Fuente: elaboración propia a partir de la ortofoto de 2007 del IGN. 
Figura 4.2.4 Evolución de la población de la ciudad y de la provincia de Salamanca desde 1900.

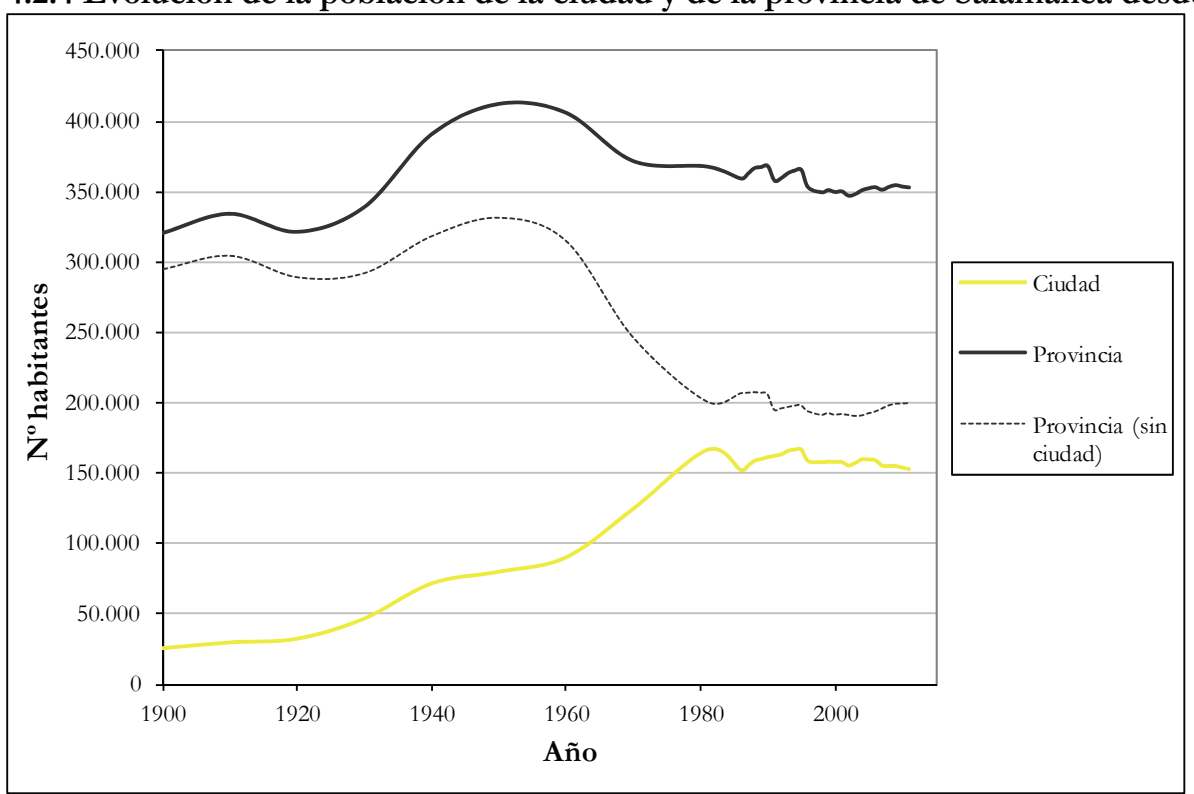

Fuente: INE.

En 1944 se aprobó el llamado Plan Maroto con los objetivos de recuperar el centro histórico y racionalizar el crecimiento espontáneo de la ciudad. Incluía una serie de propuestas de creación de áreas verdes entre las que se encontraba alguna de las previstas en el Plan D'Ors, aunque la mayor parte de ellas tampoco llegaron a materializarse (Villar, 2000). En este periodo se desarrolló una importante labor estatal en materia de construcción de vivienda social, acompañada por actuaciones urbanísticas dirigidas a la promoción del régimen mediante la construcción de edificios simbólicos del nuevo régimen en el límite oriental del centro histórico (4 y 11). A mediados de la década de los cincuenta la ciudad de Salamanca había experimentado un intenso crecimiento en superficie alcanzando las 618 ha, frente a las 162 que se estima que pudiera tener en 1900. Esta expansión estuvo motivada por el hecho de que las viviendas de autoconstrucción heredaban características del medio rural del que procedían sus pobladores, dando lugar a edificaciones de una sola planta donde se hacinaban un elevado número de habitantes. La planificación urbana se fue imponiendo progresivamente como teórico instrumento legal de ordenación del territorio municipal, lo que en palabras de Villar (2000) supone una ruptura del concepto de ciudad como obra colectiva, suma del conjunto de acciones individuales, comenzando así con una nueva etapa en la construcción dominada por los bloques de pisos. Gran parte de la población tenía serias dificultades para acceder al mercado de la vivienda, por lo que fue necesaria la actuación de la iniciativa pública a través del Instituto Nacional de la Vivienda y de la Obra Sindical del Hogar. En Salamanca, las primeras intervenciones en este sentido comenzaron a mediados de los años cuarenta, en el barrio que se llamó de Salas Pombo (15) (Senabre, 2003a). Posteriormente se levantaron los barrios de la Vega (34), del Carmen (17) y el barrio Vidal (20), junto a los del Tormes (32) y de San José (36), cuyas primeras fases concluyeron en los años sesenta. Estas actuaciones se complementaron con las llevadas a cabo por RENFE y la Caja de Ahorros tratando de hacer frente a la elevada demanda de alojamiento (Villar y Burrieza, 1995).

\section{ii) Creación de espacios verdes}

Los primeros espacios verdes de la ciudad surgen con las primeras medidas ambientalistas aplicadas a finales del siglo XVIII. Se pretendía cumplir con las exigencias de mayor ventilación e higiene en las ciudades y para ello se demolieron buena parte de las 
murallas y de sus puertas, siendo sustituidas por amplias avenidas arboladas. A comienzos del siglo XIX se crea un Jardín Botánico en los terrenos de la actual Facultad de Geografía e Historia, en el barrio de la Universidad (6), que desde 1949 se convertirá en un complejo deportivo universitario desaparecido en la década final del siglo XX (Díaz, 1998). La trama verde salmantina hunde sus raíces en el siglo XIX, ya que el Campo de San Francisco (S-9), situado en el límite occidental de la cerca medieval, se convirtió en parque en 1828 y la Alamedilla (S-10), en el sector nororiental, lo hizo en 1884. El origen del primero se encuentra en la antigua huerta del convento del mismo nombre, tomando el uso actual años después de su destrucción en la Guerra de la Independencia (Villar y Macías, 1887). Por su parte, el Parque de la Alamedilla (S-10) surgió a partir de la ocupación de una parcela agrícola próxima a la puerta de Toro durante las labores de construcción de la línea férrea Salamanca-Vilar Formoso. Acabadas las obras el Ayuntamiento adquirió dicho terreno y en 1884 se ubicó allí la Exposición de Agricultura, Ganadería, Industria y Comercio, para posteriormente convertirlo en parque (Hortelano, 1998).

La ciudad de finales del siglo XIX contaba también con algunos paseos arbolados situados en el interior de lo que hoy son el centro histórico y la primera corona de crecimiento, como el de circunvalación, que aprovechaba el espacio generado por el derribo de la muralla, el del Rollo (28), el de las Carmelitas (16), el de la Estación (26) y el de la Glorieta (21), terminado en 1854 (Villar, 2000). Con el tiempo, este último se convertiría en una de las entidades que hoy forman el verde urbano de las Salesas (S-12), junto con los espacios obtenidos de la venta de una parte del huerto del monasterio de Santa María de las Salesas Reales, construido en 1924, y de una parte de los jardines del cuartel de Ingenieros General Arroquia. En la Figura 4.2.5 aparece representado el verde urbano de Salamanca en 1956, compuesto por un total de ocho espacios verdes. Junto al Campo de San Francisco (S9) y el Parque de la Alamedilla (S-10), aparecen seis huertos urbanos que respondían a dos orientaciones diferenciadas: por un lado se encontraban los espacios asociados a la Iglesia, que eran parte de los edificios de las distintas órdenes religiosas, y por otro se encontraban aquellos huertos cuya orientación era claramente económica, ubicados en las márgenes del río. Históricamente los terrenos más explotados, debido a la alta fertilidad del suelo, han sido los vinculados a materiales fluviales sedimentarios en la vega del Tormes, tanto en su margen derecha, desde lo que hoy son los terrenos de la fábrica de fertilizantes Mirat hasta la puerta de San Pablo (12 y 13), como en la izquierda, desde el puente romano hasta el núcleo de Tejares (36 y 38). En 1956 el mayor espacio dedicado a la agricultura urbana estaba situado en la margen derecha del Tormes y contaba con más de veintiuna hectáreas de extensión. La mayor parte de las huertas que componían este espacio pertenecían a la Fundación Rodríguez Fabrés (S-32), organización constituida en 1913, encargada de gestionar la herencia de Vicente Rodríguez Fabrés, un importante empresario de la Salamanca de finales de siglo XIX (González, 2006). Además existían otros cinco huertos urbanos de origen clerical, entre los que se encontraba el verde urbano más antiguo que ha llegado hasta nuestros días: el situado en el Cerro de San Vicente (S-6). En la fecha de la fotografía aérea todavía era una huerta con bancales que ocupaba el cerro más occidental de la ciudad, perteneciente al desaparecido monasterio benedictino de San Vicente. Durante la Guerra de la Independencia el edificio fue destruido tras ser utilizado como fuerte por los franceses, retomándose posteriormente el uso agrario hasta la década de los sesenta del siglo XX. Finalmente acabó convirtiéndose en un espacio abandonado, colindante al Colegio Mayor Hispano-Americano fundado en $1951 \mathrm{y}$ derribado en 2004, que ha sido progresivamente conquistado por la vegetación espontánea y donde está prevista la apertura del Museo de la Ciudad. El resto de huertos urbanos presentes en la Salamanca de 1956 estaban vinculados a edificios religiosos creados a comienzos del siglo XX. La construcción del colegio de las Esclavas, en el noroeste de la ciudad, se inició en 1906, el de las Salesas, situado en el norte, en 1915 y el de los Jesuitas, en 
Figura 4.2.5 Verde urbano de la ciudad de Salamanca en 1956.

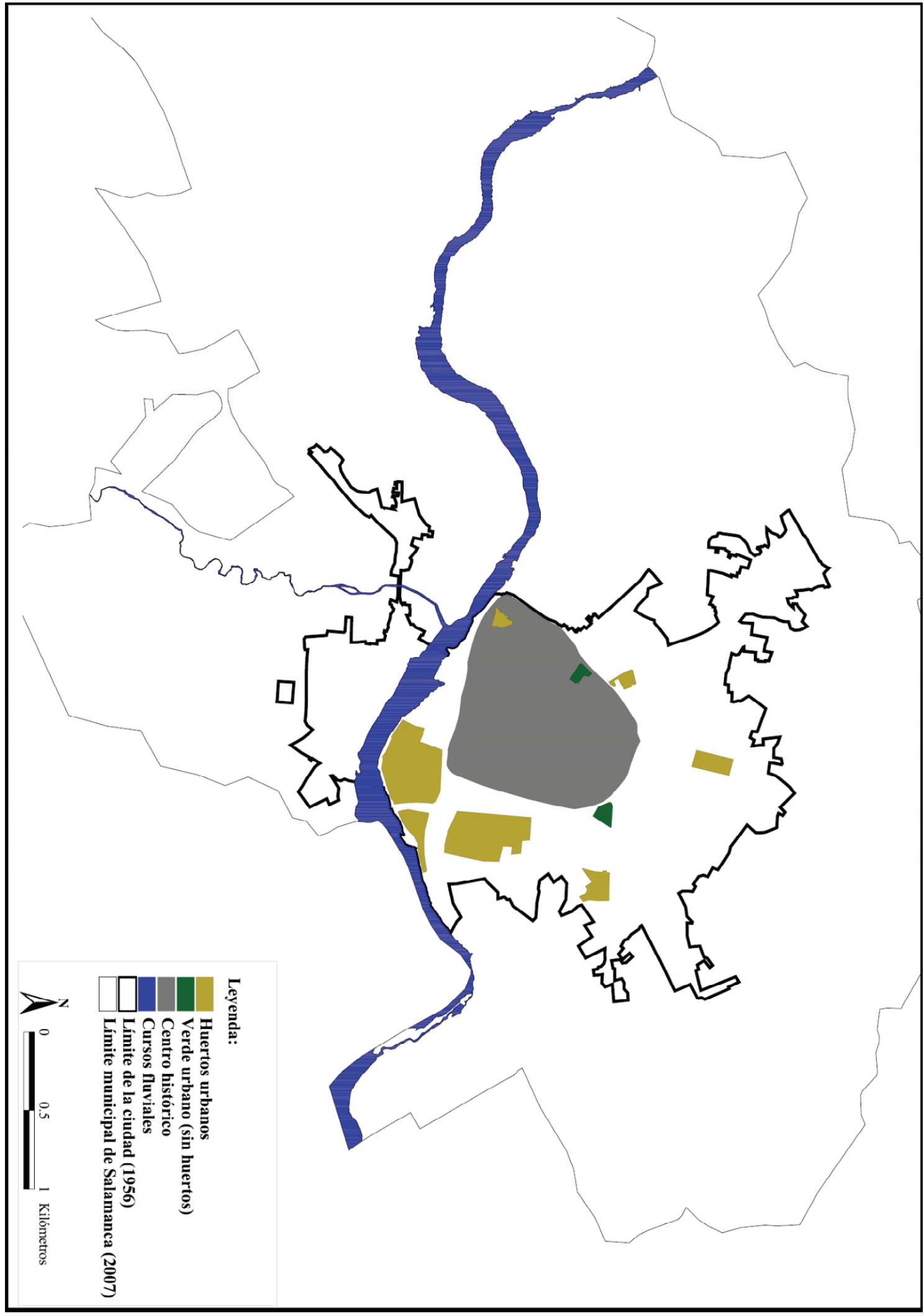

Fuente: elaboración propia a partir de la fotografía aérea de 1956 del SGE. 
el este, lo hizo en 1923. Los huertos de estos edificios se convertirán progresivamente en parques urbanos, con la excepción del de las Carmelitas que desaparecerá antes de los años setenta.

\section{iii) Recapitulación}

A mediados del siglo XX Salamanca contaba con 80.239 habitantes y la trama verde total tenía una extensión de cerca de cincuenta hectáreas, de manera que estos espacios representaban un 7,7\% de la superficie de la ciudad $\left(774,60 \mathrm{~m}^{2} / \mathrm{ha}\right)$. Sin embargo, el $95 \%$ de esta extensión estaba destinada a la agricultura urbana, por lo que a cada salmantino le correspondía la minúscula cifra de $0,30 \mathrm{~m}^{2}$ de verde urbano disponible (ver Tabla 4.2.3). No obstante, la ciudad de 1956, cuatro veces más extensa y tres veces más poblada que la de 1900, ya albergaba el germen de tres futuros parques bajo la forma de huertos urbanos.

\begin{tabular}{|c|c|}
\hline & 1956 \\
\hline $\mathbf{N}^{\circ}$ espacios verdes & 8 \\
\hline $\mathrm{N}^{\circ}$ huertos urbanos & 6 \\
\hline $\mathrm{N}^{\circ}$ espacios verdes sin huertos & 2 \\
\hline $\mathrm{N}^{\circ}$ espacios verdes disponibles & 2 \\
\hline $\mathrm{N}^{\circ}$ habitantes & 80.239 \\
\hline Extensión de la ciudad (ha) & 618 \\
\hline Extensión del verde (ha) & 47,9 \\
\hline Extensión de los huertos urbanos (ha) & 45,5 \\
\hline Extensión del verde sin huertos (ha) & 2,4 \\
\hline Extensión del verde urbano disponible (ha) & 2,4 \\
\hline Densidad de verde ( $\left.\mathrm{m}^{2} / \mathrm{hab}\right)$ & 5,97 \\
\hline Densidad verde sin huertos $\left(\mathrm{m}^{2} / \mathrm{hab}\right)$ & 0,30 \\
\hline Densidad del verde urbano disponible $\left(\mathrm{m}^{2} / \mathrm{hab}\right)$ & 0,30 \\
\hline Densidad verde por superficie $\left(\mathrm{m}^{2} / \mathrm{ha}\right)$ & 774,60 \\
\hline Densidad del verde urbano disponible por superficie $\left(\mathrm{m}^{2} / \mathrm{ha}\right)$ & 39,16 \\
\hline
\end{tabular}

\subsubsection{Evolución urbana hasta la aprobación del PGOU de 1984}

El Plan Maroto fue sustituido por el PGOU de 1966 con el objetivo de limitar el crecimiento de la ciudad y definir un moderno sistema de comunicaciones (Senabre, 2003a). Durante los primeros años del periodo de aplicación se atenuó la expansión territorial priorizándose el aprovechamiento de los vacíos existentes en la trama urbana, continuando con el modelo de crecimiento en altura de los edificios (Villar, 2000). Sin embargo, la planificación dirigida a limitar el crecimiento espacial de la ciudad se vio desbordada por el mantenimiento de elevadas tasas de crecimiento demográfico durante las décadas de 1960 y de 1970. Tratando de cumplir con las pautas de la Ley del Suelo de 1956, el consistorio salamantino redactó una serie de Planes Parciales que no llegaron a aprobarse y que ignoraban las exigencias mínimas en dotaciones y en espacios libres públicos (Senabre, 2003a). La tolerancia de la corporación municipal, en un momento en el que la iniciativa privada toma el mando del proceso urbanizador, provocó un estancamiento en la creación de espacios verdes y de otros elementos dotacionales. De esta manera se comprende el hecho de que en 1971 se mantuviera el mismo número de verdes urbanos que en 1956 (ver Figura 4.2.6). Tan solo apareció uno de los espacios que componen la trama verde en 2007, los jardines del colegio de La Salle (S-24) en las proximidades del núcleo de Tejares (39) en el suroeste de la ciudad, desapareciendo el huerto urbano de las Carmelitas. 


\section{i) Expansión urbana}

El crecimiento durante las décadas de 1960 y de 1970 fue tan intenso que la población de 1950 se dobló en 1980, alcanzando así los 167.131 habitantes. Este aumento de efectivos demográficos estuvo impulsado por el éxodo rural que experimentaron la mayor parte de los municipios de la provincia de Salamanca, cuyos habitantes se dirigieron a las aglomeraciones urbanas, entre las que destaca como primer destino la capital provincial. Este proceso tuvo repercusiones espaciales muy significativas: entre 1971 y 1984 la trama urbana salmantina se incrementó en más de 300 ha, de tal forma que el tamaño de la ciudad se amplió en un 40\% en poco más de una década (ver Figura 4.2.7). El surgimiento de la cada vez más numerosa clase media permitió una sensible reducción de la edificación de barrios enteros de promoción pública. Al sur del Tormes se produjo entre 1969 y 1978 una notable expansión del barrio San José (33), en 1981 se urbanizó el barrio del Tormes (32) y en el límite con el municipio de Carbajosa, se proyectó el polígono industrial el Montalvo (45), que comenzará a funcionar en 1971 (Hortelano, 2000). En 1966 el municipio de Salamanca se anexionó el de Tejares (39) y su núcleo acabará uniéndose al continuo urbano a medida que comience a colmatarse el terreno entre este barrio, Chamberí (38) y Alambres (37). En el norte de la ciudad se sucedieron intervenciones privadas y semipúblicas encabezadas por la Caja de Ahorros de Salamanca en Garrido (23 y 25). En 1969 la Universidad presentó varios proyectos entre los que se encontraba la construcción del Hospital Clínico Universitario (Senabre, 2002a) en el barrio del Hospital (14), en torno al que se crearán unos amplios jardines de los que en 2007 solo quedará un pequeño reducto de menos de una hectárea.

Desde los años setenta comenzó a configurarse en torno al municipio de Salamanca, un área urbana compuesta mayoritariamente por pequeños núcleos de población debido a que el elevado precio del suelo urbano en la ciudad tradicional dificultaba la adquisición de vivienda a los grupos de menores rentas, que se vieron obligados a buscar vivienda fuera de la urbe. Por otra parte, las clases con suficientes recursos se fueron asentando tanto en los principales barrios de nueva creación, Capuchinos (43), Chinchibarra (24), Rollo (28) y Prosperidad (31) (Villar, 2000), como en los municipios periféricos, donde llegaban en busca de ciertas mejoras en la calidad de vida.

Coinciden en el tiempo dos procesos urbanísticos vinculados con las congregaciones religiosas, que tendrán cierta importancia en lo que a aparición de espacios verde se refiere. Por un lado, se produjo la transformación en parques públicos de tres huertos urbanos pertenecientes a edificios religiosos construidos durante las primeras décadas del pasado siglo. Y por otro, se levantaron una serie de edificios religiosos en la periferia de Salamanca durante la década de 1960, cuyo resultado será la configuración de un cinturón de edificios religiosos, denominado cinturón de incienso por Villar (2000), origen de otras tres áreas verdes a partir de 1984. En contraste con la difícil situación que aún se vivía en algunos barrios de Salamanca, el estamento clerical levantó una serie de edificios de notable tamaño construidos con materiales nobles, que en su mayor parte contarán con grandes jardines o huertas. Las actuaciones se sucedieron tras la apertura de la Universidad Pontificia en 1940, creándose en los años posteriores más de una veintena de edificios religiosos, de los cuales los jardines de los Legionarios de Cristo (S-14) al norte de la ciudad, el huerto de las Misioneras Seculares (S-34) en el noreste, y los jardines del seminario de La Salle (S-24) acabarán convirtiéndose en espacios verdes urbanos. Junto a estas obras religiosas, el Gobierno del Estado invirtió en la Universidad de Salamanca, destacando, de entre las diversas intervenciones realizadas, la creación del gimnasio universitario, el célebre Botánico, y la apertura del Colegio Mayor Hispano-Americano en el cerro de San Vicente (Senabre, 2003a). 
Figura 4.2.6 Verde urbano de la ciudad de Salamanca en 1971.

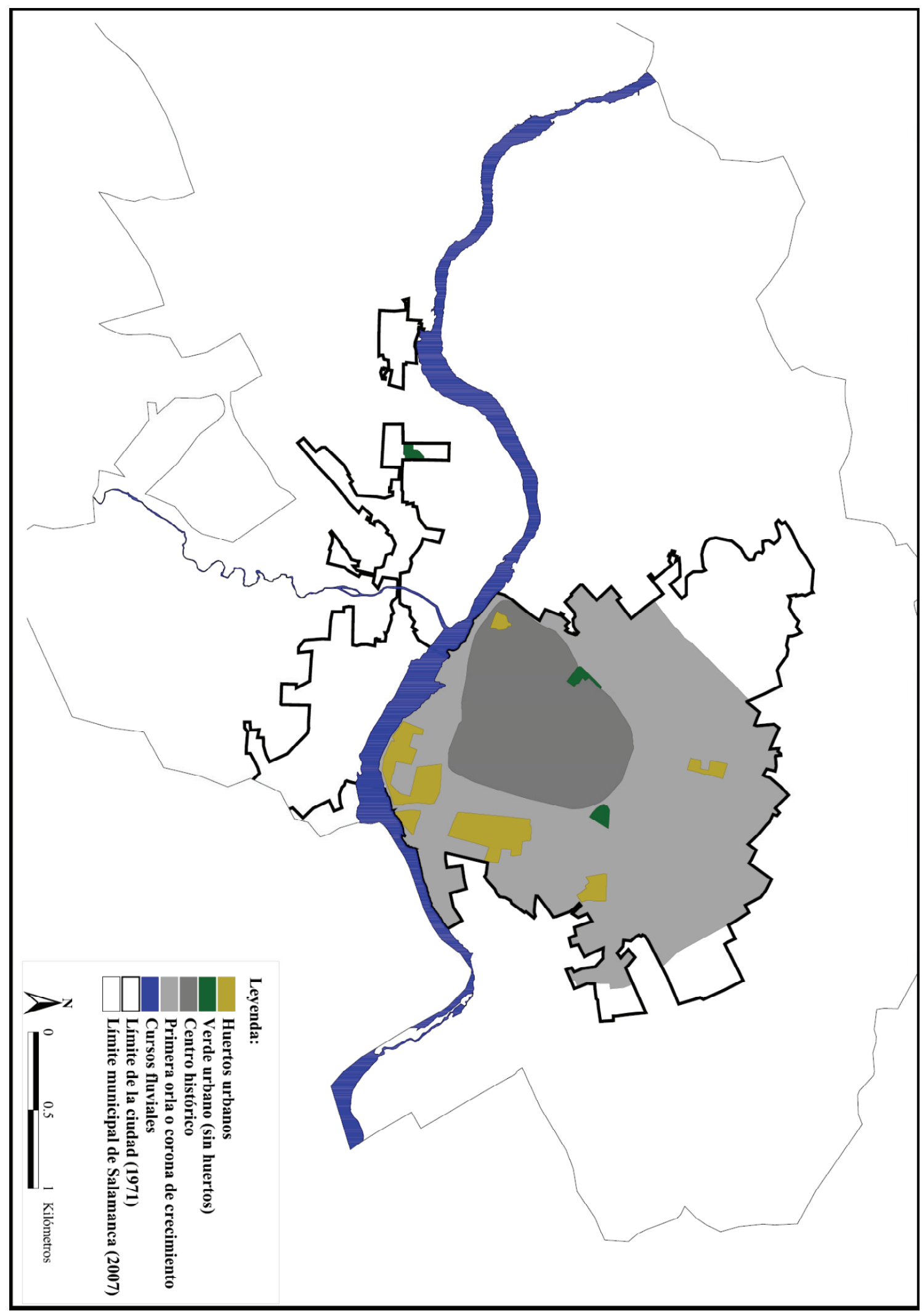

Fuente: elaboración propia a partir de la fotografía aérea de 1971 del IGN. 
Figura 4.2.7 Verde urbano de la ciudad de Salamanca en 1984.

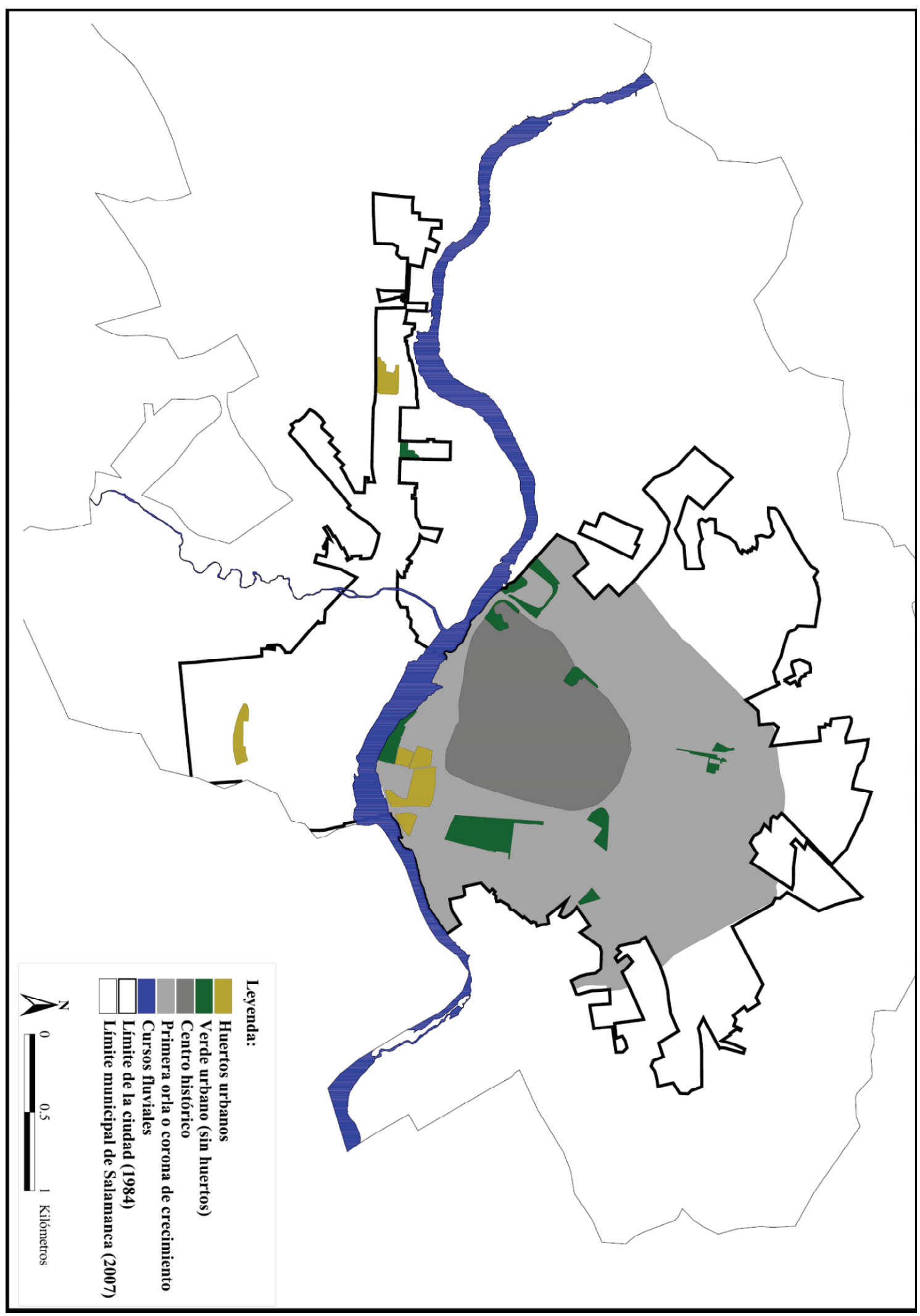

Fuente: elaboración propia a partir de la fotografía aérea de 1984 del IGN. 


\section{ii) Evolución del verde urbano}

Durante los últimos años del régimen se crearon el Parque Fluvial (S-18) en la margen derecha del Tormes (ver Figura 4.2.7), en una zona históricamente dedicada a labores agrícolas, y el Parque de Garrido, en el barrio del mismo nombre, a los que habrá que añadir los anteriormente citados Jardines del Hospital Clínico (S-5), construidos en los primeros años de la década. A partir de 1979, con la constitución de los primeros ayuntamientos democráticos, se asistirá a una serie de actuaciones encaminadas a mitigar los déficits dotacionales en determinados barrios de la ciudad, adquiriendo jardines y huertos pertenecientes a diversas órdenes religiosas, situados en el interior de la trama urbana. De los cuatro huertos urbanos que en 1956 estaban vinculados a entidades religiosas, tres acabaron convirtiéndose en parques públicos durante la década de los setenta y los primeros años de la década de los ochenta. Son el Parque de los Jesuitas (S-4), el Parque Picasso (S-11), que sustituye al huerto de las Esclavas, y el verde urbano de las Salesas (S-12), creado a partir de una parte del huerto de esta institución religiosa, al que se une el arbolado viario de la calle Torres Villarroel y del cuartel de Ingenieros. Además, el crecimiento espacial de la ciudad provocó que quedasen enclavados en el tejido urbano dos terrenos dedicados a la agricultura junto a la vía férrea, uno en el barrio de Tejares (39) de casi tres hectáreas y otro en el barrio de San José (33), al norte del futuro polígono del Montalvo (45), que se suman al de la Fundación Rodríguez Fabrés en el barrio de la Fontana (12), único huerto que mantendrá su orientación desde 1956 hasta la actualidad.

Tabla 4.2.4 Principales indicadores del verde urbano de Salamanca durante el período 1956-1984.

\begin{tabular}{|c|c|c|c|}
\hline & 1956 & 1971 & 1984 \\
\hline $\mathrm{N}^{\circ}$ espacios verdes & 8 & 8 & 12 \\
\hline $\mathrm{N}^{\circ}$ huertos urbanos & 6 & 5 & 3 \\
\hline $\mathbf{N}^{\circ}$ espacios verdes $\sin$ huertos & 2 & 3 & 9 \\
\hline $\mathrm{N}^{\circ}$ espacios verdes disponibles & 2 & 2 & 8 \\
\hline $\mathrm{N}^{\circ}$ habitantes & 80.239 & 125.220 & 167.131 \\
\hline Extensión de la ciudad (ha) & 618 & 746 & 1.039 \\
\hline Extensión del verde (ha) & 47,9 & 35,4 & 40,8 \\
\hline Extensión de los huertos urbanos (ha) & 45,5 & 31,6 & 15,3 \\
\hline Extensión del verde sin huertos (ha) & 2,4 & 3,9 & 25,5 \\
\hline Extensión del verde urbano disponible (ha) & 2,4 & 2,7 & 23,7 \\
\hline Densidad de verde $\left(\mathrm{m}^{2} / \mathrm{hab}\right)$ & 5,97 & 2,83 & 2,44 \\
\hline Densidad verde $\sin$ huertos $\left(\mathrm{m}^{2} / \mathrm{hab}\right)$ & 0,30 & 0,31 & 1,52 \\
\hline Densidad del verde urbano disponible $\left(\mathrm{m}^{2} / \mathrm{hab}\right)$ & 0,30 & 0,22 & 1,42 \\
\hline Densidad verde por superficie $\left(\mathrm{m}^{2} / \mathrm{ha}\right)$ & 774,60 & 475,07 & 392,78 \\
\hline Densidad del verde urbano disponible por superficie $\left(\mathrm{m}^{2} / \mathrm{ha}\right)$ & 39,16 & 36,19 & 228,49 \\
\hline
\end{tabular}

Fuente: elaboración propia a partir del SGE, del IGN y del INE.

\section{iii) Recapitulación}

Durante los treinta años que trascurrieron hasta 1984 se produjo un cambio claro de tendencia en la mayor parte de los indicadores referidos a espacios verdes (ver Tabla 4.2.4). En 1971 se alcanzaron los valores más reducidos del verde urbano disponible por habitante $(0,22$ $\left.\mathrm{m}^{2} / \mathrm{hab}\right)$, puesto que la ciudad contaba con 135.220 habitantes y con los mismos parques de principios del siglo XX, con la única incorporación de un espacio verde privado. Desde ese año, la superficie verde disponible aumenta en veinte hectáreas en un periodo en el que la ciudad experimenta un crecimiento muy intenso, por lo que los índices se incrementaron débilmente. Los indicadores de la trama verde total muestran una tendencia ligeramente distinta, ya que al reducirse la superficie ocupada por los huertos urbanos en treinta hectáreas, sufrieron un descenso significativo hasta alcanzar el mínimo absoluto del periodo en 1984. 


\subsubsection{La ampliación de la trama verde con el PGOU de 1984}

En 1984 se aprobaron dos documentos claves en el planeamiento urbano de Salamanca: el Plan General y el Plan Especial de Protección y Reforma Interior del Recinto Universitario y Zona Histórico-Artística (PECH). Ambos propiciaron una ocupación de los espacios urbanos hasta entonces vacíos, tratando con ello de corregir los desequilibrios existentes, y fomentaron la protección y la revitalización del centro histórico. En 1988 la UNESCO declaró a Salamanca ciudad Patrimonio de la Humanidad, lo que supuso un fuerte impulso a las intenciones del PECH en lo que a protección y recuperación de la zona monumental se refiere. Siguiendo los preceptos de la Ley del Suelo de 1976, el planeamiento urbano en Salamanca experimentó un cambio notable en su forma de concebir la ciudad, incorporando dotaciones y equipamientos suficientes en los barrios de nueva creación. En los veintitrés años en los que permaneció en vigencia el Plan General se crearon veintidós verdes urbanos a lo largo de dos etapas más o menos diferenciadas, para cuya división se toma como referencia la ortofoto de 2002, año en que la ciudad fue designada como Capital Europea de la Cultura.

\section{i) Expansión urbana entre 1984 y 2002}

El crecimiento demográfico del municipio de Salamanca se estancó en este periodo. Buena parte de la población adulta joven emigró a los núcleos periféricos en busca de precios de vivienda nueva más asequibles que los que ofrecía la ciudad tradicional y junto a ellos también abandonaron la urbe sectores de población acomodados, en busca de una mejora en la calidad de vida en las proximidades de Salamanca. El estancamiento de efectivos demográficos contrasta con la continuada expansión territorial de la ciudad, que alcanzó las 1.301 ha en 2002, en lo que supone un incremento de casi trescientas hectáreas en dieciocho años. Durante este periodo de construcción acelerada, Senabre (2003b) recoge uno de los datos más ilustrativos de hasta donde llegó el coste de la vivienda en Salamanca: en 2001 la ciudad ocupó el puesto número ocho y en 2002 el número nueve, en el ranking de precio del metro cuadrado construido del conjunto de capitales españolas. Este crecimiento se desarrolló principalmente en dirección sur y oeste, registrándose también una expansión significativa de la trama urbana en dirección norte. En 1991 se amplió el polígono industrial de el Montalvo (45), alcanzando los límites meridionales del municipio (ver Figura 4.2.8). Un año más tarde se aprobó el Plan Parcial de Alambres-Vistahermosa $(37$ y 42), propiciando la urbanización de los terrenos entre la carretera de Matilla de los Caños y de Aldeatejada, y en 1994 comenzó la construcción del barrio del Zurguén (41) (Hortelano, 2000). Con la apertura del Palacio de Congresos en 1992, ubicado en el barrio de la Universidad (6), comenzó la progresiva recuperación del sector suroccidental del centro histórico y con ella una paulatina mudanza de los pobladores que dejaron paso a personas con mayores rentas.

Dentro del municipio de Salamanca y fuera de la ciudad se produjo, a finales de 2001, la agregación de la finca de la Aldehuela de los Guzmanes, hasta entonces perteneciente a Cabrerizos. Aunque en 2007 continuaba fuera de la ciudad, es necesario destacar este hecho porque en ella se ubica el parque más grande del municipio y con el tiempo podría llegar a formar parte de la trama urbana.

\section{ii) Evolución entre 2002 y 2007}

El segundo periodo en que se ha dividido la aplicación del PGOU de 1984 se caracteriza por un fuerte crecimiento territorial de la trama urbana de 150 ha (ver Tabla 4.2.5), lo que supone un $12 \%$ en tan solo cinco años, mayoritariamente en dirección oeste y sur, una vez colmatada la superficie municipal en dirección este. El número de viviendas si 
Figura 4.2.8 Evolución del espacio urbano de Salamanca entre 1984 y 2007.

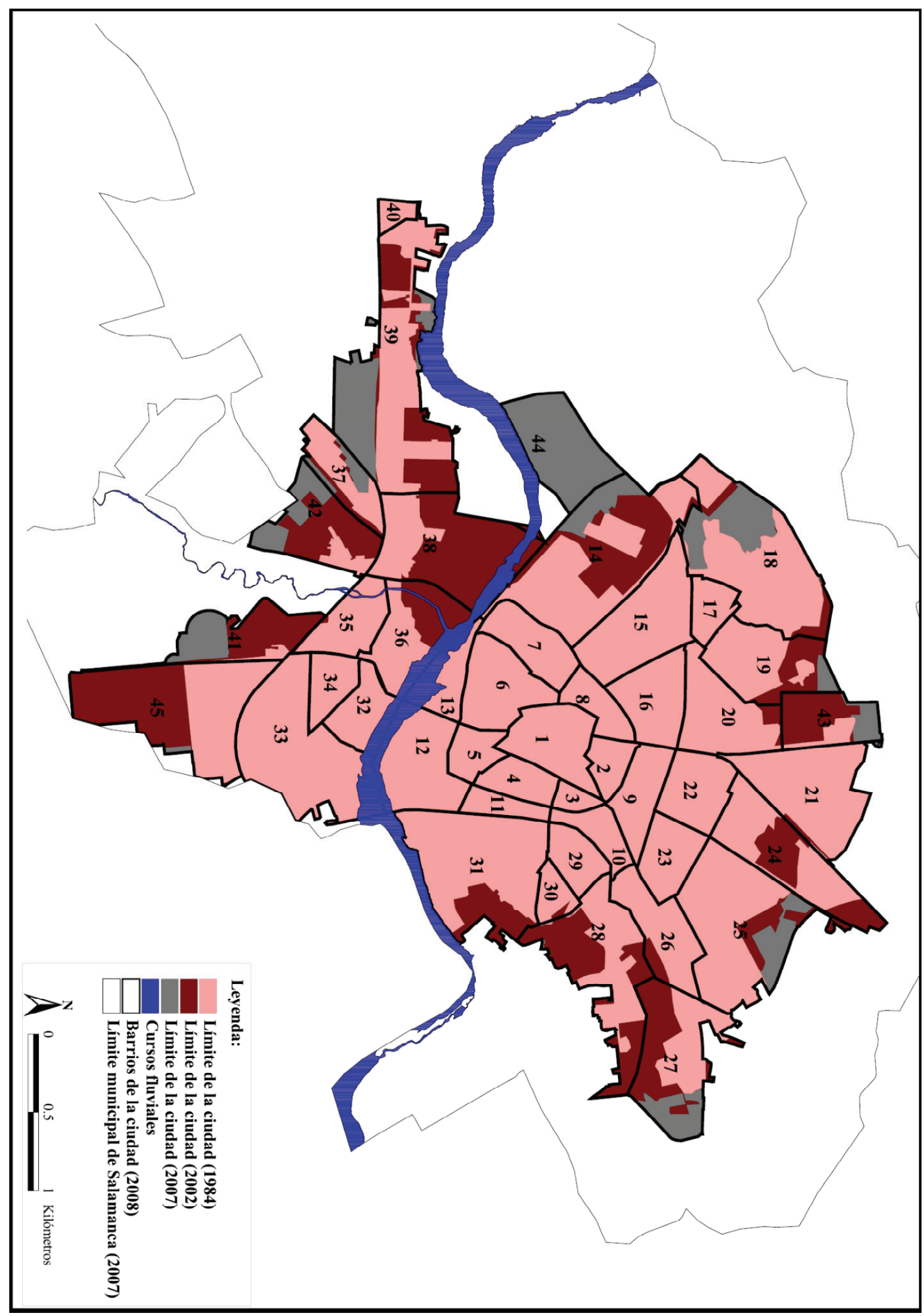

Fuente: elaboración propia a partir de la fotografía aérea de 1984, de las ortofotos de 2001 y 2007 del IGN y del Observatorio Urbano de Salamanca. 
Figura 4.2.9 Verde urbano de la ciudad de Salamanca en 2002.

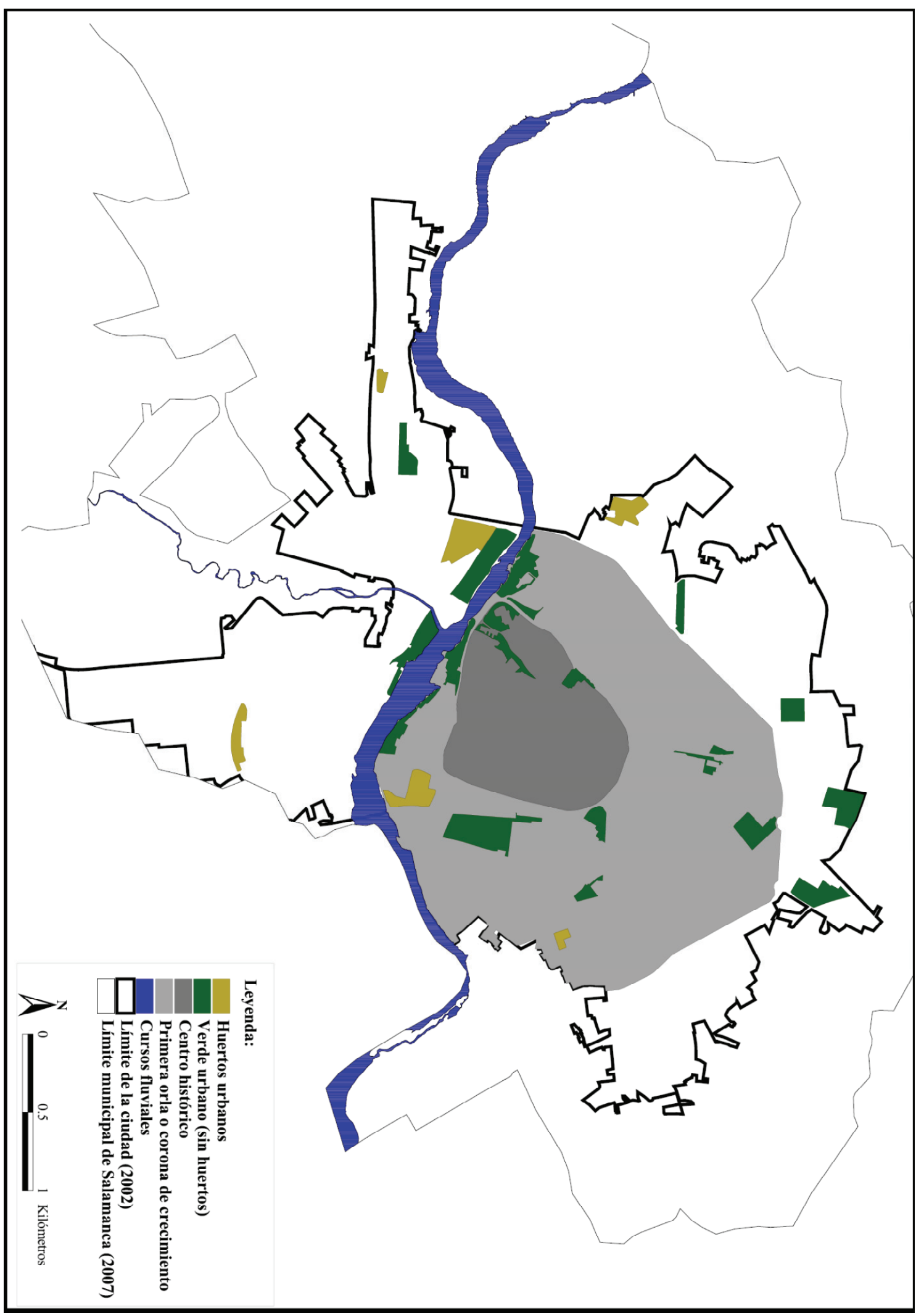

Fuente: elaboración propia a partir de la ortofoto de 2002 del IGN. 
Figura 4.2.10 Verde urbano de la ciudad de Salamanca en 2007.

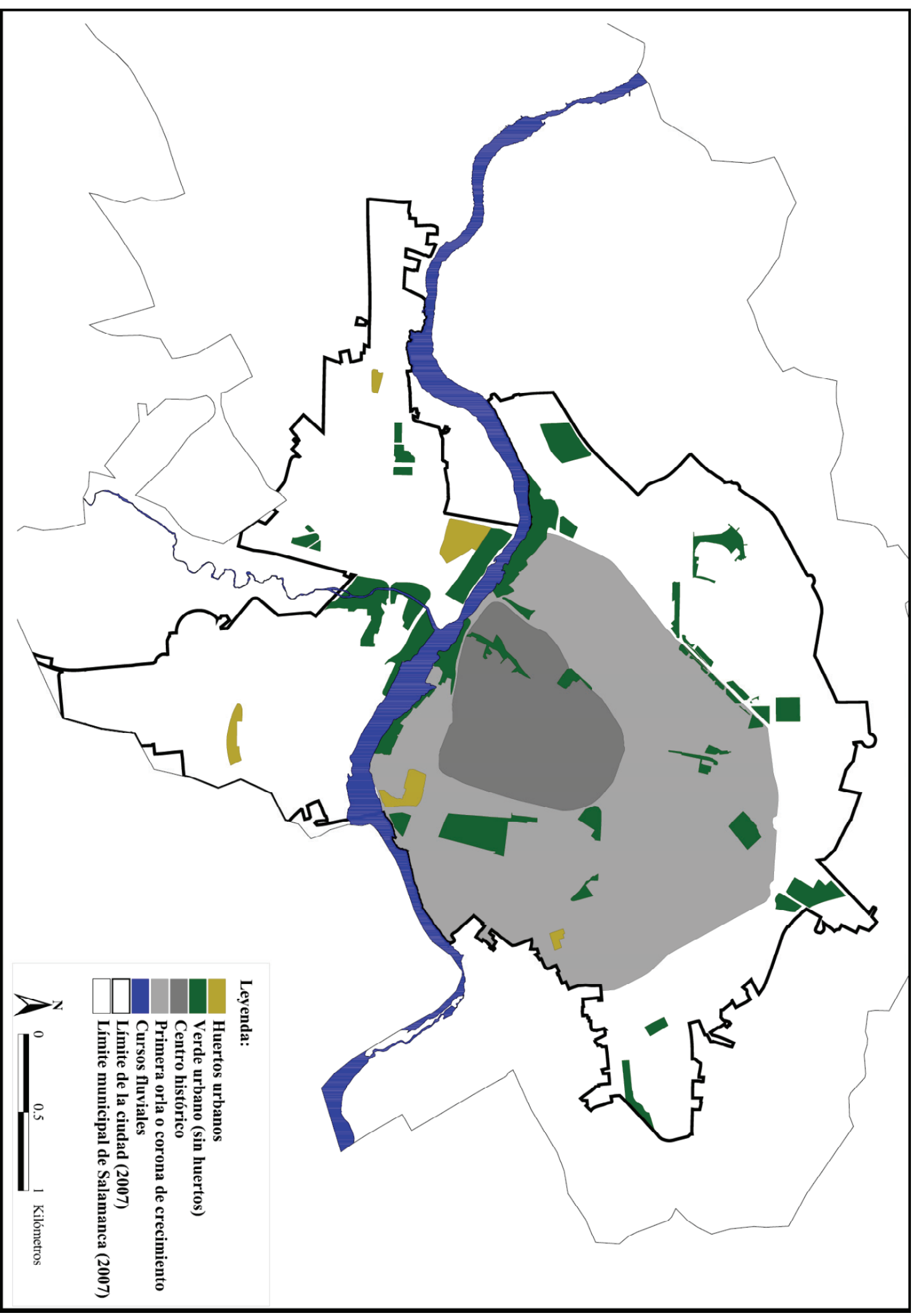

Fuente: elaboración propia a partir de la ortofoto de 2007 del IGN. 
guió incrementándose a un ritmo elevado y paralelamente continuó la escalada del precio del metro cuadrado, triplicando en una sola década el registrado en 1998. Se construyeron barrios enteros como el de La Platina (44) y se terminó la segunda fase de El Zurguén (41). Progresivamente se fueron colmatando algunos espacios existentes en la trama urbana, con edificaciones entre el barrio del Hospital (14) y el barrio de Pizarrales (18), así como entre el barrio de Chamberí (38) y el de Tejares (39). En el extremo noreste de la ciudad las actuaciones de recuperación del tejido urbano se completaron con la construcción del edificio Multiusos Sánchez Paraíso en 2002, propiciando la revitalización y el crecimiento de Garrido Norte (25). Por otro lado, la urbanización del espacio entre la carretera de Aldealengua y la vía férrea abrió nuevas posibilidades para la futura expansión territorial de la ciudad entre los barrios de Puente Ladrillo (27) y del Rollo (28).

\section{iii) Evolución del verde urbano}

Entre 1984 y 2002 aparecieron un total de doce áreas verdes, fruto de las exigencias urbanísticas en materia dotacional del nuevo planeamiento, incluyendo así reservas de suelo para espacios verdes en las nuevas piezas urbanas. De esta manera surgieron, a través del planeamiento de desarrollo, los parques de la Chinchibarra (S-22), en el entorno del depósito de aguas del mismo nombre en el norte de la ciudad, el Parque de Bretón (S-28) aprovechando un vacío en la trama urbana en el entorno de la estación de ferrocarril, y la Plaza de Burgos (S-13), en Capuchinos (43) (ver Figura 4.2.9). Por otra parte se realizaron una serie de actuaciones sobre el tejido urbano consolidado destinadas a crear espacios verdes en zonas con enormes déficits heredados. El caso paradigmático es el Parque de Wurzbürg (S-15) en Garrido Norte (25), con el que el Plan General trataba de paliar la falta de parques de suficiente entidad en uno de los barrios más densamente poblados de la ciudad. También como sistemas generales aparecieron en el límite noroeste de la ciudad junto al barrio de Pizarrales (18), el parque de Villar y Macías (S-23), y en el centro de la ciudad, al amparo de la rehabilitación de los barrios del cuadrante suroeste del centro histórico, se proyectó el verde urbano de la Vaguada de la Palma (S-7) junto al citado Palacio de Congresos. La actuación más notable de las llevadas a cabo fue la impulsada por el Plan Especial de Recuperación de las Márgenes del Tormes, donde se combinó la recuperación urbanística con la dotación de espacios verdes. Desaparecieron numerosos edificios entre los que se encontraban las antiguas tenerías en la Avenida del Rector Esperabé (en el límite entre los barrios 6 y 13) y se crearon amplios espacios verdes manteniendo pequeñas formaciones vegetales seminaturales de ribera. También se actuó en la margen izquierda aprovechando los espacios vacíos para crear el verde urbano del entorno del Puente Romano (S-17). Toda esta labor se complementó con la construcción por parte de la Universidad de Salamanca del Complejo deportivo de Salas Bajas (S-2) en las antiguas huertas frente al cerro de San Vicente. Por otra parte, la fuerte expansión territorial de la ciudad provocó la incorporación de una serie de áreas verdes preexistentes entre las que se encontraban tres huertos urbanos y un espacio también de titularidad privada: el huerto de Salas Bajas (S-30) en la vega del Tormes, un huerto urbano en las proximidades del cementerio, que desaparecerá antes de 2007, y el huerto de las Misioneras Seculares (S-34), fruto de la anexión de otro de los edificios perteneciente al cinturón de incienso, como los son también los jardines del seminario de los Legionarios de Cristo (S-14) en el extremo norte de la ciudad.

Durante los últimos cinco años aparecieron diez verdes urbanos localizados mayoritariamente en los nuevos sectores incorporados en la periferia de la ciudad, debido a la enorme dificultad que entraña la creación de espacios verdes en el interior del tejido urbano consolidado. En torno al eje fluvial del río Tormes surgieron una serie de verdes urbanos a través del planeamiento general que terminaron por consolidar este sector como un auténtico corredor verde. En la margen derecha se creó un pequeño parque en un vacío existente entre 
la fábrica de Mirat, la vía férrea y el río (S-19), y se construyó el Jardín botánico de Huerta Otea (S-3) con una extensión que supera las 10 ha (ver Figura 4.2.10). En la margen izquierda se consolidó la actuación llevada a cabo junto al Puente Romano, con el diseño del verde urbano más grande de la ciudad, el del Zurguén (S-25), que aprovecha las antiguas huertas en torno al arroyo del mismo nombre y continúa hasta el límite sur establecido por la vía férrea. A través del planeamiento parcial aparecieron el Parque de Don Juan Tenorio (S-1) en el barrio de La Platina (44), el Parque de Valhondo (S-8), que surgió al amparo de la urbanización del sector fronterizo entre el barrio del Hospital (14) y el de Pizarrales (18), el Parque de Ciudad Rodrigo (S-20), en el noroeste de la ciudad a través del Plan Parcial Carretera de Aldealengua, el verde urbano de la Facultad de Comunicación (S-27), en el barrio del Hospital (14) y junto a la facultad del mismo nombre, y el verde urbano de Vistahermosa (S-23), al desarrollarse el Plan Parcial Alambres-Vistahermosa en el extremo sur de la ciudad. Por su parte el verde urbano de la Avenida de Salamanca (S-26) es el resultado de una actuación sobre el tejido urbano consolidado, con el que en 2002 se crearon zonas ajardinadas a ambos lados del vial. A estos hay que añadir la incorporación de los jardines de la residencia para mayores de San Juan de Sahagún (S-29), en el límite nororiental del continuo urbano.

\section{iii) Recapitulación}

El periodo de aplicación del PGOU de 1984 es el más prolífico en cuanto a la creación de áreas verdes se refiere. En la Figura 4.2.10 se identifican los treinta y cuatro espacios que forman la trama verde salmantina en 2007, de los que cinco son huertos y veintiséis forman parte de la categoría de verde urbano disponible. Durante el periodo de aplicación del plan se produce una tendencia al alza de la mayor parte de indicadores referidos a estos espacios (ver Tabla 4.2.5), aunque no se consiguen los valores mínimos establecidos por los organismos internacionales como la Organización Mundial de la Salud (OMS), que fija en 9 los metros cuadrados de espacios verdes por habitante. Por tanto, Salamanca no alcanza el valor mínimo de verde urbano por habitante, ni con el verde urbano total $\left(7,95 \mathrm{~m}^{2} / \mathrm{hab}\right)$, ni con el verde urbano disponible $\left(6,41 \mathrm{~m}^{2} / \mathrm{hab}\right)$, que recoge únicamente los parques y jardines que se pueden visitar. Estos datos han sido complementados con otros referentes al número de viviendas promocionadas y al precio de la vivienda, para lo que se ha utilizado un indicador proporcionado por el Ministerio de Fomento referente a los precios medios por promoción, elaborando así la Tabla 4.2.6 y su representación en la Figura 4.2.11. Llama la atención que la ciudad de Salamanca no haya crecido en población durante los últimos siete años, sino que únicamente lo haya hecho en superficie, provocando así la construcción de zonas verdes en barrios poco poblados, que posiblemente serán poco visitadas por no haber suficientes residentes en su proximidad. En este periodo, el número de nuevas viviendas aumentó en casi un 20\%, impulsando la expansión territorial de la ciudad en un 14,4\%. Este crecimiento responde mayoritariamente a un proceso especulativo que terminará bruscamente en 2008 y que estaba respaldado por un aumento extraordinario del precio del metro cuadrado, cuya media se dobló en una década alcanzando los 3.198 euros $/ \mathrm{m}^{2}$.

\subsubsection{Síntesis de la evolución histórica del verde urbano en Salamanca}

En la Tabla 4.2.7 se clasificaron los espacios verdes de Salamanca en función del periodo en el que fueron apareciendo y del uso anterior que tenía el suelo sobre el que se asientan en la actualidad. El periodo de vigencia del PGOU de 1984 es la etapa de mayor crecimiento de la trama verde salamantina, con un total de veintidós nuevas áreas verdes. En la Figura 4.2.12 se observa que los cuatro espacios verdes creados antes de 1956 están 
situados junto al límite de la cerca medieval, mientras que el centro histórico presenta zonas con grandes vacíos verdes en su interior. El verde urbano de La Salle (S-24) es el único creado hasta 1971 y a partir de esa fecha comenzará la transformación de tres huertos en parques y la progresiva recuperación de espacios verdes en la margen derecha del Tormes.

Tabla 4.2.5 Principales indicadores del verde urbano de Salamanca durante el período 1984-2007.

\begin{tabular}{|c|c|c|c|}
\hline & 1984 & 2002 & 2007 \\
\hline $\mathrm{N}^{\circ}$ espacios verdes & 12 & 24 & 34 \\
\hline $\mathrm{N}^{\circ}$ huertos urbanos & 3 & 6 & 5 \\
\hline $\mathrm{N}^{\circ}$ espacios verdes sin huertos & 9 & 19 & 29 \\
\hline $\mathrm{N}^{\circ}$ espacios verdes disponibles & 8 & 17 & 26 \\
\hline $\mathbf{N}^{0}$ habitantes & 167.131 & 156.006 & 155.921 \\
\hline Extensión de la ciudad (ha) & 1.039 & 1.302 & 1.463 \\
\hline Extensión del verde (ha) & 40,8 & 80,6 & 124,0 \\
\hline Extensión de los huertos urbanos (ha) & 15,3 & 19,4 & 15,0 \\
\hline Extensión del verde sin huertos (ha) & 25,5 & 61,1 & 109,0 \\
\hline Extensión del verde urbano disponible (ha) & 23,7 & 53,5 & 100,0 \\
\hline Densidad de verde ( $\left.\mathrm{m}^{2} / \mathrm{hab}\right)$ & 2,44 & 5,16 & 7,95 \\
\hline Densidad verde $\sin$ huertos $\left(\mathrm{m}^{2} / \mathrm{hab}\right)$ & 1,52 & 3,92 & 6,99 \\
\hline Densidad del verde urbano disponible ( $\left.\mathrm{m}^{2} / \mathrm{hab}\right)$ & 1,42 & 3,43 & 6,41 \\
\hline Densidad verde por superficie $\left(\mathrm{m}^{2} / \mathrm{ha}\right)$ & 392,78 & 618,85 & 847,57 \\
\hline Densidad del verde urbano disponible por superficie $\left(\mathrm{m}^{2} / \mathrm{ha}\right)$ & 228,49 & 411,11 & 683,53 \\
\hline
\end{tabular}

Durante los primeros años de vigencia del PGOU de 1984 se crearon doce espacios verdes, combinando actuaciones adyacentes al tejido urbano consolidado con las reservas obligadas por ley en los nuevos sectores urbanos, mientras que en los últimos cinco años analizados, la mayor parte de las actuaciones son de este tipo. En la Figura 4.2.13 se han clasificado los espacios verdes en función del uso anterior del suelo y se ha dividido en cuatro categorías. Los "huertos", son aquellos verdes urbanos que han estado, o están actualmente, dedicados a explotaciones agroganaderas, mientras que las "huertas y jardines clericales" comprenden los terrenos de diferentes órdenes religiosas que han terminado por convertirse en zonas verdes. La categoría de "espacios recuperados" responde a todas aquellas actuaciones realizadas en el tejido urbano a fin de transformar el uso del suelo en áreas verdes, y los "espacios periféricos o de reciente urbanización", a los espacios creados antes o durante la urbanización de parcelas no urbanas. En las orillas del Tormes se incorporaron nuevas zonas verdes a través de la recuperación de baldíos urbanos, como sucede con el urbano de la margen derecha e izquierda del Puente Romano (S-16 y S-17) y Parque Fluvial (S-18), y de la transformación de antiguos huertos en parques, como ocurre con el Parque de El Zurguén (S-25) y con el Complejo deportivo Salas Bajas (S-2). Por su parte, los espacios verdes con origen en las huertas y jardines clericales se corresponden con los tres parques surgidos entre 1971 y 1984 a partir de huertos visibles en 1956, con dos verdes históricos como el Campo de San Francisco (S-9) y el verde urbano del Cerro de San Vicente (S-6), y de otros dos verdes con origen en los jardines del edificio de La Salle (S-24) y del seminario de los Legionarios de Cristo (S-14). Por último, las catorce áreas verdes surgidas en la periferia urbana aparecen durante el periodo de vigencia del PGOU de 1984 a medida que se van ejecutando las nuevas piezas urbanas, con la excepción del Parque de la Alamedilla (S-10) y de los Jardines del Hospital Clínico (S-5), que son anteriores.

En Salamanca se identifica una notable concentración de espacios verdes en torno al río Tormes y en el noroeste de la ciudad (ver Figura 4.2.14). Es posible hablar de corredor verde, entendido como aquel pasillo de vegetación que comunica el interior con otros espacios verdes de dentro o de fuera de la ciudad, facilitando el desplazamiento de animales a través del continuo urbano. Este eje fluvial atraviesa la ciudad en dirección este-oeste y se extiende hasta el interior del centro histórico. Estaría compuesto por nada menos que catorce espacios, cuatro en la margen izquierda y diez en la derecha, fruto de la combinación 
de antiguas huertas y espacios recuperados. El corredor verde del norte es algo más limitado, ya que se compone únicamente por el Parque de Valhondo (S-8), el de Villar y Macías (S-23), la Avenida de Salamanca (S-26) y por la Plaza de Burgos (S-13), y el contacto con la periferia urbana se realiza a través de espacios con una densidad vegetal bastante reducida. Estas aglomeraciones comprenden dieciocho espacios verdes y su extensión supera las ochenta hectáreas, representando un $65 \%$ de la trama verde salmantina.

Tabla 4.2.6 Crecimiento porcentual acumulado de las principales variables urbanas de Salamanca.

\begin{tabular}{|c|c|c|c|c|c|c|c|c|}
\hline Años & $\begin{array}{c}\text { Población } \\
\text { (habitantes) }\end{array}$ & $\begin{array}{c}\mathbf{\%} \\
\text { acumulado }\end{array}$ & $\begin{array}{c}\text { Territorio } \\
\text { (ha) }\end{array}$ & $\begin{array}{c}\mathbf{\%} \\
\text { acumulado }\end{array}$ & $\begin{array}{c}\text { Precio } \\
\text { vivienda } \\
\text { (euro/m } \mathbf{2})\end{array}$ & $\begin{array}{c}\mathbf{\%} \\
\text { acumulado }\end{array}$ & $\begin{array}{c}\mathbf{N}^{\mathbf{0}} \\
\text { viviendas } \\
\text { construidas }\end{array}$ & $\begin{array}{c}\mathbf{\%} \\
\text { acumulado }\end{array}$ \\
\hline $\mathbf{2 0 0 0}$ & 158.556 & $-0,1$ & & 1,1 & 1.150 & 2,0 & 1.901 & 2,4 \\
\hline $\mathbf{2 0 0 1}$ & 158.523 & $-0,1$ & & 2,2 & 1.236 & 9,0 & 2.155 & 5,1 \\
\hline $\mathbf{2 0 0 2}$ & 156.006 & $-1,7$ & 1.302 & 3,4 & 1.455 & 24,0 & 2.187 & 7,8 \\
\hline $\mathbf{2 0 0 3}$ & 157.906 & $-0,5$ & & 5,6 & 1.567 & 31,2 & 2.093 & 10,2 \\
\hline $\mathbf{2 0 0 4}$ & 160.415 & 1,0 & & 7,8 & 2.152 & 58,4 & 2.806 & 13,4 \\
\hline $\mathbf{2 0 0 5}$ & 160.331 & 1,0 & & 10,0 & 2.398 & 68,7 & 2.148 & 15,8 \\
\hline $\mathbf{2 0 0 6}$ & 159.754 & 0,6 & & 12,2 & 2.813 & 83,4 & 1.554 & 17,6 \\
\hline $\mathbf{2 0 0 7}$ & 155.921 & $-1,8$ & 1.463 & 14,4 & 3.198 & 95,5 & 1.586 & 19,3 \\
\hline
\end{tabular}

*El porcentaje acumulado de territorio se ha estimado empleando un ajuste lineal.

Fuente: elaboración propia a partir del IGN, del INE y del Ministerio de Fomento.

Figura 4.2.11 Crecimiento porcentual acumulado de las principales variables urbanas de Salamanca.

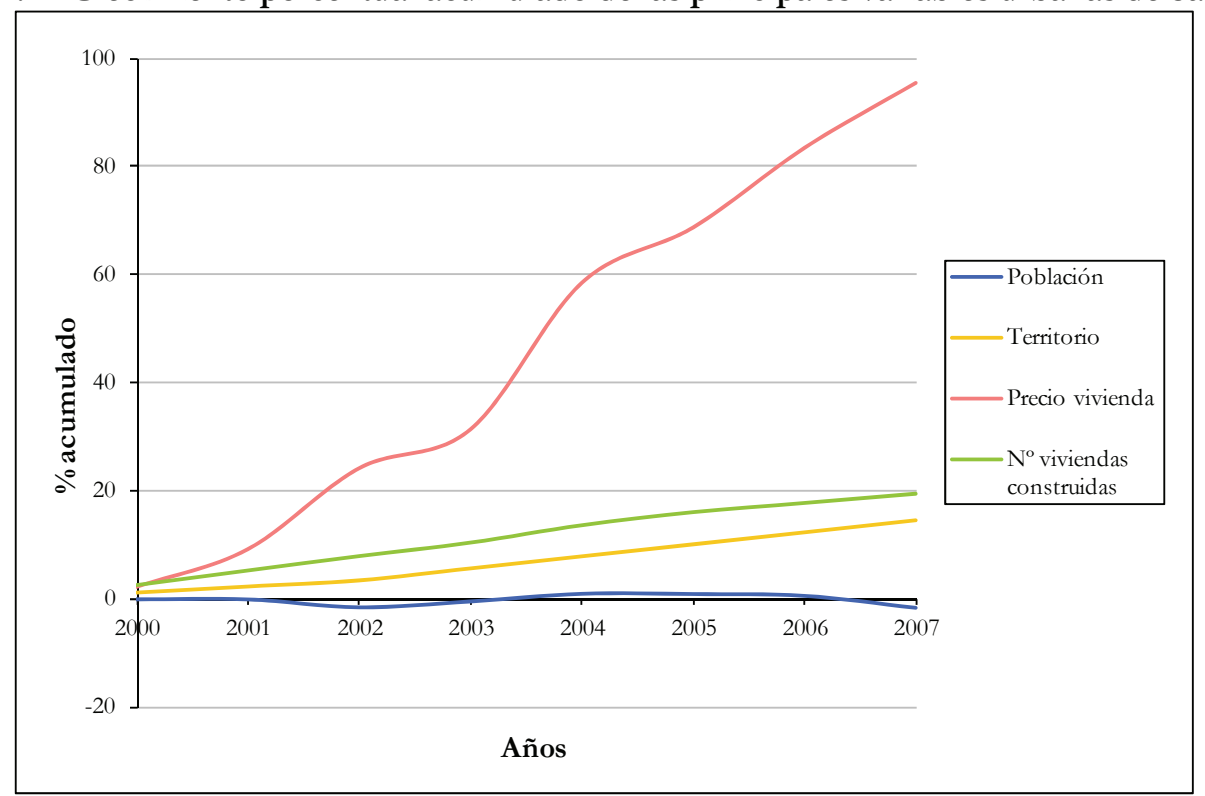

Fuente: elaboración propia a partir del IGN, del INE y del Ministerio de Fomento.

Tabla 4.2.7 Clasificación del verde urbano según distintos parámetros.

\begin{tabular}{|c|c|c|c|c|c|c|}
\hline \multicolumn{1}{|c|}{$\begin{array}{c}\text { Periodo de } \\
\text { aparición }\end{array}$} & Anterior a 1956 & 1956-1971 & 1971-1984 & 1984-2002 & 2002-2007 & Total \\
\hline Total & 4 & 1 & 7 & 12 & 10 & 34 \\
\hline $\begin{array}{c}\text { Uso anterior } \\
\text { del suelo }\end{array}$ & $\begin{array}{c}\text { Espacio } \\
\text { periférico o } \\
\text { reciente } \\
\text { urbanización }\end{array}$ & $\begin{array}{c}\text { Recuperación } \\
\text { de espacios }\end{array}$ & $\begin{array}{c}\text { Huertas y } \\
\text { jardines } \\
\text { clericales }\end{array}$ & $\begin{array}{c}\text { Huertos } \\
\text { urbanos }\end{array}$ & Total \\
\hline Total & 14 & 6 & 7 & 7 & 34 \\
\hline
\end{tabular}

Fuente: elaboración propia. 
Figura 4.2.12 Periodo de creación del verde urbano salmantino.

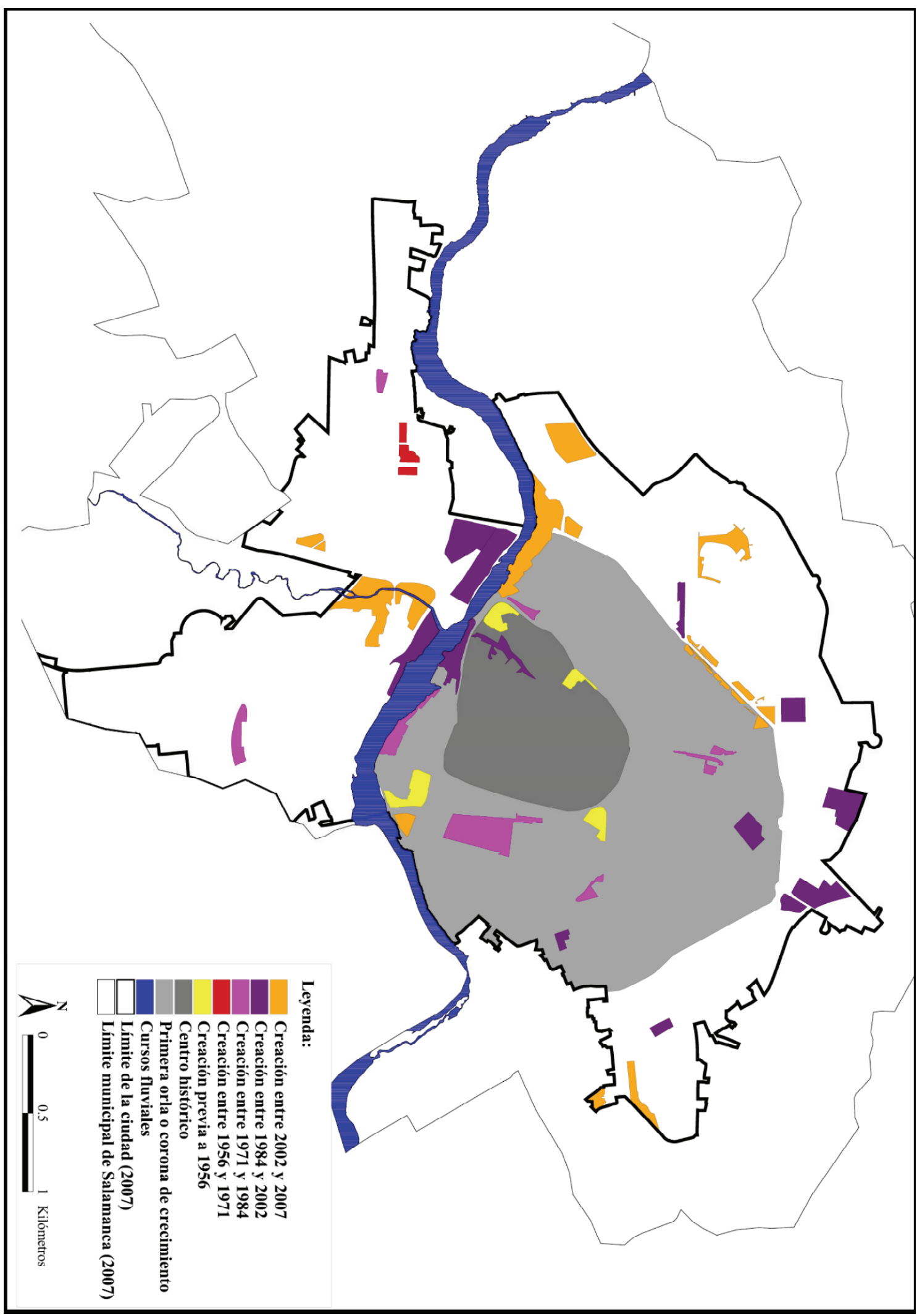

Fuente: elaboración propia a partir de la ortofoto de 2007 del IGN. 
Figura 4.2.13 Origen del verde urbano salmantino.

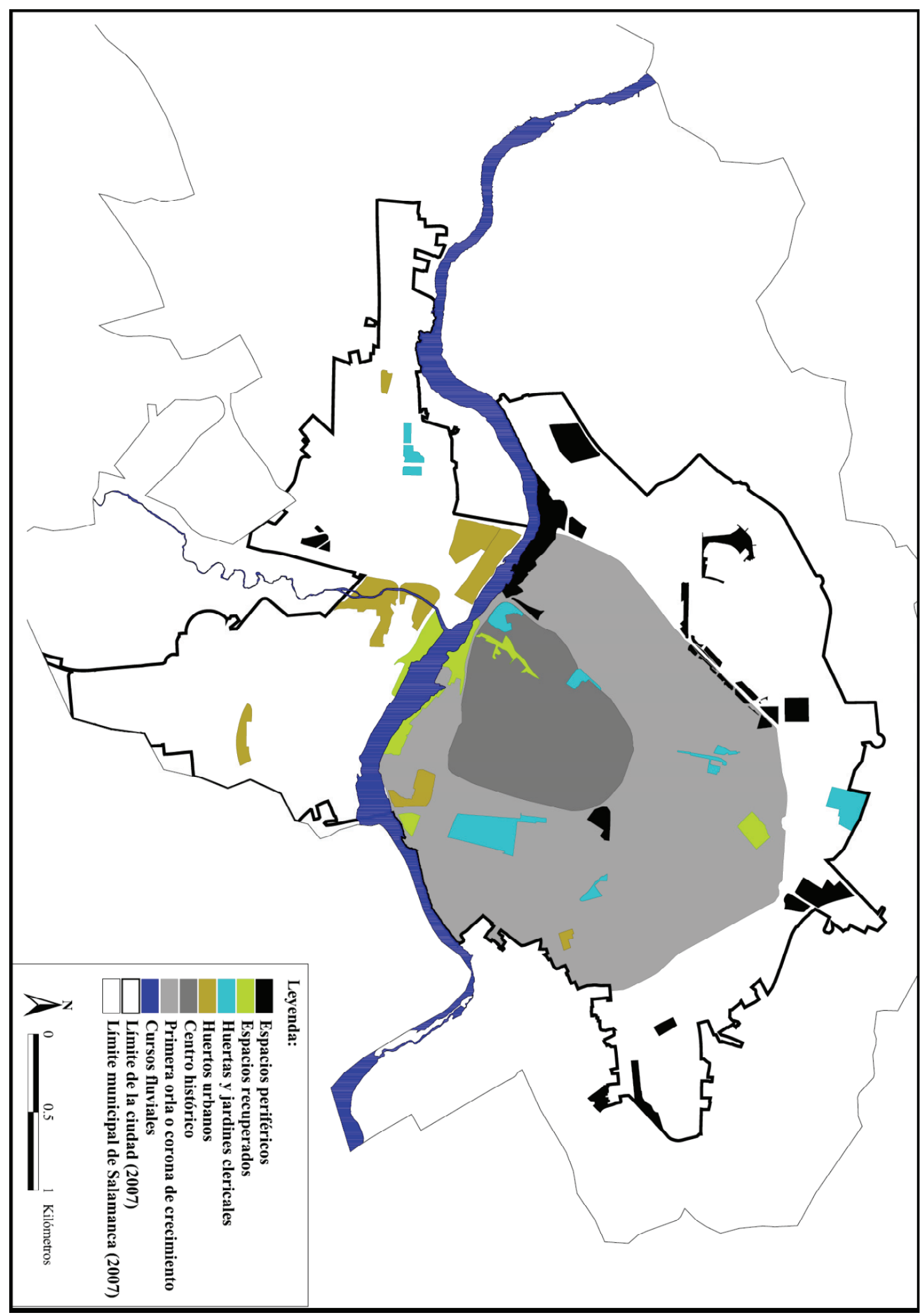

Fuente: elaboración propia a partir de la ortofoto de 2007 del IGN. 
Figura 4.2.14 Concentración de espacios verdes en Salamanca.

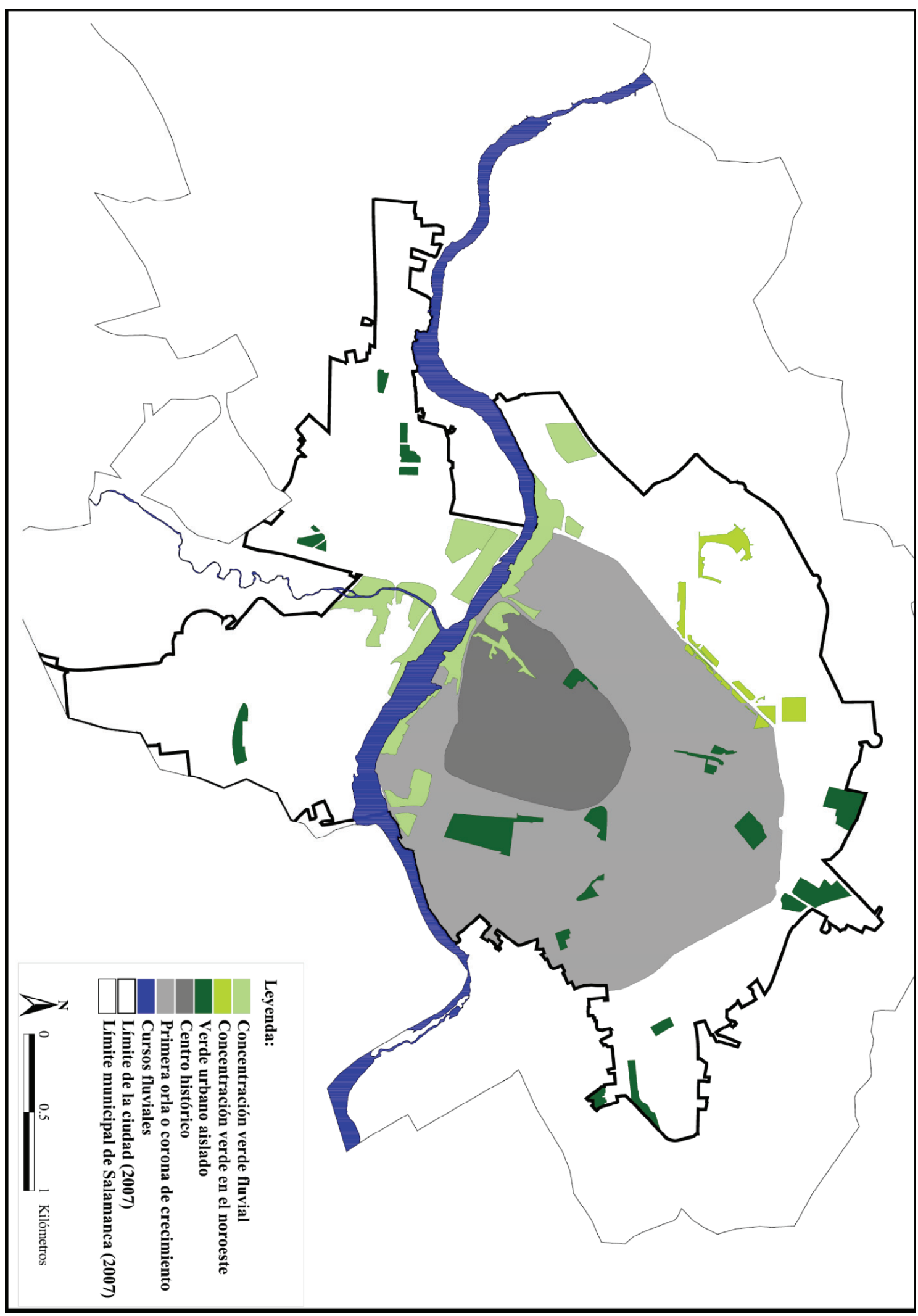

Fuente: elaboración propia a partir de la ortofoto de 2007 del IGN. 
Figura 4.2.15 Localización de los espacios verdes en los barrios de Salamanca.

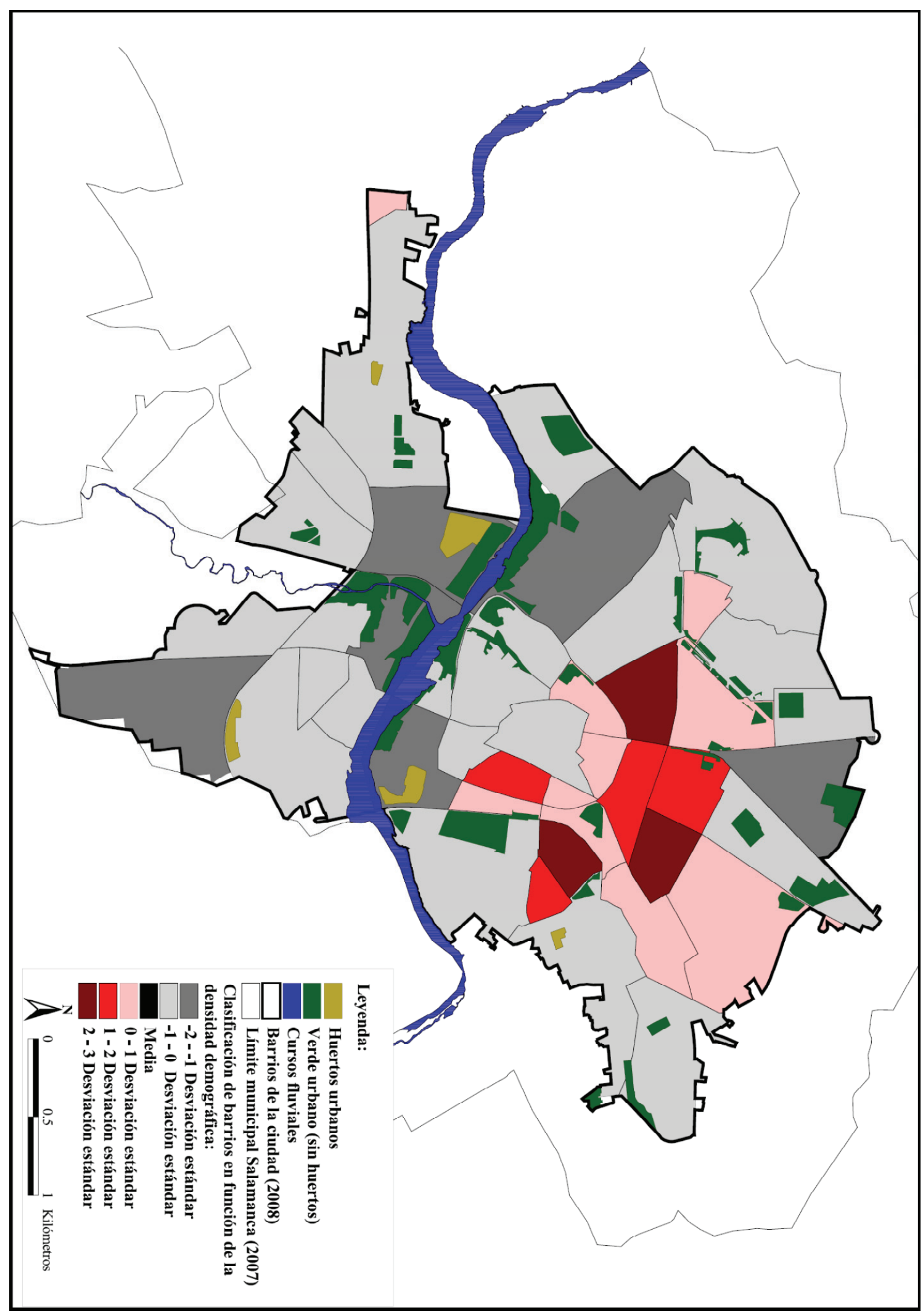

Media $=14.642 \mathrm{hab} / \mathrm{km}^{2}$. Desviación estándar $=11.144 \mathrm{hab} / \mathrm{km}^{2}$

Fuente: elaboración propia a partir de la ortofoto de 2007 del IGN y del Observatorio Urbano de Salamanca. 
En la Figura 4.2.15 se ha combinado la situación del verde urbano con la densidad demográfica de los barrios de Salamanca, empleando un color rojo para representar un valor elevado, mientras que el gris implica un valor reducido (los valores de cada barrio pueden consultarse en la Tabla 4.2.8). Destaca especialmente la ausencia de zonas verdes en los barrios más poblados de la zona norte de la primera corona de crecimiento, así como en la mayor parte de los que forman el centro histórico. Concretamente, siete de los barrios más densamente poblados de Salamanca, entre los que se encuentran Carmelitas-Oeste (16), Labradores (9), Alamedilla (10), Delicias (29), San Bernardo (20), Garrido Sur (22) y Universidad (23), apenas cuentan con zonas verdes en su interior. La segunda corona, creada principalmente en el periodo 1984-2007, alberga la mayor parte de los nuevos espacios verdes, aunque en determinados sectores presenta vacíos más intensos, si cabe, que en el sector central y en la primera corona. En barrios como San José (33), existen huertos urbanos, pero son espacios orientados hacia un aprovechamiento económico, con poca relevancia en el desarrollo de beneficios sociales. Al sur del Tormes la situación es llamativa: en la aglomeración compuesta por San José (33), La Vega (34), el Tormes (32), el Zurguén (41) y el polígono de El Montalvo (45), cuenta con una población residente de 10.650 habitantes pero no tiene ningún espacio verde a excepción de huertos urbanos. La misma situación se registra en Buenos Aires (40) y Los Alambres (37), así como en el barrio del Carmen (17) y en el de la Estación (26), que son parte de la segunda corona, y en un total de diez barrios entre el centro y la primera orla de crecimiento. Esto muestra una situación delicada en la que dos quintas partes de los ciudadanos de Salamanca, exactamente 63.674 personas, vivirían en barrios donde no hay espacios verdes.

\subsubsection{Evolución de los indicadores de Salamanca}

En la Tabla 4.2.9 aparecen todos los indicadores referentes al verde urbano durante el periodo analizado y en la Figura 4.2.16 ha sido representada la evolución de los más relevantes. Ya se ha comentado la diferencia entre los indicadores referidos al total de la trama verde y a los que únicamente tienen en cuenta el verde urbano disponible. Los primeros presentan una situación de partida únicamente superada a partir de 2007, debido al gran peso que tenía en 1956 la agricultura urbana: con 45,5 ha representaba el 95\% de la extensión verde de Salamanca. La superficie dedicada a la agricultura en el interior del tejido urbano irá disminuyendo progresivamente durante el periodo mostrando un pequeño repunte en 2002, al tiempo que la ciudad experimenta un considerable crecimiento tanto demográfico como territorial, provocando así una progresiva reducción de los índices del total de verde en Salamanca, que no se detendrá hasta que entre en vigor el PGOU de 1984. A partir de esta fecha, todos los valores experimentarán un fuerte crecimiento motivado por la aparición de ocho verdes urbanos disponibles hasta 2002 y otros diez en los últimos cinco años del periodo. La evolución de estos últimos espacios ha sido algo diferente puesto que su situación de partida era muy precaria. El Campo de San Francisco (S-9) y el Parque de la Alamedilla (S-10) eran los únicos espacios verdes de este tipo en 1956, fecha en la que a cada uno de los 80.239 salmantinos le corresponderían $0,30 \mathrm{~m}^{2}$ de verde urbano disponible. No obstante, la situación se agravó aún más puesto que quince años después la población de Salamanca alcanzó los 125.220 habitantes, distribuidos en una superficie urbana de 746 ha que contenía los mismos verdes disponibles con los que comenzó el siglo XX. En 1971 tan solo el 0,39\% del tejido urbano estaba destinado a este tipo de zonas verdes $\left(39,16 \mathrm{~m}^{2} / \mathrm{ha}\right)$ y el ratio por habitante se situó en $0,22 \mathrm{~m}^{2} /$ hab.

En 1984 la ciudad contaba con seis nuevos espacios verdes cuya extensión supera las veinte hectáreas y a partir de la aplicación del PGOU de 1984 estas actuaciones se consolidan hasta alcanzar las 100 ha en 2007, distribuidas en 26 espacios verdes disponibles. Sin embargo, el fuerte crecimiento de estos indicadores durante los últimos treinta años (ver Figura 4.2.16) 
no ha conseguido subsanar los déficits heredados a lo largo de las seis primeras décadas del siglo veinte y los resultados al final del periodo analizado no se adecuan a los estándares mínimos marcados por la OMS ( $\left.9 \mathrm{~m}^{2} / \mathrm{hab}\right)$, ni a los que Magalhães (1992) y Santana et al. (2007 y 2010) consideran como valor adecuado o deseable $\left(10 \mathrm{~m}^{2} / \mathrm{hab}\right)$, con $6,41 \mathrm{~m}^{2}$ de verde urbano disponible por habitante, cuya extensión representa el $6,8 \%\left(683,53 \mathrm{~m}^{2} / \mathrm{ha}\right)$ de la superficie urbana de Salamanca.

Tabla 4.2.8 Superficie y población de los barrios de Salamanca.

\begin{tabular}{|c|c|c|c|c|}
\hline $\mathbf{N}^{\circ}$ & Nombre barrio & $\begin{array}{c}\mathbf{N}^{\mathbf{o}} \\
\text { habitantes }\end{array}$ & $\begin{array}{l}\text { Superficie } \\
\text { (ha) }\end{array}$ & $\begin{array}{l}\text { Densidad } \\
\left(\mathrm{hab} / \mathrm{km}^{2}\right)\end{array}$ \\
\hline 1 & Centro & 4.447 & 26,6 & 16.714 \\
\hline 2 & San Juan & 2.410 & 10,0 & 24.199 \\
\hline 3 & Sancti Spíritus & 1.126 & 4,8 & 23.287 \\
\hline 4 & San Cristóbal - Claras & 3.450 & 12,7 & 27.241 \\
\hline 5 & San Esteban & 809 & 11,2 & 7.218 \\
\hline 6 & Universidad & 1.118 & 27,8 & 4.028 \\
\hline 7 & San Vicente & 1.272 & 20,4 & 6.246 \\
\hline 8 & Úrsulas - San Marcos & 2.431 & 12,6 & 19.264 \\
\hline 9 & Labradores & 6.452 & 19,1 & 33.829 \\
\hline 10 & Alamedilla & 2.388 & 11,9 & 20.095 \\
\hline 11 & Santo Tomás & 1.790 & 8,7 & 20.637 \\
\hline 12 & Fontana & 675 & 36,1 & 1.870 \\
\hline 13 & Tenerías & 675 & 16,6 & 4.077 \\
\hline 14 & Hospital & 378 & 81,8 & 462 \\
\hline 15 & San Bernardo & 5.784 & 41,9 & 13.803 \\
\hline 16 & Carmelitas - Oeste & 9.638 & 24,9 & 38.667 \\
\hline 17 & Carmen & 2.328 & 10,9 & 21.285 \\
\hline 18 & Pizarrales & 8.645 & 73,3 & 11.800 \\
\hline 19 & Blanco & 4.020 & 36,8 & 10.914 \\
\hline 20 & Vidal & 6.800 & 32,8 & 20.739 \\
\hline 21 & Glorieta - Ciudad Jardín & 859 & 45,8 & 1.874 \\
\hline 22 & \begin{tabular}{|l} 
Salesas \\
\end{tabular} & 6.701 & 22,1 & 30.282 \\
\hline 23 & Garrido Sur & 8.258 & 18,5 & 44.652 \\
\hline 24 & Chinchibarra & 5.371 & 43,7 & 12.282 \\
\hline 25 & Garrido Norte & 14.049 & 67,5 & 20.826 \\
\hline 26 & \begin{tabular}{|l|} 
Estación \\
\end{tabular} & 3.781 & 26,7 & 14.155 \\
\hline 27 & Puente Ladrillo & 4.734 & 47,2 & 10.024 \\
\hline 28 & Rollo & 6.973 & 54,4 & 12.813 \\
\hline 29 & Delicias & 5.551 & 13,7 & 40.627 \\
\hline 30 & San Isidro & 2.332 & 8,2 & 28.479 \\
\hline 31 & Prosperidad & 6.627 & 68,5 & 9.677 \\
\hline 32 & Tormes & 2.334 & 18,1 & 12.872 \\
\hline 33 & San José & 3.753 & 65,7 & 5.711 \\
\hline 34 & La Vega & 1.357 & 12,9 & 10.491 \\
\hline 35 & Teso de la Feria & 1.440 & 20,4 & 7.045 \\
\hline 36 & Arrabal & 550 & 34,7 & 1.583 \\
\hline 37 & Alambres & 1.399 & 20,8 & 6.731 \\
\hline 38 & Chamberí & 1.833 & 59,8 & 3.065 \\
\hline 39 & \begin{tabular}{|l|} 
Tejares \\
\end{tabular} & 3.436 & 92,9 & 3.699 \\
\hline 40 & Buenos Aires & 1.043 & 4,5 & 23.345 \\
\hline 41 & Zurguén & 3.206 & 29,8 & 10.742 \\
\hline 42 & Vistahermosa & 1.947 & 35,3 & 5.510 \\
\hline 43 & Capuchinos & 3.116 & 22,9 & 13.598 \\
\hline 44 & Platina & 1.713 & 35,9 & 4.775 \\
\hline \multirow[t]{2}{*}{45} & Montalvo & 0 & 68,7 & 0 \\
\hline & TOTAL & 158.999 & 1.460 & 14.694 \\
\hline
\end{tabular}

Fuente: Observatorio Urbano de Salamanca. 
Tabla 4.2.9 Principales indicadores del verde urbano de Salamanca durante el periodo 1956-2007.

\begin{tabular}{|c|c|c|c|c|c|}
\hline & 1956 & 1971 & 1984 & 2002 & 2007 \\
\hline$\overline{N^{\circ} \text { espacios verdes }}$ & 8 & 8 & 12 & 24 & 34 \\
\hline $\mathrm{N}^{\circ}$ huertos urbanos & 6 & 5 & 3 & 6 & 5 \\
\hline $\mathrm{N}^{\mathrm{o}}$ espacios verdes $\sin$ huertos & 2 & 3 & 9 & 19 & 29 \\
\hline $\mathrm{N}^{\circ}$ espacios verdes disponibles & 2 & 2 & 8 & 17 & 26 \\
\hline $\mathbf{N}^{\circ}$ habitantes & 80.239 & 125.220 & 167.131 & 156.006 & 155.921 \\
\hline Extensión de la ciudad (ha) & 618 & 746 & 1.039 & 1.302 & 1.463 \\
\hline Extensión del verde (ha) & 47,9 & 35,4 & 40,8 & 80,6 & 124,0 \\
\hline Extensión de los huertos urbanos (ha) & 45,5 & 31,6 & 15,3 & 19,4 & 15,0 \\
\hline Extensión del verde sin huertos (ha) & 2,4 & 3,9 & 25,5 & 61,1 & 109,0 \\
\hline Extensión del verde urbano disponible (ha) & 2,4 & 2,7 & 23,7 & 53,5 & 100,0 \\
\hline Densidad de verde $\left(\mathrm{m}^{2} / \mathrm{hab}\right)$ & 5,97 & 2,83 & 2,44 & 5,16 & 7,95 \\
\hline Densidad verde $\sin$ huertos $\left(\mathrm{m}^{2} / \mathrm{hab}\right)$ & 0,30 & 0,31 & 1,52 & 3,92 & 6,99 \\
\hline Densidad del verde urbano disponible $\left(\mathrm{m}^{2} / \mathrm{hab}\right)$ & 0,30 & 0,22 & 1,42 & 3,43 & 6,41 \\
\hline Densidad verde por superficie $\left(\mathrm{m}^{2} / \mathrm{ha}\right)$ & 774,60 & 475,07 & 392,78 & 618,85 & 847,57 \\
\hline Densidad del verde urbano disponible por superficie $\left(\mathrm{m}^{2} / \mathrm{ha}\right)$ & 39,16 & 36,19 & 228,49 & 411,11 & 683,53 \\
\hline
\end{tabular}

Fuente: elaboración propia a partir del SGE, del IGN y del INE.

Figura 4.2.16 Evolución de los principales indicadores del verde urbano y del verde urbano disponible en Salamanca.

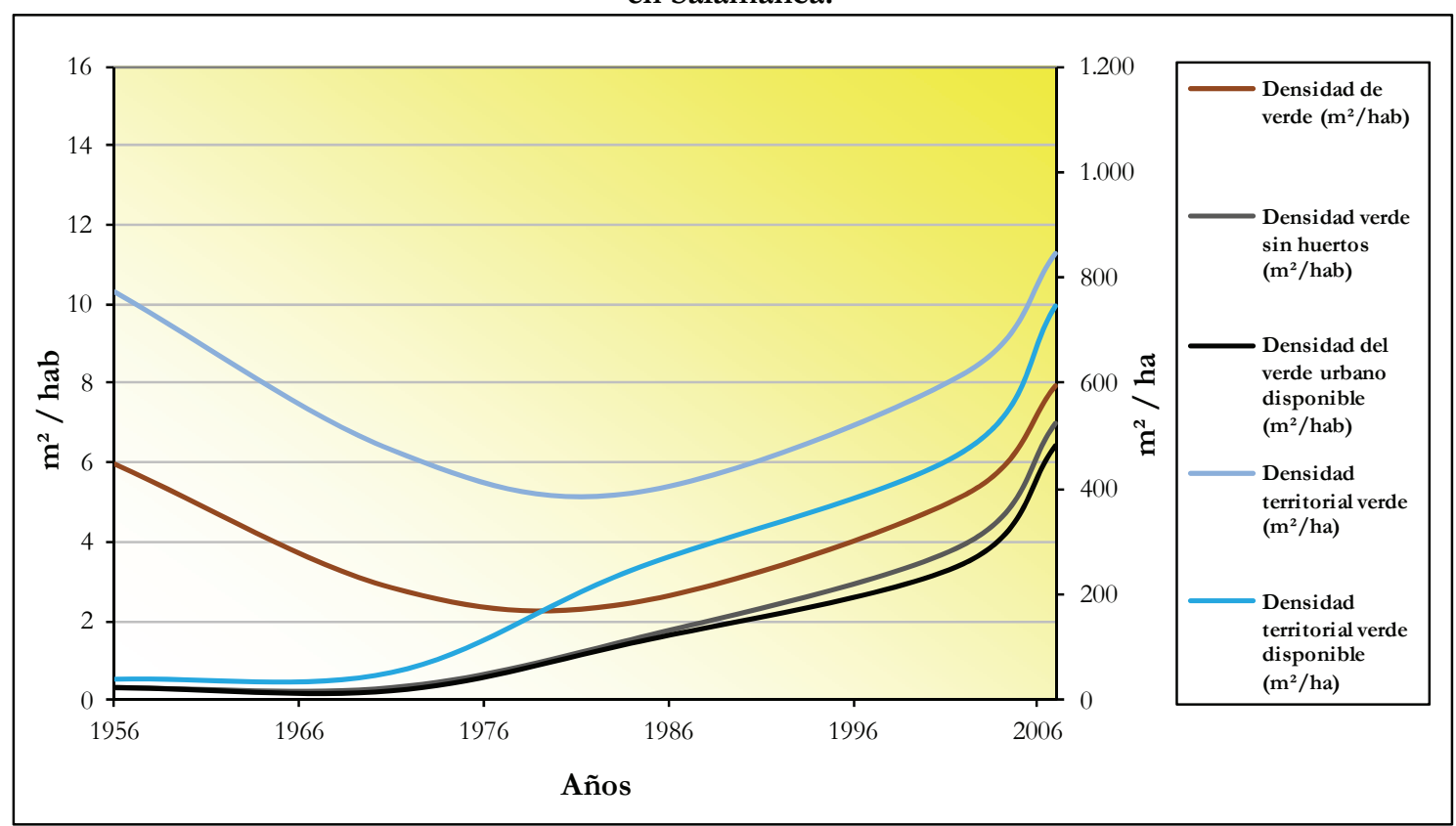

Fuente: elaboración propia a partir del SGE, del IGN y del INE. 


\subsection{Origen y evolución del verde urbano de la ciudad de Valladolid}

De las ciudades estudiadas, Valladolid es la que posee un mayor tamaño y es también la más dinámica desde la perspectiva económica, puesto que cuenta con un potente sector industrial basado en la automoción, además de ser sede de las principales instituciones de la Comunidad Autónoma de Castilla y León. En 2011 el municipio contaba con 313.437 habitantes y estaba dividido en cuarenta y seis barrios, según el Ayuntamiento. Sin embargo, en esta investigación este número se ha reducido debido a que durante el trabajo de campo se observó que los ciudadanos no hacían distinción, por ejemplo, entre las distintas fases de Huerta del Rey (Baja, Media, Alta, Gavilla e Insonusa), ni entre los sectores del Paseo Zorrilla (Alto y Bajo), ni entre los de Arturo Eyries (Alto y Bajo). Por lo tanto, estas entidades se han agrupado y se ha obtenido un total de cuarenta barrios (ver Tabla 4.3.1), cuya representación cartográfica aparece en la Figura 4.3.1. En esta última también se han incluido las principales divisiones del tejido urbano con el fin de facilitar la comprensión de los procesos y actuaciones desarrolladas en la ciudad del Pisuerga durante los últimos cincuenta años. El límite del centro histórico de Valladolid se corresponde con la almendra central de la ciudad e incluye los barrios del 1 al 15 con la excepción del 3, Campo Grande - Arco del Ladrillo, y su superficie $(185,17$ ha) es más del doble que el límite del casco histórico fijado por el Plan Especial del Casco Histórico de 1992 (PECH). Quizás hubiera sido más correcto utilizar los límites fijados por dicho documento, que coinciden con la ciudad tradicional representada por Ventura Seco en 1738, pero resulta más operativo emplear los límites de la almendra central.

Por otro lado, para establecer el perímetro de la primera orla o corona de crecimiento lo más lógico habría sido utilizar la ronda exterior, es decir, aquella que circunda la ciudad apoyándose en la Autovía de Castilla a través de la Avenida de Zamora y de las Rondas Este y Norte. Sin embargo, esta división es poco útil al incluir en 2008 numerosos vacíos urbanos y se ha optado por emplear una delimitación del espacio urbano situado en la margen izquierda del Pisuerga que fuese operativa para el objetivo de esta investigación. Para ello se ha utilizado la actual división de la estructura viaria presente en el Plan General de Tráfico Urbano de la Ciudad de Valladolid (PGTUCV), concretamente el viario transversal. De tal manera que desde el Pisuerga se ha dibujado una corona a través de la Avenida de Medina del Campo, Paseo Zorrilla, Calle de Daniel del Olmo González, Calle del Arca Real, Paseo del Arco del Ladrillo, Paseo Juan Carlos I y Ronda Norte. El territorio situado fuera de este límite en la mitad occidental de la ciudad ha sido considerado como la segunda orla o corona de crecimiento, por analogía con las otras ciudades analizadas, mientras que la orilla oriental del Pisuerga forma un conjunto diferenciado que comenzó a poblarse en la segunda mitad del siglo XX.

Como se apuntó en la metodología, el tamaño mínimo del verde urbano de Valladolid en 2008 era de 1,26 ha. En la Tabla 4.3.2, que es idéntica a la Tabla 2.6, aparecen recogidos los cincuenta y cuatro espacios verdes que pertenecen a dicha categoría, con su tamaño y nombre correspondiente, y en las Figuras 4.3.2 y 4.3.3, que también son iguales a la 2.7 y a la 2.8, se puede observar su localización en el interior de la ciudad. En la primera imagen aparecen destacados las áreas verdes sobre la ortofoto de Valladolid, diferenciando los huertos urbanos en un color amarillento, mientras que en la segunda todos los espacios están numerados y se distinguen claramente los doce verdes urbanos no disponibles. En total suman 331 ha de zonas verdes, de las que 252,5 forman parte del verde urbano disponible y 51,2 ha tienen vocación agrícola. 
Tabla 4.3.1 Nombre y número de los barrios de Valladolid.

\begin{tabular}{|c|l|c|l|}
\hline $\mathbf{N}^{\mathbf{0}}$ & Nombre barrio & $\mathbf{N}^{\mathbf{0}}$ & Nombre barrio \\
\hline 1 & Centro & 22 & Barrio España \\
\hline 2 & Caño Argales & 23 & Belén \\
\hline 3 & Campo Grande - Arco del Ladrillo & 24 & Polígono Argales \\
\hline 4 & Circular & 26 & Camino de la Esperanza \\
\hline 5 & Universidad & 27 & Cuatro de Marzo \\
\hline 6 & San Juan & 28 & Arturo León \\
\hline 7 & San Miguel & 29 & Arturo Eyries \\
\hline 8 & San Nicolás & 30 & Girón - Villa del Prado \\
\hline 9 & Rondilla & 31 & La Victoria \\
\hline 10 & San Pablo & 32 & La Overuela - Navabuena - El Berrocal \\
\hline 11 & San Juan II & 33 & San Pedro Regalado \\
\hline 12 & Vadillos & 34 & Las Flores \\
\hline 13 & Santa Clara & 35 & Páramos San Isidro - Campo de Tiro \\
\hline 14 & Hospital & 36 & Caamaño - Las Viudas - Polígono San Cristóbal \\
\hline 15 & Batallas & 37 & Las Villas - Cañada Puente Duero - Covaresa \\
\hline 16 & Pilarica & & Parque Alameda - Paula López \\
\hline 17 & Pajarillos Bajos & 38 & Parquesol \\
\hline 18 & Pajarillos Altos & 39 & Pinar de Antequera \\
\hline 19 & Delicias & 40 & La Rubia \\
\hline 20 & Paseo Zorrilla & & \\
\hline 21 & Huerta del Rey & \\
\hline
\end{tabular}

Fuente: Observatorio Urbano de Valladolid.

Tabla 4.3.2 El verde urbano de la ciudad de Valladolid.

\begin{tabular}{|c|c|c|c|c|c|}
\hline $\mathbf{N}^{0}$ & ha & Nombre & $\mathbf{N}^{\circ}$ & ha & Nombre \\
\hline $\mathrm{V}-1$ & 12,7 & Campo Grande & V-29 & 9,0 & Verde urbano Cortes de Castilla y León \\
\hline \multirow{2}{*}{ V-2 } & \multirow{2}{*}{4,6} & \multirow{2}{*}{$\begin{array}{l}\text { Parque Rosaleda Francisco Sabadell y Parque } \\
\text { de Poniente }\end{array}$} & V-30 & 4,8 & Verde urbano Auditorio Miguel Delibes \\
\hline & & & $\mathrm{V}-31$ & 15,4 & Verde urbano Mirador Parquesol \\
\hline $\mathrm{V}-3$ & 9,5 & Parque de las Moreras & V-32 & 13,8 & Verde urbano Huerta del Rey \\
\hline V-4 & 26,7 & Parque Ribera de Castilla & V-33 & 8,8 & Verde urbano Parquesol Calle Morelia \\
\hline V-5 & 5,5 & Verde urbano Camino del Cabildo & \multirow{2}{*}{ V-34 } & \multirow{2}{*}{2,5} & \multirow{2}{*}{$\begin{array}{l}\text { Verde urbano Parquesol Calle Juan de } \\
\text { Valladolid }\end{array}$} \\
\hline V-6 & 7,0 & Jardín Botánico & & & \\
\hline $\mathrm{V}-7$ & 1,2 & Darsenas del Canal Castilla & V-35 & 2,0 & Parque del Reloj de Sol \\
\hline $\mathrm{V}-8$ & 14,7 & Cementerio de las Contiendas & V-36 & 5,0 & Verde urbano Palacio de la Ribera \\
\hline V-9 & 21,0 & Parque del Mediodía & V-37 & 1,6 & Ribera de Huerta del Rey \\
\hline V-10 & 6,6 & Ladera sur Parquesol - Fuente de Dios & V-38 & 1,4 & Verde urbano Plaza Juan de Austria \\
\hline V-11 & 4,7 & Arturo Eyries & V-39 & 1,7 & Verde urbano Calle Morena - Feria Muestras \\
\hline $\mathrm{V}-12$ & 2,4 & Verde urbano Centro de Acústica (Santa Ana) & $\mathrm{V}-40$ & 1,8 & Verde urbano Colegio San Agustín \\
\hline V-13 & 2,4 & Jardines Presidencia Junta Castilla y León & \multirow{2}{*}{ V-41 } & \multirow{2}{*}{2,4} & \multirow{2}{*}{$\begin{array}{l}\text { Ribera Pisuerga entre Puente Colgante y } \\
\text { Puente Juan de Austria }\end{array}$} \\
\hline V-14 & 5,3 & Parque de Covaresa & & & \\
\hline $\mathrm{V}-15$ & 2,4 & Parque de la Alameda & $\mathrm{V}-42$ & 1,6 & Plaza del Ejército \\
\hline $\mathrm{V}-16$ & 1,8 & Verde urbano Avenida de los Castaños & $\mathrm{V}-43$ & 1,3 & Residencia de ancianos Cardenal Marcelo \\
\hline V-17 & 4,3 & Verde urbano Valparaíso - Ronda Sur & V-44 & 1,2 & Jardines de La Victoria \\
\hline V-18 & 3,9 & Parque Arturo León & V-45 & 1,6 & Verde urbano Barrio de la Esperanza \\
\hline V-19 & 4,4 & Parque de las Norias de Santa Victoria & V-46 & 1,6 & Verde urbano Pinar de Jalón \\
\hline $\mathrm{V}-20$ & 3,9 & Parque de la Paz & \multirow{2}{*}{ V-47 } & \multirow{2}{*}{1,5} & Verde urbano Calle de la Vega de \\
\hline $\mathrm{V}-21$ & 12,2 & Parque de Canterac & & & Valdetronco - Villas Sur \\
\hline V-22 & 5,9 & Parque San Isidro - Fuente de la Salud & V-48 & 1,2 & Verde urbano Escuela Deportiva Niara \\
\hline $\mathrm{V}-23$ & 7,3 & Club Militar San Isidro & V-49 & 1,8 & Verde urbano Calle Alcaparra \\
\hline $\mathrm{V}-24$ & 7,4 & Verde urbano Ronda Este & V-50 & 1,4 & Huerto urbano Norte \\
\hline $\mathrm{V}-25$ & 4,0 & Verde urbano Calle Arribes del Duero & V-51 & 4,1 & Huertos en Zambrana \\
\hline $\mathrm{V}-26$ & 6,1 & Campus Esgueva & V-52 & 32,6 & Huertos urbanos Sur \\
\hline V-27 & 8,8 & Campus Miguel Delibes & V-53 & 10,5 & Huertos Soto de la Medinilla \\
\hline \multirow[t]{2}{*}{$\mathrm{V}-28$} & 1,6 & Paseo Zorrilla Sur & V-54 & 2,5 & Huerto urbano ACOR \\
\hline & & & Total & 331,0 & \\
\hline
\end{tabular}

Fuente: elaboración propia. 
Figura 4.3.1 División en barrios de la ciudad de Valladolid.

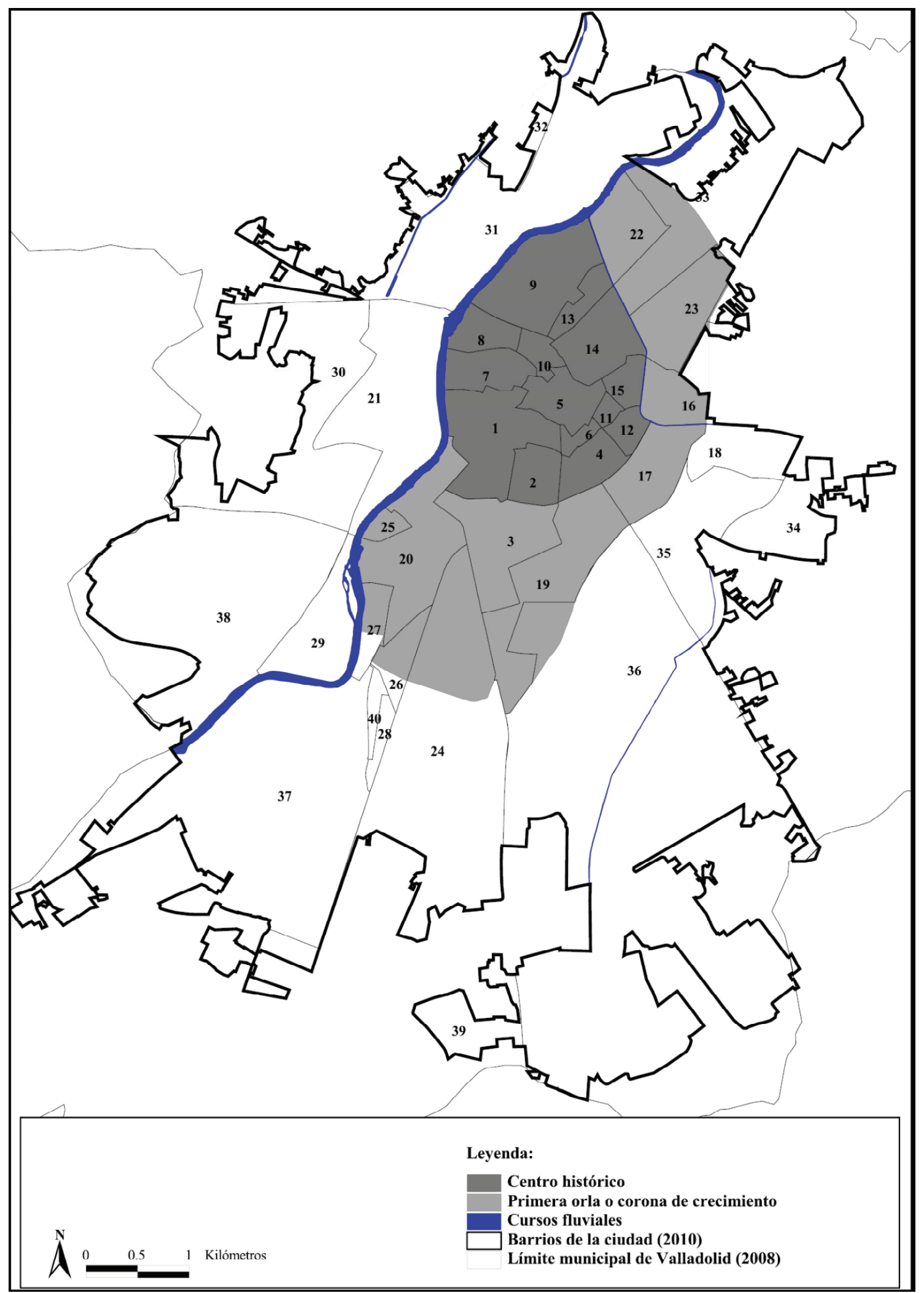

Fuente: elaboración propia a partir de la ortofoto de 2008 del IGN y del Observatorio Urbano de Valladolid. 
Figura 4.3.2 Localización espacial del verde urbano en la ciudad de Valladolid.

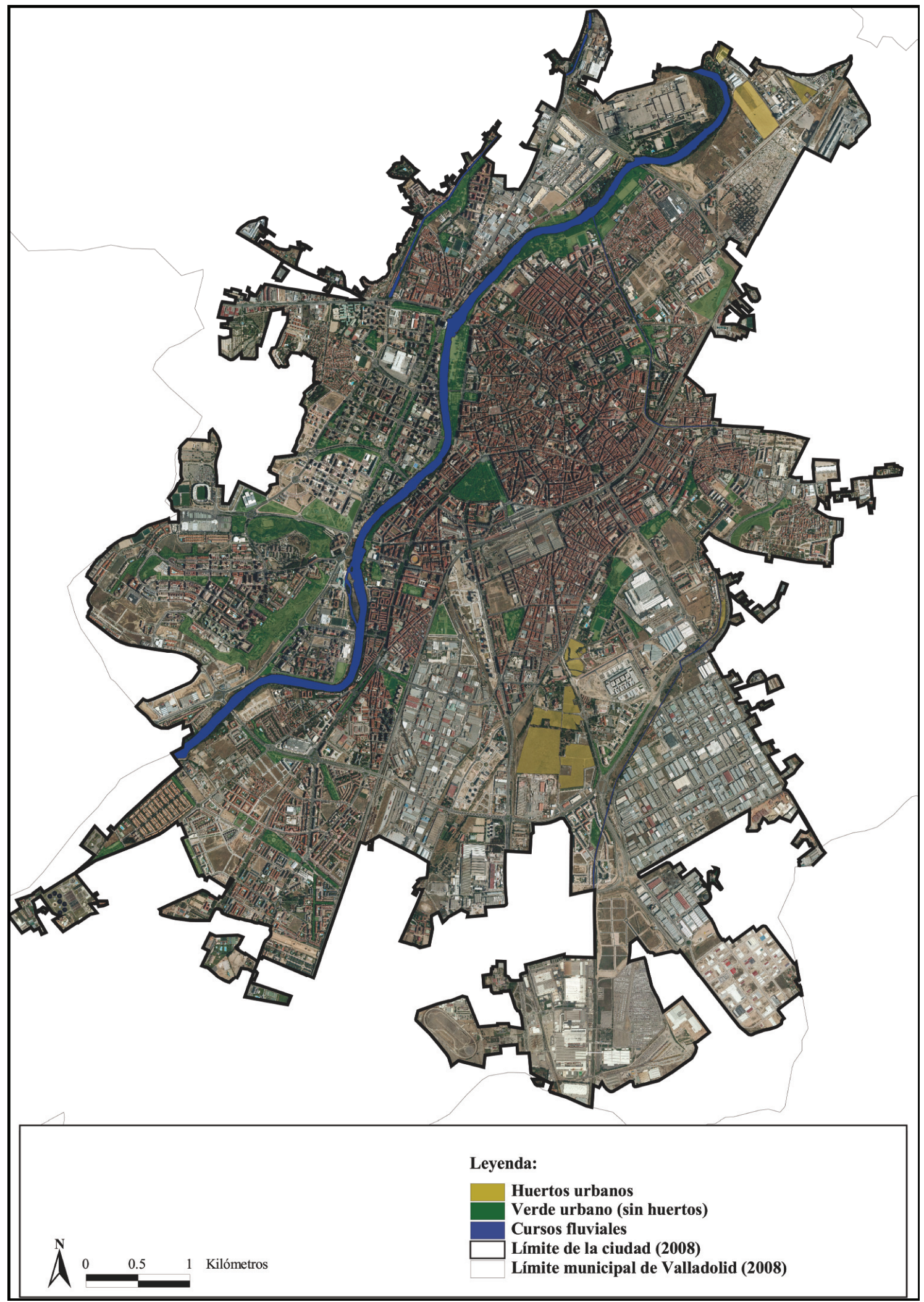

Fuente: elaboración propia a partir de la ortofoto de 2008 del IGN. 
Figura 4.3.3 Localización espacial del verde urbano disponible en la ciudad de Valladolid.

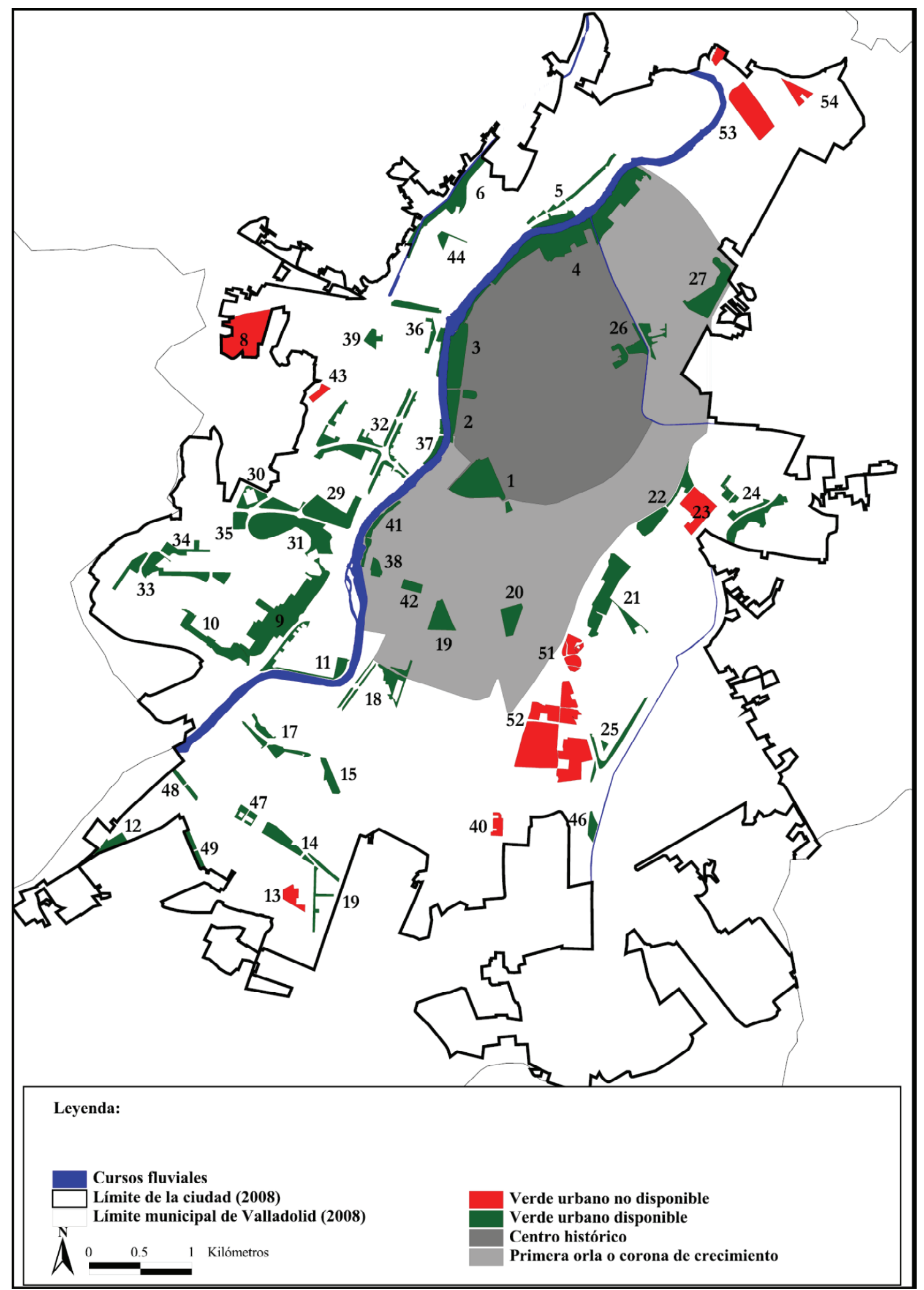

Fuente: elaboración propia a partir de la ortofoto de 2008 del IGN. 


\subsubsection{Evolución urbana de Valladolid hasta 1956}

Históricamente Valladolid ha contado con parques de gran tamaño y la mayor parte de los mismos han llegado hasta nuestros días. Durante la primera mitad del siglo XX la ciudad experimentó una serie de mejoras urbanísticas entre las que estaban proyectados algunos espacios verdes de entidad, especialmente a través del Plan de César Cort de 1939, pero no llegaron a hacerse realidad debido a la precaria situación de posguerra y a la ausencia de compromiso con el planeamiento urbano durante las primeras fases del éxodo rural que llevó a grandes contingentes de población a las principales ciudades del país.

\section{i) Expansión urbana}

Para explicar la situación en la que se encontraba la ciudad de 1956 es conveniente remontarse de manera sucinta en el tiempo para identificar el origen de los principales acontecimientos urbanísticos. Durante el siglo XVI Valladolid se había convertido en una de las ciudades más importantes de Castilla, alcanzando su mayor dimensión durante los reinados de Carlos V y de Felipe II, cuando fue sede de la Corte de manera interrumpida hasta que este último fijó la capital del reino en Madrid en 1559. A partir de entonces experimentará un progresivo declive y no conseguirá superar los límites urbanos heredados hasta bien entrado el siglo XIX, fecha en la que comienza de nuevo un proceso de expansión urbana que llega hasta nuestros días. El Valladolid histórico se extendía por la margen izquierda del Pisuerga y la única forma de cruzar el río era a través del Puente Mayor hasta que a finales del siglo XIX se inauguró el Puente Colgante. Además, la trama urbana era surcada por los ramales de un río menor, el Esgueva, que acabó por convertirse en un obstáculo urbano y en un vertedero a donde iban a parar toda clase de inmundicias. Durante el siglo XIX la ciudad desempeñó las funciones vinculadas a la capitalidad provincial y a la Universidad, así como las competencias judiciales de la audiencia territorial, heredera de la antigua Chancillería (Calderón, 1988). La industria harinera contó con una destacada importancia económica en Valladolid hasta el primer tercio del siglo XX gracias al desarrollo, en un primer período, de una infraestructura como el Canal de Castilla que agilizaba la salida del trigo hasta Santander y los puertos del norte para su posterior exportación, y que desde 1860 fue sustituida por el ferrocarril. La ciudad fue uno de los principales mercados de cereales de España hasta la creación en 1937 del Servicio Nacional del Trigo, lo que permitió la aparición de capitales autóctonos y la existencia de una burguesía harinera (Calderón et al., 1992).

En 1857 se instalaron los talleres de reparación del Ferrocarril del Norte en el sur de la ciudad, frente a la estación de Campo Grande (3) y a su amparo florecieron una serie de industrias auxiliares del ramo de la metalurgia. Esto provocó una creciente necesidad de mano de obra que se cubrió con emigrantes de origen rural, generando así cierto dinamismo en la actividad constructiva de Valladolid a partir del último cuarto del siglo XIX. La población obrera se hacinaba o bien en el interior de la ciudad tradicional o bien en los nuevos asentamientos surgidos en la periferia como la Cuesta de la Maruquesa (32), Pajarillos Altos (18), Tranque (19), Delicias (19) y Pilarica (16) (Calderón, 1988). La ciudad contaba en el año 1900 con 69.789 censados (ver Figura 4.3.4), población que creció ligeramente durante el primer tercio de siglo y que terminó por duplicarse en cincuenta años sin motivar un gran crecimiento territorial. Esta circunstancia es aprovechada para realizar mejoras urbanas como la construcción del Canal de Desviación del Esgueva, que junto al ya cubierto ramal sur, contribuyeron a liberar suelo urbanizable en el interior de la ciudad (Virgili, 1979). Continúa la llegada de inmigrantes de origen rural que se instalarán en asentimientos ya existentes o en nuevos núcleos como La Farola (24), donde predomina la autoconstrucción, La Rubia (40), que surge como proyecto de ciudad jardín, o en el que acabará por llamarse Barrio España 
(22). Con el objetivo de controlar el crecimiento urbano se aprueba el Proyecto de Limitación de la Zona Constructiva en 1931, aunque no llegó a aplicarse, y posteriormente el Plan de Urbanización de César Cort de 1939, que es considerado como uno de los últimos planes de ensanche de España. Tendrá una fuerte influencia en el futuro de la ciudad al plantear la concentración de la industria y de los barrios de mayores densidades en el este y en el sur (García, 2000). El Plan proponía la expropiación de los terrenos situados en la orilla derecha del Pisuerga, en lo que será el futuro barrio de Huerta del Rey (Virgili, 1979), así como la creación de numerosos parques y jardines públicos, entre los que se encontraba el futuro Parque de Canterac. Sin embargo, sufrirá modificaciones sustanciales como la sustitución del proyecto de barrio ajardinado en La Rubia (40) por la edificación en altura o la desaparición de algunos de los espacios verdes proyectados en Vadillos (12) o en San Pedro Regalado (33), así como la reducción del parque del Pisuerga (García, 2000).

En el periodo de posguerra, la ausencia de recursos económicos impedía que los nuevos habitantes de la ciudad adquirieran una vivienda por sus propios medios, siendo necesaria una intervención de carácter público. La Obra Sindical del Hogar y los organismos religiosos levantaron numerosos Grupos de Promoción Oficial desde principios de la década de los cuarenta hasta mediados de los sesenta, como el de José Antonio Girón (30), inaugurado en 1955, que se convirtió en la mayor intervención registrada hasta entonces en la margen derecha del Pisuerga. Buena parte de estos Grupos fueron construidos en espacios libres entre la ciudad tradicional y los suburbios, llegando en algunos casos a levantarse sobre zonas calificadas como agrícolas o como espacios verdes, como ocurrió con el Cuatro de Marzo (32), La Victoria (37), Dieciocho de Julio (13), Leones de Castilla (14), San Pedro Regalado (39) y Jesús Aramburu (42) (García, 2000). Al margen de la iniciativa pública, se produjo una intensa aparición de infravivienda y un aumento de la autoconstrucción, de los que da cuenta Calderón (1988) cuando afirma que entre 1943 y 1956, el 43\% de las viviendas eran ilegales, porcentaje que se mantuvo en la década siguiente. Para llevarla a cabo la expansión occidental de la ciudad, el Plan Cort proponía la construcción de tres nuevos puentes que conectasen la Huerta del Rey (21) con el centro de la ciudad, junto a los otros dos ya existentes. La aparición de los mismos se aplazó por las dificultades propias de la época y no fue hasta 1952 cuando se terminó el Puente del Poniente, el de Isabel la Católica se abrió al público en 1956 y a mediados de la década de los sesenta lo hizo el Puente García Morato.

Figura 4.3.4 Evolución de la población de la ciudad y de la provincia de Valladolid desde 1900.

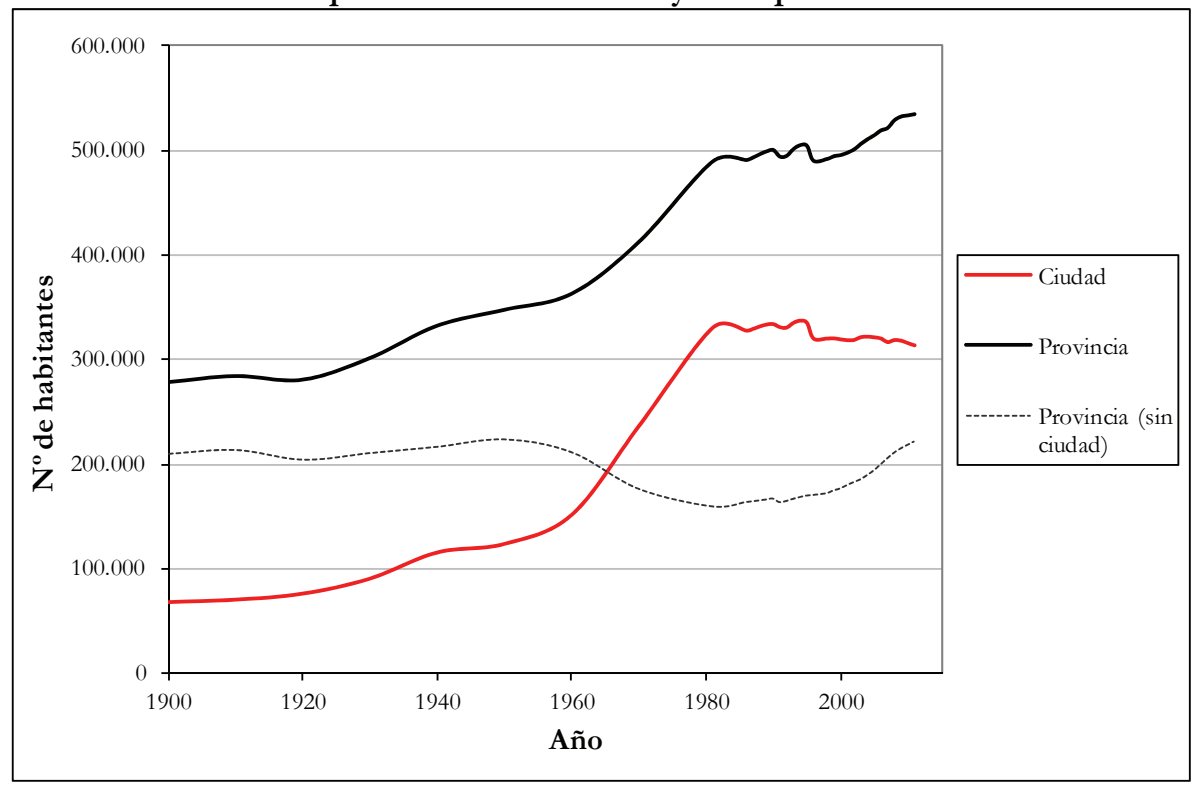

Fuente: INE. 


\section{ii) Aparición de espacios verdes}

El espacio verde más antiguo de Valladolid y uno de los más grandes de la ciudad es el Campo Grande (V-1) (ver Figura 4.3.5), situado en el exterior del límite sur de la antigua muralla medieval. Su origen no está muy claro, pero se piensa que el terreno que hoy ocupa el parque pudo haber tenido una vocación de comunal, por lo que estaría prohibido construir en él (Fernández, 1981). Los alrededores del Campo Grande comenzaron a urbanizarse en el siglo XV, pero este espacio no será integrado en la ciudad hasta la llegada del ferrocarril a mediados del siglo XIX. Se considera que fue 1878 cuando se convirtió en parque de la mano de Miguel Íscar y del encargado de jardines Francisco Sabadell, aunque a finales del siglo XVIII se realiza el primer plantío coincidiendo con la efectuada también en el Parque de las Moreras (V-3) (Fernández, 1981). Este último espacio verde surgió a finales del siglo XVIII al amparo de las políticas ilustradas de Calos III dirigidas a la mejora de la higiene urbana y a la proliferación de zonas verdes. De esta manera, la Sociedad Económica de Amigos del País creó en la orilla del Pisuerga, en lo que se conocía como Espolón Viejo, un paseo donde se plantaron mayoritariamente moreras (Fernández, 1981), dando nombre así a este verde urbano. En el último tercio del siglo XIX Valladolid presentaba serios problemas higiénicos que desembocaron en una epidemia de cólera. Los ramales del Esgueva se habían convertido en basureros y focos de infección, por lo que se decidió cubrirlos y desviar el río a su entrada en la ciudad. En el espacio generado al cubrir el ramal central en su parte más próxima al Pisuerga, se construyó en 1863 el llamado Parque de Poniente (V-2), por encontrarse en el límite occidental de la ciudad tradicional.

Anteriormente Valladolid había contado con otros espacios verdes como el Prado de la Magdalena, que con el tiempo acabó dedicado mayoritariamente a la agricultura urbana y del que en 1956 todavía quedaban algunos terrenos dedicados a esta función en el mismo lugar donde actualmente está situado el Campus del Esgueva (V-26). Conviene también mencionar que el barrio llamado Huerta del Rey (21) se asienta sobre terrenos utilizados como zona de recreo durante el reinado de los Austrias y de los que hoy solamente quedan los restos del Palacio de la Ribera. En 1956 ya existía una parte de este espacio verde, concretamente el derrame del Canal de Castilla (V-36) vinculado a la fábrica de harinas La Perla, situada en la margen derecha del Pisuerga. En 1945 surgió junto al Parque de las Moreras (V-3), en el mismo Paseo de Isabel la Católica, la Rosaleda Francisco Sabadell (V-2), llamada así en honor de uno de los artífices de la remodelación del Campo Grande. En 1956 también era posible identificar un espacio arbolado en el tramo sur del Paseo Zorrilla (V-28), junto al recién construido Grupo de Viviendas Cuatro de Marzo (27), así como nueve huertos en el interior del tejido urbano. El de mayor tamaño estaba situado en el antiguo Prado de la Magdalena, en el solar que hoy ocupa la Escuela de Ingenierías Industriales en el Campus Esgueva (V-26). Siguiendo el curso de este río en dirección hacia su desembocadura en el Pisuerga, se encontraba una pequeña zona de huertas junto a la Calle Madre de Dios y una parcela de seis hectáreas sobre la que se levantaría el Grupo de Promoción Oficial XXV Años de Paz en el año 1965. La almendra central de la ciudad aún no se había rellenado en su parte norte y en la margen izquierda del Pisuerga, junto al Puente Mayor, se construyó el Seminario Menor Diocesano (actual Instituto Juan de Juni), junto a unas huertas con una extensión superior a cuatro hectáreas. También existían otros pequeños huertos urbanos situados junto a la vía del ferrocarril, uno en el cruce de esta junto al Esgueva en el barrio de Vadillos (12) y otro en el barrio Camino de la Esperanza (26), además de otro en el barrio de Delicias (19) y unas pequeñas huertas junto al antiguo campo de fútbol del Paseo Zorrilla. En el barrio de La Victoria (31) había una parcela dedicada a la agricultura con más de seis hectáreas de extensión, desaparecida ya en el año 1971. 
Figura 4.3.5 Verde urbano de la ciudad de Valladolid en 1956.

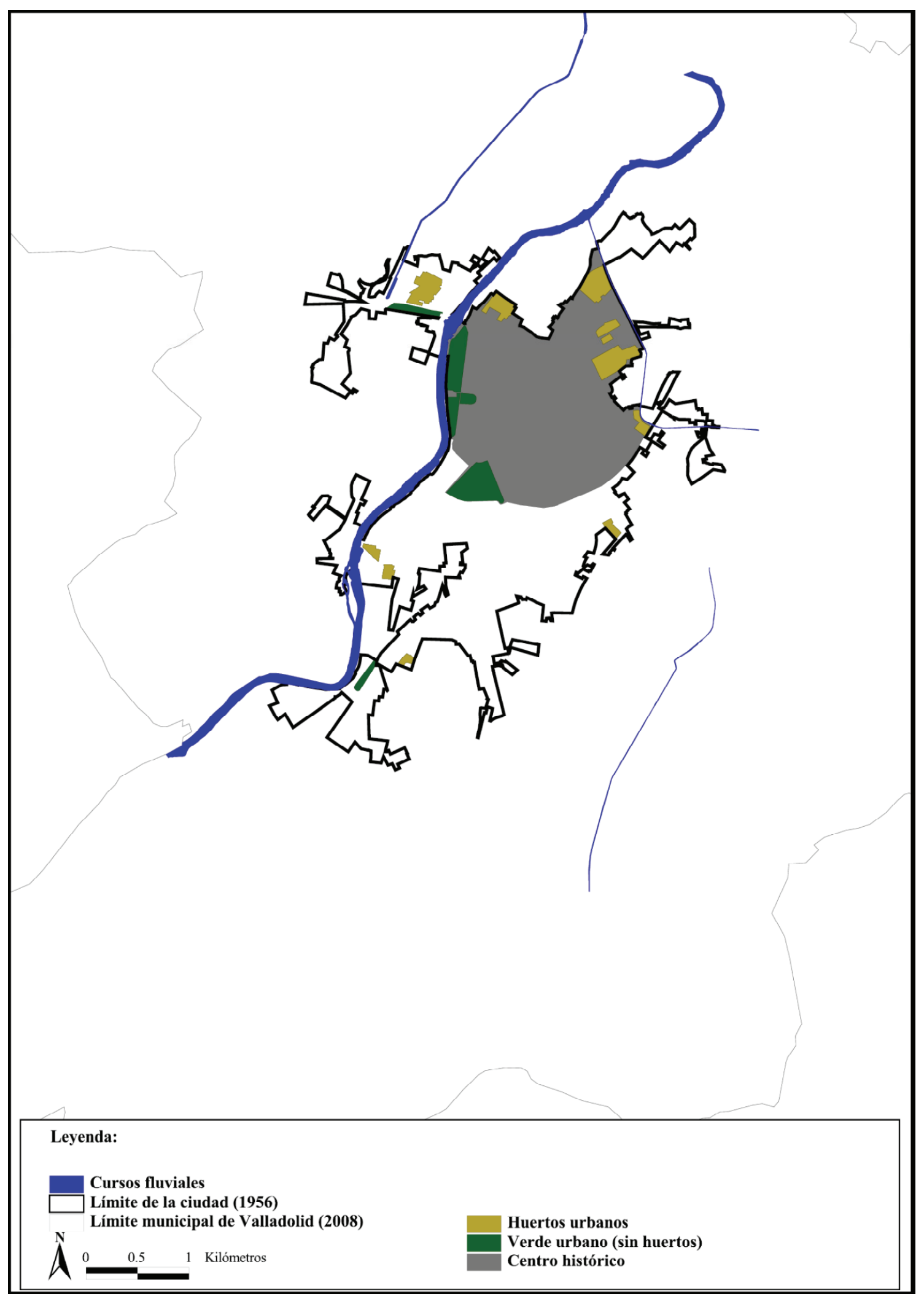

Fuente: elaboración propia a partir de la fotografía aérea de 1956 del IGE. 


\section{iii) Recapitulación}

En 1950 Valladolid contaba con 124.212 habitantes y tan solo 30,3 ha de verdes urbanos disponibles (ver Tabla 4.3.3), lo que implica que a cada habitante le correspondían 2,44 $\mathrm{m}^{2}$. La superficie de verde urbano era aproximadamente el doble (63,6 ha) debido a la gran cantidad de huertos presentes en una ciudad todavía no muy extensa pero sí con numerosos espacios abiertos, que en suma representaban un $8,2 \%$ de la superficie urbana $\left(820,64 \mathrm{~m}^{2} / \mathrm{ha}\right)$.

Tabla 4.3.3 Principales indicadores del verde urbano de Valladolid en 1956.

\begin{tabular}{|c|c|}
\hline & 1956 \\
\hline $\mathbf{N}^{\circ}$ espacios verdes & 14 \\
\hline $\mathrm{N}^{\circ}$ huertos urbanos & 9 \\
\hline $\mathrm{N}^{\circ}$ espacios verdes $\sin$ huertos & 5 \\
\hline $\mathbf{N}^{0}$ espacios verdes disponibles & 5 \\
\hline $\mathrm{N}^{0}$ habitantes & 124.212 \\
\hline Extensión de la ciudad (ha) & 775,3 \\
\hline Extensión del verde (ha) & 63,6 \\
\hline Extensión de los huertos urbanos (ha) & 33,3 \\
\hline Extensión del verde sin huertos (ha) & 30,3 \\
\hline Extensión del verde urbano disponible (ha) & 30,3 \\
\hline Densidad de verde $\left(\mathrm{m}^{2} / \mathrm{hab}\right)$ & 5,12 \\
\hline Densidad verde $\sin$ huertos $\left(\mathrm{m}^{2} / \mathrm{hab}\right)$ & 2,44 \\
\hline Densidad del verde urbano disponible $\left(\mathrm{m}^{2} / \mathrm{hab}\right)$ & 2,44 \\
\hline Densidad verde por superficie $\left(\mathrm{m}^{2} / \mathrm{ha}\right)$ & 820,64 \\
\hline Densidad del verde urbano disponible por superficie $\left(\mathrm{m}^{2} / \mathrm{ha}\right)$ & 391,10 \\
\hline
\end{tabular}

\subsubsection{Crecimiento de la ciudad hasta la aprobación del PGOU de 1984}

Desde mediados del siglo XX Valladolid experimentó un constante crecimiento económico que se prolongará hasta la década de los ochenta, vinculado mayoritariamente a la actividad fabril. En 1950 se instaló en el norte de la ciudad ENDASA, empresa del sector del aluminio, y en 1951 lo hizo FASA en la periferia sur, dedicada a la fabricación de automóviles Renault, en lo que supone el comienzo del intenso proceso industrial que se extenderá durante la década de los sesenta y especialmente de los setenta. Paralelamente la ciudad sufrirá un impresionante crecimiento demográfico que la convierte entre 1960 y 1980 en el núcleo urbano con mayor capacidad de atracción de inmigrantes en Castilla y León (Calderón et al., 1992).

\section{i) Expansión urbana}

El Plan Cort fue notablemente modificado con la intención de controlar el crecimiento desmedido, pero este objetivo se abandonó en 1959 cuando se reanudó la expansión urbana y la reforma del centro histórico a través de los Proyectos de Reforma Parcial de Alineaciones. Con esta figura, al contrario que con el planeamiento de desarrollo, se modificó el uso del suelo establecido por el Plan General, así como los volúmenes y las alturas (García, 2000). De esta manera, se comprende por qué buena parte de los parques y jardines contemplados en dicho documento no llegaron a realizarse o se redujeron sensiblemente. El fuerte crecimiento económico y demográfico provocó que en 1971 Valladolid alcanzase una extensión de 1.277,9 ha (ver Figura 4.3.6), con un incremento del $60 \%$ en un periodo de quince años. La mayor parte del crecimiento en el norte de la ciudad se realizó mediante Proyectos de Reforma Parcial de Alineaciones, creando barrios como la Rondilla (9) y consolidando otros como el Barrio España (22) o La Victoria (31) en la orilla derecha del Pisuerga. En el sur se urbanizó por completo el barrio Cuatro de Marzo (27), se fue progresivamente colmatando el barrio de las Delicias (19) y, como ya se apuntó con 
anterioridad, en La Rubia (40) los planes de crear un barrio ajardinado fueron transformados para poder levantar bloques de edificios. Este instrumento permitió actuaciones puntuales en el centro histórico de la ciudad que terminaron por destruir buena parte del patrimonio heredado y propició un fuerte crecimiento en el este de la ciudad, en barrios como Pajarillos Bajos (17), mientras que proliferaba la autoconstrucción en Las Flores (34), en Pajarillos Altos (18) y en el sur de la ciudad, en torno a la Cañada Real (37). La expansión en dirección occidental experimentó un notable impulso con la aprobación en 1963 de la primera fase de Huerta del Rey (21), proyectada ya a través de planeamiento parcial, en lo que supone una ruptura con la forma de hacer ciudad al delimitar los usos del suelo y reservar una parte del mismo para equipamientos y zonas verdes.

En 1959 el país comenzó una nueva etapa en la que se proyectó un crecimiento económico intensivo a través de Planes de Desarrollo, con una duración de cuatro años cada uno. Esta política persiguió un desarrollo regional con el que superar la concentración y la polarización económica y de población en determinadas regiones, para lo que se crearon los Polos de Desarrollo y de Promoción industrial. Valladolid fue declarada Polo de Desarrollo dos veces, desde 1964 hasta 1971, debido a que las actuaciones se centraron mayoritariamente en zonas con bajo nivel de renta, pero que ya contaran con un tejido industrial consolidado (Cebrián, 2009), ofreciendo incentivos para las empresas privadas. Desde comienzos de la década de los cincuenta se habían instalado en la ciudad grandes empresas como ENDASA, situada en el meandro norte del Pisuerga, o FASA, situada en torno a la Avenida de Madrid. Esta última había comenzado la fabricación de automóviles Renault en 1951, aprovechando la abundante mano de obra en el sector metalúrgico que había en Valladolid desde que a mediados del siglo XIX se instalaron los talleres de RENFE y también la estratégica localización de la ciudad entre Madrid y el norte industrial del país, con los que tenía buenas conexiones por ferrocarril y carretera, así como la disponibilidad de una densa red de energía eléctrica (Calderón et al., 1992) y la existencia de capitales locales y de inversores del exterior. Durante la etapa autárquica se habían definido las tendencias sectoriales de la industria en Valladolid y en 1959 la actividad fabril de la ciudad estaba concentrada en los sectores de los transformados metálicos y de la automoción (Cebrián, 2008). Con el objetivo de encauzar la posible actividad industrial generada por los Polos de Desarrollo, se aprobó la creación del polígono de Argales (24), que solo estuvo preparado en 1968, del polígono de San Cristóbal (36), que no se concluyó hasta 1977, y posteriormente de El Cabildo I y El Cabildo II, situados en La Victoria (31). Con la excepción de Michelin, instalada en estos últimos, los polígonos industriales no fueron capaces de atraer grandes empresas debido a sus reducidas dimensiones y al elevado precio del suelo, por lo que las factorías prefirieron buscar suelo a menor precio fuera de los mismos. La mayor parte de la inversión realizada durante la vigencia del Polo fue destinada a las empresas vinculadas al sector de la automoción, concretamente el 59,7\%, con FASA a la cabeza, al igual que ocurrió con los casi 10.000 nuevos puestos de trabajo (Calderón et al., 1992).

La expansión industrial producida por la instalación del Polo de Desarrollo contribuyó a fortalecer las empresas instaladas anteriormente y permitió que la ciudad creciese a un ritmo anual del 4,1\% (García, 2000), de tal manera que entre 1950 y 1970 la población de Valladolid se dobló. Buena parte de este crecimiento se debió al saldo migratorio, principalmente de emigrantes de núcleos rurales de la misma provincia (ver Figura 4.3.4). Concretamente el $61,2 \%$ del aumento de población registrado entre 1960 y 1975 tuvo este origen, aunque un tercio del mismo procedía de las provincias de Palencia, Zamora y de León (Calderón et al., 1992). Con el objetivo de encauzar la expansión de Valladolid ante la masiva llegada de población inmigrante, se elaboró el Plan General de Ordenación Comarcal de 1969, que incluía reservas de suelo para sistemas generales de acuerdo con las directrices de la Ley del Suelo de 1956 (García, 2000). Este autor señala que la influencia de este texto no se limitaba a la ciudad tradicional, sino que proponía un modelo 
de crecimiento en dirección a los espacios libres del sur y del oeste del municipio, puesto que el norte y el este estaban cerrados por un cinturón industrial que limitaba el crecimiento en esas direcciones. En el polígono industrial de El Cabildo (31) se instaló en 1972 la factoría de Michelin, en un espacio destinado a espacios verdes y deportivos, mostrando así la supeditación de la planificación urbana a las presiones de las grandes empresas industriales (Calderón et al., 1992). Se consolidó así un cerco industrial de distinta amplitud en forma de abanico que rodeaba aproximadamente la mitad oriental de la ciudad, desde el Pisuerga hasta el polígono de Argales (24).

En las proximidades del perímetro urbano se fueron aprobando varios planes parciales en los que se redujo al máximo el suelo destinado a sistemas generales, especialmente el dedicado a espacios verdes (García, 2000). En 1984 se habían colmatado los espacios urbanos situados al norte de la ciudad en La Victoria (31) y en la Rondilla (9) y continuaba la expansión en la margen derecha del Pisuerga con nuevas fases de la Huerta del Rey (21) (ver Figura 4.3.7). Este último barrio junto con Parquesol (38), cuyo Plan Parcial fue aprobado en 1977, y con Arturo Eyries, construido por el Instituto Nacional de la Vivienda en 1971, se caracterizan por una densidad edificatoria menor y por una mayor superficie de uso público, acorde con los presupuestos de la segunda Ley del Suelo de 1976 (Calderón y Delgado, 1993). Al mismo tiempo el centro histórico sufrió un intenso proceso de destrucción del antiguo caserío y de sustitución por vivienda en altura, cuya violencia queda reflejada en el siguiente dato: entre 1970 y 1974 el 63\% de la construcción total de viviendas y oficinas del municipio se realizó en este espacio (Calderón et al., 1992). El Paseo Zorrilla (3) se convirtió progresivamente en una prolongación del centro histórico conectando con la Calle Santiago mediante la Plaza Zorrilla y prolongándose por el límite occidental de Campo Grande (V-1) hasta el Centro Comercial El Corte Inglés, inaugurado en 1988. También tomarán cierta relevancia el Paseo de Isabel la Católica, junto a la Rosaleda Francisco Sabadell y Parque de Poniente (V-2) y al Parque de las Moreras (V-3), en el barrio del Centro (1), donde se levantaron numerosos bloques de viviendas.

\section{ii) Espacios verdes en 1956 y 1984}

Desde 1956 hasta 1984 la ciudad de Valladolid experimentó un crecimiento demográfico y territorial sin precedentes puesto que los valores de partida casi se triplicaron en algo menos de treinta años (ver Tabla 4.3.4). Sin embargo, esto no se tradujo en un incremento proporcional de la extensión y del número de espacios verdes, debido a que hasta que no se aprobó el Plan Comarcal de 1969 no se comenzó a realizar un planeamiento urbano con reservas de suelo para equipamientos y espacios verdes conforme con la Ley del Suelo de 1956. La Figura 4.3.6 es una muestra evidente de los enormes déficits en zonas verdes experimentados a mediados del periodo analizado en la ciudad de 1971, que prácticamente duplicaba en extensión y en habitantes a la de 1956, donde únicamente había aparecido un nuevo verde urbano disponible, la ribera del Pisuerga junto al Puente Colgante (V41). La extensión total de este tipo de espacios era de 30,8 ha para una población de 236.341 habitantes, lo que suponía una raquítica densidad de $0,48 \mathrm{~m}^{2}$ por habitante. Además se incorporó el Colegio de San Agustín (V-40) como verde urbano no disponible en el sur de la ciudad, junto al polígono de Argales (24), pero el número y la extensión de los huertos urbanos se redujeron sensiblemente motivando una caída de los valores totales del verde urbano (44,2 ha). Conviene señalar que sobre zonas calificadas como espacios verdes o áreas agrícolas se fueron levantando numerosos polígonos de viviendas como el Cuatro de Marzo (27) o el de Jesús Aramburu (36), o simplemente desaparecieron al elaborarse los Proyectos de Reforma Parcial de Alineaciones como ocurrió con los situados en Vadillos (12) o en San Pedro Regalado (33) (García, 2000). 
Figura 4.3.6 Verde urbano de la ciudad de Valladolid en 1971.

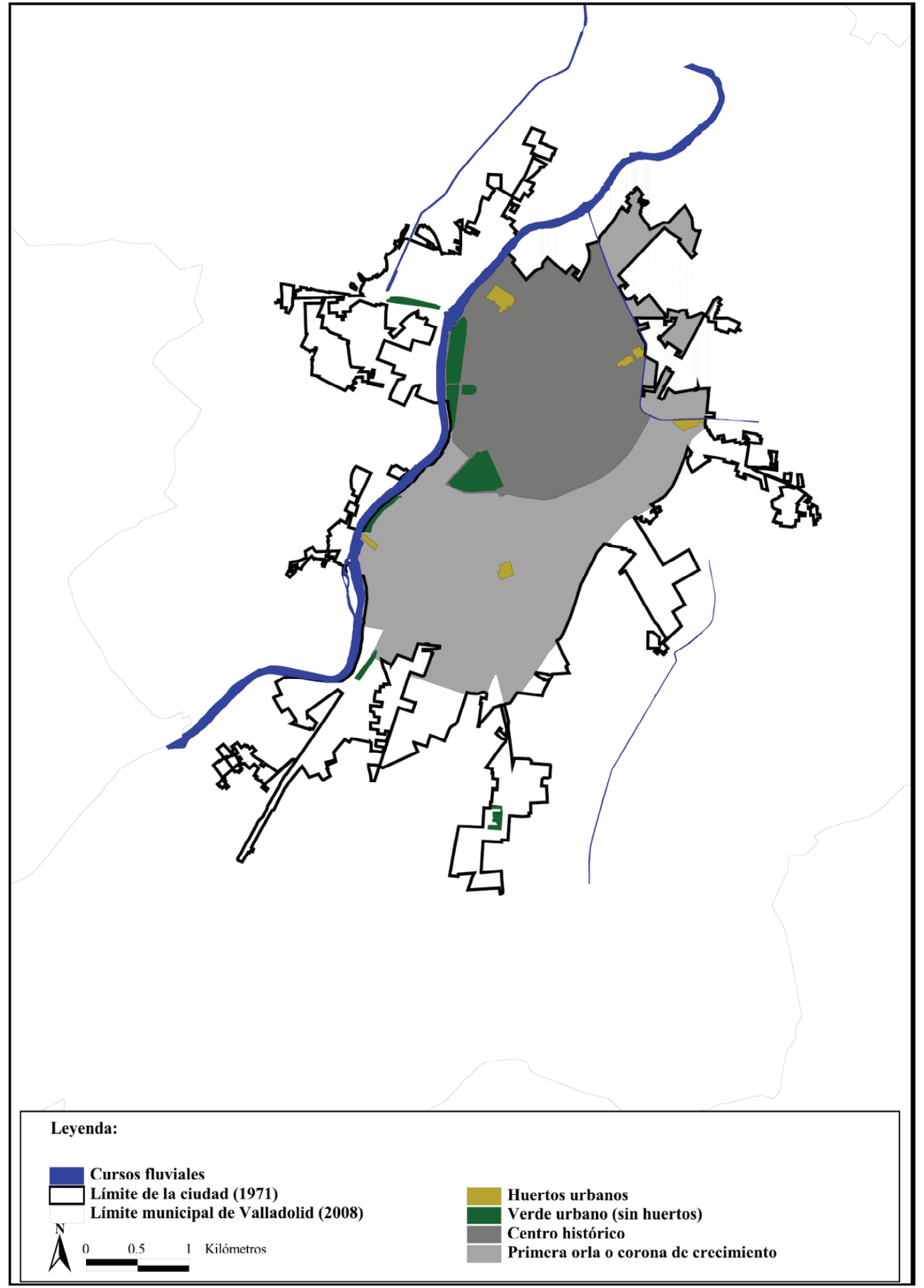

Fuente: elaboración propia a partir de la fotografía aérea de 1971 del IGN. 
Figura 4.3.7 Verde urbano de la ciudad de Valladolid en 1984.

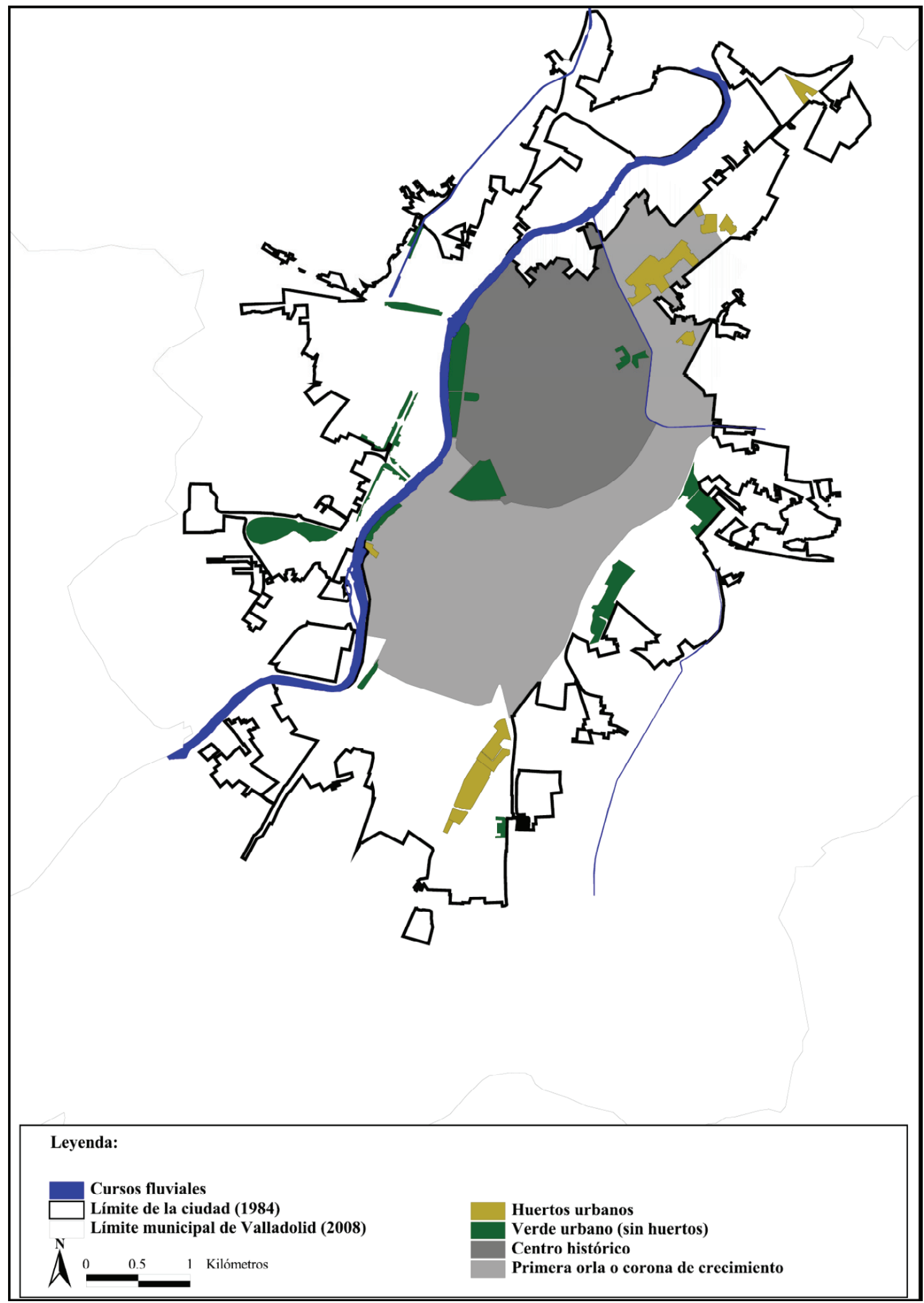

Fuente: elaboración propia a partir de la fotografía aérea de 1984 del IGN. 
La dinámica seguida por los huertos urbanos es diferente a la del resto de zonas verdes, puesto que se van incorporando con el crecimiento periférico de la ciudad, para desaparecer posteriormente al quedar confinados en el interior de la ciudad y convertirse en suelo susceptible de ser urbanizado. Valladolid ha ido generando una corona de la que desaparece la actividad agraria para ser sustituida por los llamados "barbechos sociales" (González, 1985). En 1956 eran nueve los huertos urbanos, descendiendo a seis en 1971 y en 1984, aunque en esta última fecha la superficie cultivada aumentará en cerca de treinta hectáreas. En ese último año la agricultura urbana se concentraba mayoritariamente en la periferia de la ciudad, con la excepción del pequeño huerto junto al estadio de fútbol de Zorrilla. Un amplio terreno de huertas en San Pedro Regalado (33) superaba las catorce hectáreas y siguiendo hacia el norte se encontraba un pequeño grupo de huertos junto al cementerio y otro más en el límite urbano junto a la azucarera de ACOR. También tenía una entidad notable el grupo de espacios agrícolas situado en los Páramos de San Isidro (35), con cerca de diez hectáreas, así como los huertos situados en el espacio residual entre el polígono de Argales (24), el de San Cristóbal (36) y la factoría de FASA, cuya superficie total supera las diecisiete hectáreas.

Los huertos urbanos representaban el 34,7\% de la trama verde de 1984, a la que se habían incorporado seis nuevos verdes urbanos disponibles (ver Figura 4.3.7), duplicando también su extensión al incorporar a la ciudad grandes espacios verdes como el verde urbano Mirador de Parquesol (V-31), construido en las primeras fases de dicho barrio (38). La primera fase de Huerta del Rey comenzó en 1963 y sucesivamente se fueron aprobando otras hasta su finalización en la década de los noventa. Este barrio representaba una ruptura con lo construido hasta entonces en Valladolid: desapareció la retícula de las calles y surgió una gran cantidad de espacios verdes entre los bloques de viviendas (Calderón y Delgado, 1993). En 1984 ya se habían completado seis hectáreas de verde disponible en este nuevo barrio y en la margen derecha del Pisuerga se incorporaron a la ciudad las Dársenas del Canal de Castilla (V-7). En el límite sureste surgió un espacio verde de notable magnitud, el Parque de Canterac (V-21), que ya aparecía en el Plan de Cesar Cort, junto al Parque de San IsidroFuente de la Salud (V-22) y al Club Militar San Isidro (V-23), perteneciente al ejército y que en este periodo es integrado al continuo urbano. Estas actuaciones pretendían aplacar las fuerte carencias en materia de espacios verdes en algunos de los barrios creados durante los periodos de mayor crecimiento, tales como Pajarillos Altos (18) y Bajos (17), Las Flores (34), Páramos de San Isidro - Campo de Tiro (35), Caamaño - Las Viudas - Polígono San Cristóbal (36) y Delicias (19), pero la colmatación de algunos de estos obligó a realizar actuaciones junto a los límites de los mismos. Por último hay que señalar la aparición en 1984 de las primeras tres hectáreas del verde urbano del Campus de la Universidad de Valladolid junto al Esgueva (V-26).

\section{iii) Recapitulación}

Durante el periodo estudiado se observan dos tendencias claramente diferenciadas: entre 1956 y 1971 se produce un descenso muy significativo de todos los índices relacionados con el verde urbano, siendo muy llamativo el experimentado por el verde urbano disponible por habitante que se sitúa en $1,30 \mathrm{~m}^{2}$. Como la extensión de los huertos urbanos también se redujo sensiblemente, en 1971 solamente un 3,46\% del territorio de Valladolid estaba compuesto por zonas verdes $\left(345,72 \mathrm{~m}^{2} / \mathrm{ha}\right)$. Durante los siguientes catorce años se trataron de corregir algunas carencias muy significativas, especialmente en los barrios más poblados del sureste de la ciudad y se incorporó definitivamente la reserva de suelo para espacios verdes en las nuevas piezas urbanas. Se asiste así a una recuperación de la mayoría de los índices estudiados de la mano del verde urbano disponible, que no fue más intensa debido 
a que en este periodo la ciudad experimentó un crecimiento demográfico y territorial muy intenso.

Tabla 4.3.4 Principales indicadores del verde urbano de Valladolid durante el período 1956-1984.

\begin{tabular}{|c|c|c|c|}
\hline & 1956 & 1971 & 1984 \\
\hline $\mathrm{N}^{\circ}$ espacios verdes & 14 & 13 & 20 \\
\hline $\mathrm{N}^{\circ}$ huertos urbanos & 9 & 6 & 6 \\
\hline $\mathrm{N}^{\circ}$ espacios verdes $\sin$ huertos & 5 & 7 & 14 \\
\hline $\mathrm{N}^{\circ}$ espacios verdes disponibles & 5 & 6 & 12 \\
\hline$N^{\circ}$ habitantes & 124.212 & 236.341 & 330.242 \\
\hline Extensión de la ciudad (ha) & 775,3 & $1.277,9$ & $2.100,1$ \\
\hline Extensión del verde (ha) & 63,6 & 44,2 & 118,7 \\
\hline Extensión de los huertos urbanos (ha) & 33,3 & 11,4 & 41,2 \\
\hline Extensión del verde sin huertos (ha) & 30,3 & 32,8 & 77,5 \\
\hline Extensión del verde urbano disponible (ha) & 30,3 & 30,8 & 68,7 \\
\hline Densidad de verde ( $\left.\mathrm{m}^{2} / \mathrm{hab}\right)$ & 5,12 & 1,87 & 3,59 \\
\hline Densidad verde sin huertos $\left(\mathrm{m}^{2} / \mathrm{hab}\right)$ & 2,44 & 1,39 & 2,35 \\
\hline Densidad del verde urbano disponible $\left(\mathrm{m}^{2} / \mathrm{hab}\right)$ & 2,44 & 1,30 & 2,08 \\
\hline Densidad verde por superficie $\left(\mathrm{m}^{2} / \mathrm{ha}\right)$ & 820,64 & 345,72 & 565,01 \\
\hline Densidad del verde urbano disponible por superficie $\left(\mathrm{m}^{2} / \mathrm{ha}\right)$ & 391,10 & 240,79 & 326,94 \\
\hline
\end{tabular}

Fuente: elaboración propia a partir del SGE, del IGN y del INE.

\subsubsection{Evolución urbana en democracia: PGOU 1984, 1997 y 2003.}

Desde la aprobación del primer Plan General en democracia se ha asistido a un crecimiento más equilibrado de la ciudad, en el que de manera rigurosa se incluyeron equipamientos y dotaciones de acuerdo a la legislación urbanística existente en cada momento. Este es el periodo de mayor crecimiento de la trama verde de Valladolid, debido a que los nuevos barrios nacen con importantes reservas de suelo destinadas a estos espacios. En 1992 se elaboró el PECH (Plan Especial del Casco Histórico de Valladolid), modificado en 1997 para adaptarlo al nuevo PGOU, con el objetivo de frenar el impulso destructivo experimentado en las últimas décadas, que supuso una pérdida monumental de notables consecuencias en el centro de la ciudad, y de recuperar este espacio tanto social como urbanísticamente.

\section{i) Expansión urbana con el PGOU de 1984}

El Plan General de 1984 fue impulsado por la corporación municipal elegida tras la llegada de la democracia para gestionar una urbe con una extensión de 2.100 hectáreas, en la que residían 330.242 habitantes. Era necesario solucionar problemas tales como la carencia de colegios o de zonas verdes y la protección del patrimonio edificado, puesto que el diseño de la ciudad obedecía a intereses privados sin que el planeamiento hubiera llegado a imponerse por completo. A lo largo de la década de los ochenta la población de la capital se fue estabilizando y paralelamente se fue expandiendo el fenómeno urbano por los municipios más próximos, como ya se señaló en el primer punto de este capítulo. Entre 1981 y 2011 el número de efectivos demográficos del municipio central de la aglomeración urbana se redujo en 16.805 habitantes, sin que esto supusiera un freno de la expansión territorial, que duplicó su superficie en el periodo 1984-2008 alcanzando las 4.027,5 ha. Con la instauración del Estado de las autonomías y la aprobación del Estatuto de Autonomía de Castilla y León en 1983, Valladolid se convirtió en sede de las principales instituciones de la Comunidad Autónoma y se vio obligada a destinar una parte del nuevo suelo urbano a edificios de la administración. Además, el impulso experimentado por las universidades españolas dejó su huella: el nuevo PGOU proyectó el Campus Miguel Delibes en el noreste de la ciudad, concretamente en el barrio de Belén (23) (García, 2000). Con la entrada en vigor del PGOU de 1984 se paralizó temporalmente la actividad constructiva de la ciudad con la excepción de 
la segunda fase de la Huerta del Rey (21) y del Plan Parcial Parquesol (38) aprobado en 1977 y que, debido a su amplísima superficie, no se completó hasta bien entrado el siglo XXI. Se trató de poner freno al crecimiento descontrolado en dirección sur, impulsando la expansión urbana hacia el este, conjugando los diferentes usos del suelo urbano y atenuando los usos exclusivos. Sin embargo, la Figura 4.3.8 muestra cómo este objetivo no se cumplió, puesto que durante este periodo se pusieron las bases para el fuerte crecimiento sur de la ciudad con la aprobación de cinco planes parciales en el barrio de Covaresa (37): Valparaíso, Santa Ana, Villas Norte, Parque Alameda y Paula López, que se extienden de forma continua desde el Pisuerga hasta el polígono de Argales (24).

Durante los últimos años de la década de los setenta y los primeros de la década de los ochenta la actividad industrial de Valladolid experimentó un fuerte proceso de reconversión. Desaparecieron numerosos puestos de trabajos en un periodo en que la actividad fabril de la ciudad estaba muy polarizada, con el 75\% de los empleos concentrados en el sector de los transformados metálicos, en sus diversas ramas (Calderón et al., 1992). Desde mediados de la década de los ochenta se percibió la necesidad de incrementar el suelo industrial existente, por lo que se construirá, antes de aprobarse el PGOU de 1997, el polígono de El Cabildo II en el noroeste de la ciudad, concretamente en La Overuela Navabuena - El Berrocal (32). Durante este periodo se instalan en la ciudad grandes superficies comerciales no solo para dar servicio a la propia ciudad, sino con una proyección supraprovincial, cuyo mayor ejemplo es el ya citado El Corte Inglés, inaugurado en 1988 en el Paseo Zorrilla, junto a los terrenos del antiguo campo de fútbol.

La mayor parte de las grandes industrias instaladas en Valladolid se situaron en áreas de borde urbano junto a las principales vías de comunicación. Unidas a los polígonos industriales planificados provocaron la creación de un anillo industrial de distinto espesor desde el noroeste hasta el sur, convirtiéndose en una barrera urbana que condicionó la expansión territorial de la ciudad (Calvo y Rivas, 1995). Por otra parte, los grandes equipamientos comerciales han ido apareciendo de acuerdo a criterios estrictamente económicos, provocando una gran concentración de este tipo de establecimientos en el centro, sur y oeste de la ciudad. Las grandes superficies comerciales se instalaron en las nuevas zonas residenciales, reforzando las estrategias inmobiliarias de los grupos que controlaban las bolsas de suelo urbanizable en la ciudad (Calderón y García, 2006), de los que son buena muestra los barrios de Parquesol (38) con Parquesol Plaza, o en Las Villas Cañada Puente Duero - Covaresa - Parque Alameda - Paula López (37) con el Centro Comercial Vallsur. La expansión superficial de la ciudad entre 1984 y 2001 se debe, además de a la anexión del Polígono de San Cristóbal, al fuerte crecimiento de los dos barrios anteriormente señalados y a la aprobación de planes parciales como el de La Victoria (31) o el del Soto de Medinilla, en el barrio de San Pedro Regalado (33). Este proceso está asociado al incremento del precio de las viviendas en el centro de la ciudad y a la búsqueda de alojamientos más baratos en los nuevos barrios de la ciudad o en municipios pertenecientes al área urbana de Valladolid, en los que se construyeron 12.471 viviendas entre 1991 y 2001 (Calderón y García, 2006). Además se rellenaron vacíos urbanos junto al centro de la ciudad, en la margen derecha del Pisuerga, concretamente en el barrio Arturo Eyries (29), con la aprobación en 1992 del Plan Parcial El Palero, en el que se proyectó el Museo de la Ciencia sobre la antigua fábrica de harinas del mismo nombre.

\section{ii) Expansión urbana con el PGOU de 1997}

El Plan General de 1997 se planteó como una adaptación del anterior a la Ley del Suelo de 1990, continuando así con sus principales líneas de actuación. Durante su periodo de vigencia no se consiguió detener el proceso de sustitución del caserío tradicional del centro histórico, aunque sí se consiguió avanzar en la configuración de la ronda interior, con 
la construcción del Puente de Hispanoamérica en 1999, y en el afianzamiento de las áreas industriales. Se continuó con el proceso de dotación de equipamientos urbanísticos en los barrios surgidos en el periodo de mayor crecimiento durante la década de los sesenta y setenta, aunque al tratarse de espacios colmatados, fue extremadamente difícil construir estas instalaciones en su interior y en muchos casos tuvieron que situarse en sus bordes (García, 2000). Este es el caso del sector de la Ribera de Castilla entre la Rondilla (9) y el Barrio España (22), donde se proyectó el espacio verde de mayores dimensiones de la ciudad. Valladolid creció con fuerza en dirección oeste y sur, incorporando todo tipo equipamientos y elementos dotacionales de acuerdo con la ley vigente al ejecutar los nuevos sectores del barrio de Covaresa (37). Este Plan General es un fiel reflejo del urbanismo español en el ciclo inmobiliario expansivo de la década 1996-2006, anterior por tanto a la crisis económica, ya que preveía la construcción en el municipio de Valladolid de 161.900 viviendas, lo que representaba un 35\% más de las existentes en ese año (Sánchez, 2012).

\section{iii) Expansión urbana con el PGOU de 2004}

El plan se adaptó en 2004 a la Ley de Urbanismo de Castilla y León de 1999 y en ese mismo año se aprobó el Plan Integral de Movilidad Urbana de Valladolid. Durante su periodo de aplicación se asistió a un notable crecimiento en el este de la ciudad y a la expansión en dirección oeste de los barrios de Las Villas - Cañada Puente Duero - Covaresa Parque Alameda - Paula López (37), de Parquesol (38) y de Girón - Villa del Prado (30). En este último se ha desarrollado la urbanización del Plan Parcial Villa del Prado, incorporando dos grandes equipamientos como son el edificio de las Cortes de Castilla y León y el Auditorio Miguel Delibes, junto a los que se planificaron dos verdes urbanos.

La mayor parte del suelo urbanizado en estos últimos años se ha concentrado en los bordes del PECH y en los barrios orientales de la ciudad como Pilarica (16), Pajarillos Altos (18), Las Flores (34), Páramos San Isidro - Campo de Tiro (35) y en Caamaño - Las Viudas Polígono San Cristóbal (36), con promociones en este último como Residencial Pinar Jalón, en el que el $20 \%$ del suelo tenía carácter industrial. Sin embargo, los nuevos sectores del sur y oeste de la ciudad cuentan con una población más joven, mientras que el centro, este y norte presentan una estructura demográfica notablemente envejecida (Calderón y Pascual, 2006). Durante este periodo, los ayuntamientos de Valladolid y del resto del área urbana iniciaron una carrera en la que se ofertaba gran cantidad de suelo urbano (Sánchez, 2012). Ya desde de la década de los ochenta se asistió a una periurbanización no solo residencial, sino vinculada con actividades económicas y de ocio, y algunos municipios llegaron a unirse físicamente con la ciudad. Desde 1987 hasta el año 2000 se había ocupado un 50\% más de suelo urbanizado en torno a la capital y en la última década, entre Valladolid y los municipios periféricos, sumaban en conjunto suelo clasificado para más de 100.000 viviendas (Sánchez, 2012). Este fenómeno no se redujo únicamente al suelo urbano, sino que se hizo extensivo al de uso industrial, provocado un aumento del suelo edificado en el área urbana de Valladolid. El PGOU 2004 hacía frente a la falta de suelo industrial en el municipio central proyectando una gran cuña en el noreste de la ciudad que enlazaría con la zona industrial de Santovenia de Pisuerga, de un tamaño total similar al polígono de Argales (24) (Calderón y Pascual, 2006). La falta de realismo de esta planificación se ha hecho evidente con la llegada de la crisis económica, demostrando el fuerte componente especulativo de este ciclo económico. Los municipios que integran el área urbana de Valladolid no han sabido coordinarse ni respetar el único documento de planificación existente como son las DOTVAENT y han alentado un crecimiento del número de viviendas que no se corresponde con el de potenciales compradores (Calderón y García, 2006). 


\section{iv) Evolución del verde urbano}

Durante el periodo de vigencia del PGOU de 1984 y de sus posteriores actualizaciones hasta 2008, surgieron treinta y seis nuevos espacios verdes, multiplicando por tres el número de verdes urbanos disponibles en apenas veinticinco años. El mayor crecimiento se concentró en los dos primeros tercios de este periodo (ver Figura 4.3.9) durante los que se terminaron de construir algunos de los verdes que ya aparecían en 1984 a medida que se urbanizaban las nuevas piezas urbanas, como ocurrió con el Campus Esgueva (V-26), el verde urbano Mirador de Parquesol (V-31) o el verde urbano Huerta del Rey (V-32). Aunque en el cómputo global el número de huertos urbanos se redujo entre 1984 y 2008, la superficie total era la misma. La evolución experimentada por el conjunto de parcelas agrícolas situadas junto al polígono de Argales (24) resulta paradigmática puesto que sufren una sensible reducción de su superficie hasta 2001 para comenzar su urbanización siete años más tarde a través del Plan Parcial Arcas Reales. Esta evolución es seguida por la mayor parte de los huertos urbanos pudiendo ser identificada en las parcelas situadas junto al cementerio (33), así como en las situadas en Páramos de San Isidro - Campo de Tiro (35) o en Covaresa (37) (ver Figura 4.3.10). En el Soto de Medinilla (33) los huertos han experimentado una reducción superficial cercana al 50\% en el periodo 2001-2008, anunciando una desaparición en una fecha no muy lejana.

Los nuevos sectores urbanos construidos durante el periodo estudiado, fueron incorporando importantes dotaciones en materias de espacios verdes, como ocurrió en el barrio de La Victoria (31) donde apareció el Jardín Botánico (V-6) junto a las Dársenas del Canal de Castilla (V-7), y el verde urbano Camino del Cabildo (V-5) en las proximidades del río. También en la zona norte, pero en la margen izquierda del Pisuerga, se proyectó el espacio verde de mayores dimensiones de la ciudad, el Parque Ribera de Castilla (V-4), con el objetivo de dar servicio a barrios de la zona norte de la almendra central y a algunos creados durante la fase de mayor crecimiento como el Barrio España (22) o San Pedro Regalado (33). En el límite nororiental se completaron los espacios verdes del Campus del Esgueva (V-26) y del Campus Miguel Delibes (V-27) y en el barrio más poblado de la ciudad, Delicias (19), se construyó el Parque de la Paz (V-21) antes de 2001.

A comienzos del siglo XXI surgieron en el sur de la ciudad ocho nuevos verdes urbanos entre los que se localizaban dos huertos desaparecidos en 2008: uno situado en la margen izquierda del Pisuerga y otro en el Polígono de Argales (24). De estos, dos forman parte de la categoría del verde urbano no disponible: el verde urbano del Colegio de San Agustín (V-40), ubicado en la carretera de Madrid junto a las instalaciones de Renault, y los jardines de la Presidencia de la Junta de Castilla y León (V-13), en Las Villas - Cañada Puente Duero Covaresa - Parque Alameda - Paula López (37), donde además se construyen cinco verdes disponibles y se prolongó otro ya existente: el Paseo Zorrilla Sur (V-28). En el Camino de la Esperanza (26), se situó la última de las nuevas áreas verdes surgidas en esta parte de la ciudad antes de 2001, concretamente el Parque Arturo León (V-18), y en la margen derecha del Pisuerga, en el barrio de Arturo Eyries (V-11) apareció un espacio verde con una superficie cercana a las cinco hectáreas. En Parquesol (38) se construyeron el Parque del Mediodía (V-9), con más de veinte hectáreas, el Parque del Reloj de Sol (V-35) y los verdes urbanos de la Calle Morelia (V-33) y de la Calle Juan de Valladolid (V-34), completados en el periodo 2001-2008, durante el que surgió también el parque de la ladera sur de ParquesolFuente de Dios (V-10). En Huerta del Rey (21) se consolidará el verde urbano del mismo nombre (V-32) alcanzando las 13,8 ha y en sus proximidades se planificaron la ribera de Huerta del Rey (V-37) y el verde urbano de la Calle Morena - Feria de Muestras (V-39). Al oeste de esta zona aparecieron dos verdes no disponibles junto al barrio Girón (30): el Cementerio de las Contiendas (V-8) y la Residencia de ancianos Cardenal Marcelo (V-43). 
Figura 4.3.8 Evolución del espacio urbano de Valladolid entre 1984 y 2008.

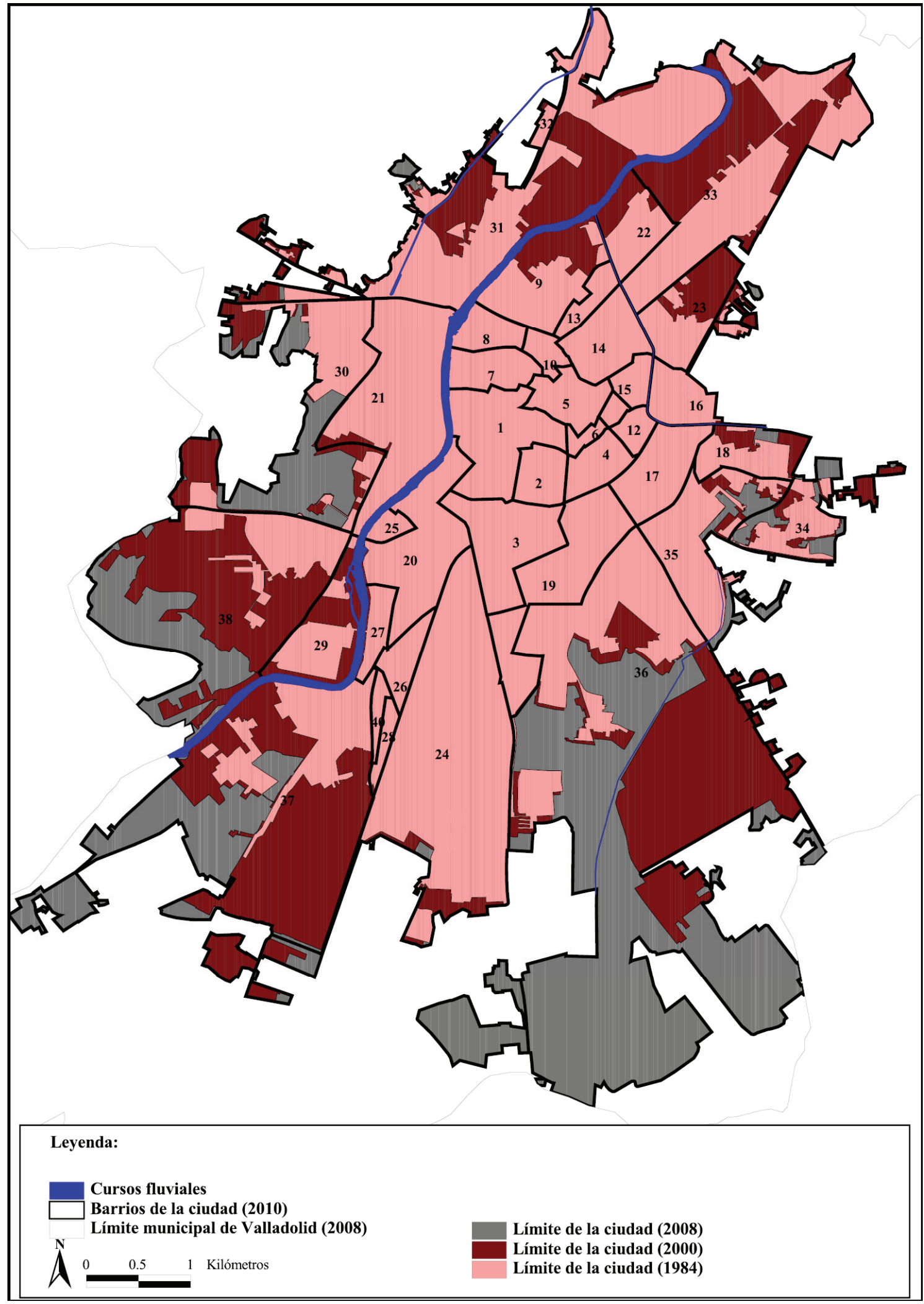

Fuente: elaboración propia a partir de la fotografía aérea de 1984, de las ortofotos de 2000 y 2008 del IGN y del Observatorio Urbano de Valladolid. 
Figura 4.3.9 Verde urbano de la ciudad de Valladolid en el año 2000.

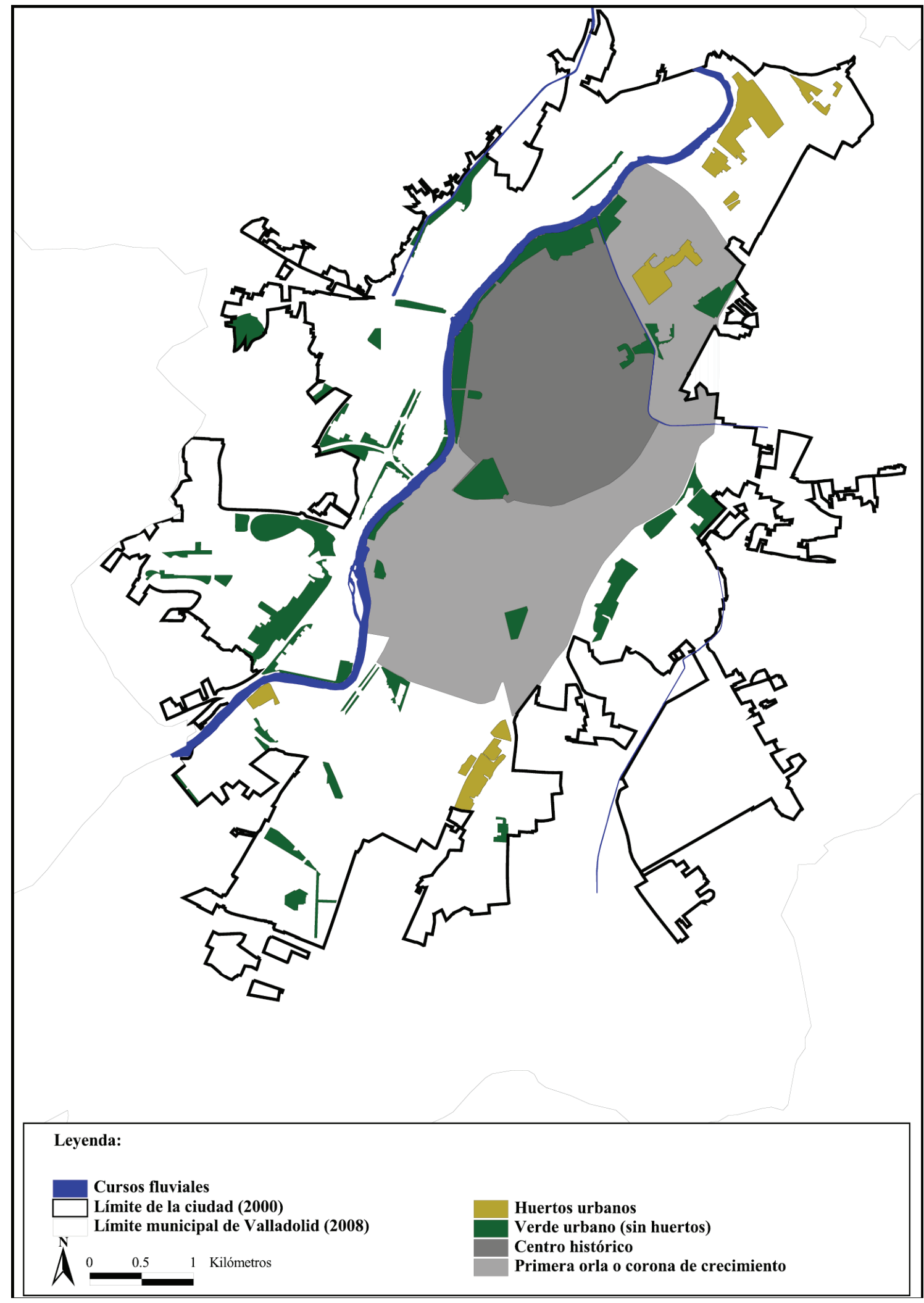

Fuente: elaboración propia a partir de la ortofoto de 2000 del IGN. 
Figura 4.3.10 Verde urbano de la ciudad de Valladolid en el año 2008.

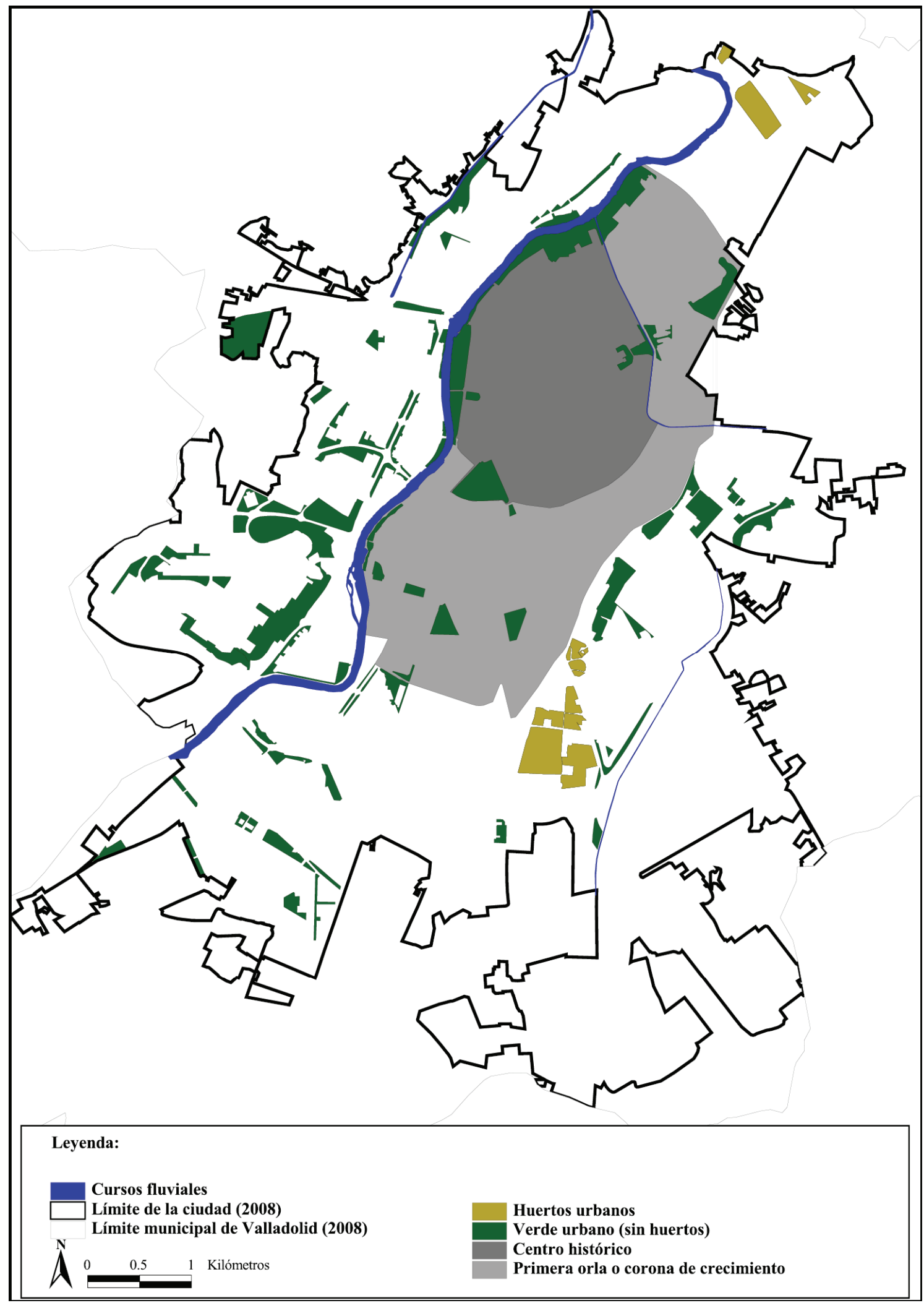

Fuente: elaboración propia a partir de la ortofoto de 2008 del IGN. 
Entre 2001 y 2008 se consolidaron algunos de los espacios verdes creados en el periodo anterior como el verde urbano Camino del Cabildo ( $\mathrm{V}-5)$ o el Jardín Botánico (V-6), junto al que se construirán los Jardines de La Victoria (V-44) (ver Figura 4.3.10). También aumentaron de tamaño el Parque Ribera de Castilla (V-4), el Campus Miguel Delibes (V-27) o el Parque de Canterac (V-21), así como el verde urbano Palacio de la Ribera (V-36), al que se incorporaron los jardines del edificio Duque de Lerma. En barrios ya consolidados como el Paseo Zorrilla (20) y el Polígono Argales (24), surgieron desde mediados de la década de los ochenta tres pequeños espacios verdes debido a tres actuaciones puntuales en el interior del tejido urbano. Por un lado se crearon el verde urbano Plaza Juan de Austria (V-38) entre el puente del mismo nombre y el Corte Inglés, por otro la Plaza del Ejército (V-42) sobre un parking subterráneo fruto de un convenio entre el Ayuntamiento, la Universidad y el Ejército, y por último el Parque de las Norias de Santa Victoria (V-19), en los terrenos de la antigua azucarera de Ebro, cedidos al ayuntamiento como espacios dotacionales. En el límite oriental de la ciudad se construyeron dos nuevas zonas verdes en sectores de nueva creación como son el verde urbano Ronda Este (V-24) y el verde urbano Barrio de la Esperanza (V45), mientras que en el sur de la ciudad van apareciendo pequeños espacios verdes a medida que se van ejecutando los distintos planes parciales. Este es el caso del verde urbano de la Calle Arribes del Duero (V-25), que aparece a través del Plan Parcial Zambrana, o del verde urbano Pinar de Jalón (V-46), en el sector del mismo nombre, ambos situados junto al polígono industrial San Cristóbal (36). Del mismo modo se crearon también el verde urbano Centro de Acústica (V-12) con el Plan Parcial de Santa Ana, el verde urbano Calle de la Vega de Valdetronco (V-47) con el de Villas Sur y el verde urbano Calle Alcaparra (V-49) con el de El Peral. Como ya se ha señalado, el Plan Parcial Villa del Prado incorporó dos grandes equipamientos junto a los que se planificaron sendos espacios verdes: el verde urbano de las Cortes de Castilla y León (V-29), con una extensión de nueve hectáreas, y el verde urbano Auditorio Miguel Delibes (V-30), con la mitad de superficie.

\section{v) Recapitulación}

Desde 1984 la trama verde de Valladolid ha crecido con mucha intensidad. Algunos parques surgieron con el objetivo de subsanar déficits generados durante las etapas de mayor crecimiento de la ciudad, pero la inmensa mayoría han aparecido de acuerdo a los criterios legales que establecen la presencia de espacios verdes en los nuevos sectores urbanos. En la Figura 4.3.10 se observa el estado de la trama verde vallisoletana en 2008, identificando cincuenta y cuatro espacios verdes de los que cinco eran huertos urbanos y cuarenta y cuatro formaban parte de la categoría de verde urbano disponible. Los principales indicadores aparecen reflejados en la Tabla 4.3.5 donde es posible observar que el conjunto de la trama verde supera en 2008 los 10,39 $\mathrm{m}^{2}$ de espacios verdes por cada habitante, aunque esa cifra es más reducida si se atiende únicamente al verde disponible $\left(7,93 \mathrm{~m}^{2} / \mathrm{hab}\right)$. Algunos de esos datos han sido complementados con otros referentes al número de viviendas promocionadas y al precio de la vivienda, para lo que se ha utilizado un indicador del Ministerio de Fomento referente a los precios medios por promoción, elaborando así la Tabla 4.3.6 y su representación en la Figura 4.3.11. En estos últimos siete años la población del municipio de Valladolid se redujo en más de 2.500 personas, mientras que la expansión territorial de la ciudad se incrementó notablemente, alcanzando un crecimiento acumulado cercano al 30\%. Este proceso no responde a necesidades reales de vivienda, sino que está fomentado por una fuerte tendencia especulativa que habría marcado los últimos años del ciclo inmobiliario expansivo previo a la crisis económica y cuyo reflejo se encuentra en el aumento mantenido del precio de la vivienda hasta mediados de 2007, cuando comienzan los efectos de la crisis económica y el desplome de la burbuja vinculada con el sector de la construcción. 
Tabla 4.3.5 Principales indicadores del verde urbano de Valladolid durante el período 1984-2008.

\begin{tabular}{|c|c|c|c|}
\hline & 1984 & 2001 & 2008 \\
\hline $\mathbf{N}^{\circ}$ espacios verdes & 18 & 42 & 54 \\
\hline $\mathrm{N}^{\circ}$ huertos urbanos & 7 & 6 & 5 \\
\hline $\mathrm{N}^{\circ}$ espacios verdes $\sin$ huertos & 11 & 36 & 49 \\
\hline $\mathbf{N}^{\circ}$ espacios verdes disponibles & 10 & 31 & 44 \\
\hline $\mathbf{N}^{\circ}$ habitantes & 330.242 & 319.129 & 318.461 \\
\hline Extensión de la ciudad (ha) & $2.100,1$ & $3.110,1$ & $4.027,5$ \\
\hline Extensión del verde (ha) & 107,8 & 260,4 & 331,0 \\
\hline Extensión de los huertos urbanos (ha) & 51,0 & 61,3 & 51,2 \\
\hline Extensión del verde sin huertos (ha) & 56,8 & 199,1 & 279,8 \\
\hline Extensión del verde urbano disponible (ha) & 55,3 & 178,3 & 252,5 \\
\hline Densidad de verde $\left(\mathrm{m}^{2} / \mathrm{hab}\right)$ & 3,26 & 8,16 & 10,39 \\
\hline Densidad verde $\sin$ huertos $\left(\mathrm{m}^{2} / \mathrm{hab}\right)$ & 1,72 & 6,24 & 8,79 \\
\hline Densidad del verde urbano disponible $\left(\mathrm{m}^{2} / \mathrm{hab}\right)$ & 1,68 & 5,59 & 7,93 \\
\hline Densidad verde por superficie $\left(\mathrm{m}^{2} / \mathrm{ha}\right)$ & 513,26 & 837,19 & 821,85 \\
\hline Densidad del verde urbano disponible por superficie $\left(\mathrm{m}^{2} / \mathrm{ha}\right)$ & 263,42 & 573,14 & 626,94 \\
\hline
\end{tabular}

Fuente: elaboración propia a partir del IGN y del INE.

Tabla 4.3.6 Crecimiento porcentual acumulado de las principales variables urbanas de Valladolid.

\begin{tabular}{|c|c|c|c|c|c|c|c|c|}
\hline Años & $\begin{array}{c}\text { Población } \\
\text { (habitantes) }\end{array}$ & $\begin{array}{c}\% \\
\text { acumulado }\end{array}$ & $\begin{array}{c}\text { Territorio } \\
\text { (ha) }\end{array}$ & $\begin{array}{c}\% \\
\text { acumulado }\end{array}$ & $\begin{array}{c}\text { Precio } \\
\text { vivienda } \\
\text { (euro/m } \mathbf{2}^{2}\end{array}$ & $\begin{array}{c}\% \\
\text { acumulado }\end{array}$ & $\begin{array}{c}\mathbf{N}^{\mathbf{0}} \\
\text { viviendas } \\
\text { construidas }\end{array}$ & $\begin{array}{c}\% \\
\text { acumulado }\end{array}$ \\
\hline $\mathbf{2 0 0 0}$ & 319.129 & $-0,3$ & & & 1265,7 & & 3.211 & \\
\hline $\mathbf{2 0 0 1}$ & 318.293 & $-0,3$ & 3.110 & 4,2 & 1366,1 & 7,9 & 3.044 & $-5,2$ \\
\hline $\mathbf{2 0 0 2}$ & 318.576 & 0,1 & & 8,4 & 1681,1 & 31,0 & 3.409 & 6,8 \\
\hline $\mathbf{2 0 0 3}$ & 321.143 & 0,8 & & 12,6 & 1749,6 & 35,1 & 3.164 & $-0,4$ \\
\hline $\mathbf{2 0 0 4}$ & 321.713 & 0,2 & & 16,9 & 2131,0 & 56,9 & 5.398 & 70,2 \\
\hline $\mathbf{2 0 0 5}$ & 321.001 & $-0,2$ & & 21,1 & 2239,2 & 61,9 & 4.378 & 51,3 \\
\hline $\mathbf{2 0 0 6}$ & 319.943 & 0,6 & & 25,3 & 2491,0 & 73,2 & 3.883 & 40,0 \\
\hline $\mathbf{2 0 0 7}$ & 316.564 & $-1,1$ & 4.028 & 29,5 & 2712,7 & 82,1 & 4.088 & 45,3 \\
\hline
\end{tabular}

* El porcentaje acumulado de territorio se ha estimado empleando un ajuste lineal.

Fuente: elaboración propia a partir del INE y del Ministerio de Fomento.

Figura 4.3.11 Crecimiento porcentual acumulado de las principales variables urbanas de Valladolid

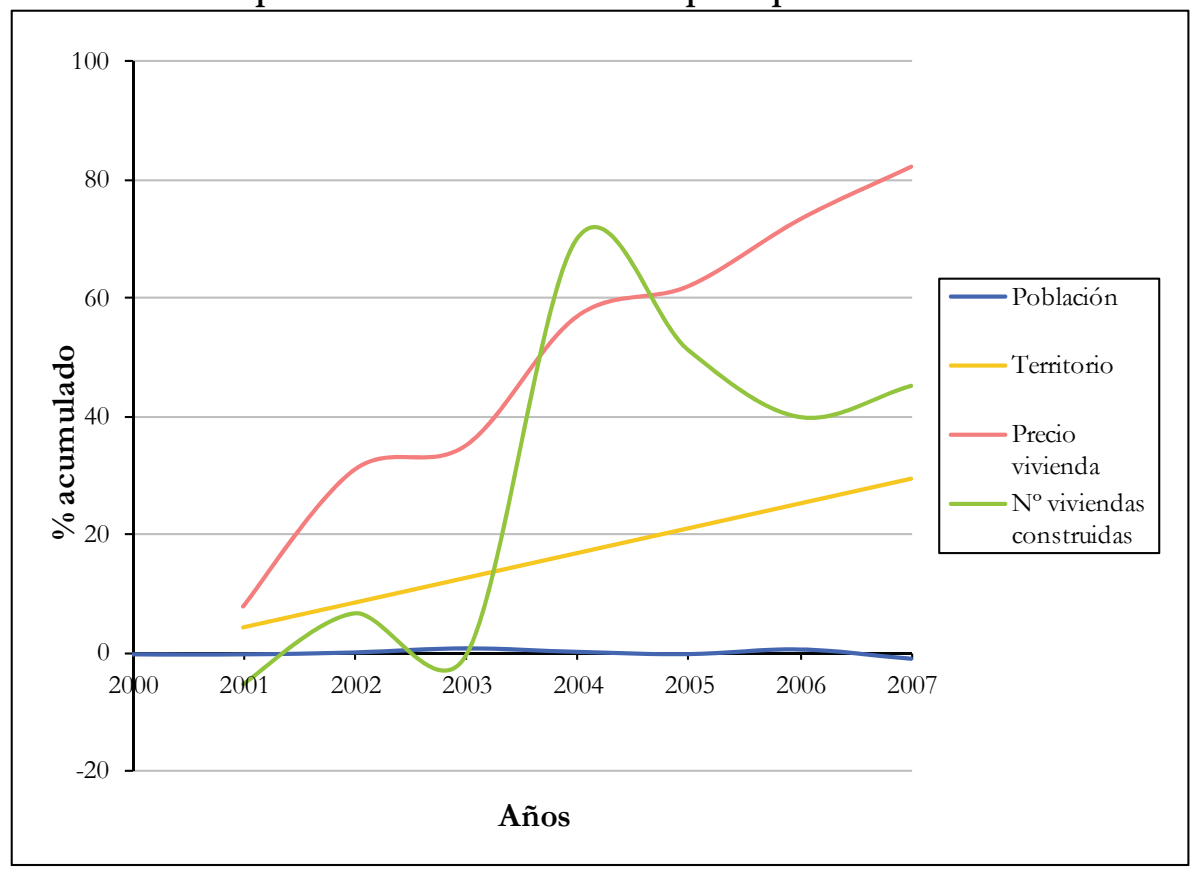

Fuente: elaboración propia a partir del INE y del Ministerio de Fomento. 


\subsubsection{Síntesis de la evolución histórica del verde urbano en Valladolid}

En la Tabla 4.3.7 aparece el periodo de creación de los espacios verdes de Valladolid y en ella se identifican claramente los años en los que estuvieron vigentes los PGOU de 1984, 1997 y de 2004, ya que fueron los más prolíficos en la creación de nuevos parques. Las áreas verdes más antiguas que han llegado hasta nuestros días están situadas en los límites de la ciudad histórica (ver Figura 4.3.12) y con la excepción de Campo Grande (V-1) se concentran en las orillas del Pisuerga. Concretamente, en la almendra central todos los espacios verdes ocupan espacios perimetrales debido a la gran dificultad que en su día implicó desarrollar actuaciones sobre el tejido urbano consolidado. Esta situación también afectó al Parque Ribera de Castilla (V-4), terminado de construir durante los primeros años del siglo XXI en una zona residual en la margen derecha del Pisuerga. Los dos verdes surgidos entre 1956 y 1971 también fueron creados en espacios residuales o perimetrales y hasta la construcción de la primera fase de Huerta del Rey (21) no se incorporaron las áreas verdes a los nuevos sectores urbanos. En este mismo periodo la corporación municipal trató de mitigar la falta de zonas verdes en el sector suroriental de la ciudad, que era uno de los más poblados, construyendo los parques de Canterac (V-21) y de San Isidro - Fuente de la Salud (V-22). Entre 1984 y 2008 se crearon treinta y nueve espacios verdes, mayoritariamente vinculados a las nuevas piezas urbanas, que se combinaron con un número reducido de áreas recuperadas y transformadas en parques.

Tabla 4.3.7 Clasificación del verde urbano de Valladolid según distintos parámetros.

\begin{tabular}{|c|c|c|c|c|c|c|}
\hline $\begin{array}{c}\text { Periodo de } \\
\text { aparición }\end{array}$ & $\begin{array}{c}\text { Anterior a } \\
1956\end{array}$ & $1956-1971$ & $1971-1984$ & $1984-2002$ & $2002-2008$ & Total \\
\hline Total & 5 & 2 & 8 & 22 & 17 & 54 \\
\hline $\begin{array}{c}\text { Uso anterior } \\
\text { del suelo }\end{array}$ & $\begin{array}{c}\text { Espacio } \\
\text { periférico o } \\
\text { reciente } \\
\text { urbanización }\end{array}$ & $\begin{array}{c}\text { Recuperación } \\
\text { de espacios }\end{array}$ & $\begin{array}{c}\text { Huertas y } \\
\text { jardines } \\
\text { clericales }\end{array}$ & $\begin{array}{c}\text { Huertos } \\
\text { urbanos }\end{array}$ & \multirow{2}{*}{ Total } \\
\cline { 1 - 5 } Total & 35 & 7 & 2 & 10 & 54 \\
\end{tabular}

Fuente: elaboración propia.

Para identificar el uso anterior del suelo ocupado por el verde urbano de 2008 se ha elaborado la Figura 4.3.13 cuyo resumen aparece en la Tabla 4.3.7. Anteriormente se mencionó que desde 1984 se crearon cinco espacios verdes a través de la recuperación o de la recalificación de terrenos urbanos: el Parque de la Paz (V-20), la Plaza del Ejército (V-42) y el Parque de las Norias de Santa Victoria (V-19), en el sur de la primera orla o corona de crecimiento, la Ribera de Huerta del Rey (V-37) en un espacio residual en la margen derecha del río y el verde urbano Barrio de la Esperanza (V-45) junto a la ronda Este, en un área reurbanizada en la primera década del siglo XXI. Habría que añadir dos espacios históricos con un origen similar: el Parque de Poniente (V-2), construido sobre terrenos liberados al soterrar el Esgueva, y el Parque de las Moreras (V-3), fruto de la recuperación del llamado Espolón Viejo.

El número de zonas verdes con origen en huertas o jardines pertenecientes a órdenes religiosas es muy reducido en la ciudad de Valladolid, puesto que solamente se pueden citar el verde urbano del Colegio San Agustín (V-40) y el Parque de Canterac (V-21), creado en unos terrenos que pertenecieron a la Orden de los Escoceses hasta la década de los setenta del siglo pasado. Por otra parte, los espacios que son o que fueron huertos urbanos representan una quinta parte del total de la trama verde e incluyen los cinco actualmente dedicados a la agricultura, así como otros tantos vinculados a los cursos de agua que atravie- 
Figura 4.3.12 Periodo de creación del verde urbano vallisoletano.

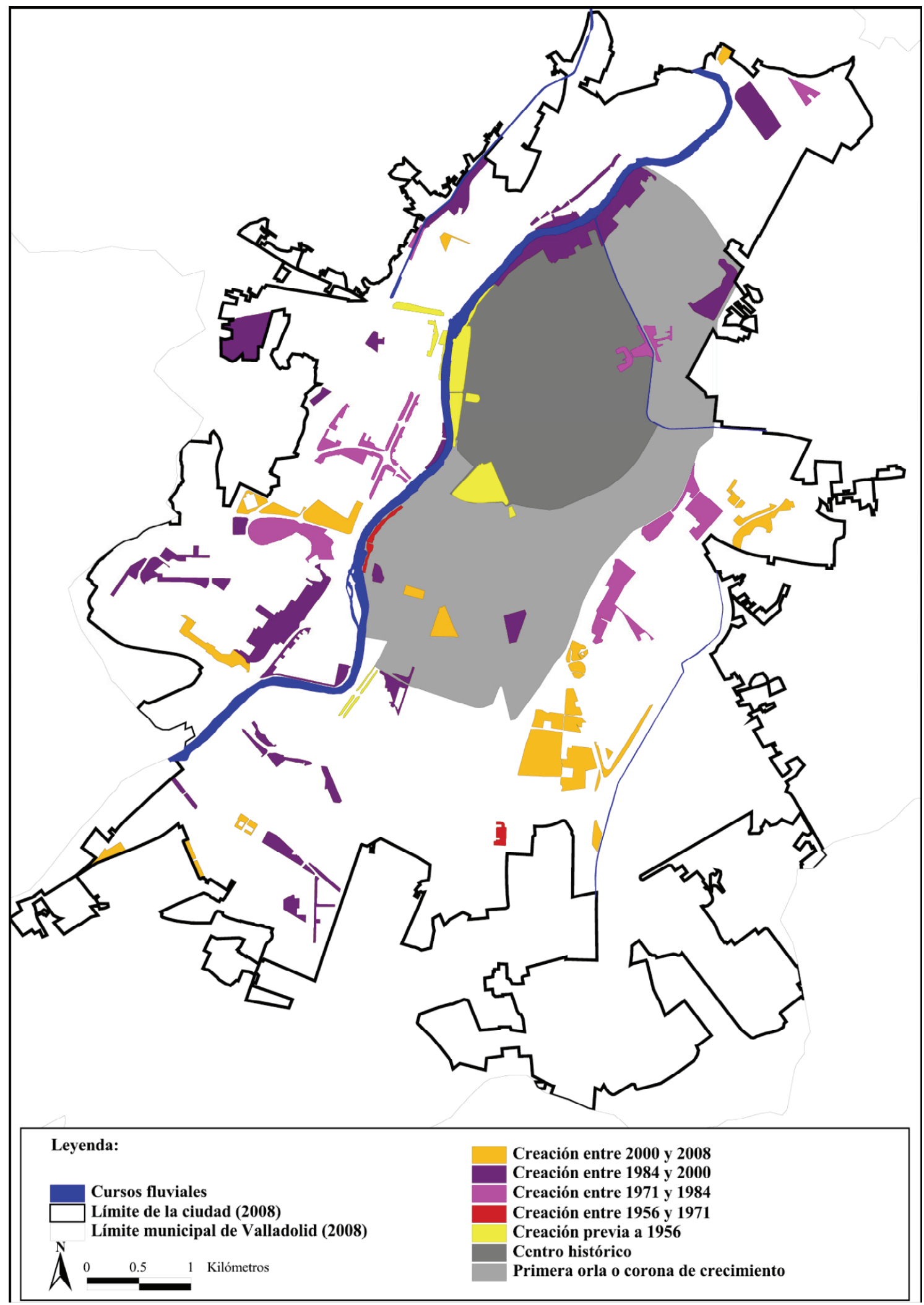

Fuente: elaboración propia a partir de la ortofoto de 2008 del IGN. 
Figura 4.3.13 Origen del verde urbano vallisoletano.

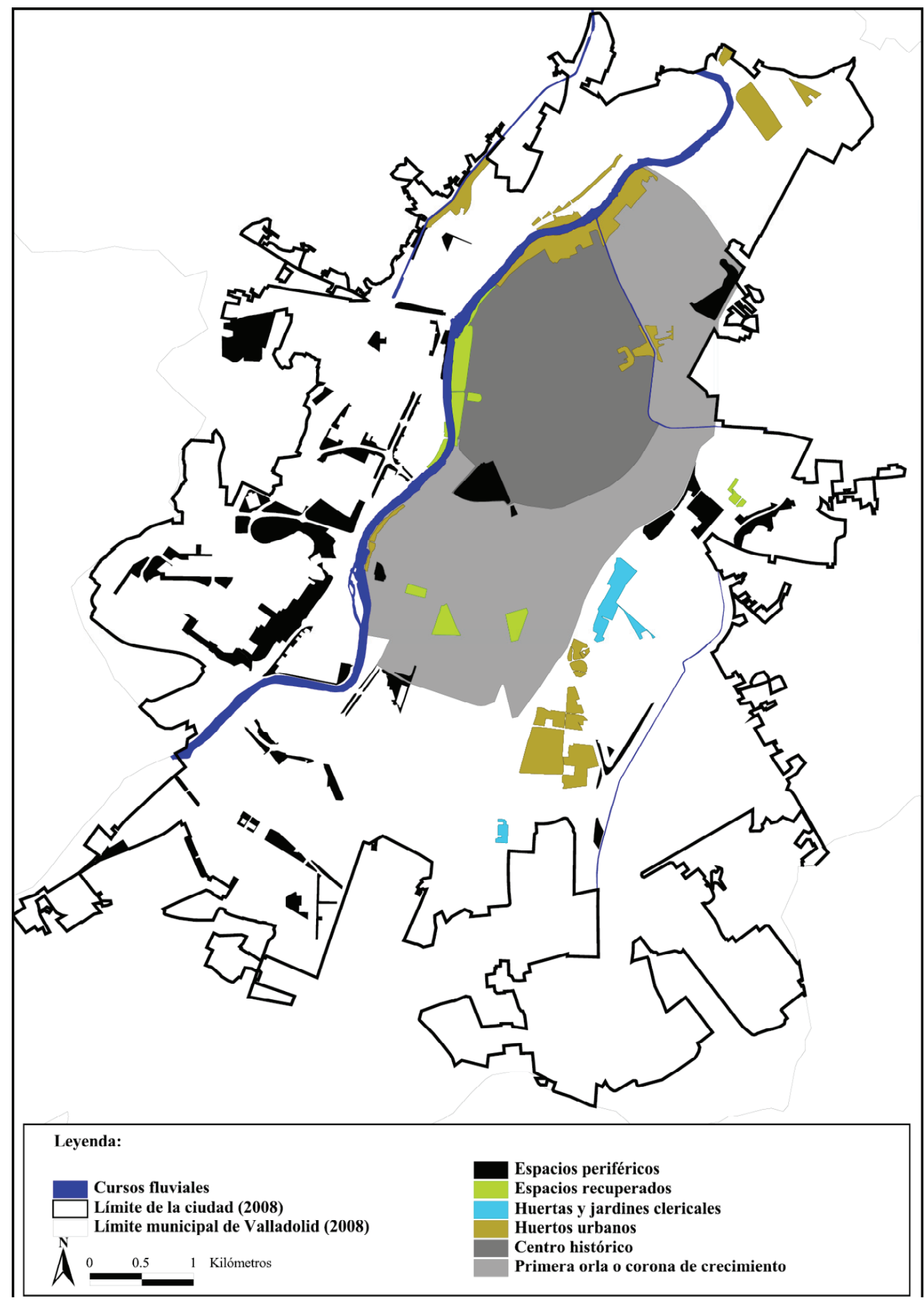

Fuente: elaboración propia a partir de la ortofoto de 2008 del IGN. 
Figura 4.3.14 Concentración de espacios verdes en Valladolid.

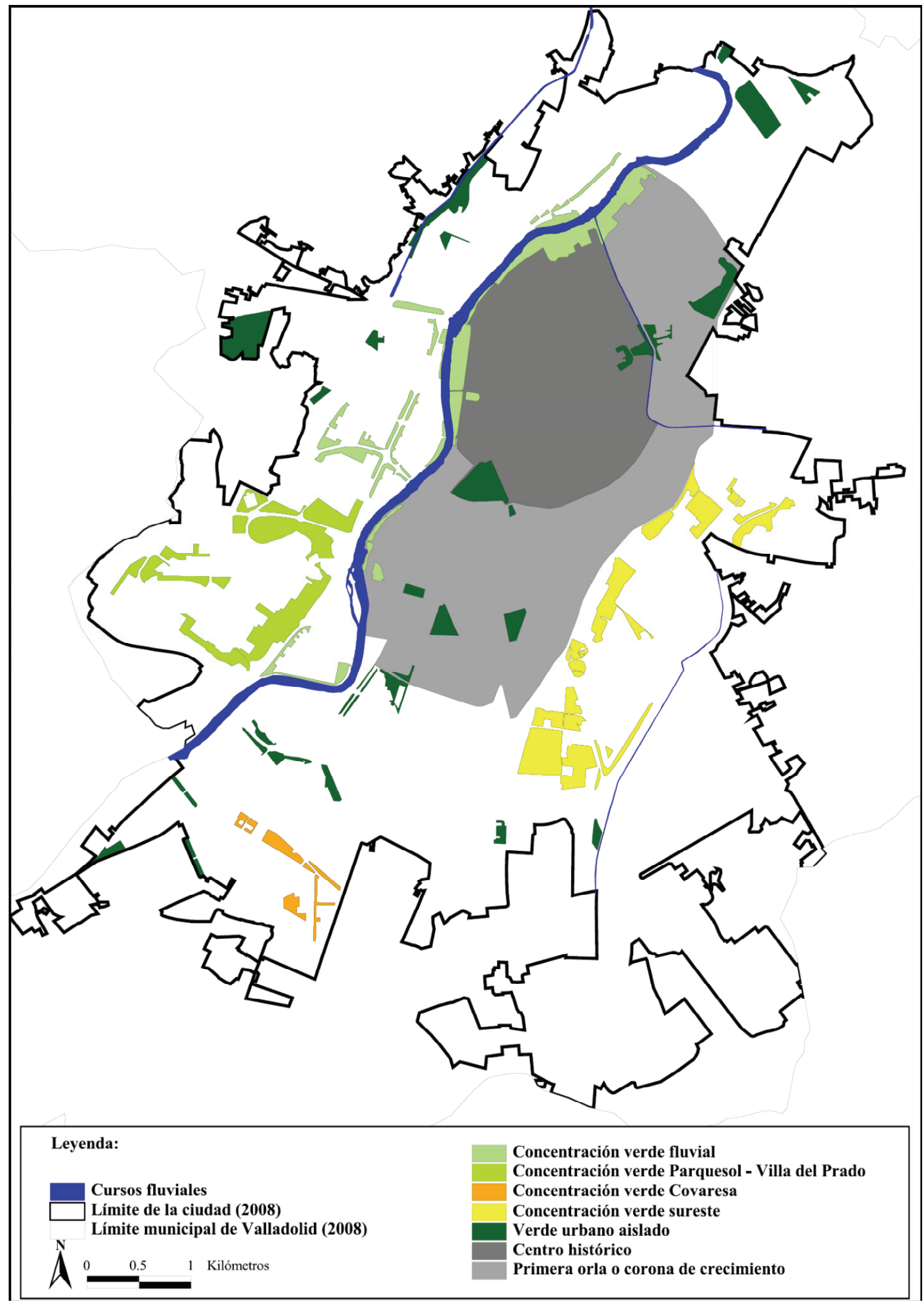

Fuente: elaboración propia a partir de la ortofoto de 2008 del IGN. 
Figura 4.3.15 Localización de los espacios verdes en los barrios de Valladolid.

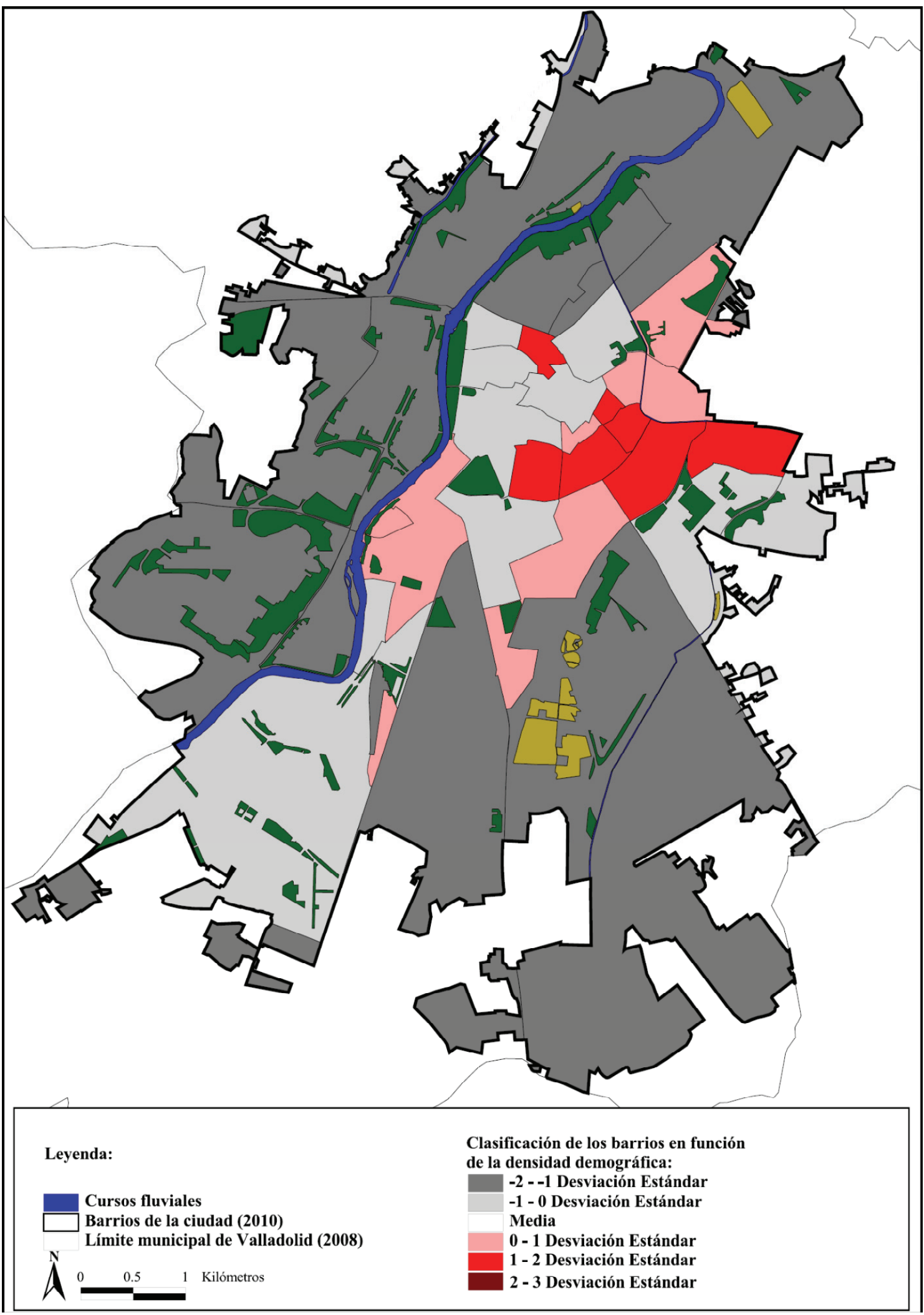

Media $=18.822 \mathrm{hab} / \mathrm{km}^{2}$. Desviación estándar $=14.349 \mathrm{hab} / \mathrm{km}^{2}$

Fuente: elaboración propia a partir de la ortofoto de 2008 del IGN y del Observatorio Urbano de Valladolid. 
san Valladolid. Por un lado aparecen los asociados al Pisuerga, como son el Parque Ribera de Castilla (V-4) y el verde urbano Camino del Cabildo (V-5), en el sector norte, y la Ribera entre el Puente Colgante y el Puente Juan de Austria (V-41), junto al antiguo emplazamiento del estadio de fútbol. Además hay que añadir el Jardín Botánico (V-6), construido sobre tierras de labor junto al Canal de Castilla y el Campus del Esgueva (V-26), levantado en el antiguo emplazamiento de las huertas que sustituyeron al Prado de la Magdalena.

La mayor concentración de espacios verdes se produce en las orillas del Pisuerga (ver Figura 4.3.14). Concretamente desde el límite norte de la primera orla o corona de crecimiento hasta su límite sur, pasando por la almendra central, es posible caminar junto al río sin abandonar un conjunto de zonas verdes que superan las 75 ha de extensión. Este recorrido comenzaría en el Parque Ribera de Castilla (V-4) y terminaría en el verde urbano Plaza Juan de Austria (V-38), sumando un total de nueve espacios a los que habría que añadir el verde urbano de Arturo Eyries (V-11), que aunque algo separado del resto en dirección sur, permitiría seguir bordeando el río hasta llegar a la Avenida de Salamanca. Esta vía actúa de bisagra entre esta y la concentración verde de Parquesol (38) - Villa del Prado (30), que es la segunda mayor de Valladolid con una extensión de 70 ha. Se trata de ocho espacios verdes que caracterizan un modelo de barrio con una densidad de vivienda elevada, acompañada de grandes dotaciones en espacios verdes muy próximas unas de otras. Además, se puede identificar otro modelo de "barrio verde" representado por Las Villas - Cañada Puente Duero - Covaresa - Parque Alameda - Paula López (37) donde predomina un hábitat menos denso que incorpora el jardín privado o semi privado, y donde los espacios verdes públicos no poseen una superficie tan grande, aunque sí permiten crear una concentración de tamaño nada despreciable en el sur de la ciudad. Por último hay que señalar la aglomeración que se produce entre los parques de Canterac $(\mathrm{V}-21)$ y de San Isidro-Fuente de la Salud (V-22) y que continúa por verdes no disponibles que posteriormente vuelven a enlazar con áreas públicas. Este conjunto de ocho espacios verdes es interesante desde el punto de vista de la conservación de la naturaleza, especialmente en el caso de las aves, debido a que estas áreas podrían facilitar la circulación de individuos por el tejido urbano actuando así como un corredor ecológico.

Por último, aparece representado el verde urbano junto con la densidad demográfica de los barrios de Valladolid (ver Figura 4.3.15) donde el color rojo alude a un valor elevado, mientras que el gris implica un valor reducido (los datos de cada barrio pueden consultarse en la Tabla 4.3.8). La primera conclusión que se obtiene es que los barrios más densamente poblados de la ciudad no cuentan con ningún espacio verde en su interior. La mayor parte de los mismos se encuentra en el sector centro-oriental de la ciudad, tanto en el interior de la almendra, Circular (4), Vadillos (12), Santa Clara (13), San Juan II (11), San Pablo (10) o Caño Argales (2), como fuera de la misma, Pajarillos Altos (18), Pajarillos Bajos (17). Se trata únicamente de 182,1 ha de las más de cuatro mil con las que cuenta la ciudad, pero son extremadamente densas: en ellas habitan 66.673 vallisoletanos, es decir, una quinta parte de la población. Todos estos barrios comparten su localización espacial, responden a un crecimiento no planificado y a la dificultad de actuar posteriormente en un tejido urbano consolidado. En el resto de barrios con densidades superiores a la media la situación es sensiblemente diferente y aunque su origen haya que buscarlo también en los periodos de mayor crecimiento demográfico de la ciudad, se llevaron a cabo actuaciones de mejora en las dotaciones de áreas verdes como ocurrió en Delicias (19), convirtiendo un espacio junto al Cuartel Conde Ansúrez en el Parque de la Paz (V-20), o en el Paseo Zorrilla (20) donde se convierte en parque la Plaza del Ejército (V-42). En el norte, los barrios del Hospital (14) y de Belén (23) cuentan con sendos espacios verdes vinculados a la Universidad de Valladolid, mientras que barrios como Batallas (15) o Arturo León (28), en el sur de la ciudad, tienen zonas verdes en sus proximidades aunque propiamente no cuentan con ninguna en su interior. Los que poseen un mayor número de verdes son los construidos desde que se 
aprobó el PGOU de 1984 hasta el final del periodo estudiado, como por ejemplo Las Villas Cañada Puente Duero - Covaresa - Parque Alameda - Paula López (37), Parquesol (38) o Girón - Villa del Prado (30), siendo también muy destacada la presencia de grandes parques en el barrio del Centro (1) y en los barrios situados en el límite occidental de la almendra central.

Tabla 4.3.8 Superficie y población de los barrios de Valladolid.

\begin{tabular}{|c|c|c|c|c|}
\hline $\mathbf{N}^{\mathbf{o}}$ & Nombre barrio & $\begin{array}{c}\mathbf{N}^{\circ} \\
\text { habitantes }\end{array}$ & $\begin{array}{l}\text { Superficie } \\
\text { (ha) }\end{array}$ & $\begin{array}{l}\text { Densidad } \\
\left(\mathrm{hab} / \mathrm{km}^{2}\right)\end{array}$ \\
\hline 1 & Centro & 9.199 & 75,24 & 12.226 \\
\hline 2 & Caño Argales & 8.059 & 24,19 & 33.322 \\
\hline 3 & Campo Grande - Arco del Ladrillo & 7.341 & 67,38 & 10.896 \\
\hline 4 & Circular & 11.025 & 24,70 & 44.631 \\
\hline 5 & Universidad & 5.407 & 29,99 & 18.029 \\
\hline 6 & San Juan & 2.067 & 6,48 & 31.879 \\
\hline 7 & San Miguel & 4.675 & 30,25 & 15.453 \\
\hline 8 & San Nicolás & 4.139 & 22,36 & 18.507 \\
\hline 9 & Rondilla & 18.584 & 78,83 & 23.574 \\
\hline 10 & San Pablo & 4.139 & 12,05 & 34.360 \\
\hline 11 & San Juan II & 1.849 & 5,33 & 34.710 \\
\hline 12 & Vadillos & 4.586 & 11,43 & 40.113 \\
\hline 13 & Santa Clara & 5.561 & 15,47 & 35.940 \\
\hline 14 & Hospital & 8.203 & 43,65 & 18.793 \\
\hline 15 & Batallas & 4.243 & 13,88 & 30.561 \\
\hline 16 & Pilarica & 7.886 & 34,17 & 23.077 \\
\hline 17 & Pajarillos Bajos & 16.803 & 47,68 & 35.243 \\
\hline 18 & Pajarillos Altos & 14.651 & 41,23 & 35.532 \\
\hline 19 & Delicias & 29.332 & 90,55 & 32.394 \\
\hline 20 & Paseo Zorrilla & 21.638 & 90,97 & 23.785 \\
\hline 21 & Huerta del Rey & 16.867 & 145,66 & 11.579 \\
\hline 22 & Barrio España & 2.826 & 42,44 & 6.659 \\
\hline 23 & Belén & 1.930 & 56,75 & 3.401 \\
\hline 24 & Polígono Argales & 1.857 & 295,32 & 629 \\
\hline 25 & Barriada Guardia Civil & 1.472 & 9,58 & 15.366 \\
\hline 26 & Camino Esperanza & 2.406 & 21,30 & 11.296 \\
\hline 27 & Cuatro de Marzo & 3.885 & 21,49 & 18.075 \\
\hline 28 & Arturo León & 3.111 & 9,48 & 32.818 \\
\hline 29 & Arturo Eyries & 4.765 & 65,86 & 7.235 \\
\hline 30 & Girón - Villa del Prado & 7.563 & 191,19 & 3.956 \\
\hline 31 & La Victoria & 15.407 & 446,02 & 3.454 \\
\hline 32 & La Overuela - Navabuena - E1 Berrocal & 2.515 & 30,88 & 8.144 \\
\hline 33 & San Pedro Regalado & 2.551 & 244,43 & 1.044 \\
\hline 34 & Las Flores & 1.995 & 63,85 & 3.124 \\
\hline 35 & Páramos San Isidro - Campo de Tiro & 2.461 & 114,71 & 2.145 \\
\hline 36 & $\begin{array}{l}\text { Caamaño - Las Viudas - Polígono San } \\
\text { Cristóbal }\end{array}$ & 14.693 & 847,40 & 1.734 \\
\hline 37 & $\begin{array}{l}\text { Las Villas - Cañada Puente Duero - Covaresa } \\
\text { Parque Alameda - Paula López }\end{array}$ & 21.610 & 392,28 & 5.509 \\
\hline 38 & Parquesol & 26.218 & 301,68 & 8.691 \\
\hline 39 & Pinar de Antequera & 913 & 98,08 & 931 \\
\hline 40 & La Rubia & 4.454 & 392,28 & 1.135 \\
\hline & TOTAL & 328.886 & $4.556,55$ & 7.218 \\
\hline
\end{tabular}

Fuente: Observatorio Urbano de Valladolid. 


\subsubsection{Evolución de los indicadores de Valladolid}

En la Tabla 4.3.9 aparecen recogidos los indicadores concernientes a los espacios verdes durante el periodo estudiado, mostrando algo que ya se ha mencionado: el fuerte incremento de zonas verdes experimentado desde 1956 y 2008 se debió principalmente a la aparición de verdes urbanos disponibles. Sin embargo la construcción de parques no se ha realizado de manera homogénea en el tiempo y para su análisis se ha elaborado la Figura 4.3.16 en la que se ha representado la evolución de los indicadores que relacionan la extensión de la trama verde con el número de habitantes y la dimensión de la ciudad, a lo largo del periodo estudiado. La fecha de partida de esta investigación es 1956 y en aquel año Valladolid contaba únicamente con cinco áreas verdes de carácter público y su extensión conjunta era de 30,3 ha, correspondiéndole únicamente $2,44 \mathrm{~m}^{2}$ de zonas verdes a cada uno de los casi ciento veinticinco mil habitantes. Se trata de una cifra muy alejada de la actualmente propuesta por la OMS $\left(9 \mathrm{~m}^{2} / \mathrm{hab}\right)$, pero superior a la de las otras ciudades analizadas debido al gran tamaño de los parques ubicados en el centro histórico. A mediados del siglo XX, Valladolid era una urbe compacta que sin embargo contaba con una gran cantidad de espacios abiertos, concretamente un $8,2 \%$ de su superficie $\left(820,6 \mathrm{~m}^{2} /\right.$ ha), debido a la notable extensión de los nueve huertos urbanos. El fuerte crecimiento experimentado por la ciudad hasta la década de los setenta no estuvo acompañado de una expansión similar de la trama verde. Incluso desaparecieron tres huertos urbanos de grandes dimensiones que fueron reemplazados por dos pequeños verdes y en el cómputo global el número de los mismos se redujo a trece. Obviamente todos los indicadores del verde urbano disminuyeron alcanzando el mínimo absoluto del periodo estudiado en 1971: la densidad de verde urbano disponible por habitante se redujo casi a la mitad hasta alcanzar $1,3 \mathrm{~m}^{2} /$ hab y la densidad verde superficial siguió una tendencia similar hasta situarse en $345,72 \mathrm{~m}^{2} / \mathrm{ha}$.

Tabla 4.3.9 Principales indicadores del verde urbano de Valladolid durante el periodo 1956-2008.

\begin{tabular}{|c|c|c|c|c|c|}
\hline & 1956 & 1971 & 1984 & 2001 & 2008 \\
\hline $\mathbf{N}^{\circ}$ espacios verdes & 14 & 13 & 20 & 42 & 54 \\
\hline $\mathbf{N}^{\circ}$ huertos urbanos & 9 & 6 & 6 & 6 & 5 \\
\hline $\mathbf{N}^{o}$ espacios verdes $\sin$ huertos & 5 & 7 & 14 & 36 & 49 \\
\hline $\mathbf{N}^{\circ}$ espacios verdes disponibles & 5 & 6 & 12 & 31 & 44 \\
\hline $\mathbf{N}^{\circ}$ habitantes & 124.212 & 236.341 & 330.242 & 319.129 & 318.461 \\
\hline Extensión de la ciudad (ha) & 775,3 & $1.277,9$ & $2.100,1$ & $3.110,1$ & $4.027,5$ \\
\hline Extensión del verde (ha) & 63,6 & 44,2 & 118,7 & 260,4 & 331,0 \\
\hline Extensión de los huertos urbanos (ha) & 33,3 & 11,4 & 41,2 & 61,3 & 51,2 \\
\hline Extensión del verde sin huertos (ha) & 30,3 & 32,8 & 77,5 & 199,1 & 279,8 \\
\hline Extensión del verde urbano disponible (ha) & 30,3 & 30,8 & 68,7 & 178,3 & 252,5 \\
\hline Densidad de verde $\left(\mathrm{m}^{2} / \mathrm{hab}\right)$ & 5,12 & 1,87 & 3,59 & 8,16 & 10,39 \\
\hline Densidad verde $\sin$ huertos $\left(\mathrm{m}^{2} / \mathrm{hab}\right)$ & 2,44 & 1,39 & 2,35 & 6,24 & 8,79 \\
\hline Densidad del verde urbano disponible $\left(\mathrm{m}^{2} / \mathrm{hab}\right)$ & 2,44 & 1,30 & 2,08 & 5,59 & 7,93 \\
\hline Densidad verde por superficie $\left(\mathrm{m}^{2} / \mathrm{ha}\right)$ & 820,64 & 345,72 & 565,01 & 837,19 & 821,85 \\
\hline Densidad del verde urbano disponible por superficie $\left(\mathrm{m}^{2} / \mathrm{ha}\right)$ & 391,10 & 240,79 & 326,94 & 573,14 & 626,94 \\
\hline
\end{tabular}

Fuente: elaboración propia a partir del SGE, del IGN y del INE.

A partir de esta fecha, y durante la primera mitad de la década de los ochenta, se tomaron medidas para paliar los déficits de zonas verdes en algunos de los barrios de la ciudad que más habían crecido, surgiendo así parques como Canterac (V-21) o San Isidro Fuente de la Salud (V-22), pero lo que sin duda supuso un cambio de rumbo fue la incorporación de la normativa urbanística a la creación de los nuevos sectores urbanos como ocurrió en Huerta del Rey (21) y en Parquesol (38). Comienza así un aumento de todos los ratios que se reafirmará durante la vigencia de los PGOU de 1984, 1997 y 2004, por el estricto cumplimiento de las ordenanzas de urbanismo en materia de espacios verdes. Desde 1984 se asiste a un estancamiento de la población de la ciudad, que perderá cerca de doce mil habitantes en veinticuatro años, contribuyendo de este modo al aumento de los ratios de 
espacios verdes por habitante hasta alcanzar en el caso del verde urbano disponible un máximo en 2008 de $7,93 \mathrm{~m}^{2} / \mathrm{hab}$, un valor que tampoco consigue superar el mínimo establecido por la OMS.

Los indicadores por superficie muestran una evolución ligeramente diferente con una sensible disminución del verde urbano por hectárea entre 2001 y 2008, debido al fuerte crecimiento territorial de la ciudad, tanto por la construcción de nuevas zonas residenciales como por la proyección de espacios industriales, situando el índice de zonas verdes por superficie en valores parejos a los de 1956, con un $8,2 \%$ del tejido urbano de Valladolid dedicado a espacios abiertos (ver Figura 4.3.16).

Figura 4.3.16 Evolución de los principales indicadores del verde urbano y del verde urbano disponible en Valladolid.

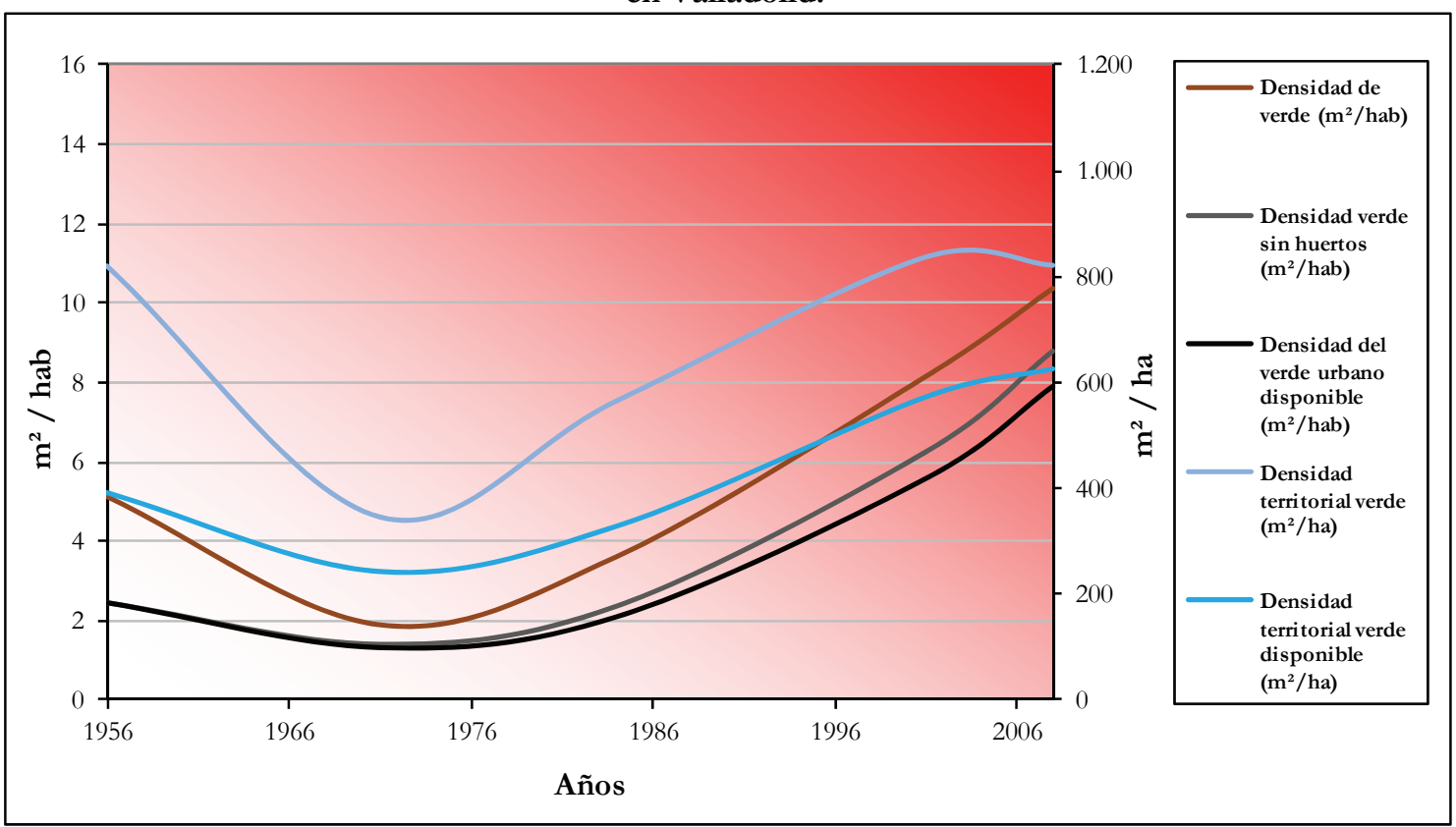

Fuente: elaboración propia a partir del SGE, del IGN y del INE. 


\subsection{Origen y evolución del verde urbano de la ciudad de Zamora}

Zamora es la ciudad de menor tamaño, tanto demográfico como territorial, de las analizadas en esta investigación. El municipio es muy extenso, supera las quince mil hectáreas, y en 2011 estaban censados 65.525 habitantes. La ciudad está dividida en diecisiete barrios de acuerdo con el Estudio Sociodemográfico del municipio de Zamora publicado por el Ayuntamiento de Zamora (2007): su numeración aparece en la Tabla 4.4.1 y su representación cartográfica en la Figura 4.4.1. Las divisiones del tejido urbano zamorano se han realizado de acuerdo con la bibliografía existente y con las referencias que ofrece el PGOU de 2001 y su sustituto de 2011, de tal forma que el centro histórico se corresponde con el recinto amurallado y tiene una extensión de 74,1 ha. Sus límites orientales, que quizás sean los que suscitan algún tipo de duda, coinciden con la actual Avenida de Portugal, con la Bajada de San Pablo, con la Ronda de la Puerta Nueva y con la Ronda del Degolladero, hasta enlazar, en el límite meridional, con la Avenida del Mengue. Más problemática resulta la delimitación de la primera orla o corona de crecimiento (102,4 ha), que de acuerdo con la literatura existente coincide con el "ensanche", es decir, con la expansión oriental de la ciudad durante los dos primeros tercios del siglo XX. Su límite occidental lo fija el centro histórico y enlaza con la Avenida Cardenal Cisneros, con la Calle del Campo de Marte y con la Calle del Ferrocarril en el norte, mientras que en el sur el límite lo marca el Duero. El resto del tejido urbano situado en la orilla derecha del río se considera la segunda orla o corona de crecimiento, mientras que la orilla izquierda recibe un trato independiente por haberse desarrollado históricamente un poblamiento en núcleos dispersos que todavía hoy se puede identificar.

En la metodología se indicó que el tamaño mínimo del verde urbano de Zamora en 2009 era de 0,66 ha. En la Tabla 4.4.2, que es idéntica a la 2.7, aparecen representados los veintinueve espacios verdes con los que contaba la ciudad, con su tamaño y nombre correspondiente, y en las Figuras 4.4.2 y 4.4.3, idénticas a la 2.9 y a la 2.10, se puede observar su posición en el interior de la ciudad. La primera de estas imágenes permite identificar las zonas verdes en el interior del tejido urbano zamorano, diferenciando los huertos urbanos en un color amarillento, mientas que en la segunda todos los espacios están numerados y se pueden distinguir en color rojo los once verdes urbanos no disponibles. En total suman 101,6 ha de zonas verdes, de las que 71,7 ha forman parte de verdes urbanos disponibles y 25,7 ha tienen vocación agrícola.

\subsubsection{Evolución urbana de Zamora hasta 1956}

La ciudad ha tenido, hasta fechas muy recientes, grandes parcelas dedicadas a la agricultura en el interior del tejido urbano. Durante la primera mitad del siglo XX el ensanche oriental se fue densificando, pero hasta entonces los espacios verdes no constituyeron una prioridad para el gobierno local porque eran numerosos los arrabales que presentaban núcleos de población a caballo entre el hábitat rural y el urbano.

Tabla 4.4.1 Nombre y número de los barrios de Zamora.

\begin{tabular}{|c|l|c|l|}
\hline $\mathbf{N}^{\mathbf{0}}$ & Nombre barrio & $\mathbf{N}^{\mathbf{0}}$ & Nombre barrio \\
\hline 1 & Casco Antiguo & 9 & Pinilla - San Ramón \\
\hline 2 & La Lana - San Esteban & 10 & Cabañales - Sepulcro \\
\hline 3 & Centro Ciudad & 11 & San Frontis - Carrascal \\
\hline 4 & Pantoja & 12 & Olivares - San Isidro - Espíritu Santo - Obelisco \\
\hline 5 & Las Viñas & 13 & San Lázaro \\
\hline 6 & Horta - Barrios Bajos & 14 & San José Obrero \\
\hline 7 & Candelaria - Peña de Francia & 15 & Alviar \\
\hline 8 & Bloques - Barriada Asturias - Villagodio & 16 & Peña Trevinca \\
\hline
\end{tabular}

Fuente: Estudio Sociodemográfico del municipio de Zamora (Ayuntamiento de Zamora, 2007). 
Figura 4.4.1 Barrios de la ciudad de Zamora.

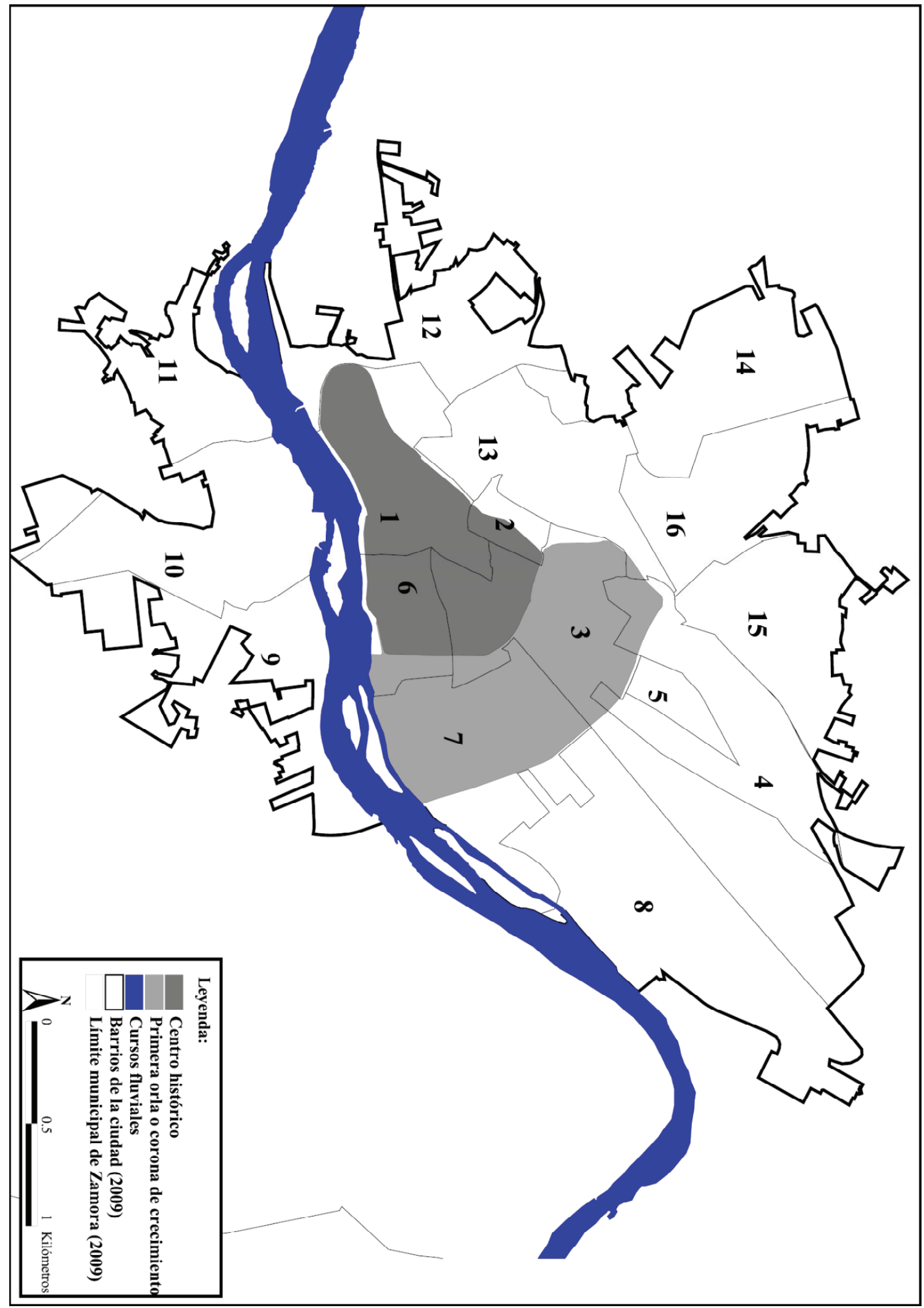

Fuente: elaboración propia a partir de la ortofoto de 2009 del IGN y del Ayuntamiento de Zamora (2007). 
Figura 4.4.2 Localización espacial del verde urbano en la ciudad de Zamora.

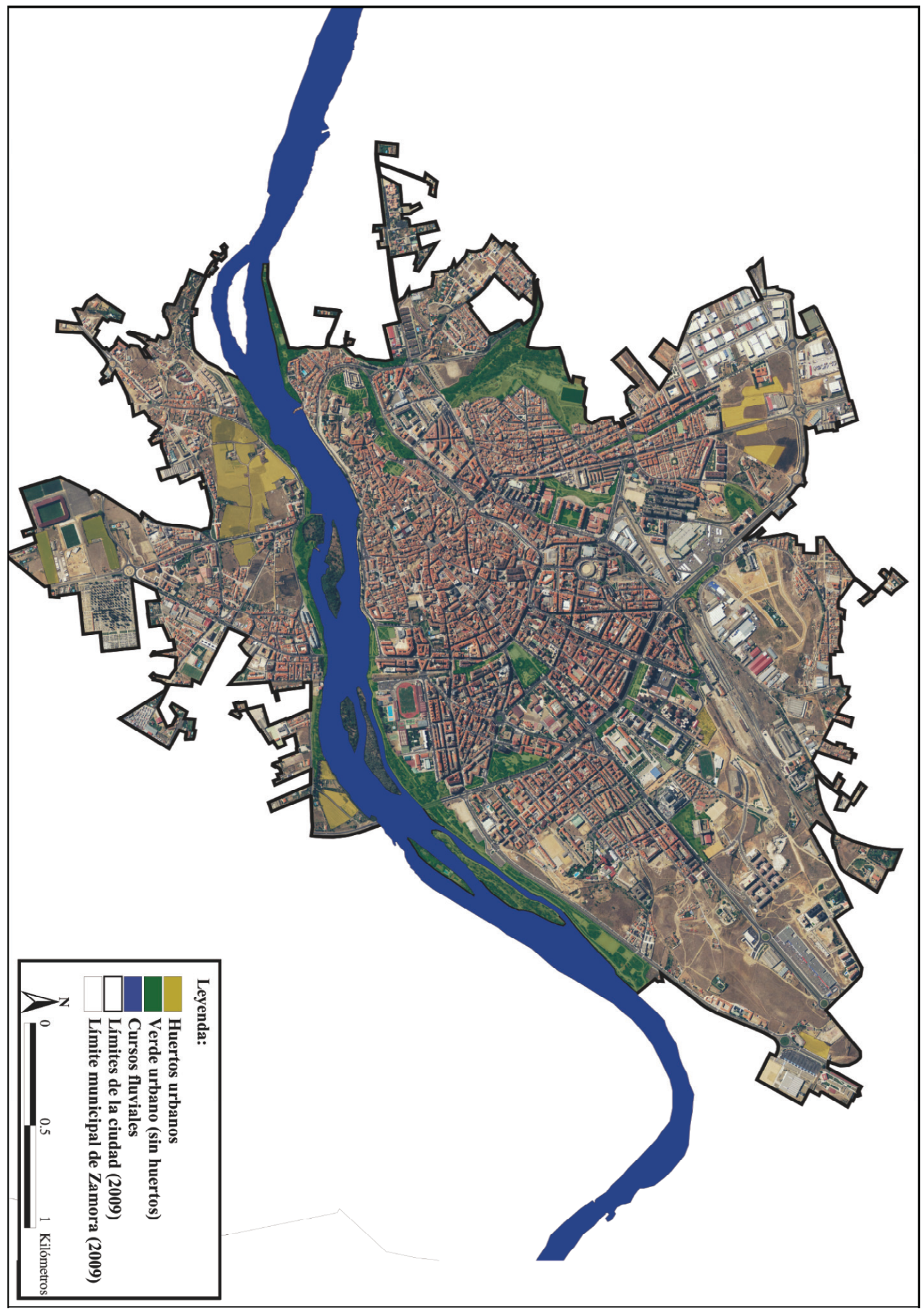

Fuente: elaboración propia a partir de la ortofoto de 2009 del IGN. 
Figura 4.4.3 Localización espacial del verde urbano disponible en la ciudad de Zamora.

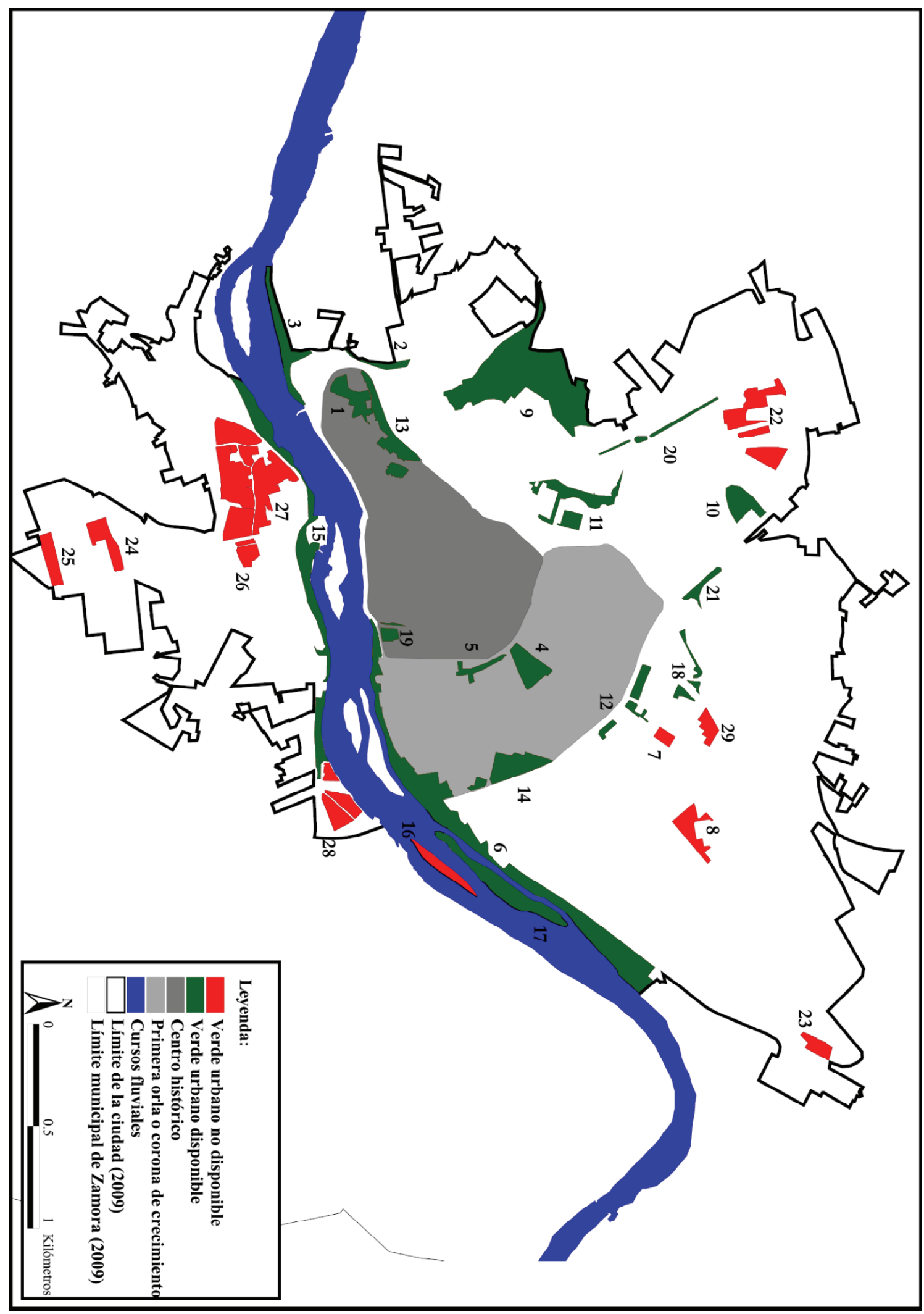

Fuente: elaboración propia a partir de la ortofoto de 2009 del IGN. 
Tabla 4.4.2 El verde urbano de la ciudad de Zamora.

\begin{tabular}{|c|c|c|c|c|c|}
\hline $\mathbf{N}^{0}$ & ha & Nombre & $\mathbf{N}^{\circ}$ & ha & Nombre \\
\hline Z-1 & 1,9 & Parque del Castillo y de la Catedral & Z-16 & 1,8 & Club naútico \\
\hline $\mathrm{Z}-2$ & 0,8 & Verde urbano Calle de los Caballeros & Z-17 & 5,0 & Isla de las Pallas \\
\hline $\mathrm{Z}-3$ & 3,4 & Parque de Olivares & Z-18 & 0,9 & Jardín Carretera de la Estación \\
\hline Z-4 & 2,2 & Parque de la Marina & Z-19 & 0,6 & Verde urbano Puerta Nueva \\
\hline Z-5 & 0,8 & Verde urbano Candelaria Ruiz del Árbol & $\mathrm{Z}-20$ & 0,9 & Verde urbano Calle Ntra Sra. de las Mercedes \\
\hline Z-6 & 16,5 & Margen derecha del Duero & $\mathrm{Z}-21$ & 0,8 & Verde urbano Av. Cardenal Cisneros (Eroski) \\
\hline $\mathrm{Z}-7$ & 0,5 & Jardín de los Salesianos & $\mathrm{Z}-22$ & 4,4 & Huertos Norte ciudad \\
\hline $\mathrm{Z}-8$ & 2,0 & Jardines del CFIE & $\mathrm{Z}-23$ & 1,0 & Huerto Este \\
\hline Z-9 & 16,5 & Bosque de Valorio (parte urbana) & $\mathrm{Z}-24$ & 1,8 & Huerto Norte estadio de fútbol \\
\hline Z-10 & 1,9 & Parque de Peña Trevinca & $\mathrm{Z}-25$ & 1,5 & Huerto Sur estadio de fútbol \\
\hline $\mathrm{Z}-11$ & 3,3 & Jardines de la Vaguada & $\mathrm{Z}-26$ & 1,1 & Huertos Cabañales \\
\hline Z-12 & 1,4 & Verde urbano Avda. Cardenal Cisneros & $\mathrm{Z}-27$ & 12,3 & Huertos San Frontis \\
\hline Z-13 & 3,7 & Parque de San Martín & Z-28 & 2,6 & Huertos Sureste \\
\hline $\mathrm{Z}-14$ & 3,0 & Parque de León Felipe & $\mathrm{Z}-29$ & 1,0 & Huerto Calle Antón de Centenera \\
\hline Z-15 & 8,3 & Margen izquierda del Duero & Total & 101,6 & \\
\hline
\end{tabular}

Fuente: elaboración propia.

\section{i) Expansión urbana}

Zamora comenzó el siglo XX con 16.827 habitantes, exactamente la mitad de los censados cincuenta años después (ver Figura 4.4.4). Su extensión territorial se limitaba al recinto amurallado medieval y a los arrabales históricos, de los que San Lázaro (13) era el de mayores dimensiones, aunque estaban separados por grandes vacíos urbanos. En el último tercio del siglo XIX la ciudad perdió la condición de plaza de guerra y la muralla dejó de tener utilidad defensiva. Desde entonces se fue derribando la fortificación entre las puertas de Santa Ana y de Santa Clara (3), lo que facilitó el crecimiento en dirección este (Ávila, 2009). Dicho proceso afectará a la mitad nororiental de la cerca y a la zona sur, donde la muralla fue sustituida por edificios de viviendas, aprovechando el espacio libre como ronda o camino perimetral de la ciudad (Gago, 1986). Aunque no había un sector secundario potente, durante el último cuarto del siglo XIX y el primero del XX se vivió un periodo de auge económico gracias a la industria harinera, que se vio favorecido por la llegada del ferrocarril y por la consolidación de la ciudad como centro administrativo y de servicios, lo que a su vez propició un sensible impulso del sector de la construcción en la capital (Ávila, 2009) y su consiguiente crecimiento superficial. La llegada del ferrocarril en 1864 dirigirá el crecimiento urbano posterior desde el recinto amurallado hasta la estación, siguiendo la Avenida de las Tres Cruces (3), eje sobre el que se instalarán posteriormente algunos de los organismos oficiales (Calderón, 1982). La expansión extramuros en dirección este no responde a un planeamiento urbano previo, sino que se apoyó en la red de caminos rurales existente (Gago, 1986). Se tomaron como ejes la mencionada vía que comunicaba la ciudad con la estación de ferrocarril y la futura Avenida de Requejo (que separa los barrios 3 y 8), surgida como prolongación de la Calle Santa Clara. El barrio de Pantoja (4) aparecerá a finales del siglo XIX junto a la estación de ferrocarril como la parte del ensanche de la ciudad donde se asienta la población obrera. En el extremo meridional del actual barrio de Centro Ciudad (3), en el límite oriental de la cerca medieval, surgió a finales del siglo XIX la fundación benéfica Candelaria Ruiz del Árbol, como una de las primeras residencias situadas fuera del casco histórico en esta zona de la ciudad (Gago, 1986). En este sector se construyó en 1900 el Puente de Hierro sobre el Duero, incorporando a la ciudad el tejido urbano existente entre dicha construcción y la Puerta Nueva, en Horta - Barrios Bajos (6).

A comienzos del siglo XX en la margen izquierda del Duero el poblamiento era muy débil, algo concentrado en San Frontis (11) y Sepulcro (10), mientras que Pinilla (9) y Cabañales (10) apenas contaban con un reducido caserío junto a los puentes. En 1920 se 
aprobó el proyecto de Saneamiento del Casco Urbano y en 1929 se presentó el Anteproyecto del Plan General de Ensanche, redactado por Francisco Herranz, en el que se incluían los terrenos entre la carretera de la Estación y el actual límite nororiental de la Horta - Barrios Bajos (6) (Ávila, 2009). Durante la década de los años treinta la población se incrementó en un cincuenta por ciento y buena parte de los nuevos habitantes se instalaron en el ensanche, que comenzó a densificarse y a compactarse al tiempo que experimentaba una notable expansión urbana en dirección este. En los arrabales del norte y del sur de la ciudad se instalaron los emigrantes con menos recursos, proliferando la autoconstrucción y la infravivienda. En 1949 se aprobó el Plan General de Ordenación con el objetivo de regular la expansión oriental, de continuar con el trazado de las principales vías del casco histórico y de completar los vacíos urbanos entre la ciudad y algunos arrabales como San Lázaro (13) o el barrio de la Vega (1), situado entre el Casco Antiguo (1) y el bosque de Valorio (Z-9). Por la repercusión que tendrá posteriormente en la configuración de la trama verde, es necesario señalar que durante este periodo se urbanizaron los terrenos sobre los que se construirán las Escuelas Salesianas de San José que darán paso a la Universidad Laboral. En la Avenida de Requejo se llevará a cabo una fuerte construcción de vivienda pública tras la Guerra Civil, promovida por la Obra Sindical del Hogar y por la Diputación de Zamora, levantando un total de seis Grupos de Promoción Oficial en la periferia de la ciudad (Calderón, 1982).

Figura 4.4.4 Evolución de la población de la ciudad y de la provincia de Zamora desde 1900.

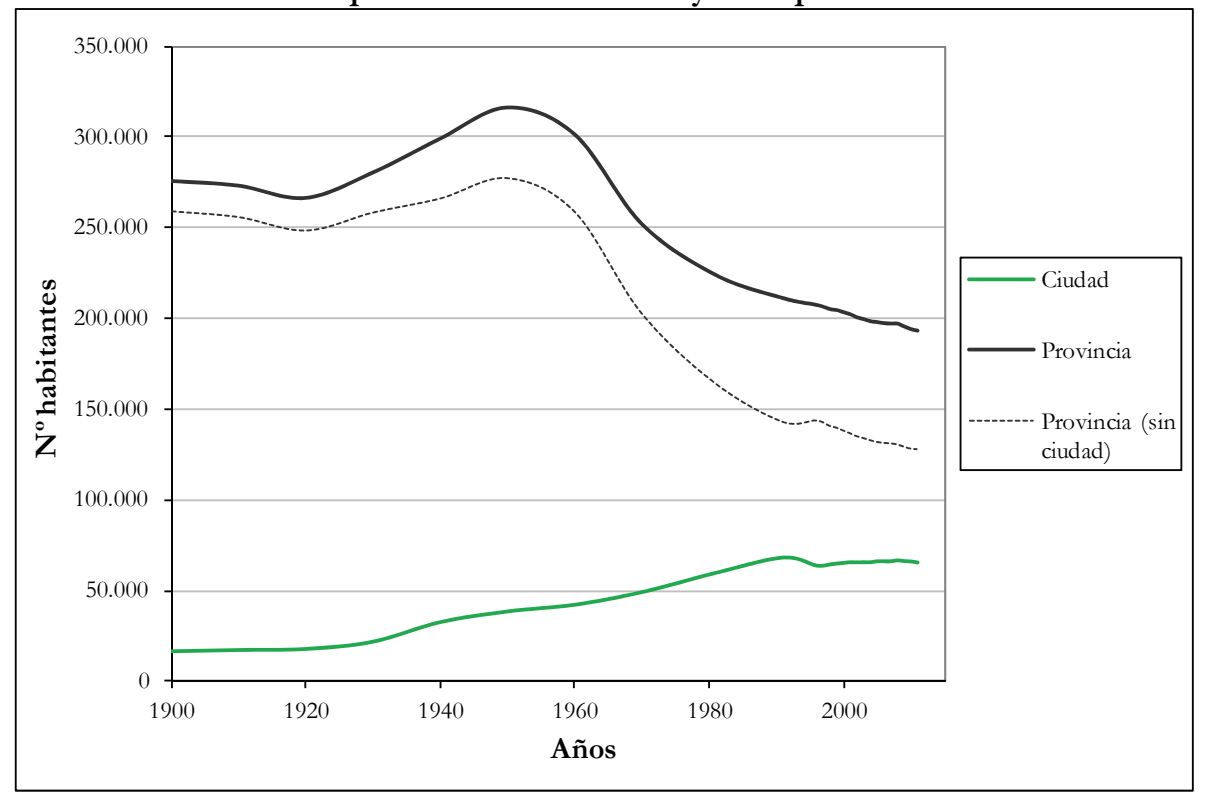

Fuente: INE.

\section{ii) Aparición de los espacios verdes}

Para analizar el origen de los actuales espacios verdes de la ciudad de Zamora habrá que remontarse, al menos, hasta el siglo XVI, fecha aproximada de la aparición del Parque del Castillo y de la Catedral (Z-1), en la que fue la antigua plaza de armas. Más certezas presenta la creación del Parque de San Martín (Z-13), situado junto al anterior y compuesto por dos entidades diferenciadas: una inferior, a lo largo de la ronda perimetral, y otra superior, situada dentro del recinto amurallado junto a la desaparecida Puerta de San Martín. Este fue durante mucho tiempo el único paseo de Zamora y a partir de 1910 la zona inferior fue ajardinada instalando una serie de parterres separados por caminos (Ávila, 2009). Durante la primera década del siglo XX y de acuerdo con el cambio de mentalidad de la época, creció el interés por las zonas verdes en el interior de la ciudad y se proyectó junto al límite oriental 
Figura 4.4.5 Verde urbano de la ciudad de Zamora en 1956.

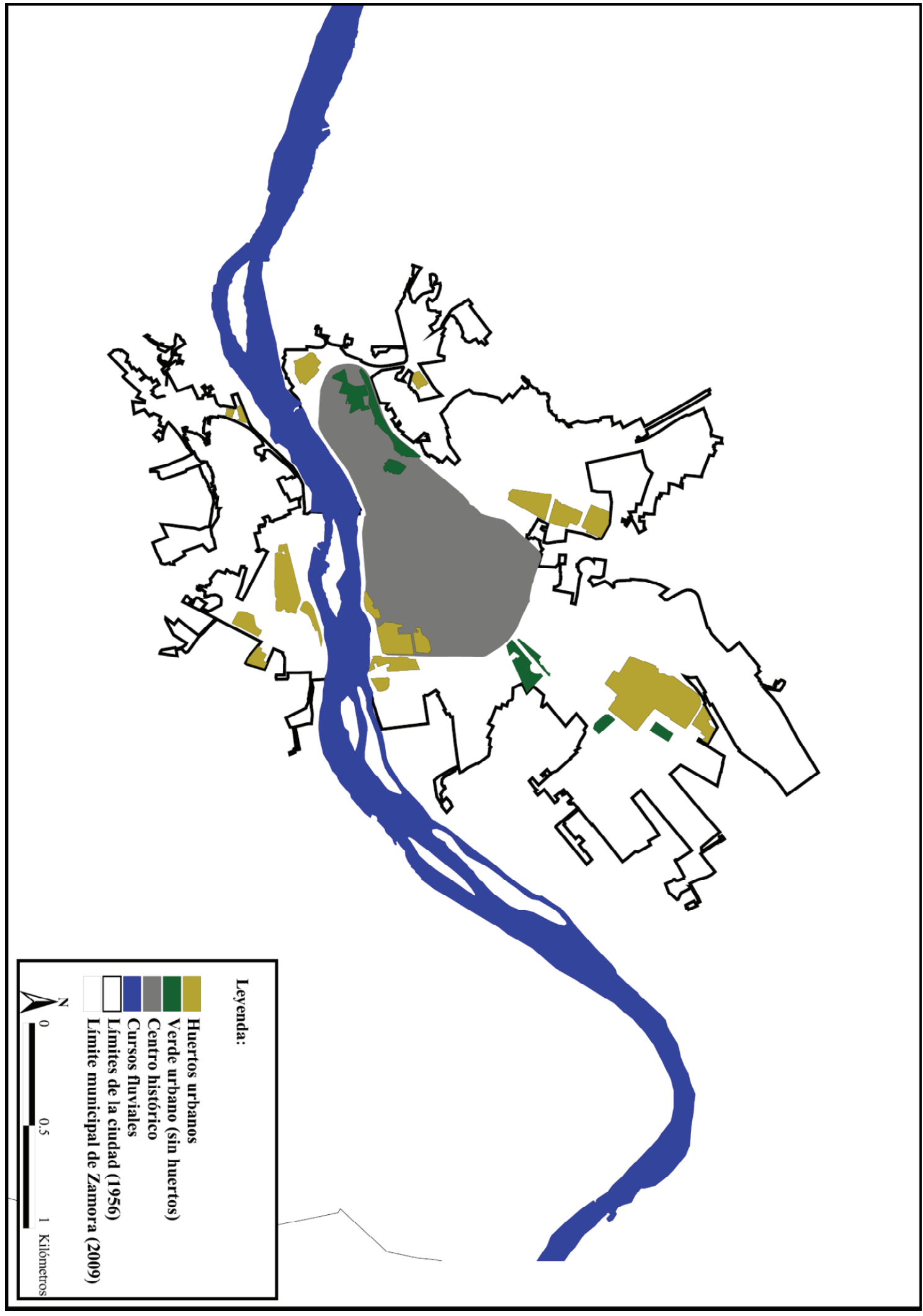

Fuente: elaboración propia a partir de la fotografía aérea de 1956 del IGE. 
del casco histórico, en el entonces denominado Paseo de Requejo, el Parque de la Glorieta que con el tiempo se convertirá en el actual Parque de la Marina (Z-4). También se elaboró un proyecto para convertir en paseo la Avenida de las Tres Cruces, que como ya se dijo, unía la estación de ferrocarril con el centro histórico. Sin embargo, este proyecto no verá la luz, como tampoco lo harán algunas de las zonas verdes previstas por el Anteproyecto del Plan General de Ensanche, puesto que el Plan General de 1949 incrementó el tamaño de las manzanas y en los arrabales se dejaron pocos espacios abiertos ya que, como apunta Ávila (2009), su carácter semirrural aseguraría el contacto con la naturaleza.

En 1956 la ciudad contaba con otros dos espacios verdes: el jardín situado frente al antiguo cuartel de Viriato, hoy Campus de la Universidad de Salamanca, que acabará integrándose en el denominado verde urbano Avenida Cardenal Cisneros (Z-12), y el Jardín de los Salesianos (Z-7), en el interior de las Escuelas Salesianas de San José (Z-7)(ver Figura 4.4.5). Tal vez resulte llamativo no haber mencionado el bosque de Valorio, pero a mediados del siglo XX todavía estaba bastante alejado del tejido urbano consolidado, aunque desde el siglo anterior ya era apreciado como área de esparcimiento. El fenómeno más característico de la ciudad de Zamora es la notable presencia de la agricultura en el interior del tejido urbano, que sería mucho mayor si se atendiese a la morfología de los barrios situados al sur del Duero, asentados de forma discontinua y alargada sobre amplios terrenos cultivados en la vega del río. En 1956 eran un total de diez los huertos enclavados en el interior de Zamora y su extensión alcanzaba las 27,5 ha. Se extendían de forma irregular por la periferia de la ciudad tradicional, quedando enclavados entre este y los barrios o núcleos satélites en proceso de expansión. En el norte, un conjunto de huertas ocupaban la zona topográficamente más deprimida entre el arrabal de San Lázaro (13) y el recinto amurallado, en la histórica vaguada del río Valderaduey, y al este de las mismas, entre la estación de ferrocarril y las Escuelas Salesianas, había un gran terreno dedicado a la agricultura de cerca de diez hectáreas, en el paraje conocido como Las Viñas y que posteriormente dará lugar al barrio del mismo nombre. En el extremo septentrional de este espacio se encontraba el huerto de la Calle Antón de Centenera (Z-29), perteneciente a la orden de las monjas clarisas, con la misma dimensión que en la actualidad. Junto al límite suroriental del recinto amurallado, un amplio terreno dedicado a la agricultura se extendía junto a la Puerta Nueva y a los puentes de hierro y del ferrocarril. Esta parte del ensanche se urbanizará con posterioridad, manteniendo así los usos tradicionales del terreno. Además, en la margen derecha del río, pero en el límite occidental de la ciudad, existía una amplia parcela dedicada a la agricultura en el barrio de Olivares (12) y un poco más al norte se encontraba un huerto de dimensiones reducidas en el arrabal de la Vega del río Valderaduey. La situación en la margen izquierda del Duero era bien distinta, ya que en 1956 todavía era posible identificar con claridad los históricos núcleos de población de Cabañales (10) y Pinilla (9) al oeste, con una gran cantidad de parcelas dedicadas a la agricultura entre ambos, mientras que por otro lado aparecía casi aislado el núcleo de San Frontis (11), con pequeños huertos en su interior.

\section{iii) Recapitulación}

A mediados del siglo XX la ciudad de Zamora contaba con 38.320 habitantes repartidos en cerca de trescientas cincuenta hectáreas, de las cuales aproximadamente un diez por ciento estaban ocupadas por áreas verdes, lo que implica que la densidad verde por superficie era muy elevada $\left(972 \mathrm{~m}^{2} / \mathrm{ha}\right.$ ) (ver Tabla 4.4.3). De toda esta superficie verde $\tan$ solo 6,3 ha pertenecían a cuatro espacios verdes disponibles, lo que arroja un índice de densidad del verde por habitante muy reducido, de tan solo 1,64 $\mathrm{m}^{2} /$ hab. La elevada extensión de los ocho huertos urbanos enclavados en 1956 en el interior del tejido urbano, caracterizaba a una Zamora con gran cantidad de espacios dedicados a la agricultura entre los arrabales históricos 
y la ciudad tradicional, que progresivamente serán absorbidos por el proceso urbanizador durante las décadas siguientes.

Tabla 4.4.3 Principales indicadores del verde urbano de Zamora en 1956.

\begin{tabular}{|c|c|}
\hline & 1956 \\
\hline $\mathrm{N}^{\circ}$ espacios verdes & 13 \\
\hline $\mathrm{N}^{\circ}$ huertos urbanos & 8 \\
\hline $\mathrm{N}^{\circ}$ espacios verdes $\sin$ huertos & 5 \\
\hline $\mathrm{N}^{\circ}$ espacios verdes disponibles & 4 \\
\hline $\mathrm{N}^{\circ}$ habitantes & 38.320 \\
\hline Extensión de la ciudad (ha) & 353,2 \\
\hline Extensión del verde (ha) & 34,3 \\
\hline Extensión de los huertos urbanos (ha) & 27,5 \\
\hline Extensión del verde sin huertos (ha) & 6,8 \\
\hline Extensión del verde urbano disponible (ha) & 6,3 \\
\hline Densidad de verde $\left(\mathrm{m}^{2} / \mathrm{hab}\right)$ & 8,96 \\
\hline Densidad verde sin huertos $\left(\mathrm{m}^{2} / \mathrm{hab}\right)$ & 1,78 \\
\hline Densidad del verde urbano disponible $\left(\mathrm{m}^{2} / \mathrm{hab}\right)$ & 1,64 \\
\hline Densidad verde por superficie $\left(\mathrm{m}^{2} / \mathrm{ha}\right)$ & 972,25 \\
\hline Densidad del verde urbano disponible por superficie $\left(\mathrm{m}^{2} / \mathrm{ha}\right)$ & 178,06 \\
\hline
\end{tabular}

\subsubsection{Crecimiento de la ciudad hasta la aprobación del PGOU de 1986}

Durante casi treinta años, la ciudad experimentó un progresivo crecimiento demográfico que se tradujo en una compactación de la trama urbana, de la que irán desapareciendo grandes extensiones dedicadas a la agricultura. La anexión del Bosque de Valorio (Z-9), en la década de los ochenta, permitirá mitigar el impacto de la falta de planeamiento urbano en materia de zonas verdes en uno de los barios más densamente poblados de la ciudad.

\section{i) Expansión urbana}

Hasta comienzos de la década de los sesenta del siglo pasado la ciudad de Zamora incrementó su superficie en más de ochenta hectáreas pese a no registrar avances económicos significativos, a las que se añadirán otras noventa hasta 1984 en un proceso potenciado por el auge de los servicios y del efecto de centralidad propio de una capital provincial. La población creció a un ritmo suave pero constante en las dos primeras décadas del periodo, experimentando un ligero repunte durante la década de los setenta hasta alcanzar los 59.734 habitantes en 1981. La conformación de una cada vez más numerosa clase media y el auge del sector de la construcción alentaron una progresiva superación del problema de la vivienda experimentado en la década de los cincuenta. Se produjo así una notable expansión del ensanche tanto en su parte norte, donde se urbanizó el terreno adyacente al barrio de La Lana (2) y a las huertas de la Vaguada, como en su parte sur (ver Figura 4.4.6). Sin embargo, el fuerte incremento de este último sector a partir de núcleos aislados como los Grupos de Protección Oficial (8) o las viviendas surgidas en el barrio de la Candelaria (7), limitaron considerablemente el crecimiento planificado de acuerdo con el texto del PGO de 1949. El barrio Alviar (15) en el norte de la ciudad, compuesto mayoritariamente por vivienda autoconstruida, experimentó un fuerte desarrollo hasta unirse con las industrias situadas junto a la estación de ferrocarril. También en el norte, pero más al oeste y tomando como eje central la carretera Villacastín-Vigo, continuó la expansión del histórico barrio de San Lázaro (13), dando lugar al barrio de San José Obrero (14).

También se incorporaron a la ciudad los terrenos agrícolas de la vega del Valderaduey junto al Parque de San Martín (1) y en el sur de la ciudad continuó la expansión y la consoli- 
Figura 4.4.6 Verde urbano de la ciudad de Zamora en 1972.

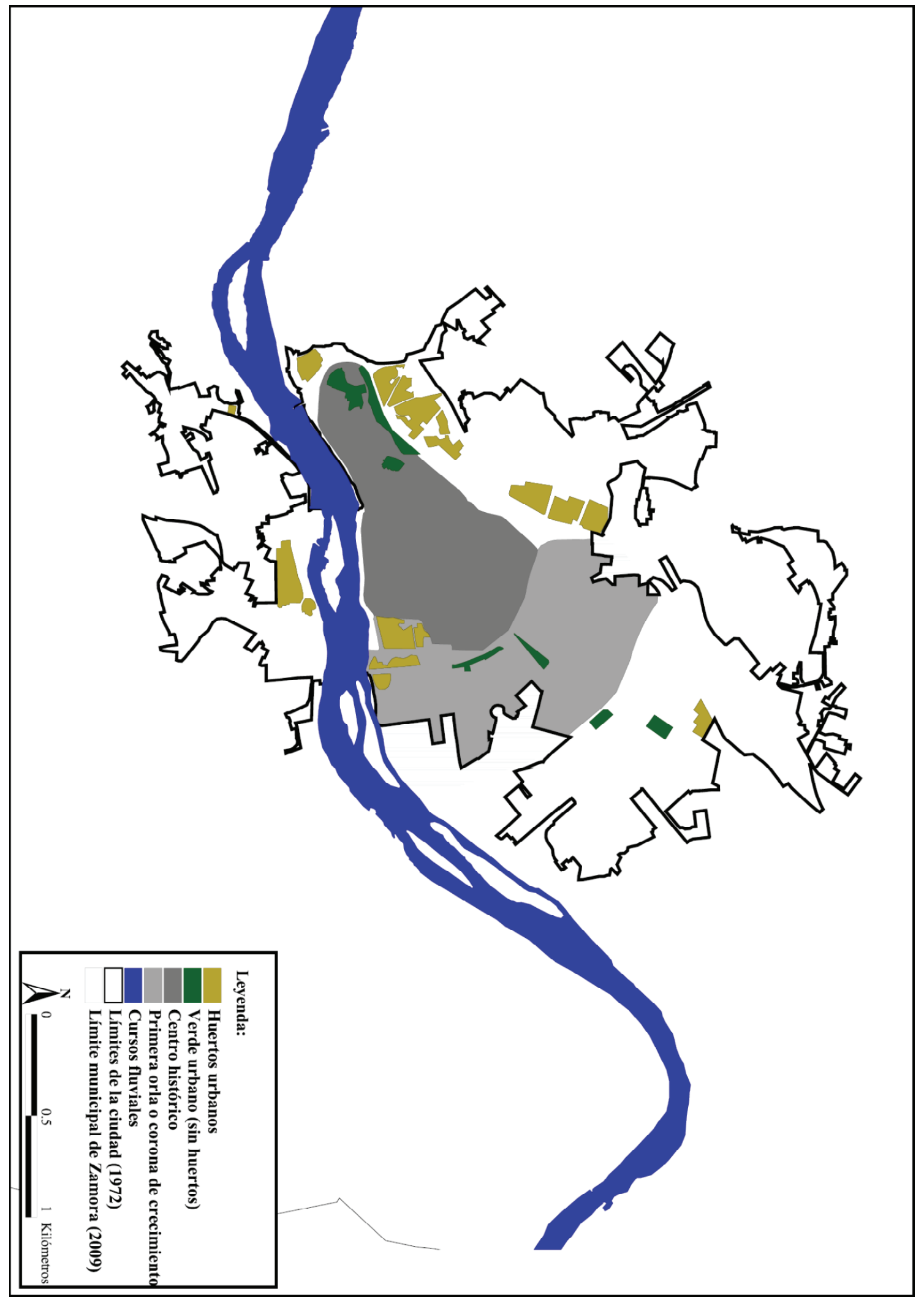

Fuente: elaboración propia a partir de la fotografía aérea del IGN de 1972. 
Figura 4.4.7 Verde urbano de la ciudad de Zamora en 1985.

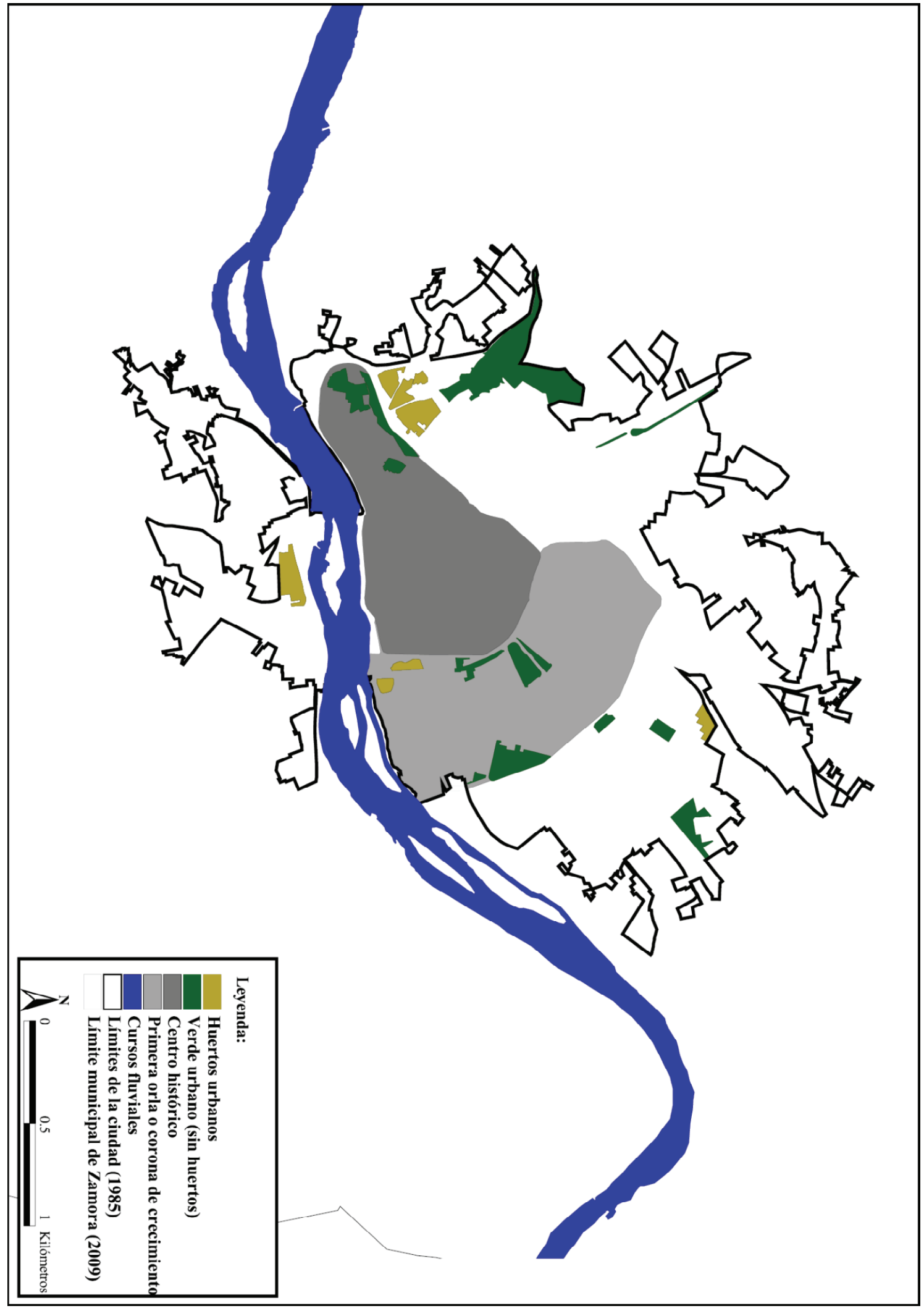

Fuente: elaboración propia a partir de la fotografía aérea del IGN de 1985. 
dación de todos los barrios, aumentando el tamaño de los núcleos originales. En 1973 se aprobó un PGOU acorde con los principios de la Ley de Suelo de 1956, cuyas directrices iban encaminadas a continuar con el ensanche de la ciudad en dirección noreste, considerando la Avenida Requejo como el eje principal. No se contemplaban actuaciones sobre un casco histórico en pleno proceso de abandono y con numerosos edificios en estado de ruina tanto en el barrio de La Lana (2), como en La Horta (6) (Calderón, 1982). Se proyectó también un nuevo puente sobre el Duero y se produjo un progresivo desplazamiento de la zona comercial de la ciudad en dirección a la parte norte del ensanche, aunque se siguió manteniendo la pujanza de las calles que conectaban la Plaza Mayor y la ronda perimetral. Entre 1971 y 1984 se asistió a un fuerte desarrollo del Plan Parcial de la Candelaria (7) (ver Figura 4.4.7), donde se irán levantando una serie de edificios sede de organismos oficiales. Acabará por cerrarse el denominado ensanche al fundirse con el barrio de los Bloques (8), cuyo límite oriental todavía lo marcaban los grupos de vivienda construidos treinta años antes. El PGOU asignó a esta zona la máxima edificabilidad y la compra de nueva vivienda recibió un fuerte impulso por parte de la población de origen rural que vio en este bien una oportunidad de inversión (Calderón, 1982).

El barrio de San Lázaro (13) se colmató en su extremo más próximo a la estación de ferrocarril, con la creación del polígono industrial del Arenal. También se instalaron numerosas industrias junto a la estación de ferrocarril y en torno a la carretera de Villalpando, provocando una notable expansión del barrio Alviar (14) potenciada por la aprobación del Plan Parcial de Los Almendros. Al norte de la ciudad se consolidó el barrio de San José Obrero (14) y comenzó la urbanización de Peña Trevinca (16) con la calle del mismo nombre. De manera general, se asistió a un destacado crecimiento de la ciudad en todas las direcciones, aunque fue algo más débil en los barrios situados al sur del Duero.

\section{ii) Espacios verdes entre 1956 y 1984}

Durante los quince primeros años de este periodo se mantuvo el número de verdes urbanos en Zamora. Desapareció el uso agrícola del barrio de Las Viñas (5) al transformarse en una parcela a la espera de recibir nuevo uso urbano y únicamente se construyó el verde urbano Candelaria Ruiz del Árbol (Z-5) junto a la ronda perimetral, gracias al soterramiento del ferrocarril que actuaba como una barrera para el desarrollo urbano en esa parte del ensanche. En la fotografía aérea de 1972 se pueden observar profundas remodelaciones en el Parque de la Marina (Z-4) para transformarlo en un espacio con bastante más vegetación de la que tiene hoy en día, aunque se mantendrá dividido por la Avenida Requejo durante algunos años. En el barrio de Pinilla (9) los huertos urbanos sufrieron una sensible reducción, así como los situados junto a la Puerta Nueva (6) y en el arrabal de la Vega (1).

Tras la aprobación del PGOU de 1973 se incrementó significativamente la trama verde zamorana con la incorporación del Bosque de Valorio (Z-9) a la ciudad. Pese a que el bosque cuenta con más de ochenta hectáreas, solamente la parte más cercana al tejido urbano consolidado puede considerarse como zona verde ya que el resto tiene un carácter eminentemente forestal. En este periodo se construyó el Parque de León Felipe (Z-14) a través del Plan Parcial de La Candelaria (7) y en el límite oriental junto al hospital, apareció un nuevo verde urbano no disponible: los jardines del actual edificio del CFIE (Z-8) en la Avenida de Requejo. En el norte de la ciudad se creó un verde viario en la Calle de Nuestra Señora de las Mercedes (Z-20), conectando los barrios de San Lázaro (13) y de San José Obrero (14), al tiempo que desapareció un gran patrimonio agrícola en la Vaguada del Valderaduey (13), en Olivares (12) y en San Frontis (11). Por su parte, los huertos situados junto al Puente de Hierro (6) y los del histórico arrabal de la Vega (1) habían sufrido reducciones muy notables, provocando que el total de hectáreas dedicadas a la actividad agrícola pasase de veintidós a nueve hectáreas en tan solo trece años. 


\section{iii) Recapitulación}

Durante los casi treinta años que transcurren durante este periodo se observa un cambio de tendencia de la mayor parte de los índices que hacen referencia al verde urbano. En 1984 se produce un fuerte aumento de la superficie verde disponible, gracias a la incorporación de cuatro espacios verdes que no eran huertos, entre los que se encontraba el Bosque de Valorio (Z-9). La desaparición de una gran extensión de terrenos dedicados a la agricultura urbana provoca que los índices generales de densidad verde por habitante y por superficie se mantengan estables entre 1972 y 1985, mientras que los referentes al verde urbano disponible experimentaron un gran avance hasta casi triplicar los valores de 1956.

Tabla 4.4.3 Principales indicadores del verde urbano de Zamora durante el periodo 1956-1985.

\begin{tabular}{|c|c|c|c|}
\hline & 1956 & 1972 & 1985 \\
\hline $\mathbf{N}^{\circ}$ espacios verdes & 13 & 13 & 14 \\
\hline $\mathrm{N}^{\circ}$ huertos urbanos & 8 & 7 & 4 \\
\hline $\mathrm{N}^{\circ}$ espacios verdes $\sin$ huertos & 5 & 6 & 10 \\
\hline $\mathrm{N}^{\circ}$ espacios verdes disponibles & 4 & 5 & 8 \\
\hline $\mathbf{N}^{\circ}$ habitantes & 38.320 & 49.029 & 59.734 \\
\hline Extensión de la ciudad (ha) & 353,2 & 433,8 & 531,5 \\
\hline Extensión del verde (ha) & 34,3 & 28,6 & 35,0 \\
\hline Extensión de los huertos urbanos (ha) & 27,5 & 22,0 & 9,0 \\
\hline Extensión del verde sin huertos (ha) & 6,8 & 6,6 & 26,0 \\
\hline Extensión del verde urbano disponible (ha) & 6,3 & 6,0 & 23,4 \\
\hline Densidad de verde $\left(\mathrm{m}^{2} / \mathrm{hab}\right)$ & 8,96 & 5,83 & 5,86 \\
\hline Densidad verde $\sin$ huertos $\left(\mathrm{m}^{2} / \mathrm{hab}\right)$ & 1,78 & 1,34 & 4,36 \\
\hline Densidad del verde urbano disponible $\left(\mathrm{m}^{2} / \mathrm{hab}\right)$ & 1,64 & 1,23 & 3,91 \\
\hline Densidad verde por superficie $\left(\mathrm{m}^{2} / \mathrm{ha}\right)$ & 972,25 & 658,84 & 658,26 \\
\hline Densidad del verde urbano disponible por superficie $\left(\mathrm{m}^{2} / \mathrm{ha}\right)$ & 178,06 & 139,45 & 439,84 \\
\hline
\end{tabular}

Fuente: elaboración propia a partir del SGE, del IGN y del INE.

\subsubsection{Evolución de la ciudad durante el periodo de aplicación del PGOU de 1986}

La aprobación a mediados de la década de los ochenta de un nuevo plan general supuso la adaptación del planeamiento urbano zamorano a la segunda Ley del Suelo de 1976. En el año 2000 se aprobará el PEPCH (Plan Especial de Protección del Conjunto Histórico de Zamora), pero durante esa década el planeamiento estará paralizado por la suspensión del PGOU de 2001. No obstante, este hecho detuvo la continua expansión de la ciudad en dirección noreste y la consolidación de los barrios situados al sur del Duero.

\section{i) Expansión urbana}

En los quince años de aplicación del plan la ciudad sufrió un proceso de crecimiento en dirección norte y especialmente de los barrios de la margen izquierda (ver Figura 4.4.8), mientras que desde 2001, fecha de publicación de un plan que posteriormente será anulado por sentencia judicial, el crecimiento se concentró en el sector noreste. En principio, las previsiones realizadas sobre el ritmo de construcción de vivienda fueron relativamente bajas, de tan solo 3.550 viviendas (un 15\% del parque de vivienda existente en 1983). Las mayores intervenciones se centraron en el barrio de Peña Trevinca (16), donde se desarrolló el Plan Parcial Valderaduey, que inclúa un gran espacio comercial con el supermercado Eroski a la cabeza, y el plan parcial de Las Viñas (5). Este último supuso la introducción de una morfología constructiva en bloque de viviendas y la incorporación de un equipamiento notable como es la estación de autobuses. En el territorio que conecta ambos espacios se urbanizará el terreno antiguamente dedicado a la agricultura en la Vaguada del Valderaduey a través del Plan Parcial Los Almendros de 1988. A finales de la década de los ochenta se aprobó la construcción del polígono industrial de La Hiniesta (14), cuyo suelo estará 
prácticamente colmatado a comienzos del siglo XXI, mientras que se proyectó otro espacio industrial de iniciativa pública fuera de la ciudad: el polígono de Los Llanos. En el mismo periodo se dará el visto bueno al Plan Parcial de Puerta Nueva, urbanizando así la parte sur del ensanche, y al Plan Especial de Protección de las Márgenes del Río Duero, aprobado en 1997 y que trató de integrar los espacios ribereños en el tejido urbano. En la década de los noventa se aprobó la reforma de los alrededores del Cuartel de Viriato, que pasará a convertirse en el campus universitario de la ciudad, y se desarrollaron actuaciones de cierto calado en la zona de Transcastillo (12) y en Pinilla (9). De manera general, en los barrios del sur del Duero se fueron incorporando a la urbanización numerosos terrenos agrícolas tanto interiores, como exteriores al tejido urbano consolidado, siendo este el periodo de mayor crecimiento superficial de esta parte de la ciudad.

Es necesario señalar la poca incidencia que han tenido los procesos de periurbanización en torno al núcleo tradicional de Zamora. Sin embargo, a partir de 1997 se observa cómo algunos de los municipios situados en la periferia más próxima comenzaron a recibir emigrantes provenientes del núcleo central, debido a que Zamora se ha consolidado como el principal centro terciario de la provincia, suministrando servicios y equipamientos a una extensa y fragmentada área urbana en la que se concentran cerca de setenta y cinco mil personas.

En el año 2000 se aprobó el Plan Especial de Protección del Conjunto Histórico de Zamora (PEPCH) con el objetivo de rehabilitar y revitalizar el Casco Antiguo (1). Al año siguiente se publicó un nuevo Plan General que pretendía ser una adaptación del de 1986 a la nueva Ley de Urbanismo de Castilla y León de 1999, pero años más tarde fue anulado y se aprobaron una serie de Normas Urbanísticas Transitorias con las que se ha dirigido el urbanismo hasta 2011. Entre 2001 y 2009, que es la fecha límite de esta investigación, la ciudad sufrió una espectacular expansión en dirección noreste apoyada por la instalación fuera del tejido urbano consolidado de dos equipamientos como son el Recinto Ferial IFEZA y el Parque Comercial Vista Alegre. También se produjo una ampliación del polígono de La Hiniesta (14), la expansión territorial en torno a la carretera de la Aldehuela, en la margen derecha del Duero (8), y la consolidación de la Avenida Cardenal Cisneros como ronda interior de la ciudad. En 2002 se inauguró el Estadio Ruta de la Plata en el extremo sur de la ciudad junto al barrio del Sepulcro (10), al que se añadirá otro equipamiento de notables dimensiones como es el proyectado auditorio al aire libre.

\section{ii) Espacios verdes surgidos entre 1986 y 2009}

En los veintidós años que trascurren desde la aprobación del PGOU de 1986 aparecen quince nuevos espacios verdes, de los que diez surgen durante los años de vigencia de dicho plan y tan solo cinco desde 2001. Los verdes urbanos de las márgenes derecha (Z-6) e izquierda del Duero (Z-15) recibieron un fuerte impulso con la aprobación en 1997 del ya mencionado Plan Especial de Protección de las Márgenes del Río Duero. De acuerdo con el crecimiento de la ciudad a través del planeamiento parcial surgió en el barrio de Las Viñas (5) un espacio ajardinado que acabó por completar el verde urbano de la Avenida Cardenal Cisneros (Z-12), y junto a este, en las proximidades de la estación de ferrocarril, se creó el pequeño jardín de la Carretera de la Estación (Z-18) (ver Figura 4.4.9). A través del Plan Parcial Valderaduey apareció el verde urbano Avenida Cardenal Cisneros junto al supermercado Eroski (Z-21) y en el barrio de Peña Trevinca (16) se acondicionó una pequeña depresión como parque (Z-10) de casi dos hectáreas. También surgieron en el interior del tejido urbano una serie de terrenos dedicados a la agricultura en torno a la Avenida de Galicia que superaban las siete hectáreas (Z-22). En los barrios situados al sur del Duero se reprodujo este mismo fenómeno, con la particularidad de que la superficie agrícola entre Cabañales (10) y San Frontis (11) sumaba veinte hectáreas, mientras que en Pinilla (9), 
Figura 4.4.8 Evolución del tejido urbano de Zamora entre 1985 y 2009.

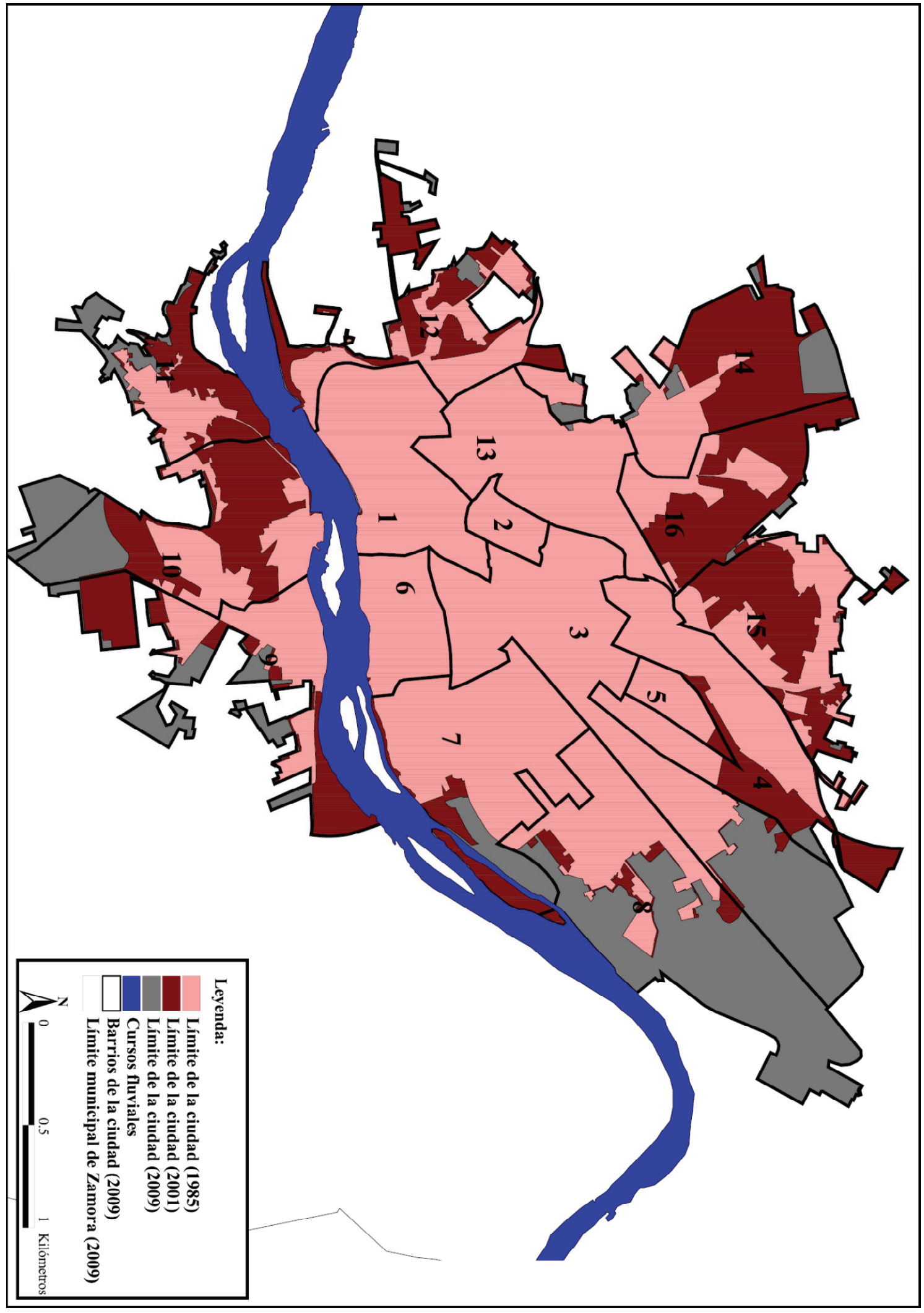

Fuente: elaboración propia a partir de la fotografía aérea del IGN de 1985, de las ortofotos de 2001 y 2009 del IGN y del Ayuntamiento de Zamora (2007). 
Figura 4.4.9 Verde urbano de la ciudad de Zamora en 2001.

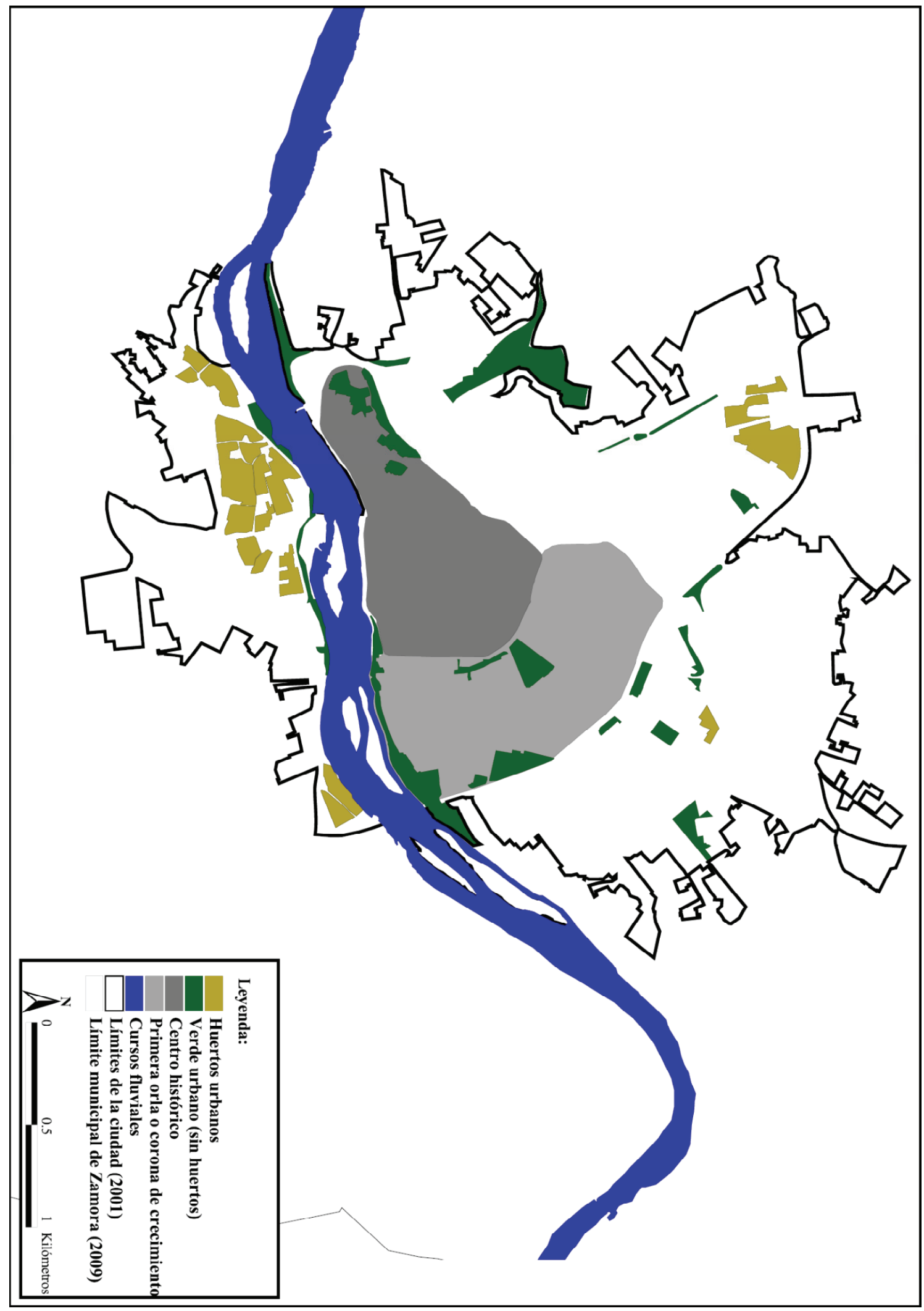

Fuente: elaboración propia a partir de la ortofoto de 2001 del IGN. 
Figura 4.4.10 Verde urbano de la ciudad de Zamora en 2009.

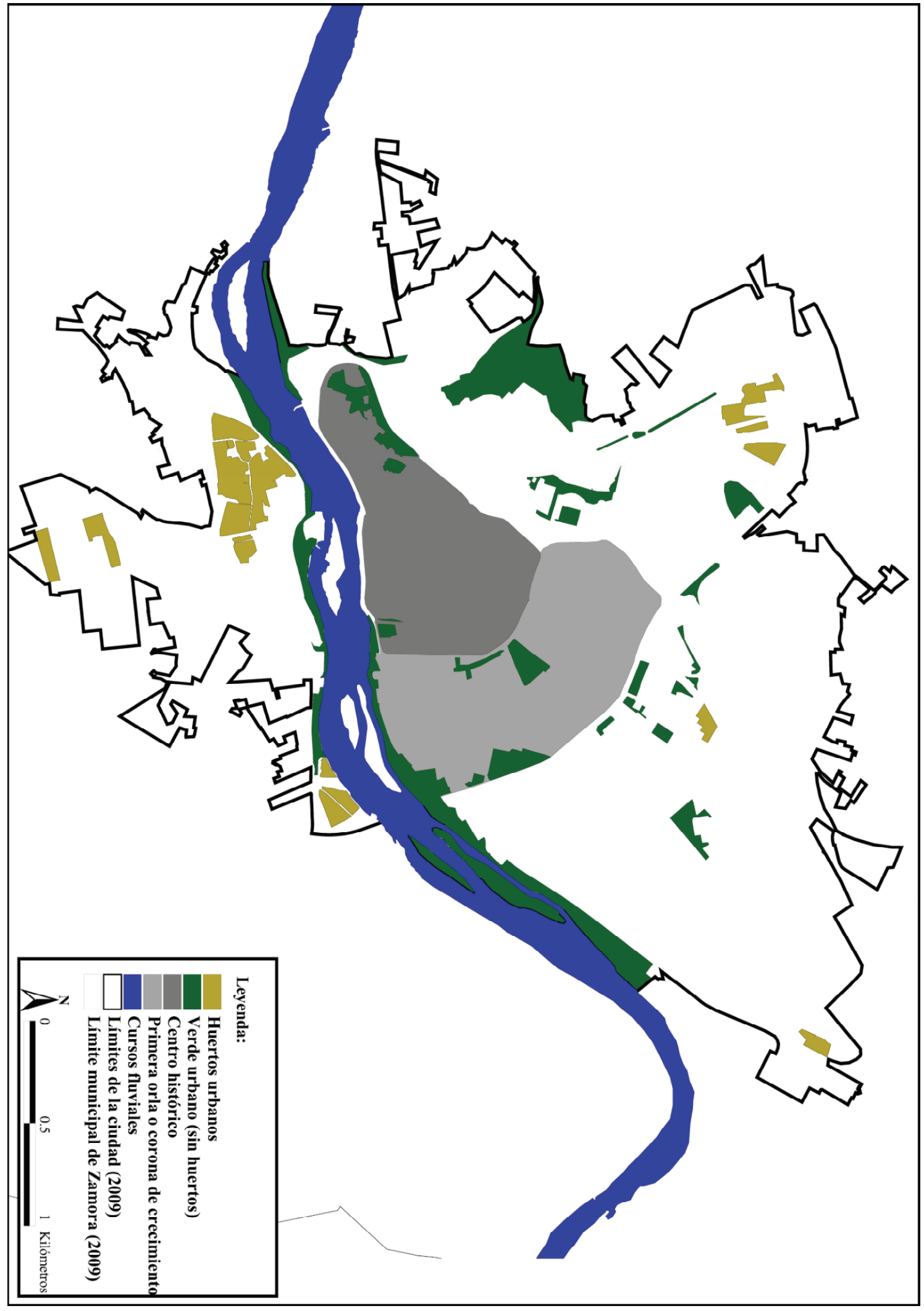

Fuente: elaboración propia a partir de la ortofoto de 2009 del IGN. 
donde también se continuó con la agricultura en el interior del tejido urbano, la extensión apenas excedía las tres hectáreas. En total, la superficie dedicada a esta actividad entre 1984 y 2001 se triplicó hasta alcanzar las 31,7 ha y ello a pesar de que en este periodo desaparecieron algunos huertos históricos de la ciudad como los de la Vega (1) y los de Puerta Nueva (6). En cuanto al resto de zonas verdes, surgió el verde urbano de la Calle de los Caballeros (Z-2), al amparo del Plan Parcial Trascastillo, concebido como parte del pasillo verde que conectaría el Bosque de Valorio (Z-9) con el Duero, a través del Parque de Olivares (Z-3), donde desembocaría este corredor. Desde 2001 solamente aparecieron dos nuevos verdes urbanos disponibles: los Jardines de la Vaguada (Z-11), que ocuparon el solar donde había estado instalado el campo de fútbol, que a su vez había sustituido a las huertas allí presentes, y el verde urbano de Puerta Nueva (Z-19), construido en un baldío urbano sin ocupación desde que se abandonasen las labores agrícolas (ver Figura 4.4.10). Durante este periodo los huertos urbanos situados en el norte de la ciudad y en los barrios al sur del río sufrieron reducciones bastante considerables, no tanto por haber sido urbanizados, sino porque desaparece la práctica agrícola en espera de una posible transformación del uso del suelo. El crecimiento de la ciudad confinó tres nuevos huertos en los bordes urbanos, concretamente uno junto a IFEZA en el límite oriental (Z-23) y dos más tanto al norte como al sur del nuevo estadio de fútbol (Z-24 y Z-25), en el barrio del Sepulcro (10).

\section{iii) Recapitulación}

Desde la aprobación del PGOU de 1986 la trama verde zamorana se duplicó en poco más de dos décadas. El caso de Zamora es singular puesto que se trata de una ciudad que históricamente ha contado con barrios con un marcado componente rural, por lo que en ocasiones no se consideró prioritario crear en ellos espacios verdes por ser núcleos en contacto permanente con la naturaleza. En la Figura 4.4.10 se observa el estado del verde urbano en 2009, identificando veintinueve espacios de los que ocho eran huertos urbanos con una extensión de 25,7 ha, es decir, una cuarta parte de la trama verde de la ciudad. Zamora tiene el índice de densidad verde por habitante más elevado de esta investigación por la elevada extensión del verde urbano disponible, con 10,76 $\mathrm{m}^{2} /$ hab (ver Tabla 4.4.4). El conjunto de la trama verde, representa un $10,6 \%$ de la superficie de la ciudad $\left(1.063,02 \mathrm{~m}^{2} / \mathrm{ha}\right)$, lo que implica que cuenta con una gran cantidad de espacios abiertos.

Para contrastar estos índices con la evolución real de Zamora se ha elaborado la Figura 4.4.11 a partir de los datos obtenidos en la Tabla 4.4.5, en los que aparecen datos referentes al número de viviendas promocionadas y al precio de la vivienda (precio medio por promoción). El estancamiento demográfico experimentado por la ciudad en los últimos siete años contrasta con la continua expansión territorial de la ciudad, impulsada por un elevado número de viviendas construidas hasta alcanzar un aumento del tamaño de la ciudad del 23,1\%. Como en los otros casos analizados, este proceso tiene un fuerte componente especulativo que se apoya en un incremento constante del precio de la vivienda durante el periodo previo a la crisis económica que se empieza a sentir desde 2008.

\subsubsection{Síntesis de la evolución histórica del verde urbano en Zamora}

En la Tabla 4.4.6 aparecen clasificados los espacios verdes en función del periodo en el que fueron creados, identificando claramente el periodo de vigencia del PGOU de 1986 como el más prolífico (ver Figura 4.4.12). Antes de 1956 habían sido creados seis parques de reducida dimensión que, sorprendentemente, superan en número al verde urbano disponible construido en los últimos años del periodo analizado. La explicación a este fenómeno seguramente se encuentre en la incertidumbre y la parálisis generada con la suspensión del PGOU de 2001 a través de un largo proceso judicial dilatado durante la última década, que 
Tabla 4.4.4 Principales indicadores del verde urbano de Zamora durante el período 1985-2008.

\begin{tabular}{|c|c|c|c|}
\hline & 1985 & 2001 & 2008 \\
\hline $\mathbf{N}^{\mathbf{o}}$ espacios verdes & 14 & 24 & 29 \\
\hline $\mathbf{N}^{\circ}$ huertos urbanos & 4 & 5 & 8 \\
\hline $\mathbf{N}^{\circ}$ espacios verdes $\sin$ huertos & 10 & 19 & 21 \\
\hline $\mathrm{N}^{\circ}$ espacios verdes disponibles & 8 & 16 & 18 \\
\hline $\mathrm{N}^{\mathrm{o}}$ habitantes & 59.734 & 65.633 & 66.672 \\
\hline Extensión de la ciudad (ha) & 531,5 & 774,5 & 956,0 \\
\hline Extensión del verde (ha) & 35,0 & 90,6 & 101,6 \\
\hline Extensión de los huertos urbanos (ha) & 9,0 & 31,7 & 25,7 \\
\hline Extensión del verde sin huertos (ha) & 26,0 & 58,9 & 76,0 \\
\hline Extensión del verde urbano disponible (ha) & 23,4 & 56,4 & 71,7 \\
\hline Densidad de verde $\left(\mathrm{m}^{2} / \mathrm{hab}\right)$ & 5,86 & 13,81 & 15,24 \\
\hline Densidad verde $\sin$ huertos $\left(\mathrm{m}^{2} / \mathrm{hab}\right)$ & 4,36 & 8,97 & 11,39 \\
\hline Densidad del verde urbano disponible $\left(\mathrm{m}^{2} / \mathrm{hab}\right)$ & 3,91 & 8,60 & 10,76 \\
\hline Densidad verde por superficie $\left(\mathrm{m}^{2} / \mathrm{ha}\right)$ & 658,26 & $1.170,22$ & $1.063,02$ \\
\hline Densidad del verde urbano disponible por superficie $\left(\mathrm{m}^{2} / \mathrm{ha}\right)$ & 439,84 & 728,49 & 750,45 \\
\hline
\end{tabular}

Fuente: elaboración propia a partir del IGN y del INE.

Tabla 4.4.5 Crecimiento porcentual acumulado de las principales variables urbanas de Zamora.

\begin{tabular}{|c|c|c|c|c|c|c|c|c|}
\hline Años & $\begin{array}{c}\text { Población } \\
\text { (habitantes) }\end{array}$ & $\begin{array}{c}\% \\
\text { acumulado }\end{array}$ & $\begin{array}{c}\text { Territorio } \\
\text { (ha) }\end{array}$ & $\begin{array}{c}\% \\
\text { acumulado }\end{array}$ & $\begin{array}{c}\text { Precio } \\
\text { vivienda } \\
\text { (euro/m } \mathbf{m}^{2}\end{array}$ & $\begin{array}{c}\% \\
\text { acumulado }\end{array}$ & $\begin{array}{c}\mathbf{N}^{\mathbf{o}} \\
\text { viviendas } \\
\text { construida }\end{array}$ & $\begin{array}{c}\% \\
\text { acumulado }\end{array}$ \\
\hline $\mathbf{2 0 0 0}$ & 65.226 & 0,5 & & & & & & \\
\hline $\mathbf{2 0 0 1}$ & 65.633 & 0,6 & 774,5 & 3,3 & & & & \\
\hline $\mathbf{2 0 0 2}$ & 65.575 & $-0,1$ & & 6,6 & $1.084,5$ & & 976 & \\
\hline $\mathbf{2 0 0 3}$ & 65.639 & 0,1 & & 9,9 & $1.178,0$ & 8,6 & 1.081 & 10,8 \\
\hline $\mathbf{2 0 0 4}$ & 65.646 & 0,0 & & 13,2 & $1.479,3$ & 34,2 & 1.724 & 70,2 \\
\hline $\mathbf{2 0 0 5}$ & 66.123 & 0,7 & & 16,5 & $1.768,8$ & 53,8 & 1.591 & 62,5 \\
\hline $\mathbf{2 0 0 6}$ & 66.135 & 0,0 & & 19,8 & $1.988,9$ & 66,2 & 1.798 & 75,5 \\
\hline $\mathbf{2 0 0 7}$ & 66.138 & 0,0 & 956,0 & 23,1 & $2.112,0$ & 72,4 & 1.613 & 65,2 \\
\hline
\end{tabular}

* El porcentaje acumulado de territorio se ha estimado empleando un ajuste lineal.

Fuente: elaboración propia a partir del INE y del Ministerio de Fomento.

Figura 4.4.11 Crecimiento porcentual acumulado de las principales variables urbanas de Zamora.

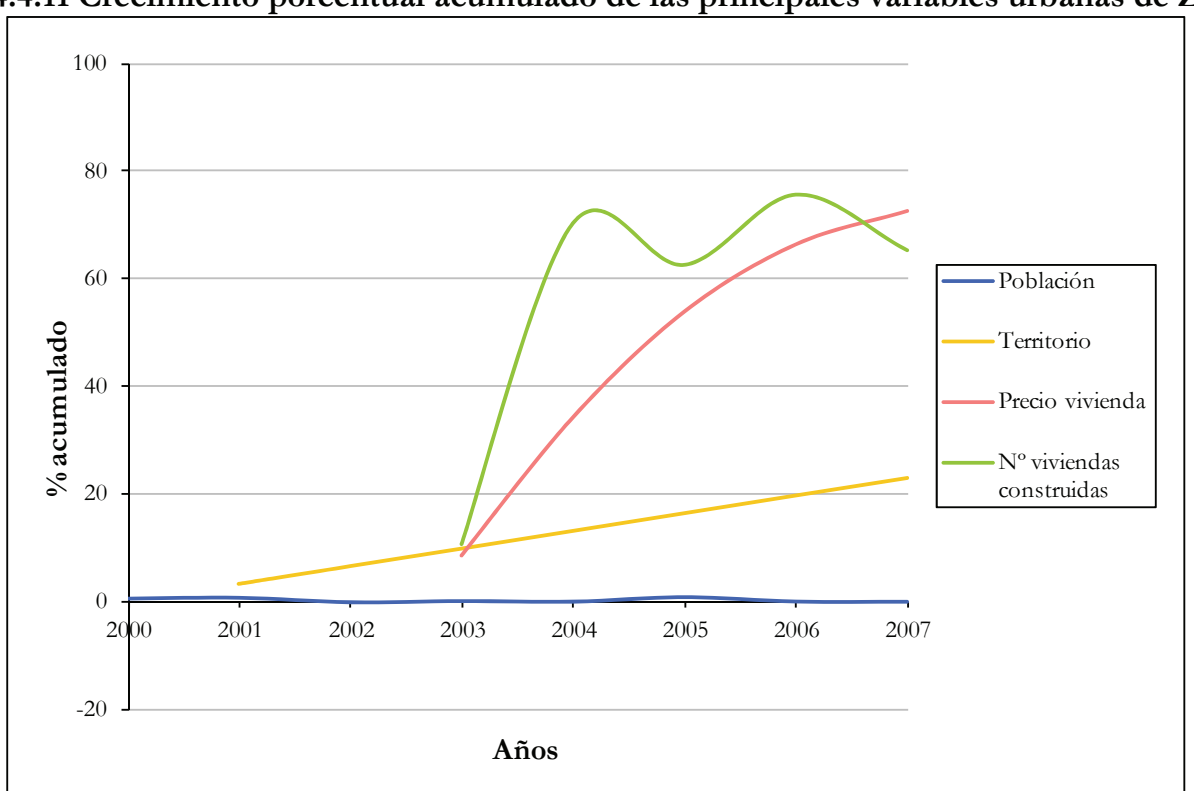

Fuente: elaboración propia a partir del INE y del Ministerio de Fomento.

no concluirá hasta la publicación en 2011 de un nuevo PGOU, ya fuera del ámbito de estudio de esta investigación. De los espacios verdes surgidos entre 1984 y 2001, siete están situados en las orillas del Duero, formando junto con el verde urbano de Puerta Nueva (Z- 
19), la única concentración verde de entidad de Zamora, mientras que otros cinco se distribuyen en torno al eje de la Avenida Cardenal Cisneros en el norte de la ciudad. Si se atiende al uso anterior del terreno sobre el que se asientan las actuales áreas verdes (ver Figura 4.4.13), se constata la histórica ligazón de la ciudad de Zamora con las actividades primarias. Once son las que estuvieron, o están, vinculadas con esta labor y en 1956 se puede comprobar cómo los huertos originales eran más extensos que los actuales Parque de Olivares (Z-3), Jardines de la Vaguada (Z-11), verde urbano Avenida Cardenal Cisneros (Z12) y verde urbano Puerta Nueva (Z-19). Igual de numerosos son los espacios incorporados en la periferia con el crecimiento progresivo de la ciudad ya que es allí donde resulta más sencillo disponer de parcelas no urbanizadas.

En Zamora, tan solo cuatro zonas verdes surgieron de actuaciones en el interior del tejido urbano consolidado y las más notables se llevaron a cabo en las orillas del río amparadas por el Plan Especial de Protección de las Márgenes del Río Duero, mientras que el soterramiento de la vía del tren permitió la aparición del pequeño verde urbano Candelaria Ruiz del Árbol (Z-5) entre 1956 y 1971. El protagonismo de las órdenes religiosas en la creación de parques es muy débil y únicamente tres espacios tienen este origen: un huerto del convento de las monjas clarisas (Z-29), el jardín de las antiguas escuelas salesianas (Z-7) y el Parque del Castillo y de la Catedral (Z-1).

Tabla 4.4.6 Clasificación del verde urbano de Zamora según distintos parámetros.

\begin{tabular}{|c|c|c|c|c|c|c|}
\hline $\begin{array}{c}\text { Periodo de } \\
\text { aparición }\end{array}$ & Anterior a 1956 & 1956-1971 & 1971-1984 & 1984-2002 & $2002-2007$ & Total \\
\hline Total & 6 & 1 & 4 & 13 & 5 & 29 \\
\hline $\begin{array}{l}\text { Uso anterior } \\
\text { del suelo }\end{array}$ & $\begin{array}{c}\text { Espacio } \\
\text { periférico o } \\
\text { reciente } \\
\text { urbanización } \\
\end{array}$ & $\begin{array}{c}\text { Recuperación } \\
\text { de espacios }\end{array}$ & $\begin{array}{l}\text { Huertas y } \\
\text { jardines } \\
\text { clericales }\end{array}$ & $\begin{array}{l}\text { Huertos } \\
\text { urbanos }\end{array}$ & Total & \\
\hline Total & 11 & 4 & 3 & 11 & 29 & \\
\hline
\end{tabular}

\section{Fuente: elaboración propia.}

Para analizar la distribución del verde urbano en los barrios de Zamora se ha elaborado la Tabla 4.4.7 en la que aparece detallado el número de habitantes, la superficie y la densidad de población de cada uno de ellos. En la Figura 4.4.14 aparecen representados los espacios verdes junto con la densidad de cada barrio, empleando un color rojo para los valores más elevados mientras que el gris fue utilizado para los más reducidos.

Todos los barrios de Zamora, con la excepción de La Lana - San Esteban (2), cuentan con alguna zona verde en su interior. Este último caso es excepcional: se trata de un barrio muy reducido en el que habitan menos de dos mil personas y que además cuenta con un espacio verde adyacente como son los Jardines de la Vaguada (Z-11). La fuerte expansión oriental de los barrios del Centro Ciudad (3) y de los Bloques - Barriada Asturias - Villagodio (8), producida durante la primera década del siglo XXI, no ha incorporado grandes espacios verdes, quizás porque se trate de un territorio compuesto por grandes vacíos urbanos a la espera de ser realmente urbanizados y ocupados. Un caso similar se vive en Alviar (15), donde únicamente hay un pequeño espacio verde, pero su sector central se encuentra en plena fase de urbanización. El caso de los barrios situados al sur del Duero es ciertamente peculiar: únicamente cuentan con un verde urbano, sin incluir los huertos, la margen izquierda del Duero (Z-15), que se extiende por el límite oriental de los tres barrios, y a medida que el caserío se aleja del curso fluvial el hábitat urbano comienza a mezclarse con terrenos agrícolas asegurando así el contacto con la naturaleza. Los barrios con mejores dotaciones en espacios verdes son Las Viñas (5), que cuenta con una de las densidades de población más 
Figura 4.4.12 Periodo de creación del verde urbano zamorano.

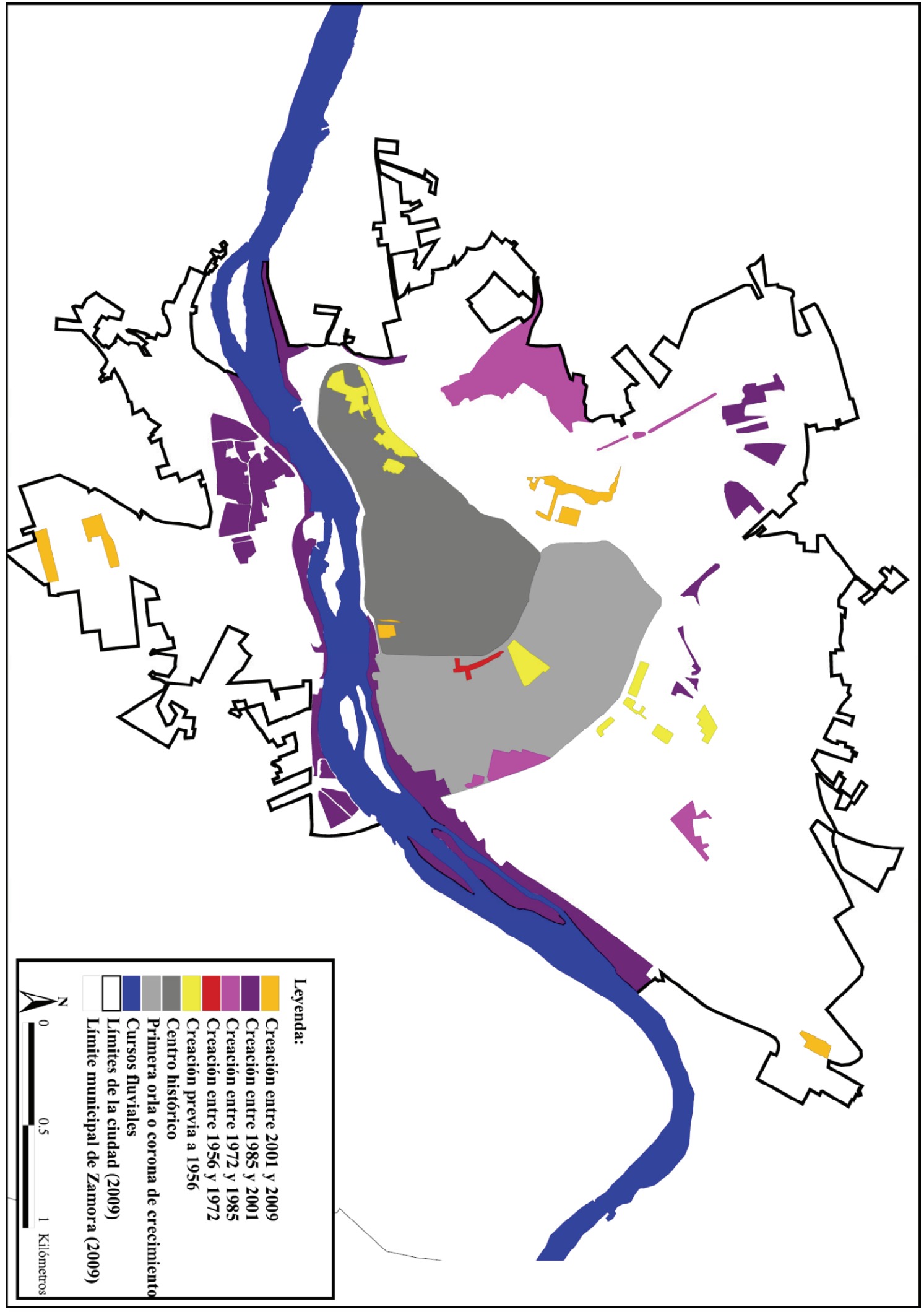

Fuente: elaboración propia a partir de la ortofoto de 2009 del IGN. 
Figura 4.4.13 Origen del verde urbano zamorano.

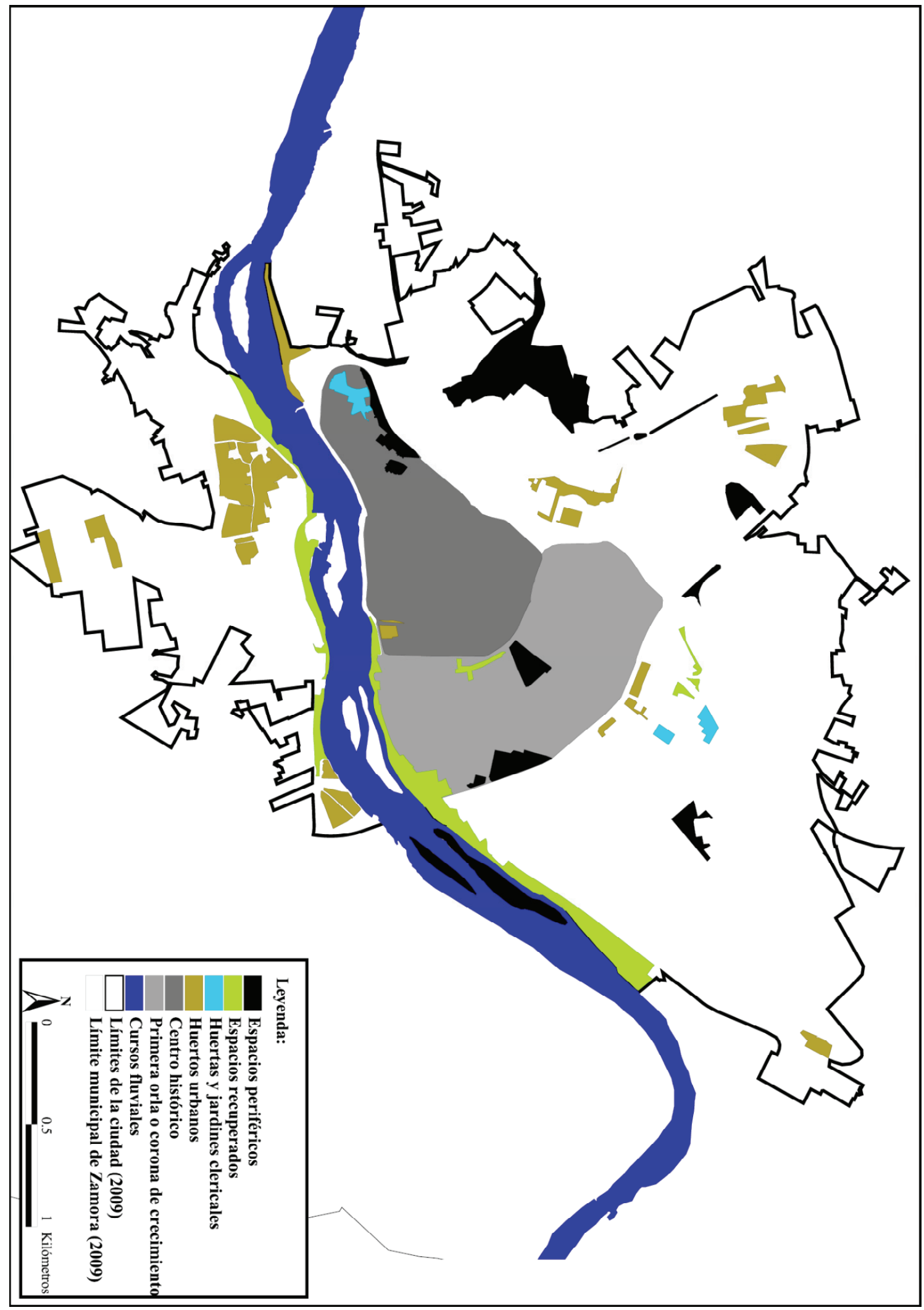

Fuente: elaboración propia a partir de la ortofoto de 2009 del IGN. 
Figura 4.4.14 Localización de los espacios verdes en los barrios de Zamora.

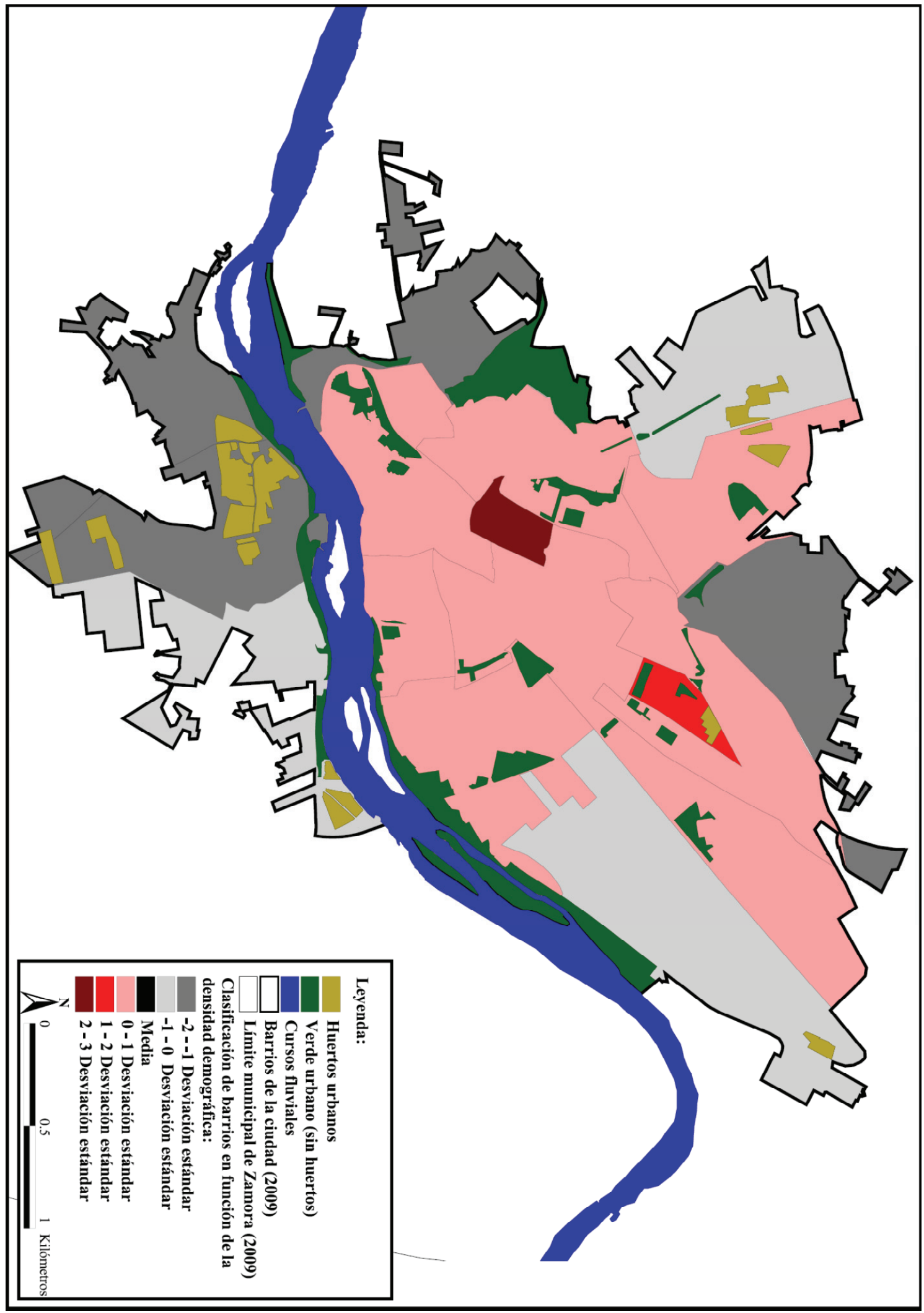

Media $=7.949 \mathrm{hab} / \mathrm{km}^{2}$. Desviación estándar $=5.052 \mathrm{hab} / \mathrm{km}^{2}$

Fuente: elaboración propia a partir de la ortofoto de 2009 del IGN y del Ayuntamiento de Zamora (2007). 
Tabla 4.4.7 Superficie y población de los barrios de Zamora.

\begin{tabular}{|c|l|c|c|c|}
\hline Número Nombre barrio & $\begin{array}{c}\mathbf{N}^{\mathbf{o}} \\
\text { habitantes }\end{array}$ & $\begin{array}{c}\text { Superficie } \\
\text { (ha) }\end{array}$ & $\begin{array}{c}\text { Densidad } \\
\left(\mathrm{hab} / \mathbf{k m}^{2}\right)\end{array}$ \\
\hline $\mathbf{1}$ & Casco Antiguo & 4.623 & 57,85 & 7.991 \\
\hline $\mathbf{2}$ & La Lana - San Esteban & 1.741 & 9,01 & 19.324 \\
\hline $\mathbf{3}$ & Centro Ciudad & 13.986 & 112,22 & 12.463 \\
\hline $\mathbf{4}$ & Pantoja & 4.711 & 57,56 & 8.184 \\
\hline $\mathbf{5}$ & Las Viñas & 1.589 & 9,84 & 16.155 \\
\hline $\mathbf{6}$ & Horta - Barrios Bajos & 3.614 & 33,25 & 10.870 \\
\hline $\mathbf{7}$ & Candelaria - Peña de Francia & 8.281 & 88,81 & 9.324 \\
\hline $\mathbf{8}$ & Bloques - Barriada Asturias - Villagodio & 6.374 & 107,94 & 5.905 \\
\hline $\mathbf{9}$ & Pinilla - San Ramón & 2.795 & 71,98 & 3.883 \\
\hline $\mathbf{1 0}$ & Cabañales - Sepulcro & 1.410 & 75,39 & 1.870 \\
\hline $\mathbf{1 1}$ & San Frontis - Carrascal & 1.110 & 46,98 & 2.363 \\
\hline $\mathbf{1 2}$ & Olivares - Isidro -Espíritu Santo - Obelisco & 1.587 & 56,70 & 2.799 \\
\hline $\mathbf{1 3}$ & San Lázaro & 6.101 & 54,23 & 11.250 \\
\hline $\mathbf{1 4}$ & San José Obrero & 2.848 & 66,05 & 4.312 \\
\hline $\mathbf{1 5}$ & Alviar & 957 & 60,25 & 1.588 \\
\hline $\mathbf{1 6}$ & Peña Trevinca & 4.271 & 47,89 & 8.918 \\
\hline & Total & $\mathbf{6 5 . 9 9 8}$ & $\mathbf{9 5 5 , 9 6}$ & $\mathbf{6 . 9 0 4}$ \\
\hline
\end{tabular}

Fuente: elaboración propia a partir del INE y del Ayuntamiento de Zamora (2007).

elevadas y con un elevado porcentaje de su suelo consagrado a este uso, Candelaria - Peña de Francia (7), con tres zonas verdes de grandes dimensiones como son el Parque de León Felipe (Z-14), el Parque de la Marina (Z-4) y la margen derecha del Duero (Z-6) y Horta Barrios Bajos (6), que junto a este último espacio cuenta también con el verde urbano de Puerta Nueva (Z-19).

\subsubsection{Evolución de los indicadores de Zamora}

En la Tabla 4.4.9 aparecen recogidos los indicadores referentes a los espacios verdes de Zamora en el periodo 1956-2009 y se observa una clara distinción entre la evolución del conjunto de la trama verde y la del conjunto del verde urbano disponible. El primero de ellos muestra una gráfica en forma de uve (ver Figura 4.4.15), con valores muy elevados al comienzo del periodo de estudio $\left(8,96 \mathrm{~m}^{2} / \mathrm{hab}\right.$ y $\left.972,25 \mathrm{~m}^{2} / \mathrm{ha}\right)$, debido a la enorme superficie agrícola enclavada en el interior de la ciudad, que representaba un $80 \%$ de la trama verde.

Hasta 1985 se produce a una reducción progresiva de la superficie cultivada en el interior de la ciudad, para después incrementarse en el siglo XXI debido a la fuerte expansión de Zamora por la periferia agrícola más cercana. Conjuntamente se realizan actuaciones decididas en la creación de espacios verdes, alcanzando así valores muy elevados tanto para la densidad verde por habitante $\left(15,24 \mathrm{~m}^{2} / \mathrm{hab}\right)$ como por la densidad verde territorial $(1.063,02$ $\mathrm{m}^{2} / \mathrm{hab}$ ). En cambio, la evolución del verde disponible sigue una evolución diferente al comenzar con valores muy bajos $\left(1,64 \mathrm{~m}^{2} /\right.$ hab y $\left.178,06 \mathrm{~m}^{2} / \mathrm{ha}\right)$, que descenderán todavía más en 1972 debido a la fuerte remodelación que sufrió el Parque de la Marina (Z-4). Estos índices se mantuvieron hasta 1985 pese a que la trama verde sufrió un fuerte incremento con la incorporación del Bosque de Valorio (Z-9) porque tanto la población como la superficie de Zamora aumentaron a un ritmo muy similar. No será hasta el siglo XXI cuando comiencen a registrarse valores elevados del verde urbano disponible, terminado el periodo con dieciocho espacios verdes de estas características y un índice de $10,76 \mathrm{~m}^{2} /$ hab, que supera los $9 \mathrm{~m}^{2} /$ hab propuestos por la OMS y los $10 \mathrm{~m}^{2} /$ hab establecidos por Magalhães (1992) y Santana et al. (2007 y 2010), con una densidad superficial de $750,45 \mathrm{~m}^{2} /$ ha que es siete veces superior a la de 1956. 
Tabla 4.4.8 Principales indicadores del verde urbano de Zamora durante el periodo 1956-2009.

\begin{tabular}{|c|c|c|c|c|c|}
\hline & 1956 & 1972 & 1985 & 2001 & 2008 \\
\hline $\mathbf{N}^{0}$ espacios verdes & 13 & 13 & 14 & 24 & 29 \\
\hline $\mathrm{N}^{\circ}$ huertos urbanos & 8 & 7 & 4 & 5 & 8 \\
\hline $\mathrm{N}^{\circ}$ espacios verdes $\sin$ huertos & 5 & 6 & 10 & 19 & 21 \\
\hline $\mathrm{N}^{\circ}$ espacios verdes disponibles & 4 & 5 & 8 & 16 & 18 \\
\hline $\mathbf{N}^{\circ}$ habitantes & 38.320 & 49.029 & 59.734 & 65.633 & 66.672 \\
\hline Extensión de la ciudad (ha) & 353,2 & 433,8 & 531,5 & 774,5 & 956,0 \\
\hline Extensión del verde (ha) & 34,3 & 28,6 & 35,0 & 90,6 & 101,6 \\
\hline Extensión de los huertos urbanos (ha) & 27,5 & 22,0 & 9,0 & 31,7 & 25,7 \\
\hline Extensión del verde sin huertos (ha) & 6,8 & 6,6 & 26,0 & 58,9 & 76,0 \\
\hline Extensión del verde urbano disponible (ha) & 6,3 & 6,0 & 23,4 & 56,4 & 71,7 \\
\hline Densidad de verde $\left(\mathrm{m}^{2} / \mathrm{hab}\right)$ & 8,96 & 5,83 & 5,86 & 13,81 & 15,24 \\
\hline Densidad verde $\sin$ huertos $\left(\mathrm{m}^{2} / \mathrm{hab}\right)$ & 1,78 & 1,34 & 4,36 & 8,97 & 11,39 \\
\hline Densidad del verde urbano disponible $\left(\mathrm{m}^{2} / \mathrm{hab}\right)$ & 1,64 & 1,23 & 3,91 & 8,60 & 10,76 \\
\hline Densidad verde por superficie $\left(\mathrm{m}^{2} / \mathrm{ha}\right)$ & 972,25 & 658,84 & 658,26 & $1.170,22$ & $1.063,02$ \\
\hline Densidad del verde urbano disponible por superficie $\left(\mathrm{m}^{2} / \mathrm{ha}\right)$ & 178,06 & 139,45 & 439,84 & 728,49 & 750,45 \\
\hline
\end{tabular}

Fuente: elaboración propia a partir del SGE, del IGN y del INE.

Figura 4.4.15 Evolución de los principales indicadores del verde urbano y del verde urbano disponible en Zamora.

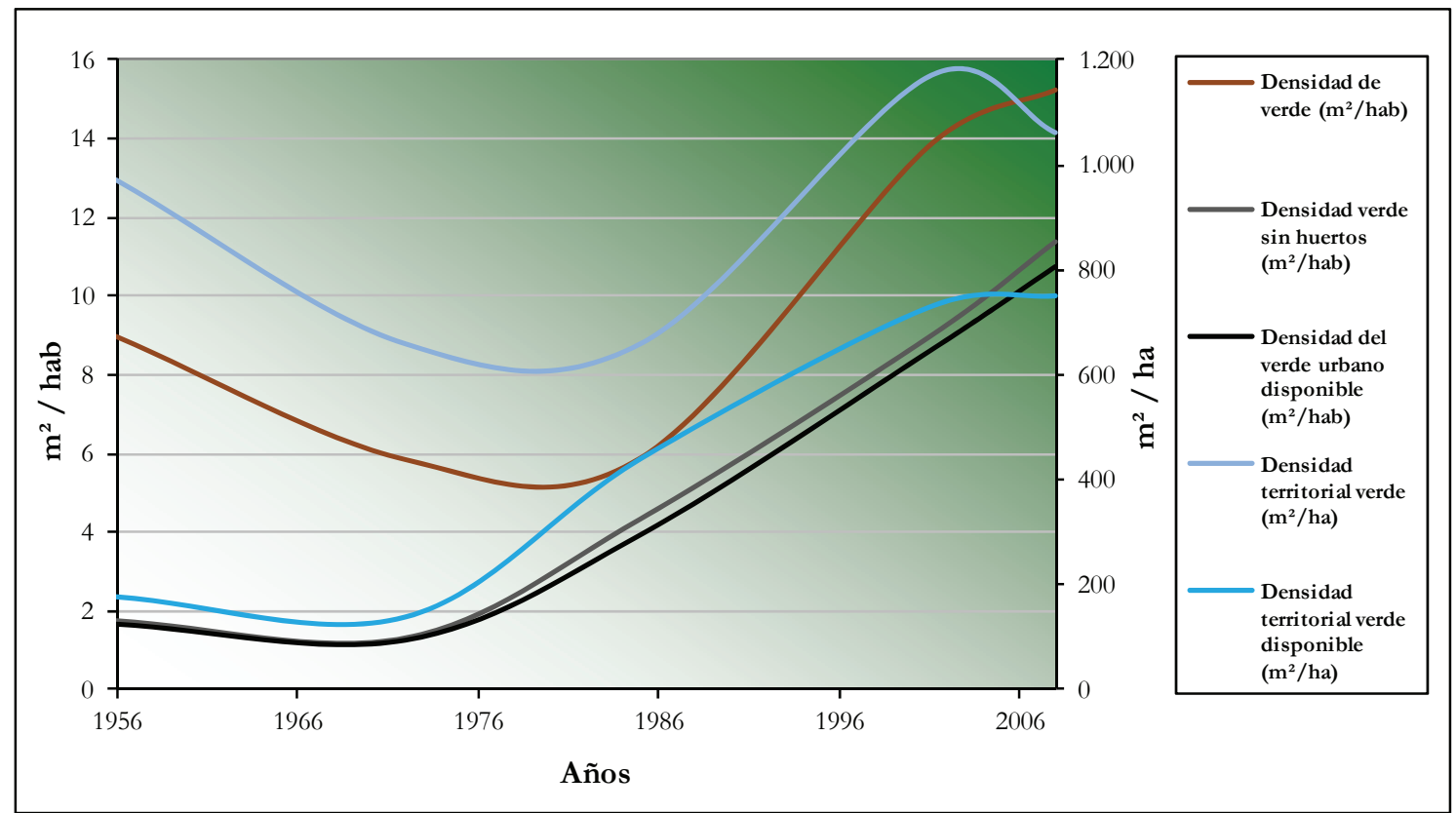

Fuente: elaboración propia a partir del SGE, del IGN y del INE. 


\subsection{Análisis conjunto de las tres ciudades}

Una vez estudiados los casos seleccionados se han identificado una serie de pautas comunes en la evolución de la trama verde de cada ciudad, especialmente desde el momento en que fueron aprobados los primeros planes generales en democracia (1984 en Salamanca y en Valladolid, 1986 en Zamora). Los indicadores que hacen referencia a los metros cuadrados del verde urbano disponible por habitante partían en las tres ciudades de valores muy reducidos a comienzos del periodo (ver Figura 4.5.1.) y desde 1971 van aumentando progresivamente en Salamanca y en Zamora, mientras que en Valladolid, debido al fuerte crecimiento de población experimentado durante las décadas de los sesenta y de los sesenta del siglo pasado, el surgimiento de nuevos verdes urbanos disponibles no consigue hacer aumentar el ratio de metros cuadrados por habitante hasta la década siguiente. Desde los años ochenta, se produce un incremento muy notable de la presencia de este tipo de zonas verdes en el interior de la ciudad debido a que el planeamiento urbano se ha llevado a cabo desde entonces de forma más o menos efectiva y en la mayor parte de las nuevas piezas urbanas se ha reservado suelo para áreas verdes que serán mantenidas por los municipios. No obstante, pese a la recuperación experimentada en las últimas décadas, la herencia recibida ha sido difícil de corregir, puesto que solamente Zamora con 10,76 $\mathrm{m}^{2} /$ hab alcanza los estándares mínimos de $9 \mathrm{~m}^{2} /$ hab fijado por la OMS, como indican Singh et al. (2010), citando a Kuchelmeister, o los $10 \mathrm{~m}^{2} /$ hab que Magalhães (1992) y Santana et al. (2007a y 2010) consideran como valor adecuado o deseable.

Figura 4.5.1 Evolución del verde urbano disponible por habitante ( $\left.\mathrm{m}^{2} / \mathrm{hab}\right)$.

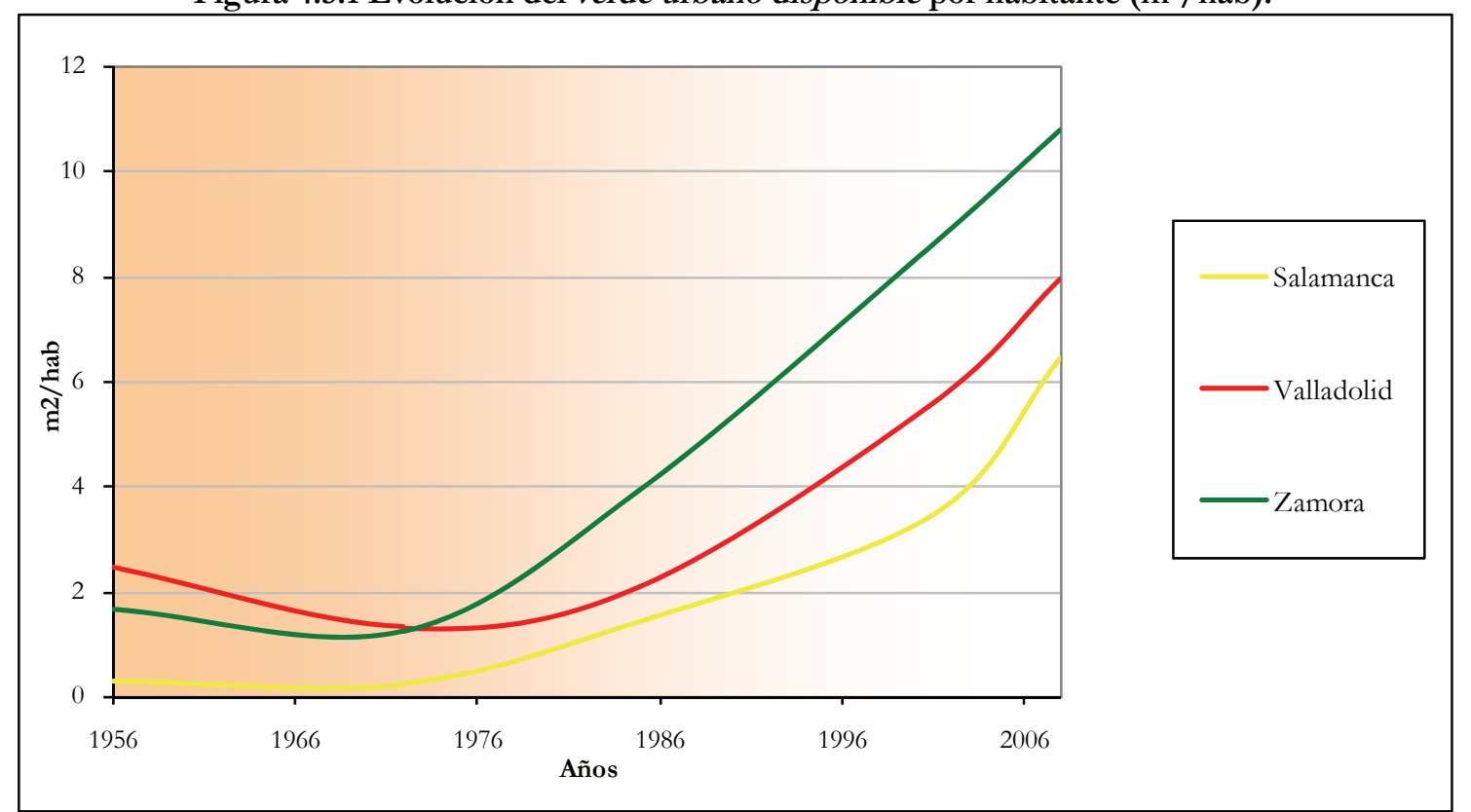

Fuente: elaboración propia a partir del SGE, del IGN y del INE.

Esta evolución tiene una repercusión obvia en el plano urbano, en la medida en que es posible identificar claramente partes de la ciudad que no cuentan con zonas verdes y que se corresponden con periodos en los que estos espacios no se incorporaron al crecimiento de la urbe. Esta idea es recogida por Sanesi y Chiarello (2006) en su estudio sobre Bari (Italia), donde identificaron un modelo de ciudad propia del sur de Europa tomando como referencia las áreas verdes. De tal modo que esta urbe estaría compuesta por el centro histórico, con calles estrechas e irregulares donde podría haber algún jardín o parque histórico, por la ciudad construida hasta el siglo XX, en la que únicamente aparecerían paseos y plazas arboladas, y por la construida durante el siglo XX, caracterizada por espacios 
residenciales densamente poblados donde la mayor parte de las zonas verdes fueron construidas durante las últimas tres décadas. En la Figura 4.5.2 aparecen varias imágenes de cada una de las ciudades analizadas donde se identifican estas zonas características. Los parques del centro histórico que aparecen representados son el Campo de San Francisco (S9), el Parque de la Rosaleda Francisco Sabadell y el Parque de Poniente (V-2) y el Parque del Castillo y de la Catedral (Z-1), todos ellos enclavados en los centros históricos de las ciudades. Las imágenes de la ciudad moderna pertenecen al periodo en el que no existe o no se aplica el planeamiento urbano y se caracterizan por la ausencia de la mayor parte de los equipamientos, tales como colegios o espacios verdes, mientras que la última columna de imágenes responde a espacios verdes surgidos en las últimas décadas, durante las que se generaliza el planeamiento urbano, incluyendo parques y jardines en los nuevos barrios de la ciudad

Con la aprobación de los primeros planes generales en democracia los Ayuntamientos adecuaron el planeamiento urbano a la normativa urbanística existente en aquel entonces, cuyos principios fundamentales se recogían en la segunda Ley del Suelo de 1976. La Constitución de 1978 transfirió las competencias urbanísticas a las Comunidades Autónomas, como ratificó la sentencia del Tribunal Constitucional de 1997, en la que se rechaza la mayor parte de la Ley del Suelo de 1990 por invadir competencias de las CCAA. En Castilla y León se aprobó en 1999 la Ley de Urbanismo, y según se puede leer en la Exposición de Motivos, durante los primeros años de ejercicio de las competencias asumidas se mantuvo en vigor la segunda Ley del Suelo de 1976. Es interesante detenerse en las referencias a los espacios verdes urbanos, aunque para ello haya que consultar la versión revisada de 2009 del Reglamento de Urbanismo. En ese documento se especifica, como se señaló en el capítulo introductorio, la reserva de espacios libres públicos que deben realizar los municipios a través de la imposición de dos requisitos. Por un lado, el planeamiento general debe incluir el sistema general de espacios libres públicos con una superficie mínima de $5 \mathrm{~m}^{2}$ por habitante, sin contabilizar los espacios libres públicos del sistema local y los Espacios Naturales Protegidos (Artículo 83 del RUCYL). Por otro lado exige una reserva de suelo para el sistema local de espacios verdes públicos que debe alcanzar en suelo urbano no consolidado, 15 metros cuadrados de suelo por cada 100 metros cuadrados construibles, y en suelo urbanizable, 20 metros cuadrados de suelo por cada 100 metros cuadrados construibles (Artículo 105 del RUCYL), y debe cumplir con una serie de condiciones ya mencionadas, pero que conviene repetir de nuevo:

1. Debe garantizarse el adecuado soleamiento y que su indice de permeabilidad, o porcentaje de superficie destinado a la plantación de especies vegetales, no sea inferior al 50 por ciento.

2. En los sectores con uso predominantemente residencial, debe distribuirse en áreas adecuadas para su utilización, evitando las zonas residuales, con una superficie unitaria minima de 500 metros cuadrados y de forma que pueda inscribirse en su interior una circunferencia de 20 metros de diámetro. En su interior deben preverse áreas especiales reservadas para juego infantil, de superficie no inferior a 200 metros cuadrados y equipadas adecuadamente para su función.

3. En los sectores con uso predominantemente industrial o de servicios, debe destinarse de forma preferente a arbolado en bandas lineales con un ancho minimo de 5 metros, que favorezica la transición con el medio ambiente circundante, así como la salvaguarda de los espacios arbolados $y$ de los cauces naturales y de las vias pecuarias afectados.

Resulta interesante observar la evolución de los patrones referentes a los espacios verdes en esta Comunidad Autónoma, ya que la actual Ley de Urbanismo de Castilla y León se considera heredera de la segunda Ley del Suelo de 1976. El reglamento de planeamiento 
Figura 4.5.2 Morfología urbana de la ciudad del sur de Europa.

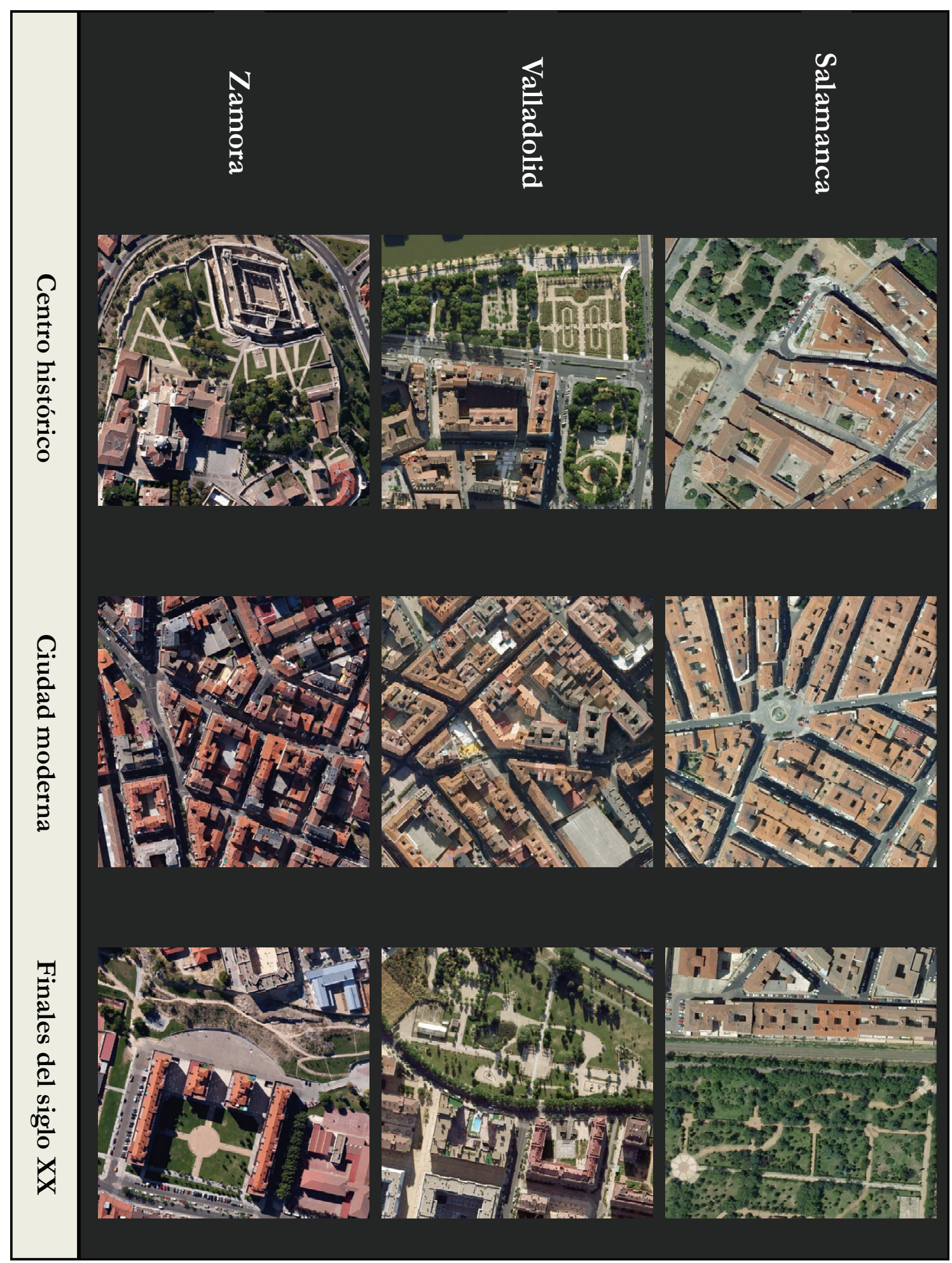

Fuente: Google Maps. 
de aquella ley contaba con un anexo en el que se hacía mención a las reservas de suelo para dotaciones en planes parciales y concretamente en el artículo 4 señala que podrían computarse como jardines públicos aquellas superficies que reunieran las siguientes condiciones mínimas:

1. Presentar una superficie no inferior a 1.000 metros cuadrados, en la que pudiera inscribirse una circunferencia de 30 metros de diámetro minimo.

\section{Poseer condiciones apropiadas para la plantación de especies vegetales.}

\section{Tener garantizado su adecuado soleamiento en relación con la posible edificación circundante.}

Por tanto, durante los últimos treinta años, en esta Comunidad Autónoma se ha producido un significativo retroceso en las características que deben tener los espacios verdes surgidos del planeamiento local. En concreto, la superficie mínima se ha reducido a la mitad y el diámetro de la circunferencia inscrita en su interior lo ha hecho en un tercio. En una sociedad que cada vez es más sensible con las cuestiones ambientales, llama la atención una disminución tan significativa del tamaño mínimo de las áreas verdes en el interior de las ciudades. Obviamente, estas modificaciones aprovechan el desconocimiento general de la sociedad en estos temas, pese a que todos los documentos relativos al planeamiento urbano son de carácter público, con el objetivo de contabilizar como zona verde cualquier pequeño espacio entre edificaciones. Las áreas verdes de reducido tamaño contribuirán a aumentar las estadísticas utilizando para ello espacios residuales de la construcción y baldíos urbanos, que por su reducido tamaño no podrían desempeñar las funciones tradicionales del verde urbano como son el ocio, el deporte, el paseo, etc. (Canosa et al., 2003). Actualmente el tamaño mínimo de los espacios libres públicos en Castilla y León es de $500 \mathrm{~m}^{2}$, una cifra ya de por sí muy reducida pero que ni siquiera es respetada por los ayuntamientos encargados de elaborar un planeamiento urbano que incorpora zonas verdes minúsculas, como se mencionó en el capítulo dedicado a la metodología. En la ciudad de Valladolid hay cincuenta y dos espacios verdes con menos de $500 \mathrm{~m}^{2}$ y ochenta y ocho en Salamanca, cuya gestión le correspondería al Servicio de Parques y Jardines de cada ciudad. La suma de todos estos espacios representa una superficie verde que no puede ser utilizada por los ciudadanos, pero que en algunos casos es empleada para alterar las estadísticas referentes a los ratios de zonas verdes por habitante tratando así de alcanzar los estándares mínimos internacionalmente reconocidos.

\subsubsection{El caso singular de los huertos urbanos}

La agricultura urbana se lleva desarrollando desde que existen las ciudades como tales, ya que la producción de alimentos fue uno de los factores clave para el surgimiento de los asentamientos humanos. La expansión territorial provoca la continua aparición de huertos en el interior del tejido urbano, confiriendo a estos espacios una dinámica distinta a la del resto de zonas verdes. El crecimiento de las ciudades se hace mayoritariamente a través de la adquisición de parcelas agrícolas en las zonas de borde, por parte de promotores urbanos. Esto provoca una notable incertidumbre entre los agricultores que continúan trabajando en sus explotaciones, que es expresada por Alberdi (2001: 96) del siguiente modo:

"[...] El resultado que provoca el avance del espacio urbanizado en el agricultor es de incertidumbre, originando que muchas explotaciones no renueven sus instalaciones, marginalizándose progresivamente la producción y, una vez que se materializa el cambio generacional al frente de la explotación, el nuevo propietario abandona la actividad agroganadera". 
En ocasiones, se producen discontinuidades espaciales cuando los huertos quedan enclavados en el tejido urbano, pero estas situaciones no suelen extenderse en el tiempo, ya que por norma general, el precio de mercado del suelo proporciona beneficios elevados a los trabajadores agrícolas. En la Tabla 4.5.1 aparece recogida la evolución de los huertos durante los últimos cincuenta años, concluyendo que su aparición en el interior del tejido urbano no responde a una tendencia claramente definida. La desaparición de la mayor parte de los terrenos dedicados a esta actividad ha supuesto una importante pérdida de patrimonio edáfico: entre 1956 y 2008 numerosos espacios agrícolas fueron abandonados o bien se vieron abocados a un cambio de uso, sin que la legislación urbanística tuviera en cuenta estos aspectos. Los huertos no son capaces de competir en el mercado con el alto precio del suelo urbano, lo que implica que su supervivencia dependa del grado de protección que les otorguen los PGOU o de la existencia de entidades sin ánimo de lucro como la Fundación Rodríguez Fabrés de Salamanca.

Tabla 4.5.1 Evolución de los huertos urbanos en las ciudades estudiadas.

\begin{tabular}{|c|c|c|c|c|c|}
\hline & 1956 & 1971 & 1984 & 2001 & 2008 \\
\hline $\mathrm{N}^{\circ}$ huertos urbanos en Salamanca & 6 & 5 & 3 & 6 & 5 \\
\hline Extensión de los huertos urbanos en Salamanca (ha) & 45,5 & 31,6 & 15,3 & 19,4 & 15,0 \\
\hline $\mathrm{N}^{\circ}$ huertos urbanos en Valladolid & 9 & 6 & 6 & 6 & 5 \\
\hline Extensión de los huertos urbanos en Valladolid (ha) & 33,3 & 11,4 & 41,2 & 61,3 & 51,2 \\
\hline $\mathrm{N}^{\circ}$ huertos urbanos en Zamora & 8 & 7 & 4 & 5 & 8 \\
\hline Extensión de los huertos urbanos en Zamora (ha) & 27,5 & 22,0 & 9,0 & 31,7 & 25,7 \\
\hline
\end{tabular}

Fuente: elaboración propia.

En la Figura 4.5.3 aparece la evolución sufrida por algunos de los huertos urbanos en las ciudades analizadas. En Salamanca, la fundación anteriormente citada permitió el mantenimiento hasta 2012 de las históricas huertas del Tormes en la ciudad, gracias a que los gestores orientaron la funcionalidad de estos espacios hacia una explotación económicosocial incorporando a personas con problemas (S-32). Sin embargo, ni siquiera este tipo de entidades escapan a la voracidad de las dinámicas urbanas y parte de sus terrenos fueron expropiados para la construcción del puente Príncipe de Asturias. En las imágenes seleccionadas se observa que desde 1956 se ha producido una progresiva desaparición de terreno cultivado: de las más de veinte hectáreas que sumaban las tierras de la fundación y las huertas vecinas, se habían reducido a escasamente cuatro en 2007. En Valladolid se han seleccionado los huertos situados junto al cauce del Esgueva, en la zona históricamente conocida como el Prado de la Magdalena, ocupada actualmente por el campus de la Universidad. En 1956 los huertos ubicados dentro del perímetro de lo que se ha considerado como ciudad cubrían una superficie de 7,66 ha y se observa cómo en la actualidad algunos han sido sustituidos por bloques de viviendas, mientras que otros han sido integrados dentro de una zona verde como es el Campus Esgueva (V-26). Se trata de una transformación de los huertos en otro tipo de verde urbano, que implica la desaparición de la actividad agrícola y la reconversión en áreas públicas.

Otro caso diferente son los huertos seleccionados en el barrio de Cabañales (10) en Zamora, donde se identifica el proceso mencionado por Alberdi (2001) en zonas que en 1956 estaban cultivadas y cuya actividad se mantuvo hasta 2001, para convertirse en 2008 en un barbecho urbano que se mantiene en la imagen de 2012. La historia de los huertos urbanos es clave para comprender la evolución de los espacios verdes de las ciudades analizadas, como quedó reflejado al analizar la evolución del verde urbano de cada una de ellas. En Salamanca son siete espacios verdes los que tienen este origen, siendo muy destacada la transformación en parques de tres de ellos entre 1971 y 1984. En Valladolid son 
Figura 4.5.3 Evolución de espacios dedicados a la agricultura urbana en 1956 en las ciudades de Salamanca, Valladolid y Zamora.

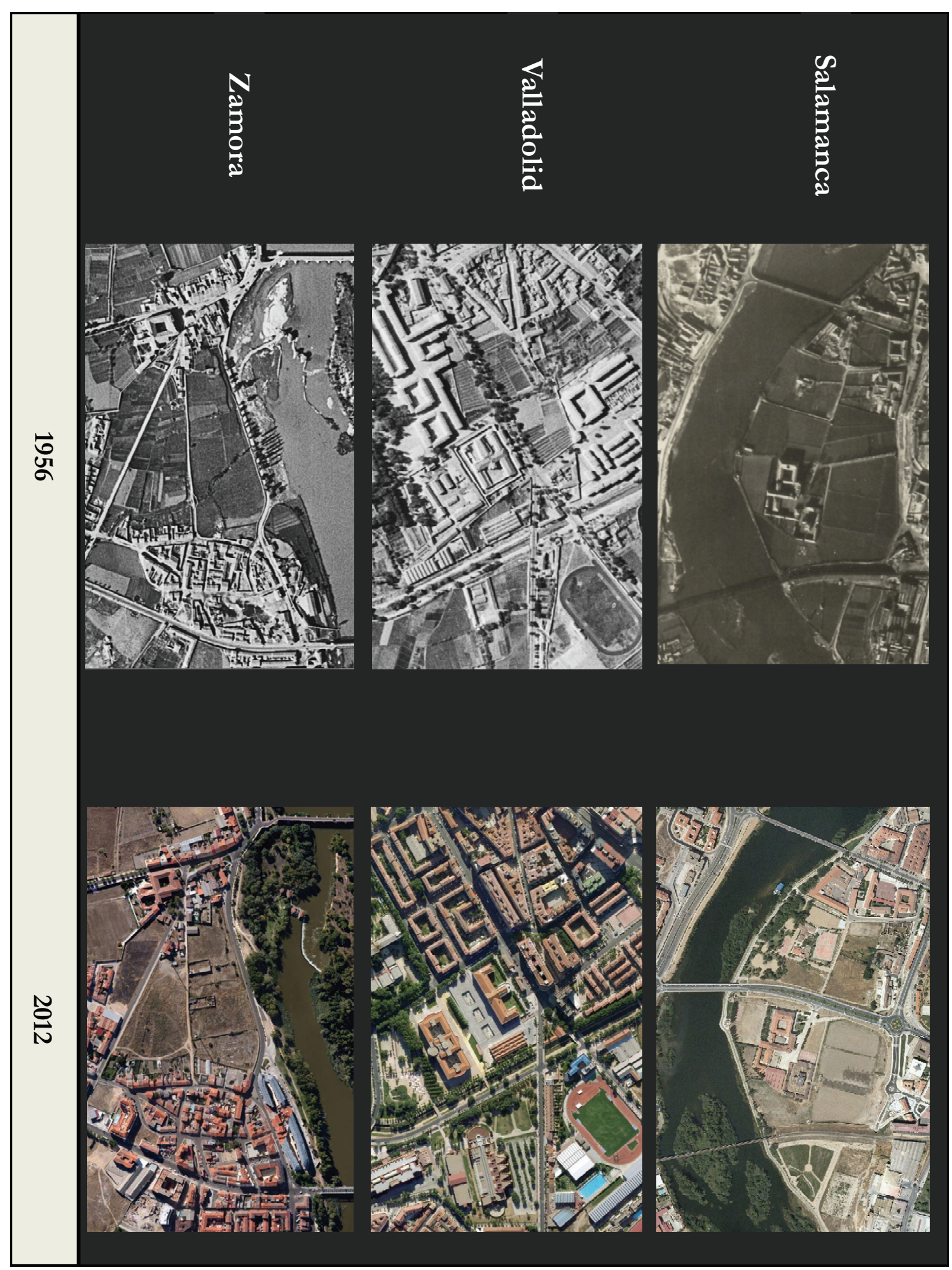

Fuente: Servicio Geográfico del Ejército (1956) y Google Maps. 
diez, de los que actualmente la mitad se sigue dedicando a la agricultura, mientras que la otra mitad fue el germen de verdes urbanos como el Campus Esgueva (V-26), el Jardín Botánico (V-6) o el Parque Ribera de Castilla (V-4). Por último, en Zamora son once los espacios con este origen siendo muy destacada la creación de los Jardines de la Vaguada (Z-11) o del Parque de Olivares (Z-3), en zonas históricamente dedicadas a la agricultura.

Las mayores concentraciones de espacios verdes de cada una de estas ciudades se encuentran en las riberas del río, sobre los fértiles terrenos agrícolas allí instalados desde antiguo y que posiblemente influyeron en la localización de los primitivos asentamientos. Este proceso de destrucción del importante patrimonio edáfico de los alrededores de las ciudades no es nuevo: en la presente investigación se ha mencionado que algunas ciudades se expandieron sobre los fértiles terrenos agrícolas que hicieron posible su existencia (Mumford, 1956). Si se atiende al surgimiento de parques a partir de huertos urbanos, podría pensarse en un futuro enriquecimiento de la trama verde de mantenerse la misma tendencia. Durante los últimos cincuenta años incluso pequeños espacios agrícolas, complementados con actuaciones puntuales, han llegado a convertirse en parte integrante del verde urbano de Salamanca, de Valladolid y de Zamora. Un proceso similar experimentaron los jardines y huertos de distintas órdenes religiosas: en Salamanca representan el origen de siete de las actuales zonas verdes, únicamente de dos en Valladolid, entre los que destaca el Parque de Canterac (V-21), y de tres en Zamora. Sumando ambos orígenes, terrenos originariamente agrícolas o todavía cultivados y terrenos originariamente religiosos, obtendríamos un total de cuarenta espacios, que representan el 34,1\% de los 117 espacios verdes seleccionados entre las tres ciudades.

\subsubsection{El inicio de la actual crisis económica}

Esta investigación se ha centrado en el periodo 1956-2007 y su fecha final coincide con el inicio de la crisis del sector de la construcción en España, que comienza a sentirse de manera evidente entre los años 2007 y 2008. En las Figuras 4.5 .4 y 4.5 .5 aparecen representadas dos variables ya utilizadas como son el número de viviendas promocionadas y el precio de la vivienda, empleando datos proporcionados por el Ministerio de Fomento, que comprenden desde los últimos años del periodo analizado en esta investigación hasta abril del año 2012. En el primer gráfico se observa claramente cómo el precio de la vivienda comienza a reducirse desde mediados de 2007, fecha que puede aceptarse como el inicio de la crisis en el sector inmobiliario en las tres ciudades analizadas. La caída de los precios contribuye a una retirada de los capitales de carácter especulativo del mercado de la construcción, provocando a su vez que un considerable volumen de viviendas no llegase ni siquiera a finalizarse generándose problemas de impacto visual o futuras zonas de marginalidad. Como muestra del proceso especulador en los casos analizados, se puede recordar un dato ya mencionado: durante años, Salamanca mantuvo un precio de la vivienda libre más elevado que el de Valladolid, alcanzando en 2001 el puesto número ocho y en 2002 el puesto número nueve, del ranking de precio del metro cuadrado construido del conjunto de capitales españolas (Senabre, 2003b). Con el progresivo descenso del precio de la vivienda debería observarse un repunte de las ventas si se tratase de un mercado libre y sin embargo, en la Figura 4.5.5 se identifica un derrumbe en el número de transacciones realizadas desde comienzos del año 2011, que tuvo como consecuencia la aparición de de un gran stock de residencias por vender que provocaron la quiebra de numerosas empresas del sector.

La crisis económica ha provocado que los ayuntamientos analizados sufran una progresiva reducción de sus recursos monetarios, con la obvia repercusión que este hecho tiene en el presupuesto de los Servicios de Parques y Jardines. Además, el freno que ha experimentado la construcción en todo el país, también tiene su repercusión en los espacios verdes urbanos. Este proceso, que no vamos a analizar en detalle, es interesante para esta 
investigación porque ha propiciado la aparición de numerosas áreas verdes de acuerdo al planeamiento vigente, con la particularidad de que en muchos casos estaban situadas en piezas urbanas en las que estaba prevista una gran promoción inmobiliaria que no llegó a completarse y que en la actualidad cuentan, en el mejor de los casos, con escasos residentes.

Figura 4.5.4 Evolución del precio de la vivienda libre total.

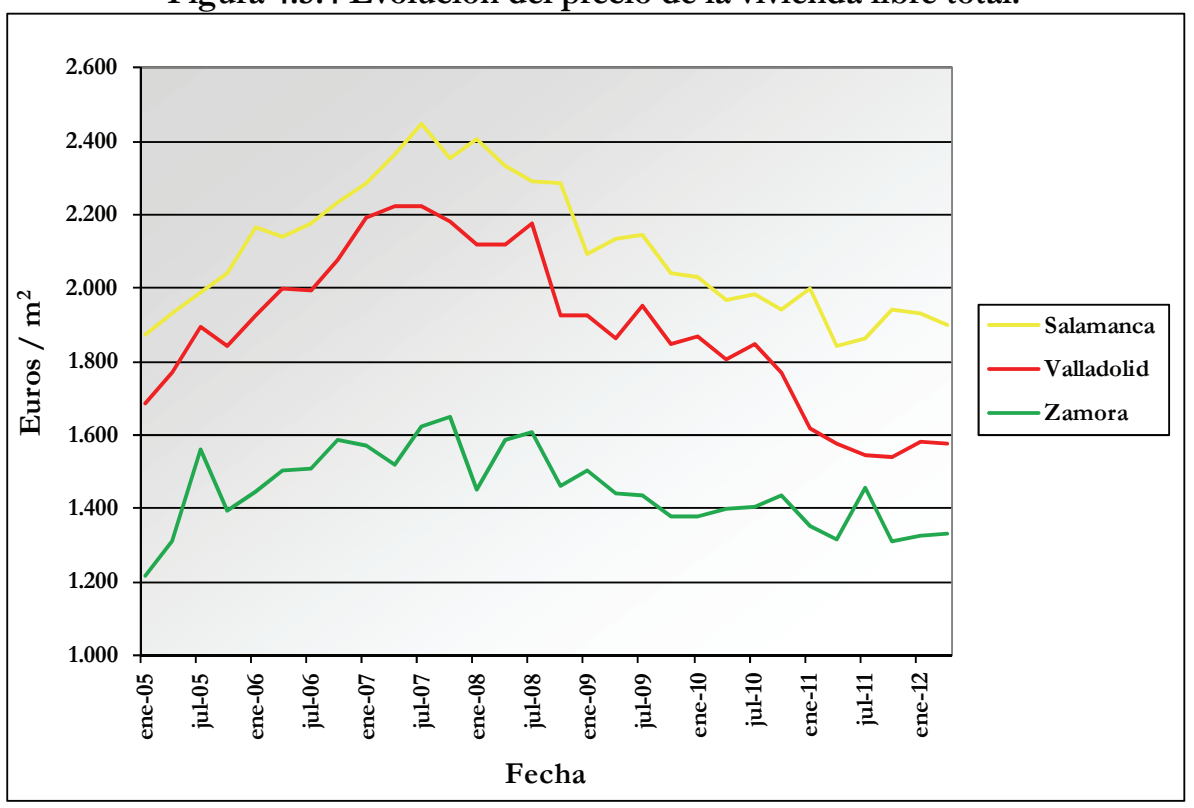

Fuente: Ministerio de Fomento.

Figura 4.5.5 Número de transacciones inmobiliarias totales.

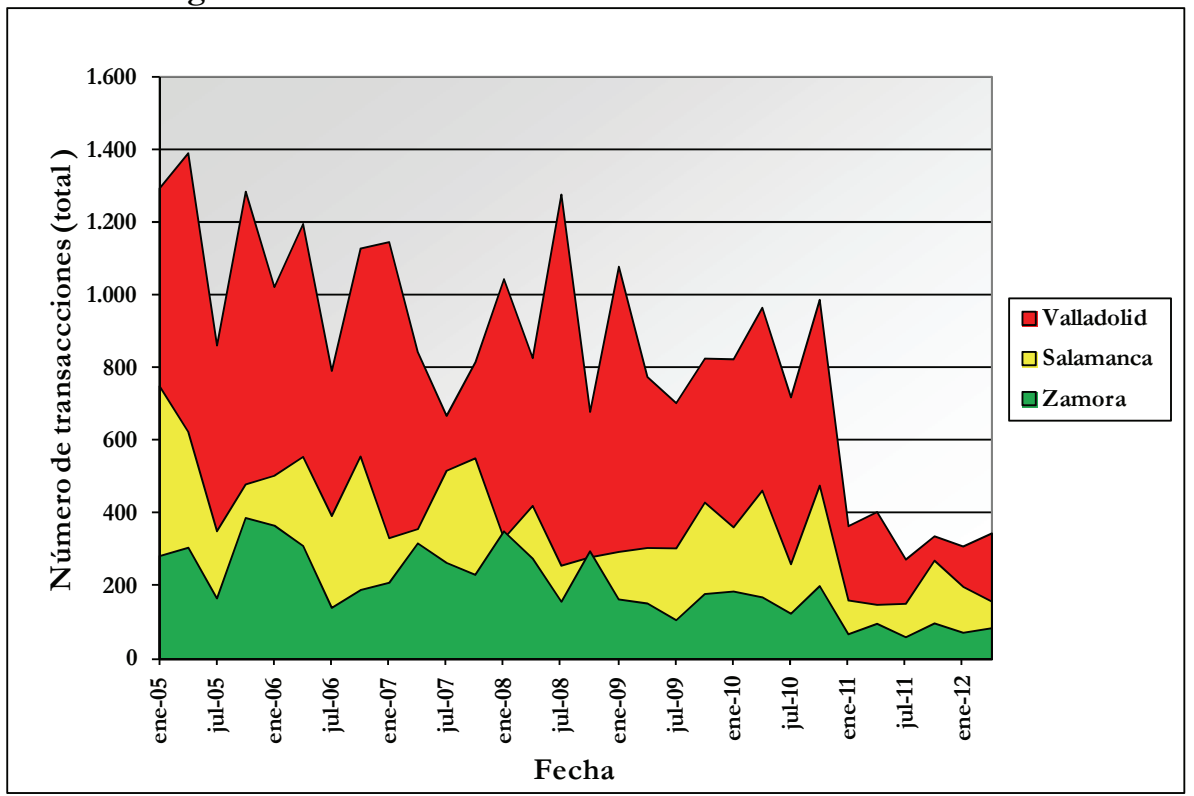

Fuente: Ministerio de Fomento.

La existencia de áreas verdes en zonas poco pobladas influirá negativamente en las visitas que realicen los ciudadanos a estos espacios debido a que aumenta la percepción de inseguridad. Ya fueron mencionados los estudios de Newman (1972) y Geason y Wilson (1989), en los que se demuestra que un espacio urbano puede transformarse en un potencial punto caliente de criminalidad cuando existe una ausencia de vigilantes naturales. Santana et al. (2010), en su trabajo sobre la ciudad portuguesa de Amadora, también evidenciaron una 
Figura 4.5.6 Contraste entre un espacio verde central muy visitado y otro periférico y con un mantenimiento deficiente: Campo Grande (V-1) y verde urbano Centro de Acústica (Santa Ana) (V-12).
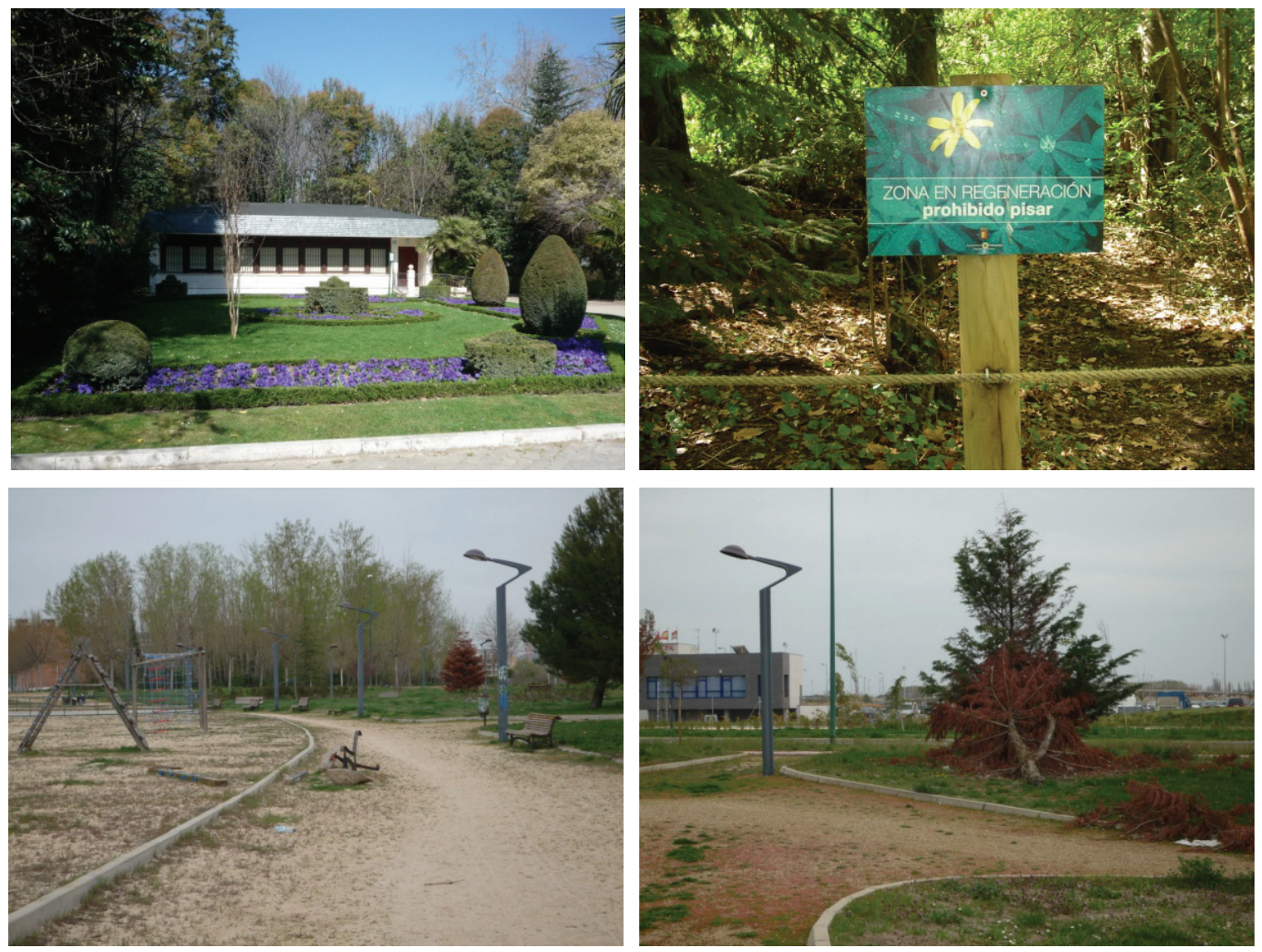

Fuente: Gómez, A. (04/04/2009 y 31/03/2011).

correlación negativa entre los espacios verdes percibidos como inseguros o con señales de vandalismo y la realización en ellos de actividades tales como el paseo, la relajación o la práctica deportiva. En un contexto de fuerte reducción del presupuesto de todas las administraciones, los encargados de mantener las áreas verdes urbanas no solo tienen que mantener la misma superficie verde con menos dinero, sino que además tienen que gestionar nuevos parques y jardines incluidos por ley en los nuevos barrios. Esto provoca que algunas veces se llegue a una situación en la que no es posible continuar con el mantenimiento habitual de las zonas verdes y en ocasiones se opta por dar prioridad a las más utilizadas y a las más visibles, abandonando algunas de las creadas recientemente a través del planeamiento parcial en barrios con pocos habitantes. De tal manera que la suma de una falta de vigilantes naturales y de una gestión deficiente provocan un aumento considerable del sentimiento de repulsa por parte de los potenciales usuarios, reduciéndose aún más el número de visitas que reciben estos parques.

Este fenómeno se ha identificado especialmente en Valladolid, donde hay una serie de zonas verdes en esta situación, localizadas mayoritariamente en la periferia oriental y meridional de la ciudad. La Figura 4.5.6 pretende mostrar el contraste entre un parque con un excelente aspecto, característica de la mayoría de los ubicados en el centro histórico como pueden ser Campo Grande (V-1), el Parque Rosaleda Francisco Sabadell y Parque de Poniente (V-2) o el Parque de las Moreras (V-3), y la situación del verde urbano Centro de Acústica (Santa Ana) (V-12). Este último está situado en un barrio de reciente creación como Las Villas - Cañada Puente Duero - Covaresa - Parque Alameda - Paula López (37), que cuenta con una gran cantidad de zonas verdes, pero donde actualmente es posible identificar 
un conjunto de zonas verdes que no reciben una gestión adecuada, situadas en sectores urbanos poco poblados. Esto obliga a recordar que con la creación de estos espacios en el interior de la ciudad se pretendía dar respuesta a determinadas necesidades sociales (Corona, 2001), por lo que es necesario rectificar y reordenar las prioridades, ya que las áreas verdes con un mantenimiento insuficiente pueden llegar a ser consideradas como peligrosas o poco seguras por una parte de la población.

En un contexto como el actual, exigir un aumento de las dotaciones económicas para el mantenimiento de parques y jardines puede parecer muy osado, pero son numerosos los estudios que demuestran los beneficios de estos espacios en la población urbana. Es necesario replantear el mantenimiento actual de las zonas verdes e imponer una racionalización de los recursos, reduciendo en primer lugar los gastos superfluos como puedan ser las flores de temporada, los paneles informativos, la construcción de nuevos equipamientos en los parques, etc., dando prioridad a un mantenimiento mínimo que permita a los ciudadanos visitar estos espacios sin temor. En ningún caso debería plantearse una paralización en su construcción, puesto que la falta de áreas verdes en el interior de la ciudad supone un déficit que es muy complicado corregir, como indicaron Rodríguez y Díaz (2003) en su estudio sobre la ciudad de Madrid. 


\section{ESTUDIO DEL VERDE URBANO DESDE UNA PERSPECTIVA SOCIAL}

Este capítulo está dedicado al estudio, desde un punto de vista geográfico, del uso que los ciudadanos hacen de los espacios verdes de Salamanca, Valladolid y Zamora. Como se mencionó en la metodología, este análisis solamente se ha llevado a cabo en el verde urbano disponible, que se definió como aquella zona verde que puede ser visitada por la mayor parte de los ciudadanos al no presentar un carácter privado o una difícil configuración. En estos espacios se llevó a cabo el trabajo de campo, obteniendo gran cantidad de información inédita que permitió identificar el comportamiento de los usuarios en las áreas verdes de cada ciudad, así como una serie de comportamientos comunes y algunas peculiaridades que responden a circunstancias locales.

\subsection{Características de los usuarios del verde urbano disponible}

En el capítulo número dos se fijó un número mínimo de 1.084 encuestas a realizar entre los 88 verdes urbanos disponibles de las tres ciudades analizadas. No obstante, este número fue superado ya que se logró encuestar a 1.104 usuarios distribuidos de la siguiente manera: 271 en los 26 espacios verdes de Salamanca, 647 en los 44 de Valladolid y 186 en los 18 de Zamora. El porcentaje de éxito en cada verde urbano aparece reflejado en las Tablas 5.1, 5.2 y 5.3, donde se observa que en determinados casos no fue posible encontrar suficientes usuarios para llevar a cabo el número de encuestas planificado. En Salamanca fueron cinco los espacios verdes en los que no se consiguió entrevistar al número de personas previsto, en Valladolid fueron ocho y dos en Zamora. Es significativo que las dos únicas áreas verdes donde no se encontró a ningún usuario en las sucesivas vistas realizadas, fueran espacios de reducidas dimensiones: el verde urbano de la Plaza de Juan de Austria (V-38), que con sus 1,4 ha de extensión es el cuarto más pequeño de los que componen la trama verde vallisoletana, y el Jardín Carretera de la Estación (Z-18), que posee solamente 0,8 ha. Parece pues, que el tamaño podría estar vinculado con el número de visitas de los espacios verdes, como apuntan Van Herzele y Wiedemann (2003) al afirmar que los parques de mayores dimensiones son más atrayentes que el resto. Sin embargo, en las tablas anteriormente mencionadas se observan algunas zonas verdes con un tamaño superior a las diez hectáreas donde no se encontró un número suficiente de usuarios como para cumplir con el número de encuestas inicialmente previsto, como ocurrió en el Parque de El Zurguén (S-25), que cuenta con 13,5 ha, o el verde urbano Mirador de Parquesol (V-31), que tiene una superficie de 15,4 ha. La mayor o menor capacidad de atracción del verde urbano se tratará con detalle a lo largo de este capítulo, aunque por el momento parece que los datos obtenidos no concuerdan con algunos de los trabajos publicados en otros países.

\subsubsection{Distribución por edades, sexo y ocupación}

De los 1.104 usuarios encuestados en esta investigación el 52,4\% eran hombres y el 47,6\% mujeres (ver Tabla 5.4), y únicamente en Valladolid el número de mujeres entrevistadas superó al de hombres. La explicación a la inferior presencia femenina en el verde urbano puede estar relacionada con la percepción que tienen las mujeres de los espacios públicos, por lo que el sentimiento de inseguridad en los parques sería más intenso en este colectivo que en otros, repercutiendo significativamente en un menor uso de las zonas verdes (Segovia y Neira, 2005). A esto habría que añadir el temor instalado en la socialización 
femenina, que se transforma en miedo a visitar determinadas zonas durante la noche (Cedeño, 2003). Sin embargo, aunque en las próximas páginas se constate que efectivamente, durante la noche es mayor el número de usuarios que de usuarias en los espacios verdes, no se poseen datos suficientes como para afirmar que el miedo sea la causa de haber encuestado a un menor número de mujeres que de hombres.

Tabla 5.1 Encuestas realizadas en el verde urbano disponible de Valladolid.

\begin{tabular}{|c|c|c|c|c|c|c|}
\hline $\mathbf{N}^{\circ}$ & Id. & ha & $\begin{array}{l}\text { Encuestas } \\
\text { planificadas }\end{array}$ & $\begin{array}{l}\text { Encuestas } \\
\text { realizadas }\end{array}$ & $\begin{array}{l}\text { Porcentaje } \\
\text { de éxito }\end{array}$ & Nombre \\
\hline 1 & $\mathrm{~V}-1$ & 12,7 & 33 & 35 & 106 & Campo Grande \\
\hline 2 & $\mathrm{~V}-2$ & 4,6 & 12 & 13 & 108 & Rosaleda Francisco Sabadell y Parque Poniente \\
\hline 3 & $\mathrm{~V}-3$ & 9,5 & 24 & 24 & 100 & Parque de las Moreras \\
\hline 4 & $\mathrm{~V}-4$ & 26,7 & 68 & 72 & 106 & Parque Ribera de Castilla \\
\hline 5 & V-5 & 5,5 & 14 & 16 & 114 & Verde urbano Camino del Cabildo \\
\hline 6 & V-6 & 7,0 & 18 & 22 & 122 & Jardín Botánico \\
\hline 7 & V-7 & 1,2 & 3 & 4 & 133 & Darsenas del Canal Castilla \\
\hline 8 & V-9 & 21,0 & 54 & 55 & 102 & Parque del Mediodia \\
\hline 9 & V-10 & 6,6 & 17 & 21 & 124 & Ladera sur Parquesol - Fuente de Dios \\
\hline 10 & V-11 & 4,7 & 12 & 13 & 108 & Arturo Eyries \\
\hline 11 & $\mathrm{~V}-12$ & 2,4 & 6 & 2 & 33 & Verde urbano Centro de Acustica (Santa Ana) \\
\hline 12 & V-14 & 5,3 & 14 & 17 & 121 & Parque de Covaresa \\
\hline 13 & V-15 & 2,4 & 6 & 4 & 67 & Parque de la Alameda \\
\hline 14 & V-16 & 1,8 & 5 & 10 & 200 & Verde urbano Avenida de los Castaños \\
\hline 15 & V-17 & 4,3 & 11 & 11 & 100 & Verde urbano de Valparaiso - Ronda Sur \\
\hline 16 & V-18 & 3,9 & 10 & 10 & 100 & Parque Arturo León \\
\hline 17 & V-19 & 4,4 & 11 & 10 & 91 & Parque de las Norias de Santa Victoria \\
\hline 18 & V-20 & 3,9 & 10 & 14 & 140 & Parque de la Paz \\
\hline 19 & $\mathrm{~V}-21$ & 12,2 & 31 & 35 & 113 & Parque de Canterac \\
\hline 20 & $\mathrm{~V}-22$ & 5,9 & 15 & 15 & 100 & Parque San Isidro - Fuente de la Salud \\
\hline 21 & V-24 & 7,4 & 19 & 12 & 63 & Verde urbano Ronda Este \\
\hline 22 & V-25 & 4,0 & 10 & 10 & 100 & Verde urbano Calle Arribes del Duero \\
\hline 23 & V-26 & 6,1 & 16 & 16 & 100 & Campus Esgueva \\
\hline 24 & $\mathrm{~V}-27$ & 8,8 & 23 & 25 & 109 & Campus Miguel Delibes \\
\hline 25 & V-28 & 1,6 & 4 & 5 & 125 & Paseo Zorrilla Sur \\
\hline 26 & V-29 & 9,0 & 23 & 30 & 130 & Verde urbano Cortes de Castilla y León \\
\hline 27 & V-30 & 4,8 & 12 & 8 & 67 & Verde urbano Auditorio Miguel Delibes \\
\hline 28 & V-31 & 15,4 & 39 & 3 & 8 & Verde urbano Mirador Parquesol \\
\hline 29 & $\mathrm{~V}-32$ & 13,8 & 35 & 35 & 100 & Verde urbano Huerta del Rey \\
\hline 30 & V-33 & 8,8 & 22 & 30 & 136 & Verde urbano Parquesol Calle Morelia \\
\hline 31 & V-34 & 2,5 & 7 & 7 & 100 & Verde urbano Parquesol Calle Juan de Valladolid \\
\hline 32 & V-35 & 2,0 & 5 & 5 & 100 & Parque del Reloj de Sol \\
\hline 33 & V-36 & 5,0 & 13 & 11 & 85 & Verde urbano Palacio de la Ribera \\
\hline 34 & V-37 & 1,6 & 4 & 5 & 125 & Ribera de Huerta del Rey \\
\hline 35 & V-38 & 1,4 & 0 & 0 & 0 & Verde urbano Plaza Juan de Austria \\
\hline 36 & V-39 & 1,7 & 4 & 4 & 100 & Verde urbano Calle Morena - Feria de Muestras \\
\hline 37 & $\mathrm{~V}-41$ & 2,4 & 6 & 6 & 100 & Ribera Pisuerga entre Pte. Colgante y Pte. Juan Austria \\
\hline 38 & $\mathrm{~V}-42$ & 1,6 & 4 & 8 & 200 & Plaza del Ejército \\
\hline 39 & V-44 & 1,2 & 3 & 3 & 100 & Jardines de La Victoria \\
\hline 40 & V-45 & 1,6 & 4 & 4 & 100 & Verde urbano Barrio de la Esperanza \\
\hline 41 & V-46 & 1,6 & 4 & 5 & 125 & Verde urbano Pinar de Jalón \\
\hline 42 & V-47 & 1,5 & 4 & 4 & 100 & Verde urbano Calle Vega de Valdetronco - Villas Sur \\
\hline 43 & V-48 & 1,2 & 3 & 3 & 100 & Verde urbano Escuela Deportiva Niara \\
\hline 44 & V-49 & 1,8 & 5 & 5 & 100 & Verde urbano Calle Alcaparra \\
\hline Total & & 252,5 & 643 & 647 & 100 & \\
\hline
\end{tabular}

Fuente: elaboración propia. 
Tabla 5.2 Encuestas realizadas en el verde urbano disponible de Salamanca.

\begin{tabular}{|c|c|c|c|c|c|c|}
\hline $\mathbf{N}^{\circ}$ & Id. & ha & $\begin{array}{c}\text { Encuestas } \\
\text { planificadas }\end{array}$ & $\begin{array}{l}\text { Encuestas } \\
\text { realizadas }\end{array}$ & $\begin{array}{c}\text { Porcentaje } \\
\text { de éxito }\end{array}$ & Nombre \\
\hline 1 & S-1 & 5,8 & 15 & 4 & 27 & Parque de Don Juan Tenorio \\
\hline 2 & S-2 & 7,4 & 19 & 20 & 105 & Complejo deportivo Salas Bajas \\
\hline 3 & S-3 & 10,8 & 27 & 35 & 130 & Jardín botánico de Huerta Otea \\
\hline 4 & S-4 & 10,1 & 26 & 39 & 150 & Parque de los Jesuitas \\
\hline 5 & S-5 & 0,8 & 2 & 6 & 300 & Jardines del Hospital Clínico \\
\hline 6 & S-7 & 2,3 & 6 & 10 & 167 & Verde urbano de la Vaguada de La Palma \\
\hline 7 & S-8 & 4 & 10 & 12 & 120 & Parque de Valhondo \\
\hline 8 & S-9 & 1,3 & 3 & 3 & 100 & Campo de San Francisco \\
\hline 9 & S-10 & 2,2 & 6 & 6 & 100 & Parque de la Alamedilla \\
\hline 10 & S-11 & 1 & 3 & 3 & 100 & Parque Picasso \\
\hline 11 & S-12 & 1,7 & 4 & 6 & 150 & Verde urbano de las Salesas \\
\hline 12 & S-13 & 2,7 & 7 & 7 & 100 & Plaza de Burgos \\
\hline 13 & S-15 & 6 & 15 & 15 & 100 & Parque de Würzburg \\
\hline 14 & S-16 & 3,6 & 9 & 9 & 100 & Verde urbano margen derecha Puente Romano \\
\hline 15 & S-17 & 5,2 & 13 & 12 & 92 & Verde urbano margen izquierda Puente Romano \\
\hline 16 & S-18 & 3,1 & 8 & 14 & 175 & Paseo fluvial \\
\hline 17 & S-19 & 1,4 & 4 & 5 & 125 & Verde urbano del entorno de Mirat \\
\hline 18 & S-20 & 2,7 & 7 & 4 & 57 & Parque de Ciudad Rodrigo \\
\hline 19 & S-21 & 3 & 7 & 7 & 100 & Parque de la Chinchibarra \\
\hline 20 & S-22 & 1,6 & 4 & 3 & 75 & Parque de Vistahermosa \\
\hline 21 & S-23 & 1,6 & 4 & 4 & 100 & Parque de Villar y Macías \\
\hline 22 & S-24 & 1,9 & 5 & 5 & 100 & Verde urbano de La Salle \\
\hline 23 & S-25 & 13,5 & 35 & 15 & 43 & Parque de El Zurguen \\
\hline 24 & S-26 & 4,3 & 11 & 13 & 118 & Verde urbano Av. Salamanca \\
\hline 25 & S-27 & 1,2 & 3 & 10 & 333 & Verde urbano de la Fac. de Comunicación \\
\hline 26 & S-28 & 1 & 3 & 4 & 133 & Parque de Bretón \\
\hline Total & & 100 & 256 & 271 & 106 & \\
\hline
\end{tabular}

Fuente: elaboración propia.

Tabla 5.3 Encuestas realizadas en el verde urbano disponible de Zamora.

\begin{tabular}{|c|c|c|c|c|c|c|}
\hline $\mathbf{N}^{\circ}$ & Id. & ha & $\begin{array}{l}\text { Encuestas } \\
\text { planificadas }\end{array}$ & $\begin{array}{l}\text { Encuestas } \\
\text { realizadas }\end{array}$ & $\begin{array}{l}\text { Porcentaje } \\
\text { de éxito }\end{array}$ & Nombre \\
\hline 1 & $\mathrm{Z}-1$ & 1,9 & 5 & 3 & 60 & Parque del Castillo y de la Catedral \\
\hline 2 & $\mathrm{Z}-2$ & 0,8 & 2 & 2 & 100 & Verde urbano Calle de los Caballeros \\
\hline 3 & $\mathrm{Z}-3$ & 3,4 & 9 & 11 & 122 & Parque de Olivares \\
\hline 4 & $\mathrm{Z}-4$ & 2,2 & 6 & 6 & 100 & Parque de la Marina \\
\hline 5 & Z-5 & 0,8 & 2 & 2 & 100 & Verde urbano Candelaria Ruiz del Árbol \\
\hline 6 & Z-6 & 16,5 & 42 & 42 & 100 & Margen derecha del Duero \\
\hline 7 & Z-9 & 16,5 & 42 & 44 & 105 & Bosque de Valorio (parte urbana) \\
\hline 8 & $\mathrm{Z}-10$ & 1,9 & 5 & 6 & 120 & Parque de Peña Trevinca \\
\hline 9 & Z-11 & 3,3 & 8 & 8 & 100 & Jardines de la Vaguada \\
\hline 10 & $\mathrm{Z}-12$ & 1,4 & 4 & 4 & 100 & Verde urbano Avda. Cardenal Cisneros (Universidad) \\
\hline 11 & $\mathrm{Z}-13$ & 3,7 & 9 & 10 & 111 & Parque de San Martín \\
\hline 12 & $\mathrm{Z}-14$ & 3,0 & 8 & 8 & 100 & Parque de León Felipe \\
\hline 13 & $\mathrm{Z}-15$ & 8,3 & 21 & 21 & 100 & Margen izquierda del Duero \\
\hline 14 & $\mathrm{Z}-17$ & 5,0 & 13 & 14 & 108 & Isla de las Pallas \\
\hline 15 & $\mathrm{Z}-18$ & 0,9 & 2 & 0 & 0 & Jardín Carretera de la Estación \\
\hline 16 & $\mathrm{Z}-19$ & 0,6 & 1 & 1 & 100 & Verde urbano Puerta Nueva \\
\hline 17 & $\mathrm{Z}-20$ & 0,9 & 2 & 2 & 100 & Verde urbano Calle Nuestra Señora de las Mercedes \\
\hline 18 & $\mathrm{Z}-21$ & 0,8 & 2 & 2 & 100 & Verde urbano Avda. Cardenal Cisneros (Eroski) \\
\hline Total & & 71,7 & 183 & 186 & 102 & \\
\hline
\end{tabular}

Fuente: elaboración propia. 
Tabla 5.4 Distribución de los usuarios encuestados por edad, sexo y actividad.

\begin{tabular}{|c|c|c|c|c|c|c|c|}
\hline Edad & Ocupación & Hombre & \% Hombre & Mujer & $\%$ Mujer & Total & $\%$ Total \\
\hline \multirow{3}{*}{$18-30$} & Estudia & 98 & 8,9 & 96 & 8,7 & 194 & 17,6 \\
\hline & Trabaja & 32 & 2,9 & 30 & 2,7 & 62 & 5,6 \\
\hline & No empleo & 25 & 2,3 & 9 & 0,8 & 34 & 3,1 \\
\hline Total 18-30 & & 155 & 14,0 & 135 & 12,2 & 290 & 26,3 \\
\hline \multirow{3}{*}{$30-45$} & Estudia & 1 & 0,1 & 2 & 0,2 & 3 & 0,3 \\
\hline & Trabaja & 65 & 5,9 & 75 & 6,8 & 140 & 12,7 \\
\hline & No empleo & 19 & 1,7 & 55 & 5,0 & 74 & 6,7 \\
\hline Total 30-45 & & 85 & 7,7 & 132 & 12,0 & 217 & 19,7 \\
\hline \multirow{4}{*}{$45-65$} & Estudia & 0 & 0,0 & 1 & 0,1 & 1 & 0,1 \\
\hline & Trabaja & 69 & 6,3 & 69 & 6,3 & 138 & 12,5 \\
\hline & No empleo & 18 & 1,6 & 53 & 4,8 & 71 & 6,4 \\
\hline & Jubilado & 41 & 3,7 & 27 & 2,4 & 68 & 6,2 \\
\hline \begin{tabular}{|l|} 
Total 45-65 \\
\end{tabular} & & 128 & 11,6 & 150 & 13,6 & 278 & 25,2 \\
\hline \multirow{2}{*}{$>65$} & Trabaja & 4 & 0,4 & 1 & 0,1 & 5 & 0,5 \\
\hline & Jubilado & 207 & 18,8 & 107 & 9,7 & 314 & 28,4 \\
\hline Total $>65$ & & 211 & 19,1 & 108 & 9,8 & 319 & 28,9 \\
\hline Total & & 579 & 52,4 & 525 & 47,6 & 1.104 & 100,0 \\
\hline
\end{tabular}

Fuente: elaboración propia.

Si al análisis por sexo se le añade información relativa a la edad de los encuestados, se identifican una serie de diferencias muy significativas. Mientras que el colectivo de jóvenes presenta unos valores relativamente similares, el de personas con más de sesenta y cinco años muestra unos contrastes muy fuertes, ya que el número de hombres casi duplica al de mujeres. Según las conclusiones obtenidas por Muga (1980) en su estudio sobre el uso de los espacios verdes de la ciudad de Logroño, las grandes diferencias en función del género de este grupo poblacional estarían motivadas por la socialización de este colectivo en unos valores tradicionales entre los que existía una fuerte diferencia de roles en función del sexo. De tal manera que los hombres viejos, al estar jubilados, utilizarían una parte de su tiempo en realizar visitas a las áreas verdes, mientras que las mujeres de esas edades asumirían la mayor parte de las labores domésticas. Las personas mayores representan aproximadamente un tercio de los usuarios encuestados en las tres ciudades castellano-leonesas, siendo los varones de más de sesenta y cinco años el grupo más numeroso en función de la edad y el sexo. En la franja de edad de treinta a cuarenta y cinco años predominan las mujeres, la diferencia supera los cuatro puntos porcentuales, y el colectivo de hombres con estas características es el grupo que menos peso tiene en la muestra.

Para comprobar si el conjunto de usuarios encuestados en los espacios verdes es representativo de la población, se ha comparado el porcentaje que representa cada grupo de edad y sexo entre el total de censados en cada municipio, con el porcentaje que representa en la muestra obtenida en cada ciudad, como ya hicieran Fonseca et al. (2010) en su estudio sobre la ciudad de Bragança, utilizando para ello la información del padrón municipal y los datos obtenidos en la encuesta (ver Tabla 5.5). La población real de cada franja de edad se ha calculado sumando los grupos quinquenales que componen cada una de ellas y excluyendo a los menores de edad. En esta investigación no se ha trabajado con niños, estableciendo la edad mínima en la mayoría de edad legal, que en el caso de España está fijada en los dieciocho años. A la hora de comparar los datos obtenidos en las encuestas con los datos demográficos, se produjo un desfase significativo puesto que el INE posee un grupo de edad de entre quince y diecinueve años y otro de entre veinte y veinticuatro. Como no existen datos desagregados por edad, se optó por excluir el primero de ellos del cómputo de la población joven porque recoge a personas con menos de dieciocho años, no encuestadas ni incluidas en esta investigación. Por lo tanto, quedaron descartados de esta comparación los 
Tabla 5.5 Comparación entre la población encuestada y el padrón municipal de 2010.

\begin{tabular}{|c|c|c|c|c|c|c|}
\hline \multirow{2}{*}{\multicolumn{2}{|c|}{ SALAMANCA }} & \multicolumn{5}{|c|}{ Grupos de edad } \\
\hline & & $* 18-30$ & $30-45$ & $45-65$ & $>65$ & Total \\
\hline \multirow{5}{*}{ Hombres } & $\mathrm{N}^{\mathbf{o}}$ personas & 9.501 & 15.754 & 18.880 & 14.001 & 58.136 \\
\hline & $\%$ & 7,37 & 12,23 & 14,65 & 10,87 & 45,12 \\
\hline & $\mathrm{N}^{\circ}$ encuestados & 43 & 36 & 34 & 41 & 154 \\
\hline & $\%$ & 16,04 & 13,43 & 12,69 & 15,30 & 57,46 \\
\hline & Diferencia \% & 8,67 & 1,21 & $-1,97$ & 4,43 & 12,34 \\
\hline \multirow{5}{*}{ Mujeres } & $\mathrm{N}^{\mathrm{o}}$ personas & 9.530 & 17.310 & 22.630 & 21.239 & 70.709 \\
\hline & $\%$ & 7,40 & 13,43 & 17,56 & 16,48 & 54,88 \\
\hline & $\mathrm{N}^{\mathrm{o}}$ encuestados & 44 & 29 & 27 & 14 & 114 \\
\hline & $\%$ & 16,42 & 10,82 & 10,07 & 5,22 & 42,54 \\
\hline & Diferencia $\%$ & 9,02 & $-2,61$ & $-7,49$ & $-11,26$ & $-12,34$ \\
\hline \multirow{5}{*}{ Total } & $\mathrm{N}^{\circ}$ personas & 19.031 & 33.064 & 41.510 & 35.240 & 128.845 \\
\hline & $\%$ & 14,77 & 25,66 & 32,22 & 27,35 & 100,00 \\
\hline & $\mathrm{N}^{\circ}$ encuestados & 87 & 65 & 61 & 55 & 268 \\
\hline & $\%$ & 32,46 & 24,25 & 22,76 & 20,52 & 100,00 \\
\hline & Diferencia \% & 17,69 & $-1,41$ & $-9,46$ & $-6,83$ & 0,00 \\
\hline
\end{tabular}

\begin{tabular}{|c|c|c|c|c|c|c|}
\hline \multirow{2}{*}{\multicolumn{2}{|c|}{ VALLADOLID }} & \multicolumn{5}{|c|}{ Grupos de edad } \\
\hline & & $* 18-30$ & $30-45$ & $45-65$ & $>65$ & Total \\
\hline \multirow{5}{*}{ Hombres } & $\mathrm{N}^{\circ}$ personas & 18.759 & 36.475 & 42.203 & 26.184 & 123.621 \\
\hline & $\%$ & 7,11 & 13,83 & 16,00 & 9,93 & 46,88 \\
\hline & $\mathrm{N}^{\circ}$ encuestados & 83 & 38 & 74 & 126 & 321 \\
\hline & $\%$ & 12,77 & 5,85 & 11,38 & 19,38 & 49,38 \\
\hline & Diferencia $\%$ & 5,66 & $-7,99$ & $-4,62$ & 9,45 & 2,50 \\
\hline \multirow{5}{*}{ Mujeres } & $\mathrm{N}^{\circ}$ personas & 18.103 & 37.031 & 48.192 & 36.745 & 140.071 \\
\hline & $\%$ & 6,87 & 14,04 & 18,28 & 13,93 & 53,12 \\
\hline & $\mathrm{N}^{\circ}$ encuestados & 78 & 84 & 95 & 69 & 326 \\
\hline & $\%$ & 12,00 & 12,92 & 14,62 & 10,62 & 50,15 \\
\hline & Diferencia $\%$ & 5,13 & $-1,12$ & $-3,66$ & $-3,32$ & -3 \\
\hline \multirow{5}{*}{ Total } & $\mathrm{N}^{\circ}$ personas & 36.862 & 73.506 & 90.395 & 62.929 & 263.692 \\
\hline & $\%$ & 13,98 & 27,88 & 34,28 & 23,86 & 100,00 \\
\hline & $\mathrm{N}^{\circ}$ encuestados & 161 & 122 & 169 & 195 & 647 \\
\hline & $\%$ & 24,77 & 18,77 & 26,00 & 30,00 & 99,54 \\
\hline & Diferencia $\%$ & 10,79 & $-9,11$ & $-8,28$ & 6,14 & $-0,46$ \\
\hline
\end{tabular}

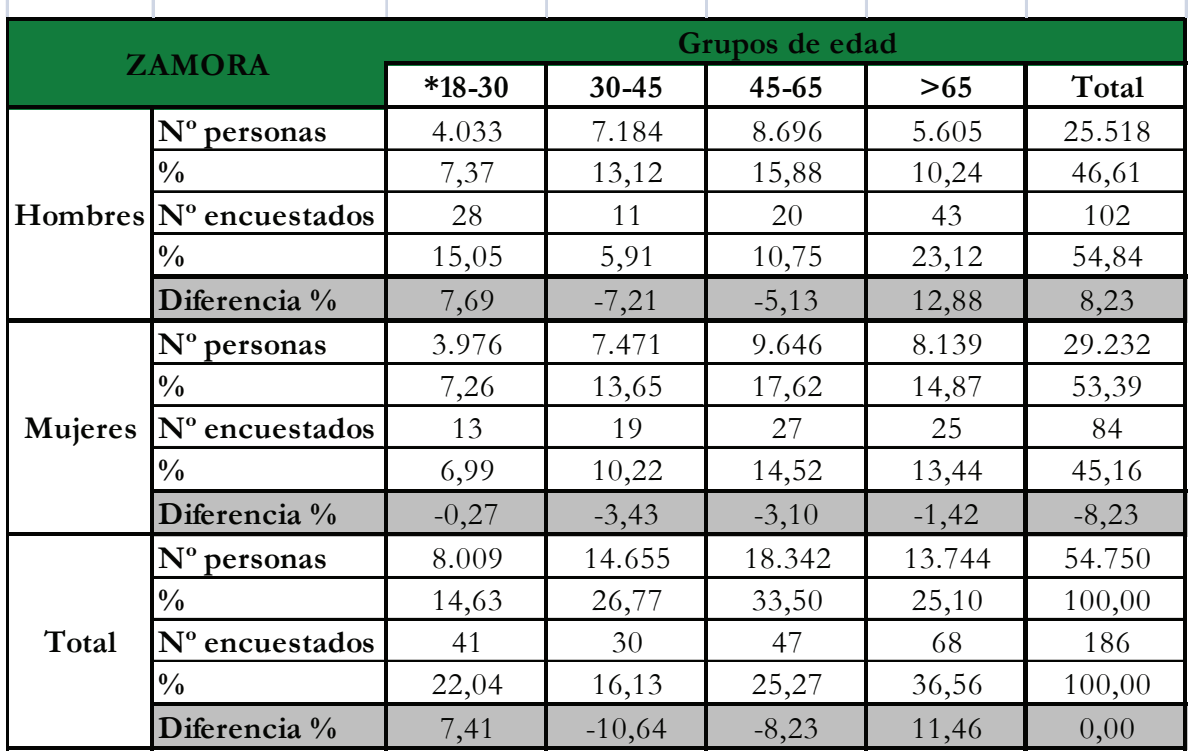

*No están incluidos los jóvenes de 18 y 19 años.

Fuente: elaboración propia a partir de datos del INE. 
jóvenes de dieciocho y diecinueve años, alterando de esta manera este grupo de edad. En total, la población encuestada representa el $0,21 \%$ de la población con más de veinte años censada en Salamanca en 2010, el 0,25\% en el caso de Valladolid y el 0,34\% en Zamora.

Existe una notable discordancia entre la población censada y la población encuestada en cada uno de los municipios, ya que esta última fue seleccionada de manera aleatoria en el interior del perímetro del verde urbano. Sin embargo, comparando las diferencias obtenidas en las tres ciudades se identifican patrones comunes entre los distintos grupos de edad y sexo (ver Figura 5.1). De ellos, son únicamente tres los que tienen más representatividad entre el conjunto de usuarios de los espacios verdes que entre la población censada: los jóvenes de ambos sexos y los hombres mayores de sesenta y cinco años. Esta diferencia tan notable implica una fuerte utilización de las zonas verdes por el colectivo de jóvenes, que se ve intensificada por el hecho de que en los datos del padrón utilizados no se hayan incluido a las personas de dieciocho y diecinueve años. El porcentaje de jóvenes sería superior a su peso relativo en la población censada, con la única excepción de las jóvenes zamoranas, mientras que en las dos siguientes franjas de edad, entre treinta y cuarenta y cinco años y entre cuarenta y cinco años, es en todos los casos inferior a la población censada, con la excepción de los hombres adultos-jóvenes de Salamanca.

El contraste entre los usuarios mayores de sesenta y cinco años y la población censada es muy llamativo, tanto entre hombres como entre las mujeres. Los primeros muestran una diferencia positiva que oscilaba entre los 4,4 puntos porcentuales de Salamanca y los 12,9 de Zamora, mientras que entre las mujeres fue negativa en las tres ciudades, siendo destacable la situación de Salamanca donde la diferencia superaba los 12 puntos porcentuales. El análisis conjunto de las tres ciudades demuestra que el elevado número de encuestados con más de sesenta y cinco años no responde únicamente al envejecimiento de la población censada, sino que existe una voluntad manifiesta de estos colectivos por utilizar, o no, estos espacios. Todo ello muestra un uso muy similar de las áreas verdes en las ciudades estudiadas, con diferencias notables atendiendo a la edad y al sexo de los individuos.

Figura 5.1 Diferencia entre población encuestada y población censada.

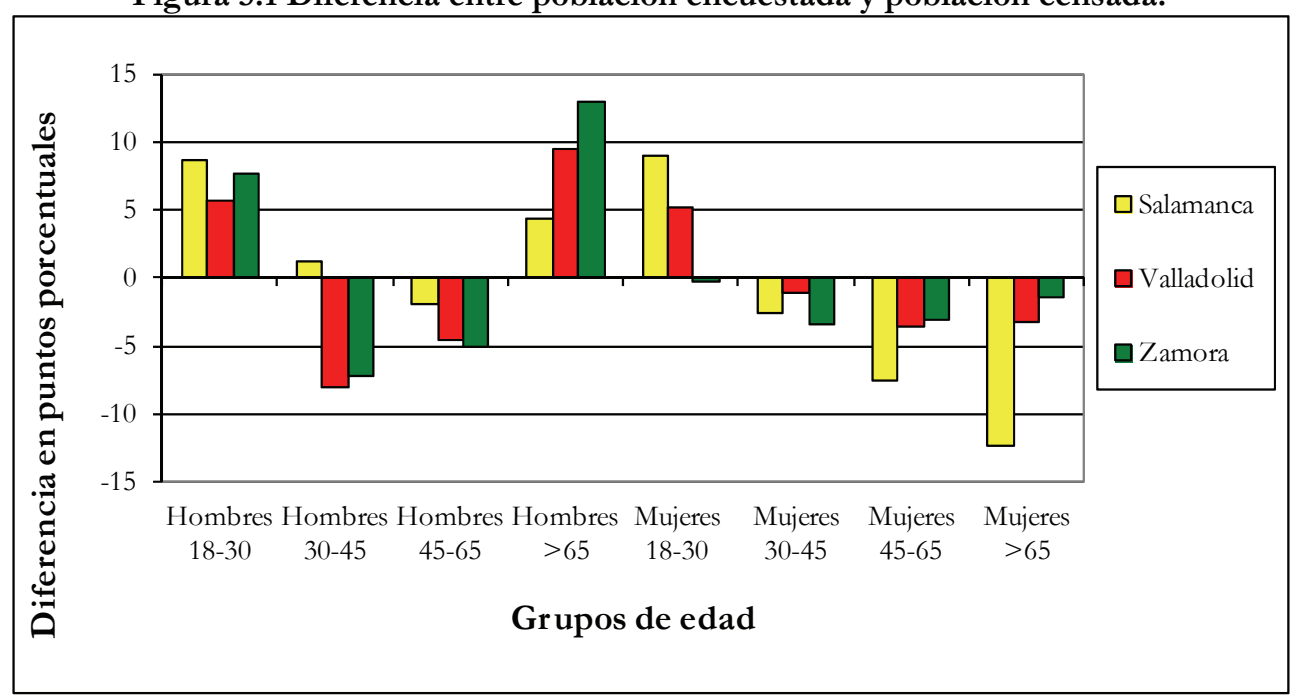

Fuente: elaboración propia a partir de datos del INE.

La Figura 5.2 representa la distribución de los usuarios en función de su actividad y en ella se corrobora la importancia de la población jubilada entre los usuarios del verde urbano. Este colectivo es especialmente numeroso en Zamora, donde representa al 42,5\% de los encuestados en esa ciudad, y supone una diferencia de casi veinte puntos porcentuales con la cifra obtenida en Salamanca $(25 \%)$. Esto termina por demostrar la gran influencia de la población mayor y jubilada en la muestra obtenida en Zamora, como se señaló anteriormente 
en la Figura 5.1. El colectivo que engloba a ocupados y parados, tiene una representatividad cercana a la mitad de los encuestados de cada ciudad, mientras que el porcentaje promedio de estudiantes en los tres casos es del 17,4\%, superando por dos puntos al colectivo de desempleados, compuesto mayoritariamente por mujeres.

Figura 5.2 Población encuestada por ocupación.

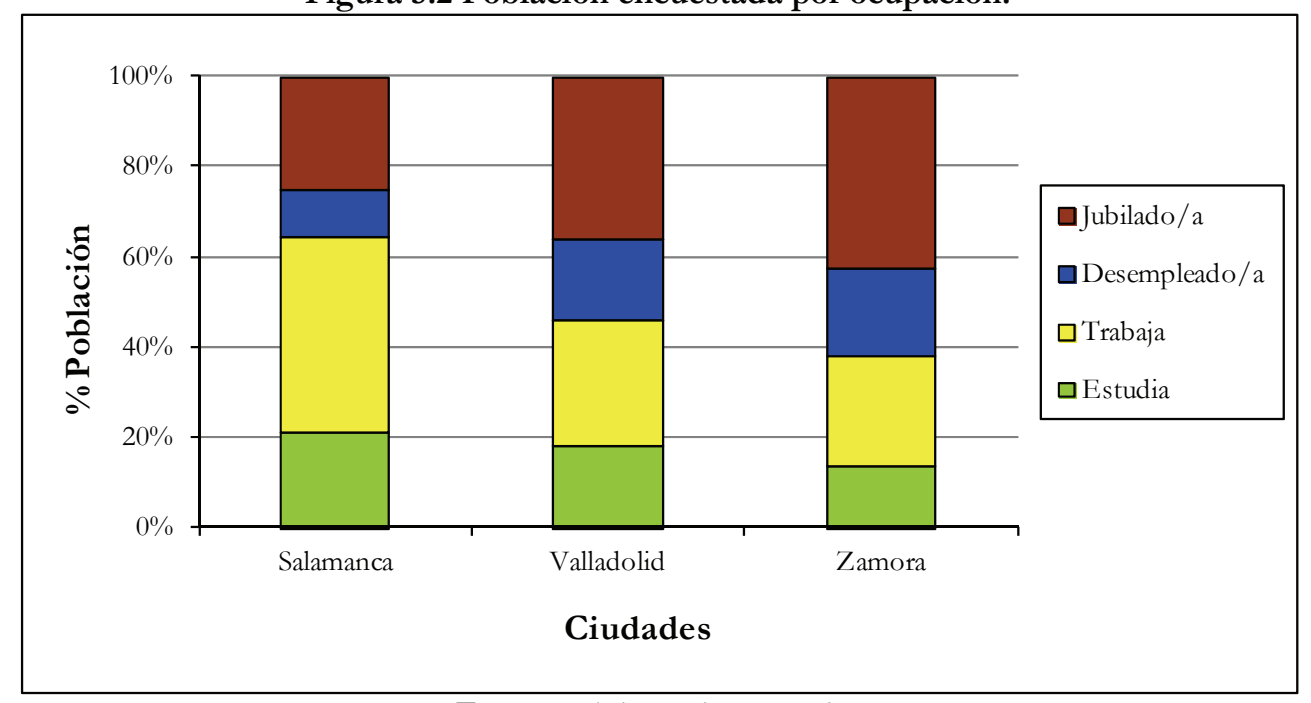

Fuente: elaboración propia.

\subsubsection{Frecuencia de las visitas al verde urbano}

Los datos referidos a la frecuencia de las visitas tratan de suplir la enorme labor que habría que realizar para obtener un estudio detallado. A través de las preguntas cinco, seis y siete del cuestionario, se ha obtenido una panorámica general de la distribución temporal en las visitas de los usuarios a las áreas verdes, identificando un total de 721 personas que visitan estos espacios más de cinco veces por semana, es decir, un 65,3\% de los encuestados en las tres ciudades. Esta cifra confirma que la mayor parte de los usuarios del verde urbano son visitantes asiduos, quedando corroborado por el hecho de que solamente 33 personas aseguraron realizar tres o menos visitas al mes, lo que representa menos de un 3\% del total. La distribución por sexo de los datos referentes a la frecuencia de las visitas apunta a que el grupo de hombres mayores es el que más veces acude a los espacios verdes, ya que el 86,6\% de los mismos aseguró visitarlos más de cinco veces a la semana, seguido del grupo de hombres adultos-viejos y de las mujeres mayores, que presentaban porcentajes superiores al setenta por ciento. Este último dato es llamativo: demuestra que pese a representar un porcentaje pequeño, las mujeres viejas que visitan el verde urbano lo hacen con asiduidad.

Si en vez de agrupar los datos por edad y sexo, se agrupan por ocupación y sexo, se obtiene la Figura 5.3, donde se identifica al grupo de hombres jubilados como los que visitan las zonas verdes con mayor frecuencia, seguidos de las mujeres jubiladas, confirmando la extraordinaria frecuencia de visita de las pocas mujeres de este grupo. Este gráfico permite comprobar la influencia del tiempo libre en las visitas, ya que junto al colectivo de jubilados aparece en segundo lugar del ranking de frecuencias, el de personas desempleadas. Los estudiantes, por su parte, acuden con muy poca periodicidad a estos espacios debido, posiblemente, al enorme condicionante que suponen los horarios académicos y al gusto por otro modelo de ocio vinculado con lugares cerrados. Combinando estos datos con los anteriormente mencionados se llega a la conclusión de que los jubilados representan un porcentaje de usuarios muy elevado que visita casi todos los días los espacios verdes, mientras que los estudiantes, que representan tan solo un $17,9 \%$ del total de los encuestados 
(los jóvenes son el 26,3\%) acuden a los espacios verdes con menos frecuencia, mayoritariamente una o dos veces por semana.

Para contextualizar el estudio realizado se han comparado los datos de frecuencia con los publicados por algunos de los autores que han analizado las visitas a los espacios verdes urbanos. Por ejemplo, Arnberger (2006) examinó en profundidad las visitas realizadas en dos parques de Viena durante un año, empleando distintos métodos de conteo que fueron apoyados con entrevistas personales. El número de visitas que este autor registró en los espacios verdes donde llevó a cabo su trabajo fue de 1,24 millones en un parque que se encontraba dentro de la ciudad y de 0,6 millones en un verde periurbano, distinguiendo en ellas el tipo de usuario entre las categorías de ciclista, caminante, gente que paseaba al perro y gente que corría. La media de visitas obtenidas en el parque urbano fue de 4.300 los días durante el fin de semana y de 3.000 visitas los días de diario, mientras que en el periurbano los datos durante el fin de semana fueron de 3.000 y los días entre semana de 1.000 usuarios de media.

Figura 5.3 ¿Con qué frecuencia visitan los usuarios los espacios verdes?

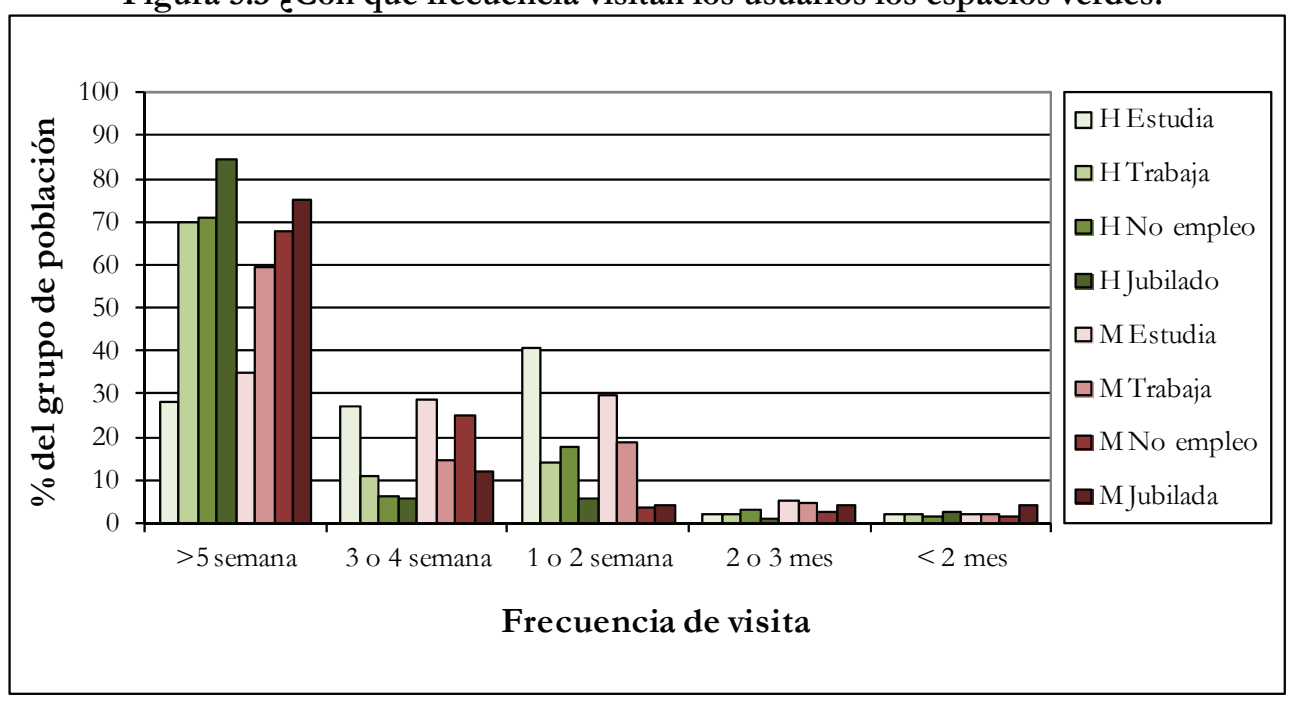

Fuente: elaboración propia.

Un estudio más próximo al desarrollado en esta investigación fue el llevado a cabo por Fonseca et al. (2010) en los espacios verdes de la ciudad de Bragança, una localidad portuguesa situada a poco más de $100 \mathrm{~km}$ de Zamora. Los datos publicados en dicho trabajo afirman que un $45 \%$ de los encuestados acudían a las áreas verdes cualquier día de la semana, un $44 \%$ lo hacía únicamente el fin de semana y un $11 \%$ solamente los visitaba durante los días laborables. Tanto Arnberger (2006) como Fonseca et al. (2010) concluyen que los espacios verdes son visitados más intensamente durante el fin de semana porque es cuando las personas disponen de más tiempo libre y muestran una diferencia que en ambos casos es de treinta puntos porcentuales, mientras que en la presente investigación los resultados fueron notablemente distintos. Por un lado aparece la ciudad de Salamanca, donde la diferencia fue bastante inferior, de tan solo 11,3 puntos, mientras que en Valladolid y en Zamora eran mayoritarias las visitas durante la semana con diferencias de 4,8 y de 16,1 puntos porcentuales respectivamente (ver Figura 5.4).

Esto obliga a detenerse en los datos obtenidos en las dos últimas urbes, donde se muestra una clara preferencia por las visitas en días entre semana. La explicación a este fenómeno puede encontrarse en el formidable peso que tiene en la muestra la población jubilada, que en ambos casos se aproxima a un tercio de los usuarios entrevistados, cuyos hábitos no estarán condicionados por los horarios de estudio ni de trabajo. No obstante, parece más probable que este resultado tan diferente esté influenciado por la formulación de 
la pregunta, al cuestionar únicamente a los usuarios que acudían a los espacios verdes para reunirse con otras personas, excluyendo a todos aquellos que no afirmaron tal cosa. En futuras investigaciones sería necesario incluir este criterio por separado, al igual que existe otra pregunta diferente sobre las estaciones del año en que se visitan los espacios verdes.

Figura 5.4 ¿Cuándo se reúnen los usuarios con otras personas en las zonas verdes?

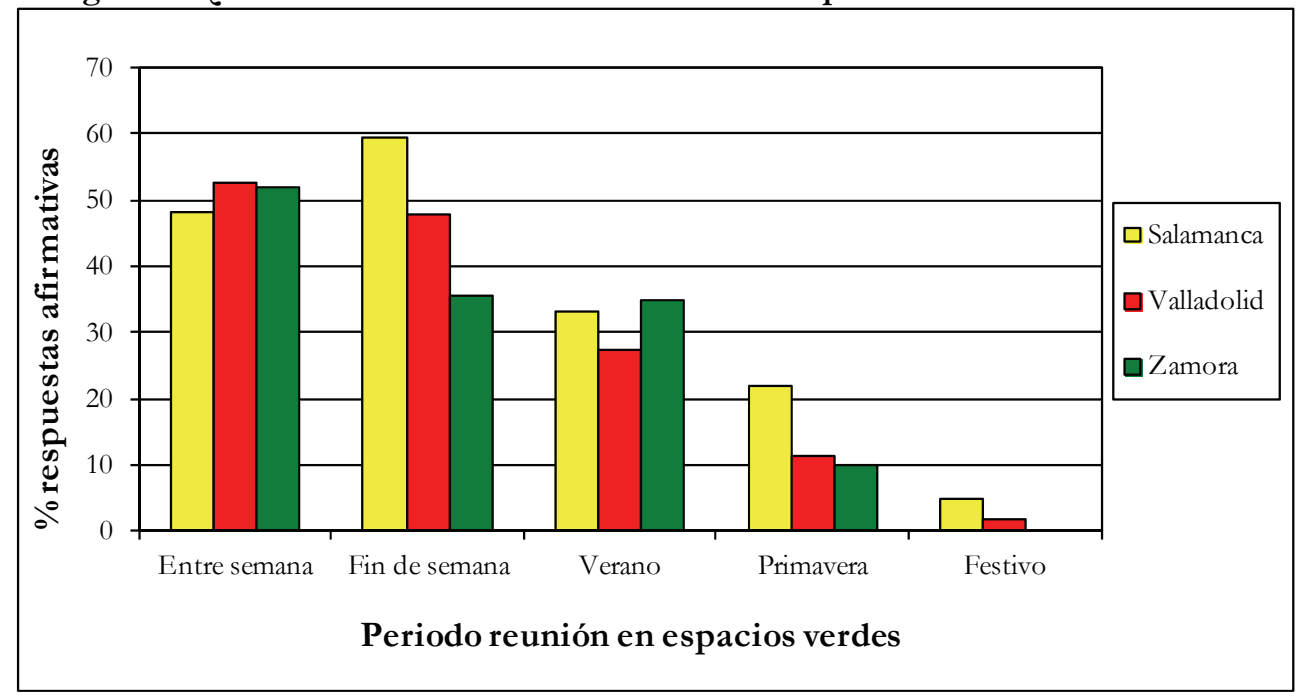

Fuente: elaboración propia.

No obstante, esta controvertida cuestión sí permite identificar al colectivo de jóvenes como el que utiliza con mayor intensidad los espacios verdes para reunirse con otras personas, ya que entre chicos y chicas alcanzan un tercio de los encuestados que realizan esta actividad. Por otra parte, el grupo de hombres de más de sesenta y cinco años supone un $18,5 \%$ de los mismos, lo que concuerda con los resultados del trabajo elaborado por Puyuelo et al. (2005) en los espacios abiertos urbanos de Castellón, en el que identificaron los parques como uno de los lugares de socialización de las personas mayores. En dicha ciudad los ancianos acudían a los espacios verdes para reunirse con otras personas y para establecer relaciones sociales.

En la Figura 5.4 también se observa que durante el verano se intensifican las visitas por parte de aquellos que acuden a las áreas verdes para reunirse con otras personas. Este hecho concuerda, en parte, con los datos anteriormente señalados, ya que se trata del periodo de vacaciones escolares durante el cual los estudiantes mayores de edad, que representan un $17,9 \%$ de los encuestados, y las personas que acuden acompañando a niños, que representan un 15,5\% del total, tendrán más libertad de horarios pudiendo dedicar una parte del tiempo a visitar las zonas verdes. Algunos autores han identificado una notable influencia del tiempo en el uso de estos espacios, tanto en su sentido cronológico como en su sentido meteorológico (Cedeño, 2003). Fonseca et al. (2010) demostraron una significativa influencia del estado del tiempo asociado a las estaciones del año y a la duración del día, en la frecuencia de las visitas a las áreas verdes de la ciudad de Bragança. Tales afirmaciones fueron corroboradas en la presente investigación al registrarse un aumento de las visitas a los parques y jardines durante las estaciones cálidas, así como una distribución de las mismas asociada mayoritariamente con las horas que transcurren entre la salida y la puesta de sol. Concretamente, en la cuestión número siete se preguntó a los usuarios sobre la estación en que realizaban el mayor número de visitas al verde urbano: un 91,3\% de los encuestados afirmó acudir en verano y un $82,5 \%$ en primavera, mientras que los visitantes en otoño y en invierno descendían hasta cifras ligeramente superiores al cincuenta por ciento, excepto en Zamora, donde un 66\% de los usuarios entrevistados acudían también durante las estaciones frías. 
La distribución horaria de las visitas muestra una situación que no por obvia, deja de de ser interesante subrayarla: la inmensa mayoría de las visitas a las zonas verdes se realizan durante las horas que trascurren entre la salida y la puesta del sol, siendo muy reducido el colectivo de usuarios que acude a partir de las ocho de la tarde (ver Figuras 5.5, 5.6 y 5.7). La representación horaria, que retomando el símil anterior sería el tiempo en sentido cronológico, muestra que hay dos periodos del día en el que se concentran la mayor parte de las visitas. El primero comprende las primeras horas de la mañana, desde las ocho hasta las doce, y los usuarios mayoritarios durante este periodo son los hombres de más de sesenta y cinco años que, como se indicó anteriormente, tienen tiempo libre y pueden acudir a los espacios verdes en este horario, acompañados de manera menos intensa de hombres adultosviejos. El segundo concentra una mayor cantidad de usuarios y tiene una extensión únicamente de dos horas, desde las seis a las ocho de la tarde, durante las cuales acude al verde urbano un tercio de los usuarios, especialmente hombres jóvenes y mujeres de entre dieciocho y sesenta y cinco años. Esta última franja horaria sería la utilizada por buena parte de los estudiantes y de las personas que tienen que cuidar de los niños, debido a la influencia de las obligaciones laborales y académicas, lo que evidencia que el tiempo libre es un condicionante de las visitas a las áreas verdes.

Por otra parte, la población anciana masculina al disponer de mucho tiempo libre presenta una mayor variedad de horarios, pudiendo incluso repetir visita a lo largo del día. El grupo de mujeres jóvenes concentra mayoritariamente sus visitas en horario de tarde, al igual que el de los hombres de la misma edad, cuya presencia es especialmente destacada entre las seis y las ocho. Una vez que se hace de noche, el número de usuarios se reduce de manera sensible debido a que algunos de estos espacios comienzan a ser percibidos como poco seguros por una parte importante de la población, especialmente por las mujeres (Cedeño, 2003), lo que explicaría que en este estudio sean mayoritariamente hombres los usuarios del verde urbano durante este periodo. Hay que destacar el hecho de que entre las dos y las cuatro de la tarde apenas se registren visitas al coincidir con la hora de la comida y del reposo de gran parte de la población. Además, como la mayor parte de los usuarios dijo visitar los espacios verdes en las estaciones cálidas, hay que pensar que se estarían evitando las horas de más calor, especialmente durante el verano.

En el único parque situado en el interior de la ciudad en que desarrolló su trabajo, Arnberger (2006) constató que el periodo en el que los usuarios acudieron con más frecuencia fue el comprendido entre las doce del mediodía y las cinco de la tarde, con la excepción de aquellos que visitaron el parque correr, que lo hicieron a primera hora de la mañana y desde las cuatro de la tarde hasta las siete. Comparando estos resultados con las frecuencias horarias obtenidas en el verde urbano disponible de las tres ciudades estudiadas se percibe una gran diferencia en cuanto a la distribución de las visitas, debida posiblemente a la diferencia entre los ritmos u horarios de vida de un país centroeuropeo y de otro mediterráneo, a lo que contribuiría como ya se ha mencionado, el clima, la hora de salida y de puesta del sol y los distintos horarios laborales. Un ejemplo de la influencia de estos factores es la escasa presencia de visitantes en los espacios verdes entre las dos y las cuatro de la tarde, por las razones antes mencionadas, mientras que en Viena este es el periodo de mayor afluencia.

\subsubsection{Actividades y sentimientos en el verde urbano}

A los usuarios encuestados se les preguntó por la razón de las visitas a las zonas verdes y las respuestas obtenidas se representaron en la Figura 5.8 junto a las publicadas por Chiesura (2004) en su estudio sobre un parque de Ámsterdam. Se observa que en todas las ciudades castellano-leonesas la actividad más realizada por los usuarios del verde urbano fue hacer deporte o pasear, con un 39,7\% de las respuestas recogidas, mientras que la relajación, 
Figuras 5.5, 5.6 y 5.7 Distribución horaria de las visitas a los espacios verdes de Salamanca, Valladolid y Zamora.
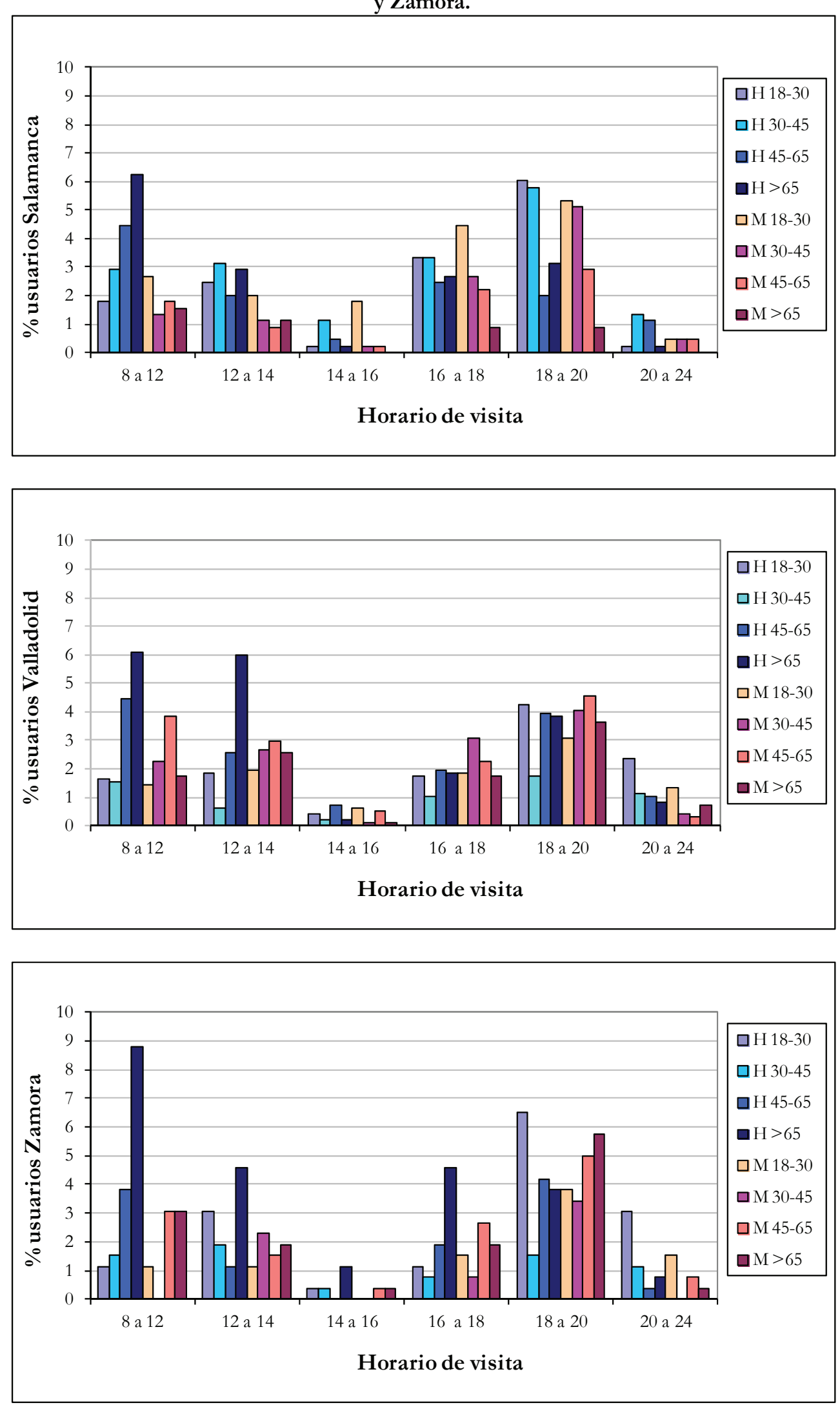

Fuente: elaboración propia. 
que en el apartado dedicado a las funciones sociales fue denominado como recuperación del estrés producido por la vida urbana, aparece en segundo lugar citada por el 18,3\%. A continuación se encuentran actividades realizadas en los espacios verdes que se podrían calificar como de "responsabilidad", esto es, pasear al perro $(13,9 \%)$ y cuidar de niños $(10,5 \%)$, siendo la primera una actividad destacada en los espacios verdes de la ciudad de Zamora y la segunda en los de Salamanca.

Estos datos son notablemente diferentes a los obtenidos en Ámsterdam y publicados por Chiesura (2004). Por ejemplo, hay una gran diferencia entre las actividades deportivas y de paseo, ya que en el Vondelpark apenas representan un 4,4\% de las respuestas, frente a un valor cercano al cuarenta por ciento de las actividades realizadas por los más de mil usuarios encuestados en las ciudades castellano-leonesas. Sucede algo parecido con aquellos que acuden a relajarse, con la particularidad de que en la capital neerlandesa el porcentaje de respuestas casi dobla a la media de las otras tres. En definitiva, podría afirmarse que los usuarios del parque de Ámsterdam acuden principalmente por motivos psicológicos (un tercio de los encuestados lo hizo para relajarse, un 13,6\% para escapar de la ciudad y un 7,4\% para meditar), mientras que en las ciudades españolas los motivos están relacionados con la actividad física.

Figura 5.8 ¿Qué actividades realizan los usuarios en los espacios verdes?

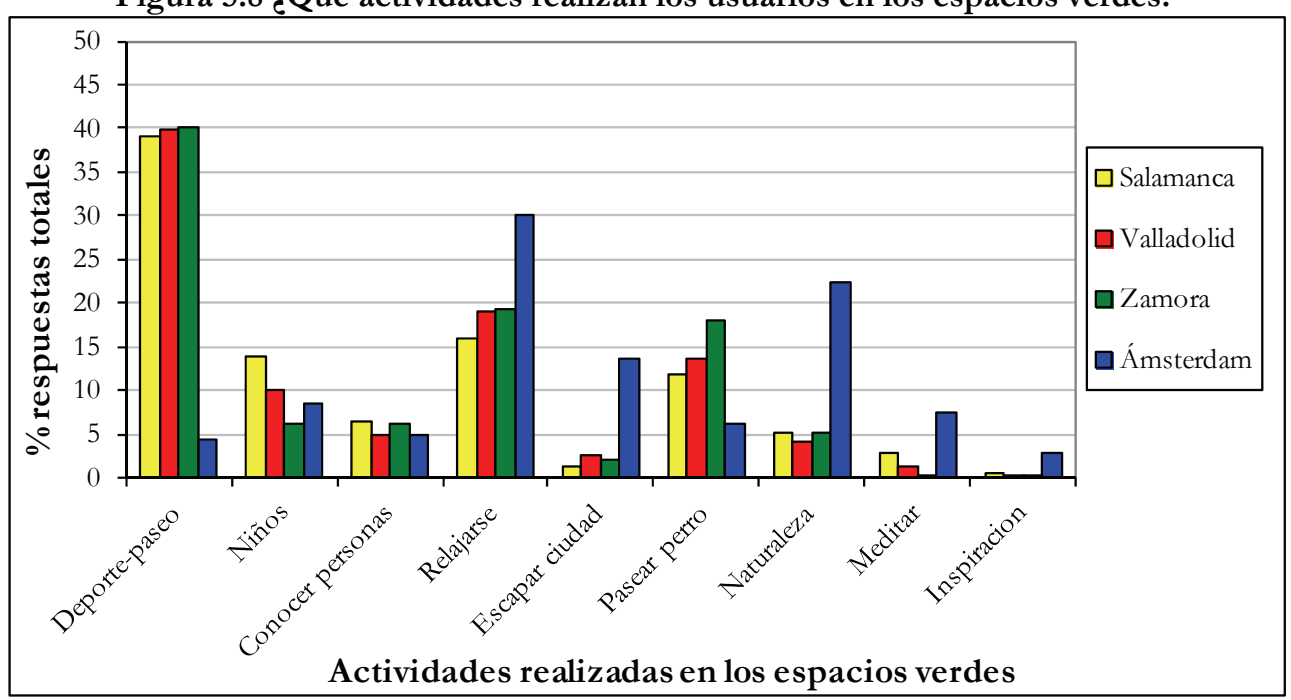

Fuente: elaboración propia a partir de los resultados de Chiesura (2004).

Entre estas últimas parece que el tamaño o la escala de la ciudad no tienen una influencia significativa en el uso de las áreas verdes, identificándose un comportamiento propio de la sociedad castellano-leonesa que contrasta con la neerlandesa. Habría que pensar que otros factores como las inquietudes de la población, los hábitos, los horarios de trabajo o incluso el estrés, así como la obvia disponibilidad de zonas verdes y de equipamientos deportivos, pueden estar influyendo en el surgimiento de diferentes necesidades que buscan ser satisfechas con la visita a estos espacios.

Resulta llamativo que más de una quinta parte de los usuarios encuestados en Ámsterdam acudiera a las áreas verdes en busca de contacto con la naturaleza, mientras que en las ciudades castellano-leonesas este porcentaje no alcanzó siquiera un cinco por ciento del total de las respuestas. Para comprender este dato es interesante analizar qué sentimientos les producen los parques y jardines a los habitantes de estas ciudades (ver Figura 5.9). Los usuarios encuestados en el presente trabajo afirmaron que el principal sentimiento que experimentan al visitar las zonas verdes es el contacto con la naturaleza, lo que contrasta de manera destacada con las actividades que realizan en ellas. La explicación a esta aparente contradicción puede encontrarse en que en estas tres ciudades, el verde urbano es el único 
contacto diario con el medio natural, ya que las tierras que rodean estas poblaciones han tenido históricamente una clara vocación agrícola, dando como resultado un paisaje de campos cultivados característico de la submeseta norte. En Ámsterdam los ciudadanos acudirían a los parques para realizar actividades en la naturaleza y el mayor sentimiento que experimentan en ellos es el de libertad, mientras que el contacto con el medio natural aparece en un segundo lugar. Esto indica que las zonas verdes en la capital neerlandesa se convierten en lugares donde escapar de la ciudad (mencionado por casi un 15\% de los allí encuestados), donde sentirse libre, bien sea por la presión o el estrés al que se ven sometidos los habitantes de las grandes ciudades, o por otros motivos como puedan ser los largos desplazamientos hasta el lugar de trabajo o de estudio. En las tres ciudades castellano-leonesas el sentimiento de libertad es mencionado por una quinta parte de los usuarios, lo que implica que también se acude a los espacios verdes para romper con los ritmos de la vida urbana. Esta característica quizás pueda explicar algo que se verá posteriormente, como es el escaso atractivo que presentan las áreas verdes en torno a vías de comunicación o construidas en vacíos urbanos, donde las personas no consiguen alcanzar un sentimiento de libertad, debido a que la morfología de estos espacios verdes no consigue aislar al ciudadano del estrés diario.

Aproximadamente un $20 \%$ de las respuestas de los usuarios en cada una de las cuatro ciudades comparadas afirmaron sentir felicidad en los espacios verdes. Este porcentaje es similar al de personas que en Ámsterdam afirmaron acudir a los parques para buscar el contacto consigo mismo (denominado meditación en la Tabla 5.9), sentimiento que es muy débil en las otras ciudades. Es preciso añadir que cuarenta y cinco personas, el $4 \%$ de los encuestados, afirmaron tener miedo o sentirse inseguros en las zonas verdes. Santana et al. (2009) demostraron una correlación inversa entre inseguridad y utilización del verde urbano, por lo que será muy probable que las personas que manifestaron este sentimiento estén posponiendo algunas visitas a estos espacios.

Figura 5.9 ¿Qué sentimientos les producen los espacios verdes a los usuarios?

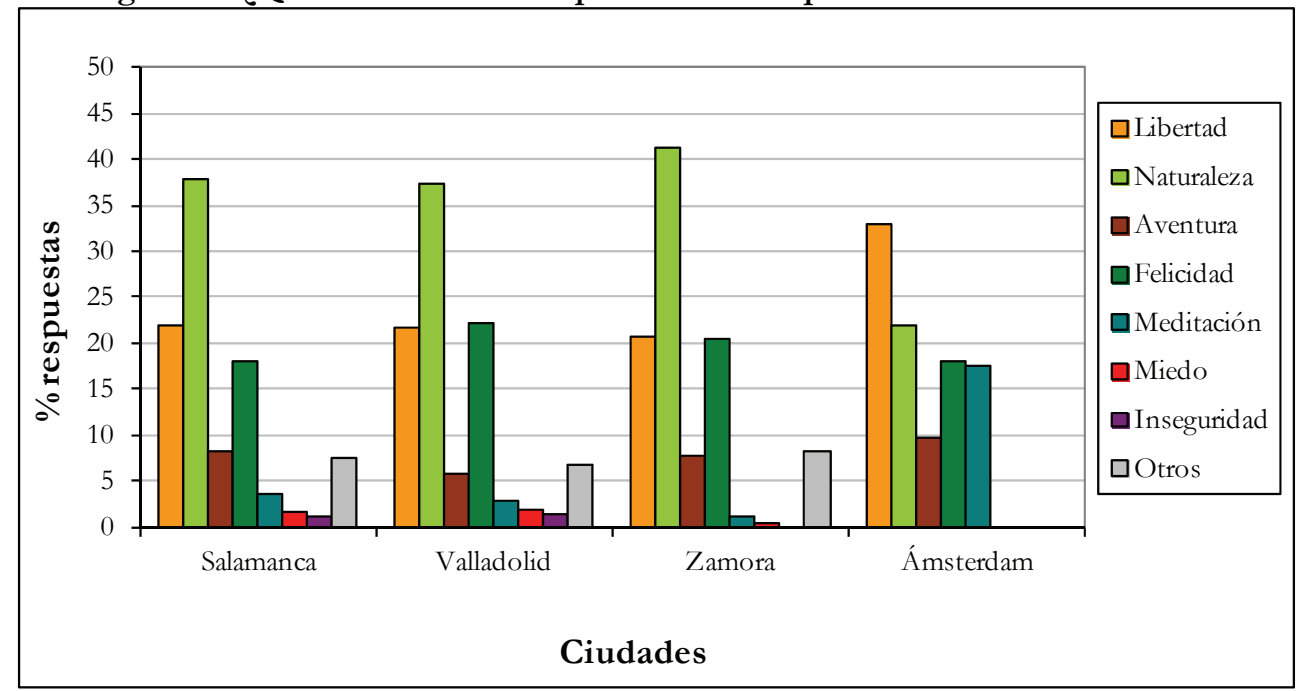

Fuente: elaboración propia a partir de los resultados de Chiesura (2004).

Las semejanzas en las respuestas recogidas en las tres ciudades estudiadas demuestran que no hay diferencias significativas al aumentar el tamaño de la ciudad, como se puede comprobar en las Figuras 5.8 y 5.9, donde además coinciden casi por completo en el orden jerárquico de las actividades y de los sentimientos que les producen los espacios verdes. Esta similitud también se constata al incrementar el detalle del análisis, puesto que las actividades realizadas en función de la edad y el sexo de los usuarios también coinciden en los tres casos analizados: en la Figura 5.10 se ha calculado un promedio de los valores obtenidos en cada ciudad, analizando las actividades realizadas sobre el total de la población de cada colectivo. 
Además, el gráfico se ha complementado con la información derivada de la Figura 5.11 donde aparecen representados los equipamientos de las zonas verdes utilizados por cada uno de estos grupos. Estas dos imágenes contribuyen también a explicar la distribución horaria de las visitas expuesta anteriormente, puesto que muestran qué tipo de actividades y qué equipamientos utiliza cada grupo de edad y sexo en los que se ha dividido la muestra de población. Por ejemplo, se observa que el colectivo de jóvenes acude a los espacios verdes para pasear o realizar actividades deportivas y para relajarse, siendo las primeras preferidas por los hombres y la segunda por las mujeres. Casi una cuarta parte de los hombres menores de treinta años utilizan habitualmente las instalaciones deportivas, mientras que aproximadamente un tercio de ambos sexos utiliza el césped como lugar de esparcimiento y relajación. Por otra parte, el $54,4 \%$ de las mujeres de entre treinta y cuarenta y cinco años acuden a las áreas verdes para acompañar a sus hijos, siendo este porcentaje mucho más reducido entre los hombres de esta edad. Esto tiene su reflejo en los equipamientos utilizados, ya que una cuarta parte de este colectivo de mujeres visita las zonas de juego infantil, se sobreentiende que para acompañar a sus hijos, y por tanto, se acaba por comprender que acudan a los espacios verdes en horario de tarde, ya que lo harán condicionadas por los horarios escolares de los más pequeños.

Figura 5.10 Actividades realizadas en los espacios verdes por cada grupo de edad y sexo.

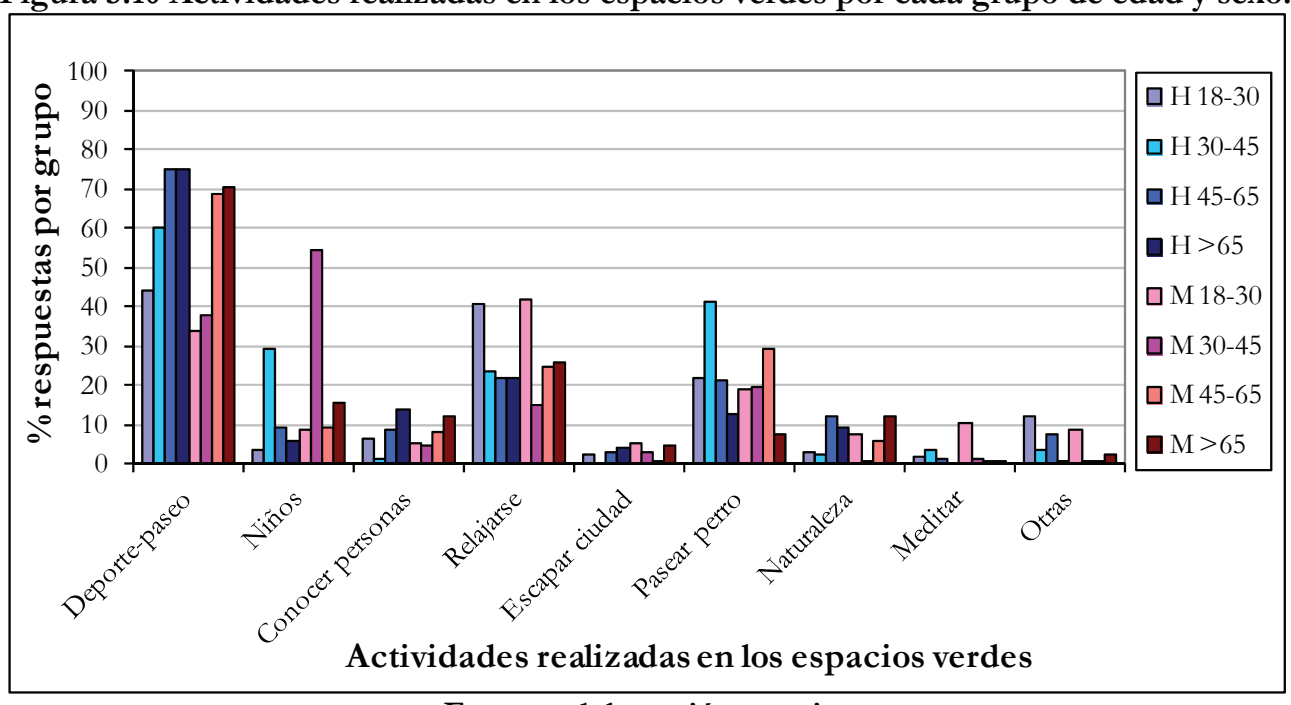

Fuente: elaboración propia.

Figura 5.11 Equipamientos utilizados en los espacios verdes por cada grupo de edad y sexo.

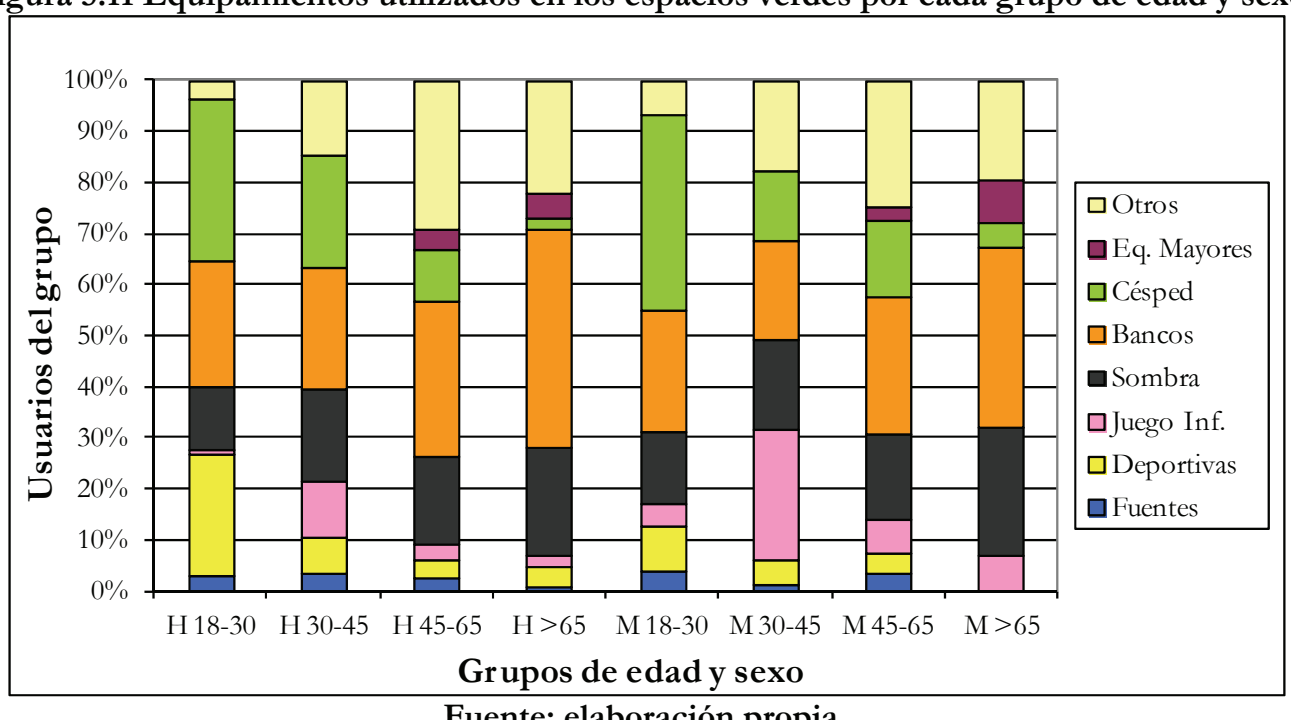

Fuente: elaboración propia. 
Por otro lado, el grupo de adultos-viejos dedica más de dos tercios de sus visitas a la actividad física y menos de un tercio a pasear al perro o a relajarse. Los bancos son el equipamiento más utilizado por los hombres y las mujeres de esta edad, especialmente por la población vieja. En cuanto a los jóvenes, el porcentaje que acude a los parques y jardines para pasear al perro se aproxima al $20 \%$ en ambos sexos, pero son los hombres de entre treinta y cuarenta y cinco años quienes más los visitan acompañados de su animal de compañía $(41,2 \%)$, mientras que esta actividad apenas es practicada por los ancianos debido a los cambios asociados al envejecimiento. Este proceso provoca cambios físicos tales como la menor movilidad articular o la reducción de la fuerza muscular (Puyuelo et al., 2005), que obviamente condicionan las actividades que los mayores llevarán a cabo en las áreas verdes. Por tanto, estas personas visitarán los parques fundamentalmente para pasear, para relajarse y para conocer a otras personas, siendo el colectivo que más desarrolla esta tarea socializadora, y por el tipo de equipamientos que más utilizan, hay que pensar que se desarrollará en bancos situados a la sombra. Las mujeres ancianas representan el tercer grupo poblacional que más acude al verde urbano para cuidar niños, dedicando a ello el 15,7\% de las visitas. Esto refleja la importancia de los mayores en el modelo de familia actual, ya que asumen una parte del cuidado de los nietos al existir una implicación generalizada de la pareja en el ámbito laboral (Puyuelo et al., 2005). Otras actividades realizadas en los espacios verdes como escapar de la ciudad, meditar o estar en contacto con la naturaleza son muy poco representativas.

\subsubsection{Recapitulación}

El resultado más llamativo obtenido al analizar las características de los visitantes del verde urbano disponible es que la escala o el tamaño de las ciudades no parece tener una influencia destacada en el uso. Atendiendo al número de visitas, a los horarios, a la frecuencia, a las actividades, a los equipamientos utilizados y a las sensaciones transmitidas, se ha identificado un comportamiento común de la sociedad castellano-leonesa, que presenta notables diferencias con otros trabajos publicados. Además, se ha comprobado que los espacios verdes son lugares de convivencia donde pueden identificarse algunos de los comportamientos más característicos de una sociedad, diferenciando los roles de cada grupo de edad y sexo. Por ejemplo, se puede intuir que las mujeres son quienes se encargan mayoritariamente de las labores familiares, ya que las adultas-jóvenes acuden con mucha frecuencia a las zonas verdes para cuidar de sus hijos, mientras que el reducido número de mujeres mayores registrado puede deberse a la gran cantidad de tareas domésticas que tienen que asumir, como señalaba el trabajo de Muga (1980).

Este trabajo ha demostrado el importante papel de los mayores en el modelo actual de familia, ya que el 15,7\% de las visitas de las mujeres y el 6,2\% de los hombres de este grupo de edad están dirigidas a cuidar de los más pequeños. Además, las áreas verdes se muestran como lugares de socialización, que como ya recogieron Puyuelo et al. (2005), constituyen uno de los puntos de reunión y estancia de las personas mayores. Conviene también destacar el papel que tienen los espacios verdes para la práctica deportiva en las ciudades donde se llevó a cabo la investigación, ya que en otros países europeos se prefiere acudir a recintos cerrados como gimnasios o pabellones para hacer deporte, por razones vinculadas con el clima, con las horas de luz o con otro tipo de cuestiones sociológicas en las que no se ha profundizado.

Parece evidente que el tiempo libre es otro de los condicionantes de las visitas a las zonas verdes, puesto que se observó la influencia directa o indirecta de los horarios escolares entre algunos de los grupos de edad y sexo. El análisis de las características y del comportamiento de los usuarios del verde urbano disponible de las tres ciudades seleccionadas ha permitido realizar una identificación detallada de los principales grupos atendiendo a la edad: 
Jóvenes: se trata de un colectivo que representa aproximadamente a una cuarta parte del total de los usuarios encuestados. Más de dos tercios de este grupo está compuesto por estudiantes, lo que explica que visiten los espacios verdes en horario de tarde, especialmente después de las 18:00 h, siendo pocos los que acuden por la mañana. El 77\% de los mismos van a las zonas verdes para reunirse con otras personas, especialmente durante el fin de semana, realizando actividades vinculadas con la relajación, en el caso de las mujeres, y con el deporte y el paseo, en el caso de los hombres. Se trata de un colectivo que acude con poca frecuencia a estos espacios, siendo mayoría los que afirman visitarlos menos de cuatro veces por semana.

Adultos-jóvenes: es el grupo de edad menos numeroso entre los usuarios del verde urbano disponible, con una representatividad sensiblemente menor a la población censada de este colectivo. Un $76 \%$ de los hombres y un $57 \%$ de las mujeres encuestadas de este grupo tienen trabajo, lo que implica que la mayor parte de las visitas a los espacios verdes se realice por la tarde. Las mujeres acuden mayoritariamente a los parques para estar con sus hijos, siendo esta una motivación importante dentro del colectivo de los hombres, pero secundaria, ya que principalmente visitan las áreas verdes para realizar actividades deportivas.

Adultos-viejos: pese a representar una cuarta parte de los encuestados, este grupo de edad muestra una notoria diferencia negativa con respecto a la población censada. La mitad de ellos tiene empleo y la otra mitad está compuesta a partes iguales por jubilados y por individuos sin empleo. Sin embargo, a la hora de acudir a los espacios verdes, se distinguen claramente dos tipos de usuarios con unos horarios muy característicos. Por un lado estarían los jubilados, que realizan un $60 \%$ de sus visitas en horario de mañana, frente a trabajadores y personas sin empleo que escalonan las visitas en función de las obligaciones de cada uno. Tanto hombres como mujeres acuden a las áreas verdes con mucha frecuencia para realizar deporte $y$, en menor proporción, para pasear al perro y para relajarse.

Viejos: este es el colectivo con mayor presencia en las áreas verdes y el que presenta una diferencia entre sexos más amplia: al ser encuestados, el número de ancianos prácticamente dobló al de ancianas. Esta gran afluencia de personas mayores no se debe únicamente al envejecimiento de la población de las ciudades analizadas, sino a que los hombres de esta edad utilizan con mucha frecuencia los parques y jardines. Para caracterizar el comportamiento de este grupo se han comparado los datos obtenidos con los publicados por Puyuelo et al. (2005). En dicho trabajo fueron encuestados usuarios de los espacios abiertos urbanos de Castellón con más de sesenta y cinco años, obteniendo una distribución por sexos muy similar a la de esta investigación, ya que el porcentaje de hombres duplicaba al de mujeres (68\% frente al 32\%). Los mayores son un público muy fiel: en torno al ochenta por ciento de los entrevistados en Salamanca, Valladolid y Zamora, acudía más de cinco veces a la semana a las zonas verdes, datos similares a los publicados en el trabajo de Castellón, donde un 65\% asistía a diario. La mayor parte de las visitas de este colectivo se registran en horario de mañana (54\%), siendo relevante su presencia por la tarde $(40 \%)$, mientras que después de las 20:00 h son muy pocos los usuarios de esta edad que visitan las áreas verdes. En las ciudades castellano-leonesas, dos tercios de los mayores visitaban estos espacios para reunirse con otras personas, ya fueran amigos o familiares, mientras que Puyuelo et al. (2005) recogen una cifra más elevada en su estudio (89,4\%).

\subsection{Lugar de residencia y acceso al verde urbano}

Cuando a los más de mil cien usuarios se les preguntó por el motivo que les llevaba a visitar un espacio verde y no otro, un 65,2\% apuntó a la cercanía desde el lugar de residencia. 
Analizando las respuestas entre ciudades, llama la atención que en Salamanca el porcentaje supere esta cifra en casi un diez por ciento, mientras que en Zamora fueron poco más de la mitad de los usuarios los que afirmaron que esta era su motivación principal (ver Figura 5.12). Estos resultados concuerdan con varios trabajos donde se ha identificado este factor como el determinante principal de las visitas a las áreas verdes (Magalhães, 1992; Nilsson et al., 1997; Van Herzele y Wiedemann, 2003; Santana et al., 2007a), por lo que su utilización permitirá determinar qué parte de la ciudad posee acceso a dichos espacios.

Figura 5.12 Motivos para visitar un espacio verde.

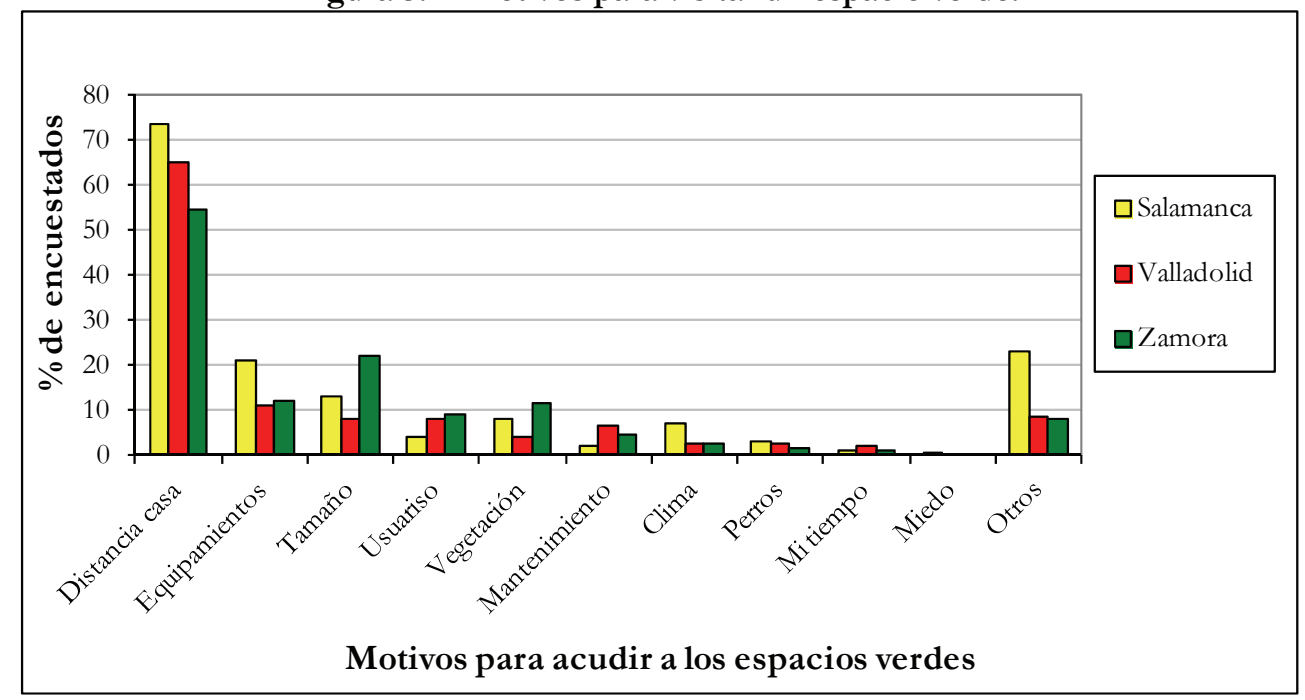

Fuente: elaboración propia.

En el capítulo anterior se mencionó la necesidad de completar los índices tradicionalmente utilizados para medir las zonas verdes de una ciudad (extensión total, metros cuadrados de verde por habitante, metros cuadrados de verde por hectárea, etc.) con otros indicadores que incluyan la posibilidad de uso de las áreas verdes por parte de los ciudadanos. Esta preocupación se inscribe también dentro de las políticas de sostenibilidad urbana surgidas como respuesta a los problemas ambientales que afectan al planeta y cuyo origen está directamente vinculado con el modelo de desarrollo actual.

En el año 1972 se publicó el Informe Meadows alertando de la necesidad de modificar el modelo actual de desarrollo y algunos organismos gubernamentales y supranacionales comenzaron a preocuparse por cómo combatir los problemas ambientales y por cómo llevar a la práctica el concepto de desarrollo sostenible, formulado en el Informe Brundtland de 1987. La ONU celebró en 1992 la Conferencia sobre Medio Ambiente y Desarrollo Sostenible de Río de Janeiro, donde por primera vez se definieron las Agendas 21 locales, esto es, un instrumento con el que integrar el desarrollo sostenible a las políticas municipales. Por su parte, a nivel europeo los Acuerdos de Río fueron seguidos por la Carta de Aalborg en 1994 y por el informe Ciudades europeas sostenibles de 1996. Posteriormente, en la Tercera Conferencia Europea sobre Ciudades Sostenibles celebrada en Hannover en el año 2000, se establecieron una serie de indicadores sobre la sostenibilidad local con el objetivo de recoger las interacciones entre aspectos medioambientales, sociales y económicos, publicados en el informe Hacia un perfil de la sostenibilidad local. Indicadores comunes europeos. Con estos se pretendía suministrar información objetiva y comparable de la sostenibilidad en las ciudades. En cada caso se podrían medir los progresos realizados y las tendencias seguidas en materia de sostenibilidad, proporcionando una valiosa información a las autoridades al identificar los puntos fuertes y débiles de cada municipio.

La Primera Generación de Indicadores Comunes Europeos se componía de cinco indicadores principales u obligatorios y cinco indicadores adicionales o voluntarios, y entre 
los primeros aparece la existencia de zonas verdes públicas y de servicios locales. Se define claramente cómo medir el acceso a estos espacios, para lo que se emplea una distancia o área de influencia de dichas dotaciones de 300 metros y posteriormente se calcula cuántos habitantes del municipio vivirían cerca de un área verde o de alguno de los servicios básicos señalados, para así evaluar la sostenibilidad de la comunidad y su calidad de vida. Se sugiere la utilización de un SIG para su medición o, en su defecto, la realización de entrevistas a los ciudadanos utilizando la equivalencia de la distancia en tiempo, estimada en quince minutos como distancia máxima.

Barbosa et al. (2007) citan las recomendaciones de la antigua English Nature, una agencia del gobierno británico hoy absorbida por la Natural England, en las que aconsejaban que los habitantes tuvieran una zona verde a menos de cinco minutos a pie desde el lugar de residencia, o a menos de 300 metros. La propia Comisión Europea utiliza en la citada publicación la misma distancia para determinar el acceso al verde urbano, aunque su equivalente en tiempo es sensiblemente diferente. Nilsson et al. (1997) citan estudios suecos en los que se demostró que cuando esta excede los 300 metros, una de cada cuatro personas pospone una visita diaria a las áreas verdes. Estos autores hacen alusión a un trabajo de Grahn publicado en 1991 (al que no se ha podido tener acceso), en el que se aseguraría que el $56 \%$ de personas se abstienen de caminatas regulares al parque cuando la distancia supera los 500 metros. Por lo tanto, se identifica claramente que a mayor distancia desde el lugar de residencia, mayor es el número de visitas que se posponen a los espacios verdes. Sin embargo, no existe un acuerdo en la literatura consultada sobre qué distancia media debe emplearse, ya que otras publicaciones utilizan 400 metros desde las zonas verdes (Magalhães, 1992; Van Herzele y Wiedemann, 2003; Santana et al., 2007a). Aquí se ha optado por utilizar esta última cifra por considerarla integradora, tratando con ello de asegurar que en las zonas sin acceso los ciudadanos posponen un elevado número de visitas a los espacios verdes.

Van Herzele y Wiedemann (2003) sostienen que el tamaño de un área verde puede modificar la distancia que una persona está dispuesta a recorrer, al existir una clara vinculación entre la superficie y la cantidad de equipamientos de los parques, lo que serviría de atractivo potencial para un mayor número de usuarios. Estos autores utilizaron una clasificación de los espacios verdes en función de la superficie mínima (ver Tabla 5.6) en la que cada categoría aparece acompañada de una distancia diferente de irradiación, esto es, el trayecto máximo que sería recorrido por los usuarios entre el local de origen, que normalmente es el lugar de residencia, y el equipamiento. Esta distancia se mide en metros y permitiría determinar un área de influencia diferente para cada espacio verde en función de su tamaño. Observando la terminología original es posible comparar la situación de los espacios verdes en las tres ciudades de Castilla y León con la realidad existente en las cuatro ciudades flamencas de Bélgica donde estos autores llevaron a cabo su investigación: Alost, Cortrique, Gante y Amberes. Debido a que en la presente investigación se ha establecido un tamaño mínimo del verde urbano distinto en cada una de las ciudades estudiadas y a que la zona verde censada de mayores dimensiones es el vallisoletano Parque Ribera de Castilla (V4), que posee 26,7 ha, solo se podrían emplear dos de las categorías propuestas: neighbourbood green, que se ha traducido por verde de vecindario y que recogería aquellos espacios de entre una y diez hectáreas, y quarter green o verde de barrio, donde se incluirían los que superaran este tamaño. La comparación entre la situación que presentan las ciudades belgas y las castellano-leonesas es muy llamativa: los grandes parques que poseen estas últimas estarían situados dentro de la categoría denominada como quarter green, lo que haría referencia a que su uso estaría mayoritariamente vinculado a los habitantes del distrito o del barrio.

Utilizando como referencia los parques y jardines es posible identificar dos modelos de ciudad sensiblemente diferentes: por un lado parecería la ciudad mediterránea, ya citada en el capítulo anterior, que a grandes rasgos presenta un centro urbano compacto dentro del cual existen considerables deficiencias en lo que la dotación de zonas verdes se refiere y un 
espacio periférico en el que la mayor parte de parques han sido creados en los últimos treinta años, y por otro lado aparece otro modelo de ciudad del norte de Europa donde es frecuente encontrar una gran cantidad de parques que superan las diez hectáreas. Por lo tanto, no parece adecuado aplicar en tres ciudades del sur de Europa la tipología de espacios verdes empleada en Flandes (Bélgica), ya que las categorías establecidas no se adaptan a la funcionalidad real de estos espacios. Sin embargo, dicho artículo resulta de gran utilidad ya que la hipótesis de que una persona estaría dispuesta a recorrer una distancia mayor para acceder a las zonas verdes de mayor tamaño, se traduciría en un aumento de la distancia de irradiación.

Tabla 5.6 Clasificación de los espacios verdes urbanos propuesta por Van Herzele y Wiedemann.

\begin{tabular}{|l|c|c|}
\hline \multicolumn{1}{|c|}{ Nivel funcional* } & $\begin{array}{c}\text { Distancia máxima } \\
\text { desde casa (m) }\end{array}$ & Superficie mínima (ha) \\
\hline Residential green & 150 & 1 \\
\hline Neighbourhood green & 400 & 10 \\
\hline Quarter green & 800 & 30 \\
\hline District green & 1.600 & 60 \\
\hline City green & 3.200 & $>200$ (en ciudades pequeñas) \\
\hline Urban Forest & 5.000 & $>300$ (en ciudades grandes) \\
\hline
\end{tabular}

*Terminología original

Fuente: Van Herzele y Wiedemann (2003).

Tratando de averiguar si, efectivamente, el número de visitas que reciben las áreas verdes está en relación con su tamaño, se ha comparado la dimensión del verde urbano analizado con el índice de atracción, cuyo cálculo fue explicado en la metodología. El número de encuestas realizadas en las zonas verde estaba determinado por la superficie de cada una de ellas, puesto que se planificaron las encuestas siguiendo un ratio de 2,56 por cada hectárea de verde urbano. El índice de atracción se concibió para valorar la capacidad de atracción real de estos espacios tratando de evitar la influencia del número de encuestas realizadas.

Su análisis pormenorizado se realizará en el punto 5.5, pero el punto de mira se centrará ahora en la capacidad de atracción de las zonas verdes de más de diez hectáreas. En la Tabla 5.7 se observa que entre las diez primeras posiciones del ranking de más atrayentes hay seis que tienen un tamaño superior al mencionado. Aparecen también áreas verdes con una superficie reducida que sin embargo son muy valoradas por los ciudadanos, como son el Parque de la Alamedilla (S-10) y la Rosaleda Francisco Sabadell y el Parque de Poniente (V2). En la Figura 5.13 se ha representado la relación entre la superficie de los ochenta y ocho espacios verdes censados, con el índice de atracción de cada uno de ellos, obteniendo una correlación lineal notable $\left(\mathrm{R}^{2}=0,27\right)$, que es significativa al $99 \%$ (valor $\mathrm{p}<0,0100$ ). Esto quiere decir que, aunque haya otros factores que intervienen en las visitas, el tamaño de las zonas verdes explica estadísticamente un tercio de las mismas. Por tanto, habrá más factores que contribuyan a explicar el uso del verde urbano, pero el tamaño aparece como un factor clave. Por tanto, si se admiten los postulados de Van Herzele y Wiedemann (2003) y se acepta que hay personas que estarían dispuestas a recorrer una distancia mayor para acceder a los espacios verdes de mayor tamaño, habrá que determinar cuáles serán los que verdaderamente tienen un atractivo extra.

Los once parques de más de diez hectáreas formarían parte del llamado verde de ciudad, siempre y cuando se verifique que son más atrayentes que el resto. Su extensión total es de 169,2 ha, equivalente a un $40 \%$ de la superficie verde total estudiada, sumando un total de once entidades distribuidas de la siguiente manera: seis en Valladolid, tres en Salamanca y dos 
en Zamora. Para valorar la capacidad de los espacios verdes de mayor tamaño se utilizó el índice de atracción. En la Tabla 5.8 fueron ordenados en función del citado índice y se observó que algunos de ellos no tenían tanta capacidad de reclamo como cabría esperar. De tal manera que de la categoría verde de ciudad fueron excluidos (y aparecen en tono anaranjado) en primer lugar, las zonas verdes con un índice de atracción negativo o igual a cero, es decir, en las que se realizó un número de entrevistas igual o mayor al del número de personas que dijeron que esa era la que más veces visitaban. Y en segundo lugar, también se excluyeron aquellas en las que no fue posible encontrar a suficientes usuarios como para llevar a cabo las encuestas planificadas, por lo que finalmente la nueva categoría quedó reducida a siete entidades, descartando el Parque de El Zurguén (S-25), el verde urbano Huerta del Rey (V32), el Jardín Botánico de Huerta Otea (S-3) y el verde urbano Mirador de Parquesol (V-31).

Tabla 5.7 Espacios verdes más atrayentes de las ciudades de Salamanca, Valladolid y Zamora.

\begin{tabular}{|c|c|c|c|c|c|c|c|c|}
\hline $\mathrm{N}^{\circ}$ & Id. & ha & Nombre & $\begin{array}{c}\text { Encuestas } \\
\text { asignadas }\end{array}$ & $\begin{array}{l}\text { Encuestas } \\
\text { realizadas }\end{array}$ & $\begin{array}{c}\text { Porcentaje } \\
\text { de éxito }\end{array}$ & $\begin{array}{c}\text { Visitas } \\
\text { realizadas }\end{array}$ & $\begin{array}{l}\text { Índice de } \\
\text { atracción }\end{array}$ \\
\hline 1 & Z-6 & 16,5 & Margen derecha del Duero & 42 & 42 & 100,0 & 88 & 24,73 \\
\hline 2 & V-1 & 12,7 & Campo Grande & 33 & 35 & 106,1 & 157 & 18,86 \\
\hline 3 & Z-9 & 16,5 & Bosque de Valorio (parte urbana) & 42 & 44 & 104,8 & 69 & 13,44 \\
\hline 4 & $\mathrm{~V}-3$ & 9,5 & Parque de las Moreras & 24 & 24 & 100,0 & 107 & 12,83 \\
\hline 5 & S-10 & 2,2 & Parque de la Alamedilla & 6 & 6 & 100,0 & 31 & 9,23 \\
\hline 6 & Z-15 & 8,3 & Margen izquierda del Duero & 21 & 21 & 100,0 & 38 & 9,14 \\
\hline 7 & S-4 & 10,1 & Parque de los Jesuitas & 26 & 39 & 150,0 & 63 & 8,86 \\
\hline 8 & $\mathrm{~V}-4$ & 26,7 & Parque Ribera de Castilla & 68 & 72 & 105,9 & 122 & 7,73 \\
\hline 9 & $\mathrm{~V}-2$ & 4,6 & Rosaleda Francisco Sabadell y Parque Poniente & 12 & 13 & 108,3 & 62 & 7,57 \\
\hline 10 & V-9 & 21,0 & Parque del Mediodía & 54 & 55 & 101,9 & 100 & 6,96 \\
\hline
\end{tabular}

Fuente: elaboración propia.

Figura 5.13 Correlación entre el tamaño del verde urbano disponible y el índice de atracción.

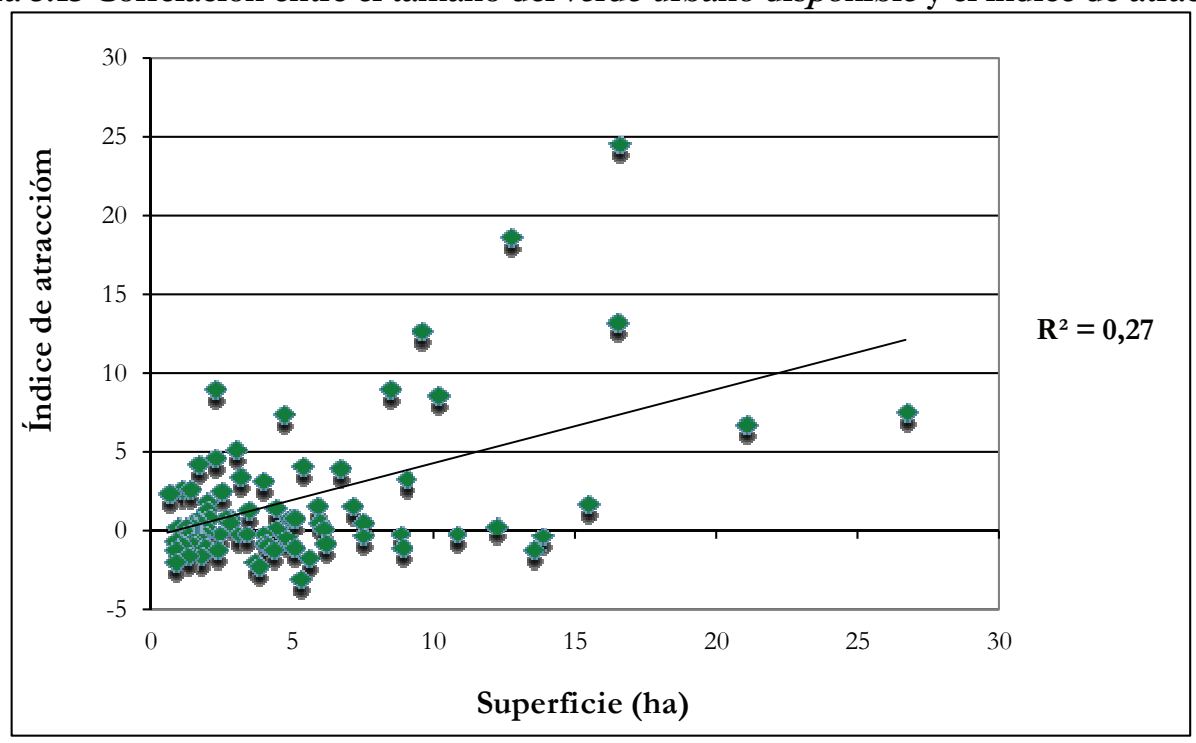

Fuente: elaboración propia.

Una vez qué se ha determinado que áreas verdes forman parte del verde de ciudad se calculó el área de influencia del conjunto de la trama verde para así estimar qué porcentaje de población de cada una de las urbes objeto de estudio tendría acceso a la misma. Se empleó la distancia máxima que una persona estaría dispuesta a recorrer a pie desde su lugar de residencia hasta llegar a ellas, aplicando un radio de acceso de 800 metros para estos espacios y de 400 metros para el resto, tal como aparece en la Tabla 5.9. De manera complementaria se añadió la distancia máxima de 100 metros desde los espacios verdes con equipamientos infantiles con los que se tratarían de cubrir las necesidades de familias con niños de entre $0 \mathrm{y}$ 5 años (Magalhães, 1992; Santana et al., 2010). La construcción de este tipo de dotaciones 
aparece recogida en el artículo 105 del RUCYL, al menos en los espacios libres públicos creados por el planeamiento local, donde se obliga a reservar áreas especiales dedicadas al juego infantil, fijando unas características mínimas.

En el capítulo anterior se analizó la distribución del verde urbano disponible en el interior del tejido urbano de cada ciudad y ahora se ha determinado la accesibilidad de los ciudadanos a estos espacios. Para ello se ha creado, en cada caso, una imagen en la que aparece delimitada el área de influencia utilizando las distancias referidas anteriormente, a través del buffering, una operación de proximidad de los SIG vectoriales que consiste en generar polígonos por una condición de proximidad a un conjunto de elementos geográficos, en este caso las áreas verdes urbanas. En las zonas que no poseen acceso a la trama verde aparece la densidad de población (hab $/ \mathrm{km}^{2}$ ) de cada barrio, donde el color rojo representa una mayor concentración de habitantes. La estimación de la población que no posee acceso a los espacios verdes se ha calculado multiplicando el porcentaje de superficie sin acceso por la densidad poblacional de cada uno de los barrios. Junto a estas imágenes se han creado otras que permiten identificar cuáles son los barrios más alejados de los espacios verdes, utilizando para ello otra herramienta de los SIG, en este caso el spatial join entre el centroide de cada barrio y el centroide de los espacios verdes, cuyo resultado determina cuál es la distancia mínima entre dichas categorías.

Tabla 5.8 Verdes de ciudad de Salamanca, Valladolid y Zamora.

\begin{tabular}{|c|c|c|c|c|c|c|c|c|}
\hline $\mathbf{N}^{\circ}$ & Id. & ha & Nombre & $\begin{array}{c}\text { Encuestas } \\
\text { asignadas }\end{array}$ & $\begin{array}{l}\text { Encuestas } \\
\text { realizadas }\end{array}$ & $\begin{array}{c}\text { Porcentaje } \\
\text { de éxito }\end{array}$ & $\begin{array}{c}\text { Visitas } \\
\text { realizadas } \\
\end{array}$ & $\begin{array}{l}\text { Índice de } \\
\text { atracción }\end{array}$ \\
\hline 1 & Z-6 & 16,5 & Margen derecha del Duero & 42 & 42 & 100,0 & 88 & 24,73 \\
\hline 2 & V-1 & 12,7 & Campo Grande & 33 & 35 & 106,1 & 157 & 18,86 \\
\hline 3 & Z-9 & 16,5 & Bosque de Valorio (parte urbana) & 42 & 44 & 104,8 & 69 & 13,44 \\
\hline 7 & S-4 & 10,1 & Parque de los Jesuitas & 26 & 39 & 150,0 & 63 & 8,86 \\
\hline 8 & $\mathrm{~V}-4$ & 26,7 & Parque Ribera de Castilla & 68 & 72 & 105,9 & 122 & 7,73 \\
\hline 10 & V-9 & 21,0 & Parque del Mediodía & 54 & 55 & 101,9 & 100 & 6,96 \\
\hline 44 & $\mathrm{~V}-21$ & 12,2 & Parque de Canterac & 31 & 35 & 112,9 & 38 & 0,46 \\
\hline 24 & V-31 & 15,4 & Verde urbano Mirador Parquesol & 39 & 3 & 7,7 & 16 & 2,01 \\
\hline 58 & S-3 & 10,8 & Jardín botánico de Huerta Otea & 27 & 35 & 129,6 & 35 & 0,00 \\
\hline 61 & V-32 & 13,8 & Verde urbano Huerta del Rey & 35 & 35 & 100,0 & 34 & $-0,15$ \\
\hline 80 & S-25 & 13,5 & Parque de El Zurguén & 35 & 15 & 42,9 & 12 & $-1,11$ \\
\hline
\end{tabular}

Fuente: elaboración propia.

Tabla 5.9 Tipología del verde urbano disponible.

\begin{tabular}{|l|c|c|}
\hline \multicolumn{1}{|c|}{ Nivel funcional } & $\begin{array}{c}\text { Distancia máxima } \\
\text { desde casa (m) }\end{array}$ & Superficie mínima (ha) \\
\hline Verde de barrio & 300 & $0,9 / 1,26 / 0,66$ \\
\hline Verde de ciudad & $800^{*}$ & 10 \\
\hline
\end{tabular}

*Requisitos mínimos adicionales. Fuente: elaboración propia a partir de Van Herzele y Wiedemann (2003).

\subsubsection{Acceso al verde urbano salmantino}

En Salamanca hay barrios que no tienen verdes urbanos disponibles en su interior pero sin embargo, tienen una accesibilidad muy buena debido a la proximidad de alguna zona verde (ver Figura 5.14). Este es el caso de los situados en el centro histórico y de algunos muy densamente poblados como Labradores (9) o Carmelitas - Oeste (16), mientras que en el extremo contrario se sitúan barrios como Buenos Aires (40) o el Montalvo (45) que no tienen accesibilidad a las zonas verdes en ninguna parte de su territorio. En total son veintidós los barrios que cuentan con alguna zona sin acceso a estos espacios y entre ellos se encuentran algunos de los más poblados de la ciudad como Garrido Norte (25), Garrido Sur (23) o el Rollo (28). Los datos referentes a cada una de estas unidades territoriales están reflejados en la Tabla 5.10, donde aparece también la superficie sin acceso total de la ciudad, 
que es de 299,6 ha. Esta cifra representa una quinta parte del tejido urbano, estimándose en 23.991 las personas que no dispondrían de estas dotaciones en las proximidades de su vivienda, lo que equivale a un $15,1 \%$ de los censados en esa fecha, y cuya distribución mayoritaria permite distinguir dos sectores con características propias. El primero se compone de los barrios emplazados al sur del Tormes, concretamente los situados en los extremos oriental y occidental del continuo urbano, y el segundo agrupa los barrios ubicados en el tercio norte donde se concentra una gran cantidad de población.

En el sur de la ciudad, la población sin acceso a la trama verde es menos numerosa de lo que cabría esperar, tan solo 9.326 residentes, si se tiene en cuenta que la extensión de esta zona supera las 205,3 ha. En este sector se encuentra el barrio de Buenos Aires (40), que está situado a más de 1.500 metros del verde urbano disponible más cercano (ver Figura 5.15), y el Zurguén (41), también sensiblemente alejado de estos espacios. La considerable distancia que separa a los residentes de estos barrios de las áreas verdes más próximas contribuye a explicar por qué solamente se ha podido encuestar a tres de los más de 4.249 residentes de estas dos unidades poblacionales. En el sector sur, y también notablemente alejados del verde urbano, aparecen una serie de barrios de carácter industrial, entre los que destaca el Montalvo (45) y buena parte de Tejares (39), donde acuden a diario cientos de trabajadores que no tendrán oportunidad de acceder en las inmediaciones de su puesto de trabajo a los beneficios proporcionados por las áreas verdes.

La situación del tercio norte de la ciudad es diferente, al contar con algunos de los barrios más poblados de Salamanca. Esto explica que el área sin acceso que se extiende de manera continua por una parte de los barrios de la Estación (26), de Garrido Norte (25), de Garrido Sur (23) y del Rollo (28), sume un total de 58,4 ha y sin embargo, la población residente estimada sea aproximadamente de 12.000 personas. La ausencia de zonas verdes en este sector del continuo urbano tiene su origen en una falta de planeamiento previo a la urbanización y en la consiguiente ausencia de elementos dotacionales al construir las nuevas piezas de la ciudad. Esta situación se corresponde mayoritariamente con el periodo anterior a la entrada en vigor del PGOU de 1984, con el que comienza la aplicación efectiva de la normativa urbanística en Salamanca. Durante la aplicación de ese Plan General se proyectaron algunos barrios ubicados en la periferia urbana en los que la densidad de población es relativamente baja y que además cuentan con una dotación de áreas verdes muy superior a los mínimos exigidos por la normativa urbanística, como ocurre en La Platina (44) o en Capuchinos (43). Este hecho resulta destacable considerando que la búsqueda de espacios abiertos y de zonas ajardinadas ha sido uno de los factores, que aunque de manera secundaria, ha contribuido a que determinados habitantes abandonaran la vieja ciudad en busca de residencias en los municipios próximos.

Los tres verdes urbanos con más de 10 ha están situados en las proximidades del río, aunque se ha demostrado que el único verdaderamente capaz de atraer un mayor número de potenciales usuarios es el Parque de los Jesuitas (S-4), situado en la mitad este de la ciudad. Si se aplica un buffer de 800 metros desde estos espacios se observa que la accesibilidad al único verde de ciudad de Salamanca queda limitada a la parte oriental del centro histórico y al barrio de la Prosperidad (31). Su posición en las proximidades del perímetro exterior de la cerca medieval mejora sensiblemente la accesibilidad en el interior de la misma, donde solamente hay dos áreas verdes. Sin embargo, un $75 \%$ de la superficie de la ciudad quedaría fuera del área de influencia de este espacio verde, evidenciándose una situación delicada ya que tres cuartas partes de la población no tienen acceso al único verde de ciudad. Además, algunos barrios situados al sur del río Tormes, así como los ubicados en la periferia norte y oeste, están situados a una distancia de este espacio que en ocasiones supera los dos kilómetros. 
Figura 5.14 Acceso al verde urbano disponible de Salamanca.

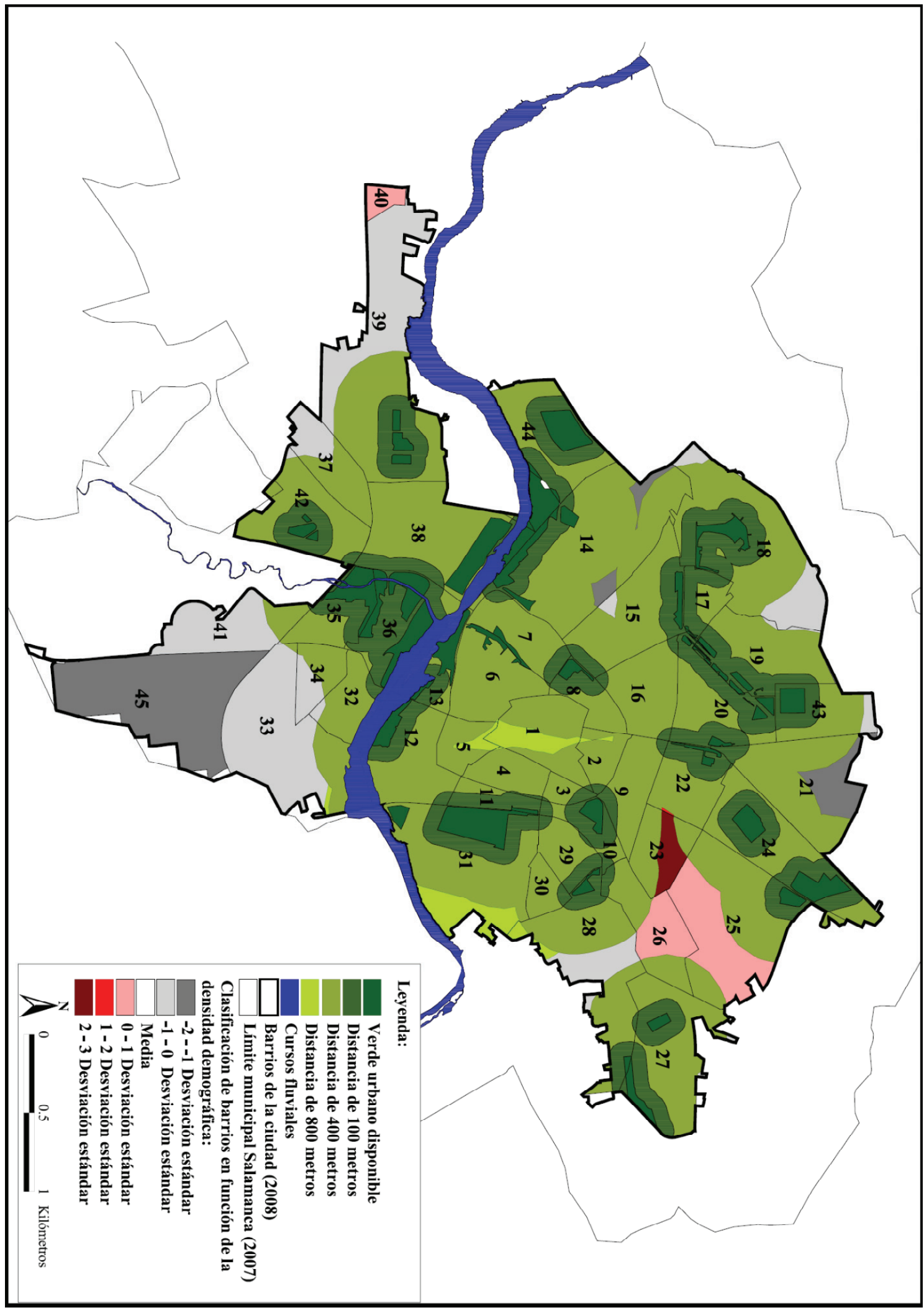

Media $=14.642 \mathrm{hab} / \mathrm{km}^{2}$. Desviación estándar $=11.145 \mathrm{hab} / \mathrm{km}^{2}$.

Fuente: elaboración propia a partir de la ortofoto de 2007 del IGN y del Observatorio Urbano de Salamanca. 
Figura 5.15 Distancia desde el centroide de cada barrio al del espacio verde más próximo de Salamanca.

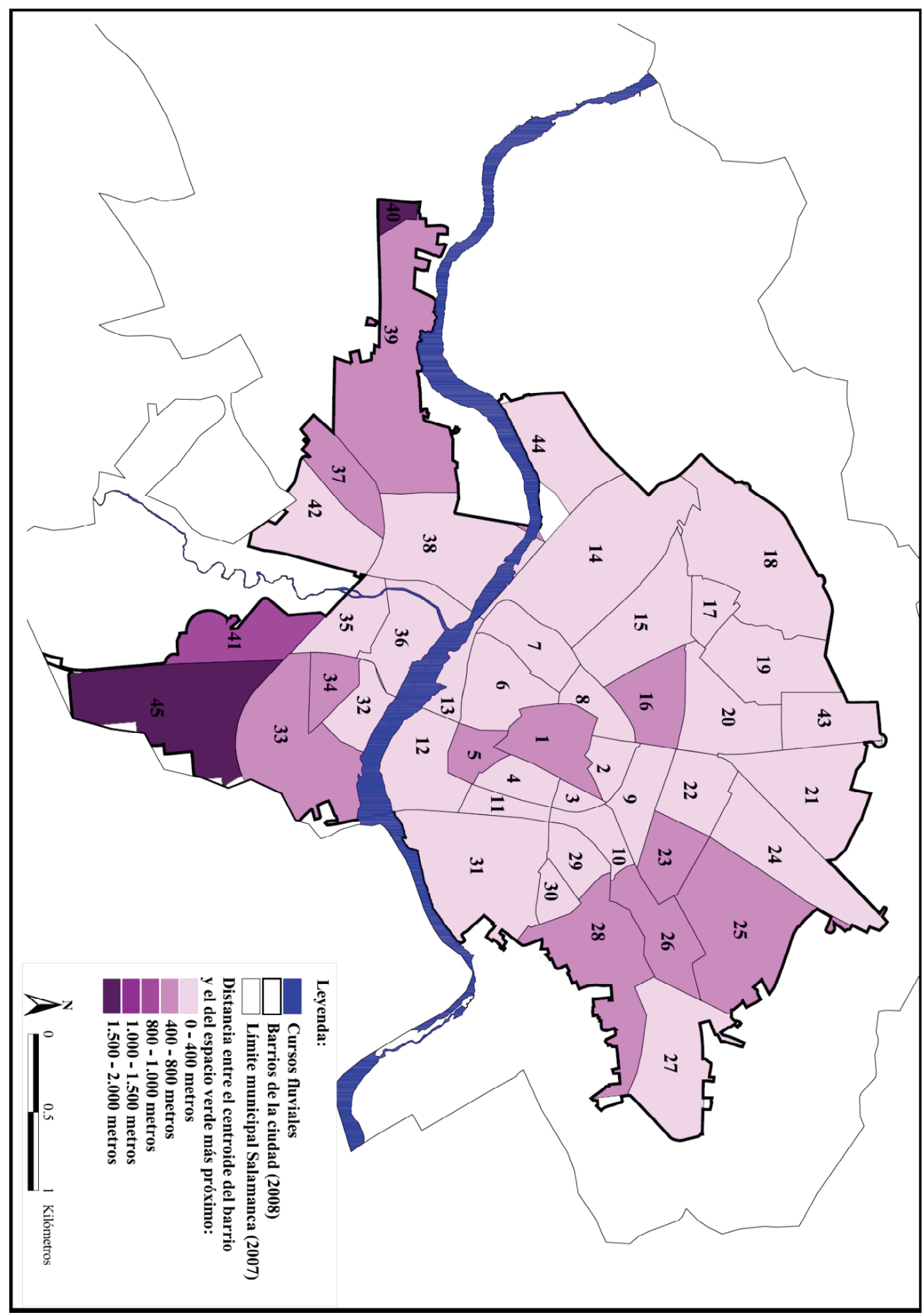

Fuente: elaboración propia a partir de la ortofoto de 2007 del IGN y del Observatorio Urbano de Salamanca. 
Tabla 5.10 Número de encuestados y población estimada sin acceso en los barrios de Salamanca.

\begin{tabular}{|c|c|c|c|c|c|c|c|c|c|}
\hline $\mathbf{N}^{\circ}$ & Nombre barrio & $\begin{array}{c}\mathbf{N}^{\circ} \\
\text { encuestados }\end{array}$ & $\begin{array}{c}\% \\
\begin{array}{c}\text { encuestados } \\
\text { total }\end{array} \\
\end{array}$ & $\begin{array}{c}\mathbf{N}^{\circ} \\
\text { habitantes }\end{array}$ & $\begin{array}{c}\text { Superficie } \\
\text { (ha) }\end{array}$ & $\begin{array}{c}\text { Densidad } \\
\left(\mathrm{hab} / \mathrm{km}^{2}\right)\end{array}$ & $\begin{array}{c}\text { Superficie sin } \\
\text { acceso verde } \\
\text { urbano } \\
\end{array}$ & $\begin{array}{c}\% \text { superficie } \\
\text { sin acceso } \\
\text { verde urbano }\end{array}$ & \begin{tabular}{|c|}
$\begin{array}{c}\text { Población sin } \\
\text { acceso verde } \\
\text { urbano }\end{array}$ \\
\end{tabular} \\
\hline 1 & Centro & 13 & 4,89 & 4.447 & 26,6 & 16.714 & 0,0 & 0,0 & 0 \\
\hline 2 & San Juan & 0 & 0,00 & 2.410 & 10,0 & 24.199 & 0,0 & 0,0 & 0 \\
\hline 3 & Sancti Spiritus & 0 & 0,00 & 1.126 & 4,8 & 23.287 & 0,0 & 0,0 & 0 \\
\hline 4 & San Cristóbal - Claras & 4 & 1,50 & 3.450 & 12,7 & 27.241 & 0,0 & 0,0 & 0 \\
\hline 5 & San Esteban & 0 & 0,00 & 809 & 11,2 & 7.218 & 0,0 & 0,0 & 0 \\
\hline 6 & Universidad & 2 & 0,75 & 1.118 & 27,8 & 4.028 & 0,0 & 0,0 & 0 \\
\hline 7 & San Vicente & 3 & 1,13 & 1.272 & 20,4 & 6.246 & 0,0 & 0,0 & 0 \\
\hline 8 & Úrsulas - San Marcos & 0 & 0,00 & 2.431 & 12,6 & 19.264 & 0,0 & 0,0 & 0 \\
\hline 9 & Labradores & 4 & 1,50 & 6.452 & 19,1 & 33.829 & 0,0 & 0,0 & 0 \\
\hline 10 & Alamedilla & 2 & 0,75 & 2.388 & 11,9 & 20.095 & 0,0 & 0,0 & 0 \\
\hline 11 & Santo Tomás & 9 & 3,38 & 1.790 & 8,7 & 20.637 & 0,0 & 0,0 & 0 \\
\hline 12 & Fontana & 2 & 0,75 & 675 & 36,1 & 1.870 & 0,0 & 0,0 & 0 \\
\hline 13 & Tenerías & 0 & 0,00 & 675 & 16,6 & 4.077 & 0,0 & 0,0 & 0 \\
\hline 14 & Hospital & 3 & 1,13 & 378 & 81,8 & 462 & 4,8 & 5,8 & 22 \\
\hline 15 & San Bernardo & 6 & 2,26 & 5.784 & 41,9 & 13.803 & 1,3 & 3,0 & 173 \\
\hline 16 & Carmelitas -Oeste & 8 & 3,01 & 9.638 & 24,9 & 38.667 & 0,0 & 0,0 & 0 \\
\hline 17 & Carmen & 8 & 3,01 & 2.328 & 10,9 & 21.285 & 0,0 & 0,0 & 0 \\
\hline 18 & Pizarrales & 18 & 6,77 & 8.645 & 73,3 & 11.800 & 13,7 & 18,7 & 1.616 \\
\hline 19 & Blanco & 3 & 1,13 & 4.020 & 36,8 & 10.914 & 0,7 & 1,9 & 77 \\
\hline 20 & Vidal & 5 & 1,88 & 6.800 & 32,8 & 20.739 & 0,0 & 0,0 & 0 \\
\hline 21 & Glorieta - Ciudad Jardín & 0 & 0,00 & 859 & 45,8 & 1.874 & 11,7 & 25,6 & 220 \\
\hline 22 & Salesas & 6 & 2,26 & 6.701 & 22,1 & 30.282 & 0,1 & 0,6 & 38 \\
\hline 23 & Garrido Sur & 4 & 1,50 & 8.258 & 18,5 & 44.652 & 6,9 & 37,0 & 3.059 \\
\hline 24 & Chinchibarra & 3 & 1,13 & 5.371 & 43,7 & 12.282 & 0,0 & 0,0 & 0 \\
\hline 25 & Garrido Norte & 24 & 9,02 & 14.049 & 67,5 & 20.826 & 27,9 & 41,3 & 5.804 \\
\hline 26 & Estación & 3 & 1,13 & 3.781 & 26,7 & 14.155 & 12,3 & 45,9 & 1.735 \\
\hline 27 & Puente Ladrillo & 10 & 3,76 & 4.734 & 47,2 & 10.024 & 0,5 & 1,1 & 51 \\
\hline 28 & Rollo & 8 & 3,01 & 6.973 & 54,4 & 12.813 & 11,4 & 21,0 & 1.461 \\
\hline 29 & Delicias & 6 & 2,26 & 5.551 & 13,7 & 40.627 & 0,0 & 0,0 & 0 \\
\hline 30 & San Isidro & 4 & 1,50 & 2.332 & 8,2 & 28.479 & 0,0 & 0,0 & 0 \\
\hline 31 & Prosperidad & 17 & 6,39 & 6.627 & 68,5 & 9.677 & 0,0 & 0,0 & 0 \\
\hline 32 & Tormes & 1 & 0,38 & 2.334 & 18,1 & 12.872 & 0,9 & 4,7 & 110 \\
\hline 33 & San José & 8 & 3,01 & 3.753 & 65,7 & 5.711 & 50,0 & 76,1 & 2.857 \\
\hline 34 & La Vega & 0 & 0,00 & 1.357 & 12,9 & 10.491 & 5,6 & 43,1 & 585 \\
\hline 35 & Teso de la Feria & 0 & 0,00 & 1.440 & 20,4 & 7.045 & 0,0 & 0,2 & 3 \\
\hline 36 & Arrabal & 2 & 0,75 & 550 & 34,7 & 1.583 & 0,0 & 0,0 & 0 \\
\hline 37 & Alambres & 0 & 0,00 & 1.399 & 20,8 & 6.731 & 8,0 & 38,6 & 540 \\
\hline 38 & Chamberí & 11 & 4,14 & 1.833 & 59,8 & 3.065 & 0,0 & 0,0 & 0 \\
\hline 39 & Tejares & 6 & 2,26 & 3.436 & 92,9 & 3.699 & 43,1 & 46,4 & 1.593 \\
\hline 40 & Buenos Aires & 0 & 0,00 & 1.043 & 4,5 & 23.345 & 4,5 & 100,0 & 1.043 \\
\hline 41 & Zurguén & 3 & 1,13 & 3.206 & 29,8 & 10.742 & 25,0 & 83,7 & 2.685 \\
\hline 42 & Vistahermosa & 3 & 1,13 & 1.947 & 35,3 & 5.510 & 0,4 & 1,2 & 22 \\
\hline 43 & Capuchinos & 10 & 3,76 & 3.116 & 22,9 & 13.598 & 2,2 & 9,5 & 297 \\
\hline 44 & Platina & 29 & 10,90 & 1.713 & 35,9 & 4.775 & 0,0 & 0,0 & 0 \\
\hline 45 & Montalvo & 0 & 0,00 & 0 & 68,7 & 0 & 68,7 & 100,0 & 0 \\
\hline 46 & Otros & 18 & 6,77 & - & - & - & - & - & - \\
\hline & TOTAL & 266 & 100 & 158.999 & 1.460 & 14.694 & 299,6 & 20,5 & 23.991 \\
\hline
\end{tabular}

Fuente: elaboración propia a partir de la ortofoto del IGN y del Observatorio Urbano de Salamanca.

Por otra parte, el acceso a las zonas verdes que poseen zonas de juego infantil se estima en una cuarta parte de la superficie de la ciudad, lo que supone una deficiencia considerable. Nueve barrios no tienen ninguna parte de su territorio con acceso al verde urbano que posee equipamientos infantiles, mientras que en la situación opuesta aparece el Arrabal (36), que cuenta con un $92 \%$ de su superficie con acceso a los mismos.

Una fuente de información relevante para caracterizar a los usuarios de los espacios verdes es la referente al barrio de residencia. En Salamanca se observa que los más repetidos son aquellos que cuentan con buenos accesos al verde urbano y los que poseen un mayor número de habitantes (ver Tabla 5.10). La suma de los usuarios de los diez barrios de origen más veces repetidos equivale al 59,8\% del total de encuestados, evidenciando una fuerte desproporción cuya explicación habrá que buscarla en el elevado peso demográfico de estos en el conjunto de la población de la ciudad. Entre ellos se encuentran la Platina (44), Garrido Norte (25), Pizarrales (18), Centro (1), Chamberí (38), Puente Ladrillo (27), Capuchinos (43) 
y Santo Tomás (11), destacando algunos de los barrios con mayor número de residentes y que cuentan con un bajo porcentaje de superficie con acceso al verde disponible, lo que provoca que los espacios verdes cercanos sean, en ocasiones, sobrefrecuentados, con los efectos negativos que ello conlleva. Pero hay indicios de que el número de usuarios entrevistados está influenciado por la distribución actual de los parques y jardines, como ocurre en la Platina (44), Chamberí (38), el Arrabal (36) o el barrio del Hospital (14), que tienen buen acceso a los espacios verdes, al igual que aquellos situados junto al único verde de ciudad, que ejerce una atracción notable entre los habitantes del Centro (1), Santo Tomás (11) y la Prosperidad (31) y la mayor parte de la Fontana (12). En la situación contraria aparecen once barrios de origen que no fueron mencionados durante la encuesta, entre los que se encuentran algunos de los situados al sur del Tormes y que poseen porcentajes sin acceso al verde urbano muy elevados, como es el caso de Alambres (37), de Buenos Aires (40) o de La Vega (34), junto a cuatro barrios del centro histórico, que no tienen áreas verdes en su interior.

Finalmente se analizaron los datos obtenidos en las encuestas referidos a la percepción de los usuarios sobre su proximidad a las zonas verdes. En una de las preguntas se pidió una valoración de la accesibilidad a estos espacios y el 26,7\% de los encuestados dijo que no era buena. Si esta cifra se compara con la información representada en la Figura 5.16, en la que aparece el tiempo que tarda cada usuario en llegar desde su casa al espacio verde más cercano, puede resultar contradictorio, porque parece que son muchos más los que tienen una accesibilidad aparentemente mala. Un 40,2\% dijo tardar entre cinco y quince minutos en llegar al área verde más cercana, pero es de suponer que dentro de este grupo estarán incluidos aquellos que tienen su lugar de residencia a menos de 800 metros del Parque de los Jesuitas (S-4). La situación de los usuarios encuestados en Salamanca es un tanto deficiente, ya que una cuarta parte de los mismos afirmó que la accesibilidad a los parques y jardines no era buena y casi la mitad del total dijo que tardaba más de cinco minutos en llegar a pie desde su lugar de residencia, lo que sugiere que, posiblemente, una parte de los mismos pospondrá alguna de sus visitas a la trama verde.

Figura 5.16 ¿Cuánto tardan los usuarios en llegar desde casa hasta el espacio verde más cercano de Salamanca?

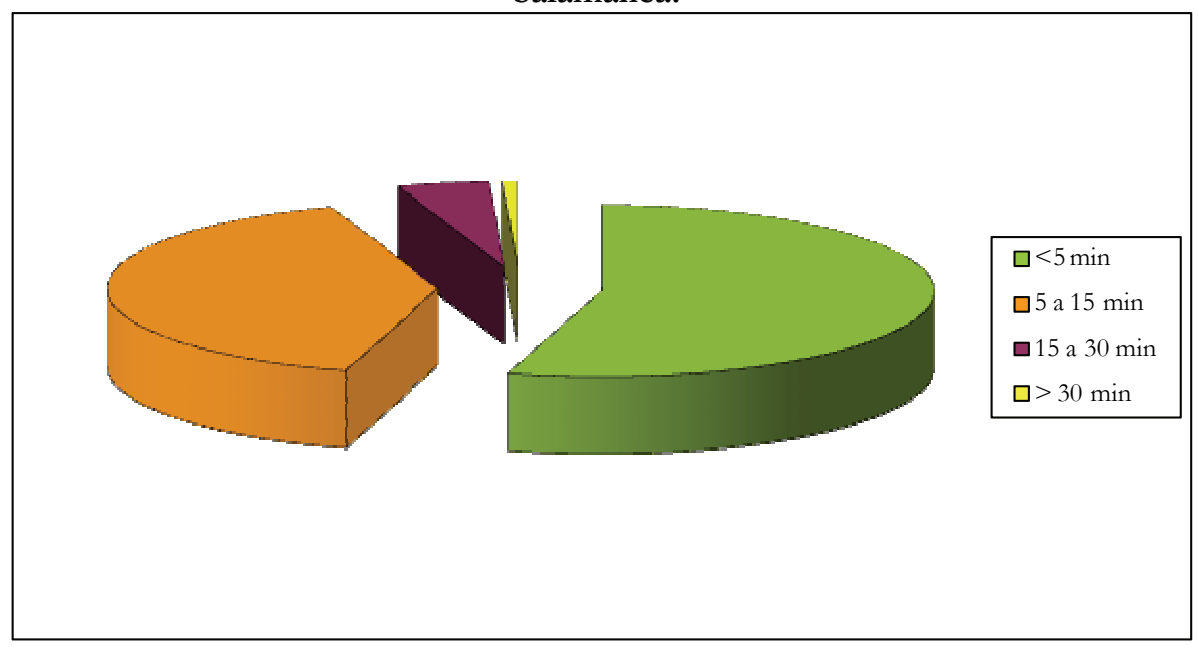

Fuente: elaboración propia.

\subsubsection{Acceso al verde urbano vallisoletano}

El río Pisuerga actúa de eje vertebrador de la trama verde vallisoletana (ver Figura 5.17) y su disposición, siguiendo una dirección norte-sur, genera un amplio espacio con un excelente acceso a la misma, que incluye el Barrio España (22), la Rondilla (9), San Nicolás (8), el Centro (1), Huerta del Rey (21), la Barriada de la Guardia Civil (25), el Paseo de 
Zorrilla (20), el Camino de la Esperanza (26), el barrio de Cuatro de Marzo (27), Parquesol (38) y Arturo Eyries (29). En este mismo eje están emplazados otros barrios que poseen un acceso relativamente bueno a las zonas verdes, aunque no es extensible a todo su territorio, como ocurre en Las Villas - Cañada Puente Duero -Covaresa - Parque Alameda - Paula López (37), en la Victoria (31), en Girón - Villa del Prado (30) y en San Miguel (7). En el primer grupo de barrios residen 111.999 personas y se estima que únicamente 918 no contarían con acceso al verde urbano, mientras que en el segundo, donde viven 49.255, serían 5.308 los residentes que tendrían los espacios verdes a una distancia suficiente para pensar que habitualmente posponen una parte de sus visitas.

La superficie total sin acceso al verde urbano disponible es de 1.183,3 ha, lo que equivale a una cuarta parte del tejido urbano consolidado, y se estima que serán 48.477 los vallisoletanos residentes en estas zonas de la ciudad, es decir, un 14,7\% de la población censada. El hecho de que esta cifra no sea mayor se debe a que las zonas sin acceso están compuestas mayoritariamente por espacios industriales donde la densidad de población es muy baja, como ocurre por ejemplo en Caamaño - Las Viudas - Polígono de San Cristóbal (36), en el Polígono de Argales (24) o en el barrio del Pinar de Antequera (39), donde está situada la fábrica de Renault, o por una combinación de uso industrial y de grandes equipamientos públicos como son los cementerios, como ocurre en Girón - Villa del Prado (30) y en San Pedro Regalado (33), donde también hay una amplia superficie dedicada a la agricultura urbana. Entre los cinco barrios citados suman 976,6 ha sin acceso a las zonas verdes y con el método de cálculo utilizado se ha estimado en 14.418 el número de residentes en este determinado territorio. Frente a estos espacios industriales y de equipamientos públicos, se ha identificado también una situación deficitaria en un sector situado en el centro-oeste de la ciudad, que tiene una superficie de 165,4 ha extendiéndose por buena parte del barrio de la Circular (4), de la Universidad (5), de San Juan (6), de San Pablo (10), de San Juan II (11), de Vadillos (12), de Pilarica (16) y de Pajaritos Altos (18), en el que se calcula que residen 24.727 personas. En este pequeño sector, que equivale a menos de un quince por ciento del total de la superficie urbana sin acceso a la trama verde, viven más de la mitad de los vallisoletanos que no poseen zonas verdes en las proximidades de su lugar de residencia.

La ciudad cuenta con seis espacios verdes que superan las 10 ha, pero solamente cuatro han sido catalogados como verdes de ciudad. Estos son el Parque Ribera de Castilla (V-4) y Campo Grande (V-1), situados, al menos en parte, dentro de la almendra central, mientras que el Parque del Mediodía (V-9) está situado en la margen derecha del Pisuerga y el Parque de Canterac (V-21) en el sector oriental de la segunda orla o corona de crecimiento. La distancia de irradiación desde estas zonas verdes forma un conjunto casi continuo de 2.156 ha, trazando una diagonal en dirección noreste-suroeste que sigue el curso del Pisuerga y que cuenta con una prolongación oriental que se extiende por los barrios de Delicias (19), Páramos de San Isidro - Campo de Tiro (35) y Caamaño - Las Viudas - Polígono San Cristóbal (36). Cerca de la mitad de la superficie urbana no contaría con acceso a estos espacios verdes, estimándose en 148.682 los habitantes en esta situación, entre los que se incluirían los residentes en algunos de los barrios más poblados como Las Villas - Cañada Puente Duero - Covaresa - Parque Alameda - Paula López (37), Pajarillos Bajos (17) o Pajarillos Altos (18). Por otro lado, buena parte de los barrios históricos como el Centro (1), Caño Argales (2), San Nicolás (8) y la mayor parte de Campo Grande - Arco Ladrillo (3) cuentan con muy buen acceso a la trama verde de la ciudad gracias a los grandes parques situados en ellos, cubriendo así carencias muy significativas en este tipo de equipamientos. Esta situación se originó durante fases de expansión urbana que se realizaron sin una planificación previa que incluyera reservas de suelo destinadas a parques y jardines, cuyos efectos más visibles son las escasas zonas verdes de entidad en algunos de los barrios más poblados de la ciudad, como Delicias (19), o en el sector oriental del centro histórico y en los 
Figura 5.17 Acceso al verde urbano disponible de Valladolid.

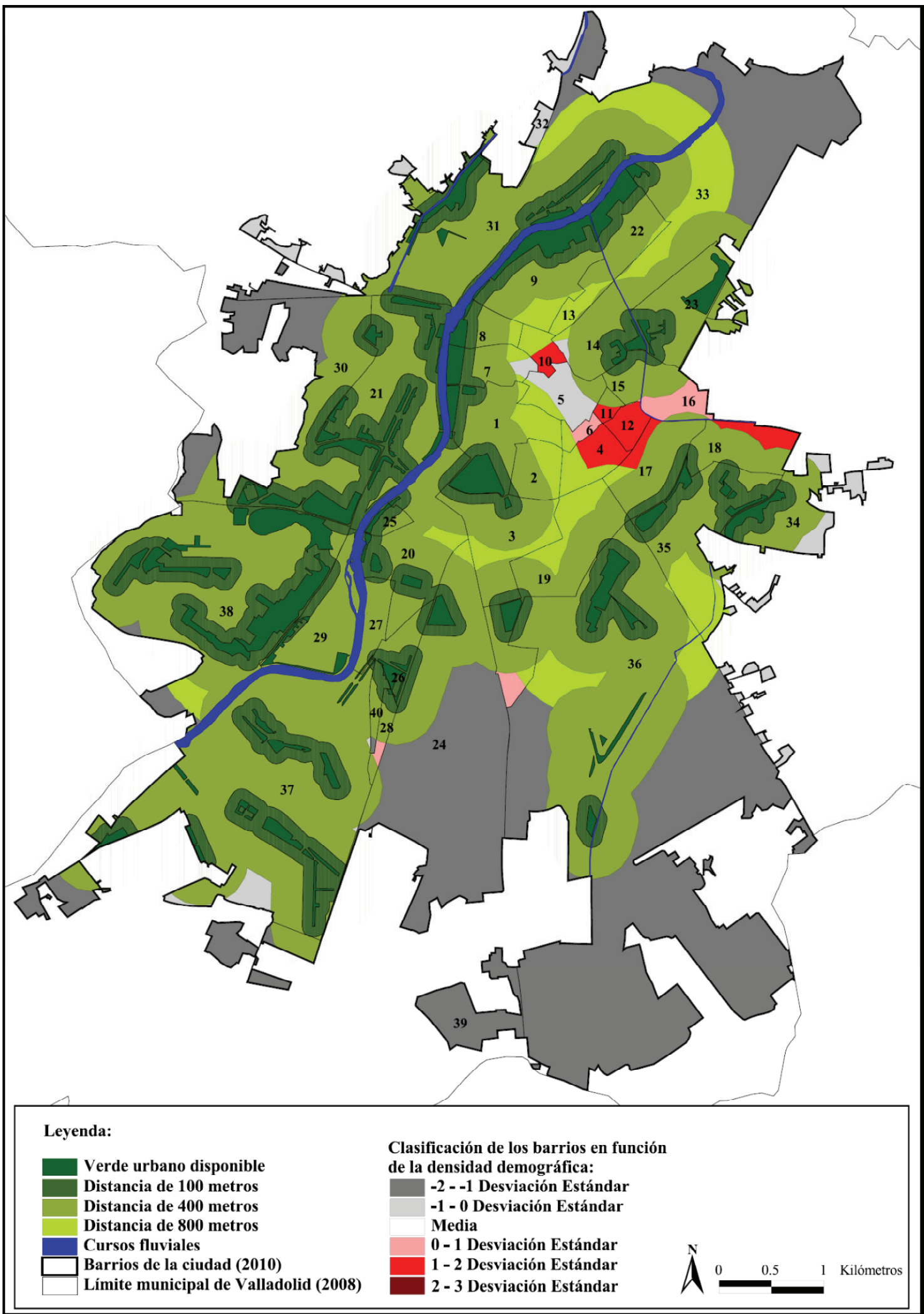

Media $=18.822 \mathrm{hab} / \mathrm{km}^{2}$. Desviación estándar $=14.349 \mathrm{hab} / \mathrm{km}^{2}$.

Fuente: elaboración propia a partir de la ortofoto de 2008 del IGN y del Observatorio Urbano de Valladolid. 
Figura 5.18 Distancia desde el centroide de cada barrio al espacio verde más próximo de Valladolid.

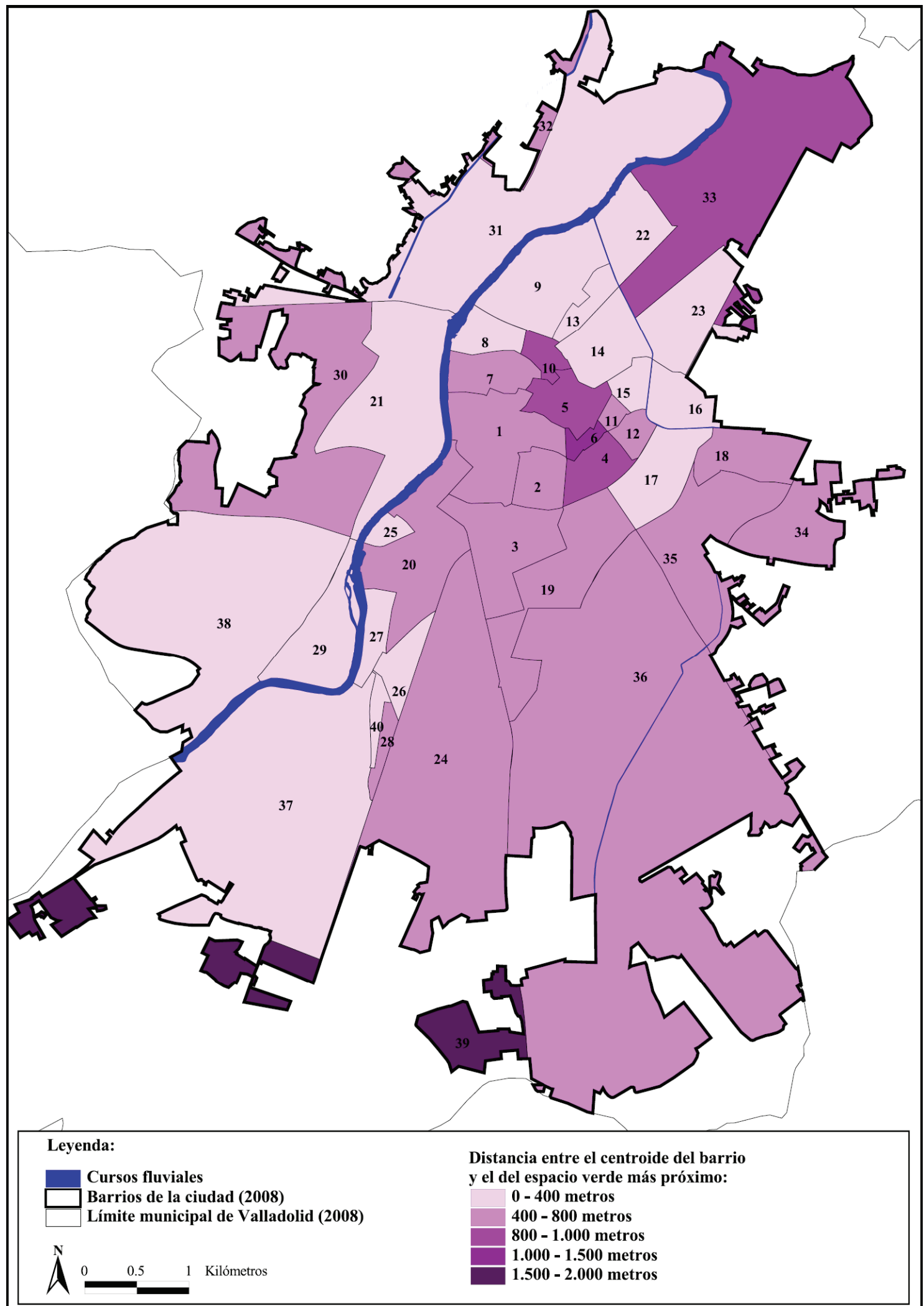

Fuente: elaboración propia a partir de la ortofoto de 2008 del IGN y del Observatorio Urbano de Valladolid. 
Tabla 5.11 Número de encuestados y población estimada sin acceso en los barios de Valladolid.

\begin{tabular}{|c|c|c|c|c|c|c|c|c|c|}
\hline $\mathbf{N}^{\circ}$ & Nombre barrio & $\begin{array}{c}\mathbf{N}^{\circ} \\
\text { encuestados }\end{array}$ & \begin{tabular}{|c|}
$\%$ \\
encuestados \\
total
\end{tabular} & $\begin{array}{c}\mathbf{N}^{\circ} \\
\text { habitantes }\end{array}$ & $\begin{array}{l}\text { Superficie } \\
\text { (ha) }\end{array}$ & $\begin{array}{l}\text { Densidad } \\
\left(\mathrm{hab} / \mathrm{km}^{2}\right)\end{array}$ & $\begin{array}{c}\text { Superficie sin } \\
\text { acceso verde } \\
\text { urbano }\end{array}$ & $\begin{array}{c}\% \text { superficie } \\
\text { sin acceso } \\
\text { verde urbano }\end{array}$ & $\begin{array}{c}\text { Población sin } \\
\text { acceso verde } \\
\text { urbano }\end{array}$ \\
\hline 1 & Centro & 41 & 6,3 & 9.199 & 75,24 & 12.226 & 0,0 & 0,0 & 0 \\
\hline 2 & Caño Argales & 4 & 0,6 & 8.059 & 24,19 & 33.322 & 0,0 & 0,0 & 0 \\
\hline 3 & $\begin{array}{l}\text { Campo Grande - Arco del } \\
\text { Ladrillo }\end{array}$ & 2 & 0,3 & 7.341 & 67,38 & 10.896 & 0,0 & 0,0 & 0 \\
\hline 4 & Circular & 2 & 0,3 & 11.025 & 24,70 & 44.631 & 12,8 & 51,8 & 5.706 \\
\hline 5 & Universidad & 1 & 0,2 & 5.407 & 29,99 & 18.029 & 18,9 & 63,1 & 3.412 \\
\hline 6 & SanJuan & 12 & 1,9 & 2.067 & 6,48 & 31.879 & 3,8 & 59,1 & 1.222 \\
\hline 7 & San Miguel & 4 & 0,6 & 4.675 & 30,25 & 15.453 & 3,3 & 10,9 & 509 \\
\hline 8 & San Nicolás & 4 & 0,6 & 4.139 & 22,36 & 18.507 & 0,0 & 0,0 & 0 \\
\hline 9 & Rondilla & 32 & 4,9 & 18.584 & 78,83 & 23.574 & 0,0 & 0,0 & 0 \\
\hline 10 & San Pablo & 3 & 0,5 & 4.139 & 12,05 & 34.360 & 5,8 & 48,1 & 1.992 \\
\hline 11 & San Juan II & 0 & 0,0 & 1.849 & 5,33 & 34.710 & 1,1 & 21,3 & 395 \\
\hline 12 & Vadillos & 1 & 0,2 & 4.586 & 11,43 & 40.113 & 11,4 & 99,4 & 4.560 \\
\hline 13 & Santa Clara & 3 & 0,5 & 5.561 & 15,47 & 35.940 & 0,0 & 0,0 & 0 \\
\hline 14 & Hospital & 6 & 0,9 & 8.203 & 43,65 & 18.793 & 1,7 & 3,8 & 313 \\
\hline 15 & Batallas & 4 & 0,6 & 4.243 & 13,88 & 30.561 & 0,1 & 0,6 & 24 \\
\hline 16 & Pilarica & 7 & 1,1 & 7.886 & 34,17 & 23.077 & 15,3 & 44,9 & 3.541 \\
\hline 17 & Pajarillos Bajos & 11 & 1,7 & 16.803 & 47,68 & 35.243 & 5,4 & 11,4 & 1.908 \\
\hline 18 & Pajarillos Altos & 5 & 0,8 & 14.651 & 41,23 & 35.532 & 11,0 & 26,6 & 3.899 \\
\hline 19 & Delicias & 65 & 10,0 & 29.332 & 90,55 & 32.394 & 5,3 & 5,9 & 1.727 \\
\hline 20 & Paseo Zorrilla & 13 & 2,0 & 21.638 & 90,97 & 23.785 & 0,0 & 0,0 & 0 \\
\hline 21 & Huerta del Rey & 46 & 7,1 & 16.867 & 145,66 & 11.579 & 0,0 & 0,0 & 0 \\
\hline 22 & Barrio España & 21 & 3,2 & 2.826 & 42,44 & 6.659 & 0,0 & 0,0 & 0 \\
\hline 23 & Belén & 10 & 1,5 & 1.930 & 56,75 & 3.401 & 0,0 & 0,0 & 0 \\
\hline 24 & Polígono Argales & 6 & 0,9 & 1.857 & 295,32 & 629 & 206,0 & 69,8 & 1.295 \\
\hline 25 & Barriada Guardia Civil & 1 & 0,2 & 1.472 & 9,58 & 15.366 & 0,0 & 0,0 & 0 \\
\hline 26 & Camino Esperanza & 0 & 0,0 & 2.406 & 21,30 & 11.296 & 0,0 & 0,0 & 0 \\
\hline 27 & Cuatro de Marzo & 4 & 0,6 & 3.885 & 21,49 & 18.075 & 0,0 & 0,0 & 0 \\
\hline 28 & Arturo León & 2 & 0,3 & 3.111 & 9,48 & 32.818 & 1,7 & 17,5 & 544 \\
\hline 29 & Arturo Eyries & 15 & 2,3 & 4.765 & 65,86 & 7.235 & 0,0 & 0,0 & 0 \\
\hline 30 & Girón - Villa del Prado & 48 & 7,4 & 7.563 & 191,19 & 3.956 & 59,2 & 31,0 & 2.343 \\
\hline 31 & La Victoria & 30 & 4,6 & 15.407 & 446,02 & 3.454 & 50,2 & 11,3 & 1.736 \\
\hline 32 & $\begin{array}{l}\text { La Overuela - Navabuena - El } \\
\text { Berrocal }\end{array}$ & 0 & 0,0 & 2.515 & 30,88 & 8.144 & 0,0 & 0,0 & 0 \\
\hline 33 & San Pedro Regalado & 16 & 2,5 & 2.551 & 244,43 & 1.044 & 130,9 & 53,6 & 1.366 \\
\hline 34 & Las Flores & 6 & 0,9 & 1.995 & 63,85 & 3.124 & 19,0 & 29,7 & 592 \\
\hline 35 & $\begin{array}{l}\text { Páramos San Isidro - Campo } \\
\text { de Tiro }\end{array}$ & 12 & 1,9 & 2.461 & 114,71 & 2.145 & 15,6 & 13,6 & 334 \\
\hline 36 & $\begin{array}{l}\text { Caamaño - Las Viudas - } \\
\text { Poligono San Cristóbal }\end{array}$ & 8 & 1,2 & 14.693 & 847,40 & 1.734 & 499,3 & 58,9 & 8.658 \\
\hline 37 & $\begin{array}{l}\text { Las Villas - Cañada Puente } \\
\text { Duero-Covaresa - Parque } \\
\text { Alameda - Paula López }\end{array}$ & 53 & 8,2 & 21.610 & 392,28 & 5.509 & 13,1 & 3,3 & 720 \\
\hline 38 & Parquesol & 119 & 18,4 & 26.218 & 301,68 & 8.691 & 10,6 & 3,5 & 918 \\
\hline 39 & Pinar de Antequera & 0 & 0,0 & 913 & 98,08 & 931 & 81,2 & 82,7 & 756 \\
\hline 40 & La Rubia & 13 & 2,0 & 4.454 & 392,28 & 1.135 & 0,7 & 0,2 & 7 \\
\hline 41 & Otros & 17 & 2,6 & - & - & - & - & - & - \\
\hline & TOTAL & 647 & 100 & 328.886 & $4.556,55$ & $7.217,87$ & $1.183,29$ & 25,97 & 48.477 \\
\hline
\end{tabular}

Fuente: elaboración propia a partir de la ortofoto del IGN y del Observatorio Urbano de Valladolid.

barrios colindantes. En la Figura 5.18 se observa que en algunos casos puntuales el verde urbano más cercano está a más de un kilómetro, como ocurre en San Juan (6), mientras que en otros tres barrios esta distancia es ligeramente menor, como ocurre en Circular (4), Universidad (5) y en San Pablo (10). Además de los situados en el centro histórico, hay dos barrios cuyo centroide se encuentra situado a una distancia considerable del área verde más cercana: las zonas urbanas del Pinar de Antequera (39), ocupadas mayoritariamente por industria y equipamientos, y San Pedro Regalado (33), un barrio muy extenso que cuenta con una pequeña zona verde en su extremo occidental y en el que más de la mitad de su territorio no tiene acceso a la trama verde.

En lo referido a la distribución de las áreas verdes que cuentan con equipamientos infantiles, es destacable que únicamente el $22 \%$ de la superficie urbana tenga acceso a las mismas, lo que implica que 257.935 personas no podrán acceder en las proximidades de su lugar de residencia. Los únicos tres barrios que poseen un acceso a las áreas de juego infantil en más de la mitad de su superficie son la Barriada de la Guardia Civil (25), el Camino de la 
Esperanza (26) y Huerta del Rey (21). El resto presenta un acceso deficiente en la mayor parte de su territorio, llegando a situaciones de carencia total en los barrios situados en la mitad oriental del centro histórico y en la mayor parte del curso urbano del Esgueva.

Los tres barrios de procedencia más veces mencionados por los encuestados se encuentran entre los más poblados de la ciudad: son Parquesol (38), Delicias (19) y Las Villas - Cañada Puente Duero - Covaresa - Parque Alameda - Paula López (37) y todos ellos cuentan con un buen acceso al verde urbano disponible. La suma de los diez barrios más repetidos representa un $72,8 \%$ del total de encuestados, destacando entre este grupo al contingente de residentes en Parquesol (38), que por sí solos representan al 18,4\% de los entrevistados. Como se explicó en la metodología, el número de encuestas realizadas dependía del tamaño de los espacios verdes. En barrios como este, con una trama verde muy extensa (56,3 ha), se han realizado una gran cantidad de entrevistas, nada menos que a 121 personas diferentes, debido a la alta probabilidad de encontrar en estas áreas verdes a un residente del mismo barrio. El resto de los diez barrios más repetidos se corresponde mayoritariamente con aquellos que están situados en las proximidades de la concentración verde del Pisuerga, con la excepción del que aparece en cuarto lugar, Girón - Villa del Prado (30), cuyos verdes urbanos están asociados a dos edificios notables, como ya se apuntó en el capítulo anterior. Es destacable el hecho de que tan solo haya cuatro barrios de residencia que no hayan sido mencionados por los encuestados en esta investigación: por un lado aparecen San Juan II (11) y el Camino de la Esperanza (26), dos pequeños territorios con una población inferior a 2.500 personas, y por otro La Overuela - Navabuena - El Berrocal (32) y el Pinar de Antequera (39), que comparten su reducida población y el hecho de que la mayor parte de su superficie haya sido excluida de esta investigación por estar fuera de lo que en la presente investigación se ha considerado como ciudad. También es necesario apuntar que entre los barrios de origen menos repetidos parecen algunos muy poblados como Circular (4), Santa Clara (13) o Campo Grande - Arco del Ladrillo (3), que con la excepción de este último, no cuentan con espacios verdes en su interior.

Figura 5.19 ¿Cuánto tardan los usuarios en llegar desde casa hasta el espacio verde más cercano de Valladolid?

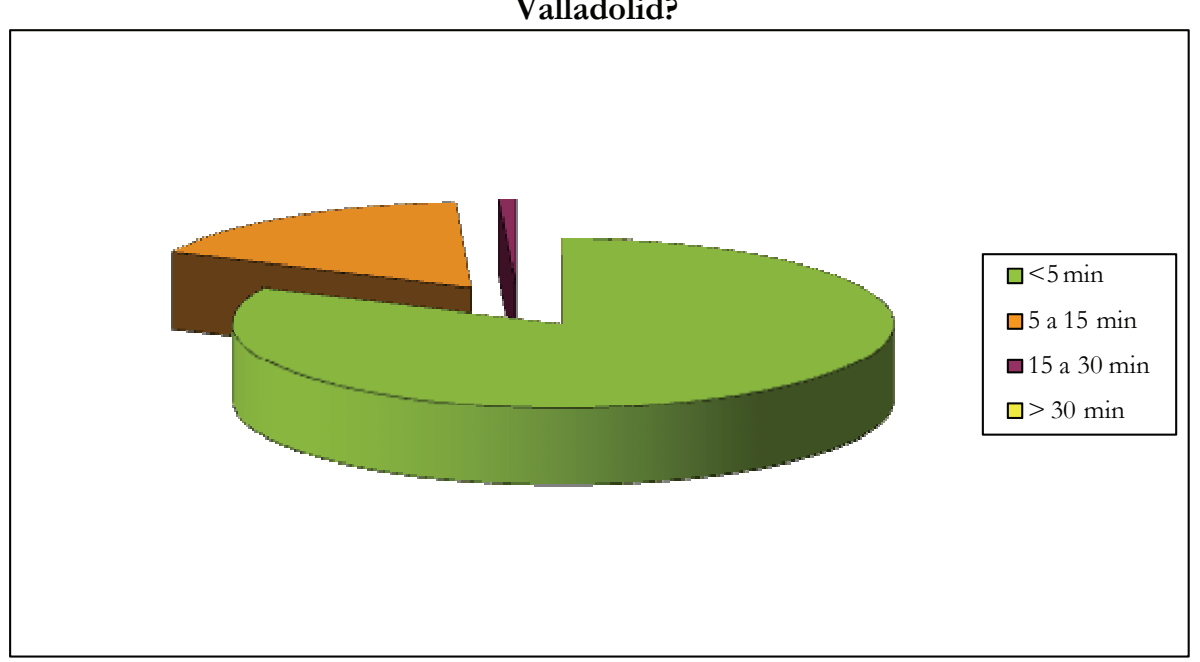

Fuente: elaboración propia.

Solamente un 8,5\% de los encuestados en Valladolid afirmó que la accesibilidad que tenían a los espacios verdes no era buena. La mayor parte, el 81,9\%, afirmó contar con el espacio que más veces visitaban a menos de cinco minutos de casa (ver Figura 5.19). Uno de cada cinco afirmó tardar más de cinco minutos hasta llegar a la trama verde y es de suponer que entre estos se encontrarían los usuarios que tienen su residencia a una distancia de hasta 800 metros a los cuatro verdes de cindad de Valladolid, lo que muestra que la población encuestada dispone de un acceso a los parques y jardines considerablemente bueno. 


\subsubsection{Acceso al verde urbano zamorano}

En la ciudad de Zamora únicamente dos de los dieciséis barrios que componían la ciudad de 2009 no contaban con áreas verdes en su interior (ver Figura 5.20): La Lana - San Esteban (2) y Bloques - Barriada Asturias - Villagodio (8). Sin embargo, la densidad de la trama verde provoca que estos barrios dispongan de un acceso muy bueno a la misma, situación que se repite en la totalidad del centro histórico y del ensanche. La superficie total sin acceso es de 173 ha en las que se estima que viviría el 12,3\% de la población residente, esto es, 8.095 personas (ver Tabla 5.12). Las zonas sin acceso están localizadas en la periferia de la ciudad, concretamente 103 ha en el límite norte y 70 ha en el límite sur de la margen izquierda del río. Los barrios comprendidos en esta última ubicación como Pinilla - San Ramón (9), Cabañales - Sepulcro (10) y San Frontis - Carrascal (11) poseen un poblamiento poco denso, que se va dispersando a medida que aumenta la distancia con el Duero. Esto provoca que el número de residentes sin acceso a las zonas verdes en esta zona sea relativamente reducido, menos de 2.000 personas, que sin embargo podrán disfrutar, en ocasiones, de algunos de los beneficios generados por otros espacios como son los huertos urbanos o periurbanos, al tratarse de barrios en contacto directo con estas actividades primarias.

Por otro lado, en el sector nororiental de la ciudad se concentra la mayor parte de las zonas que no cuentan con acceso a la trama verde en los barrios de Alviar (15), San José Obrero (14), Pantoja (4) y Centro Ciudad (3), destacando el apéndice oriental de este último que se extiende desde el Hospital Virgen de la Concha hasta el Parque Comercial Vista Alegre. En el barrio Alviar (15) la parte norte es la más poblada, pero también están incluidas áreas industriales en Pantoja (4) y una parte del polígono de Higueras, así como buena parte de las instalaciones vinculadas a la estación de ferrocarril. El primero de ellos es el barrio con mayor superficie sin acceso al verde urbano, aunque solamente se estiman en 499 los residentes en dicha situación, mientras que en el conjunto de la zona norte de la ciudad serían 5.214 los habitantes sin espacios verdes en las proximidades de su vivienda. Las zonas con mayores déficits están poco pobladas, lo que da como resultado una cifra relativamente positiva, puesto que en el 18,1\% de la ciudad se estima que reside el 12,3\% de la población. La distribución de las áreas verdes por barrios es bastante regular, lo que provoca que sean pocos los que se encuentren alejados del más próximo (ver Figura 5.21). Únicamente en Bloques - Barriada Asturias - Villagodio (8) y en Pinilla - San Ramón (9), el centroide se encuentra a más de ochocientos metros del espacio verde más cercano, lo que indica que hay zonas de estos barrios muy alejadas de los parques y jardines.

Zamora cuenta con dos zonas verdes de más de 10 ha, la margen derecha del Duero (Z-6) y el Bosque de Valorio (Z-9), ambos con una superficie de 16,5 ha, aunque en este último solamente se ha tenido en cuenta la parte urbana al tratarse de un bosque con una extensión superior a las 80 ha. Están situados en los límites oriental y occidental de la ciudad tradicional y su área de irradiación forma un continuo que se extiende por más de 600 ha abarcando todo el casco antiguo y los barrios situados en el extremo este y oeste, llegando incluso hasta los situados al sur del Duero como Pinilla - San Ramón (9) y Cabañales Sepulcro (10).

A más de 800 metros de estos grandes parques estarían situados los barrios de Las Viñas (5), Alviar (15) y Pantoja (4) en el norte de Zamora, acompañados por otros que poseen más de un tercio de su superficie sin acceso a estos dos verdes de ciudad como son Peña Trevinca (16), Centro Ciudad (3), San José Obrero (14) y en la margen izquierda del río San Frontis - Carrascal (11). En total se estima que serían 18.659 personas las que viven en el $35 \%$ de la ciudad que no posee acceso a los grandes parques. Si se analiza el acceso a los equipamientos de juego infantil se observa que estos únicamente dan servicio a un tercio de la superficie urbana, dejando en una situación deficitaria a 43.483 zamoranos. A las ya men- 
Figura 5.20 Acceso al verde urbano disponible de Zamora.

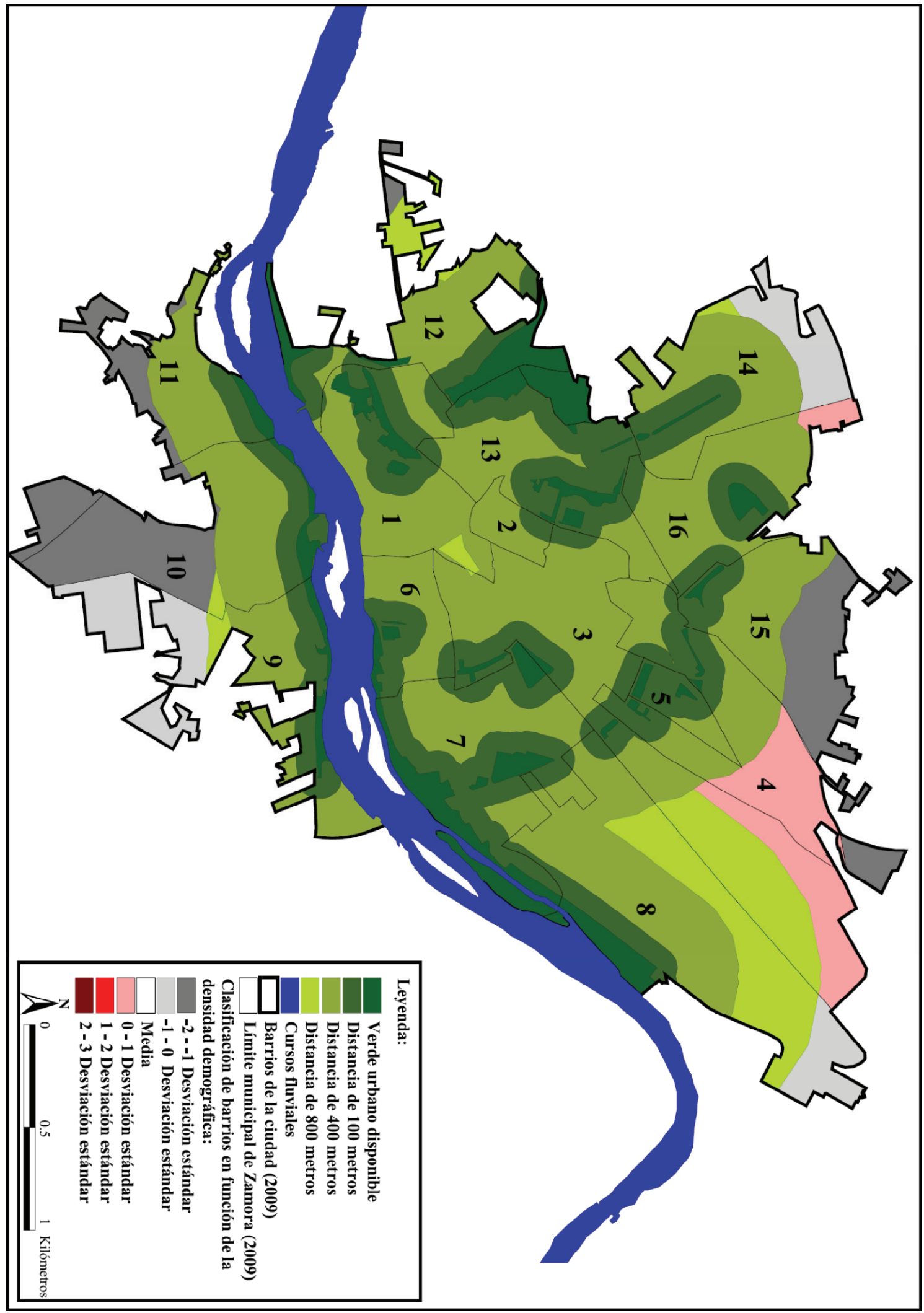

Media $=7.949 \mathrm{hab} / \mathrm{km}^{2}$. Desviación estándar $=5.052 \mathrm{hab} / \mathrm{km}^{2}$.

Fuente: elaboración propia a partir de la ortofoto de 2009 del IGN y del Ayuntamiento de Zamora (2007). 
Figura 5.21 Distancia desde el centroide de cada barrio al espacio verde más próximo de Zamora.

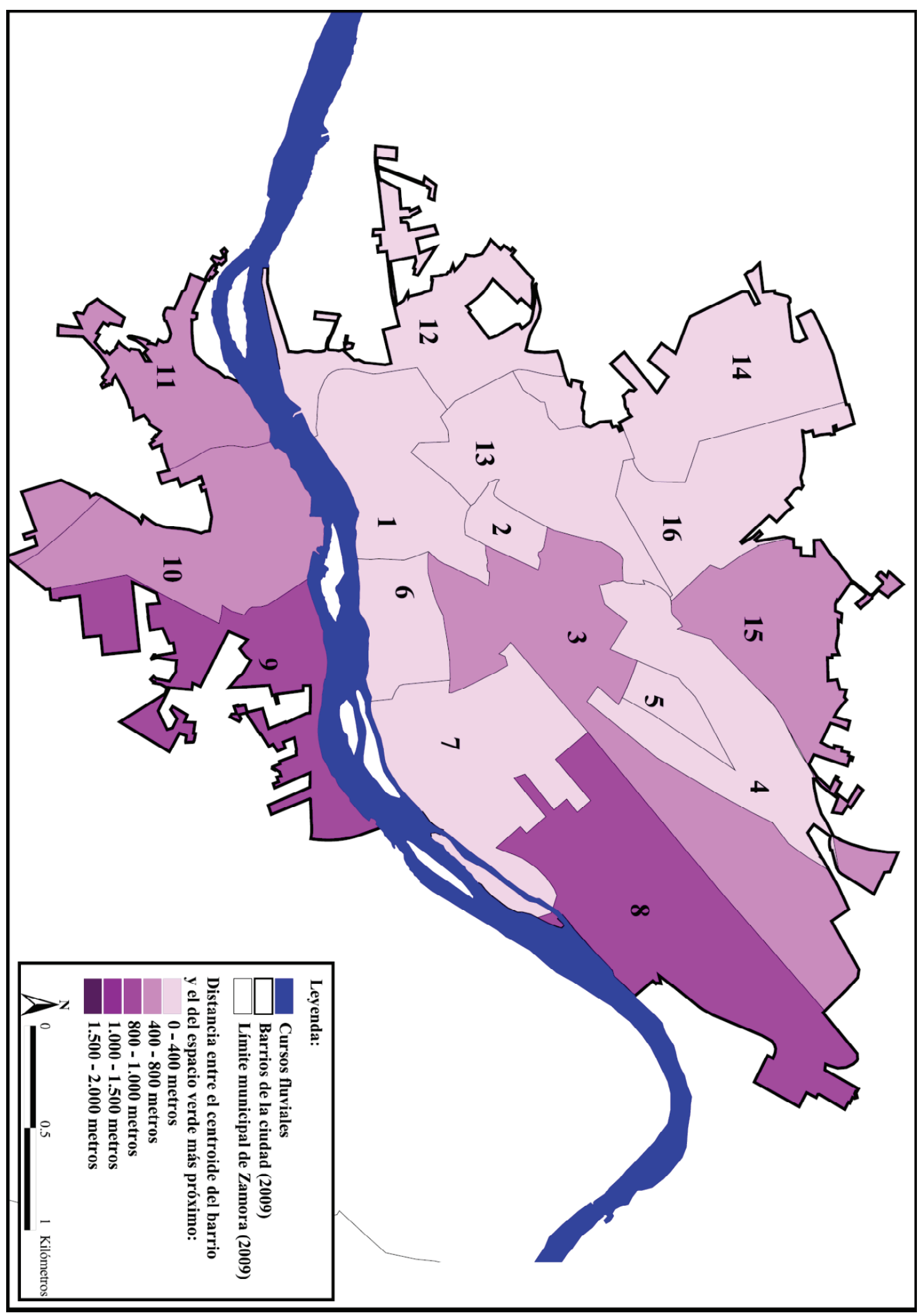

Fuente: elaboración propia a partir de la ortofoto de 2009 del IGN y del Ayuntamiento de Zamora (2007). 
cionadas zonas periféricas, se les unirían amplios espacios en torno a la Plaza Mayor, hasta las proximidades de la Avenida Cardenal Cisneros, como lugares sin acceso a las áreas verdes que tengan equipamientos específicos para los más pequeños. Esta última vía y el río Duero son los ejes que articulan la trama verde zamorana y presentan una situación bastante buena de acceso a las zonas de juego infantil.

Tabla 5.12 Número de encuestados y población estimada sin acceso en los barrios de Zamora.

\begin{tabular}{|c|c|c|c|c|c|c|c|c|c|}
\hline $\mathbf{N}^{\circ}$ & Nombre barrio & $\begin{array}{c}\mathrm{N}^{\circ} \\
\text { encuestados }\end{array}$ & $\begin{array}{c}\% \\
\text { encuestados } \\
\text { total }\end{array}$ & $\begin{array}{c}\mathbf{N}^{\circ} \\
\text { habitantes }\end{array}$ & $\begin{array}{l}\text { Superficie } \\
\text { (ha) }\end{array}$ & $\begin{array}{c}\text { Densidad } \\
\left(\mathrm{hab} / \mathrm{km}^{2}\right)\end{array}$ & $\begin{array}{c}\text { Superficie sin } \\
\text { acceso verde } \\
\text { urbano }\end{array}$ & $\begin{array}{c}\% \text { superficie } \sin \\
\text { acceso verde } \\
\text { urbano }\end{array}$ & $\begin{array}{l}\text { Población sin } \\
\text { acceso verde } \\
\text { urbano }\end{array}$ \\
\hline 1 & Casco Antiguo & 15 & 8,1 & 4.623 & 57,9 & 7.991 & 0,0 & 0,0 & 0 \\
\hline 2 & La Lana - San Esteban & 1 & 0,5 & 1.741 & 9,0 & 19.324 & 0,0 & 0,0 & 0 \\
\hline 3 & Centro Ciudad & 25 & 13,4 & 13.986 & 112,2 & 12.463 & 20,1 & 17,9 & 2.502 \\
\hline 4 & Pantoja & 5 & 2,7 & 4.711 & 57,6 & 8.184 & 18,7 & 32,4 & 1.528 \\
\hline 5 & Las Viñas & 1 & 0,5 & 1.589 & 9,8 & 16.155 & 0,0 & 0,0 & 0 \\
\hline 6 & Horta-Barrios Bajos & 10 & 5,4 & 3.614 & 33,2 & 10.870 & 0,0 & 0,0 & 0 \\
\hline 7 & Candelaria - Peña de Francia & 32 & 17,2 & 8.281 & 88,8 & 9.324 & 0,0 & 0,0 & 0 \\
\hline 8 & $\begin{array}{l}\text { Bloques - Barriada Asturias - } \\
\text { Villagodio }\end{array}$ & 11 & 5,9 & 6.374 & 107,9 & 5.905 & 11,4 & 10,5 & 672 \\
\hline 9 & Pinilla - San Ramón & 11 & 5,9 & 2.795 & 72,0 & 3.883 & 22,5 & 31,2 & 873 \\
\hline 10 & Cabañales - Sepulcro & 2 & 1,1 & 1.410 & 75,4 & 1.870 & 29,5 & 39,2 & 552 \\
\hline 11 & San Frontis - Carrascal & 7 & 3,8 & 1.110 & 47,0 & 2.363 & 18,0 & 38,3 & 425 \\
\hline 12 & $\begin{array}{l}\text { Olivares - Isidro - Espíritu } \\
\text { Santo - Obelisco }\end{array}$ & 7 & 3,8 & 1.587 & 56,7 & 2.799 & 2,2 & 3,9 & 61 \\
\hline 13 & San Lázaro & 30 & 16,1 & 6.101 & 54,2 & 11.250 & 0,0 & 0,0 & 0 \\
\hline 14 & San José Obrero & 15 & 8,1 & 2.848 & 66,0 & 4.312 & 15,9 & 24,1 & 685 \\
\hline 15 & Alviar & 1 & 0,5 & 957 & 60,2 & 1.588 & 31,4 & 52,2 & 499 \\
\hline 16 & Peña Trevinca & 7 & 3,8 & 4.271 & 47,9 & 8.918 & 3,3 & 7,0 & 297 \\
\hline 17 & Otros & 6 & 3,2 & - & - & - & - & - & - \\
\hline & TOTAL & 186 & 0,28 & 65.998 & 956,0 & 6.904 & 173,0 & 18,1 & 8.095 \\
\hline
\end{tabular}

Fuente: elaboración propia a partir de la ortofoto del IGN y del Ayuntamiento de Zamora (2007).

Figura 5.22 ¿Cuánto tardan los usuarios en llegar desde casa hasta el espacio verde más cercano de Zamora?

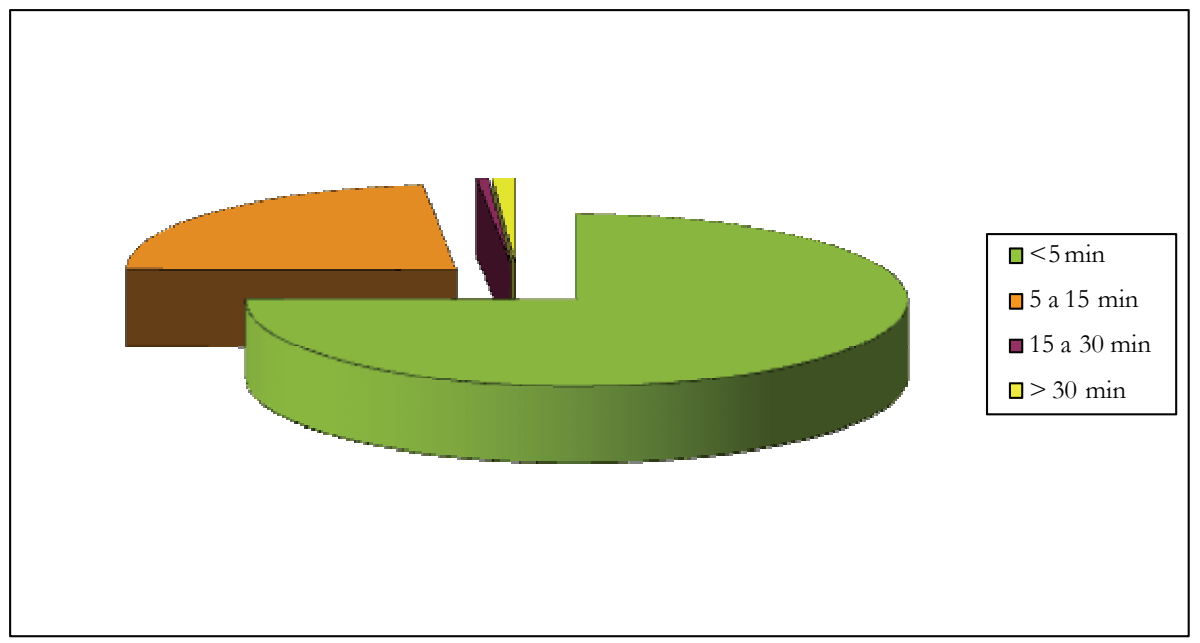

Fuente: elaboración propia.

Entre los barrios de origen de la población encuestada en Zamora destacan Candelaria - Peña de Francia (7) y San Lázaro (13), con una treintena de entrevistados cada uno, lo que representa un tercio de la muestra obtenida en esta ciudad. Son dos barrios densamente poblados que cuentan con una considerable extensión de espacios verdes en su interior y cada uno de estos territorios tiene acceso a cinco áreas verdes. El tercer barrio de procedencia es el que presenta un mayor contingente poblacional, esto es, el Centro de la Ciudad (3). En la muestra obtenida en Zamora aparecen representados todos los barrios aunque en tres de ellos solo se entrevistó a una persona: Las Viñas (5), La Lana - San Esteban (2) y Alviar (15), mientras que de Cabañales - Sepulcro (10) fueron dos. En todos los casos se trata de barrios que cuentan con pocas zonas verdes; los dos primeros tienen un 
tamaño reducido, aunque cuentan con muy buen acceso al verde urbano, y los otros poseen una mayor superficie sin acceso a la trama verde.

Al ser preguntados directamente, los usuarios calificaron la accesibilidad a los espacios verdes como buena o muy buena, siendo un 7,7\% los que la consideraron como regular y un 1,6\% los que dijeron que era muy mala. En la Figura 5.22 aparece representado el tiempo que los usuarios tardan en llegar desde casa hasta la zona verde más cercana, observándose que tres cuartas partes de los entrevistados tardan menos de cinco minutos. Los que tardan entre cinco y quince representan casi una cuarta parte, y sin embargo, únicamente el 10\% dijo no tener buena accesibilidad. Es posible que esto se deba a que una parte de los que caminan entre cinco y quince minutos para llegar a un parque, visite alguno de los verdes de cindad y a que probablemente también se percibe la accesibilidad de forma distinta a la aquí mencionada.

\subsubsection{Recapitulación}

El análisis llevado a cabo ha permitido identificar dos grandes tipos de zonas sin acceso a las zonas verdes. La primera de ellas, que solo ha sido identificada en las dos ciudades de mayor tamaño, se corresponde con los barrios y las parcelas urbanas creadas hasta mediados de la década de los ochenta del siglo pasado, cuando en los casos analizados se impone de manera efectiva el planeamiento urbano y la reserva de suelo para áreas verdes, como se indicó de manera detallada en el capítulo anterior. Esta situación muestra la enorme dificultad de corregir déficits heredados en el interior del tejido consolidado, reforzando así la tesis de Rodríguez y Díaz (2003) cuando afirman que los espacios verdes son verdaderos indicadores de los déficits en la expansión urbana. El segundo tipo de zona sin acceso a la trama verde está asociada a barrios periféricos de carácter industrial. A este respecto el RUCYL señala en el Artículo 105, donde trata los requisitos del sistema local de espacios libres públicos, que la reserva de suelo para este tipo de equipamientos en sectores con uso predominantemente industrial o de servicios debe estar destinada a arbolado de alineación. Esto puede contribuir a explicar la escasez de parques y jardines en las zonas industriales, ya que la legislación urbanística no es tan exigente como en el resto de la ciudad. En todo caso parece una medida poco adecuada puesto que en la mayoría de estas zonas se concentran a diario grandes contingentes de población que no dispondrán de áreas verdes en las proximidades de su lugar de trabajo, con la correspondiente pérdida de los beneficios generados por estos equipamientos en la recuperación del estrés diario (Ulrich et al., 1991; Galindo et al., 1997; Bolund y Hunhammar, 1999), o en la mejora de las relaciones sociales y personales de los trabajadores (Bendimo-Rung et al., 2005).

Además de estas zonas, en el capítulo anterior se identificaron los centros históricos como partes de la ciudad con escasos equipamientos verdes. Sin embargo, se observa que mayoritariamente tienen un acceso bastante bueno a los mismos, debido a la progresiva aparición de grandes espacios verdes en la periferia de la ciudad histórica, subsanando así las deficiencias existentes.

En todos los casos analizados se ha identificado el río como eje vertebrador de la trama verde y, consecuentemente, algunos de los barrios ribereños se encuentran entre los que poseen mejor acceso a los espacios verdes. Otras áreas con estas características son algunas de las nuevas piezas urbanas creadas en cada ciudad, como por ejemplo, el barrio de Parquesol (38) en Valladolid o el de la Platina (44) en Salamanca. Es necesario destacar estas situaciones ya que, en ocasiones los espacios abiertos y la búsqueda de zonas ajardinadas se encuentran entre los motivos que contribuyen a que determinados habitantes opten por un lugar de residencia y no por otro.

En la Tabla 5.13 se han comparado los datos de acceso al verde urbano, tanto de superficie como de población estimada, con las respuestas recogidas en los cuestionarios a las 
preguntas sobre el tiempo que tardan los usuarios en llegar al espacio verde más cercano y sobre la valoración de su propia accesibilidad. En primer lugar se observa, que la superficie de la ciudad que cuenta con zonas verdes a una distancia razonable parece estar relacionada con el tamaño de la misma, ya que Valladolid no cuenta con acceso en más de una cuarta parte de su territorio y esta cifra se reduce a medida que disminuye la entidad urbana. Sin embargo, al realizar una estimación del porcentaje de personas que viven en estos sectores urbanos, Salamanca ocuparía el primer lugar, con un 15,6\% de la población total, puesto que estas zonas presentan una densidad mucho más elevada que en las otras ciudades, donde estos espacios tienen una orientación mayoritariamente industrial. Cuando se preguntó a los usuarios cómo consideraban su accesibilidad al verde urbano, los valores obtenidos en Valladolid y en Zamora fueron similares a los anteriormente mencionados, mientras que en Salamanca un $26,7 \%$ dijo que no era buena. Atendiendo a datos ya comentados, las actividades que mayoritariamente realizan los encuestados en las áreas verdes de esta ciudad son la práctica deportiva $(39 \%)$ y la relajación $(16,1 \%)$, por lo que podría pensarse que para llevarlas a acabo no se conformarían con pequeños parques o con aquellos que no consiguen aislarles de la ciudad, sino que buscarían grandes espacios. Solamente un tercio de los residentes en dicha urbe tienen acceso al único verde de ciudad, mientras que en Valladolid este porcentaje alcanza el 54,8\% y en Zamora el 71,7\%. La gran atracción que ejercen este tipo de espacios queda reflejada en el hecho de que entre el 45,5\% de los salmantinos que dijeron caminar más de cinco minutos hasta llegar a las áreas verdes, había una mayoría que visitaba el Parque de los Jesuitas (S-4). Por tanto, parece que no solamente sería necesario poseer una zona verde en las proximidades del lugar de residencia, sino que sería preciso que la mayor parte de la población contase con acceso al verde de cindad puesto que para realizar las actividades que habitualmente llevan a cabo en los parques y jardines, los ciudadanos necesitarían espacios de mayores dimensiones.

Tabla 5.13 Acceso al verde urbano en las tres ciudades analizadas.

\begin{tabular}{|l|c|c|c|c|c|}
\hline Ciudad & $\begin{array}{c}\text { \% superficie } \\
\text { sin acceso al } \\
\text { verde urbano }\end{array}$ & $\begin{array}{c}\text { \% población } \\
\text { sin acceso al } \\
\text { verde urbano }\end{array}$ & $\begin{array}{c}\text { encuestados } \\
\text { sin acceso al } \\
\text { verde urbano }\end{array}$ & $\begin{array}{c}\text { \%oblación con } \\
\text { acceso verde de } \\
\text { ciudad }\end{array}$ & $\begin{array}{c}\% \text { encuestados } \\
\text { a }>5 \text { min del } \\
\text { verde urbano }\end{array}$ \\
\hline Salamanca & 20,5 & 15,1 & 26,7 & 25,0 & 45,5 \\
\hline Valladolid & 26,0 & 14,7 & 8,5 & 54,8 & 18,1 \\
\hline Zamora & 18,1 & 12,3 & 9,3 & 71,7 & 24,9 \\
\hline
\end{tabular}

Fuente: elaboración propia.

Conviene mencionar también el porcentaje de superficie urbana con acceso a los espacios verdes que cuentan con equipamientos infantiles, ya que en todos los casos se trata de cifras muy reducidas: en Salamanca y en Valladolid se sitúa en torno al veinte por ciento, mientras que en Zamora supone un tercio del total. Autores como Van Herzele y Wiedemann (2003) señalan que para determinados colectivos como son los niños o las personas con movilidad reducida, los parques de menos de una hectárea podrían desempeñar un papel destacado, por lo que sería conveniente analizar en futuros trabajos el porcentaje de visitas que un usuario de la trama verde destina a las áreas verdes de pequeñas dimensiones.

\subsection{Calidad del verde urbano}

La calidad ha sido definida como el conjunto de condiciones que hacen que los espacios verdes satisfagan las demandas y las necesidades de los ciudadanos. Para cuantificar este parámetro se pidió a los encuestados que valoraran trece áreas verdes de cada ciudad, que habían sido elegidas cuidadosamente a la hora de diseñar la encuesta, calificándolas con una nota de entre 0 y 10. En la Tabla 5.14 aparecen clasificadas las zonas verdes 
seleccionadas en función de la media de las notas asignadas por los ciudadanos a cada una de ellas y junto a la calificación aparece el porcentaje de los usuarios encuestados que dieron una nota a cada espacio.

El motivo más veces repetido para no calificar un verde urbano fue no conocerlo o no visitarlo con suficiente frecuencia como para poder realizar una valoración total del mismo. En el momento en que se realizó el trabajo de campo en Salamanca, el Parque de Würzburg (S-15) se encontraba cerrado por reformas, por lo que la mayor parte de las encuestas realizadas en ese espacio se llevaron a cabo en la entidad más pequeña de esta zona verde, es decir, el jardín junto al colegio Montessori. Este hecho repercutió lógicamente en su valoración, ya que algunos decidieron no calificarlo hasta no ver finalizada la ejecución de las obras, otros puntuaron el estado del verde previo a la reforma y los más osados evaluaron los avances que fueron viendo en el parque. Otro espacio verde que se encontraba en obras durante el desarrollo del trabajo de campo fue Campo Grande (V-1), aunque las reformas se concentraban en el paseo central que atraviesa este espacio de norte a sur y era posible transitar por la mayor parte del parque sin dificultad.

Estas calificaciones permitieron comprobar la representatividad de las áreas verdes elegidas en el cuestionario, puesto que se comparó la nota asignada por los ciudadanos al conjunto de zonas verdes de cada ciudad (pregunta número 17), con la media aritmética de las notas asignadas a los trece verdes disponibles. Este procedimiento mostró una alta representatividad del verde seleccionado ya que la diferencia fue de 0,09 puntos en Salamanca, de 0,22 en Valladolid y de 0,39 en Zamora, validando en cierta manera la metodología utilizada para medir la calidad del verde urbano. Junto a las notas medias obtenidas, se ha incluido información sobre los equipamientos de las áreas verdes de las tres ciudades (ver Tablas 5.15, 5.16 y 5.17) para poder contrastar la opinión de los usuarios con las características de cada verde urbano.

En cuanto a la valoración de los espacios verdes, se observa que Valladolid obtuvo la nota más elevada en la calificación promedio del total de la trama verde, con 7,43 puntos, seguida de Zamora con 6,99 y de Salamanca con 6,04. La satisfacción entre los vallisoletanos encuestados se refleja también en cada una de las áreas verdes por las que se preguntó, puesto que no hay ningún suspenso entre las calificaciones y la menor de las puntuaciones es de 6,52 puntos (Ladera sur de Parquesol-Fuente de Dios, V-10). Además, en el ranking de valoración en el que se incluyen todos los espacios verdes por los que se preguntó en esta investigación, tres parques de Valladolid se encuentran en los cuatro primeros lugares, concretamente Campo Grande (V-1), el Parque de las Moreras (V-3) y el Parque del Mediodía (V-9). Entre ellos se situaría en tercer lugar el zamorano Parque del Castillo y de la Catedral (Z-1) con 7,84 puntos que sin embargo tiene una dimensión muy reducida, inferior a las dos hectáreas, frente a los otros que superan las nueve hectáreas. En el extremo opuesto se encuentran dos zonas verdes de Salamanca que recibieron una nota muy baja: los Jardines del Hospital Clínico (S-13) con 4,62 puntos y el Parque de San Francisco (S-9), que obtuvo un aprobado muy justo. En Zamora se identifican dos áreas verdes de similares características, ya que la media de sus notas da como resultado una calificación de 4,90 puntos para la margen Izquierda del Duero (Z-15) y de 5,18 para el verde urbano de la Avenida Cardenal Cisneros (Eroski) (Z-21).

Parece existir cierta relación entre los parques mejor valorados y los más conocidos por los usuarios, lo que podría deberse a que los espacios verdes bien equipados acaban por convertirse en zonas atractivas que son visitadas por la mayor parte de los usuarios, mientras que el resto de situaciones son muy diversas. Entre estos últimos se distingue un tipo que podría denominarse como parque histórico, cuyo ejemplo aparece representado por los salmantinos Campo de San Francisco (S-9) y Parque de la Alamedilla (S-10). Estos dos espacios verdes, situados en el centro de la ciudad, son conocidos por más del noventa por 
Tabla 5.14 Valoración del verde urbano disponible de Salamanca, Valladolid y Zamora.

\begin{tabular}{|c|c|l|c|c|}
\hline Posición & Id. & \multicolumn{1}{|c|}{ Espacios verdes } & Nota media & \% respuestas \\
\hline 1 & S-4 & Parque de los Jesuitas & 7,46 & 91,4 \\
\hline 2 & S-18 & Parque Fluvial & 7,02 & 84,6 \\
\hline 3 & S-20 & Parque de Ciudad Rodrigo & $\mathbf{6 , 4 0}$ & 14,7 \\
\hline 4 & S-3 & Parque botánico de Huerta Otea & $\mathbf{6 , 3 6}$ & 71,4 \\
\hline 5 & S-7 & Verde urbano Vaguada de la Palma & $\mathbf{6 , 3 2}$ & 74,8 \\
\hline 6 & S-22 & Parque de Vistahermosa & $\mathbf{6 , 1 5}$ & 19,2 \\
\hline 7 & S-11 & Parque Pablo Picasso & $\mathbf{6 , 0 2}$ & 79,3 \\
\hline $\mathbf{8}$ & S-15 & Parque de Würzburg* & 5,92 & 43,2 \\
\hline $\mathbf{9}$ & S-10 & Parque de la Alamedilla & 5,91 & 97,4 \\
\hline 10 & S-23 & Parque de Villar y Macías & 5,72 & 64,3 \\
\hline 11 & S-24 & Verde urbano de La Salle & 5,45 & 28,2 \\
\hline 12 & S-9 & Parque de San Francisco & 5,13 & 90,6 \\
\hline 13 & S-6 & Jardines del Hospital Clínico & 4,62 & 68,8 \\
\hline Media & & $\mathbf{6 , 1 3}$ & \\
\hline Diferencia percepción & $-0,09$ & \\
\hline \multicolumn{2}{|l|}{ Valoración de la trama verde salmantina } & $\mathbf{6 , 0 4}$ & \\
\hline
\end{tabular}

\begin{tabular}{|c|c|c|c|c|}
\hline Posición & Id. & Espacios verdes & Nota media & $\%$ respuestas \\
\hline 1 & $\mathrm{~V}-1$ & Campo Grande & 8,65 & 97,7 \\
\hline 2 & V-3 & Parque de las Moreras & 7,89 & 97,2 \\
\hline 3 & V-9 & Parque del Mediodía & 7,47 & 65,2 \\
\hline 4 & $\mathrm{~V}-6$ & Jardín Botánico & 7,42 & 48,8 \\
\hline 5 & V-14 & Parque de Covaresa & 7,35 & 60,3 \\
\hline 6 & V-21 & Parque de Canterac & 7,31 & 73,4 \\
\hline 7 & V-15 & Parque de la Alameda & 7,02 & 59,7 \\
\hline 8 & V-25 & Verde urbano Calle Arribes del Duero & 6,92 & 37,5 \\
\hline 9 & V-47 & Verde urbano Calle Vega de Valdetronco - Villas Sur & 6,87 & 20,9 \\
\hline 10 & V-42 & Plaza del Ejército & 6,80 & 84,2 \\
\hline 11 & V-39 & Verde urbano Calle Morena - Feria de Muestras & 6,80 & 46,8 \\
\hline 12 & V-32 & Verde urbano Huerta del Rey & 6,65 & 67,7 \\
\hline 13 & V-10 & Ladera sur Parquesol - Fuente de Dios & 6,52 & 52,8 \\
\hline Media & & & 7,21 & \\
\hline \multicolumn{2}{|c|}{ Diferencia percepción } & & 0,22 & \\
\hline \multicolumn{3}{|c|}{ Valoración de la trama verde vallisoletana } & 7,43 & \\
\hline
\end{tabular}

\begin{tabular}{|c|l|l|c|c|}
\hline Posición & Id. & \multicolumn{1}{|c|}{ Espacios verdes } & Nota media & \% respuestas \\
\hline 1 & Z-1 & Parque del Castillo y de la Catedral & 7,84 & 93,5 \\
\hline 2 & Z-6 & Margen Derecha del Duero & 7,35 & 91,4 \\
\hline 3 & Z-9 & Bosque de Valorio (parte urbana) & 7,17 & 93,0 \\
\hline 4 & Z-14 & Parque de León Felipe & 7,01 & 90,9 \\
\hline 5 & Z-19 & Verde urbano Puerta Nueva & $\mathbf{6 , 7 8}$ & 81,7 \\
\hline 6 & Z-13 & Parque de San Martín & $\mathbf{6 , 7 6}$ & 90,3 \\
\hline 7 & Z-12 & Verde urbano Avda. Cardenal Cisneros (Universidad) & $\mathbf{6 , 6 7}$ & 89,2 \\
\hline $\mathbf{8}$ & Z-20 & Verde urbano Calle Nuestra Señora de las Mercedes & $\mathbf{6 , 5 0}$ & 51,6 \\
\hline $\mathbf{9}$ & Z-4 & Parque de la Marina & $\mathbf{6 , 2 7}$ & 98,4 \\
\hline 10 & Z-10 & Parque de Peña Trevinca & 5,87 & 57,5 \\
\hline 11 & Z-11 & Jardines de la Vaguada & 5,78 & 75,8 \\
\hline 12 & Z-21 & Verde urbano Avda. Cardenal Cisneros (Eroski) & 5,18 & 56,5 \\
\hline 13 & Z-15 & Margen Izquierda del Duero & 4,90 & 75,3 \\
\hline \multicolumn{2}{|l|}{ Media } & & $\mathbf{6 , 6 0}$ & \\
\hline Diferencia percepción & & 0,39 & \\
\hline \multicolumn{2}{|l|}{ Valoración de la trama verde zamorana } & $\mathbf{6 , 9 9}$ & \\
\hline
\end{tabular}

*Espacio verde en obras durante la realización del trabajo de campo.

Fuente: elaboración propia. 

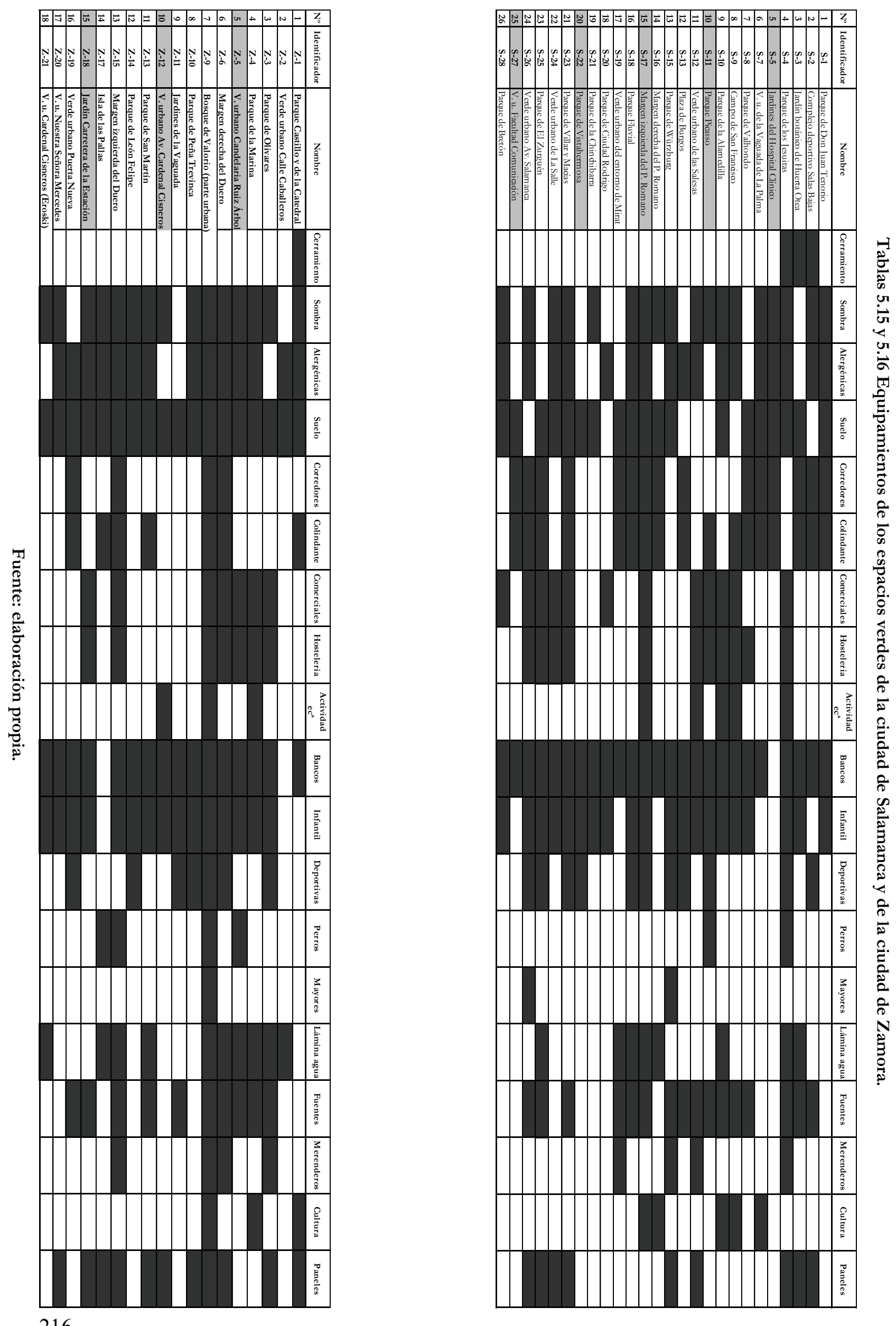


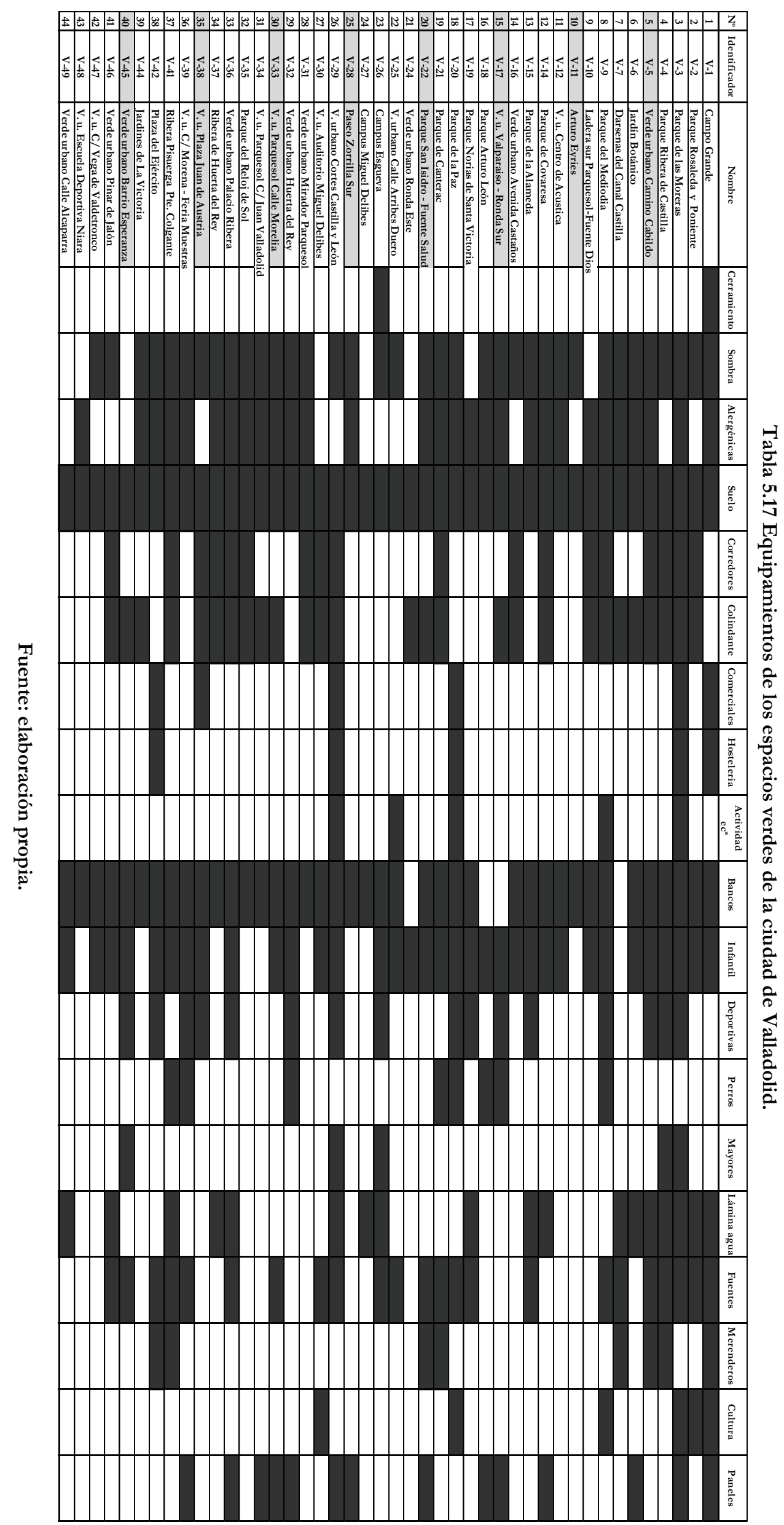


ciento de los encuestados y sin embargo presentan unas calificaciones bastante bajas, 5,13 y 5,91 puntos respectivamente. Un caso similar se observa en el Parque de la Marina (Z-4), situado en uno de los últimos puestos en el ranking de notas de Zamora, mientras que en una situación opuesta se encuentran espacios verdes de reciente construcción en algunos de los barrios más modernos de cada ciudad, poco conocidos pero con una valoración muy elevada. Como ejemplos se pueden citar el Parque de Ciudad Rodrigo (S-20), que tiene una calificación media de 6,40 puntos, el verde urbano Calle de la Vega de Valdetronco - Villas Sur (V-47) con 6,87 o el verde urbano Calle Arribes del Duero (V-25) con 6,92. Además, estas calificaciones podrían aumentar en un futuro cercano, cuando la vegetación de estas zonas verdes crezca y se consolide, para así ofrecer nuevas áreas de sombra que, como se comprobará posteriormente, son muy valoradas por la población.

Uno de los resultados más llamativos respecto de la calidad de los espacios verdes es la elevada puntuación que han recibido algunos de los parques que menos equipamientos poseían. El Parque del Castillo y de la Catedral de Zamora (Z-1) es un buen ejemplo ya que, con menos de dos hectáreas y con unos equipamientos muy escasos, obtuvo una valoración de 7,84 puntos, siendo el mejor valorado de esa ciudad, por delante de otros verdes urbanos con más de diez hectáreas y que contaban con bastantes más equipamientos. En la misma situación se encuentra el verde urbano de la Calle Arribes del Duero en Valladolid (V-25) que recibió una media de 6,92 y en Salamanca el verde urbano de la Vaguada de la Palma (S-7) con 6,32 puntos, ambos sin instalaciones deportivas, ni zonas de recreo infantil, ni equipamientos para personas mayores. Esto sugiere la posibilidad de que, a la hora de valorar la calidad de las zonas verdes, los ciudadanos también valoren criterios más subjetivos como son el desarrollo de la vegetación o la centralidad de un parque. Observando los espacios peor valorados se puede concluir que los usuarios encuestados exigen realmente poco para asignarles un aprobado, ya que por el mero hecho de encontrarse en el interior del tejido urbano y presentar buen aspecto, una zona verde contaría, independientemente de su tamaño, con una calidad suficiente aunque no tuviera equipamientos y fuera un espacio de paso. Esto queda reflejado en la puntuación media obtenida en cada espacio seleccionado en esta investigación: de los treinta y nueve solamente dos recibieron una nota de suspenso, la margen Izquierda del Duero (Z-15), que recibió una puntuación muy cercana al aprobado, y los Jardines del Hospital Clínico (S-13), que obtuvieron una nota media de 4,62 pese a ser el espacio más pequeño de la trama urbana salmantina, presentar una topografía que dificultaba su uso y carecer, casi por completo, de equipamientos.

El contacto con los usuarios al realizar el trabajo de campo, aparentemente sugería una cierta vinculación entre el tamaño del verde urbano y las calificaciones asignadas a los espacios seleccionados. En la Figura 5.23 se puso en relación el tamaño de los treinta y nueve verdes urbanos seleccionados al diseñar las encuestas y el promedio de las calificaciones asignada por los usuarios, al igual que anteriormente se hizo con el índice de atracción, identificando una correlación significativa $\left(R^{2}=0,27\right.$ ), que es significativa al $99 \%$ (valor $\mathrm{p}<$ 0,0100). Por tanto, una parte de las calificaciones de las áreas verdes estarían determinadas por su tamaño ya que, por ejemplo, algunos autores apuntan a que los grandes parques tienen mayor capacidad de albergar un mayor número de equipamientos. Sin embargo, algunas zonas verdes de mayor tamaño obtuvieron un suspenso pese a contar con una gran cantidad de equipamientos, como le ocurrió a la anteriormente citada Margen Izquierda del Duero (Z-15). La explicación que dieron los usuarios a este caso concreto fue que se trataba de un área verde con un mantenimiento deficiente, aunque las visitas realizadas desmintieron este extremo. Se identificó una tendencia que es común en las tres ciudades estudiadas y que consistente en penalizar a las zonas verdes que no se ajusten al mantenimiento de un jardín tradicional. El ejemplo citado es un espacio semi-forestal de ribera sujeto a las crecidas del río, a la aparición de troncos caídos, a la acumulación de residuos vegetales arrastrados por el agua y al surgimiento espontáneo de vegetación. 
Se ha identificado una serie de factores que influyen negativamente en las calificaciones que los ciudadanos hacen de las zonas verdes, entre los que se encuentra el mantenimiento insuficiente o la falta de seguridad. Para comprender la influencia de este último aspecto conviene analizar uno de los ejemplos más expresivos, el salmantino Campo de San Francisco (S-9), que obtuvo una nota media de 5,13 pese a estar situado en el centro histórico. La explicación obtenida de los usuarios encuestados para tan baja calificación fue la notoria presencia de personas con conductas delictivas. Dentro del propio parque se percibe una clara zonalidad en el uso, ya que las personas dependientes con vicios ilícitos se concentran en la parte baja, mientras que el resto de los usuarios realizan un uso intensivo de la parte superior del parque, donde padres y madres mantienen controlados a sus hijos.

Figura 5.23 Correlación entre la puntuación y la superficie de los espacios verdes por los que se preguntó a los encuestados en las tres ciudades.

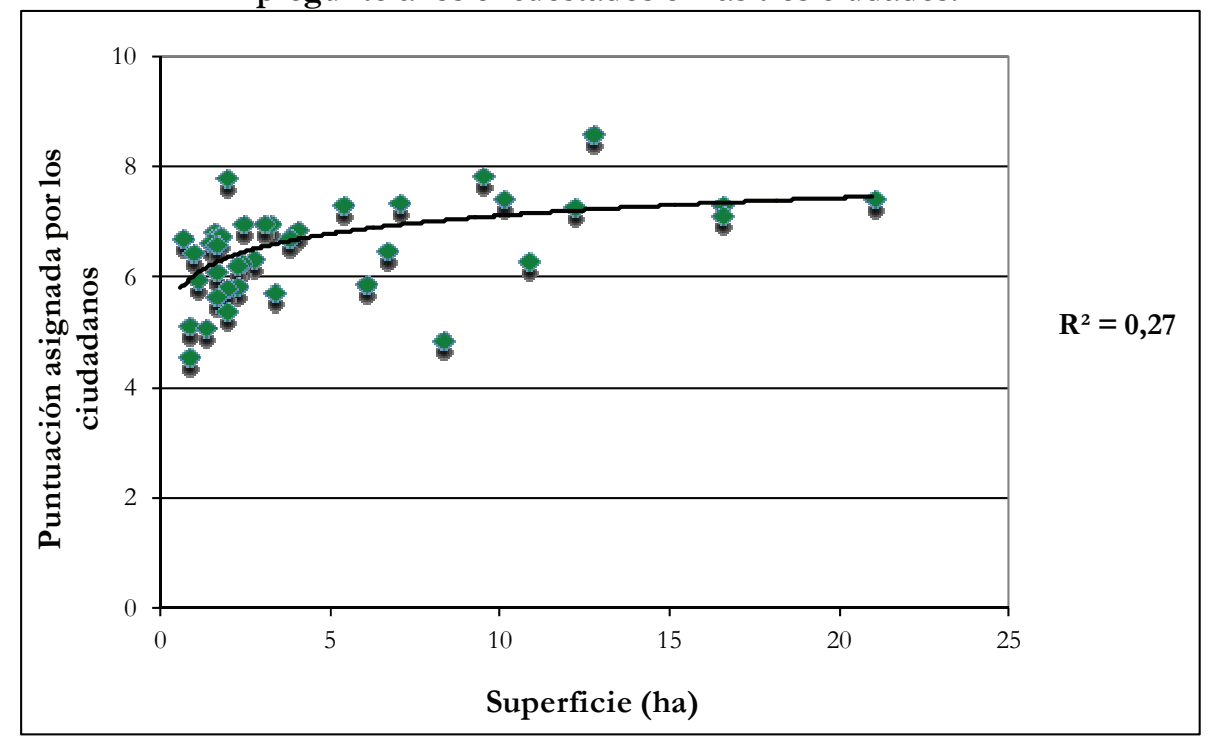

Fuente: elaboración propia.

Esa es una muestra de cómo influye la percepción de inseguridad en la calificación del verde urbano, aunque no siempre es fácil identificar factores tan subjetivos. Santana et al. (2009) demostraron una correlación negativa entre los espacios verdes percibidos como inseguros o con señales de vandalismo y la realización en ellos de actividades tales como el paseo, la relajación o la práctica deportiva. En el análisis de las calificaciones medias obtenidas en las zonas verdes seleccionadas resulta interesante el hecho de que se haya demostrado que la falta de usuarios convierte un espacio público en potencialmente peligroso, ya que los parques poco frecuentados, es decir, aquellos en los que el número de personas que afirmaron visitar ese espacio verde fue inferior al de usuarios encuestados en el mismo, podrían sufrir una penalización a causa de la sensación de inseguridad provocada por la falta de vigilantes naturales.

Por tanto, se pueden identificar al menos tres elementos que influyen negativamente en la calificación de los espacios verdes: el mantenimiento, la inseguridad y la falta de usuarios o de potenciales vigilantes. Entre los elementos positivamente valorados por los encuestados se encontraría el tamaño, como se demostró identificando una correlación significativa entre superficie e índice de atracción, y para identificar el resto de factores que influyen en las calificaciones finales se preguntó directamente a los encuestados.

Con el valor promedio de las respuestas obtenidas se elaboró la Figura 5.24, en la que se identifica una fuerte influencia de la vegetación ya que, además de ser el elemento constitutivo del verde urbano, está asociada a los tres equipamientos que más dijeron utilizar los entrevistados: los bancos, mencionados por aproximadamente la mitad de la población 
encuestada, la sombra y el césped, siendo estos dos últimos citados por un tercio de los encuestados. En la mayor parte de las ocasiones, las zonas de sombra fueron citadas conjuntamente con los bancos. Conviene recordar que la mayor parte de las visitas se concentran en estaciones cálidas, y para sentarse en un banco algunas personas necesitarán una sombra en la que resguardarse del sol y del calor propios de este periodo.

Figura 5.24 ¿Qué equipamientos utilizan los usuarios en los espacios verdes?

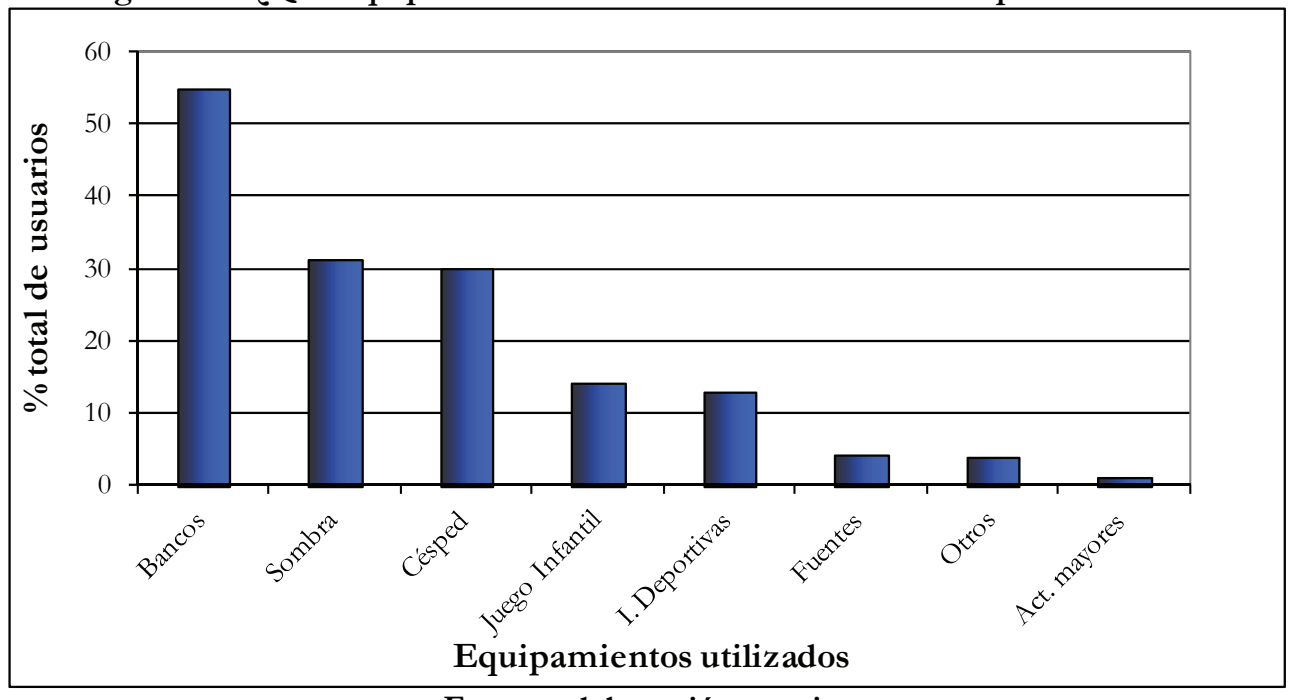

Fuente: elaboración propia.

El caso del césped es llamativo: se trata en un elemento atractivo tanto para las personas que acuden para disfrutar de él, como para las que acuden con su perro. La presencia de estos animales genera opiniones encontradas, como se puede observar en la Figura 5.25 en la que se representan las respuestas obtenidas al preguntar a los encuestados qué mejorarían de los espacios verdes. Un 8,4\% de los usuarios afirmó que sería necesario restringir el uso actual que los perros hacen de los áreas verdes, puesto que en la mayoría de los casos no hay un control efectivo sobre los lugares por los que pasean estos animales y sobre la recogida de sus deposiciones, tratándose de una responsabilidad que no siempre es asumida por sus dueños. Es muy destacable el hecho de que estas personas que expresaron desagrado por ver sueltos a los perros, señalaron que trataban de evitar las visitas a las zonas verdes en las que estos animales transitan habitualmente sin estar sujetos. Frente a este colectivo se posiciona el 1,9\% de los encuestados, mayoritariamente integrado por personas que acuden habitualmente con perros, que solicitan la mejora, y en algunos casos, la creación de un mayor número de áreas restringidas para estos animales en los verdes públicos. A este respecto hay que señalar que la cantidad total de estos equipamientos en las ciudades analizadas es de catorce, lo que representa únicamente un $15,7 \%$ de los ochenta y ocho verdes urbanos disponibles.

Retomando los equipamientos utilizados, se observa que también aparecen destacadas las zonas deportivas y las zonas de juego infantil, señaladas por más del 13\% de los usuarios, mientras que las fuentes y las zonas de actividad física para mayores apenas fueron mencionadas. Anteriormente, al comentar la Figura 5.11 se apuntó que los ciudadanos que utilizaban mayoritariamente los equipamientos deportivos eran menores de treinta años, con una destacada presencia de hombres, mientras que las zonas de juegos infantiles eran utilizadas por niños que acudían acompañados por adultos-jóvenes, especialmente mujeres, y en mayor medida por señoras de más de sesenta y cinco años.

El dato más relevante que ofrece la Figura 5.25 es que un $58,2 \%$ de los encuestados considera imperiosa una reforma del mantenimiento de los parques y jardines. Esta demanda tan mayoritaria tiene su explicación en los desperfectos que sufren actualmente las zonas 
verdes, tanto en materia de equipamientos como de arbolado, ya que más de un treinta por ciento de los encuestados mencionó alguna de estas dos cuestiones. Una quinta parte de los usuarios sugirió la necesidad de mejorar los equipamientos de los espacios verdes, ya sea porque sufren desperfectos o porque no hay suficientes para satisfacer las necesidades de todos los que acuden habitualmente. Aunque no se pueden cuantificar, parece que las quejas de la mayor parte de los ciudadanos no van dirigidas a los responsables municipales en la gestión de los parques y jardines, sino que se centran en la actitud irrespetuosa de algunos usuarios, lo que incluso motivó que un 4\% de los encuestados exigiera una mayor vigilancia en las áreas verdes con el fin de reducir el vandalismo, el deterioro y la inseguridad generada por el comportamiento de unos pocos. A este respecto conviene apuntar una de las conclusiones a las que llegaron Segovia y Neira (2005) en su estudio de los espacios públicos urbanos de la ciudad de Santiago de Chile, que es compartida también por Santana et al. (2009): es necesario que la vigilancia de los espacios verdes se lleve a cabo por parte de los mismos usuarios, fomentando el autocontrol y evitando una sobreprotección de las autoridades locales. Esta idea fue expresada por las personas entrevistadas al afirmar que cuando un parque no cuenta con suficientes usuarios, se convierte en un entorno repulsivo, por lo que sería interesante reflexionar sobre la importancia que a este respecto pueden llegar a tener algunos colectivos, como son las personas que pasean a sus perros. Estos usuarios visitan las zonas verdes dos o más veces al día, acudiendo incluso en horario de noche, y con su mera presencia podrían contribuir a mantener el control social de los parques, fomentando lo que las primeras autoras entienden por capital social, es decir la confianza, las normas y las redes que mejoran el funcionamiento de la sociedad. Sería importante incidir en este aspecto porque el resultado del mal uso de los espacios verdes, y sobre todo de un alto grado de vandalismo, provoca que se destine una parte importante del presupuesto manejado por la Sección de Parques y Jardines de cada ciudad a la reparación de equipamientos y a la sustitución del arbolado gravemente dañado.

Figura 5.25 ¿Qué mejorarían los usuarios en los espacios verdes de su ciudad?

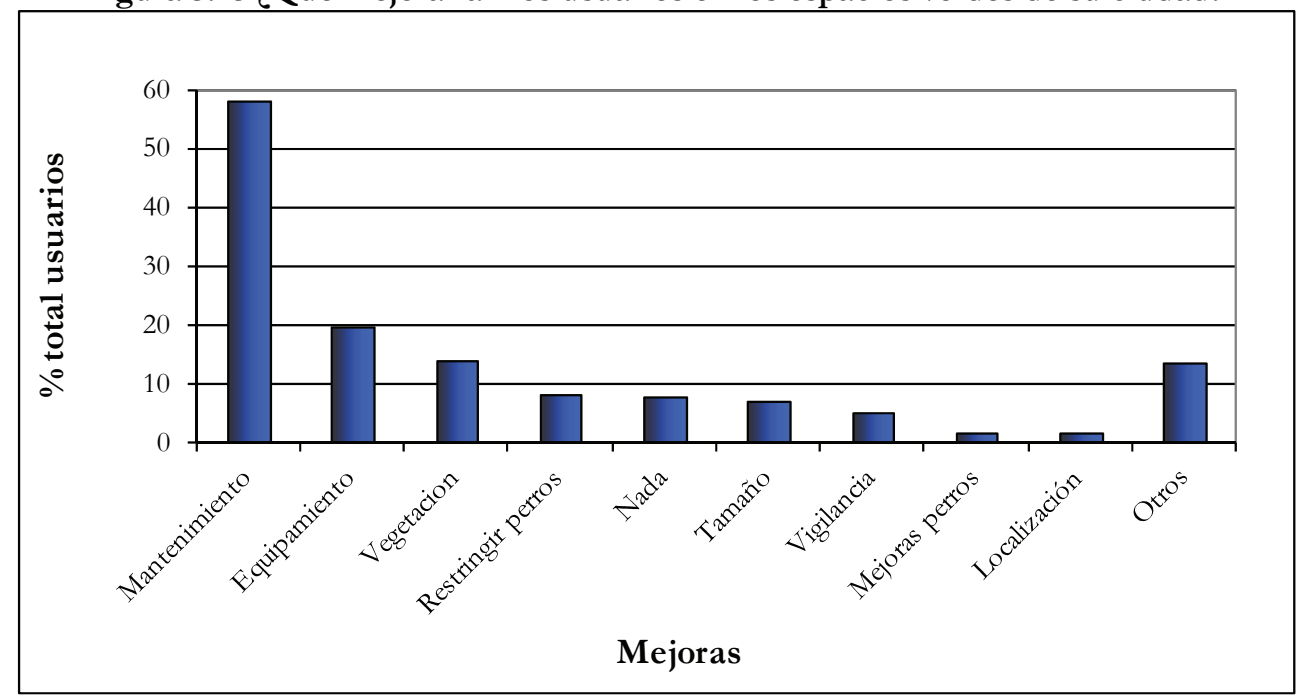

Fuente: elaboración propia.

Con el objetivo de realizar una primera aproximación a la distinta funcionalidad del verde urbano en cada ciudad, se ha creado una tipología empleando el uso que los ciudadanos hacen de cada espacio. Esta clasificación se ha realizado atendiendo a las prácticas mayoritarias mediante el análisis in situ del comportamiento de los usuarios en cada una de las ochenta y ocho áreas verdes estudiadas, generándose así las Tablas 5.18, 5.19 y 5.20, compuestas por cuatro categorías a las que se le ha asignado un color distinto. Los verdes llamados de "actividad física", son aquellos espacios en los que la actividad dominante entre 
los usuarios es la realización de deportes o de ejercicio físico, entre los que se incluyen los paseos. Han sido denominados como de "estancia" aquellos en los que las actividades mayoritarias son el descanso personal o la práctica de actividades sociales que no entrañen actividades deportivas. Aquí se incluirían los juegos infantiles, ya que se trata, en la mayoría de los casos, de sujetos que acuden a los espacios verdes para jugar y pasar un rato de ocio. La tercera categoría combina las dos anteriormente expuestas y se llama "actividad física y estancia", y en último lugar aparece la categoría de "zona de tránsito", que se refiere a los espacios que únicamente son utilizados como sitios de paso, por carecer de equipamientos o porque de ellos se hace un uso muy limitado.

Repasando las cuatro categorías definidas se observa que la mayor parte de los verdes de actividad física y estancia, y de actividad física se ubican fuera del centro histórico de las ciudades. La distribución de este tipo de parques está fuertemente condicionada por la época de construcción, ya que la práctica deportiva en espacios públicos es una actividad relativamente reciente. De este modo se explica que las áreas verdes situadas en la ciudad tradicional no cuenten con este tipo de equipamientos, ni siquiera cuando superan las diez

Tabla 5.18 Tipo de uso mayoritario de los espacios verdes de Valladolid.

\begin{tabular}{|c|c|c|c|c|c|c|}
\hline & & & \multicolumn{4}{|c|}{ Uso mayoritario de cada espacio verde estudiado } \\
\hline $\mathbf{N}^{\circ}$ & Id. & Nombre & Actividad fisica & $\begin{array}{c}\text { Actividad fisica y } \\
\text { estancia }\end{array}$ & Estancia & Zona de Tránsito \\
\hline 1 & $\mathrm{~V}-1$ & Campo Grande & & & & \\
\hline 2 & V-2 & Rosaleda Francisco Sabadell y Parque Poniente & & & & \\
\hline 3 & V-3 & Parque de las Moreras & & & & \\
\hline 4 & $\mathrm{~V}-4$ & Parque Ribera de Castilla & & & & \\
\hline 5 & V-5 & Verde urbano Camino del Cabildo & & & & \\
\hline 6 & V-6 & Jardín Botánico & & & & \\
\hline 7 & $\mathrm{~V}-7$ & Darsenas del Canal Castilla & & & & \\
\hline 8 & V-9 & Parque del Mediodía & & & & \\
\hline 9 & $\mathrm{~V}-10$ & Ladera sur Parquesol - Fuente de Dios & & & & \\
\hline 10 & V-11 & Arturo Eyries & & & & \\
\hline 11 & $\mathrm{~V}-12$ & Verde urbano Centro de Acústica (Santa Ana) & & & & \\
\hline 12 & $\mathrm{~V}-14$ & Parque de Covaresa & & & & \\
\hline 13 & V-15 & Parque de la Alameda & & & & \\
\hline 14 & V-16 & Verde urbano Avenida de los Castaños & & & & \\
\hline 15 & V-17 & Verde urbano de Valparaiso - Ronda Sur & & & & \\
\hline 16 & V-18 & Parque Arturo León & & & & \\
\hline 17 & $\mathrm{~V}-19$ & Parque de las Norias de Santa Victoria & & & & \\
\hline 18 & $\mathrm{~V}-20$ & Parque de la Paz & & & & \\
\hline 19 & $\mathrm{~V}-21$ & Parque de Canterac & & & & \\
\hline 20 & $\mathrm{~V}-22$ & Parque San Isidro - Fuente de la Salud & & & & \\
\hline 21 & $\mathrm{~V}-24$ & Verde urbano Ronda Este & & & & \\
\hline 22 & $\mathrm{~V}-25$ & Verde urbano Calle Arribes del Duero & & & & \\
\hline 23 & $\mathrm{~V}-26$ & Campus Esgueva & & & & \\
\hline 24 & $\mathrm{~V}-27$ & Campus Miguel Delibes & & & & \\
\hline 25 & $\mathrm{~V}-28$ & Paseo Zorrilla Sur & & & & \\
\hline 26 & $\mathrm{~V}-29$ & Verde urbano Cortes de Castilla y León & & & & \\
\hline 27 & $\mathrm{~V}-30$ & Verde urbano Auditorio Miguel Delibes & & & & \\
\hline 28 & $\mathrm{~V}-31$ & Verde urbano Mirador Parquesol & & & & \\
\hline 29 & $\mathrm{~V}-32$ & Verde urbano Huerta del Rey & & & & \\
\hline 30 & V-33 & Verde urbano Parquesol Calle Morelia & & & & \\
\hline 31 & V-34 & Verde urbano Parquesol Calle Juan de Valladolid & & & & \\
\hline 32 & $\mathrm{~V}-35$ & Parque del Reloj de Sol & & & & \\
\hline 33 & V-36 & Verde urbano Palacio de la Ribera & & & & \\
\hline 34 & V-37 & Ribera de Huerta del Rey & & & & \\
\hline 35 & V-38 & Verde urbano Plaza Juan de Austria & & & & \\
\hline 36 & V-39 & Verde urbano Calle Morena - Feria de Muestras & & & & \\
\hline 37 & V-41 & Ribera Pisuerga entre Pte. Colgante y Pte. Juan Austri & & & & \\
\hline 38 & $\mathrm{~V}-42$ & Plaza del Ejército & & & & \\
\hline 39 & $\mathrm{~V}-44$ & Jardines de La Victoria & & & & \\
\hline 40 & V-45 & Verde urbano Barrio de la Esperanza & & & & \\
\hline 41 & V-46 & Verde urbano Pinar de Jalón & & & & \\
\hline 42 & $\mathrm{~V}-47$ & Verde urbano Calle Vega de Valdetronco - Villas Sur & & & & \\
\hline 43 & $\mathrm{~V}-48$ & Verde urbano Escuela Deportiva Niara & & & & \\
\hline 44 & $\mathrm{~V}-49$ & Verde urbano Calle Alcaparra & & & & \\
\hline Total & & & 3 & 10 & 18 & 13 \\
\hline
\end{tabular}

Fuente: elaboración propia. 
Tabla 5.19 Tipo de uso mayoritario de los espacios verdes de Salamanca.

\begin{tabular}{|c|c|c|c|c|c|c|}
\hline \multirow[b]{2}{*}{$\mathbf{N}^{\circ}$} & \multirow[b]{2}{*}{ Id. } & \multirow[b]{2}{*}{ Nombre } & \multicolumn{4}{|c|}{ Uso mayoritario de cada espacio verde estudiado } \\
\hline & & & Actividad fisica & $\begin{array}{c}\text { Actividad fisica y } \\
\text { estancia }\end{array}$ & Estancia & Zona de Tránsito \\
\hline 1 & S-1 & Parque de Don Juan Tenorio & & & & \\
\hline 2 & S-2 & Complejo deportivo Salas Bajas & & & & \\
\hline 3 & S-3 & Jardín botánico de Huerta Otea & & & & \\
\hline 4 & S-4 & Parque de los Jesuitas & & & & \\
\hline 5 & S-5 & Jardines del Hospital Clínico & & & & \\
\hline 6 & S-7 & Verde urbano de la Vaguada de La Palma & & & & \\
\hline 7 & S-8 & Parque de Valhondo & & & & \\
\hline 8 & S-9 & Campo de San Francisco & & & & \\
\hline 9 & S-10 & Parque de la Alamedilla & & & & \\
\hline 10 & S-11 & Parque Picasso & & & & \\
\hline 11 & S-12 & Verde urbano de las Salesas & & & & \\
\hline 12 & $\mathrm{~S}-13$ & Plaza de Burgos & & & & \\
\hline 13 & S-15 & Parque de Würzburg & & & & \\
\hline 14 & S-16 & Verde urbano margen derecha Puente Romano & & & & \\
\hline 15 & S-17 & Verde urbano margen izquierda Puente Romano & & & & \\
\hline 16 & S-18 & Paseo fluvial & & & & \\
\hline 17 & S-19 & Verde urbano del entorno de Mirat & & & & \\
\hline 18 & S-20 & Parque de Ciudad Rodrigo & & & & \\
\hline 19 & $\mathrm{~S}-21$ & Parque de la Chinchibarra & & & & \\
\hline 20 & S-22 & Parque de Vistahermosa & & & & \\
\hline 21 & S-23 & Parque de Villar y Macías & & & & \\
\hline 22 & S-24 & Verde urbano de La Salle & & & & \\
\hline 23 & S-25 & Parque de El Zurguen & & & & \\
\hline 24 & S-26 & Verde urbano Av. Salamanca & & & & \\
\hline 25 & S-27 & Verde urbano de la Fac. de Comunicación & & & & \\
\hline 26 & S-28 & Parque de Bretón & & & & \\
\hline Total & & & 3 & 8 & 9 & 6 \\
\hline
\end{tabular}

Fuente: elaboración propia.

Tabla 5.20 Tipo de uso mayoritario de los espacios verdes de Zamora.

\begin{tabular}{|c|c|c|c|c|c|c|}
\hline \multirow[b]{2}{*}{$\mathbf{N}^{\circ}$} & \multirow[b]{2}{*}{ Id. } & \multirow[b]{2}{*}{ Nombre } & \multicolumn{4}{|c|}{ Uso mayoritario de cada espacio verde estudiado } \\
\hline & & & Actividad fisica & $\begin{array}{c}\text { Actividad fisica y } \\
\text { estancia }\end{array}$ & Estancia & Zona de Tránsito \\
\hline 1 & Z-1 & Parque del Castillo y de la Catedral & & & & \\
\hline 2 & $\mathrm{Z}-2$ & Verde urbano Calle de los Caballeros & & & & \\
\hline 3 & Z-3 & Parque de Olivares & & & & \\
\hline 4 & $\mathrm{Z}-4$ & Parque de la Marina & & & & \\
\hline 5 & Z-5 & Verde urbano Candelaria Ruiz del Árbol & & & & \\
\hline 6 & Z-6 & Margen derecha del Duero & & & & \\
\hline 7 & Z-9 & Bosque de Valorio (parte urbana) & & & & \\
\hline 8 & Z-10 & Parque de Peña Trevinca & & & & \\
\hline 9 & Z-11 & Jardines de la Vaguada & & & & \\
\hline 10 & $\mathrm{Z}-12$ & Verde urbano Avda. Cardenal Cisneros (Universidad) & & & & \\
\hline 11 & Z-13 & Parque de San Martín & & & & \\
\hline 12 & Z-14 & Parque de León Felipe & & & & \\
\hline 13 & Z-15 & Margen izquierda del Duero & & & & \\
\hline 14 & $\mathrm{Z}-17$ & Isla de las Pallas & & & & \\
\hline 15 & Z-18 & Jardín Carretera de la Estación & & & & \\
\hline 16 & Z-19 & Verde urbano Puerta Nueva & & & & \\
\hline 17 & $\mathrm{Z}-20$ & Verde urbano Calle Nuestra Señora de las Mercedes & & & & \\
\hline 18 & $\mathrm{Z}-21$ & Verde urbano Avda. Cardenal Cisneros (Eroski) & & & & \\
\hline Total & & & 3 & 4 & 7 & 4 \\
\hline
\end{tabular}

Fuente: elaboración propia.

hectáreas, como es el caso de Campo Grande (V-1). Sin embargo, se observa que en ocasiones sí aparecen equipamientos deportivos en espacios recuperados en los centros históricos, especialmente en el entorno de los ríos, como ocurre en el verde urbano de Puerta Nueva (Z-19), que tiene una extensión inferior a una hectárea y está situado en el borde del centro histórico de Zamora, o en el Parque de las Moreras (V-3), situado en la orilla izquierda del Pisuerga. El resto de zonas verdes consideradas de actividad física, o de actividad física y estancia, están ubicadas en espacios periféricos debido al gran tamaño que normalmente ocupan. Por su parte, las zonas de tránsito se dividen mayoritariamente entre las que no tienen suficiente entidad para ser consideradas como zonas de estancia y entre las estructuradas en torno a una vía de comunicación, las denominadas calles arboladas, por lo 
que el usuario no consigue aislarse del resto de la ciudad, ni alcanzar un sentimiento de libertad. Este último caso es el del verde urbano del Camino del Cabildo (V-5) o del verde urbano de la Vaguada de la Palma (S-6), que al estar construidos junto a una calle con tráfico relativamente fluido, no son capaces de atraer a los suficientes usuarios como para ser considerados verdes de estancia.

\subsection{Técnica para estimar la calidad del verde urbano en las tres ciudades estudiadas}

La calidad de las zonas verdes de las tres ciudades objeto de estudio se ha estimado utilizando algunos de los elementos analizados anteriormente. Conviene recordar que en la Figura 5.12 fueron analizados los motivos que llevaron a los usuarios a visitar estos espacios y se constató que la distancia desde el lugar de residencia fue mencionada por un $65,2 \%$ de los encuestados, seguida de los equipamientos $(13,4 \%)$, el tamaño $(11,7 \%)$ y los usuarios habituales $(7,3 \%)$. La calidad recoge los elementos de un área verde que satisfacen las necesidades de los ciudadanos, mientras que la distancia supone una limitación que no influye en el disfrute o en las actividades que un visitante espera hacer en ellas. Se ha empleado una técnica de ensayo-error con la que se han probado la mayor parte de los factores que han aparecido a lo largo de este trabajo como determinantes en la percepción que los encuestados tenían de los espacios verdes. La clasificación inicial con la que parten todos ellos es de cinco puntos, ya que la existencia de un espacio arbolado en el interior de la ciudad es suficiente para que los ciudadanos le asignen una valoración inicial de aprobado. La mayor o menor nota obtenida por el verde urbano responde a los siguientes factores:

1. Tamaño: son numerosos los trabajos que afirman que los espacios verdes con una superficie más grande son capaces de atraer a una cantidad mayor de usuarios, debido a que tienen capacidad de satisfacer un mayor número de necesidades sociales. En el caso concreto de esta investigación, se ha observado que el tamaño explica casi un tercio de las puntuaciones recibidas por los treinta y nueve espacios verdes por los que se preguntó en las encuestas. Además, al ser preguntados directamente, el 11,7\% de los encuestados (129 personas) afirmó que el tamaño de las zonas verdes era el motivo que les llevaba a visitar un espacio en concreto y no otro, siendo esta la tercera mayor motivación. Utilizando como referencia los trabajos de Van Herzele y Wiedemann (2003) se ha fijado en 10 ha el límite de los grandes parques.

2. Zonas deportivas: la presencia de campos de fútbol, baloncesto o de otros deportes ha sido considerada como un factor positivo, puesto que un 13,4\% de los usuarios señaló que eran los equipamientos más utilizados. Además, un 39,7\% de los encuestados en las tres ciudades dijo acudir a las zonas verdes para realizar actividades deportivas o de paseo, siendo estas la más practicadas en estos espacios.

3. Sombras y bancos: es necesario recordar que actividades como la relajación, la meditación o el aislamiento del ambiente urbano son practicadas por el 21,9\% de los usuarios de las áreas verdes. Para relajarse harán falta, entre otros, equipamientos como bancos o zonas de sombra que son los dos elementos más utilizados por los usuarios encuestados, mencionados concretamente por 550 y 313 personas, es decir, un 54,8\% y un $31,2 \%$ de los encuestados. Como en la mayor parte de las ocasiones aparecen juntos, se ha optado por asignarle medio punto a cada uno de ellos.

4. Zonas de juego infantil: el 14,3\% de la población encuestada afirmó visitar las zonas verdes para que sus hijos o nietos utilizaran estos equipamientos. 
5. Centro histórico: su presencia responde a la evidencia de que entre los treinta y nueve verdes urbanos que fueron evaluados por los usuarios, la mayor parte de los situados en el centro de las tres ciudades recibieron una puntuación superior a la estimada, intuyendo una posible influencia fruto de su localización espacial en lugares centrales de la ciudad tradicional.

6. Falta de usuarios: algunos autores han demostrado que los espacios verdes con pocos usuarios se convierten en repelentes para algunos ciudadanos. Para determinar qué zonas verdes cuentan con estas características se ha utilizado la información proporcionada por el índice de atracción y se catalogaron como espacios con falta de usuarios a todos aquellos con un valor inferior a cero.

7. Exceso de usuarios: se ha observado que, en determinados parques de pequeño tamaño, una elevada concentración de usuarios puede derivar en conflictos por el uso de determinados equipamientos, lo que suele influir negativamente en la percepción de los encuestados. Se ha optado por utilizar también el índice de atracción para valorar los espacios verdes sobrefrecuentados, calificando negativamente a los parques con menos de 2,5 ha y con un índice mayor de cero. No se ha considerado que una zona verde tenga exceso de usuarios en los casos en los que no se consiguió entrevistar al menos a un número de usuarios igual al de encuestas previamente planificadas.

8. Inseguridad: se valoró negativamente la presencia de personas conflictivas en las áreas verdes. Como no siempre es posible identificar las situaciones de miedo y de inseguridad, se utilizó la información proporcionada por los usuarios, teniendo en cuenta únicamente aquellas situaciones que fueron mencionadas por un número significativo de personas.

9. Mantenimiento insuficiente $\mathbf{y} / \mathbf{o}$ abundancia de perros: un $58,2 \%$ de los usuarios de las tres ciudades afirmó que era necesario mejorar el mantenimiento de los parques y jardines. De manera general, se ha observado que las personas califican negativamente los espacios verdes poco mantenidos, como son los parques semiforestales o las orillas de los ríos, o que no se ajusten al modelo de jardín con césped bien cuidado. También se valoraron negativamente las zonas en las que se registró una intensa presencia de personas que pasean a sus perros dejándolos en libertad en áreas no habilitadas para ello.

Es necesario mencionar que no se tuvo en cuenta la presencia de las fuentes o de las zonas con césped, por considerar que se trata de elementos que no tienen una influencia significativa en la calificación de estos espacios. Tampoco se valoró negativamente el pequeño tamaño de algunos parques ya que se ha demostrado que, pese sus reducidas dimensiones, todo el verde urbano disponible cumple con una gran cantidad de funciones sociales.

Empleando estos parámetros se asignó una puntuación a cada uno de los espacios verdes por los que se preguntó en las encuestas realizadas en cada una de las ciudades (ver Tabla 5.21). De esta manera se obtuvo una nota estimada de la calidad que fue comparada con la media de las respuestas de los ciudadanos, calculándose posteriormente la diferencia entre la estimación y la percepción de los usuarios en cada uno de los casos. La aplicación de esta técnica ha dado como resultado unas calificaciones que mayoritariamente se ajustan a la media de las notas asignadas, existiendo un rango de error aproximado de \pm 1 punto. El promedio de la diferencia existente entre las notas estimadas y la media de las notas de cada uno de los treinta y nueve parques por los que se preguntó a los ciudadanos, es de 0,29 puntos. Las áreas verdes que presentan una mayor desviación respecto de la calificación estimada son el Parque Alameda (V-15), el verde urbano Calle Arribes del Duero (V-25), el 
verde urbano Calle Vega de Valdetronco - Villas Sur (V-47) y el Parque del Castillo y de la Catedral (Z-1). La estimación de la calidad del primero de ellos superó en casi un punto la media de las notas asignadas por los 388 vallisoletanos que valoraron este espacio verde, mientras que en los otros dos situados en la misma ciudad, la calificación estimada fue inferior a las notas asignadas, que en ambos casos se situó aproximadamente en siete puntos pese a no contar con equipamientos deportivos. Mención aparte merece el espacio verde zamorano mejor valorado, en el que están situados dos edificios de extraordinario valor histórico-artístico: la catedral y el castillo, que contribuyen a aumentar de manera considerable la calidad de dicho espacio.

La técnica empleada para valorar la calidad tiene la ventaja de que a través de variables sencillas y relativamente fáciles de obtener, se puede calcular la calificación del verde urbano disponible con un margen de error de \pm 1 punto, con una media de error de 0,29 puntos en los treinta y nueve espacios verdes seleccionados. Las Tablas 5.22, 5.23 y 5.24 fueron elaboradas aplicando la técnica anteriormente mencionada al conjunto de la trama verde de cada ciudad, y los resultados de calidad se ordenaron y se clasificaron de mayor a menor en cada caso.

Para evaluar este método es preciso reconocer que siempre se tiende a adaptar los resultados del trabajo a las hipótesis planteadas, pero en este caso se han tratado de reducir todo lo posible las interpretaciones personales del autor. Además de la limitación derivada de la utilización de unidades de 1 y de 0,5 puntos, otros factores subjetivos provocan que haya una cierta variación entre el valor estimado y la calificación por parte de los usuarios, como ocurre con percepciones tan subjetivas como la belleza, el ambiente que se respira en las zonas verdes o factores percibidos como negativos y que los encuestados no están dispuestos a reconocer, tales como los sentimientos contrarios a ciertas minorías, el racismo o simplemente la presencia de personas con las que los usuarios no se encuentran a gusto. En la Figura 5.26 aparecen representadas las respuestas de los usuarios a la pregunta de si le parecían bonitos los espacios verdes de su ciudad, observándose que en Valladolid hay una clara mayoría que los considera muy bonitos, pudiendo influir en que algunos parques de esta ciudad reciban calificaciones más elevadas de lo que en un principio podría pensarse.

Figura 5.26 ¿Le parecen bonitos los espacios verdes de su ciudad?

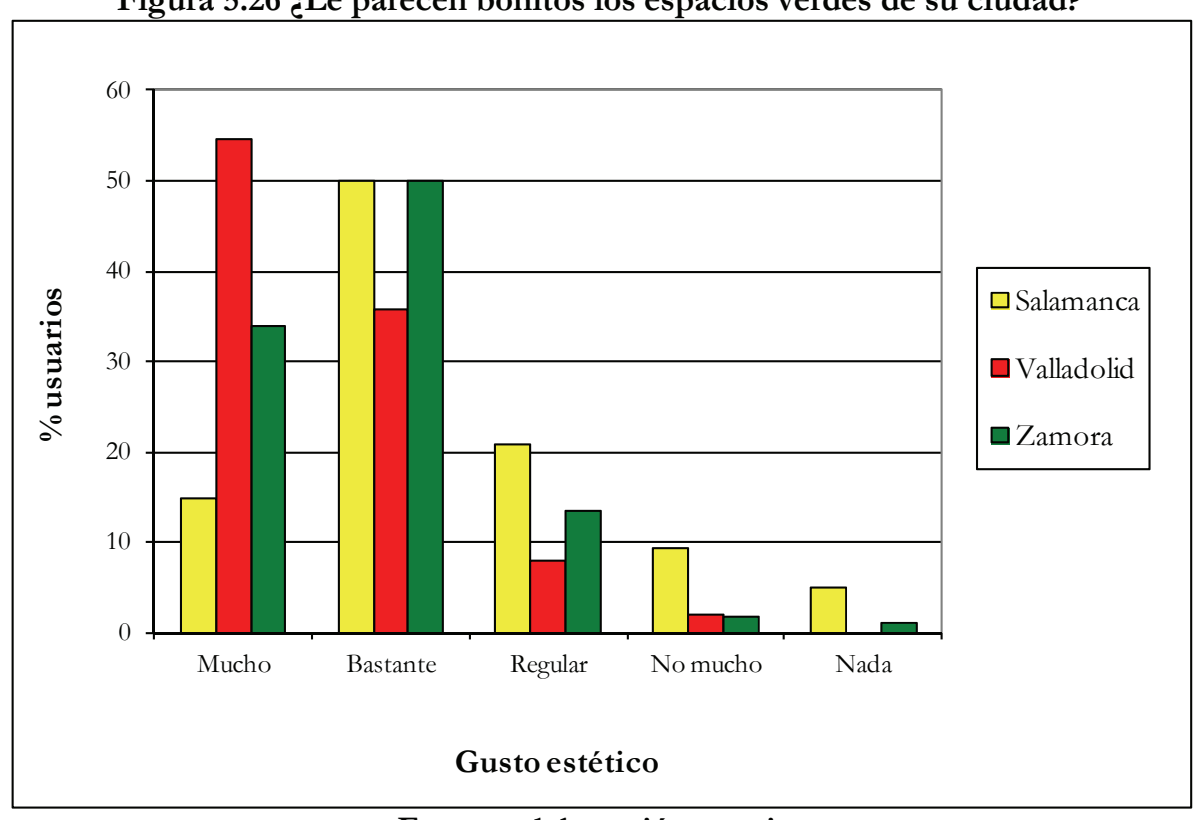

Fuente: elaboración propia. 


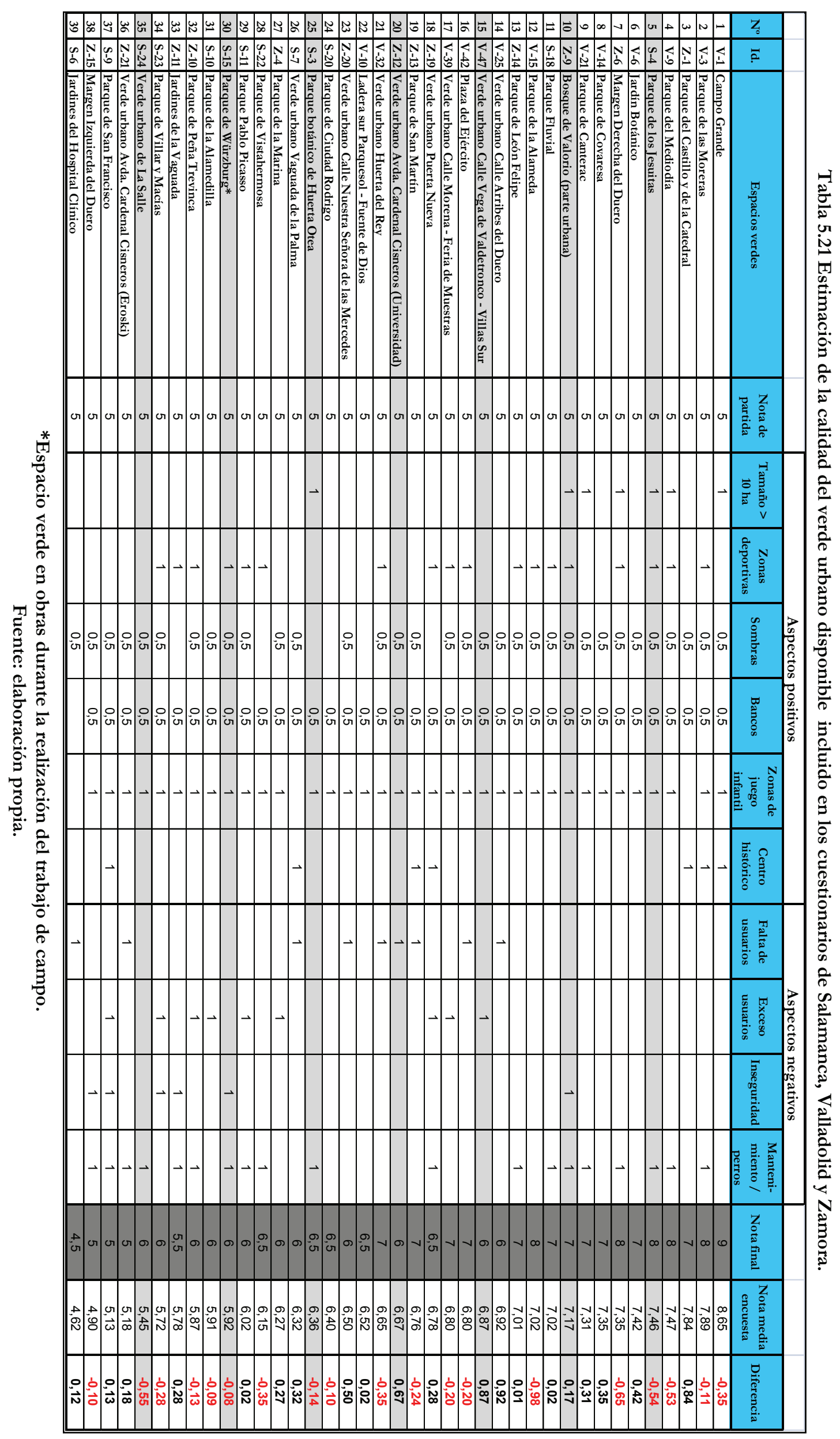




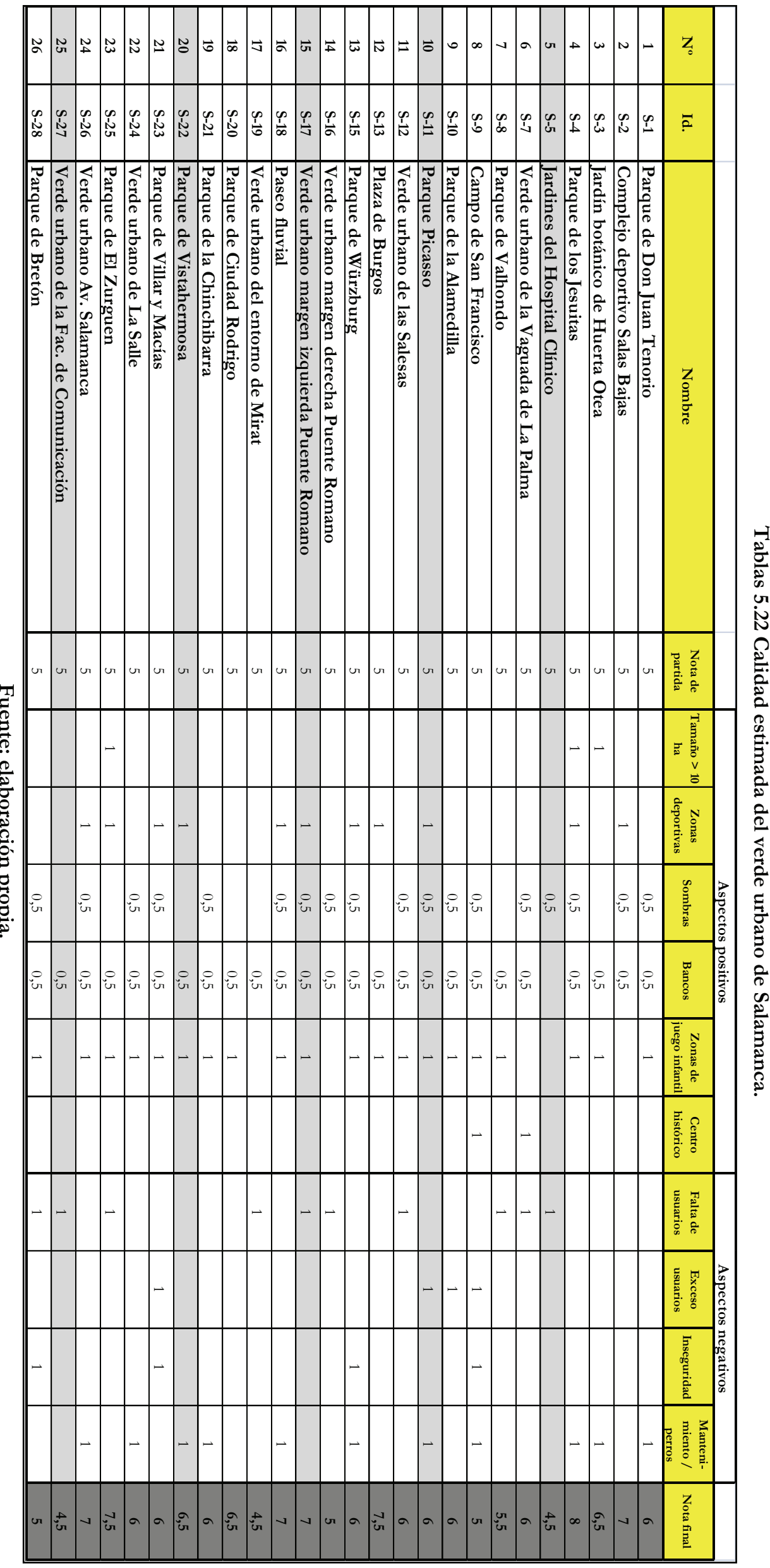




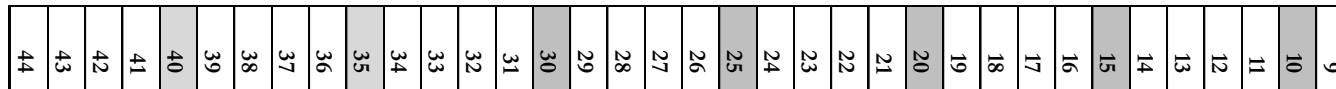

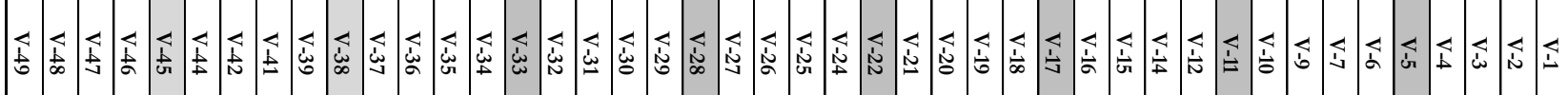

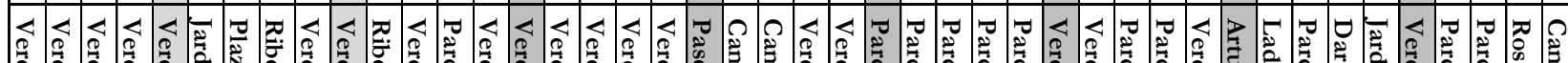

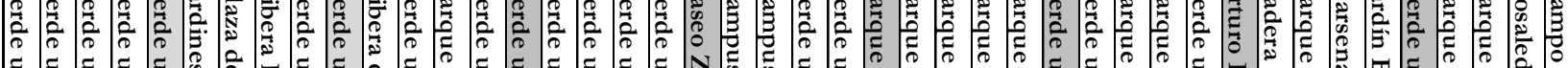

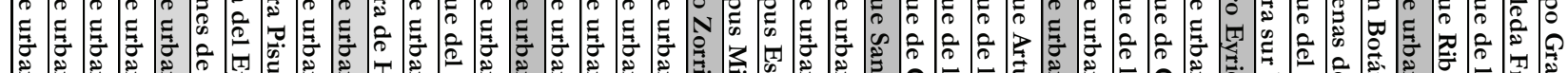

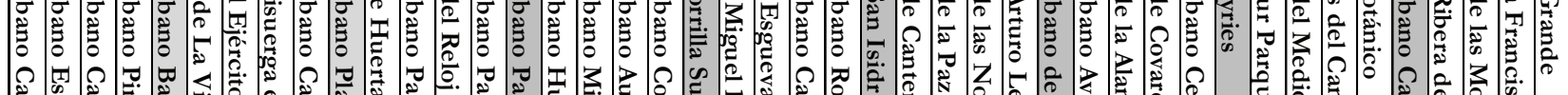

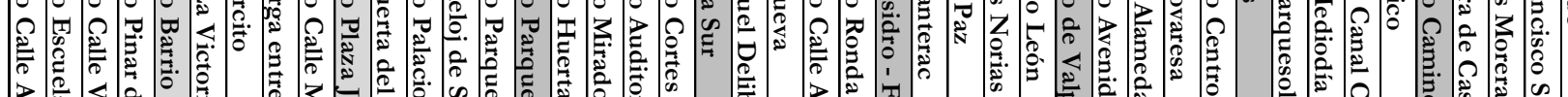

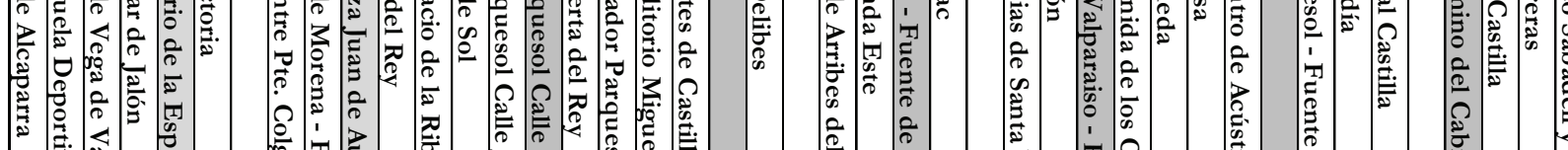

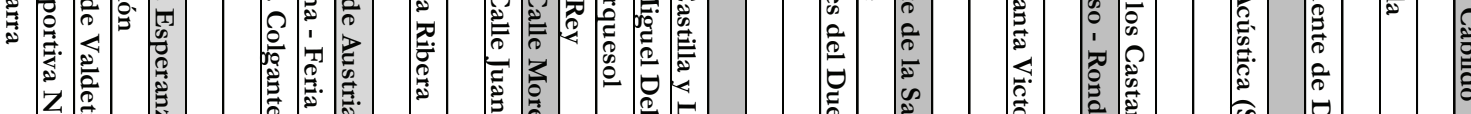

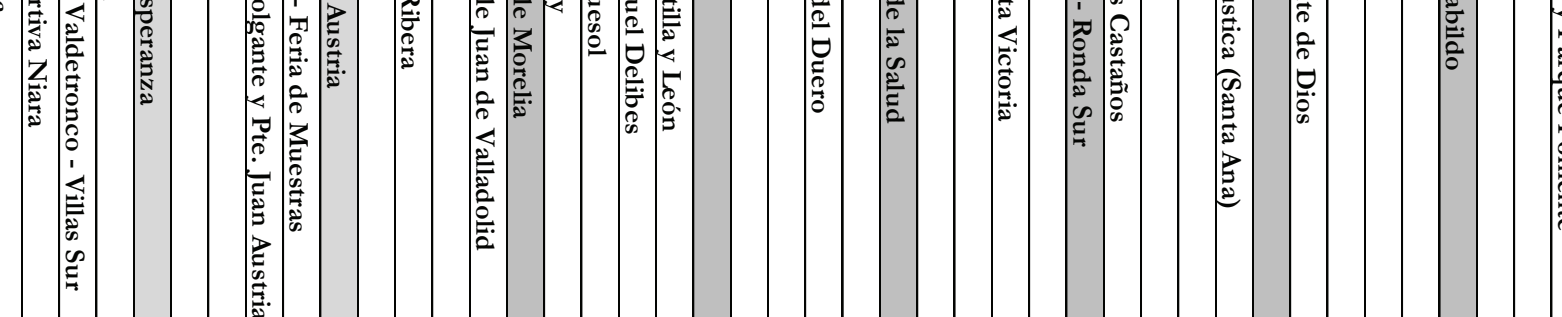

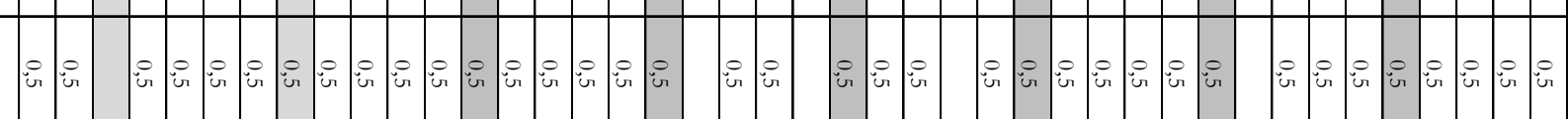

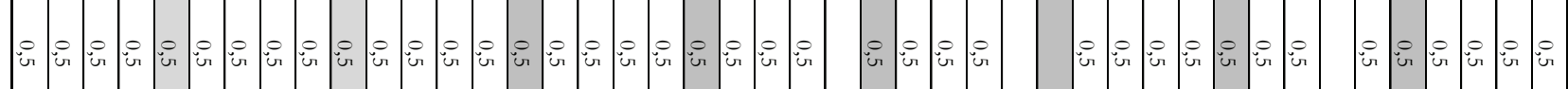

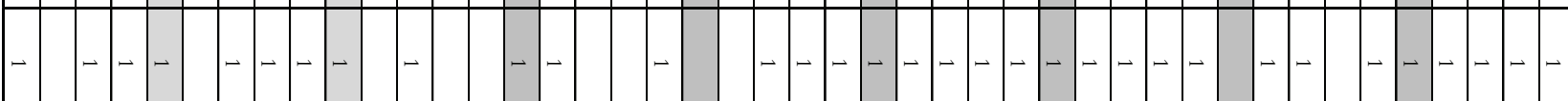
$-+-\infty$ 


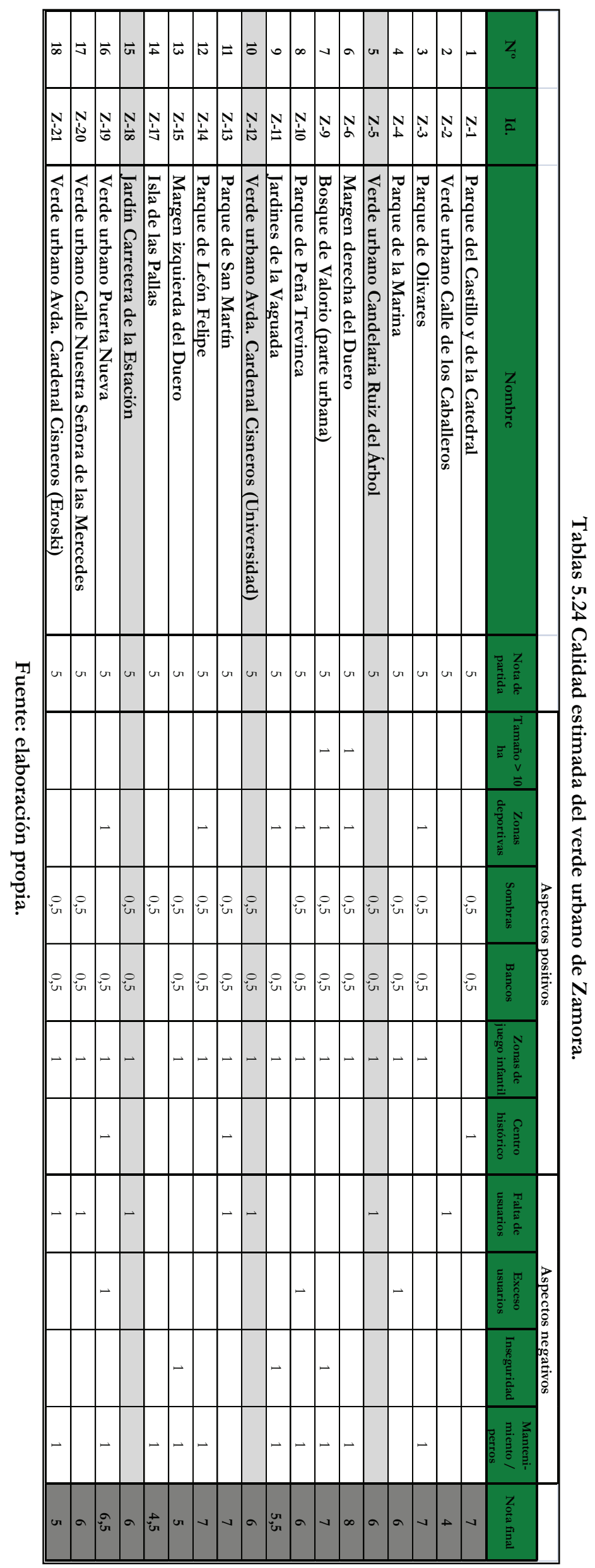


En Zamora y en Salamanca son mayoritarios los encuestados que escogieron la opción de "bastante", identificando en esta última ciudad un 14,2\% que tenía una opinión negativa acerca del aspecto del verde urbano, mientras que este porcentaje era muy minoritario en las otras dos. Esto podría influir en que algunos usuarios califique a la baja alguno de los parques seleccionados, aunque este extremo no ha sido confirmado por esta investigación. Sin embargo, existen sospechas razonables de que este y otros factores influyen de manera consciente o inconsciente en la valoración que hacen los ciudadanos de la trama verde de su ciudad. A continuación se analizó la calidad de las zonas verdes de cada una de las ciudades estudiadas, atendiendo además a su posición en la ciudad y al tipo de uso mayoritario, para finalmente tratar de obtener algunas conclusiones.

\subsubsection{Calidad del verde urbano salmantino}

El valor promedio estimado de la calidad de la trama verde salmantina es de 6,09 puntos, frente a la media de los trece espacios verdes puntuados por los usuarios, que como se vio anteriormente fue de 6,04, validando de este modo su representatividad. En la Tabla 5.25 se han ordenado las estimaciones de calidad en orden descendente, añadiendo en la última columna información sobre el uso mayoritario de cada área verde. Los tres primeros lugares del ranking están ocupados por zonas utilizadas mayoritariamente como lugares para desarrollar actividad física o de estancia, apareciendo a continuación cuatro áreas con el mismo uso o empleadas únicamente para la práctica de actividad física. Esto concuerda con las actividades realizadas por los salmantinos en estos espacios, que como se vio anteriormente, en un 39\% de los casos acudían para hacer deporte o pasear, lo que explica que los parques que cuenten con estos equipamientos se encuentren entre los mejor valorados. En el extremo contrario se encuentran las zonas de tránsito: tres de estos espacios tienen una calidad estimada de 4,5 puntos. Se trata de verdes urbanos muy diferentes que, sin embargo, tienen en común su pequeño tamaño y su ubicación en áreas de la ciudad poco pobladas. Las zonas de estancia cuentan con una puntuación hasta de 6,5 puntos y si no presentan elementos negativos siempre obtendrán una valoración igual o superior al aprobado.

En Salamanca parece existir cierta relación entre el uso mayoritario de cada espacio verde y la calidad estimada. De esta manera se podrían vincular de manera general los espacios de actividad física y estancia con un notable, o una puntuación igual o superior a siete, los de actividad física con una calificación máxima de hasta siete puntos, los de estancia con un bien, es decir, con una puntuación entre seis y seis y medio, y en último lugar, las zonas de tránsito con un aprobado. Sin embargo, son los factores negativos los que harán que la calidad de las áreas verdes descienda en mayor medida, como les ocurre a los Parques de Villar y Macías (S-23) y de Würzburg (S-15), en los que la inseguridad expresada por una parte de los usuarios encuestados derivó en un descenso de la calificación.

En la Figura 5.27 han sido representados espacialmente los valores de la Tabla 5.25, y destaca que los parques con mayor calidad, representados en colores verdes y azules, se encuentren fuera del centro histórico de la ciudad y en su mayor parte estén situados en lugares periféricos. En la primera orla o corona de crecimiento la calidad del verde urbano es bastante reducida: con la excepción del corredor fluvial y del Parque de los Jesuitas (S-4), no hay ningún espacio con una puntuación superior a seis puntos. La explicación a esta situación hay que buscarla en el periodo en el que fueron construidos la mayor parte de los barrios que componen este territorio, que se diferencian claramente de las piezas urbanas incorporadas a la ciudad desde 1984, fecha en la que comienza a ser efectivo el planeamiento urbano. Así se entiende que la mayor parte de los espacios verdes que han sido bien valorados se encuentren en la periferia de la ciudad, ya que la expansión urbana en este territorio se realizó reservando suelo para incorporar zonas verdes a las nuevas piezas urbanas. 
Tabla 5.25 Calidad del verde urbano disponible de Salamanca.

\begin{tabular}{|c|c|l|c|c|}
\hline $\mathbf{N}^{\circ}$ & Id. & \multicolumn{1}{|c|}{ Nombre } & Nota final & Uso mayoritario \\
\hline 1 & S-4 & Parque de los Jesuitas & 8 & Actividad física y estancia \\
\hline 2 & S-13 & Plaza de Burgos & 7,5 & Actividad física y estancia \\
\hline 3 & S-25 & Parque de El Zurguén & 7,5 & Actividad física y estancia \\
\hline 5 & S-17 & Verde urbano margen izquierda Puente Romano & 7 & Actividad física \\
\hline 6 & S-18 & Paseo fluvial & 7 & Actividad física \\
\hline 4 & S-2 & Complejo deportivo Salas Bajas & 7 & Actividad física \\
\hline 7 & S-26 & Verde urbano Av. Salamanca & 7 & Actividad física y estancia \\
\hline 9 & S-20 & Parque de Ciudad Rodrigo & 6,5 & Estancia \\
\hline 10 & S-22 & Parque de Vistahermosa & 6,5 & Actividad física y estancia \\
\hline 8 & S-3 & Jardín botánico de Huerta Otea & 6,5 & Estancia \\
\hline 11 & S-1 & Parque de Don Juan Tenorio & 6 & Estancia \\
\hline 13 & S-10 & Parque de la Alamedilla & 6 & Estancia \\
\hline 14 & S-11 & Parque Picasso & 6 & Actividad física y estancia \\
\hline 15 & S-12 & Verde urbano de las Salesas & 6 & Zona de tránsito \\
\hline 16 & S-15 & Parque de Würzburg & 6 & Actividad física y estancia \\
\hline 17 & S-21 & Parque de la Chinchibarra & 6 & Estancia \\
\hline 18 & S-23 & Parque de Villar y Macías & 6 & Actividad física y estancia \\
\hline 19 & S-24 & Verde urbano de La Salle & 6 & Estancia \\
\hline 12 & S-7 & Verde urbano de la Vaguada de La Palma & 6 & Zona de tránsito \\
\hline 20 & S-8 & Parque de Valhondo & 5,5 & Estancia \\
\hline 22 & S-16 & Verde urbano margen derecha Puente Romano & 5 & Zona de tránsito \\
\hline 23 & S-28 & Parque de Bretón & 5 & Estancia \\
\hline 21 & S-9 & Campo de San Francisco & 5 & Estancia \\
\hline 25 & S-19 & Verde urbano del entorno de Mirat & 4,5 & Zona de tránsito \\
\hline 26 & S-27 & Verde urbano de la Fac. de Comunicación & 4,5 & Zona de tránsito \\
\hline 24 & S-5 & Jardines del Hospital Clínico & & \\
\hline & & & & \\
\hline
\end{tabular}

Fuente: elaboración propia.

El planeamiento urbano también ha propiciado el surgimiento de pequeñas áreas verdes de baja calidad, bien por tratarse de planes parciales de pequeña entidad o por haber sido diseñadas así específicamente, como ocurre con el Parque de Bretón (S-28) o con el verde urbano de la Facultad de Comunicación (S-27). Las riberas del Tormes y del Zurguén son un caso singular porque se trata de espacios dedicados a usos diversos y que han sido progresivamente transformados en áreas verdes. El corredor verde fluvial cuenta con cuatro espacios con una calidad igual o superior a siete puntos, convirtiéndose en la mayor concentración de zonas verdes de elevada calidad: Parque del Zurguén (S-25), Margen izquierda del Puente Romano (S-17), Parque Fluvial (S-18) y Complejo deportivo Salas Bajas (S-2).

La calidad del verde urbano salmantino no supera los seis puntos debido a que los ciudadanos perciben bastantes aspectos negativos en ellos. Junto a los casos aislados en los que las labores de jardinería parecen deficientes, como ocurre en el Parque de Don Juan Tenorio (S-1), el problema del mantenimiento de las áreas verdes se inscribe dentro del proceso de deterioro que sufren bastantes espacios públicos de la ciudad. En este sentido, es poca la responsabilidad que puede achacarse a la Sección de Parques y Jardines, ya que durante el trabajo de campo se constató la intensa labor desarrollada tanto por los operarios del Ayuntamiento como por los de la empresa concesionaria del servicio de jardinería. Hay que destacar que las zonas verdes de reciente creación, es decir, aquellas creadas entre 2002 y 2007, que apenas presentan aspectos negativos, verán aumentar en breve su calificación si la situación se mantiene estable porque la vegetación todavía se encuentra en una fase inicial y los espacios con sombra son muy limitados. En cambio, los espacios de pequeñas dimensiones instalados en el centro histórico y en la primera corona, seguirán presentando factores negativos como la sobrefrecuentación, generando de esta manera una competencia por el uso de los equipamientos entre los usuarios de las diversas franjas de edad. Además 
Figura 5.27 Calidad del verde urbano disponible de Salamanca.

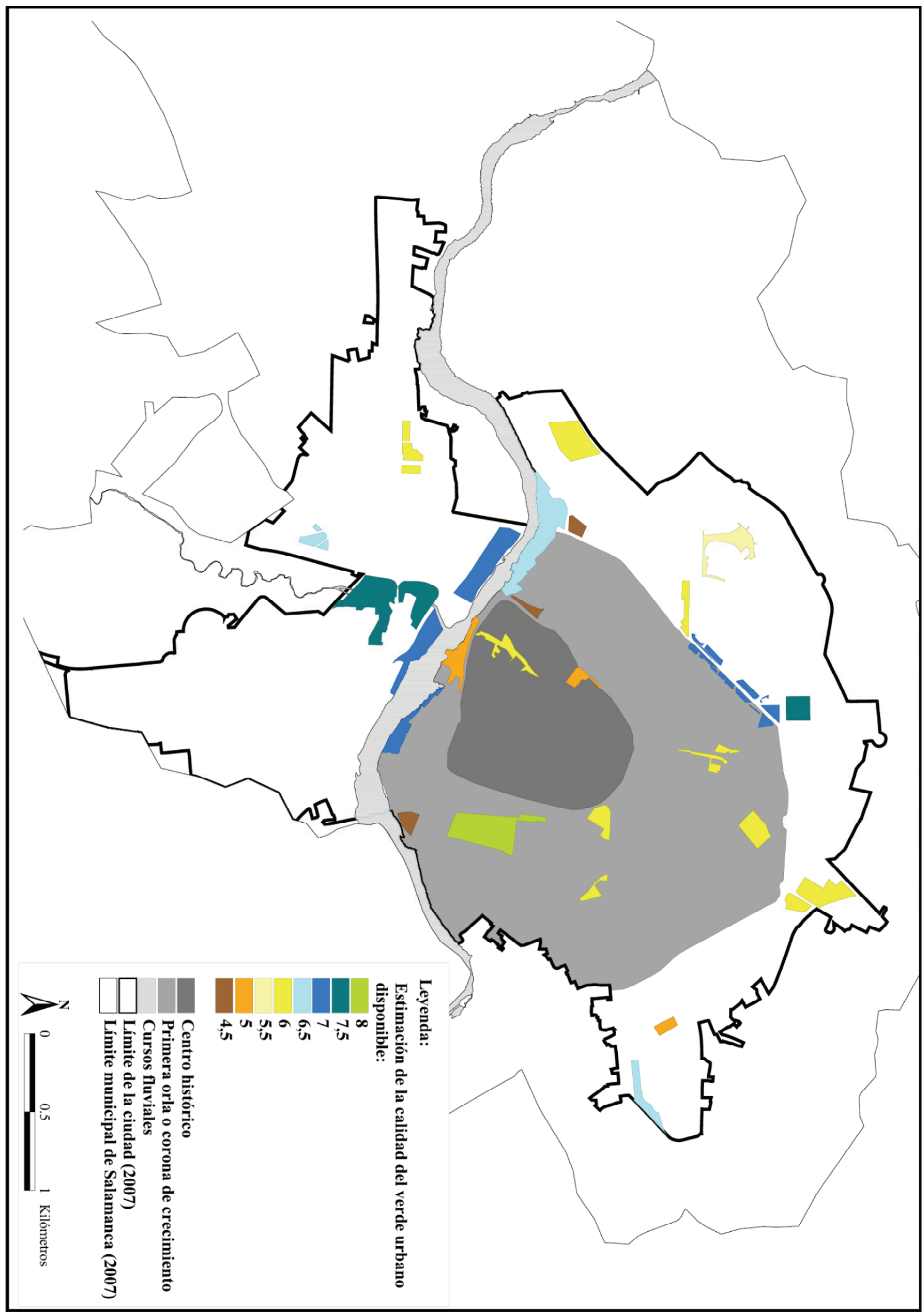

Fuente: elaboración propia a partir de la ortofoto de 2007 del IGN. 
existe una percepción generalizada de que las zonas de ribera no están bien cuidadas debido a que la vegetación crece libremente y no se eliminan las ramas caídas, ni los juncos y carrizos que crecen en las orillas, así como algunas basuras flotantes que son arrastradas por el río.

Dos aspectos concretos de difícil solución contribuyen a que la calidad de algunas de las áreas verdes de Salamanca sea más baja de lo esperado. Por una lado aparece la polémica cuestión de la presencia de perros, en la que una parte de los usuarios encuestados se siente molesto con la actitud de los dueños que llevan a sus animales a los espacios verdes para que hagan sus necesidades, en algunos casos hay quejas por dejarlos sueltos, mientras los propietarios de los perros reclaman más zonas para pasear y poder dejar libres a sus animales. Y junto a esta, aparece otra situación molesta como es la presencia notoria de usuarios que realizan actividades delictivas en algunos de los espacios verdes, como el Parque de San Francisco (S-9) y el Parque del Bretón (S-28). A este respecto cabe señalar que un 4,1\% de los encuestados aseguró utilizar estos espacios públicos para consumir alcohol y realizar "botellones", lo que confirma que una parte de los usuarios acuden específicamente al verde urbano para realizar estas actividades.

\subsubsection{Calidad del verde urbano vallisoletano}

El valor promedio de la calidad estimada en Valladolid es de 6,48 puntos, mientras que la media de las calificaciones asignadas por los usuarios a los trece espacios verdes seleccionados en la encuesta fue de 7,20. Esta diferencia muestra un pequeño desfase entre el método utilizado y la percepción ciudadana, aunque este ha permitido identificar los principales factores que se encontraban detrás de las notas asignadas. En la Tabla 5.26 han sido ordenadas las zonas verdes en función de su calidad, apareciendo entre los diez primeros lugares del ranking y con una calificación igual o superior a 7,5 puntos, ocho verdes urbanos donde se realizan actividades deportivas y dos cuyo uso mayoritario es de estancia: el Campo Grande (V-1) y la Rosaleda de Francisco Sabadell y el Parque de Poniente (V-2). Estas últimas se encuentran en el centro histórico, son dos de las más antiguas de la ciudad y además se encuentran entre las más visitadas por los vallisoletanos. En el capítulo anterior se mencionaron las importantes dotaciones en zonas verdes con las que cuenta el centro histórico, en claro contraste con la situación de los otros dos casos, y que además se vieron aumentadas con la construcción del verde urbano más grande de Valladolid, el Parque Ribera de Castilla (V-4) con 26,7 ha. Según las estimaciones realizadas este tendría la puntuación más alta de entre todos los parques y jardines analizados en esta investigación. Se trata de un lugar donde mayoritariamente se realizan actividades deportivas o de paseo, aunque también hay personas que practican juegos tradicionales como la petanca o la calva.

En la Figura 5.28 ha sido representada territorialmente la tabla mencionada, constatando que en el centro histórico están situados espacios verdes con una calidad muy alta, igual o superior a ocho puntos, mientras que los otros cuatro parques con esta puntuación se encuentran ubicados en la mitad sur de la ciudad, en zonas de expansión relativamente recientes. Además, una serie de áreas verdes de actividad física y estancia cuentan con una calificación de 6,5 o de 7 puntos debido a la reducida presencia de vigilantes naturales, como le ocurre al verde urbano de la Plaza Juan de Austria (V-38), o a una cierta sobrefrecuentación de los pequeños parques, como es el caso del verde urbano de la Calle Morena-Feria de Muestras (V-39), lo que redunda siempre en una disminución de la calidad inicialmente prevista. La zona de tránsito con mayor calidad es el verde urbano Camino del Cabildo (V-5) recientemente unido mediante una pasarela con el Parque Ribera de Castilla (V-4), lo que previsiblemente contribuirá a aumentar el número de usuarios que lo incluyan en la ruta de paseo por la concentración verde del Pisuerga en el sector norte de la ciudad.

En las orillas del río hay otras tres zonas de tránsito que presentan una baja valoración: Arturo Eyries (V-11), la ribera del Pisuerga entre el Puente Colgante y el Puente 
Juan de Austria (V-40) y la ribera de Huerta del Rey (V-37). Esta última presenta un mantenimiento muy deficiente y es percibida por los usuarios como peligrosa, ya que está situada junto a un centro de acogida y no es difícil identificar usuarios del verde urbano con comportamientos ilícitos. El resto de zonas con baja o muy baja calidad están situadas en la periferia y su uso mayoritario es de estancia o de tránsito: en el sector nororiental se encuentran el Campus Miguel Delibes (V-27) y el verde urbano Ronda Este (V-24), que son dos zonas verdes poco frecuentadas y con muy pocos equipamientos, mientras que en el sector suroccidental se identifican algunos espacios verdes con notas no muy altas en el barrio de Parquesol, así como el verde urbano de la Escuela Deportiva Niara (V-48).

Tabla 5.26 Calidad del verde urbano disponible de Valladolid.

\begin{tabular}{|c|c|c|c|c|}
\hline $\mathbf{N}^{\circ}$ & Id. & Nombre & Nota final & Uso mayoritario \\
\hline 1 & V-4 & Parque Ribera de Castilla & 10 & Actividad física \\
\hline 2 & V-1 & Campo Grande & 9 & Estancia \\
\hline 3 & $\mathrm{~V}-2$ & Rosaleda Francisco Sabadell y Parque Poniente & 8 & Estancia \\
\hline 4 & $\mathrm{~V}-3$ & Parque de las Moreras & 8 & Actividad física y estancia \\
\hline 5 & V-9 & Parque del Mediodía & 8 & Actividad física \\
\hline 6 & $\mathrm{~V}-15$ & Parque de la Alameda & 8 & Actividad física y estancia \\
\hline 7 & $\mathrm{~V}-20$ & Parque de la Paz & 8 & Actividad física y estancia \\
\hline 8 & V-26 & Campus Esgueva & 8 & Actividad física y estancia \\
\hline 9 & V-29 & Verde urbano Cortes de Castilla y León & 8 & Actividad física y estancia \\
\hline 10 & V-19 & Parque de las Norias de Santa Victoria & 7,5 & Actividad física y estancia \\
\hline 11 & V-5 & Verde urbano Camino del Cabildo & 7 & Zona de tránsito \\
\hline 12 & V-6 & Jardín Botánico & 7 & Estancia \\
\hline 13 & V-14 & Parque de Covaresa & 7 & Estancia \\
\hline 14 & $\mathrm{~V}-21$ & Parque de Canterac & 7 & Estancia \\
\hline 15 & $\mathrm{~V}-22$ & Parque San Isidro - Fuente de la Salud & 7 & Estancia \\
\hline 16 & V-32 & Verde urbano Huerta del Rey & 7 & Actividad física y estancia \\
\hline 17 & V-33 & Verde urbano Parquesol Calle Morelia & 7 & Estancia \\
\hline 18 & V-36 & Verde urbano Palacio de la Ribera & 7 & Zona de tránsito \\
\hline 19 & V-39 & Verde urbano Calle Morena - Feria de Muestras & 7 & Actividad física y estancia \\
\hline 20 & $\mathrm{~V}-42$ & Plaza del Ejército & 7 & Actividad física \\
\hline 21 & V-38 & Verde urbano Plaza Juan de Austria & 7 & Actividad física y estancia \\
\hline 22 & $\mathrm{~V}-10$ & Ladera sur Parquesol - Fuente de Dios & 6,5 & Zona de tránsito \\
\hline 23 & $\mathrm{~V}-17$ & Verde urbano de Valparaiso - Ronda Sur & 6,5 & Zona de tránsito \\
\hline 24 & $\mathrm{~V}-18$ & Parque Arturo León & 6,5 & Zona de tránsito \\
\hline 25 & $\mathrm{~V}-45$ & Verde urbano Barrio de la Esperanza & 6,5 & Actividad física y estancia \\
\hline 26 & V-49 & Verde urbano Calle Alcaparra & 6,5 & Estancia \\
\hline 27 & $\mathrm{~V}-12$ & Verde urbano Centro de Acústica (Santa Ana) & 6 & Estancia \\
\hline 28 & $\mathrm{~V}-16$ & Verde urbano Avenida de los Castaños & 6 & Estancia \\
\hline 29 & $\mathrm{~V}-25$ & Verde urbano Calle Arribes del Duero & 6 & Zona de tránsito \\
\hline 30 & $\mathrm{~V}-30$ & Verde urbano Auditorio Miguel Delibes & 6 & Estancia \\
\hline 31 & V-46 & Verde urbano Pinar de Jalón & 6 & Estancia \\
\hline 32 & V-47 & Verde urbano Calle Vega de Valdetronco - Villas Sur & 6 & Estancia \\
\hline 33 & $\mathrm{~V}-7$ & Darsenas del Canal Castilla & 5,5 & Zona de tránsito \\
\hline 34 & V-11 & Arturo Eyries & 5 & Zona de tránsito \\
\hline 35 & $\mathrm{~V}-28$ & Paseo Zorrilla Sur & 5 & Estancia \\
\hline 36 & $\mathrm{~V}-31$ & Verde urbano Mirador Parquesol & 5 & Zona de tránsito \\
\hline 37 & V-34 & Verde urbano Parquesol Calle Juan de Valladolid & 5 & Estancia \\
\hline 38 & V-35 & Parque del Reloj de Sol & 5 & Estancia \\
\hline 39 & V-41 & Ribera Pisuerga entre Pte. Colgante y Pte. Juan Austria & 5 & Zona de tránsito \\
\hline 40 & V-44 & Jardines de La Victoria & 5 & Estancia \\
\hline 41 & $\mathrm{~V}-27$ & Campus Miguel Delibes & 4,5 & Zona de tránsito \\
\hline 42 & V-48 & Verde urbano Escuela Deportiva Niara & 4,5 & Estancia \\
\hline 43 & $\mathrm{~V}-24$ & Verde urbano Ronda Este & 4 & Zona de tránsito \\
\hline 44 & V-37 & Ribera de Huerta del Rey & 4 & Zona de tránsito \\
\hline
\end{tabular}

Fuente: elaboración propia. 
Figura 5.28 Calidad del verde urbano disponible de Valladolid.

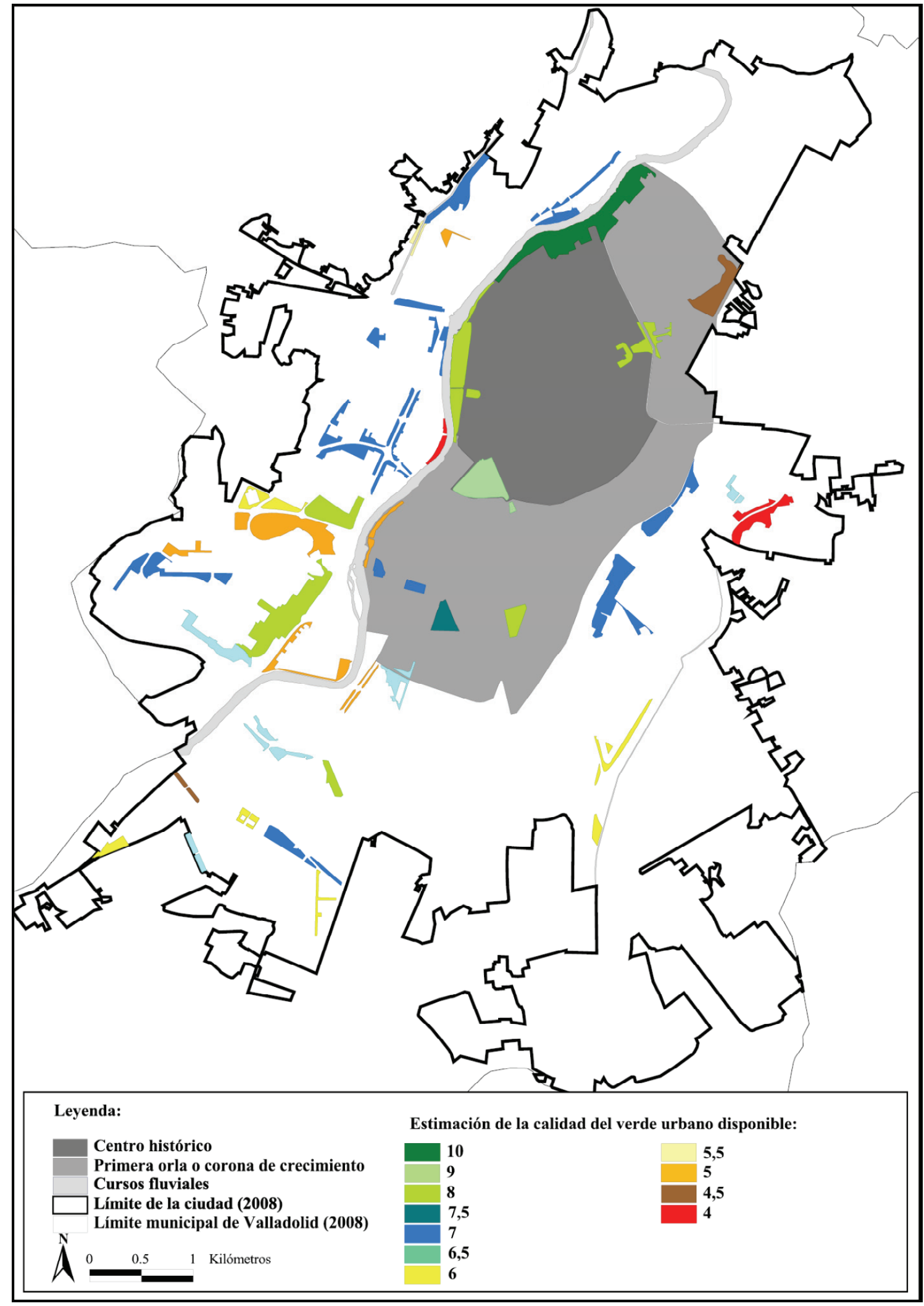

Fuente: elaboración propia a partir de la ortofoto de 2008 del IGN. 
En Valladolid también se percibe cierta relación entre calidad y el uso mayoritario de los espacios verdes, aunque existen más excepciones que en Salamanca. Las zonas de actividad física y de actividad física y estancia poseen mayoritariamente calificaciones de sobresaliente y notable, es decir, notas superiores o iguales a siete, por ser espacios muy valorados por los usuarios (el 39,9\% de los encuestados en esta ciudad dijo acudir para realizar actividades deportivas y de paseo). Por otro lado, las zonas de estancia estarían asociadas a una nota en torno al seis y medio, aumentando o disminuyendo en función de la cantidad de elementos positivos o negativos que posean, mientras que las zonas de tránsito obtendrían un aprobado, aunque aquí existen numerosas excepciones.

Curiosamente, en esta ciudad son algunos de los espacios verdes de nueva creación los que sufren una mayor sobrefrecuentación, ya que los situados en la almendra central tienen una dimensión considerable. De esta manera, algunos parques situados en nuevas piezas urbanas como el verde urbano Parquesol Calle Juan de Valladolid (V-34), el verde urbano Barrio de la Esperanza (V-45) o el verde urbano Pinar de Jalón (V-46), reciben un elevado número de visitas en áreas que no superan las 2,5 ha. A nivel general, los aspectos negativos tienen una gran influencia sobre la calificación final de los espacios verdes de Valladolid. En concreto, se han identificado varias zonas verdes que presentan un mantenimiento muy deficiente, como ocurre con el verde urbano Centro de Acústica (Santa Ana) (V-12) o con el verde urbano Mirador de Parquesol (V-31), analizados con detalle más adelante, así como algunas de reciente creación que no reciben un mantenimiento adecuado, por lo que previsiblemente la calidad disminuirá en un futuro próximo. En otros parques, la presencia de perros resulta muy molesta para los usuarios habituales, como ocurre en el Parque de las Moreras (V-3) o en el Parque de Canterac (V-21), aunque en este último haya una zona específica de grandes dimensiones para estos animales. Respecto a esta última cuestión hay que apuntar que el 7,8\% de los vallisoletanos encuestados dijo que era necesario restringir la presencia de perros en las áreas verdes, señalando además que estos animales suponían un condicionante muy importante para visitar determinados espacios. En sentido contrario, un 2,6\% de los entrevistados, compuesto mayoritariamente por dueños de perros, sugirió la necesidad de crear zonas específicas para estos animales para así poder soltarlos.

En el conjunto de parques de Valladolid, la presencia de personas con comportamientos ilícitos no fue tan notoria como en Salamanca, aunque hay que señalar que dieciocho personas $(2,8 \%$ del total de encuestados) dijeron realizar "botellones" habitualmente, lo que implica que estas zonas se convierten en espacios donde se consumen bebidas alcohólicas de forma ilegal.

\subsubsection{Calidad del verde urbano zamorano}

El promedio de la calidad estimada de los espacios verdes de Zamora es de 6,08 puntos, frente a la media de los parques por los que se les preguntó a los usuarios que fue de 6,47 , lo que implica una diferencia relativamente reducida, demostrando una notable representatividad en el conjunto de la trama verde. En la Tabla 5.27 ha sido ordenado el verde urbano zamorano en función de la calidad, distinguiendo seis espacios utilizados para la práctica deportiva entre los diez primeros lugares, ya que fue mencionada por el $40,1 \%$ de los encuestados como la actividad principal que realizan las zonas verdes. En las primeras posiciones destaca la presencia de dos áreas de estancia muy próximas entre sí que están situadas en el centro histórico: el Parque del Castillo y de la Catedral (Z-1), que fue el mejor valorado por los usuarios, y el Parque de San Martín (Z-13). En cambio, las últimas posiciones del ranking están ocupadas por zonas de tránsito, identificándose así una relación similar a la de las otras ciudades entre tipo de uso mayoritario y calidad del verde urbano. En la Figura 5.29 se ha representado la calidad en el territorio, observando fuertes contrastes entre los parques situados en las dos orillas del río. La margen derecha del Duero (Z-6) es la 
Figura 5.29 Calidad del verde urbano disponible de Zamora.

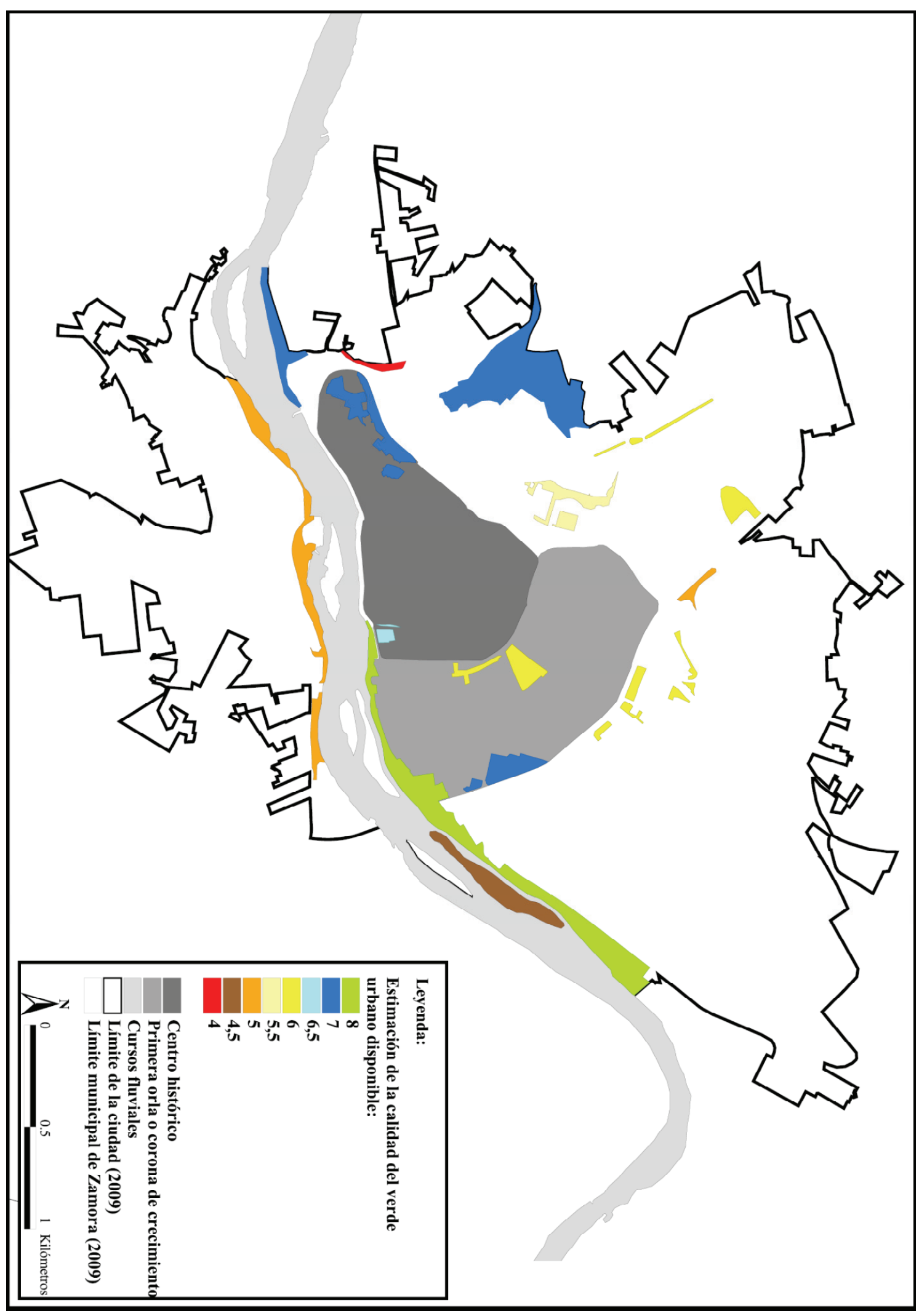

Fuente: elaboración propia a partir de la ortofoto de 2009 del IGN. 
zona verde con mayor calidad estimada y junto a ella, en dirección norte, se sitúan dos espacios verdes con una puntuación superior a 6,5 puntos. En el río se encuentra la Isla de las Pallas (Z-17), a la que se accede a través de un puente desde el parque anteriormente citado, y como se trata de un espacio donde crece vegetación de ribera de manera natural, es identificada por los usuarios como mal cuidada o con un mantenimiento deficiente.

Tabla 5.27 Calidad del verde urbano disponible de Zamora.

\begin{tabular}{|c|c|l|c|c|}
\hline $\mathbf{N}^{\circ}$ & Id. & \multicolumn{1}{|c|}{ Nombre } & Nota final & Uso mayoritario \\
\hline 1 & Z-6 & Margen derecha del Duero & 8 & Actividad física y estancia \\
\hline 2 & Z-1 & Parque del Castillo y de la Catedral & 7 & Estancia \\
\hline 3 & Z-3 & Parque de Olivares & 7 & Actividad física y estancia \\
\hline 4 & Z-9 & Bosque de Valorio (parte urbana) & 7 & Actividad física y estancia \\
\hline 5 & Z-13 & Parque de San Martín & 7 & Estancia \\
\hline 6 & Z-14 & Parque de León Felipe & 7 & Actividad física \\
\hline 7 & Z-19 & Verde urbano Puerta Nueva & 6 & Actividad física \\
\hline 8 & Z-4 & Parque de la Marina & 6 & Estancia \\
\hline 9 & Z-5 & Verde urbano Candelaria Ruiz del Árbol & 6 & Actividad física y estancia \\
\hline 10 & Z-10 & Parque de Peña Trevinca & 6 & Estancia \\
\hline 11 & Z-12 & Verde urbano Avda. Cardenal Cisneros (Universidad) & 6 & Estancia \\
\hline 12 & Z-18 & Jardín Carretera de la Estación & 6 & Zona de tránsito \\
\hline 13 & Z-20 & Verde urbano Calle Nuestra Señora de las Mercedes & 5,5 & Actividad física \\
\hline 14 & Z-11 & Jardines de la Vaguada & 5 & Estancia \\
\hline 15 & Z-15 & Margen izquierda del Duero & 5 & Zona de tránsito \\
\hline 16 & Z-21 & Verde urbano Avda. Cardenal Cisneros (Eroski) & 4,5 & Zona de tránsito \\
\hline 17 & Z-17 & Isla de las Pallas & 4 & Zona de tránsito \\
\hline 18 & Z-2 & Verde urbano Calle de los Caballeros & & \\
\hline
\end{tabular}

Fuente: elaboración propia.

En la ciudad de Zamora ha sido donde más claramente se ha observado el sentimiento contrario al libre funcionamiento de los ecosistemas naturales o semi-naturales, tanto en las riberas, con la Margen izquierda del Duero (Z-15) y la isla mencionada, como en la parte urbana del Bosque de Valorio (Z-9), donde se observó un aparente rechazo a la gestión actual, tan contraria al modelo tradicional de jardín con césped, que permite el libre crecimiento de plantas y la no recogida de materia vegetal en descomposición. El sector occidental de la ciudad concentra cuatro espacios verdes con una calidad estimada de siete puntos, junto a los que aparece el verde urbano Calle de los Caballeros (Z-2) que es el peor valorado, aunque en un futuro está llamado a conectar el Bosque de Valorio (Z-9) con el Duero, por lo que su calidad podría llegar a aumentar. En torno a las avenidas Cardenal Cisneros y de Portugal-Ronda de la Feria, límites de la primera orla o corona de crecimiento de Zamora, se sitúan hasta ocho áreas verdes de pequeñas dimensiones que tienen una calidad de entre cinco y seis puntos debido a que presentan elementos negativos de algún tipo: exceso de usuarios, como el Parque de la Marina (Z-4), ausencia de los mismos, Jardín Carretera de la Estación (Z-18), un mantenimiento deficiente, Parque de Peña Trevinca (Z10) e incluso problemas relacionados con la seguridad, Jardines de la Vaguada (Z-11).

En esta ciudad no se percibe que exista un serio conflicto originado por la presencia de perros en las zonas verdes puesto que únicamente el 4,8\% de los encuestados se quejó por este motivo, pero se observa que al igual que en las otras dos ciudades analizadas, en estos espacios una pequeña parte de los encuestados realiza actividades ilícitas, ya que un 3,8\% de los mismos dijo acudir a ellos para beber alcohol.

\subsubsection{Reflexiones sobre la calidad del verde urbano}

Tras analizar las zonas verdes de las tres ciudades se ha observado que, de manera general y con algunas excepciones significativas, existe una relación entre la calidad y el uso que de ellas hacen la mayoría de los ciudadanos. En todos los casos aparecen espacios 
dedicados a la práctica deportiva en los primeros lugares del ranking, ya que como se mostró en la Figura 5.8, el 39,7\% de los usuarios encuestados dijo que esta era la motivación principal para visitar las zonas verdes. De esta manera, en Castilla y León se identifica el verde urbano como lugar para la práctica deportiva, frente a otros países europeos donde se prefiere acudir a recintos cerrados como gimnasios o pabellones para hacer deporte. En el extremo contrario se sitúan las zonas de tránsito, que ocupan habitualmente los últimos lugares, destacando en esta categoría el tipo de verde diseñado en torno a una vía de comunicación y que no conseguiría aislar al ciudadano de los ruidos de la ciudad, ni le permitirá alcanzar un sentimiento de libertad. Sin embargo, este tipo de espacios, llamados también calles arboladas, han sido señalados como una intervención con cierto interés en un momento de crisis como el actual, aunque sean los menos visitados por la población. Madureira (2012) destaca las ventajas que presentan: se trata de una actuación fácilmente adaptable a la ciudad porque aprovecha la retícula urbana y además, puede aumentar la percepción de la estructura verde, consolidando parques existentes.

Se han observado contrastes muy fuertes en la situación de los centros históricos de las tres ciudades. Valladolid y Zamora poseen parques con una calidad muy alta en el interior de la ciudad tradicional, entre los que se encuentran los tres que recibieron mejor calificación por parte de los más de mil entrevistados, mientras que en el centro de Salamanca ningún espacio verde superó los seis puntos.

En cuanto a los ríos, se ha mencionado en numerosas ocasiones que constituyen uno de los ejes verdes más importantes de la estructura verde de cada ciudad y en ellos se encuentran situadas áreas con una calidad muy elevada junto a otras con calificaciones más reducidas. En todas las ciudades se ha constatado un sentimiento contrario a la existencia de bosques de ribera, ya que son numerosas las críticas sobre el aspecto que presentan los ríos en algunos tramos donde se combina la presencia de plantas acuáticas con el crecimiento no controlado de árboles y de arbustos. Para conseguir aumentar la puntuación que le dan los ciudadanos a las zonas verdes semi-forestales habría que solucionar estos problemas, pero tal vez fuera más interesante realizar una labor de formación mediante carteles u otros medios en los que se informase sobre el funcionamiento de los ecosistemas forestales y de ribera, y sobre la vegetación que llevan asociados. Esta preferencia tan marcada por una naturaleza domesticada, que no solo se evidencia en las riberas sino que se observa especialmente en la baja puntuación recibida por el Bosque de Valorio (Z-9), muestra una predilección por un tipo de parque con césped bien cuidado, cercano al modelo de jardín francés típico del barroco, caracterizado por el trazado geométrico y cuyo mejor exponente se encuentra en Versalles (Batlle, 2011). Frente a este control absoluto de la naturaleza existe otro modelo de jardín, propio de la Inglaterra victoriana del siglo XVIII, en el que se imitan los paisajes próximos buscando incluir la naturaleza en el interior de las ciudades y que, aparentemente, no está muy arraigado en la sociedad castellano-leonesa.

En general se puede afirmar que el mantenimiento de las zonas verdes que realizan los ayuntamientos de las ciudades estudiadas es relativamente bueno, aunque ya se apuntó en el capítulo anterior que las consecuencias de la crisis económica están comenzando a sentirse también en la gestión de los parques y jardines. Sin embargo, es necesario reflexionar sobre el hecho de que un $58,2 \%$ de los encuestados piense que esta labor no es suficiente y que habría que mejorarla, especialmente cuando se ha constatado in situ el buen estado que presenta la mayor parte del verde urbano analizado. Dentro del mantenimiento habría que incorporar los desperfectos causados por los propios usuarios, incluso en la vegetación, la acumulación de basuras cuando se realizan "botellones" u otras actividades ilícitas y también la presencia de excrementos caninos que no son recogidos por algunos de los dueños de los perros. En este sentido hay que señalar que un $8,4 \%$ de los encuestados se quejaron de la presencia de perros que se mueven libremente por los parques realizando sus necesidades sin control de sus dueños, lo que afectó gravemente a la calidad de alguno de los espacios verdes que más 
visitan estos animales, como son el Parque de los Jesuitas (S-4) o el Parque de Canterac (V21). La inseguridad en el verde urbano es un tema mencionado por el $6 \%$ de los encuestados en Salamanca y en Valladolid, mientras que este no fue un aspecto que los encuestados en Zamora consideren necesario mejorar.

Esta investigación ha permitido identificar las zonas verdes como lugares donde se realizan actividades ilícitas como el consumo de alcohol, que fue mencionado por un 13,6\% del total de usuarios menores de treinta años. La realización de "botellones" en el interior de los parques genera un sentimiento repulsivo para el resto de usuarios durante la celebración de esta actividad y durante el día siguiente, ya que la basura generada tiene que ser retirada por los servicios de limpieza, contribuyendo así a acentuar la necesidad de mejora del mantenimiento. Para evitar estos comportamientos sería necesaria la intervención de profesionales del gobierno local para tratar de ayudar a esas personas y así lograr una cierta integración de todos los usuarios de los espacios verdes.

Uno de los problemas más graves y de más difícil solución a los que se enfrentan algunas de las áreas verdes de menor tamaño es la sobrefrecuentación, que provoca una competencia por el uso del espacio entre los usuarios. El ejemplo más evidente es el salmantino Parque de la Alamedilla (S-10), que con sus 2,2 ha es el que presenta un índice de atracción más elevado de la ciudad de Salamanca, debido a que se encuentra situado junto al centro histórico, en un sector de la ciudad muy densamente poblado. La solución a este problema pasaría por crear nuevos espacios verdes en las cercanías de aquellos que presenten estos problemas, lo que resulta extremadamente difícil en zonas urbanas consolidadas, especialmente en un contexto económico como el actual.

\subsection{Espacios verdes más frecuentados: síntesis de la calidad y de la distancia desde el lugar de residencia}

En el punto 5.2 se identificó claramente el motivo principal que llevó a los usuarios encuestados a visitar una zona verde y no otra: la distancia desde el lugar de residencia, mencionada por 720 personas, esto es un $65,2 \%$ del total. Sin embargo, el concepto de calidad utilizado en esta investigación integra otros aspectos que también son determinantes para los ciudadanos, como los equipamientos $(13,4 \%)$, el tamaño $(11,7 \%)$, el tipo de usuarios habituales $(7,3 \%)$, la vegetación $(6,3 \%)$ y el mantenimiento $(4,9 \%)$. Sumando todos estos aspectos se obtendría un elevado porcentaje de las respuestas a la pregunta anteriormente referida $(43,7 \%)$, por lo que podría pensarse que la distancia y la calidad son los mayores condicionantes de las visitas a los espacios verdes, llegando a ser más importante la última en el caso de Zamora (volver a la Figura 5.12).

Con el objetivo de identificar qué factor tiene más influencia en cada caso concreto, se analizó el índice de atracción de cada espacio verde, cuyo cálculo fue detallado en el capítulo número dos (ver punto 2.6.5). El resultado de aplicar este índice a los ochenta y ocho verdes urbanos disponibles se puede observar en la Tabla 5.28, donde aparecen colocados en orden descendente. Los primeros lugares del ranking están ocupados mayoritariamente por las zonas verdes de alta calidad (nota igual o superior a siete), pero llama la atención que en tres de las cinco últimas posiciones aparezcan espacios verdes que tienen una calidad estimada de siete puntos. Es probable que la proximidad desde el lugar de residencia sea el factor principal para explicar la elevada frecuentación de algunos verdes urbanos de poca calidad situados en barrios muy poblados, como ocurre en los casos del Parque de la Alamedilla (S-10), del Parque de la Marina (Z-4) o de la Ladera Sur de Parquesol - Fuente de Dios (V-10), que se encuentran entre los quince más visitados por los usuarios que han participado en esta investigación. En cambio, las áreas verdes con una calidad bastante elevada pero que se encuentran alejadas de los grandes contingentes poblacionales presentan una frecuentación muy débil. Tal es el caso de la margen izquierda del Puente Romano (S-16) 
y del Parque del Zurguén (V-25) en Salamanca, situados al sur del río Tormes en una zona poco poblada y que pese a contar con una calidad igual o superior a siete puntos, ocupan un lugar entre los diez espacios verdes menos atractivos de esta investigación. En esta situación se encuentran también los vallisoletanos verde urbano Camino del Cabildo (V-5) y verde urbano de Valparaíso - Ronda Sur (V-17), así como el zamorano Parque de San Martín (Z13). Este último caso es muy llamativo: es una zona verde ubicada en un pequeño barrio densamente poblado, como es el Casco Antiguo (1), y sin embargo registra pocas visitas. Podría deberse a que está situado junto al límite occidental de la ciudad y entre dos espacios verdes muy frecuentados, el Bosque de Valorio (Z-9) y el Parque del Castillo y de la Catedral (Z-1), por lo que tres zonas verdes próximas podrían estar compitiendo por el mismo público.

En cada ciudad se ha clasificado el verde urbano en función del índice de atracción para así poder identificar rápidamente los espacios verdes más visitados. Los valores obtenidos han sido agrupados utilizando una medida de posición como son los quintiles, de tal manera que se han generado cinco categorías con intervalos diferentes pero que agrupan a un número similar de espacios verdes. Junto a esta información aparecen unas columnas en color rosa en las que se expresa la calidad estimada, manteniendo de fondo una capa referente a la densidad de población de los barrios. Como información adicional se ha añadido una trama rayada con la que aparece representada la parte de la ciudad que no posee acceso a las zonas verdes.

\subsection{1 Índice de atracción en el verde urbano salmantino}

Los espacios verdes de Salamanca que presentan un índice de atracción más elevado aparecen representados en la Figura 5.30 en color rojo y se encuentran situados en las proximidades del límite oriental del centro histórico, con la excepción del Parque de Villar y Macías (S-23). El más atractivo es el Parque de la Alamedilla (S-10), que con sus 2,2 hectáreas de extensión y una calidad estimada de seis puntos, es el más conocido por los usuarios encuestados (fue puntuado por un $97,4 \%$ ). Se trata de un parque situado en una de las zonas más densamente pobladas de la ciudad y a diferencia del Parque Picasso (S-11), que posee un índice de atracción sensiblemente menor, se encuentra junto a una de las arterias que se dirige hasta el centro de la ciudad.

Por su parte, el Parque de los Jesuitas (S-4) es el espacio que recibe más visitas. Cuenta con una gran extensión, una calidad estimada de ocho puntos y un emplazamiento a menos de 800 metros del barrio del Centro, lo que explica el gran número de personas que lo frecuentan. El Paseo Fluvial (S-18) es el único verde urbano situado en la vega del Tormes, se encuentra entre los más visitados y posiblemente sea el preferido por los salmantinos para acercarse al río. Los tres parques mencionados hasta ahora dentro de la categoría de más visitados se encuentran situados junto al centro histórico, en una parte de la ciudad muy poblada, y son espacios verdes consolidados, es decir, tienen más de treinta años y poseen una estructura vegetal robusta.

La última zona verde que compone esta categoría es el Parque de Villar y Macías (S23), construido hace menos de quince años, pero al igual que las otras, está situada junto a barrios muy densamente poblados. Otros espacios verdes que reciben más visitas de las que cabría esperar son el Campo de San Francisco (S-9), situado en el interior de la cerca medieval y que posiblemente no sea visitado por un mayor número de usuarios debido a la notoria presencia de personas con vicios ilícitos durante la mayor parte del día, y el ya mencionado Parque Picasso (S-11), que se encuentra en el sector centro-oriental de la ciudad, entre barrios muy densamente poblados. Junto con el Parque de la Alamedilla (S-10), estos dos últimos casos reflejan la importancia de la distancia desde el lugar de residencia a la hora de realizar las visitas. En ocasiones un pequeño verde urbano es el único situado a menos de 
Tabla 5.28 Índice de atracción del verde urbano de las ciudades de Salamanca, Valladolid y Zamora.

\begin{tabular}{|c|c|c|c|c|c|c|c|c|c|}
\hline $\mathrm{N}^{\circ}$ & Id. & ha & Nombre & \begin{tabular}{r|}
$\begin{array}{l}\text { Encuestas } \\
\text { asignadas }\end{array}$ \\
\end{tabular} & \begin{tabular}{|l|}
$\begin{array}{l}\text { Encuestas } \\
\text { realizadas }\end{array}$ \\
\end{tabular} & $\begin{array}{c}\begin{array}{c}\text { Porcentaje } \\
\text { de éxito }\end{array} \\
\end{array}$ & \begin{tabular}{c|} 
Visitas \\
realizadas
\end{tabular} & \begin{tabular}{|l|}
$\begin{array}{l}\text { indice de } \\
\text { atracción }\end{array}$ \\
\end{tabular} & \begin{tabular}{|c|}
$\begin{array}{c}\text { Calidad } \\
\text { estimada }\end{array}$ \\
\end{tabular} \\
\hline 1 & $\mathrm{Z}-6$ & 16,5 & Margen derecha del Duero & 42 & 42 & 100,0 & 88 & 24,73 & 8 \\
\hline 2 & V-1 & 12,7 & Campo Grande & 33 & 35 & 106,1 & 157 & 18,86 & 9 \\
\hline 3 & Z-9 & 16,5 & Bosque de Valorio (parte urbana) & 42 & 44 & 104,8 & 69 & 13,44 & 7 \\
\hline 4 & $\mathrm{~V}-3$ & 9,5 & Parque de las Moreras & 24 & 24 & 100,0 & 107 & 12,83 & 8 \\
\hline 5 & s-10 & 2,2 & Parque de la Alamedilla & 6 & 6 & 100,0 & 31 & 9,23 & 6 \\
\hline 6 & $\mathrm{Z}-15$ & 8,3 & Margen izquierda del Duero & 21 & 21 & 100,0 & 38 & 9,14 & 5 \\
\hline 7 & S-4 & 10,1 & Parque de los Jesuitas & 26 & 39 & 150,0 & 63 & 8,86 & 8 \\
\hline 8 & $\mathrm{~V}-4$ & 26,7 & Parque Ribera de Castilla & 68 & 72 & 105,9 & 122 & 7,73 & 10 \\
\hline 9 & $\mathrm{~V}-2$ & 4,6 & Rosaleda Francisco Sabadell y Parque Poniente & 12 & 13 & 108,3 & 62 & 7,57 & 8 \\
\hline 10 & V-9 & 21,0 & Parque del Mediodia & 54 & 55 & 101,9 & 100 & 6,96 & 8 \\
\hline 11 & Z-14 & 3,0 & Parque de León Felipe & 8 & 8 & 100,0 & 18 & 5,38 & 7 \\
\hline 12 & $\mathrm{Z}-4$ & 2,2 & Parque de la Marina & 6 & 6 & 100,0 & 15 & 4,84 & 6 \\
\hline 13 & S-23 & 1,6 & Parque de Villar y Macías & 4 & 4 & 100,0 & 16 & 4,43 & 6 \\
\hline 14 & V-14 & 5,3 & Parque de Covaresa & 14 & 17 & 121,4 & 45 & 4,33 & 7 \\
\hline 15 & $\mathrm{~V}-10$ & 6,6 & Ladera sur Parquesol - Fuente de Dios & 17 & 21 & 123,5 & 48 & 4,17 & 6,5 \\
\hline 16 & S-18 & 3,1 & Paseo fluvial & 8 & 14 & 175,0 & 24 & 3,69 & 7 \\
\hline 17 & $\mathrm{v}-29$ & 9,0 & Verde urbano Cortes de Castilla y León & 23 & 30 & 130,4 & 53 & 3,55 & 8 \\
\hline 18 & $\mathrm{v}-20$ & 3,9 & Parque de la Paz & 10 & 14 & 140,0 & 36 & 3,40 & 8 \\
\hline 19 & s-11 & 1,0 & Parque Picasso & 3 & 3 & 100,0 & 11 & 2,95 & 6 \\
\hline 20 & S-9 & 1,3 & Campo de San Francisco & 3 & 3 & 100,0 & 11 & 2,95 & 5 \\
\hline 21 & $\mathrm{~V}-15$ & 2,4 & Parque de la Alameda & 6 & 4 & 66,7 & 22 & 2,78 & 8 \\
\hline 22 & Z-19 & 0,6 & Verde urbano Puerta Nueva & 1 & 1 & 100,0 & 6 & 2,69 & 6,5 \\
\hline 23 & $\mathrm{z}-1$ & 1,9 & Parque del Castillo y de la Catedral & 5 & 3 & 60,0 & 7 & 2,15 & 7 \\
\hline 24 & $\mathrm{~V}-31$ & 15,4 & Verde urbano Mirador Parquesol & 39 & 3 & 7,7 & 16 & 2,01 & 5 \\
\hline 25 & $\mathrm{~V}-6$ & 7,0 & Jardín Botánico & 18 & 22 & 122,2 & 34 & 1,85 & 7 \\
\hline 26 & S-1 & 5,8 & Parque de Don Juan Tenorio & 15 & 4 & 26,7 & 9 & 1,85 & 6 \\
\hline 27 & $\mathrm{~V}-19$ & 4,4 & Parque de las Norias de Santa Victoria & 11 & 10 & 90,9 & 21 & 1,70 & 7,5 \\
\hline 28 & Z-10 & 1,9 & Parque de Peña Trevinca & 5 & 6 & 120,0 & 9 & 1,61 & 6 \\
\hline 29 & $\mathrm{Z}-3$ & 3,4 & Parque de Olivares & 9 & 11 & 122,2 & 14 & 1,61 & 7 \\
\hline 30 & s-13 & 2,7 & Plaza de Burgos & 7 & 7 & 100,0 & 10 & 1,11 & 7,5 \\
\hline 31 & $\mathrm{v}-30$ & 4,8 & Verde urbano Auditorio Miguel Delibes & 12 & 8 & 66,7 & 15 & 1,08 & 6 \\
\hline 32 & $\mathrm{~V}-34$ & 2,5 & Verde urbano Parquesol Calle Juan de Valladolid & 7 & 7 & 100,0 & 14 & 1,08 & 5 \\
\hline 33 & $\mathrm{v}-35$ & 2,0 & Parque del Reloj de Sol & 5 & 5 & 100,0 & 12 & 1,08 & 5 \\
\hline 34 & Z-17 & 5,0 & Isla de las Pallas & 13 & 14 & 107,7 & 16 & 1,08 & 4,5 \\
\hline 35 & $\mathrm{~V}-46$ & 1,5 & Verde urbano Calle Vega de Valdetronco - Villas Sur & 4 & 4 & 100,0 & 10 & 0,93 & 6 \\
\hline 36 & $\mathrm{v}-22$ & 5,9 & Parque San Isidro - Fuente de la Salud & 15 & 15 & 100,0 & 20 & 0,77 & 7 \\
\hline 37 & $\mathrm{~V}-44$ & 1,6 & Verde urbano Barrio de la Esperanza & 4 & 4 & 100,0 & 9 & 0,77 & 6,5 \\
\hline 38 & s-20 & 2,7 & Parque de Ciudad Rodrigo & 7 & 4 & 57,1 & 6 & 0,74 & 6,5 \\
\hline 39 & S-2 & 7,4 & Complejo deportivo Salas Bajas & 19 & 20 & 105,3 & 22 & 0,74 & 7 \\
\hline 40 & $\mathrm{~V}-38$ & 1,7 & Verde urbano Calle Morena - Feria de Muestras & 4 & 4 & 100,0 & 8 & 0,62 & 7 \\
\hline 41 & Z-18 & 0,9 & Jardin Carretera de la Estación & 2 & 0 & 0,0 & 1 & 0,54 & 6 \\
\hline 42 & $\mathrm{v}-50$ & 1,4 & Verde urbano Plaza Juan de Austria & 3 & 0 & 0,0 & 3 & 0,46 & 7 \\
\hline 43 & $\mathrm{~V}-43$ & 1,2 & Jardines de La Victoria & 3 & 3 & 100,0 & 6 & 0,46 & 5 \\
\hline 44 & $\mathrm{~V}-21$ & 12,2 & Parque de Canterac & 31 & 35 & 112,9 & 38 & 0,46 & 7 \\
\hline 45 & S-15 & 6,0 & Parque de Würzburg & 15 & 15 & 100,0 & 16 & 0,37 & 6 \\
\hline 46 & S-24 & 1,9 & Verde urbano de La Salle & 5 & 5 & 100,0 & 6 & 0,37 & 6 \\
\hline 47 & S-26 & 4,3 & Verde urbano Av. Salamanca & 11 & 13 & 118,2 & 14 & 0,37 & 7 \\
\hline 48 & $\mathrm{~V}-47$ & 1,2 & Verde urbano Escuela Deportiva Niara & 3 & 3 & 100,0 & 4 & 0,15 & 4,5 \\
\hline 49 & $\mathrm{~V}-45$ & 1,6 & Verde urbano Pinar de Jalón & 4 & 5 & 125,0 & 6 & 0,15 & 6 \\
\hline 50 & $\mathrm{~V}-12$ & 2,4 & Verde urbano Centro de Acústica (Santa Ana) & 6 & 2 & 33,3 & 2 & 0,00 & 6 \\
\hline 51 & S-22 & 1,6 & Parque de Vistahermosa & 4 & 3 & 75,0 & 3 & 0,00 & 6,5 \\
\hline 52 & S-21 & 3,0 & Parque de la Chinchibarra & 7 & 7 & 100,0 & 7 & 0,00 & 6 \\
\hline 53 & $\mathrm{~V}-18$ & 3,9 & Parque Arturo León & 10 & 10 & 100,0 & 10 & 0,00 & 6,5 \\
\hline 54 & $\mathrm{~V}-40$ & 2,4 & Ribera Pisuerga entre Pte. Colgante y Pte. Juan Austria & 6 & 6 & 100,0 & 6 & 0,00 & 5 \\
\hline 55 & $\mathrm{~V}-48$ & 1,8 & Verde urbano Calle Alcaparra & 5 & 5 & 100,0 & 5 & 0,00 & 6,5 \\
\hline 56 & Z-11 & 3,3 & Jardines de la Vaguada & 8 & 8 & 100,0 & 8 & 0,00 & 5,5 \\
\hline 57 & V-7 & 1,2 & Darsenas del Canal Castilla & 3 & 4 & 133,3 & 4 & 0,00 & 5,5 \\
\hline 58 & S-3 & 10,8 & Jardin botánico de Huerta Otea & 27 & 35 & 129,6 & 35 & 0,00 & 6,5 \\
\hline 59 & $\mathrm{~V}-33$ & 8,8 & Verde urbano Parquesol Calle Morelia & 22 & 30 & 136,4 & 30 & 0,00 & 7 \\
\hline 60 & $\mathrm{~V}-24$ & 7,4 & Verde urbano Ronda Este & 19 & 12 & 63,2 & 11 & $-0,15$ & 4 \\
\hline 61 & $\mathrm{v}-32$ & 13,8 & Verde urbano Huerta del Rey & 35 & 35 & 100,0 & 34 & $-0,15$ & 7 \\
\hline 62 & $\mathrm{v}-37$ & 1,6 & Ribera de Huerta del Rey & 4 & 5 & 125,0 & 4 & $-0,15$ & 4 \\
\hline 63 & $\mathrm{~V}-11$ & 4,7 & Arturo Eyries & 12 & 13 & 108,3 & 11 & $-0,31$ & 5 \\
\hline 64 & $\mathrm{v}-28$ & 1,6 & Paseo Zorrilla Sur & 4 & 5 & 125,0 & 3 & $-0,31$ & 5 \\
\hline 65 & $\mathrm{~V}-41$ & 1,6 & Plaza del Ejército & 4 & 8 & 200,0 & 5 & $-0,46$ & 7 \\
\hline 66 & Z-12 & 1,4 & Verde urbano Avenida. Cardenal Cisneros & 4 & 4 & 100,0 & 3 & $-0,54$ & 6 \\
\hline 67 & Z-20 & 0,9 & Verde urbano Calle Nuestra Señora de las Mercedes & 2 & 2 & 100,0 & 1 & $-0,54$ & 6 \\
\hline 68 & $\mathrm{Z}-5$ & 0,8 & Verde urbano Candelaria Ruiz del Árbol & 2 & 2 & 100,0 & 1 & $-0,54$ & 6 \\
\hline 69 & $\mathrm{v}-25$ & 4,0 & Verde urbano Calle Arribes del Duero & 10 & 10 & 100,0 & 6 & $-0,62$ & 6 \\
\hline 70 & $\mathrm{v}-26$ & 6,1 & Campus Esgueva & 16 & 16 & 100,0 & 12 & $-0,62$ & 8 \\
\hline 71 & s-19 & 1,4 & Verde urbano del entorno de Mirat & 4 & 5 & 125,0 & 3 & $-0,74$ & 4,5 \\
\hline 72 & S-28 & 1,0 & Parque de Bretón & 3 & 4 & 133,3 & 2 & $-0,74$ & 5 \\
\hline 73 & S-8 & 4,0 & Parque de Valhondo & 10 & 12 & 120,0 & 10 & $-0,74$ & 5,5 \\
\hline 74 & $\mathrm{v}-36$ & 5,0 & Verde urbano Palacio de la Ribera & 13 & 11 & 84,6 & 5 & $-0,93$ & 7 \\
\hline 75 & $\mathrm{v}-27$ & 8,8 & Campus Miguel Delibes & 23 & 25 & 108,7 & 19 & $-0,93$ & 4,5 \\
\hline 76 & $\mathrm{~V}-16$ & 1,8 & Verde urbano Avenida de los Castaños & 5 & 10 & 200,0 & 4 & $-0,93$ & 6 \\
\hline 77 & $\mathrm{Z}-2$ & 0,8 & Verde urbano Calle de los Caballeros & 2 & 2 & 100,0 & 0 & $-1,08$ & 4 \\
\hline 78 & Z-21 & 0,8 & Verde urbano Avda. Cardenal Cisneros (Eroski) & 2 & 2 & 100,0 & 0 & $-1,08$ & 5 \\
\hline 79 & V-17 & 4,3 & Verde urbano de Valparaiso - Ronda Sur & 11 & 11 & 100,0 & 4 & $-1,08$ & 6,5 \\
\hline 80 & S-25 & 13,5 & Parque de El Zurguén & 35 & 15 & 42,9 & 12 & $-1,11$ & 7,5 \\
\hline 81 & S-7 & 2,3 & Verde urbano de la Vaguada de La Palma & 6 & 10 & 166,7 & 7 & $-1,11$ & 6 \\
\hline 82 & s-12 & 1,7 & Verde urbano de las Salesas & 4 & 6 & 150,0 & 2 & $-1,48$ & 6 \\
\hline 83 & s-27 & 1,2 & Verde urbano de la Fac. de Comunicación & 3 & 10 & 333,3 & 6 & $-1,48$ & 4,5 \\
\hline 84 & $\mathrm{~V}-5$ & 5,5 & Verde urbano Camino del Cabildo & 14 & 16 & 114,3 & 6 & $-1,55$ & 7 \\
\hline 85 & s-16 & 3,6 & Verde urbano margen derecha Puente Romano & 9 & 9 & 100,0 & 4 & $-1,85$ & 5 \\
\hline 86 & S-5 & 0,8 & Jardines del Hospital Clínico & 2 & 6 & 300,0 & 1 & $-1,85$ & 4,5 \\
\hline 87 & Z-13 & 3,7 & Parque de San Martín & 9 & 10 & 111,1 & 6 & $-2,15$ & 7 \\
\hline 88 & \begin{tabular}{|l|l|} 
S-17 \\
\end{tabular} & \begin{tabular}{l|l|}
5,2 \\
\end{tabular} & Verde urbano margen izquierda Puente Romano & 13 & 12 & 92,3 & 4 & $-2,95$ & 7 \\
\hline
\end{tabular}

Fuente: elaboración propia. 
400 metros, lo que genera una elevada concentración de usuarios en determinados parques y jardines con una baja calidad. Algunas de las áreas verdes situadas en nuevas piezas urbanas presentan un índice de atracción elevado, como ocurre en el Parque de Don Juan Tenorio (S1), en la Plaza de Burgos (S-13) y en menor medida en el Parque de Ciudad Rodrigo (S-20), únicos espacios con suficiente entidad en el barrio en el que están ubicados, con una calidad igual o superior a 6,5 puntos, que previsiblemente se incrementará a medida con el paso de los años y con la consolidación de la vegetación.

Uno de los datos más destacados de esta investigación es la constatación de la poca capacidad de atracción del corredor verde del Tormes. Con la excepción del Paseo Fluvial (S18), llama la atención que los otros seis espacios que lo componen presenten índices tan bajos, contando además con una calidad que en algunos casos es muy elevada. Dos de estos poseen más de diez hectáreas, el Jardín Botánico de Huerta Otea (S-3) y el Parque del Zurguén (S-25), y este último, junto con la margen izquierda del Puente Romano (S-17), que es el verde menos frecuentado de Salamanca, poseen además equipamientos deportivos. Entre las zonas verdes menos visitadas aparecen también pequeños parques situados en las proximidades de la margen derecha del Tormes, como son el verde urbano de la Facultad de Comunicación (S-27), los Jardines del Hospital Clínico (S-5) y el verde urbano de la Vaguada de la Palma (S-7). En total suman un conjunto de ocho verdes urbanos y la explicación para el poco uso que de ellos hacen los ciudadanos habrá que buscarla en la baja densidad de población de los barrios de esta parte de la ciudad. Por consiguiente, el análisis de la calidad y del índice de atracción del verde urbano salmantino permite identificar la calidad como condición secundaria, mientras que parece que la distancia desde el lugar de residencia determina el número de visitas al verde urbano. La preeminencia de la distancia sobre la calidad queda reflejada en la situación de los espacios verdes situados en las orillas del Tormes y del Zurguén, puesto que tienen una calidad relativamente alta y sin embargo se encuentran entre las áreas verdes menos visitadas de la ciudad. También se ha constatado el mismo fenómeno pero a la inversa, esto es, que pequeños parques con reducida calidad y situados en barrios muy densamente poblados, presentan índices de atracción muy elevados, lo que redundará en una disminución de su valoración al provocar una competencia entre los ciudadanos por el uso de los pocos equipamientos y del poco espacio disponible.

Por último hay que mencionar que un $11,9 \%$ de los encuestados se refirió a alguno de los espacios verdes no incluidos en la categoría de verde urbano disponible, cuando mencionó el que más veces visitaba. Entre estos destaca el Parque de la Aldehuela con más de la mitad de las respuestas de esta categoría, seguida de la Plaza de Anaya $(21,8 \%)$ y del Huerto de Calixto y Melibea $(9,3 \%)$. El motivo por el que estos espacios fueron excluidos de este estudio, fue el incumplir alguna de las condiciones necesarias para pertenecer a la categoría de verde urbano, aunque el caso de la Aldehuela es excepcional, ya que es un espacio verde de 18,8 ha, situado dentro del municipio de Salamanca pero fuera del perímetro de lo que en esta investigación se ha considerado como ciudad, al estar situado a más de 200 metros del continuo urbano. La parcela en la que está ubicado fue anexionada en 2001 al municipio de Salamanca, habiendo pertenecido históricamente a Cabrerizos. Se trata de un parque alejado de la ciudad y una parte importante de la población utiliza un medio de transporte público o privado para acceder hasta él. Tomando como referencia la puerta más cercana a la ciudad, puesto que posee cerramiento, se ha trazado un radio de 800 metros obteniendo que solamente un $0,6 \%$ de la superficie urbana tendría acceso a este espacio verde. Es decir, tan solo 9 ha de las 1.459,7 ha totales, tendrían acceso al Parque de la Aldehuela y estarían distribuidas entre los barios de la Prosperidad (31) y del Rollo (28). Este espacio verde, más que verde urbano se podría denominar como verde periurbano o verde supramunicipal, ya que acuden usuarios tanto de Cabrerizos, como de Santa Marta o de Salamanca, aunque su gestión le corresponda al Ayuntamiento de Salamanca. 
Figura 5.30 ¿Qué parques de Salamanca son los más atractivos?

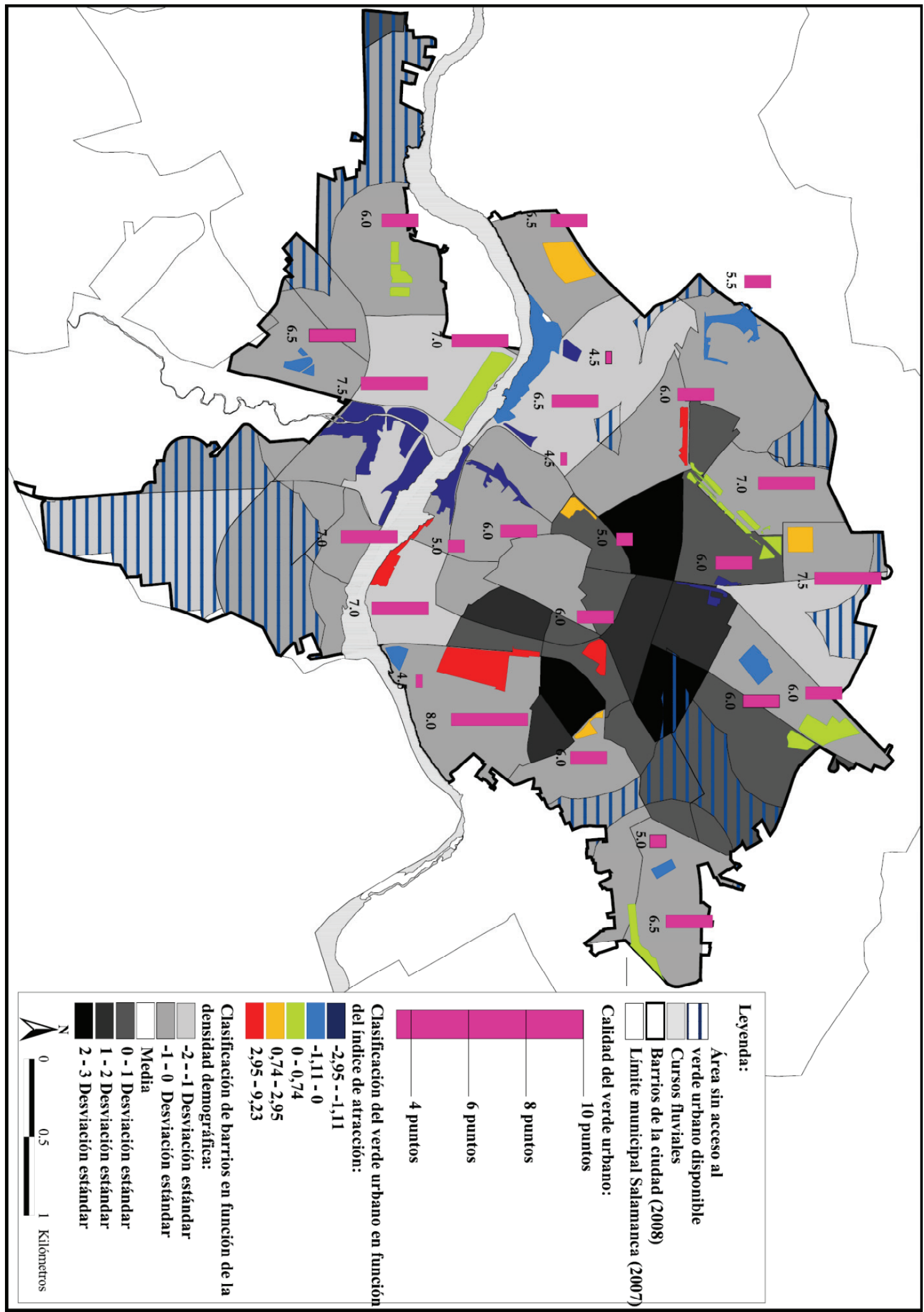

Fuente: elaboración propia a partir de la ortofoto de 2007 del IGN y del Observatorio Urbano de Salamanca. 
Pese a no haber sido incluido en la investigación, diecisiete de los encuestados dijeron acudir hasta el Parque de la Aldehuela más veces que a ninguna otra zona verde, situándose en el sexto lugar de las más visitadas de Salamanca. Esto sugiere que quizás, en futuras investigaciones, se deberían incluir aquellos espacios que pese a estar fuera del continuo urbano, tuvieran un radio de atracción que abarcase una parte de la ciudad.

\subsection{2 Índice de atracción en el verde urbano vallisoletano}

En Valladolid, los espacios verdes más atrayentes cuentan con una calidad muy elevada y varios están situados en el corredor verde fluvial (ver Figura 5.31). Concretamente, en la margen izquierda del Pisuerga se encuentran, en dirección norte-sur, el Parque de Ribera de Castilla (V-4), el Parque de las Moreras (V-3) y la Rosaleda Francisco Sabadell y el Parque de Poniente (V-2), zonas verdes que forman un continuo donde se reúnen a diario gran cantidad de usuarios, y ligeramente en dirección sureste se sitúa Campo Grande (V-1) que es el parque más visitado de la ciudad. Todos estos espacios son centenarios, presentan una calidad igual o superior a ocho puntos, se encuentran en algunos de los barrios más poblados como son la Rondilla (9) o el Paseo Zorrilla (20) y están situados en una posición central de la ciudad.

En la mitad norte del cauce urbano del Pisuerga se observa una fuerte distinción en el uso de las áreas verdes. Las situadas en la margen izquierda concentran diariamente una gran cantidad de visitas, ya que forman parte de un circuito seguido por una parte de los que acuden al verde urbano vallisoletano para hacer deporte o pasear, y como ya se apuntó al hablar de la calidad, es muy posible que en un futuro cercano esta ruta se extienda también a la otra orilla a través de un puente abierto recientemente que comunica el Parque Ribera de Castilla (V-4) con el verde urbano Camino del Cabildo (V-5), que es el espacio verde con un índice de atracción más bajo de toda la ciudad. Además de las zonas verdes mencionadas, el corredor verde fluvial está formado por otras cuatro de pequeña dimensión poco visitadas, lo que supone un enorme contraste con la situación anteriormente descrita. En la mitad occidental de la ciudad y adyacentes a la Avenida de Salamanca (límite entre los barrios 38 y 29), se encuentran situados tres de los espacios verdes más visitados por los vallisoletanos en Parquesol (38) y Girón - Villa del Prado (30), surgidos durante el proceso, relativamente reciente, de ocupación de la margen derecha del Pisuerga. Son el Parque del Mediodía (V-9), la Ladera Sur de Parquesol-Fuente de Dios (V-10) y el verde urbano de las Cortes de Castilla y León (V-29). Se trata de áreas verdes surgidas en las últimas tres décadas, cuya creación está ligada a la reserva de suelo para espacios libres públicos durante la expansión occidental de la ciudad que, como se vio en el capítulo anterior, comenzó con la aprobación de la primera fase de Huerta del Rey (21) en 1963 y se consolidó con la posterior aprobación del Plan Parcial Parquesol (38) catorce años después y del Plan Parcial Villa del Prado (30) ya en el siglo XXI.

Entre estos dos últimos barrios suman ocho verdes urbanos con una extensión total de 70,1 ha, entre los que existe una gran diferencia de calidad, especialmente en el mantenimiento. Posiblemente el espacio verde más degradado de los incluidos en esta investigación sea el verde urbano Mirador de Parquesol (V-31). Presenta una topografía con un desnivel muy pronunciado y, sorprendentemente, en su parte inferior tiene una zona de aspecto bastante atractivo donde están situados algunos equipamientos. Es en la parte superior, concretamente en su extremo occidental, donde existe una zona que presenta un deterioro muy evidente, con restos de los numerosos "botellones" y basura de todo tipo entre árboles y arbustos que crecen libremente (ver Figura 5.32). En este verde se ha registrado una situación infrecuente, puesto que se planificaron treinta y nueve encuestas de las que solamente llegaron a realizarse tres, de tal manera que la impresión percibida sobre el terreno era la de un parque muy poco atractivo. Sin embargo, de entre todas las personas encuestadas 
Figura 5.31 ¿Qué parques de Valladolid son los más atractivos?

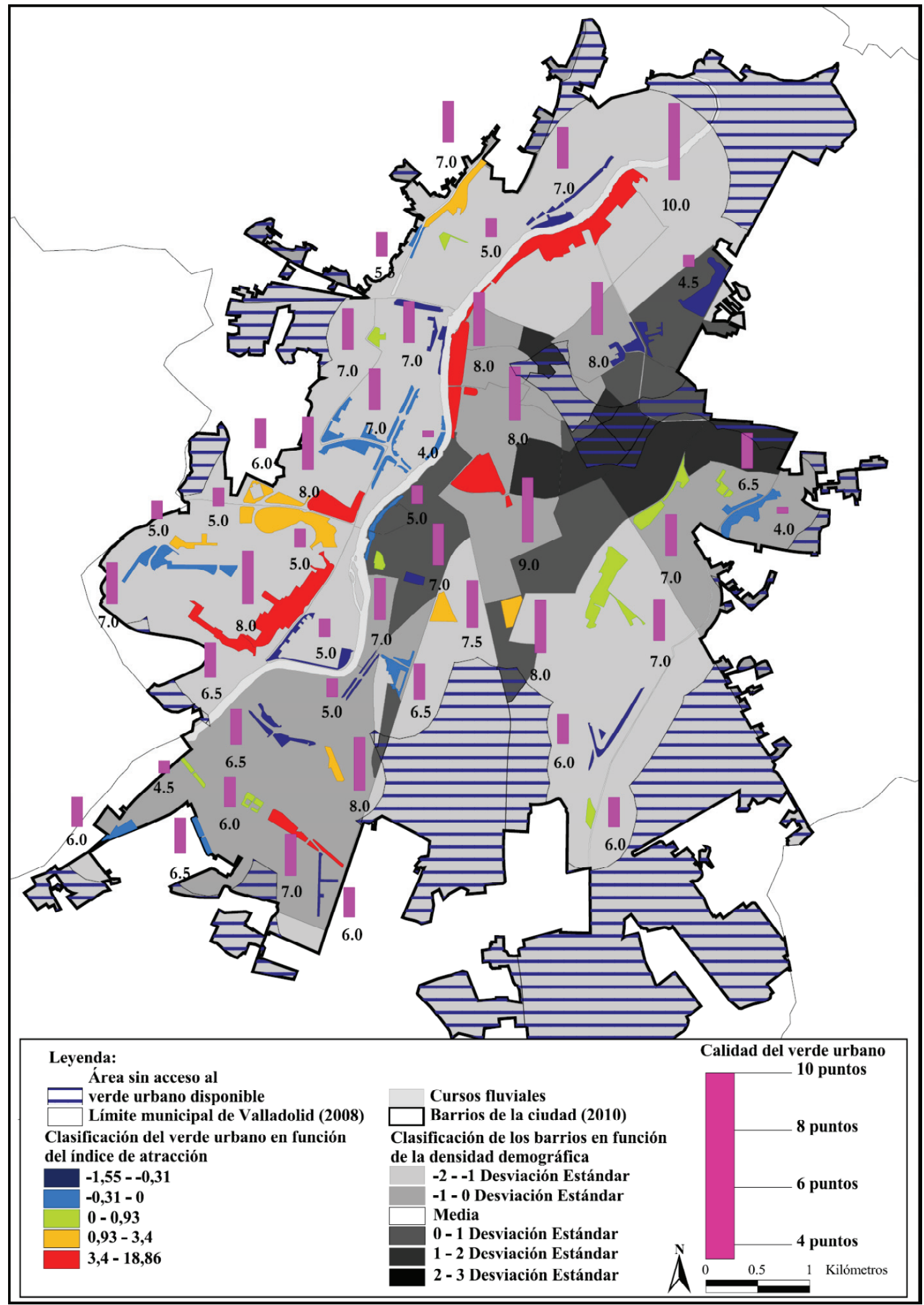

Fuente: elaboración propia a partir de la ortofoto de 2008 del IGN y del Observatorio Urbano de Valladolid. 
Figura 5.32 Contrastes en un espacio degradado: verde urbano Mirador de Parquesol (V-31).
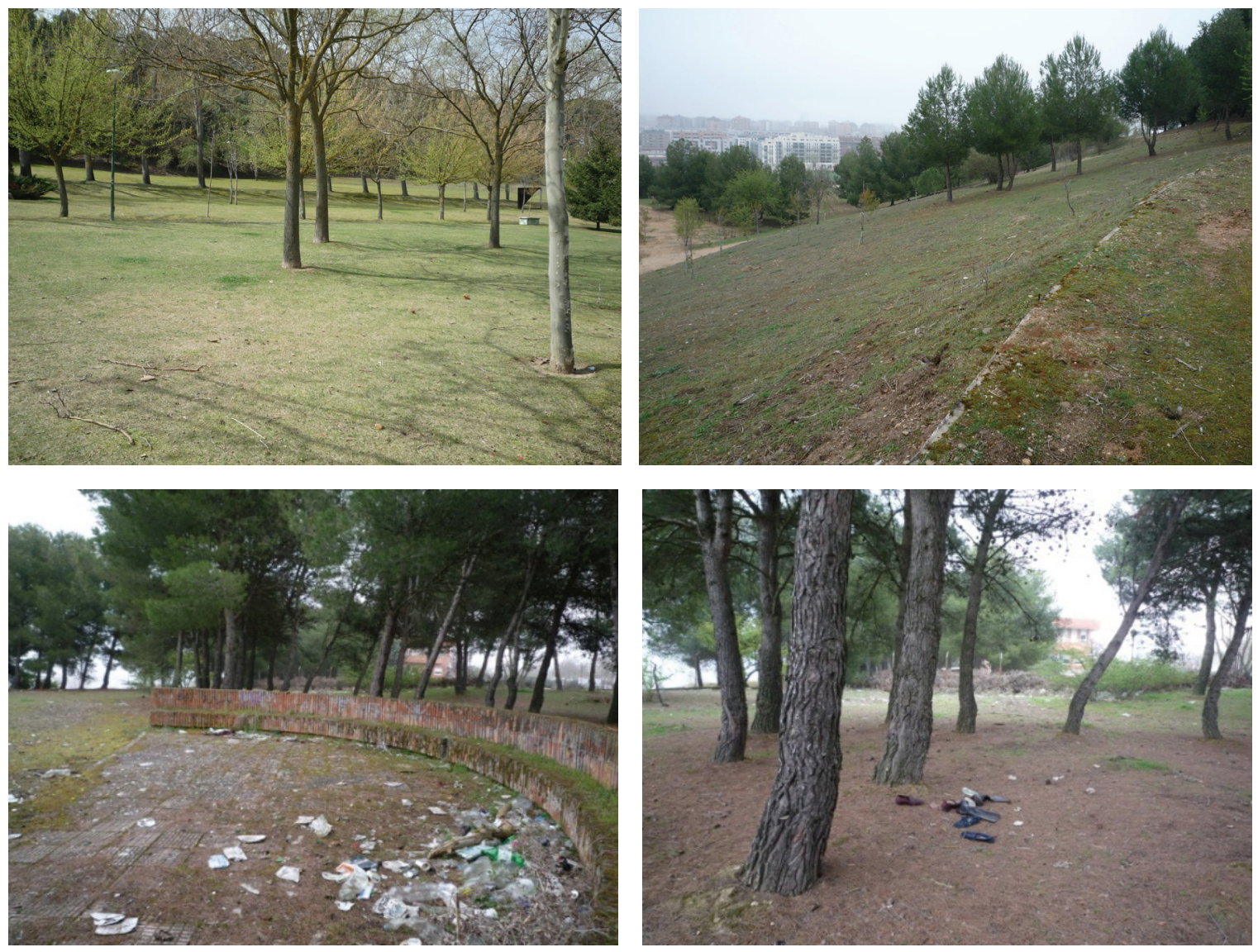

Fuente: Gómez, A. (31/3/2011).

en Valladolid dieciséis dijeron que ese era el parque que más veces visitaban y además al aplicar el índice de atracción aparece como una zona verde atractiva. De este modo se constata que las visitas realizadas a este espacio para intentar entrevistar a potenciales usuarios no coinciden con los horarios de mayor afluencia: las botellas vacías son testimonio de que este parque sí recibe uso, por lo que podría pensarse que los usuarios realizan visitas nocturnas para llevar a cabo prácticas o usos ilícitos.

El último de los espacios verdes integrado en el primer intervalo en que se ha clasificado el índice de atracción del verde urbano vallisoletano es el Parque de Covaresa (V14), situado en el cuarto barrio con más habitantes de la ciudad. Se trata de un área verde con una calidad de siete puntos localizada en una zona poblada por residentes adultos-jóvenes, donde al igual que en el Parque Alameda (V-15), es frecuente encontrar a niños jugando. El barrio de Las Villas - Cañada Puente Duero - Covaresa -Parque Alameda - Paula López (37) ha ido creciendo en dirección sur a medida que se iban aprobando los sucesivos planes parciales, en los que iban incluidas las respectivas reservas para espacios verdes públicos. En las últimas piezas urbanas anexionadas a este barrio se identifican algunos de los efectos que la crisis económica y el estallido de la burbuja especulativa del sector inmobiliario, han tenido en las zonas verdes. Los casos más llamativos son el verde urbano Centro de Acústica (Santa Ana) (V-12), el verde urbano Escuela Deportiva Niara (V-48), el verde urbano de la Vega de Valdetronco-Villas sur (V-47) y en menor medida el verde urbano de la Calle Alcaparra (V49). Todos ellos fueron creados mediante la planificación parcial en zonas en las que se iban a construir numerosas residencias y que en la actualidad cuentan, en el mejor de los casos, con muy pocos residentes. 
Esta situación no es exclusiva de esta parte de la ciudad puesto que la existencia de áreas verdes en zonas poco pobladas influye muy negativamente en su calidad, debido a que por un lado, puede aumentar la inseguridad por falta de vigilantes naturales, como ocurre en el Campus Miguel Delibes (v-27), y por otro, disminuye notablemente su mantenimiento, como por ejemplo se observa en el verde urbano Ronda Este (V-24) (ver Figura 5.33). Ambos espacios se encuentran situados en el sector nororiental de la ciudad y evidencian la fragilidad de los parques y jardines en zonas de poblamiento débil, puesto que en un contexto de reducción de los gastos en todas las administraciones públicas, el SPYJAV deja estas áreas verdes en un segundo plano, priorizando por el contrario los lugares más visitados.

Volviendo a las áreas verdes atrayentes, habrá que mencionar las que aparecen en color naranja, que están mayoritariamente situadas en la mitad sur de la ciudad. Además de las situadas en Parquesol (38) y Girón - Villa del Prado (30), que tienen una calidad bastante alta, aparecen en dirección oeste-este el Parque de la Alameda (V-15), el Parque de las Norias de Santa Victoria (V-19) y el Parque de la Paz (V-20). Todas tienen una calidad igual o superior a siete puntos y medio, un tamaño inferior a 4,5 ha y están situadas junto a algunos de los barrios más densamente poblados de la ciudad, lo que contribuye a explicar la gran afluencia de usuarios. En este mismo sector y muy próximos a las mencionadas, se encuentran una serie de verdes urbanos muy poco atrayentes y que en el mejor de los casos cuentan con una calidad de seis puntos y medio. Son el verde urbano Arribes del Duero (V16), el verde urbano de Valparaíso - Ronda Sur (V-17), el verde urbano Avenida de los Castaños (V-27), el Paseo Zorrilla Sur (V-28), el Parque de Arturo León (V-18) y del otro lado del Pisuerga, Arturo Eyries (V-11). Tienen en común su diseño en torno a ejes de comunicación, por lo que serán utilizados mayoritariamente como zonas de tránsito, debido a que su configuración no permite la separación con la ciudad y el contacto con la naturaleza.

Este es el caso también del verde urbano Huerta del Rey (V-32), construido en el barrio del mismo nombre desde mediados de los años sesenta del siglo pasado con el objetivo de romper con la forma tradicional de hacer ciudad. Se crearon de esta manera jardines y pequeños parques en torno a los bloques de viviendas y a las vías de circulación convirtiendo a este sector en uno de los mejor dotados en materia de zonas verdes. Sin embargo, el citado espacio verde, pese a estar situado en el sexto barrio más poblado de Valladolid, es uno de los menos visitados de entre los que cuentan con una extensión superior a diez hectáreas debido, posiblemente, a su falta de aislamiento del continuo urbano.

Por otra parte, el tercio oriental de la ciudad cuenta con pocas zonas verdes y con la excepción del Parque Ribera de Castilla (4), ninguna se encuentra entre las más visitadas. Realizando un análisis norte-sur se observa lo poco atrayentes que son los dos verdes urbanos de la Universidad de Valladolid, lo que resulta chocante en el caso del Campus del Esgueva (V-26), con una calidad de ocho puntos y atravesado diariamente por cientos de estudiantes. En torno a la Avenida Juan Carlos I se encuentran ubicados dos espacios verdes próximos, el Parque de Canterac (V-21) y el Parque San Isidro - Fuente de la Salud (V-22) que cuentan con una calidad de siete puntos y dan cobertura a barrios muy densamente poblados como Pajarillos Bajos (17), Pajarillos Altos (18) y Delicias (19).

Como resumen de lo mencionado hasta ahora, se observa que los espacios verdes situados junto al Pisuerga y al centro histórico son los más atrayentes de la ciudad. En el extremo opuesto se situarían una serie de zonas verdes diseñadas junto a ejes viarios, cuyo mayor exponente es el verde urbano de Huerta del Rey (V-32), que no consiguen atraer a tantos usuarios como podría pensarse atendiendo únicamente a su superficie. Un fenómeno que hasta ahora solo se ha observado en la ciudad de Valladolid es el progresivo abandono de espacios verdes diseñados y construidos en nuevas piezas urbanas que han sido dotadas de infraestructuras básicas, que en la actualidad cuentan con un escaso número de habitantes debido a que las viviendas no llegaron a venderse y en algunos casos, ni siquiera a construir- 
Figura 5.33 Espacios verdes en sectores urbanos poco poblados. E1 Campus Miguel Delibes (V-27) es poco visitado y el verde urbano Ronda Este (V-24) presenta una degradación evidente.
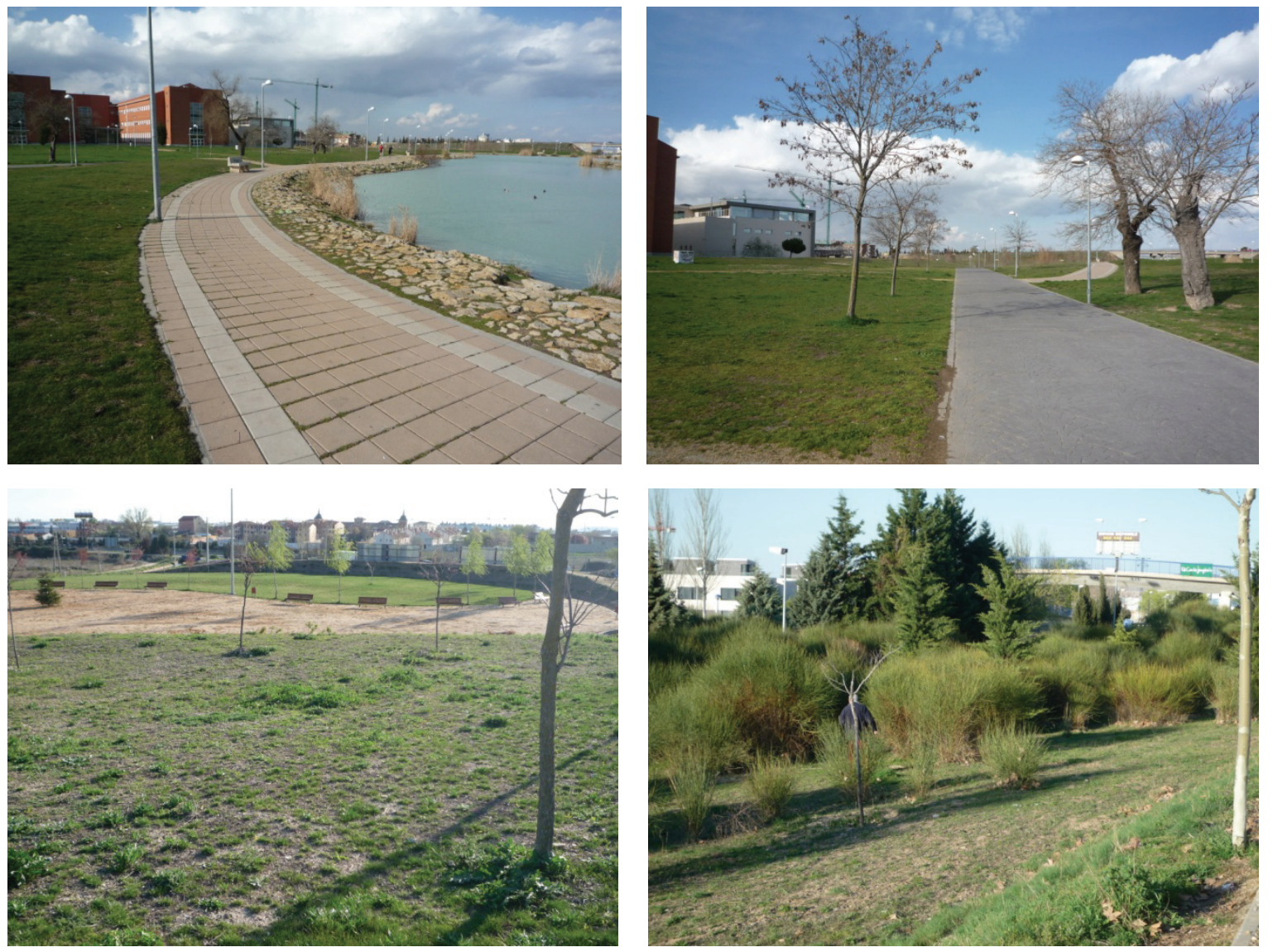

Fuente: Gómez, A. (02/04/2011).

se. Esto influye muy negativamente en la calidad de estas zonas verdes ya que hace disminuir la seguridad por la falta de usuarios y las convierte en candidatas para dejar de recibir un mantenimiento adecuado.

De los 650 usuarios encuestados en Valladolid tan solo 41, es decir, un 6,3\%, mencionaron algún espacio verde no incluido en esta investigación como el que más veces visitaban. Los citados un mayor número de veces fueron el Pinar de Antequera, con cinco menciones, el Cerro de las Contiendas y el Parque de las Flores, ambos con cuatro, y el Parque de los Bomberos y el de Santos - Pilarica, con tres. Atendiendo al ranking de zonas verdes más veces visitadas, el Pinar de Antequera aparecería en una discreta $34^{\circ}$ posición, lo que indica que los usuarios encuestados en esta ciudad visitaban mayoritariamente los espacios verdes incluidos en la categoría de verde urbano disponible.

\subsection{3 Índice de atracción en el verde urbano zamorano}

Los espacios verdes más atractivos de Zamora son los situados en las márgenes del Duero (ver Figura 5.34) y el Bosque de Valorio (Z-9), ubicado en el límite occidental de la ciudad. El corredor verde fluvial cuenta con cinco áreas verdes que tienen una calidad elevada, mientras que en el grupo de las peor valoradas destacan aquellas creadas en vacíos urbanos o en torno a las vías de comunicación. Tal es el caso de los dos verdes urbanos de la Avenida Cardenal Cisneros (Z-12 y Z-21), del verde urbano de la Calle Nuestra Señora de las Mercedes (Z-20), del verde urbano Candelaria Ruiz del Árbol (Z-5) y del verde urbano de la Calle de los Caballeros (Z-2). Estos cinco espacios tienen una extensión menor a 1,5 ha y una 
Figura 5.34 ¿Qué parques de Zamora son los más atractivos?

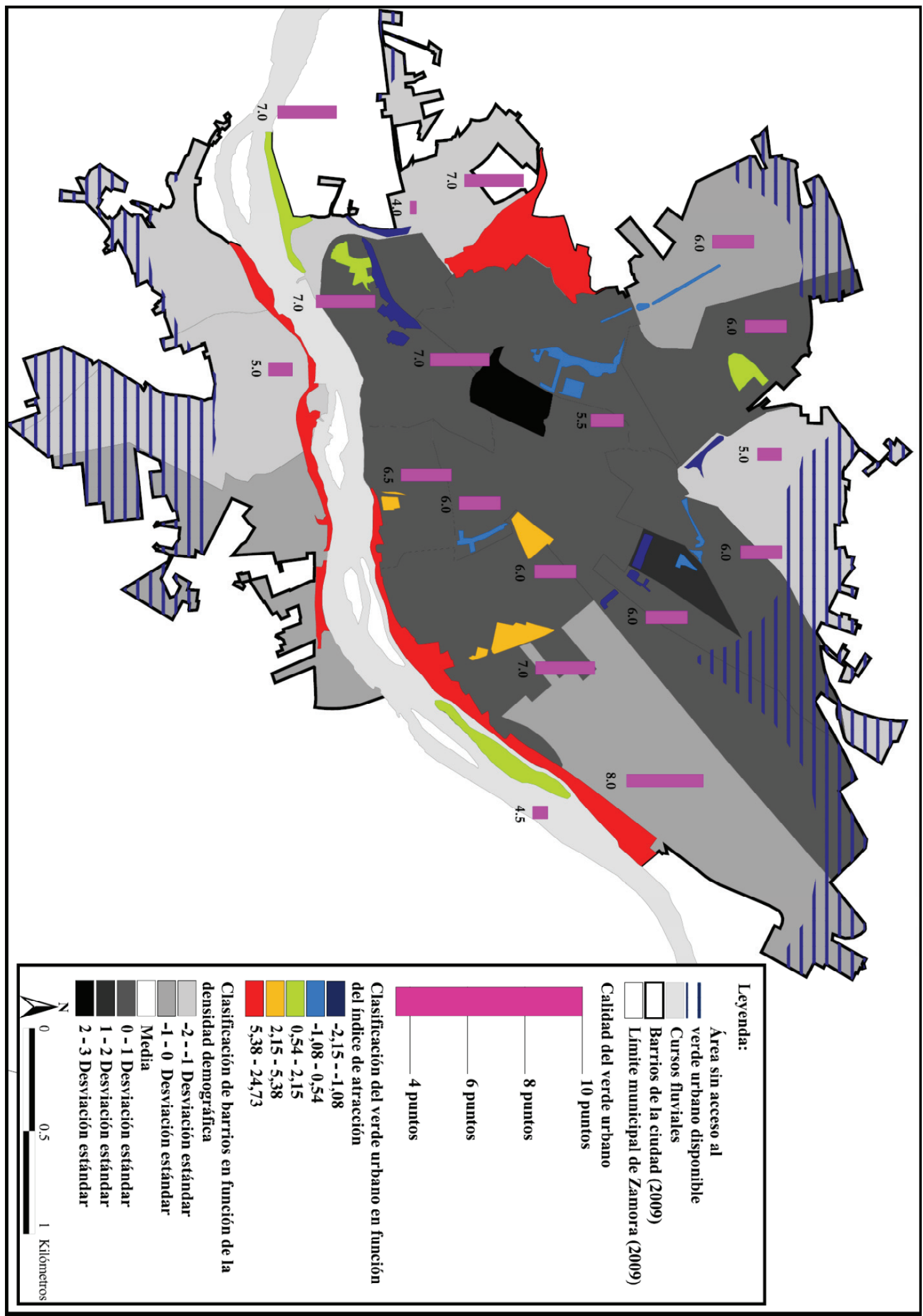

Fuente: elaboración propia a partir de la ortofoto de 2009 del IGN y del Ayuntamiento de Zamora (2007). 
calidad inferior o igual a seis puntos, pero parece que su diseño es el que les confiere un atractivo tan bajo, a pesar de que están situados en zonas de la ciudad con una densidad de población considerable.

Sin embargo, no todas las zonas verdes con estas características son poco atrayentes. Por ejemplo, el verde urbano de Puerta Nueva (Z-19) está construido en un pequeño vacío urbano, presenta una calidad de 6,5 puntos y se encuentra entre los más atrayentes, quizás porque los ciudadanos lo utilizaran mayoritariamente como área de actividad física. En el centro histórico se encuentra el espacio verde menos atractivo de la ciudad, el histórico Parque de San Martín (Z-13), formando un continuo con el Parque del Castillo y de la Catedral (Z-1), que fue el mejor valorado por los zamoranos, aunque no posee un índice de atracción elevado. A menos de 400 metros de ambos se encuentra el Bosque de Valorio (Z9), por lo que al realizar sus visitas, los ciudadanos tienen la opción de escoger entre al menos tres verdes situados en las proximidades de su lugar de residencia, y si se atiende al índice de atracción, el menos visitado será el Parque de San Martín (Z-13). En la misma situación se encuentran los Jardines de la Vaguada (Z-11), ubicados en una zona muy densamente poblada, pero a menos de 800 metros del Bosque de Valorio (Z-9), lo que podría explicar las pocas visitas que recibe este verde urbano.

En torno al río Duero se ubican algunos de los parques y jardines más visitados de la ciudad, observándose un contraste profundo entre la orilla derecha, con espacios con una calidad alta como son la margen derecha (Z-6) y el Parque de Olivares (Z-3), y la situación de la Isla de las Pallas (Z-17) y de la margen izquierda (Z-15) que cuentan con una calidad muy baja. Sin embargo todos ellos son visitados con relativa frecuencia puesto que se encuentran en una zona de la ciudad donde residen importantes contingentes demográficos, como ocurre en los barrios del Casco Antiguo (1) o de Candelaria-Peña de Francia (7). El mismo fenómeno se ha observado en los parques de la Marina (Z-4) y de León Felipe (Z-14), situados en dirección norte y con un alto índice de atracción por su posición central en la ciudad.

Como resumen puede apuntarse que las zonas verdes con mayor índice de atracción de Zamora se encuentran situadas junto al Duero, con la excepción de Valorio (Z-9). Este bosque ha sido progresivamente integrado en la ciudad y a día de hoy, aproximadamente quince de sus más de ochenta hectáreas cuentan con los equipamientos propios de un parque y reciben un mantenimiento regular. Es llamativo el contraste entre la puntuación recibida por los ciudadanos, muy penalizada por la opinión negativa que transmite un bosque no "domesticado", es decir, un espacio verde semi-natural con cierto parecido a los jardines de tradición inglesa, y la fuerte atracción que ejerce sobre los barrios más próximos, que en parte explicaría las pocas visitas que reciben otros parques. En el extremo opuesto se sitúan una serie de áreas verdes creadas en vacíos urbanos en las proximidades de las vías de comunicación, que resultan poco atractivas para la población pese a encontrarse en barrios densamente poblados.

En esta ciudad el número de personas que dijeron acudir a algún espacio verde no incluido e esta investigación fue muy reducido, solamente cuatro, y visitaban con frecuencia la Plaza de Sagasta y los Jardines de Santa Clara.

\subsubsection{Recapitulación: espacios verdes más visitados en tres ciudades castellano- leonesas}

El análisis conjunto de las tres ciudades ha permitido constatar que la calidad es una condición secundaria para visitar el verde urbano, mientras que lo realmente determinante para que un parque sea más o menos visitado es la cantidad de población que reside en sus proximidades. El índice de atracción ha demostrado ser útil para comparar áreas verdes de distintas ciudades y la utilización en cada localidad de una medida de posición como son los 
quintiles, ha permitido identificar fácilmente las zonas verdes más atrayentes y las más repulsivas.

Solamente un 7\% de los 1.104 usuarios encuestados mencionó entre las áreas verdes que más visitaba alguna no incluida en esta investigación. Esto confirma las ideas de partida y la definición final de verde urbano disponible, puesto que la inmensa mayoría de los espacios seleccionados son los más visitados de cada ciudad. El caso más llamativo es el del Parque de la Aldehuela, situado fuera de los límites urbanos de Salamanca, mencionado por 17 de los usuarios encuestados en dicha ciudad. En futuros estudios que traten una problemática similar a la de esta investigación, será conveniente identificar los factores que influyen en que este parque sea tan visitado y por el contrario, espacios verdes de similares características no sean apenas mencionados por los encuestados, como ocurrió con los vallisoletanos Cerro de las Contiendas, Pinar de Antequera o Cuesta de Tomillo.

En cuanto al índice de atracción, se observa que los espacios verdes con valores más elevados son aquellos que están situados junto a grandes contingentes de población como ocurre con la Margen derecha del Duero (Z-6), con Campo Grande (V-1), con el Parque de las Moreras (V-3) o con el Parque de la Alamedilla (S-10). Esto explica que algunas de las zonas con mayor concentración de áreas verdes, como puedan ser los ríos, reciban más o menos visitas en función de lo poblados que estén los barrios cercanos. Lo mismo ocurre con las zonas verdes situadas en los centros históricos, que pese a encontrarse entre las más valoradas, no siempre estarán entre las más visitadas por la fuerte influencia del número de ciudadanos con residencia en las proximidades.

Además de la distancia, otros factores parecen tener cierta influencia en las visitas al verde urbano. Como se ha mencionado a lo largo de esta investigación, el tamaño parece determinar una parte significativa de las visitas, algo que parece demostrarse con el hecho de que entre los diez espacios verdes más visitados haya seis con más de 10 ha. Aunque entre este tipo de parques hay excepciones muy notables, no se pueden rechazar las tesis de Van Herzele y Wiedemann (2003) en las que afirman que los que superan esa extensión son más atractivos que los de menor tamaño. En estrecha relación con el tamaño, también se ha reconocido una clara asociación entre los espacios verdes cuyo uso mayoritario está vinculado a la actividad física, que en muchos casos tendrán una gran dimensión, y los más veces visitados. Esto se explica por el hecho de que cerca del $40 \%$ de los encuestados acude a las zonas verdes para realizar actividades deportivas o de paseo, por lo que se dirigirán a aquellas en las que puedan desarrollar esta actividad.

En la ciudad de Zamora se ha observado que determinados parques situados en zonas muy pobladas reciben menos visitas de las que cabría esperar. Es posible que cuando un usuario cuente con acceso a varios parques, se vea en la necesidad de escoger entre ellos y quizás en esa situación la calidad juegue un papel relevante. Conviene recordar que los habitantes de esta ciudad fueron los únicos que dieron más importancia a los factores que componen la calidad que a la distancia desde el lugar de residencia, como motivo principal para visitar los espacios verdes.

Parece identificarse un patrón de verde urbano poco visitado cuyas características principales son una forma alargada y estrecha y una situación en torno a una vía de comunicación. La explicación al reducido número de visitas que reciben estas áreas verdes puede estar relacionada con las emociones que experimentan los ciudadanos (ver Figura 5.9). Anteriormente se expuso que de las respuestas recogidas sobre los sentimientos que les transmiten los espacios verdes a los ciudadanos, el contacto con la naturaleza apareció en cerca de un cuarenta por ciento en cada ciudad, mientras que el sentimiento de libertad registró un valor superior al veinte por ciento. Una zona verde que por su configuración o por su emplazamiento no consiga aislar al individuo del resto de la ciudad, no le permitirá alcanzar esos sentimientos y es posible que alguno de ellos posponga alguna visita. Observando la cartografía de las tres ciudades estudiadas se identifican claramente los 
parques creados en vacíos urbanos junto a una carretera, una calle o un bloque de edificios y que presentan un índice de atracción muy bajo, aunque cuenten con una extensión superior a las 10 ha, como ocurre con el verde urbano Huerta del Rey (V-32). Sin embargo, algunos autores han visto en estos espacios una herramienta útil para incrementar la trama verde en momentos de crisis económica y en ciudades cuya expansión urbana se ha detenido (Madureira, 2012).

Las visitas a las zonas verdes han permitido identificar una problemática reciente que se asocia principalmente a aquellas surgidas en las nuevas piezas urbanas de acuerdo con la normativa vigente. La construcción de estos barrios ha coincidido con el desplome del sector de la construcción y el número de residentes es mucho menor del previsto, lo que terminará repercutiendo en la calidad del verde urbano al convertirse en zonas inseguras por no contar con vigilantes naturales. Además, las reducciones en los presupuestos de las administraciones han alcanzado a los ayuntamientos y también a las secciones de parques y jardines, lo que se deja sentir especialmente en el mantenimiento de las zonas verdes poco visitadas, agravando aún más el descenso de la calidad de estos espacios.

\subsection{Reflexiones sobre el uso y la construcción del verde urbano}

Después de haber analizado todos los datos obtenidos a través del trabajo de campo es necesario retomar algunas de las cuestiones planteadas en la metodología sobre las que había algunas dudas. La base sobre la que se asienta esta investigación es el concepto de verde urbano, que fue definido como "aquel espacio tridimensional dominado por la vegetación y caracterizado por el desarrollo de diversas funciones sociales, con una superficie minima de 0,9 ha en el caso de la ciudad de Salamanca de 2007, de 1,26 ha en el caso de la ciudad de Valladolid de 2008 y de 0,66 ha en el caso de la ciudad de Zamora de 2009”. Este enunciado tan controvertido, se ha mostrado enormemente operativo al permitir realizar un estudio del uso que los ciudadanos hacen de las áreas verdes en tres ciudades de dimensiones diferentes. Además, se ha comprobado que la diferenciación entre verde urbano no disponible y verde urbano disponible ha sido acertada puesto que ninguno de los ciudadanos encuestados mencionó visitar algún espacio situado en la primera de las citadas categorías y eso pese a que en el capítulo tres se demostró que este tipo de espacios desempeñan funciones de notable importancia para la vida en la ciudad. Los datos obtenidos permiten afirmar que los ciudadanos entienden por zonas verdes lo que en esta investigación se ha denominado como verde urbano disponible, puesto que de los más de mil encuestados, un 93\% dijo que el espacio verde que más visitaba pertenecía a esta categoría.

En la Tabla 5.29 se han comparado los datos que ofrecen los Servicios de Parques y Jardines de los diferentes ayuntamientos con las cifras del verde urbano manejadas en el presente trabajo. Es significativo que la superficie total del verde urbano disponible de cada ciudad represente porcentajes tan reducidos del total gestionado por los gobiernos locales. De los tres casos, únicamente en Salamanca no se alcanza la mitad de la superficie verde gestionada por los gobiernos locales (44,7\%), por los motivos expuestos en el punto 2.4 del presente trabajo. Pese a la gran cantidad de parques y jardines excluidos, se ha demostrado que los ciudadanos encuestados visitan mayoritariamente el verde urbano disponible, siendo muy pocas las personas que dijeron visitar otro espacio verde no integrado en esta categoría. En total se han censado 425,2 ha de verde urbano disponible, frente a las 718,5 ha que mantienen entre los Servicios de Parques y Jardines (SPYJ) de Salamanca, Valladolid y Zamora, y únicamente 77 personas, es decir, un 6,97\% del total de encuestados, dijeron visitar una de las 29 áreas verdes no incluidas en esta investigación. A través de la selección de un número reducido de los mayores espacios verdes de cada ciudad, se puede trabajar con las zonas verdes que visita la inmensa mayoría de los usuarios encuestados, validando así la creación de un concepto a priori tan discutido como es el verde urbano disponible. Así se agiliza y se simplifica mucho el trabajo, centrando el análisis en los parques visitados por los ciudadanos 
y evitando así el análisis de los pequeños jardines de centenas o decenas de metros cuadrados, que son mucho más numerosos que los grandes parques, aunque se ha constatado que son mucho menos visitados ya que, en definitiva, son poco relevantes para el desarrollo de las funciones básicas de las zonas verdes.

El porcentaje de espacios verdes mantenidos por los SPYJ analizado en esta investigación es llamativamente reducido. Una parte de la explicación de este fenómeno se debe a la gran cantidad de zonas verdes de pequeño tamaño mantenidas por cada ciudad, cuya existencia se ha visto favorecida por una reducción sensible del tamaño mínimo que deberían tener los parques y jardines creados mediante el planeamiento local, experimentada desde que las competencias de urbanismo fueron asumidas por las Comunidades Autónomas. En el caso concreto de Castilla y León, el umbral mínimo disminuyó desde $1.000 \mathrm{~m}^{2}$ a $500 \mathrm{~m}^{2}$, con el agravante de que esta cifra no es respetada por los ayuntamientos analizados. En el capítulo anterior se indicó que Valladolid cuenta con cincuenta y dos espacios verdes con una superficie inferior a la mencionada y Salamanca con ochenta y ocho, lo que permite comprender por qué el verde urbano disponible representa un número tan reducido del total de parques y jardines, y sin embargo, representa en todos los casos, casi la mitad de la superficie verde mantenida por cada ayuntamiento.

En efecto, los verdes urbanos disponibles utilizados en esta investigación tienen una alta representatividad entre el conjunto de zonas verdes urbanas, lo que concuerda con los datos publicados por Rodríguez y Díaz (2003) en su estudio sobre la ciudad de Madrid, que ya fue mencionado en el capítulo segundo. En dicha publicación fueron considerados tan solo 51 parques de la capital española, cuya extensión equivalía al 61\% de la superficie verde pública de la ciudad. Estas autoras seleccionaron únicamente los espacios verdes de la ciudad de Madrid que tuvieran más de 4 hectáreas, que presentaran límites bien definidos e individualizados y donde pudieran desarrollarse ciertas funciones sociales. En esta definición se pueden identificar claramente algunas de las características utilizadas para definir el verde urbano disponible y los resultados obtenidos terminan por confirmar la influencia de la escala de la ciudad en el tamaño mínimo de las áreas verdes, ya que para trabajar con un porcentaje significativo de la trama verde, utilizaron un tamaño mínimo de parque superior al empleado en las tres ciudades castellano-leonesas.

Tabla 5.29 Comparación entre los datos de los Servicios de Parques y Jardines (SPYJ) de cada ciudad y los utilizados en esta investigación.

\begin{tabular}{|l|c|c|c|c|c|c|}
\cline { 2 - 7 } \multicolumn{1}{c|}{} & Salamanca & $\%$ total & Valladolid & $\%$ total & Zamora & $\%$ total \\
\hline $\mathbf{N}^{\text {o }}$ parques y jardines (SPYJ) & 315 & 100 & 300 & 100 & $152^{*}$ & 100,0 \\
\hline Superficie total (ha) (SPYJ) & 223,7 & 100 & 357,1 & 100 & $137,7 *$ & 100,0 \\
\hline $\mathbf{N}^{\circ}$ verdes urbanos & 34 & 10,8 & 55 & 18,3 & 28 & 18,42 \\
\hline Supf. verde urbano (ha) & 124 & 55,4 & 333 & 93,3 & 101,1 & 73,42 \\
\hline $\mathbf{N}^{\circ}$ verdes urbanos disponibles & 26 & 8,3 & 44 & 14,7 & 18 & 11,84 \\
\hline Supf. verde urbano disponible (ha) & 100 & 44,7 & 253,5 & 71,0 & 71,7 & 52,07 \\
\hline
\end{tabular}

*Dato que no ha podido ser contrastado al no disponer de un censo de parques y jardines.

Fuente: Servicio de Parques y Jardines del Ayuntamiento de Salamanca, Servicio de Parques y Jardines del Ayuntamiento de Valladolid y www.ayto-zamora.org.

Las citadas autoras mencionaban tres etapas diferentes en la creación de los parques urbanos de la capital: la primera llegaría hasta la posguerra y en ella se heredaron grandes espacios verdes pertenecientes a la corona, a la nobleza y a la villa de Madrid, la segunda estaría caracterizada por una reducción del verde urbano por habitante motivado por un fuerte crecimiento de la ciudad debido a la llegada de una fuerte inmigración con un alto contenido rural, cuya extensión alcanzaría hasta los años setenta, y durante la última etapa comenzaron a incorporarse dotaciones de espacios verdes al planeamiento urbano. Esta descripción coincide a grandes rasgos con el modelo de ciudad del sur de Europa 
mencionado en el capítulo anterior y que tan gráficamente se identifica al observar la figura que muestra la evolución del verde urbano disponible por habitante, reproducida a continuación como Figura 5.35. En dicho gráfico se observa que Salamanca, Valladolid y Zamora no recibieron una herencia tan "sustanciosa" en materia de zonas verdes como la capital española, con la excepción de Valladolid que sí contaba con buenos parques en el interior del centro histórico. Es necesario repetir algo que ya se dijo con anterioridad: la recuperación experimentada en las últimas décadas del índice de espacios verdes por habitante, no ha conseguido alcanzar el ratio mínimo manejado por la OMS $\left(9 \mathrm{~m}^{2} / \mathrm{hab}\right)$, ni el considerado por Magalhães (1992) y Santana et al. (2007a y 2010) como deseable $\left(10 \mathrm{~m}^{2} / \mathrm{hab}\right)$, excepto en la ciudad de Zamora, debido a la herencia tan negativa en materia de parques y jardines, recibida a comienzos de la década de los setenta del siglo pasado.

La dificultad de crear zonas verdes en sectores urbanos consolidados ha llevado a las autoras mencionadas a afirmar que la ausencia de espacios verdes en el interior del tejido urbano es un indicador válido de los déficits en la expansión urbana (Rodríguez y Díaz, 2003), siendo corroborado por la presente investigación. Partiendo de esta reflexión y retomando las etapas en la creación de espacios verdes, parece probado lo apuntado en el capítulo anterior acerca del modelo de ciudad del sur de Europa identificado por Sanesi y Chiarello (2006). Con ligeros matices, se identifica de manera general una ciudad compacta con tres sectores bien identificados (centro histórico, ciudad moderna y ciudad de finales del siglo $\mathrm{XX}$ ), en la que las áreas verdes han surgido mayoritariamente en las últimas tres décadas en barrios creados a través del planeamiento urbano, reservando una parte del suelo para parques y jardines, motivando así un progresivo aumento de los índices de verde urbano por habitante y por hectárea.

Figura 5.35 Evolución del verde urbano disponible por habitante $\left(\mathrm{m}^{2} / \mathrm{hab}\right)$.

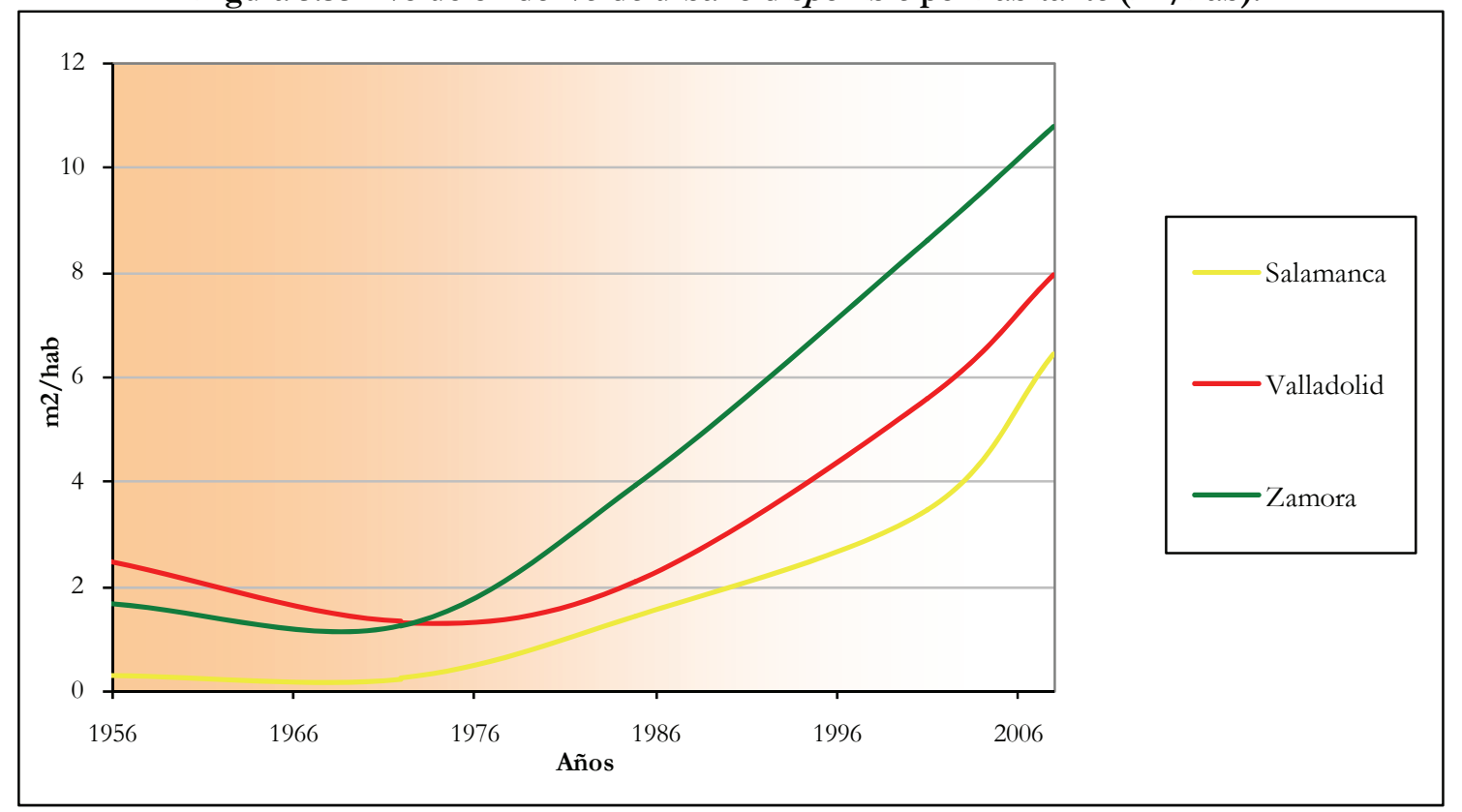

Fuente: elaboración propia a partir del SGE, del IGN y del INE.

En cuanto al estudio de la categoría de verde urbano, dentro de la cual se incluye el no disponible, ha mostrado cierta utilidad debido a que en las últimas décadas, algunos de los huertos urbanos han terminado por convertirse en parques públicos. Es interesante destacar que las mayores concentraciones de verde urbano en cada una de las ciudades analizadas se encuentran junto a los cursos fluviales, en terrenos históricamente destinados a la agricultura. En los últimos cincuenta años, han sido numerosas las áreas verdes surgidas a partir de huertos urbanos y es posible que en el futuro se sigan aprovechando estos espacios en las 
márgenes de los ríos para este mismo cometido. Sin embargo, se ha observado que esta parte de cada uno de los casos estudiados está compuesta por algunas áreas muy poco visitadas, pese a tratarse de grandes concentraciones verdes. Esto es debido al número relativamente reducido de residentes en los barrios próximos, lo que sirve de ejemplo a un hecho evidente: existe una fuerte relación entre la proximidad de sectores urbanos muy poblados y el uso del verde urbano. En concreto, aproximadamente dos tercios de los usuarios encuestados aseguraron que la distancia era el motivo por el que acudían al espacio verde que visitaban con más frecuencia.

En segundo lugar aparecía un conjunto de factores que integraban lo que en esta investigación se ha llamado calidad, mencionados por casi la mitad de los encuestados. Sin embargo, ha quedado demostrado que la calidad es un elemento secundario en las visitas mientras que el factor más determinante es la distancia desde el lugar de residencia. Por tanto, el empleo de los indicadores tradicionalmente utilizados para medir la cantidad de espacios verdes por habitante o por hectárea no es suficiente para analizar la posibilidad de uso del verde urbano, puesto que la posición de los parques y jardines en el interior del tejido urbano es un elemento limitante de la accesibilidad de la población.

Una de las conclusiones más interesantes a las que ha llegado esta investigación es que el tamaño de la ciudad no influye en el uso que hacen los ciudadanos del verde urbano, al menos para el rango de ciudades aquí considerado, que incluye dos ciudades medias y una capital regional que no supera el medio millón de habitantes. En efecto, los usuarios de Salamanca, Valladolid y Zamora tienen un comportamiento social muy similar, como se observó al analizar la distribución por sexo y edad, los horarios, la frecuencia de las visitas, los motivos para acudir y las actividades que realizan en los espacios verdes. Se puede hablar de un comportamiento homogéneo de la sociedad castellano-leonesa o de la sociedad española, distinto del que muestran trabajos llevados a cabo en otros países europeos.

Los espacios verdes son verdaderos laboratorios sociales, ya que son lugares de convivencia donde se pueden analizar los comportamientos de una sociedad. Por ejemplo, parece muy probable que el colectivo de mujeres sea el que asume la mayor parte de las tareas u obligaciones familiares, lo que se refleja en las áreas verdes a través de la ausencia de mujeres mayores por la mañana y de la gran cantidad de usuarias de entre treinta y cuarenta y cinco años que acuden acompañadas de sus hijos (54,5\%). El verde urbano es un lugar de socialización donde jóvenes y ancianos son los que más practican esta actividad, con un porcentaje de cada uno de estos colectivos del $77 \%$ y del $63,9 \%$.

El perfil del usuario del verde urbano de las tres ciudades estudiadas es un varón jubilado de más de sesenta y cinco años, que acude mayoritariamente en horario de mañana, para realizar actividades deportivas o de paseo. La población encuestada acude con mucha frecuencia a los espacios verdes, ya que más de dos tercios de los usuarios aseguró visitarlos cinco o más veces por semana, al igual que en el estudio realizado por Santana et al. (2010) en la ciudad portuguesa de Amadora, en el que el 83,8\% de los entrevistados afirmó frecuentarlos regularmente. Estas autoras demostraron la importancia de los espacios verdes situados en las proximidades del lugar de residencia en la salud de la población, ya que proporcionan un ambiente físico que incentiva la práctica deportiva (Santana et al., 2007a), confirmando además una fuerte correlación entre proximidad, calidad ambiental y utilización (Santana et al., 2011).

Para cerrar esta reflexión, es posible afirmar que la mayor parte de los usuarios sí son conscientes de algunas de las funciones que desempeñan las áreas verdes en el interior de la ciudad. En las preguntas 26 y 27 del cuestionario se pidió a los encuestados que valoraran la capacidad de estos espacios para producir beneficios sociales, y el porcentaje promedio de respuestas positivas fue del $88,8 \%$ y del $61,3 \%$ respectivamente. 


\section{CONCLUSIONES}

Los objetivos de esta Tesis Doctoral eran la delimitación del concepto de verde urbano, mediante la puesta a punto de una metodología de identificación adecuada al tamaño de la ciudad, el análisis de la distribución espacial de los espacios verdes en tres ciudades castellano-leonesas y el estudio del uso que los visitantes hacen de tales espacios y del valor que les atribuyen. Las conclusiones obtenidas son las siguientes.

- El concepto de verde urbano disponible manejado ha demostrado ser operativo, debido a que esta categoría engloba la inmensa mayoría de parques y jardines visitados por los ciudadanos encuestados. En concreto, un 93\% de las 1.104 personas a las que se preguntó cuál era el espacio verde que más veces visitaba mencionó alguno de los incluidos en esta investigación. La validación de este término facilitará la realización de estudios futuros sobre las zonas verdes urbanas, puesto que se ha demostrado que con un número reducido de los parques y jardines gestionados por los gobiernos locales se cubre un porcentaje muy elevado de las visitas de los ciudadanos a estos espacios. Además, con estos resultados se puede concluir que, al menos en las ciudades analizadas, la vinculación del tamaño mínimo del verde urbano al tamaño de la ciudad ha sido una decisión acertada. También se ha constatado que las zonas verdes privadas o con una difícil configuración, el denominado verde urbano no disponible, no reciben apenas visitas, justificando así su exclusión del estudio de las zonas verdes desde una perspectiva social.

- La revisión de algunos de los trabajos que tratan las diversas funciones de las áreas verdes urbanas ha permitido corroborar que la presencia de estos espacios genera numerosos beneficios tanto para los ciudadanos como para el medio ambiente urbano. El análisis pormenorizado de la literatura especializada ha permitido identificar una realidad difícil de percibir en su integridad, lo que justifica la realización de una investigación como la aquí desarrollada.

- En cuanto al proceso de construcción de zonas verdes en el interior de las ciudades analizadas, este trabajo ha identificado una estrecha vinculación entre la aprobación de los primeros planes generales en democracia, a mediados de la década de los ochenta del siglo pasado, con el aumento del número de espacios verdes, debido a que en este momento comienzan a aplicarse de manera efectiva las principales directrices de la segunda Ley del Suelo de 1976. También se ha comprobado la enorme dificultad para dotar de zonas verdes a los barrios consolidados que no incluyeron estos equipamientos cuando fueron construidos, algo que nunca debería de olvidarse a la hora de planificar las nuevas piezas urbanas.

- La ausencia de áreas verdes en determinados sectores urbanos ha permitido identificar un modelo de ciudad propio del sur de Europa, ya mencionado por algunos autores, compuesto por el centro histórico, donde podría encontrarse algún parque o jardín, por la ciudad construida hasta el siglo XX, en la que únicamente aparecerían paseos y plazas arboladas, y por la construida durante el último siglo, muy densamente poblada y donde la mayor parte de espacios verdes fueron levantados en las últimas tres décadas. 
- El Reglamento de Urbanismo de Castilla y León del año 2009 establece una reducción significativa de la superficie mínima de los espacios libres públicos con respecto a la fijada por la segunda Ley de Suelo de 1976, que ni siquiera es cumplida por los ayuntamientos analizados. Se trata en muchos casos de espacios verdes heredados, pero será necesario corregir esta situación, puesto que se ha demostrado que la mayor parte de los usuarios del verde urbano visita los espacios verdes de mayores dimensiones, donde pueden desempeñar alguna de las funciones tradicionales de estos espacios como son el ocio, el deporte o el paseo.

- De todos modos, se ha comprobado que, en las últimas décadas el planeamiento urbano ha conseguido un incremento muy notable del número y de la superficie total del verde urbano en las ciudades analizadas. Sin embargo, con el comienzo de la crisis económica en 2008 se ha identificado una problemática reciente en algunos espacios verdes de Valladolid, donde se ha registrado un deterioro en las labores de mantenimiento, lo cual exige el replanteamiento inmediato de la gestión actual de estos espacios.

- El empleo de índices para analizar la cantidad de verde por habitante, o por unidad de superficie ha resultado ser de gran utilidad para identificar el cambio de tendencia en la creación de parques y jardines durante los últimos cincuenta años, pero no expresa por sí solo las posibilidades de uso de las zonas verdes por parte de los ciudadanos. A tal efecto, ha sido necesario estimar la accesibilidad de la población a las áreas verdes, dado que se ha verificado que la distancia hasta el verde urbano disponible es el principal factor limitante para visitar estos espacios. De esta manera se han obtenido datos sobre la posibilidad de uso de estos equipamientos y se han identificado las áreas urbanas que no cuentan con accesibilidad a las zonas verdes. En concreto, en las tres ciudades analizadas se han identificado importantes deficiencias en algunos barrios nacidos sin planeamiento urbano previo, donde no se reservó suelo para espacios verdes, y en algunas áreas industriales en las que la legislación actual limita la presencia de áreas verdes al arbolado viario.

- La distancia desde el lugar de residencia provoca que algunos parques situados en barrios muy poblados sean visitados por una gran cantidad de personas, mientras que algunas zonas, como las riberas, muy bien dotadas, son poco visitadas porque cuentan con pocos residentes en sus proximidades. Concretamente, los cursos fluviales son auténticos ejes vertebradores de la trama verde en las ciudades analizadas y en torno a ellos se identifican las mayores concentraciones de espacios verdes, situadas sobre los fértiles terrenos de las márgenes de los ríos que en algunos casos se habían destinado a la agricultura urbana. Se han identificado los huertos urbanos como terrenos muy interesantes para el crecimiento de la ciudad, y especialmente de su estructura verde, puesto que sobre suelos agrícolas se han creado algunas zonas verdes en las ciudades analizadas.

- Con el diseño y cálculo del índice de atracción se ha logrado identificar los parques más visitados y los menos transitados de cada ciudad y, una vez comparado con la calidad de cada uno, se ha certificado que esta última es una condición secundaria para que los ciudadanos visiten estos espacios. A la hora de realizar las visitas, se ha observado que el tamaño de las áreas verdes tiene un peso relevante en las mismas, por lo que no se puede rechazar la idea de que los parques de mayor superficie son más atractivos que el resto, aunque en esta Tesis Doctoral se ha comprobado que esto no sucede así en todos los casos. Parece que la atracción tiene cierta vinculación con las 
actividades que los usuarios realizan habitualmente, que en las ciudades analizadas están vinculadas mayoritariamente con la práctica deportiva y con el paseo, por lo que los ciudadanos se dirigirán a aquellos parques donde puedan desempeñar dichas actividades.

- Se ha observado un comportamiento social muy similar entre las personas que visitan los espacios verdes de las tres ciudades analizadas. Existiría, pues, una sociedad homogénea con los mismos valores y con gustos muy similares en materia de uso de los espacios verdes, como se puede comprobar al analizar las respuestas ante cuestiones tales como por qué visitan los parques, qué sentimientos provocan o qué equipamientos utilizan. Aparentemente, la disponibilidad de tiempo libre jugaría un papel relevante en la frecuencia y distribución de las visitas. Además, las áreas verdes actuarían como laboratorios sociales y en ellas es posible distinguir, por ejemplo, el protagonismo de las mujeres en la mayor parte de las tareas familiares en comportamientos concretos, así como el notable papel que juegan los mayores en el modelo de familia actual, al asumir el cuidado de los más pequeños.

- Por último, debe destacarse la preferencia de la mayor parte de los usuarios encuestados por la naturaleza domesticada, es decir, por un modelo de parque en el que la vegetación esté totalmente controlada, que conlleva una penalización de los espacios verdes donde la vegetación crece de forma semi-natural, como ocurre en algunos de los situados en las márgenes de los ríos y que han sido valorados a la baja por presentar árboles y arbustos de ribera que crecen libremente.

Sin duda, algunos de los resultados obtenidos en esta Tesis Doctoral podrían incorporarse al planeamiento urbano y al diseño de los parques y jardines, demostrando así la vertiente práctica y aplicada del conocimiento geográfico. La obtención de datos sobre los usuarios habituales del verde urbano y los factores que condicionan la decisión de visitar un espacio verde debería orientar las decisiones futuras sobre la localización y el diseño de estos equipamientos hacia la satisfacción de las necesidades reales de la población, tratando así de limitar el actual desfase entre su ubicación y concepción, por una parte, y las prácticas y demandas ciudadanas, por otra.

Esta investigación se ha llevado a cabo en ciudades localizadas en un territorio muy concreto, una comunidad autónoma del interior de España, y aunque parece intuirse que los fenómenos en ellas identificados se repiten en otros ámbitos geográficos (Madrid, ciudades del sur de Europa...), habrá que realizar estudios en detalle en otro tipo de entidades urbanas con morfologías diferentes para verificar la validez tanto del método empleado como de los resultados obtenidos. Además, la coyuntura económica actual invita a continuar con este análisis para observar cómo afecta la reducción del gasto público a la gestión del verde urbano y, en último lugar, al potencial uso que los ciudadanos hacen y podrán hacer de estos espacios.

El futuro de las áreas verdes en Salamanca, Valladolid y Zamora se presenta, por tanto, lleno de incógnitas. Durante los últimos años se ha identificado un proceso de sensible degradación del mantenimiento de algunos parques situados en los barrios de nueva creación, lo que parece haber generado un incremento del miedo y de la inseguridad entre sus usuarios, lo que a su vez redunda en una disminución de las visitas y en el agravamiento paulatino de su deterioro.

En este sentido, la presente Tesis Doctoral puede convertirse en el punto de partida de un programa de investigación a largo plazo que analice dos grandes conjuntos de problemas. Desde una perspectiva más territorial, debe discutirse la idoneidad del modelo de crecimiento urbano imperante durante los últimos años de bonanza económica, utilizando para ello como 
indicador la dotación y el mantenimiento del verde urbano. Desde una aproximación más social, debe prestarse atención a las repercusiones que la falta de acceso a los espacios verdes puede generar en la población, entre las que cabe avanzar la pérdida de ámbitos de interacción comunitaria y el empeoramiento de las condiciones de salud. Es decir, y continuando con la línea argumental que ha sustentado esta Tesis, es posible continuar analizando la relación entre espacio urbano, espacio verde y espacio social en el contexto general definido por una nueva orientación de las políticas públicas en tiempos de crisis profunda y de transformaciones que aún están por definir. 


\section{BIBLIOGRAFÍA}

Alberdi, J.C. (2001): La ciudad elimina la función agraria en su proximidad: el ejemplo de San Sebastián. Cuadernos Geográficos de la Universidad de Granada 31: 87-114.

Alcanforado, M.; Andrade, H. (2007): Clima e Saúde na cidade. Implicações para o ordenamento. En Santana, P. coord: A Cidade e a Saúde. Almedina. Coimbra: 99-118.

Almeida, L. (2009): Diagnóstico Socioambiental das Hortas Urbanas da Cidade de Salvador, Babia, Brasil. Universidad de Salamanca. Salamanca. Trabajo de Grado.

Akbari, H. (2002): Shade trees reduce building energy use and CO2 emissions from power plants. Environmental Pollution 116: 119-126

Akbari, H.; Davis,S.; Dorsano,S.; Huang, J.; Winnett, S. (1992): Cooling our communities. A guidebook on tree planting and light-colored surfacing. U.S.Environmental Protection Agency. Washington.

Arnberger, A. (2006): Recreation use of urban forest: an inter-area comparison. Urban Forestry and Urban Greening 4: 135-144.

Ascher, F. (2010): Novos principios do Urbanismo. Livros Horizonte. Lisboa.

Ávila, Á. (2009): Arquitectura y urbanismo en Zamora (1850-1950). Instituto de Estudios Zamoranos Florián de Ocampo. Zamora.

Banco Mundial (2009): Informe sobre el desarrollo mundial 2009. Una nueva Geografía Económica. Banco Mundial. Washington, D.C.

Barbosa, O.; Tratalos, J.A.; Armsworth, P.R.; Davies, R.G.; Fuller, R.A.; Johnson, P.; Gaston, K.J. (2007): Who benefits from access to green space? A case study from Sheffield, UK. Landscape Urban Plan 83: 187-195.

Batlle, E. (2011): El jardín de la metrópoli. Del paisaje romántico al espacio libre para una ciudad sostenible. Gustavo Gili. Barcelona.

Bauman, Z. (2007): Tiempos líquidos. Tusquets Editores. Barcelona.

Bedimo-Rung, A.L.; Mowen, A.J.; Cohen, D.A. (2005): The significance of parks to physical activity and public health. A conceptual model. American Journal of Preventive Medicine 28 (252): 159-168.

Benevolo, L. (1987): As origens da urbanistica moderna. Editorial Presença. Lisboa.

Blanc, N. (2012): Les nouvelles esthétiques urbaines. Armand Colin. Paris.

Bolund, P.; Hunhammar, S. (1999): Ecosystem services in urban areas. Ecological Economics 29: 293-301.

Bonsignore, R. (2003): The diversity of green spaces. DCAUL. University of Minnesota. Minneapolis.

Bonsignore, R.; Fitzgerald, F.; Forsyth, A.; Zimmerman, J. (2003): Taking notice: green spaces in urbanized settings. DCAUL. University of Minnesota. Minneapolis.

Byrne, J.; Wolch, J. (2009): Nature, race, and parks: past research and future directions for geographic research. Progress in Human Geography 33(6): 743-765.

Cabo, A. (1995): Salamanca: la ciudad histórica. En Cabero, V.; Izquierdo, I.; Llorente, J.M. coords.: Salamanca y sus comarcas. Editorial Mediterráneo, D.L. Madrid: 321-328.

Calderón, B. (1982): La reciente expansión de la ciudad de Zamora. En Congreso de Geografía de Castilla La Vieja y León. Burgos: 285-298.

Calderón, B. (1988): El crecimiento urbano de Valladolid. Caja de Ahorros Popular de Valladolid. Valladolid.

Calderón, B. (2007): Nuevos usos para el patrimonio arquitectónico industrial en Valladolid: completar equipamientos y generar valor. Scripta Nova vol. XI, no 247: 229-255.

Calderón, B.; Delgado, J.M.; Pastor, L. (1992): Crecimiento y transformación de Valladolid 1960-1988. Análisis de un proceso complejo y contradictorio. Ayuntamiento de Valladolid. Valladolid. 
Calderón, B.; Delgado, J.M. (1993): Conocer la Huerta del Rey: una periferia residencial en la ciudad de Valladolid. Grapheus. Valladolid.

Calderón, B.; García, J.L. (2006): Formatos y estrategias para el control del espacio comercial urbano: el caso de Valladolid y su entorno. Scripta Nova vol. X, n 266: 205-228.

Calderón, B.; Pascual, H. (2006): Singularidad funcional y especialización territorial de la industria en la ciudad de Valladolid. En Méndez, R. y Pascual, H. coords.: Industria y ciudad en España: nuevas realidades, nuevos retos. Editorial Civitas. Madrid: 309-346.

Calderón, B.; Pascual, H. (2007): El lugar del patrimonio industrial en los procesos de transformación urbana: de la ruina a la explotación de las reliquias fabriles en Valladolid. Ería: Revista Cuatrimestral de Geografia 72: 55-73.

Calvo, S.; Rivas, J.L. (1995): Competitividad industrial y medio urbano: El caso de Valladolid. Ciudad y Territorio: Estudios Territoriales 106: 793-823.

Canosa, E.; Sáez, E.; Sanabria, C.; Zavala, I. (2003): Metodología para el estudio de los parques urbanos: la Comunidad de Madrid. Geofocus Revista Internacional de Ciencia y Tecnología de la Información Geográfica 3: 160-185.

Cantón, M.A.; Cortegoso, J.L.; de Rosa, C. (2000): Evaluación energético-ambiental del bosque urbano: desarrollo y puesta a punto de un método de análisis. Avances en Energías Renovables y Medio Ambiente 4 (1): 1.13-1.17.

Castro, S. (2005): Evaluación de un índice para la valorar las áreas verdes urbanas: su aplicación y análisis en la localidad de Barrio Dent y Altos del Escalante con una perspectiva geográfica. Revista Reflexiones 84 (1): 107-125.

Cebrián, M. (2009): La mano visible del Estado frente a la mano invisible en la planificación indicativa franquista: la política de Polos en Castilla y León, 1964-1975. IX Congreso Internacional de la Asociación Española de Historia Económica. Murcia: 1-33.

Cedeño, M.C. (2003): Usos y prácticas sociales en un parque público. El caso del parque metropolitano Les Planes de L’Hospitalet de Llobregat- Barcelona. Zainak. Cuadernos de Antropología-Etnografía 23: 545-566.

Chiesura, A. (2004): The role of urban parks for the sustainable city. Landscape and Urban Planning 68: 129-138.

Cobo, W. (1997): Areas verdes urbanas en América Latina y el Caribe. Participación pública en la arborización urbana. Universidad Autónoma de Chapingo. Chapingo.

Coombes, E.; Jones, A.; Hillsdon, M. (2010): The relationship of physical activity and overweight to objectively measured green space accessibility and use. Social Science and Medicine 70(6): 816-822.

Coq, D. (2004): Economía y territorio: una sucinta revisión. RAE: Revista Asturiana de Economía 31: 119-149.

Corona, M.A. (2001): Las áreas verdes en el contexto urbano. Estudio de caso: ciudad de Guadalajara. CIIEMAD. México D.F.

Corona, M.A. (2002): Los parques urbanos y su panorama en la zona metropolitana de Guadalajara. Revista de Vinculación y Ciencia 9: 4-16.

Cortez Vaz, A.M.; Barros, C.; Fernandes, J.L.J. (2012): A perceção da insegurança nos espaços verdes da cidade de Coimbra. XIII Coloquio Ibérico de Geografía. Respuestas de la Geografía ibérica a la crisis actual. Santiago de Compostela: 1.742-1.752.

Costa, A.; Martínez, M.E.; Bermúdez de Castro, F. (1985): Parques y jardines de la ciudad de Salamanca. Ayuntamiento de Salamanca. Salamanca.

De Sousa, C.A. (2003): Turning brownfields into green space in the City of Toronto. Landscape and Urban Planning 62: 181-198.

De Vries, S.; Verheij, R.A.; Groenewegen, P.P.; Spreeuwenberg, P. (2003): Natural environments -- healthy environments? An exploratory analysis of the relationship between greenspace and health. Environment and Planning 35(10): 1717-1731. 
Díaz, L. (1998): Salamanca ciudad. Historia. En Díaz, L. coord.: El libro de oro de Salamanca: un siglo en imágenes. El Adelanto de Salamanca y Ediciones. Salamanca: 8-65.

Doyle, S.; Kelly-Schawartz, A.; Scholossberg, M.; Stockard, J. (2006): Active community environments and health: the relationship of walkable and safe communities to individual health. Journal of the American Planning Association 72 (1): 19 - 31.

Dula, N.J. (2008): Parks and Economic Development: The relationship between public amenities, quality of life and urban growth. University of North Carolina. Chapel Hills.

Dunnett, N.; Swanwick, C.; Woollwy, H. (2002): Improving Urban Parks, Play Areas and Open Spaces. DTRL. London.

Dwyer, J.F.; McPherson, E.G.; Schroeder, H.W.; Rowntree, R.A. (1992): Assessing the benefits and costs of the urban forest. Journal of Arboriculture 18 (5): 227-234.

Echenique, M. (1995): Entender la ciudad. EURE 21 (64): 9-23.

Escobar, L.A. (2006): Indicadores sintéticos de calidad ambiental: un modelo general para grandes zonas urbanas. EURE 32 (96):73-98.

Fadigas, L. (2010): Urbanismo e Natureza. Os desafios. Silabo. Lisboa.

Falcón, A. (2008): Espacios verdes para una ciudad sostenible. Gustavo Gili. Barcelona.

FEDENATUR (2004): La place des espaces naturels périurbains pour une ville durable. Comisión Europea. Barcelona.

Feria, J.M.; Santiago, J. (2009): Funciones ecológicas del espacio libre y planificación territorial en ámbitos metropolitanos: perspectivas teóricas y experiencias recientes en el contexto español. Scripta Nova vol. XIII, n 299: 281-309.

Fernández, M.A. (1981): Desarrollo urbano y proceso histórico de Campo Grande de Valladolid. Ayuntamiento de Valladolid. Valladolid.

Fidalgo, C. (1998): Componente biótico del ecosistema urbano desde la perspectiva biogeográfica. Estudios Geográficos 59 (230): 125-133.

Flores, R.; González, M.J. (2007): Consideraciones sociales en el diseño y planificación de parques urbanos. Economía, Sociedad y Territorio 4 (24): 913-951.

Fonseca, F.; Gonçalves, A.; Rodrigues, O. (2010): Comportamentos e percepções sobre os espaços verdes na cidade de Bragança. Finisterra: Revista Portuguesa de Geografia 15 (89): 119139.

Foster, C.; Hielsdon, M.; Jones, A.; Panter, J. (2007): Assessing the relationship between the quality of urban green space and physical activity. CABE Space Report. London.

Frutos, P. (2004): Determinantes de las visitas a los parques y jardines urbanos: aplicación de un modelo de gravedad. Estudios de Economía Aplicada 22 (2): 349-364.

Gago, J.L. (1986): La arquitectura y los arquitectos en el ensanche: Zamora 1920-1950. Universidad de Las Palmas de Gran Canaria. Las Palmas de Gran Canaria. Tesis Doctoral.

Galindo, M.P.; Arias, M.A.; de Castro, R. (1997): Usos psicosociales del espacio verde urbano. Revista de Psicología Social Aplicada 2-3: 35-52.

Galindo, M.P.; Corraliza, J.A. (1999): Estética ambiental y bienestar psicológico: algunas relaciones existentes entre los juicios de preferencias por paisajes urbanos y otras respuestas afectivas relevantes. Apuntes de Psicología 17 (1-2): 49-76.

Gámez, V. (2005): Sobre sistemas, tipologías y estándares de áreas verdes en el planeamiento urbano. Revista Electrónica DU\&O. Diseño Urbano y Paisaje 2 (6): 1-22.

García, A.M. (1989): El parque urbano como espacio multifuncional: origen, evolución y principales funciones. Paralelo 37 13: 105-111.

García, I. (2007): Los espacios periurbanos como recurso didáctico: el caso de la huerta de Valencia. Didáctica de las Ciencias Experimentales y Sociales 21: 197-210.

García, J.L. (2000): De la urgencia social al negocio inmobiliario: promoción de viviendas y desarrollo urbano en Valladolid (1960-1992). Universidad de Valladolid. Valladolid.

Garzón, B.; Brañes, N.; Abella, M.L.; Auad, A. (2004): Vegetación urbana y hábitat popular: el caso de San Miguel de Tucumán. Boletín del Instituto de la Vivienda 18 (409): 21-42. 
Geason, S.; Wilson, P. (1989): Designing out Crime: Crime prevention trough environmental design. Australian Institute of Criminology. Canberra.

Gómez, A. (2007): Espacios forestales en el entorno del área metropolitana salmantina: una necesidad nueva dentro de la "ciudad difusa". El caso concreto del municipio de Salamanca. Universidad de Salamanca. Salamanca. Documento inédito.

Gómez, A. (2012): La utilización del verde urbano. Estudio de caso en tres ciudades españolas. Cadernos de Geografia de Coimbra 30-31. En prensa.

Gómez, A. (2013): Localización y acceso al verde urbano de la ciudad de Salamanca. Boletín de la $A G E$ 63. En prensa.

Gómez, A.; Costa, C.; Santana, P. (2013): Os espaços verdes nas cidades de Coimbra e Salamanca. Finisterra: Revista Portuguesa de Geografia. En prensa.

Gómez, F. (2005): Las zonas verdes como factor de calidad de vida en las ciudades. Ciudady Territorio: Estudios Territoriales 37 (144): 417-436.

González, E. (1985): Valladolid, ciudad y territorio. Procesos de articulación territorial inducidos por el desarrollo industrial y urbano. Universidad de Cantabria. Santander.

González, V.M. (2006): La Fundación Vicente Rodríguez Fabrés: antecedentes y creación de una obra social en Salamanca. Universidad de Salamanca. Salamanca. Trabajo de Grado.

Gumuchian, H. E.; Marois, C. (2000): Initiation a la recherche en géographie, aménagement, développement territorial, environnement. Anthropos, Presses de l'Université de Montréal. Montreal.

Gutiérrez, M.E. (2001): El espacio urbano en la ciudad de Salamanca, escenario físico de un equilibrio de poderes. Revista de Estudios Extremeños 57 (1): 181-198.

Harvey, D. (1989): Urbanismo y desigualdad social. Siglo Veintiuno de España. Madrid.

Herrero, T.R.; Gómez-Elvira, M.A.; Pérez, E.; Martín, J.L. (2006): Estudio de accesibilidad a las zonas verdes urbanas mediante sistemas de información geográfica. En XVIII Congreso de Ingeniería Gráfica. Barcelona: 1-12.

Hillsdon, M.; Panter, J.; Foster, C.; Jones, A. (2006): The relationship between access and quality of urban green space with population physical activity. Public Health 20(12): 11271132.

Honjo,T.; Takakura,T. (1991): Simulation of thermal effects of urban green areas on their surrounding areas. Energy and Buildings 15-16: 443-446.

Hortelano, L.A. (1998): Salamanca ciudad. Desarrollo espacial. En Díaz, L. coord.: El libro de oro de Salamanca: un siglo en imágenes. El Adelanto de Salamanca y Ediciones. Salamanca: 66121.

Hortelano, L.A. (2000): Cambios territoriales y retos de futuro de la ciudad de Salamanca al sur del río Tormes. Salamanca: Revista de Estudios 44: 67-81.

Howard, E. (1965): Garden Cities of To-morrow. The M.I.T. Press. Massachusetts.

Huertos, A. (2007): El espacio periurbano de la ciudad de Zamora. Génesis y desarrollo de un proceso de transformación espacial en la periferia de una pequeña ciudad española. Anuario del Instituto de Estudios Zamoranos Florián de Ocampo 24: 335-398.

Humpel, N.; Owen, N.; Leslie, E.; Marshall, A. ; Bauman, A.E.; Sallies, J.F. (2004): Associations of location and perceived environmental attributes with walking in neighbourhoods. American Journal of Health Promotion 18: 239-242.

Hungría, P. (2003): Estudio de biogeografía urbana. Propuesta metodológica y aplicación al distrito de Hortaleza (Madrid). UAM Ediciones. Madrid

Kaplan, R. (1993): The role of nature in the context of the workplace. Landscape and Urban Planning 26: 193-201.

Kaplan, S. (1995): The restorative benefits of nature: toward an integrative framework. Journal of Environmental Psychology 15: 169-182.

Kim, J.; Kaplan, R. (2004): Physical and psychological factors in sense of community: New urbanist Kentlands and nearby Orchard Village. Environment and Behavior 36(3): 313-340. 
Konijnendijk, C.C.; Nilsson, K.; Randrup, T.B.; Schipperijn, J. (2005): Urban forest and trees. A reference book. Springer. Heidelberg.

Konijnendijk, C.C.; Ricard, R.M.; Kenney, A.; Randrup, T.B. (2006): Defining urban forestry. A comparative perspective of North America and Europe. Urban Forestry and Urban Greening 4(3-4): 93-103.

Kuchelmeister, G.; Braatz, S. (2000): Una nueva visión de la silvicultura urbana. Revista Internacional de Silvicultura e Industrias Forestales Unasylva 173: 3-12.

Kuo, F.; Sullivan, W. (2001): Aggression And Violence In The Inner City. Environment and Behavior 33 (4): 543-571.

Levent, T.B.; Vreeker, R.; Nijkamp, P. (2004): Multidimensional Evaluation of Urban Green Spaces: A Comparative Study on European Cities. Serie Research Memoranda 0017, VU University Amsterdam. Amsterdam.

Levent, T.B.; Vreeker, R.; Nijkamp, P. (2009): A Multi-Criteria Evaluation of Green Spaces in European Cities. European Urban and Regional Studies 16 (2): 193-213.

López-Torrecilla, J. (2009): Experiencia infantil del medio urbano y la calidad ambiental percibida en barrios de la ciudad de Madrid. Medio Ambiente y Comportamiento Humano 10 (1-2): 97-115.

Maas, J.; Verheij, R.; Groenewegwn, P.; De Vries, S.; Spreeuwenberg, P. (2006): Green space, urbanity, and health: how strong is the relation? Journal of Epidemiology \& Community Health 60-7: 587-592.

Madureira, H. (2012): Revitalizar a cidade pelo planeamento da estrutura verde. XIII Coloquio Ibérico de Geografía. Respuestas de la Geografía ibérica a la crisis actual. Santiago de Compostela: 644-654.

Madureira, H.; Andersen, T.; Monteiro, A. (2011): Green structure and planning evolution in Porto. Urban Forestry \& Urban Greening 10(2): 141-149.

Magalhães, M. (1992): Espaços Verdes Urbanos. Direção Geral do Ordenamento do Território. Lisboa.

Mallarach, J.; Vilagrasa, J. (2002): Los procesos de desconcentración urbana en las ciudades medias españolas. Ería: Revista Cuatrimestral de Geografía 57: 57-70.

Maller, C.; Townsend, M.; Pryor, A.; Brown, P.; St. Leger, L. (2005): Healthy nature healthy people: 'Contact with nature' as an upstream health promotion intervention for populations. Health Promotion International 21: 45-54.

Martinez-Fernández, C.; Audirac, I., Fol, S.; Cunningham-Sabot, E. (2012): Shrinking Cities: Urban Challenges of Globalization. International Journal of Urban and Regional Research 36: 213-225.

McPherson, E.G. (1992): Accounting for benefits and costs of urban green space. Landscape and Urban Planning 22: 41-51.

McPherson, E.G..; Nowak, D.J.; Heisler, G.; Grimmond, S.; Souch, C.; Grant, R.; Rowntree, R.A. (1997): Quantifying urban forest structure, function, and value: the Chicago Urban Forest Climate Project. Urban Ecosystems 1: 49-61.

McPherson, E.G.; Nowak, D.J.; Rowntree, R.A. (1994): Chicago's urban forest ecosystem: results of the Chicago urban forest climate project. U.S. Department of Agriculture. Pennsylvania.

McPherson, E.G.; Simpson, J.R. (1995): Shade Trees as a Demand-Side Resource. Home energy March/April: 9-17.

McPherson, E.G.; Simpson, J.R.; Peper, P.J.; Xiao, Q. (1999): Benefit-cost analysis of Modesto's municipal urban forest. Journal of Arboriculture 25 (5): 235-248.

Miller, R.W. (1998): Planeación del enverdecimiento urbano. En: Krishnamurthy, L., Nacimiento, J. eds.: Areas verdes urbanas en Latinoamérica y el Caribe. Universidad Autónoma de Chapingo. Chapingo: 83-108.

Miranda, F. (1985): Desarrollo urbanístico de postguerra en Salamanca. Colegio de Arquitectos de León. Salamanca. 
Muga, M. (1980): La utilización de los espacios verdes en la ciudad de Logroño. Cuadernos de Investigación Geográfica 6: 71-93.

Mumford, L. (1956): Historia natural de la urbanización. En Gutiérrez, A. y Naredo, J.M. coords: La incidencia de la especie humana sobre la faz de la Tierra (1955-2005). Universidad de Granada. Granada: 503-527.

Naredo, J.M. (1998): Sobre la insostenibilidad de las actuales conurbaciones y el modo de paliarla. Gaceta Ecológica 55: 21-40.

Naredo, J.M. (2000): Ciudades y crisis de civilización. Documentación Social 119: 13-38.

Nel-lo, O., Muñoz, F. (2004): El proceso de urbanización. En Romero, J. coord.: Geografía bumana: procesos, riesgos e incertidumbres en un mundo globalizado. Ariel. Barcelona: 255-332.

Newman, O. (1972): Defensive Space: Through Urban Design. Macmillan. New York.

Nielsen, T.; Hansen, K. (2007): Do green areas affect health? Results from a Danish survey on the use of green areas and health indicators. Health \& Place 13-4: 839-850.

Nilsson, K.; Randrup, T. (1998): Silvicultura urbana y periurbana. Revista Internacional de Silvicultura e Industrias Forestales Unasylva 173: 87-101.

Nilsson, K.; Randrup, T.; Tvedt, T. (1997): Aspectos tecnológicos del enverdecimiento urbano. En: Krishnamurthy, L., Nacimiento, J. eds.: Universidad Autónoma de Chapingo. Chapingo: 39-81.

Nowak, D.J. (1993): Atmospheric carbon reduction by urban trees. Journal of Environmental Management 37: 207-217.

Nowak, D.J.; Civerolo, K.L.; Rao, S.T.; Sistla, G. (2000): A modelling study of the impact of urban trees on ozone. Atmospheric Environment 34: 1601-1613.

Nowak, D.J.; Crane, D.E. (2002): Carbon storage and sequestration by urban trees in the USA. Environmental Pollution 116: 381-389.

Nowak, D.J.; Crane, D.E.; Stevens, J.C.; Ibarra, M. (2001): Brooklyn's urban forest. USDA Forest Service General Technical Report. Newtown Square, Pennsylvania.

Nowak, D.J.; Dwyer, J.F. (2007): Understanding the benefits and costs of urban forest ecosystem. En Kuser, J.E.: Handbook of urban and Community Forestry in the Northeast. Kluweer Academic / Plenum Publishers. New York: 11-22.

Nowak, D.J.; Dwyer, J.F.; Childs, G. (1997): Los beneficios y costos del enverdecimiento urbano. En: Krishnamurthy, L., Nacimiento, J. coords.: Areas verdes urbanas en Latinoamérica y el Caribe. Universidad Autónoma de Chapingo. Chapingo: 17-38.

Nowak, D.J.; McPherson, E.G. (1993): Cuantificación del impacto ambiental de los árboles en Chicago. Revista Internacional de Silvicultura e Industrias Forestales Unasylva 173: 39-44.

Nowak, D.J.; Stevens, J.C.; Sisinni, S.M.; Luley, C.J. (2002): Effects of urban tree management and species selection on atmospheric carbon dioxide. Journal of Arboriculture 28 (3): 113-122.

Ochoa, J.M. (1999): La vegetación como instrumento para el control microclimático. Universitat Politècnica de Catalunya. Barcelona.

Ochoa, J.M. (2009): Ciudad, vegetación e impacto climático. Erasmus Ediciones. Villafranca del Penedés.

Pardinas, F. (1969): Metodología y técnica de investigación en ciencias sociales. Ciclo Veintiuno Editores. México D.F.

Parra, F. (1996): Ciudad y entorno natural. En VVAA: Primer catálogo de buenas prácticas. Ciudades para un futuro más sostenible. Ministerio de Fomento. Madrid. http://habitat.aq.upm.es/cs/p3/a015.html.

Pérez R.; Talavera, R. (2008): "Verde Urbano" y calidad ambiental: claves para una intervención más sostenible en el espacio urbano. En $9^{\circ}$ Congreso Nacional del Medio Ambiente. Madrid: 1-20.

Pikora, T.; Giles-Corti, B.; Bull, F.; Jamrozik, K,; Donovan, A. (2003): Developing a framework for assessment of the environmental determinants of walking and cycling. Social Science and Medicine 56: 1693-1703. 
Polése, M. (1994): Économie urbaine et régionale: logique spatiale des mutations économiques. Economica. París.

Priego-González, C. (2004): El paisaje y los espacios públicos urbanos en el desarrollo de las sociedades. CNEAM. Valsaín (Segovia).

Priego-González, C. (2008): Environmental, social and economic benefits of tree plantations for urban societies. IESA-CSIC. Córdoba.

Puyuelo, M.; Gual, J.; Galbis, M. (2005): Espacios abiertos urbanos y personas mayores: una experiencia llevada a cabo en distintos parques de la ciudad de Castellón sobre el diseño y su interacción con la población anciana. Universitat Jaume I. Castellón de la Plana.

Ramos, D. (2001): Transporte aéreo, territorio e insularidad en Canarias: una aproximación en el umbral del siglo XXI. Tauro Producciones. Tegueste (Tenerife).

Ramos, D. (2006): Cuando el mercado levanta el vuelo. Transporte aéreo, territorio y sustentabilidad en la Unión Europea: un análisis crítico. Universidad de Salamanca. Salamanca. Tesis Doctoral.

Roca, J. (2003): La delimitación de la ciudad: ¿una cuestión imposible? Ciudad y Territorio: Estudios Territoriales 135: 17-36.

Rodero, V. (2008): Diseño metodológico para la evaluación del desarrollo territorial en comarcas rurales productoras de alimentos de calidad. Universidad de Salamanca. Salamanca. Trabajo de Grado.

Rodríguez, I.; Díaz, E. M. (2003): Las secuelas de la ciudad negocio: los parques urbanos de Madrid. En VVAA: La ciudad: nuevos procesos, nuevas respuestas. Universidad de León, Secretariado de Publicaciones y Medios Audiovisuales. León: 193-204.

Rodríguez, L.; Alarcón, M. (2003): Para llamarse ciudad. Áreas verdes y espacios de paz en la ciudad presente. Revista Austral de Ciencias Sociales 7: 129-138.

Romero, H.; Toledo, X.; Órdenes, F.; Vásquez, A. (2001): Ecología urbana y gestión sustentable de las ciudades intermedias chilenas. Ambiente y Desarrollo 17 (4): 45-51.

Romero, J.L. (2006): Estudio de accesibilidad a las zonas verdes urbanas mediante sistemas de información geográficos. INGEGRAF. XVIII Congreso Internacional de Ingeniería Gráfica. Barcelona: 1-12.

Rubio, J.M. (1995): Ambiente urbano y fauna beneficiada por el mismo. Anales de Geografía de la Universidad Complutense 15: 619-624.

Sánchez, F. (2012): El modelo urbanístico en época de bonanza. Universidad de Valladolid. Valladolid. Tesis Doctoral.

Sánchez-Barbudo, M.C. (1989): El método de trabajo de campo y laboratorio en las ciencias naturales de EGB. Aula: Revista de Pedagogía de la Universidad de Salamanca 2: 89-91.

Sánchez-Barbudo, M.C. (1993): Modelo de un proyecto interdisciplinar para Educación Primaria: Estudio de un jardín de un pueblo o ciudad. Aula: Revista de Pedagogía de la Universidad de Salamanca 5: 201-208.

Salom, J.; Casado, J.M. (2007): Movilidad cotidiana y mercados locales de trabajo en el Comunidad Valenciana, 1991-2001. Boletín de la AGE 44: 5-28.

Salvo, A.E.; García-Verdugo, J.C. (1993): Naturaleza urbanizada: estudios sobre el verde en la ciudad. Universidad de Málaga. Málaga.

Sanesi, G.; Chiarello, F. (2006): Residents and urban green spaces: The case of Bari. Urban Forestry Urban Greenning 4(3-4): 125-134.

Santana, P.; Costa, C.; Santos, R.; Loureiro, A. (2008): Amadora, Cidade Saudável e Activa. $3^{\circ}$ Prémio de Reconhecimento da Rede Portuguesa de Cidades Saudáveis. Lisboa.

Santana, P.; Costa, C.; Santos, R.; Loureiro, A. (2010): O papel dos Espaços Verdes Urbanos no bem-estar e saúde das populações. Revista de Estudos Demográficos 48: 6-33.

Santana, P.; Nogueira, H.; Santos, R.; Costa, C. (2007a): Avaliação da Qualidade Ambiental dos Espaços Verdes Urbanos no Bem-estar e na Saúde. En Santana, P. coord: $A$ Cidade e a Saúde. Almedina. Coimbra: 219-237. 
Santana, P.; Nogueira, H.; Santos, R.; Costa, C. (2007b): Melhorar a Saúde na Amadora Intervindo no Ambiente Físico e Social. En Santana, P. coord: A Cidade e a Saúde. Almedina. Coimbra: $147-154$.

Santana, P.; Santos, R.; Costa, C.; Loureiro, A. (2011): Urban green spaces and their impact in the health of a population. TRIA Rivista Internazionale di Cultura Urbanistica 6: 57-69.

Santana, P.; Santos, R.; Costa, C.; Roque, N.; Loureiro, A. (2010): Crime: Impacts of Urban Design. TRLA Rivista Internazionale di Cultura Urbanistica 5: 39-48.

Santana, P.; Santos, R.; Nogueira, H. (2009): The link between local environment and obesity: a multilevel analysis in the Lisbon Metropolitan Area, Portugal. Social Science and Medicine 68 (4): 601-609.

Sanz, R. (2005): Los espacios verdes urbanos en A Coruña. IDEGA. Documentos de Traballo. Xeografía 17: 7-54.

Savard, J.G. (1978): Statistiques. MRW. Montreal.

Segovia, O.; Neira, H. (2005): Espacios públicos urbanos: una contribución a la identidad y confianza social y privada. Revista INVI 20(55): 126-182.

Senabre, D. (2002a): Desarrollo urbanístico de Salamanca en el siglo XX: planes y proyectos en la organización de la ciudad. Junta de Castilla y León, Consejería de Fomento. Valladolid.

Senabre, D. (2002b): Rehabilitar cascos históricos. Los paradigmas de Vitoria y Salamanca. En Turismo y transformaciones urbanas en el siglo XXI. Coloquio de Geografía Urbana. Almería: 581591.

Senabre, D. (2003a): Desarrollo urbano y urbanística del municipio de Salamanca en el siglo XX. Scripta Nova, vol. VII, no 146.

Senabre, D. (2003b): La construcción de viviendas en Salamanca (1984-2002). Scripta Nova, vol. VII, no 146.

Seoane, F.A.; Evans, J.M. (2001): Beneficios del arbolado urbano evaluación del balance entre secuestro, demanda energética y otros impactos. Avances en Energías Renovables y Medio Ambiente 5 (01): 07-11.

Serrano, J.M. (2006): Aglomeraciones y áreas urbanas en España, dimensión y tendencias. Breves precisiones. Lurralde: Investigación y Espacio 29: 115-142.

Simpson, J.R.; McPherson, E.G. (1998): Simulation of tree shade impacts on residential energy use for space conditioning in Sacramento. Atmospheric Environment 32 (1): 69-74.

Singh, V.S.; Pandey, D.N.; Chaudhry, P. (2010): Urban Forests and Open Green Spaces: Lessons for Jaipur, Rajasthan (India). Rajasthan State Pollution Control Board, Jaipur (India).

Smardon, R.C. (1988): Perception and Aesthetics of the Urban Environment: Review of the Role of Vegetation. Landscape and Urban Planning 15: 85-106.

Soleckiav, W.D.; Welchb, J.M. (1995): Urban parks: green spaces or green walls? Landscape and Urban Planning 32: 93-106.

Sorensen, M.; Barzetti, V.; Keipi, K.; Williams, J. (1998): Manejo de las áreas verdes urbanas. Documento de buenas prácticas $\mathrm{n}^{\mathrm{o}} 109$. Washington D.C.

Sukkopp, H., Werner, P. (1989): Naturaleza en las ciudades. MOPT. Madrid.

Taylor, A.; Kuo, F.; Sullivan, W. (2001): Coping with ADD. The surprising connection to green play settings. Environment and Behaviour 33(1): 54-77.

Terán, F. (1978): Planeamiento urbano en la España contemporánea: historia de un proceso imposible. Gustavo Gili. Barcelona.

Tzoulas, K.; Korpela, K.; Yli-Pelkonen, V.; Kazmierczak, A.; Niemela, J.; James, P. (2007): Promoting ecosystem and human health in urban areas using green infrastructure: A literature review. Landscape Urban Planning 81 (3): 167-178.

Ulrich, R.S. (1984): View thought a window may influence recovery from surgery. Science, New Series 224: 420-421.

Ulrich, R.S. (1986): Human responses to vegetation and landscapes. Landscape and Urban Planning 13: 29-44. 
Ulrich, R.S.; Simons, R.F.; Losito, B.D.; Fiorito, E.; Miles, M.A.; Zelson, M. (1991): Stress recovery during exposure to natural and urban environments . Journal of Environmental Psychology 11: 201-230.

UNFPA (2007): Estado de la población mundial 2007. http://www.unfpa.org/swp/2007/

Urones, C.; Sánchez-Barbudo, M.C.; Vacas, J.M. (1995): La investigación del entorno natural de la escuela como recurso didáctico. Aula: Revista de Pedagogía de la Universidad de Salamanca 7: 307-316.

Van Herzele, A.; Wiedemann, T. (2003): A monitoring tool for the provision of accessible and attractive urban green spaces. Landscape Urban Plan 63: 109-126.

Viela Lozano, J. (2004): Distribución del arbolado urbano en la ciudad de Fuenlabrada y su contribución a la calidad del aire. Ciudady Territorio: Estudios Territoriales 140: 419-427.

Villar, J. (2000): De ciudad encorsetada a desparramada metrópolis: Salamanca en el siglo XX. Salamanca: Revista de Estudios 45: 189-220.

Villar, J.; Alonso, J.L.; Sánchez, J.L. (1995): Salamanca: etapa de gran crecimiento. En Cabero, V.; Izquierdo, I.; Llorente, J.M. coords.: Salamanca y sus comarcas. Editorial Mediterráneo, D.L. Madrid: 337-344.

Villar, J.; Burrieza, B. (1995): Salamanca: la consolidación como capital de provincia. En Cabero, V.; Izquierdo, I.; Llorente, J.M. coords.: Salamanca y sus comarcas. Editorial Mediterráneo, D.L. Madrid: 329-336.

Villar, J.; Hortelano, L.A.; Ortega, V.M. (1995): Salamanca: la ciudad actual y la expansión hacia la periferia. En Cabero, V.; Izquierdo, I.; Llorente, J.M. coords.: Salamanca y sus comarcas. Editorial Mediterráneo, D.L. Madrid: 345-352.

Villar y Macías, M. (1887): Historia de Salamanca. Libro IX, Desde la Guerra de la Independencia hasta nuestros días. Librería Cervantes. Salamanca.

Virgili, M.A. (1979): Desarrollo urbanístico y arquitectónico de Valladolid: (1851-1936). Ayuntamiento, Servicio de Información y de Publicaciones. Valladolid.

VVAA (1991): NUREC atlas of agglomerations in the European Union, vol 1-3. NUREC Network. Duisburg.

VVAA (2001): Directrices de Ordenación del Territorio de Valladolid y Entorno. Junta de Castilla y León. Valladolid.

VVAA (2007): Estudio sociodemográfico del municipio de Zamora. Ayuntamiento de Zamora. Zamora.

Westphal, L.M. (2003): Urban greening and social benefits: a study of empowerment outcomes. Journal of Arboriculture 29: 137-147.

Whitford, V.; Ennos, A.R.; Handley, J.F. (2001): City form and natural process indicators for the ecological performance of urban areas and their application to Merseyside, UK. Landscape and Urban Planning 57(2): 91-103.

\section{$\underline{\text { Recursos electrónicos }}$}

Ayuntamiento de Salamanca: <http://87.106.254.62/navegador_web_aytosalamanca $>$ Ayuntamiento de Valladolid: < http://www.valladolidencifras.es/zonas.html>

Ayuntamiento de Zamora: < http://www.ayto-zamora.org $>$

Direction Générale Institutions et Population: <http://www.ibz.rrn.fgov.be>

El escarabajo verde (Paraísos de Barrio):

<http://www.rtve.es/television/20130420/paraisos-barrio/641080.shtml>

Instituto Nacional de Estadística (INE): <htttp://www.ine.es $>$

Instituto Geográfico Nacional (IGN): < htttp://www.ign.es $>$

Ministerio de Fomento: <http://www.fomento.gob.es>

Normativa sobre urbanismo y ordenación del territorio en Castilla y León:

<http://www.jcyl.es/web/jcyl/ViviendaUrbanismo> 


\section{ANEXOS}

\subsection{Cuestionarios}

\section{CUESTIONARIO ANÓNIMO SOBRE EL VERDE URBANO EN LA CIUDAD DE SALAMANANCA}

VNIVERSïDAD

DSALAMANCA

Dia y fecha:

Departamento de Geografia Nombre del Parque:

$\begin{array}{llll}\text { 1. Edad: aEntre } 18 \text { y } 30 & \text { a Entre } 30 \text { a } 45 & \text { a Entre } 45 \text { a } 65 & \text { Más de } 65\end{array}$

2. Ocupación: a Estudia a Trabaja a No tiene empleo a Jubilado

$\begin{array}{lll}\text { 3. Sexo: } \square \text { M Hujer } & \text { 4. Barrio: }\end{array}$

5. ¿Con qué frecuencia visita los espacios verdes de la ciudad?

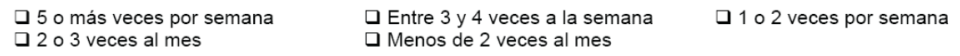

6. ¿En qué época del año visita con más frecuencia a los espacios verdes?

$$
\text { 口Primavera a Verano a Otoño alnvierno a Entodas JEnninguna }
$$

7. ¿A qué hora del día suele visitarlos?

$$
\begin{array}{lll}
\text { a De 8:00 a 12:00 } & \text { a De 12:00 a 14:00 } & \text { D De 14:00 a 16:00 } \\
\text { De 16:00 a 18:00 } & \text { व De 18:00 a 20:00 } & \text { व De 20:00 a-24:00 }
\end{array}
$$

8. ¿Suele visitar un espacio concreto o alterna entre varios?

$$
\text { a Suelo visitar uno a Suelo visitar dos a Suelo visitar tres a Suelo visitar más de tres }
$$

\begin{tabular}{|c|c|c|c|}
\hline $\begin{array}{l}\text { La distancia desde mi casa } \\
\text { El tipo de usuarios habituales } \\
\text { El mantenimiento }\end{array}$ & $\begin{array}{l}\text { El clima a El miedo } \\
\text { Mi disponibilidad de tiempo } \\
\text { Otros: }\end{array}$ & $\begin{array}{l}\text { L Los equipamientos } \\
\text { La presencia de perros }\end{array}$ & $\begin{array}{l}\text { D El tamaño } \\
\square \text { La vegetación }\end{array}$ \\
\hline
\end{tabular}

9. ¿Qué espacio verde de la ciudad es el que más veces visita?

10. ¿Qué le hace acudir a ese espacio verde y no a otro?

11. ¿Cuánto tarda en llegar desde su casa al espacio verde más cercano?

$$
\text { a Menos de } 5 \mathrm{~min} \quad \mathrm{De} 5 \mathrm{~min} \text { a } 15 \mathrm{~min} \quad \square \text { De } 15 \mathrm{~min} \text { a } 30 \mathrm{~min} \text { प Más de } 30 \mathrm{~min}
$$

12. ¿Por qué visita los espacios verdes?

\begin{tabular}{|c|c|c|}
\hline $\begin{array}{l}\text { a Fuentes } \\
\text { ZZonas de agua } \\
\square \text { Zonas deportivas } \\
\text { Zona de actividad física pera mayores } \\
\end{array}$ & $\begin{array}{l}\text { Z Zonas de juego infantil } \\
\text { Barbacoas } \\
\text { Otros: }\end{array}$ & $\begin{array}{l}\text { ZZonas de sombra } \\
\square \text { Áreas aisladas para perros }\end{array}$ \\
\hline
\end{tabular}

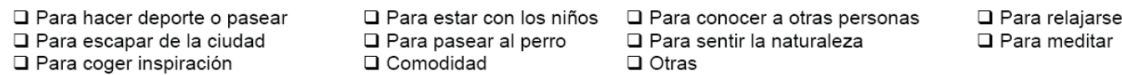

13. ¿Qué sentimientos le producen las áreas verdes?

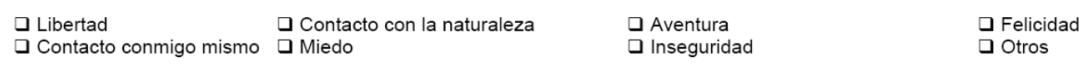

14. ¿Qué equipamientos utiliza en los espacios verdes urbanos?

15. ¿Cómo valora la accesibilidad que tiene desde su casa a los espacios verdes?

Muymala a Mala a Regular a Buena a Muybuena

16. ¿Cree que los espacios verdes son necesarios en la ciudad? a 
NiVERSIDAD

DSALAMANCA

Departamento de Geografia
CUESTIONARIO ANÓNIMO SOBRE EL VERDE URBANO EN LA CIUDAD DE SALAMANANCA

Día y fecha:

Nombre del Parque:

17. Evalúe de 1 a 10 el conjunto de espacios verdes de la ciudad:

18. ¿Realiza actividades para las que no está preparado el parque?

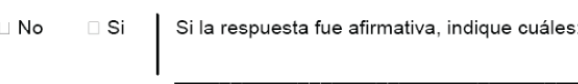

19. ¿Qué mejoraría de los espacios verdes de la ciudad?

\begin{tabular}{|c|c|}
\hline $\begin{array}{l}\text { Sus equipamientos } \\
\text { Su localización }\end{array}$ & $\begin{array}{l}\text { La vegetación } \\
\text { Nada }\end{array}$ \\
\hline
\end{tabular}

20. Evalúe de 1 a 10, los siguientes espacios verdes de la ciudad de Salamanca:

\begin{tabular}{|l|l|}
\hline \multicolumn{1}{|c|}{ Espacios verdes } & Calificación \\
\hline Jardines del Hospital Clínico & \\
\hline Parque botánico de Huerta Otea & \\
\hline Parque Pablo Picasso & \\
\hline Parque de los Jcsuitas & \\
\hline Parque de Ciudad Rodrigo & \\
\hline Parque de San Francisco & \\
\hline Verde urbano de la Vaguada de la Palma & \\
\hline Parque de la Alamedilla & \\
\hline Parque de Würzburg & \\
\hline Paseo fluvial & \\
\hline Parque de Villar y Macías & \\
\hline Verde urbano de La Salle & \\
\hline Parque de Vistahermosa & \\
\hline
\end{tabular}

21. A parte de los anteriormente citados, ¿visita usted otros espacios verdes?

22. ¿Cree que en los espacios verdes urbanos habitan especies animales salvajes?

23. ¿Tiene algún tipo de alergia vinculada a la vegetación urbana?

24. ¿Le parecen bonitos los espacios verdes de la ciudad?
口 Si, mucho
口 Si, bastante
$\square$ Regular
a No, no mucho
a No, nada

25. ¿Utiliza los espacios verdes de la ciudad como sitio de reunión con otras personas?
\lrcorner No Si $\mid$
Si la respuesta fue afirmativa, indique cuándo:
๑ En días entre semana
๑ Durante la primavera
$\square$ Los fines de semana
व Durante el verano
๑ En días festivos

26. ¿Cree que los espacios verdes son un buen lugar para mejorar la relación entre los ciudadanos?

$\square \mathrm{Si}$

$\square$ No

27. ¿Le parece que los espacios verdes urbanos pueden llegar a ser lugar de vacaciones para personas que quieran o no puedan viajar fuera de la ciudad, como personas mayores o personas con menos ingresos?

a $\mathrm{Si}$

№ 
CUESTIONARIO ANÓNIMO SOBRE EL VERDE URBANO EN LA CIUDAD DE VALLADOLID

VNIVERSIDAD

DSALAMANCA

Día y fecha:

Departamento de Geografia

Nombre del Parque:

1. Edad:

口 Entre 30 a 45

口 Entre 45 a 65

\ Más de 65

2. Ocupación: a Estudia

$\square$ Trabaja

$\square$ No tiene empleo

Jubilado

3. Sexo:

$\square$ Hombre

․ Mujer

4. Barrio

5. ¿Con que frecuencia visita los espacios verdes de la ciudad?

$$
\begin{array}{lll}
\text { a } 50 \text { más veces por semana } & \text { antre } 3 \text { y } 4 \text { veces a la semana } & \square 102 \text { veces por semana } \\
\text { a } 203 \text { veces al mes } & \text { Menos de } 2 \text { veces al mes } &
\end{array}
$$

6. ¿En qué época del año visita con más frecuencia a los espacios verdes?
a Primavera
$\square$ Verano
๑ Otoño
$\square$ Invierno
En todas
$\square$ En ninguna

7. ¿A qué hora del día suele visitarlos?

$\begin{array}{lll}\text { a De 8:00 a 12:00 } & \text { प De 12:00 a 14:00 } & \text { D De 14:00 a 16:00 } \\ \text { व De 16:00 a 18:00 } & \text { D De 18:00 a 20:00 } & \text { व De 20:00 a-24:00 }\end{array}$

8. ¿Suele visitar un espacio concreto o alterna entre varios?
Suelo visitar uno
๑ Suelo visitar dos
$\square$ Suelo visitar tres
प Suelo visitar más de tres

9. ¿Qué espacio verde de la ciudad es el que más veces visita? (MÁXIMO 3 ESPACIOS VERDES)

10. ¿Qué le hace acudir a ese espacio verde y no a otro?

\begin{tabular}{|c|c|c|c|}
\hline $\begin{array}{l}\text { La distancia desde mi casa } \\
\text { El tipo de usuarios habituales } \\
\text { El mantenimiento }\end{array}$ & $\begin{array}{l}\text { El clima } \\
\text { Mi disponibilidad de tiempo } \\
\text { Otros: }\end{array}$ & $\begin{array}{l}\text { Los equipamientos } \\
\text { La presencia de perros }\end{array}$ & $\begin{array}{l}\square \text { El tamaño } \\
\square \text { La vegetación }\end{array}$ \\
\hline
\end{tabular}

11. ¿Cuánto tarda en llegar desde su casa al espacio verde más cercano?
Menos de 5 min
$\square$ De 5 min a 15 min
$\square$ De $15 \mathrm{~min}$ a $30 \mathrm{~min}$
Más de $30 \mathrm{~min}$

12. ¿Por qué visita los espacios verdes?

$\begin{array}{ll}\text { D Para hacer deporte o pasear } & \text { Q Para estar con los niños } \\ \text { D Para escapar de la ciudad } & \text { Q Para pasear al perro } \\ \text { a Para coger inspiración } & \text { C Comodidad }\end{array}$

Para conocer a otras personas Para sentir la naturaleza

13. ¿Qué sentimientos le producen las áreas verdes?

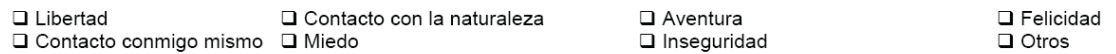

14. ¿Qué equiparnierılus ulili<a en los espacius verdes urbarıus?

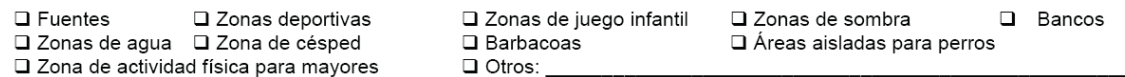

15. ¿Cómo valora la accesibilidad que tiene desde su casa a los espacios verdes?

Muy mala a Mala a Regular a Buena a Muy buena

16. ¿Cree que los espacios verdes son necesarios en la ciudad? uSi 
CUESTIONARIO ANÓNIMO SOBRE EL VERDE URBANO EN LA CIUDAD DE VALLADOLID

VNiVERSIDAD

DSALAMANCA

Día y fecha:

Número de encuesta

Departamento de Geografia

Nombre del Parque:

17. Evalúe de 1 a 10 el conjunto de espacios verdes de la ciudad:

18. ¿Realiza actividades para las que no está preparado el parque?

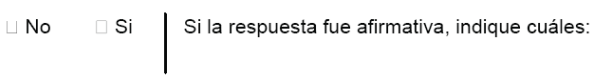

19. ¿Qué mejoraría de los espacios verdes de la ciudad?

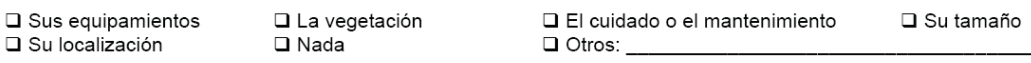

20. Evalúe de 1 a 10 , los siguientes espacios verdes de la ciudad de Valladolid:

\begin{tabular}{|l|l|}
\hline \multicolumn{1}{|c|}{ Espacios verdes } & Calificación \\
\hline Verde urbano Calle Morena - Feria de Muestras & \\
\hline Parque del Mediodía & \\
\hline Plaza del Ejército & \\
\hline Campo Grande & \\
\hline Verde urbano Calle de la Vega de Valdetronco - Villas sur & \\
\hline Parque de CANTERAC & \\
\hline Verde urbano de Huerta del Rey & \\
\hline Parque de las Moreras & \\
\hline Parque de COVARESA & \\
\hline Jardín botánico & \\
\hline Ladera Sur Parquesol - Fuente de Dios & \\
\hline Parque de la Alameda & \\
\hline Verde urbano Calle Arribes del Duero (UEMdC) & \\
\hline
\end{tabular}

21. A parte de los anteriormente citados, ¿visita usted otros espacios verdes?

22. ¿Cree que en los espacios verdes urbanos habitan especies animales salvajes?

23. ¿Tiene algún tipo de alergia vinculada a la vegetación urbana?

24. ¿Le parecen bonitos los espacios verdes de la ciudad?
a Si, mucho
口 Si, bastante
๑ Regular
] No, no mucho
$\square$ No, nada

25. ¿Utiliza los espacios verdes de la ciudad como sitio de reunión con otras personas?
No $\mathrm{Si} \mid \mathrm{Si}$ Si la respuesta fue afirmativa, indique cuándo: $\square$ En días entre semana $\square$ Los fines de semana ๑ Durante el verano ๑ Durante la primavera ๑n días festivos

26. ¿Cree que los espacios verdes son un buen lugar para mejorar la relación entre los ciudadanos?

$$
\text { a Si a No }
$$

27. ¿Le parece que los espacios verdes urbanos pueden llegar a ser lugar de vacaciones para personas que quieran 0 no puedan viajar fuera de la ciudad, como personas mayores o personas con menos ingresos? 
CUESTIONARIO ANÓNIMO SOBRE EL VERDE URBANO EN LA CIUDAD DE ZAMORA

VNiVERSIDAD

DSALAMANCA

Día y fecha:

Número de encuesta

Departamento de Geografí

Nombre del Parque:

1. Edad: aEntre 18 y 30

口 Entre 30 a 45

D Entre 45 a 65

口 Más de 65

2. Ocupación: a Estudia

๑ Trabaja

$\square$ No tiene empleo

$\square$ Jubilado

3. Sexo:

] Hombre

․ Mujer

4. Barrio:

5. ¿Con qué frecuencia visita los espacios verdes de la ciudad?

$$
\begin{array}{lll}
\text { a } 5 \text { o más veces por semana } & \text { Dentre } 3 \text { y } 4 \text { veces a la semana } & \square 102 \text { veces por semana } \\
\square 203 \text { veces al mes } & \square \text { Menos de } 2 \text { veces al mes } &
\end{array}
$$

6. ¿En qué época del año visita con más frecuencia a los espacios verdes?
๑ Primavera
$\square$ Verano
○ Otoño
$\square$ Invierno
$\square$ En todas
• En ninguna

7. ¿A qué hora del día suele visitarlos?

\begin{tabular}{|c|c|}
\hline $\begin{array}{l}\square \text { De } 8: 00 \text { a } 12: 00 \\
\square \text { De } 16: 00 \text { a } 18: 00\end{array}$ & $\begin{array}{l}\text { a De } 12: 00 \text { a } 14: 00 \\
\text { a De } 18: 00 \text { a } 20: 00\end{array}$ \\
\hline
\end{tabular}

8. ¿Suele visitar un espacio concreto o alterna entre varios?
๑ Suelo visitar uno
口 Suelo visitar dos
- Suelo visitar tres
๑ Suelo visitar más de tres

9. ¿Qué espacio verde de la ciudad es el que más veces visita? (MÁXIMO 3 ESPACIOS VERDES)

10. ¿Qué le hace acudir a ese espacio verde y no a otro?

\begin{tabular}{|c|c|c|c|}
\hline $\begin{array}{l}\text { La distancia descle mi casa } \\
\text { El tipo de usuarios habituales }\end{array}$ & $\begin{array}{l}\text { El clima El miedo } \\
\text { Mi disponibilidad de tiempo }\end{array}$ & $\begin{array}{l}\text { Los equipamientos } \\
\text { La presencia de perros }\end{array}$ & $\begin{array}{l}\text { 口 El tamaño } \\
\text { a La vegetación }\end{array}$ \\
\hline
\end{tabular}

11. ¿Cuánto tarda en llegar desde su casa al espacio verde más cercano?
口 Menos de $5 \mathrm{~min}$
De 5 min a 15 min
De $15 \mathrm{~min}$ a $30 \mathrm{~min}$
Más de 30 min

12. ¿Por qué visita los espacios verdes?

a Para hacer deporte o pasear
Para escapar de la ciudad

- Para estar con los niños Q Para pasear al perro Comodidad
Para conocer a otras personas Para sentir la naturaleza

$\square$ Para relajarse

13. ¿Qué sentimientos le producen las áreas verdes?
$\square$ Libertad
Contacto con la naturaleza
a Aventura
Aventura
$\checkmark$ Contacto conmigo mismo $\square$ Miedo

14. ¿Qué equipamientos utiliza en los espacios verdes urbanos?

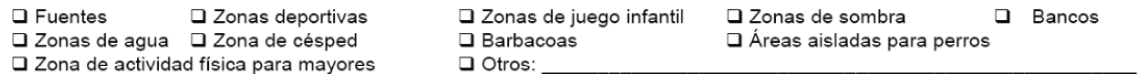

15. ¿Cómo valora la accesibilidad que tiene desde su casa a los espacios verdes?
Muy mala
a Mala
๑ Regular
Buena
auy buena

16. ¿Cree que los espacios verdes son necesarios en la ciudad?

$\square \mathrm{Si}$

$\square$ No 
CUESTIONARIO ANÓNIMO SOBRE EL VERDE URBANO EN LA CIUDAD DE ZAMORA

VNiVERSIDAD

DSALAMANCA

Día y fecha:

Número de encuesta

Departamento de Geografia

Nombre del Parque:

17. Evalúe de 1 a 10 el conjunto de espacios verdes de la ciudad:

18. ¿Realiza actividades para las que no está preparado el parque?

No

Si $\mid$

Si la respuesta fue afirmativa, indique cuáles:

19. ¿Qué mejoraria de los espacios verdes de la ciudad?

\begin{tabular}{|c|c|}
\hline $\begin{array}{l}\text { Sus equipamientos } \\
\text { Su localización }\end{array}$ & $\begin{array}{l}\text { La vegetación } \\
\text { Nada }\end{array}$ \\
\hline
\end{tabular}

20. Evalúe de 1 a 10, los siguientes espacios verdes de la ciudad de Zamora:

\begin{tabular}{|l|l|}
\hline \multicolumn{1}{|c|}{ Espacios verdes } & Calificación \\
\hline Verde urbano Avenida Cardenal Cisneros - Universidad & \\
\hline Parque del Castillo y de la Catedral & \\
\hline Verde urbano Puerta Nueva & \\
\hline Parque de la Marina & \\
\hline Bosque de Valorio (parte urbana) & \\
\hline Margen derecha del Duero & \\
\hline Parque de Peña Trevinca & \\
\hline Jardines de la Vaguada & \\
\hline Verde urbano Avda Cardenal Cisneros - Frente EROSKI & \\
\hline Parque de San Martín & \\
\hline Parque de León Felipe & \\
\hline Margen Izquierda del Duero & \\
\hline Verde urbano C/ Nta Sra de las Mercedes - S. José Obrero & \\
\hline
\end{tabular}

21. A parte de los anteriormente citados, ¿visita usted otros espacios verdes?

22. ¿Cree que en los espacios verdes urbanos habitan especies animales salvajes?

23. ¿Tiene algún tipo de alergia vinculada a la vegetación urbana?

24. ¿Le parecen bonitos los espacios verdes de la ciudad?
Si, mucho
$\square \mathrm{Si}$, bastante
$\square$ Regular
No, no mucho
№, nada

25. ¿Utiliza los espacios verdes de la ciudad como sitio de reunión con otras personas?
No
Si la respuesta fue afirmativa, indique cuándo:
- En dias entre semana
- Los fines de semana
๑ Durante el verano
$\checkmark$ Durante la primavera
๑ En días festivos

26. ¿Cree que los espacios verdes son un buen lugar para mejorar la relación entre los ciudadanos?

a $\mathrm{Si}$

a No

27. ¿Le parece que los espacios verdes urbanos pueden llegar a ser lugar de vacaciones para personas que quieran 0 no puedan viajar fuera de la ciudad, como personas mayores o personas con menos ingresos?

$\square \mathrm{Si}$

$\square$ No 


\subsection{Descripción paisajística del verde urbano disponible}

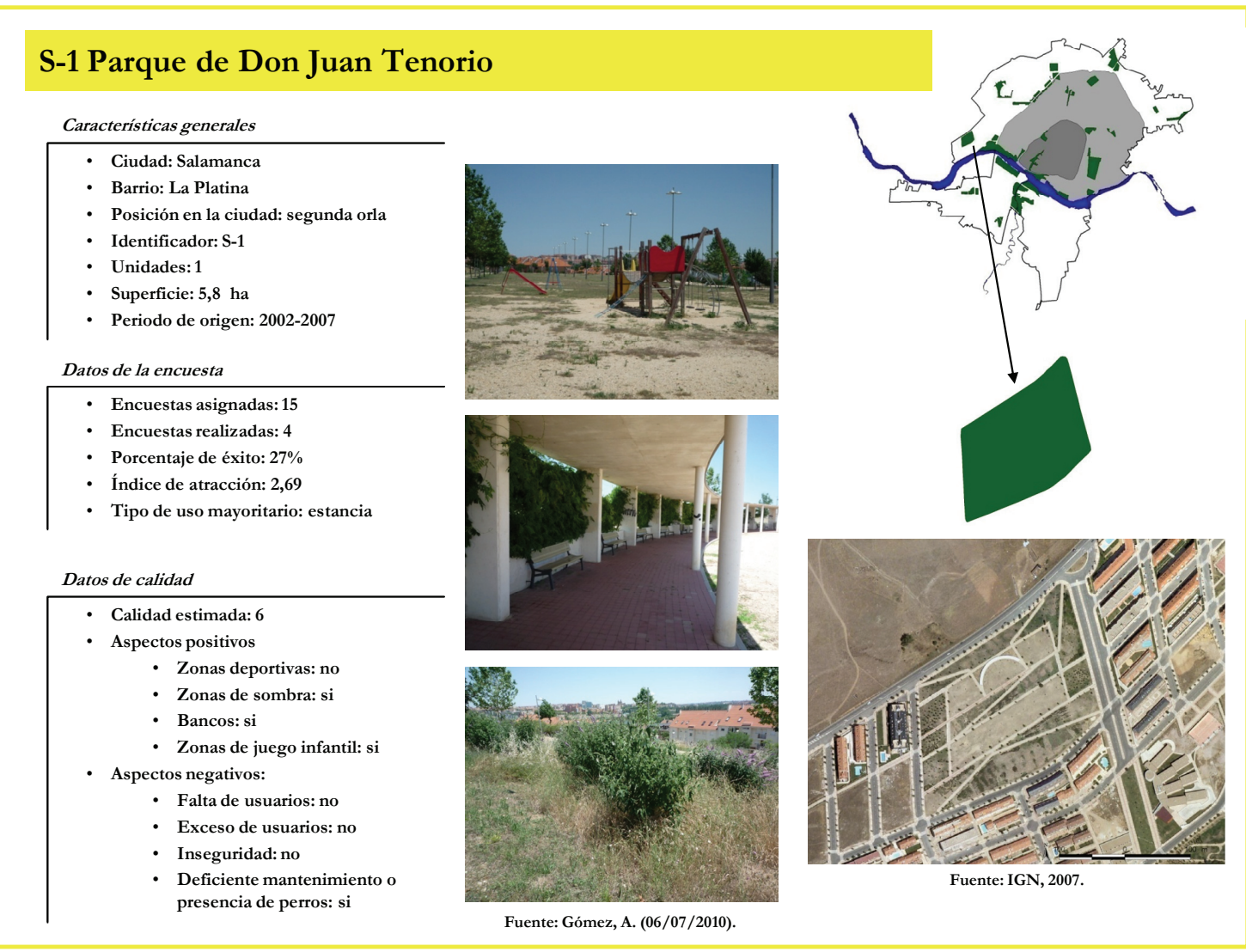

\section{S-2 Complejo deportivo Salas Bajas}

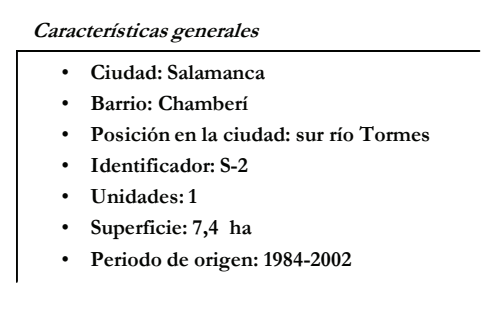

\section{Datos de la encuesta \\ - Encuestas asignadas: 19 \\ - Encuestas realizadas: 20 \\ - Porcentaje de éxito: $105 \%$ \\ - Índice de atracción: 1,08 \\ - Tipo de uso mayoritario: actividad física}

Datos de calidad

- Aspectos positivos

- Zonas deportivas: si

- Zonas de sombra: si

- Bancos: si

- Zonas de juego infantil: no

- Aspectos negativos:

- Falta de usuarios: no

- Exceso de usuarios: no

- Inseguridad: no

- Deficiente mantenimiento o presencia de perros: no
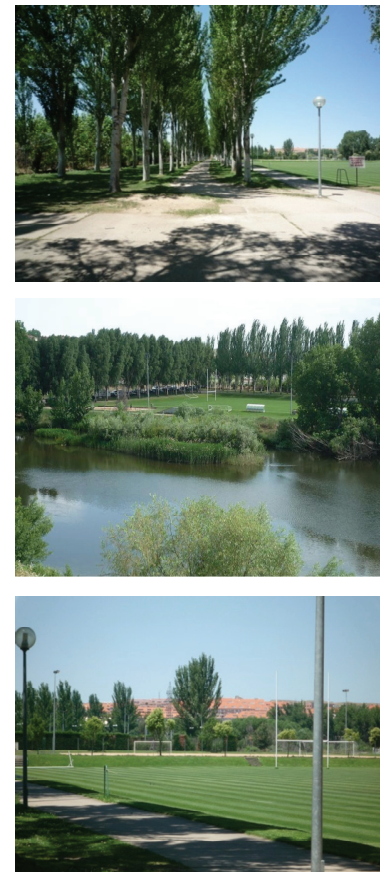

Fuente: Gómez, A. (06/07/2010).

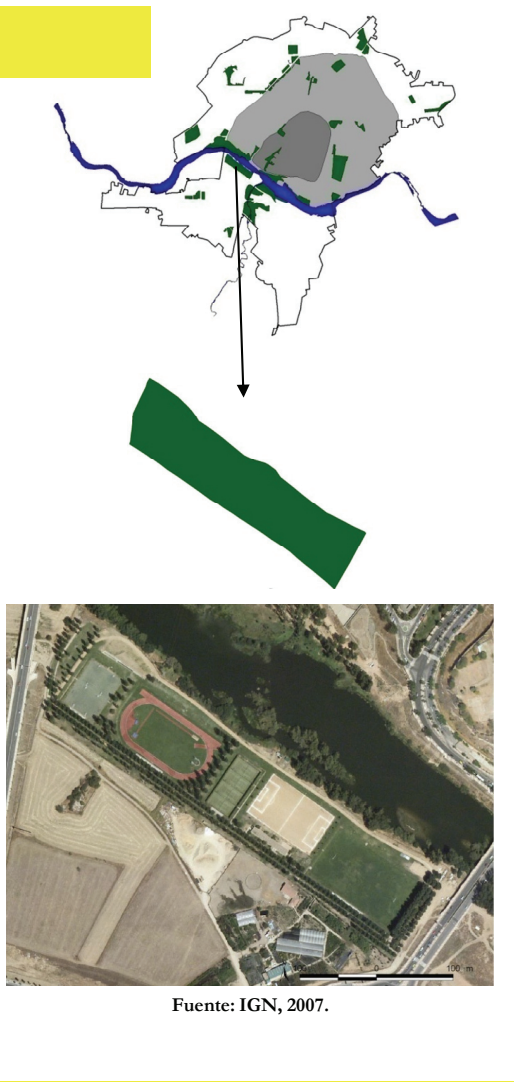




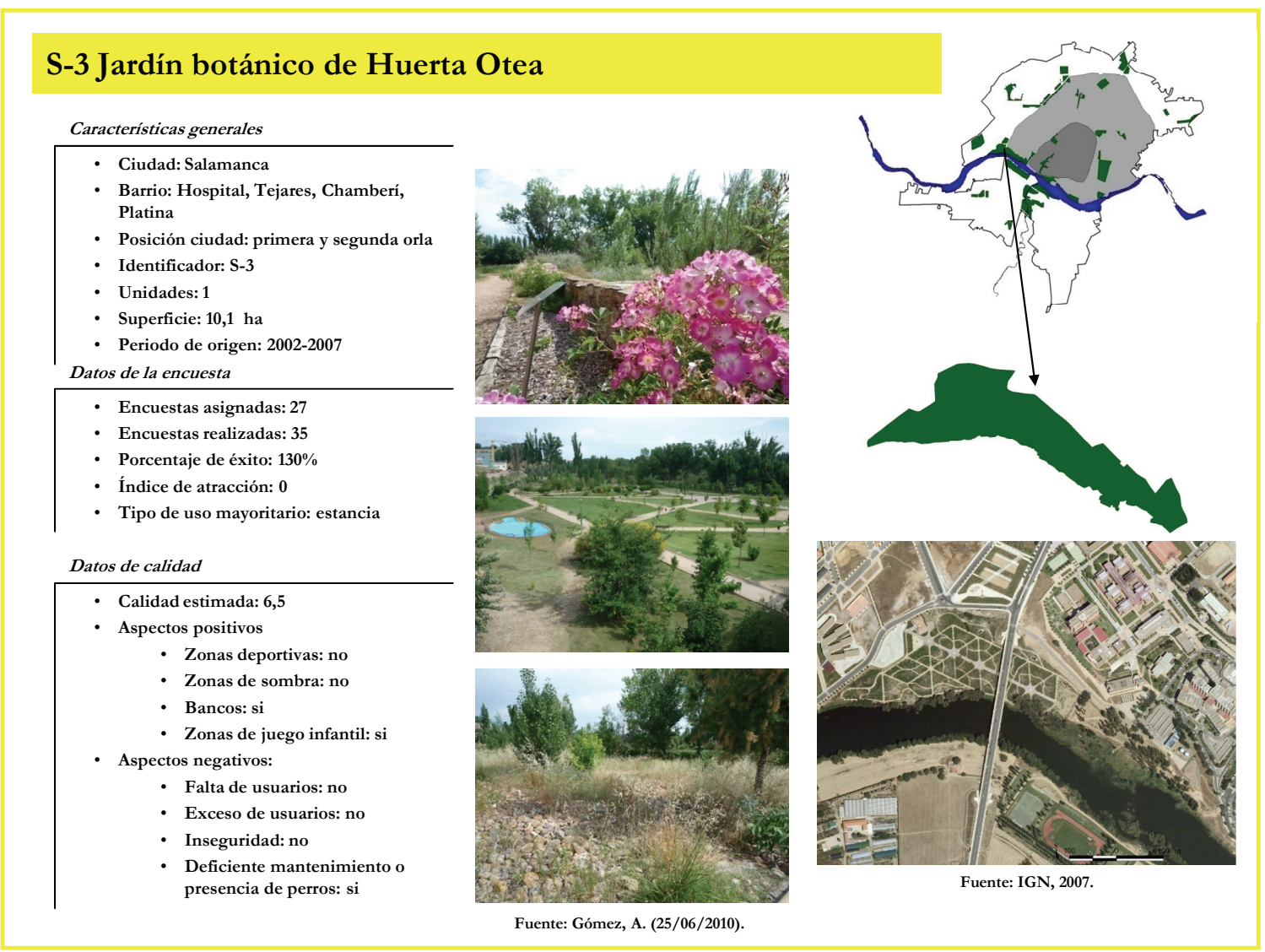

\section{S-4 Parque de los Jesuitas}

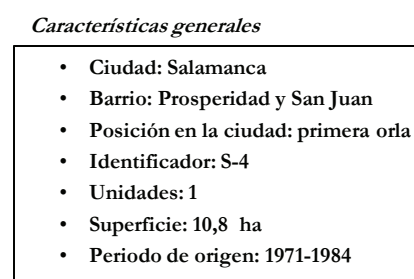

Datos de la encuesta

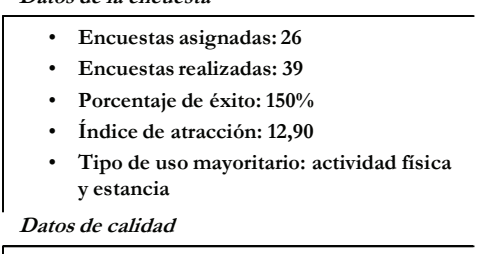

Datos de calidad

- Aspectos positivos

- Zonas deportivas: si

- Zonas de sombra: si

- Bancos: si

- Zonas de juego infantil: si

- Aspectos negativos:

- Falta de usuarios: no

- Exceso de usuarios: no

- Inseguridad: no

- Deficiente mantenimiento o presencia de perros: si
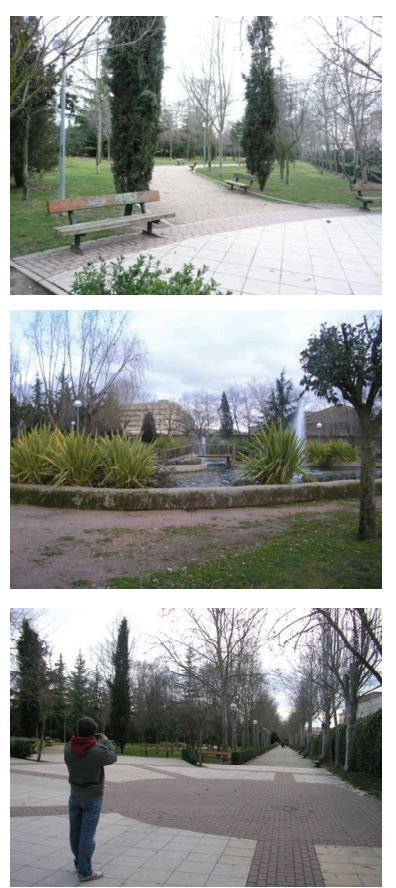

Fuente: Gómez, A. (01/02/2009).

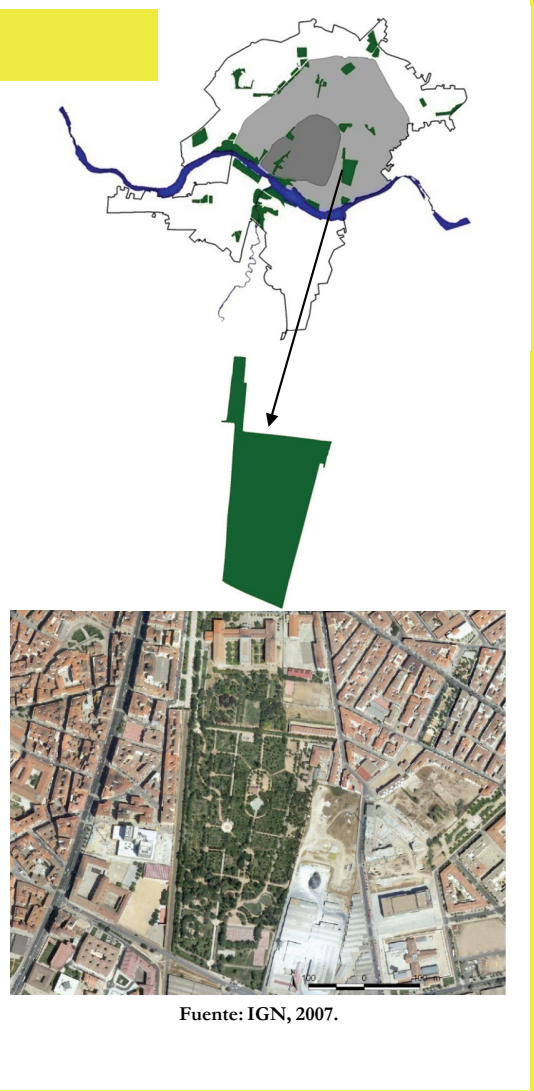




\section{S-5 Jardines del Hospital Clínico}

Características generales

- Ciudad: Salamanc

- Barrio: Hospital

- Posición en la ciudad: primera orla

- Identificador: S-5

- Unidades: 1

- Superficie: 0,8 ha

- Periodo de origen: 1971-1984

Datos de la encuesta

- Encuestas asignadas: 2

- Encuestas realizadas: 6

- Porcentaje de éxito: $300 \%$

- Índice de atracción: $-2,69$

- Tipo de uso mayoritario: zona de tránsito

Datos de calidad

\section{- Calidad estimada: 4,5}

- Aspectos positivos

- Zonas deportivas: no

- Zonas de sombra: si

- Bancos: no

Zonas de juego infantil: no

- Aspectos negativos:

- Falta de usuarios: no

- Exceso de usuarios: si

- Inseguridad: no

- Deficiente mantenimiento o presencia de perros: no
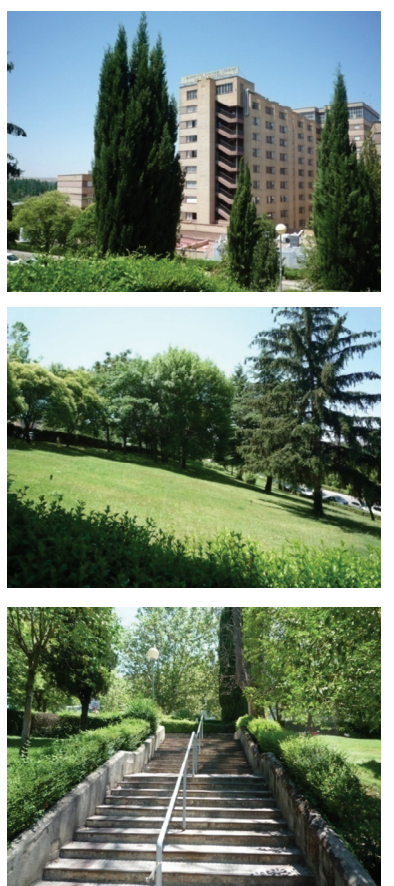

Fuente: Gómez, A. (06/07/2010).

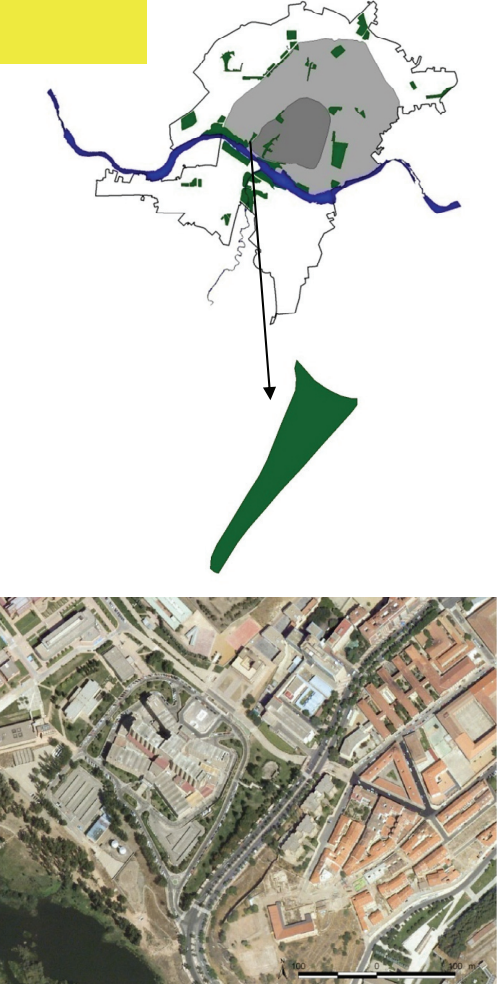

Fuente: IGN, 2007.

S-7 Verde urbano de la Vaguada de la Palma

Características generales

Ciudad: Salamanca

- Barrio: Universidad y San Vicente

- Posición en la ciudad: centro histórico

- Identificador: S-7

- Unidades: 1

- Superficie: 2,3 ha

- Periodo de origen: 1984-2002

Datos de la encuesta

- Encuestas asignadas: 6

- Encuestas realizadas: 10

- Porcentaje de éxito: $167^{\circ}$

- Índice de atracción: $-0,46$

- Tipo de uso mayoritario: zona de tránsito

Datos de calidad

- Calidad estimada: 6

- Aspectos positivos

- Zonas deportivas: no

- Zonas de sombra: si

- Bancos: si

- Zonas de juego infantil: no

- Aspectos negativos:

- Falta de usuarios: si

- Exceso de usuarios: no

- Inseguridad: no

- Deficiente mantenimiento o presencia de perros: no
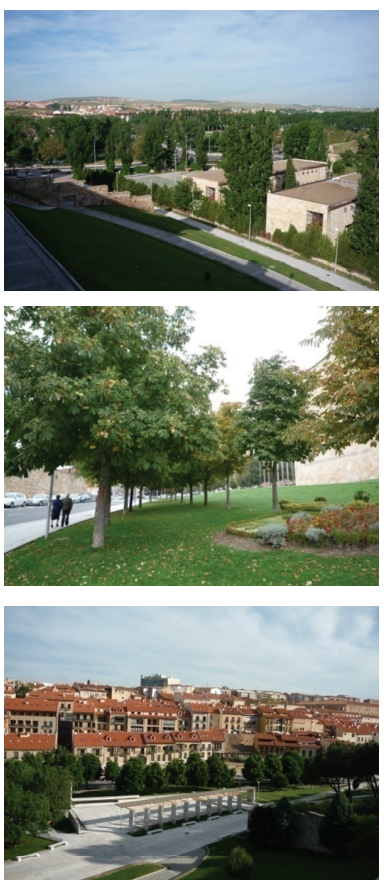

Fuente: Gómez, A. (09/10/2009 y 01/06/2010)

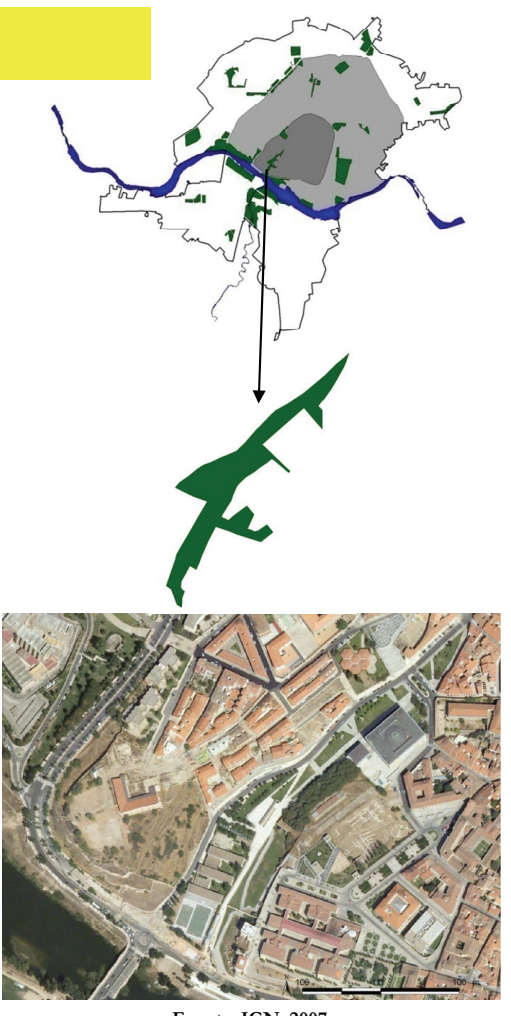

Fuente: IGN, 2007. 


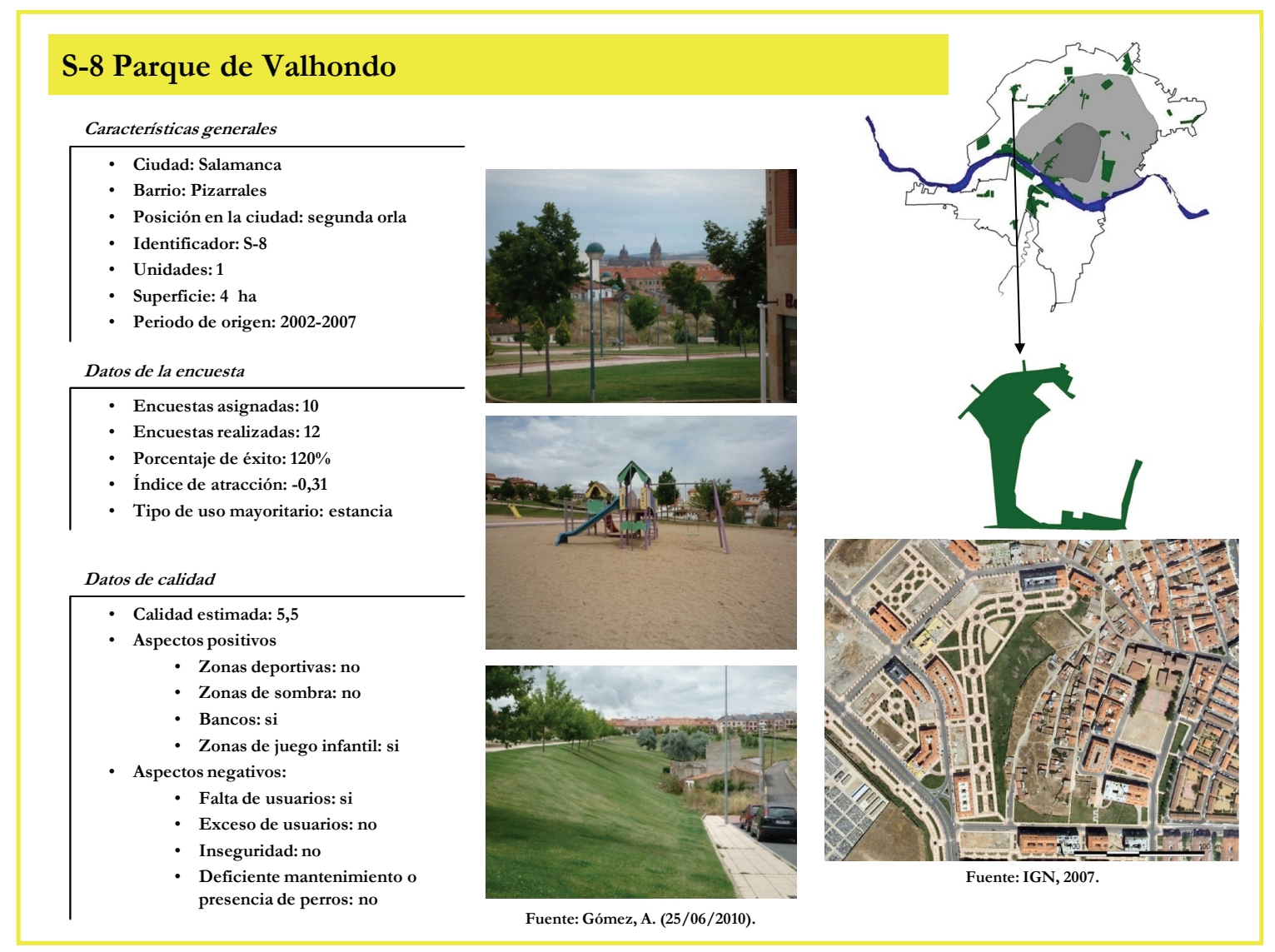

\section{S-9 Campo de San Francisco}

Características generales
$\begin{aligned} & \text { - Ciudad: Salamanca } \\ & \text { - Barrio: Úrsulas - San Marcos } \\ & \text { - Posición en la ciudad: centro histórico } \\ & \text { - Identificador: S-9 } \\ & \text { - Unidades: } 1 \\ & \text { - Superficie: } 1,3 \text { ha } \\ & \text { - Periodo de origen: anterior a } 1956\end{aligned}$

Datos de la encuesta

- Encuestas asignadas: 3

- Encuestas realizadas: 3

- Porcentaje de éxito: $100 \%$

- Índice de atracción: 2,95

- Tipo de uso mayoritario: estancia

Datos de calidad

$$
\begin{aligned}
& \text { - Calidad estimada: } 5 \\
& \text { - Aspectos positivos } \\
& \text { • Zonas deportivas: no } \\
& \text { - Zonas de sombra: si } \\
& \text { - } \text { Bancos: si } \\
& \text { - Zonas de juego infantil: si } \\
& \text { Aspectos negativos: } \\
& \text { - Falta de usuarios: no } \\
& \text { - Inseguridad: si } \\
& \text { - Deficiente mantenimiento o } \\
& \text { presencia de perros: si }
\end{aligned}
$$

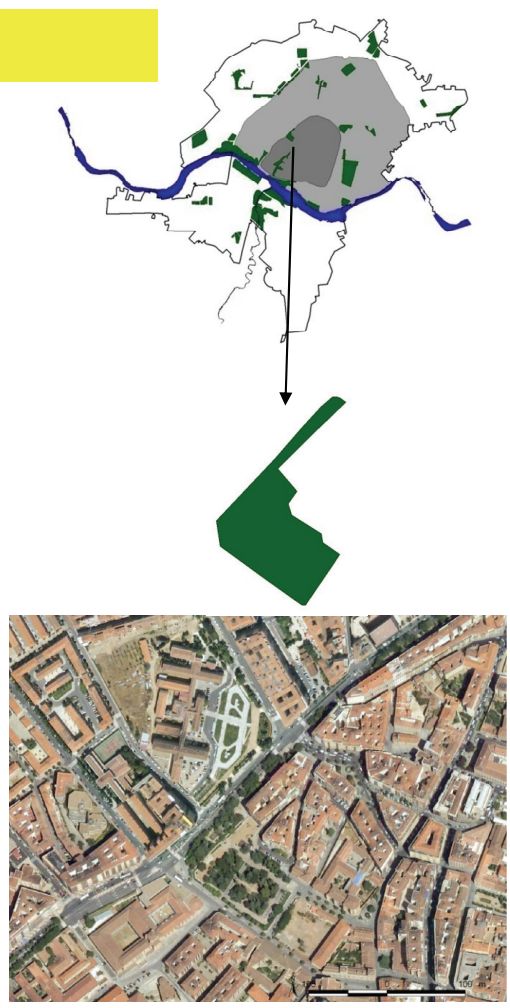

Fuente: IGN, 2007.
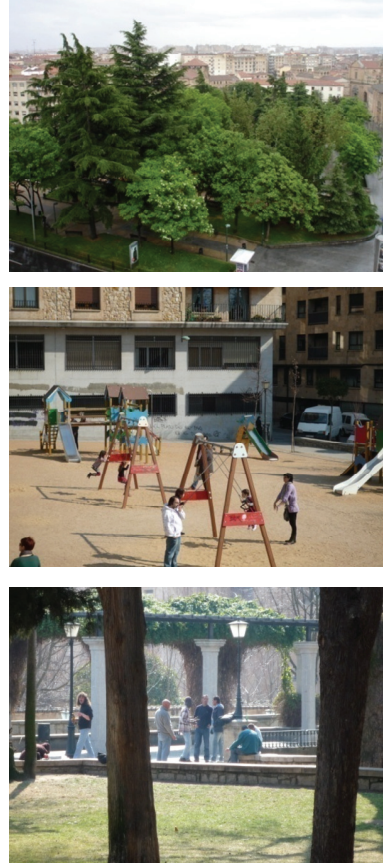

Fuente: Gómez, A. (20/06/2010y 25/02/2012). 


\section{S-10 Parque de la Alamedilla}

Características generales

- Barrio: Alamedilla

- Posición en la ciudad: primera orla

- Identificador: S-10

- Unidades: 1

- Superficie: 2,2 ha

- Periodo de origen: anterior a 1956

Datos de la encuesta

- Encuestas asignadas: 6

- Encuestas realizadas: 6

- Porcentaje de éxito: $100 \%$

- Índice de atracción: 3,86

- Tipo de uso mayoritario: estancia

Datos de calidad

- Calidad estimada: 6

- Aspectos positivos

- Zonas deportivas: no

- Zonas de sombra: si

- Bancos: si

- Zonas de juego infantil: si

- Aspectos negativos:

- Falta de usuarios: no

- Exceso de usuarios: si

- Inseguridad: no

- Deficiente mantenimiento o presencia de perros: no
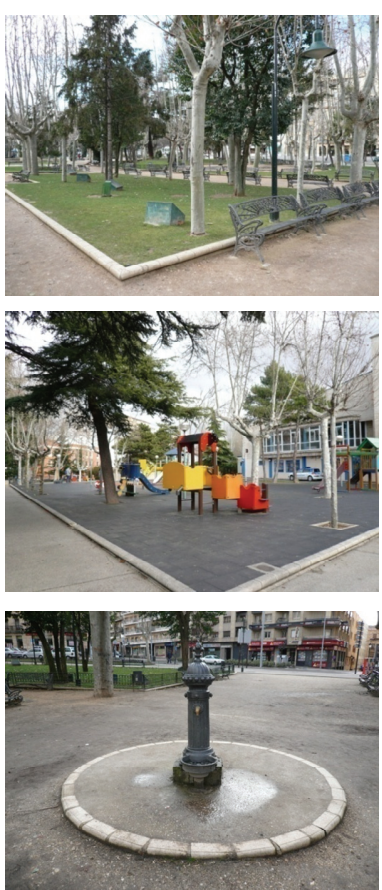

Fuente: Gómez, A. (01/02/2009).
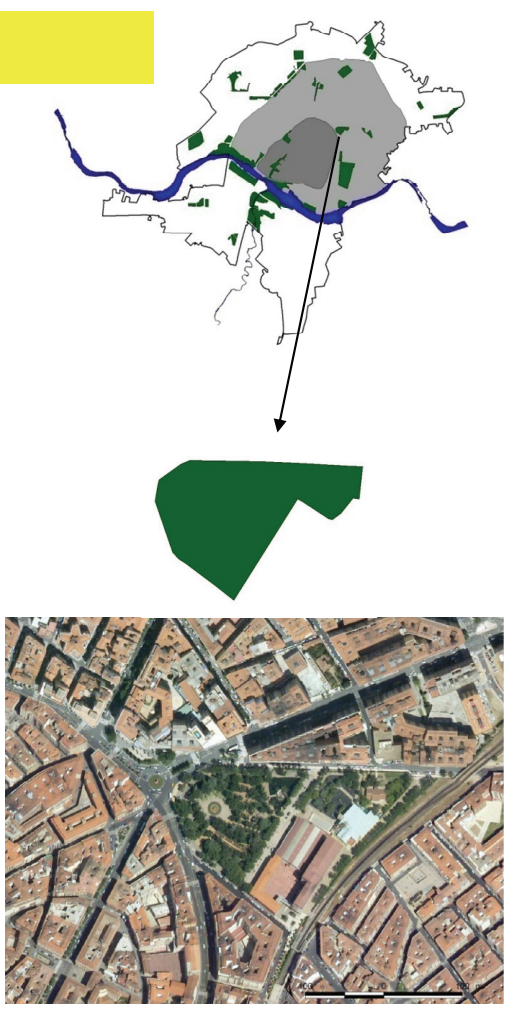

Fuente: IGN, 2007.

\section{S-11 Parque Picasso}

- Ciudad: Salamanca

- Barrio: Rollo

- Posición en la ciudad: primera orla

- Identificador: S-11

- Unidades: 2

- Superficie: 1 ha

- Periodo de origen: entre 1971 y 1984

\section{Datos de la encuesta}

- Encuestas asignadas: 3

- Encuestas realizadas: 3

- Porcentaje de éxito: $100 \%$

- Índice de atracción: 4,30

- Tipo de uso mayoritario: estancia

Datos de calidad

- Calidad estimada: 6

- Aspectos positivos

- Zonas deportivas: no

- Zonas de sombra: si

- Bancos:si

- Zonas de juego infantil: si

- Aspectos negativos:

- Falta de usuarios: no

- Exceso de usuarios:

- Inseguridad: no

- Deficiente mantenimiento o presencia de perros: no
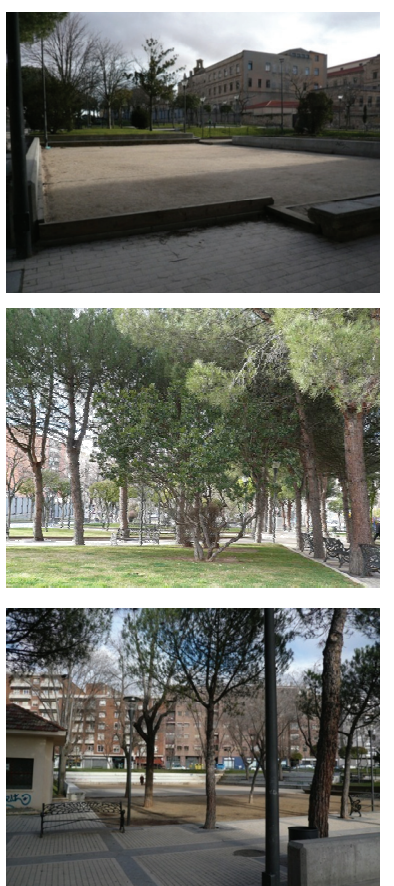

Fuente: Gómez, A. (01/02/2009).

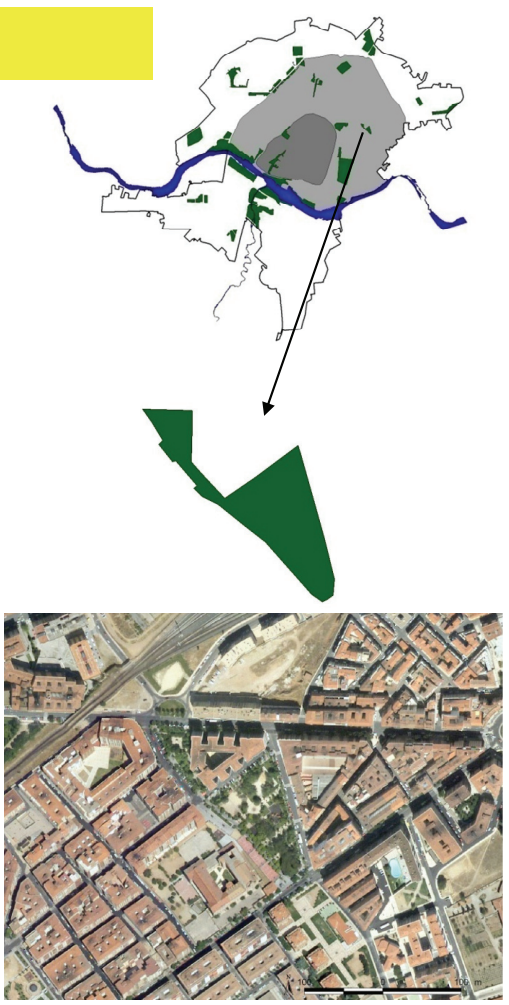

Fuente: IGN, 2007. 


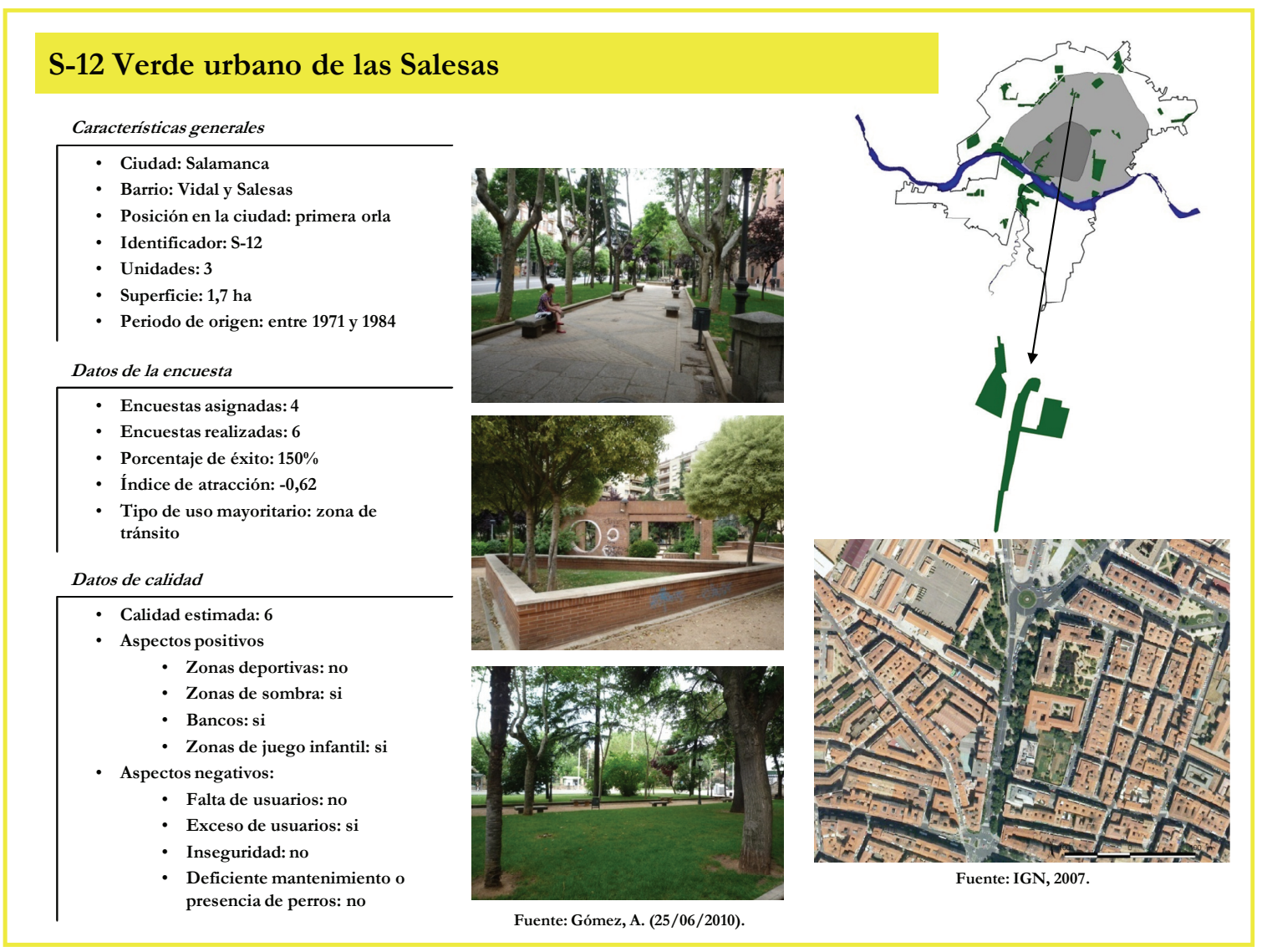

\section{S-13 Plaza de Burgos}

Características generales

- Ciudad: Salamanca

- Barrio: Capuchinos

- Posición en la ciudad: segunda orla

- Identificador: S-13

- Unidades: 1

- Superficie: 2,7 ha

- Periodo de origen: entre 1984 y 2002

Datos de la encuesta

- Encuestas asignadas: 7

- Encuestas realizadas: 7

- Porcentaje de éxito: $100 \%$

- Índice de atracción: 1,11

- Tipo de uso mayoritario: actividad física y estancia

Datos de calidad

- Calidad estimada: 7,5

- Aspectos positivos

- Zonas deportivas: si

- Zonas de sombra: no

- Bancos: si

- Zonas de juego infantil: si

- Aspectos negativos:

- Falta de usuarios: no

- Exceso de usuarios: no

- Inseguridad: no

- Deficiente mantenimiento o presencia de perros: no
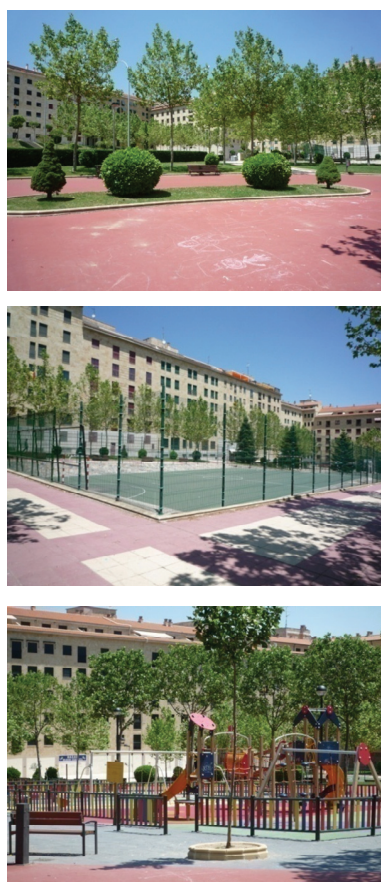

Fuente: Gómez, A. (06/07/2010).
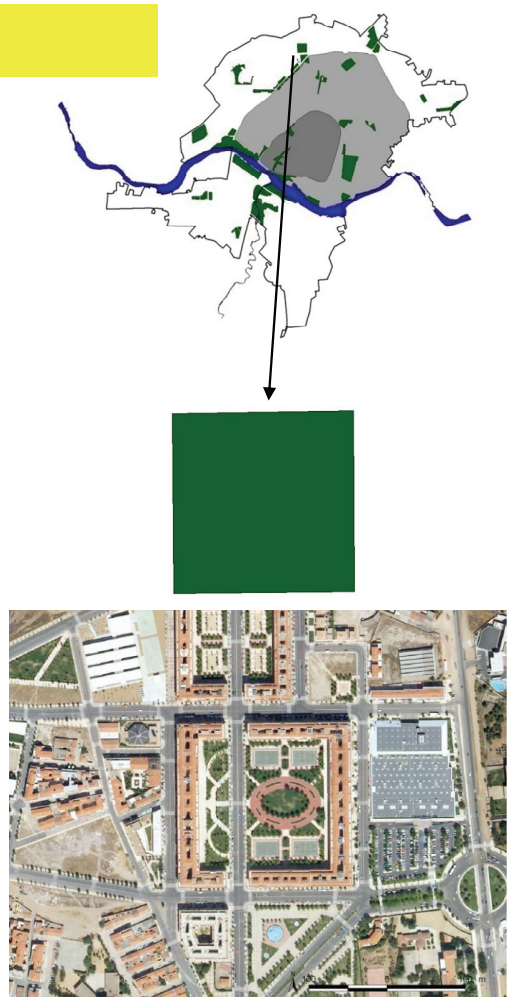

Fuente: IGN, 2007. 


\section{S-15 Parque de Würzburg}

Características generales

- Ciudad: Salamanca

- Barrio: Chinchibarra y Garrido Norte

- Posición en la ciudad: segunda orla

- Identificador: S-15

- Unidades: 2

- Superficie: 6 ha

- Periodo de origen: entre 1984 y 2002

Datos de la encuesta

- Encuestas asignadas: 15

- Encuestas realizadas: 15

- Porcentaje de éxito: $100 \%$

- Índice de atracción: 0,54

- Tipo de uso mayoritario: actividad física y estancia

Datos de calidad

- Calidad estimada: 6

- Aspectos positivos

- Zonas deportivas: si

- Zonas de sombra: si

- Bancos: si

- Zonas de juego infantil: si

- Aspectos negativos:

- Falta de usuarios: no

- Exceso de usuarios: no

- Inseguridad:si

- Deficiente mantenimiento o presencia de perros: si
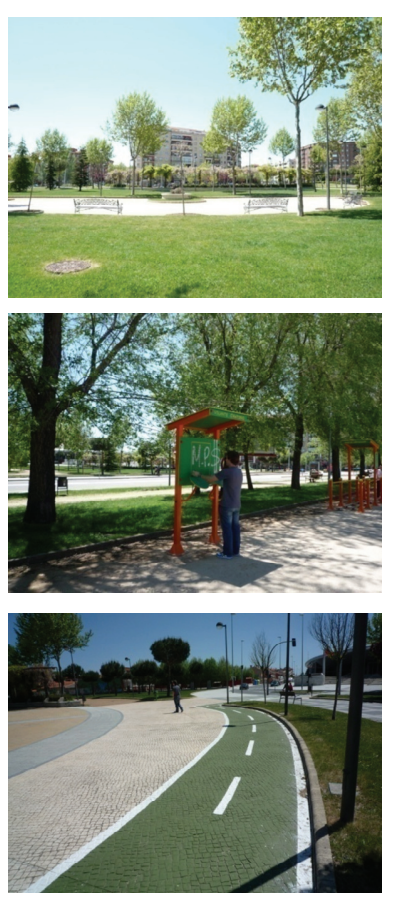

Fuente: Gómez, A. (16/05/2010).

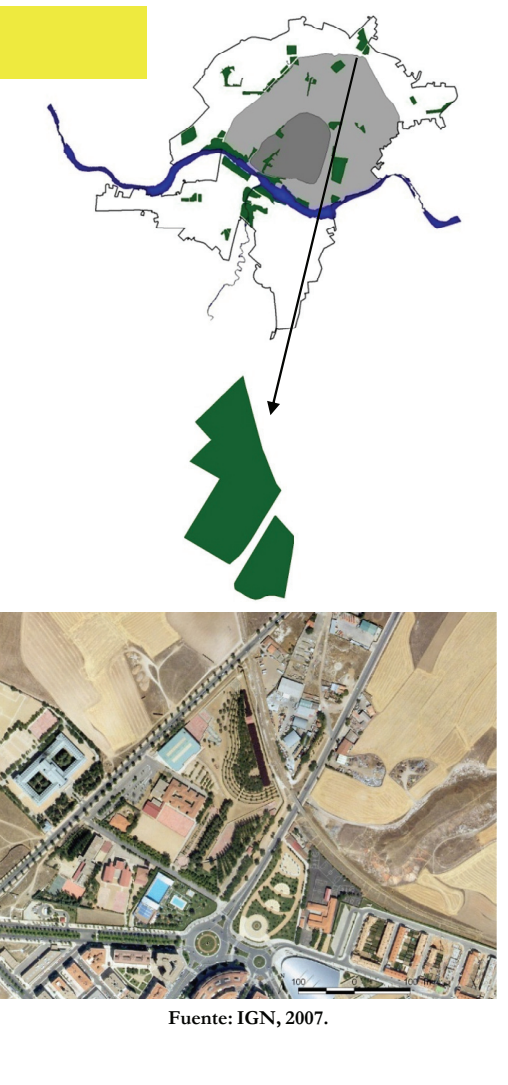

S-16 Margen derecha del Puente Romano

Características generales

- Ciudad: Salamanca

- Barrio: Tenerías

- Posición en la ciudad: primera orla

- Identificador: S-16

- Unidades: 1

- Superficie: 3,6 ha

- Periodo de origen: entre 1984 y 2002

Datos de la encuesta

- Encuestas asignadas: 9

- Encuestas realizadas: 9

- Porcentaje de éxito: $100 \%$

- Índice de atracción: $-1,85$

- Tipo de uso mayoritario: zona de tránsito

Datos de calidad

- Calidad estimada: 5

- Aspectos positivos

- Zonas deportivas: no

- Zonas de sombra: si

- Bancos:si

- Zonas de juego infantil: no

- Aspectos negativos:

- Falta de usuarios: si

- Exceso de usuarios: no

- Inseguridad: no

- Deficiente mantenimiento o presencia de perros: no
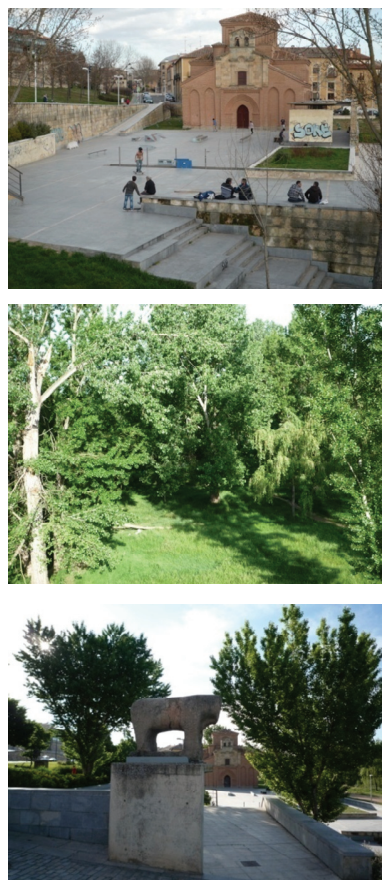

Fuente: Gómez, A. (07/03/2011 y 01/06/2010).

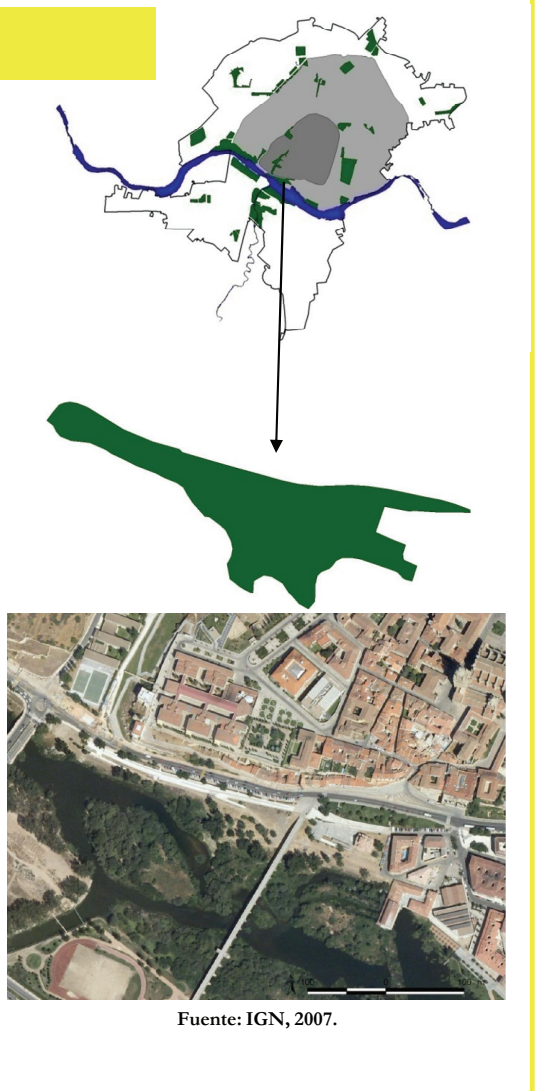




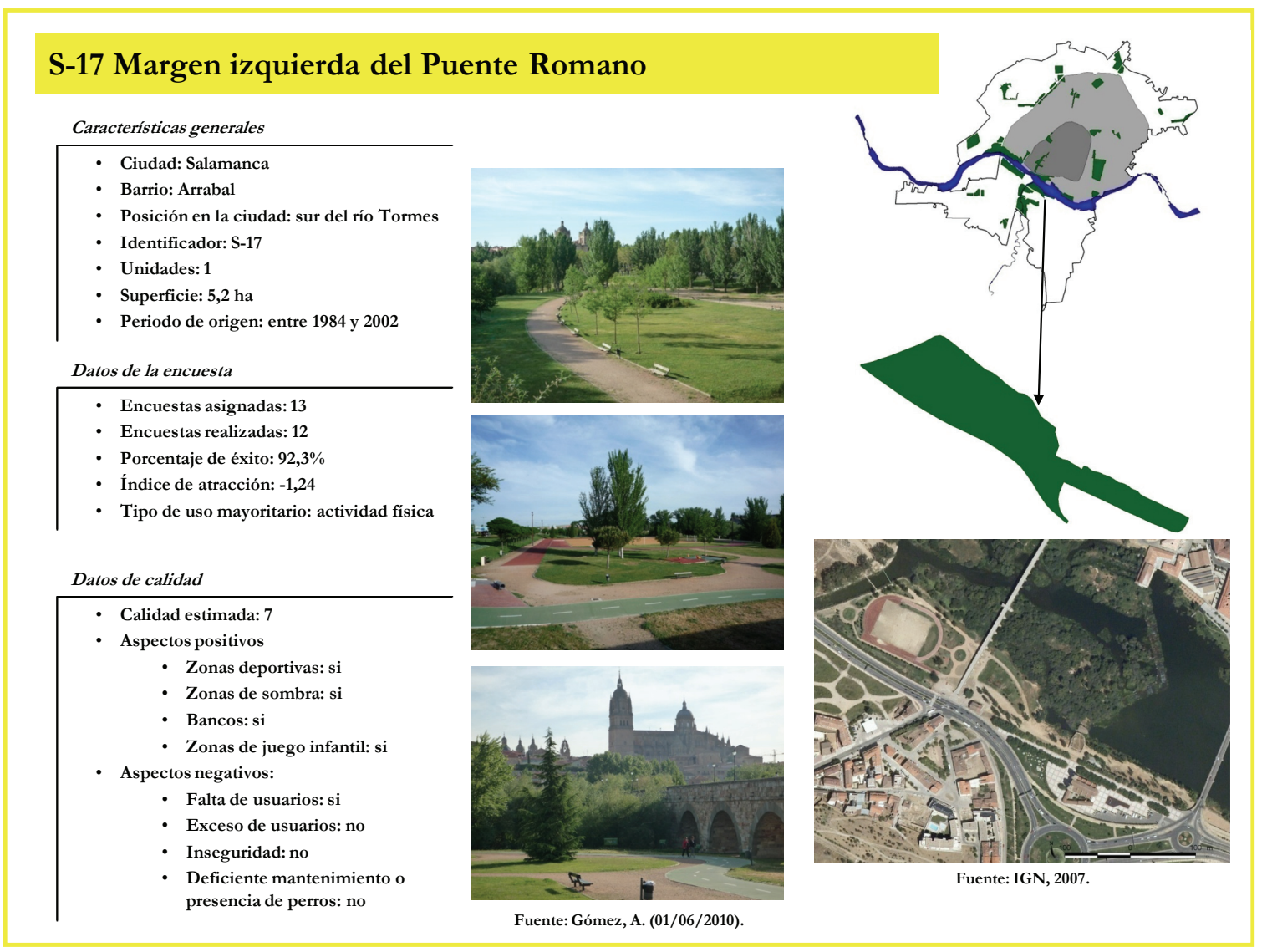

\section{S-18 Paseo Fluvial}

Características generales

- Ciudad: Salamanca

- Barrio: Fontana y Tenerías

- Posición en la ciudad: sur del río Tormes

- Identificador: S-18

- Unidades: 1

- Superficie: 3,1 ha

- Periodo de origen: entre 1971 y 1984

Datos de la encuesta

- Encuestas asignadas: 8

- Encuestas realizadas: 14

- Porcentaje de éxito: $175 \%$

- Índice de atracción: 1,55

- Tipo de uso mayoritario: actividad física

Datos de calidad

- Calidad estimada: 7

- Aspectos positivos

- Zonas deportivas: si

- Zonas de sombra: si

- Bancos: si

- Zonas de juego infantil: si

- Aspectos negativos:

- Falta de usuarios: no

- Exceso de usuarios: no

- Inseguridad: no

- Deficiente mantenimiento o presencia de perros: si
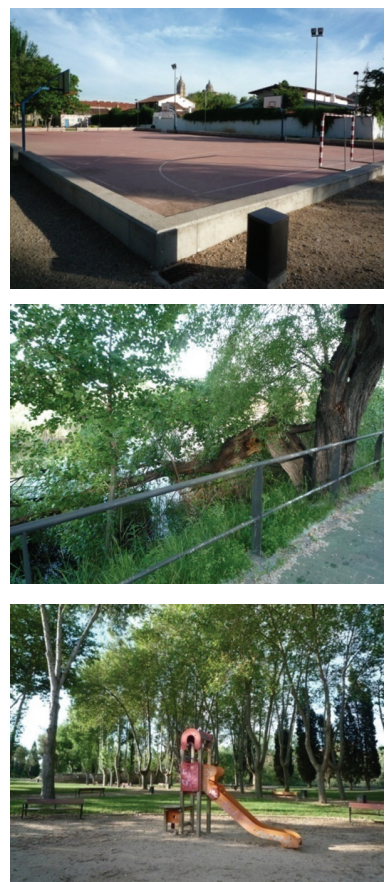

Fuente: Gómez, A. (01/06/2010).

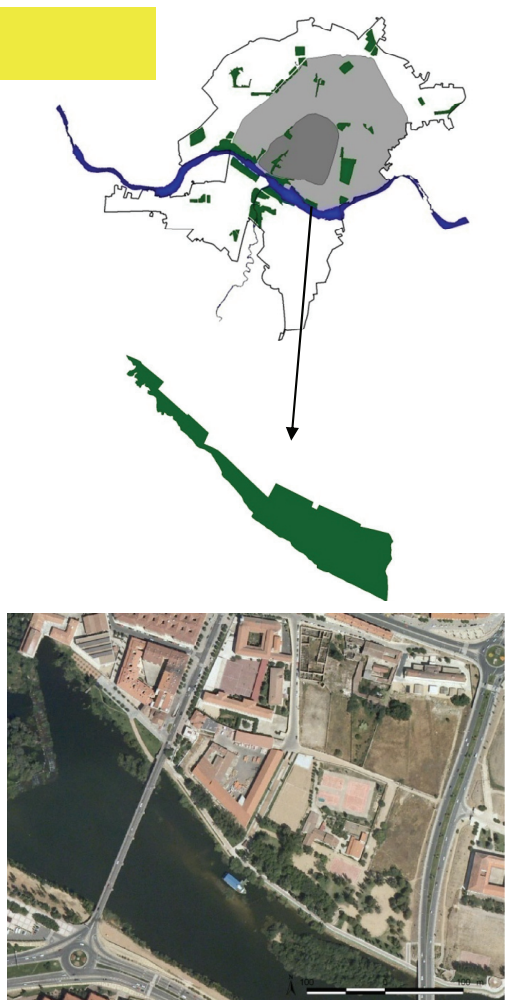

Fuente: IGN, 2007. 


\section{S-19 Verde urbano del entorno de Mirat}

Características generales

- Ciudad: Salamanca

- Barrio: Prosperidad

- Posición en la ciudad: primera orla

- Identificador: S-19

- Unidades: 1

- Superficie: 1,4 ha

- Periodo de origen: entre 2002 y 2007

Datos de la encuesta

- Encuestas asignadas: 4

- Encuestas realizadas: 5

- Porcentaje de éxito: $125 \%$

- Índice de atracción: $-0,31$

- Tipo de uso mayoritario: zona de tránsito

Datos de calidad

- Calidad estimada: 4,

- Aspectos positivos

- Zonas deportivas: no

- Zonas de sombra: no

- Bancos:si

- Zonas de juego infantil: no

- Aspectos negativos:

- Falta de usuarios: si

- Exceso de usuarios: no

- Inseguridad: no

- Deficiente mantenimiento o presencia de perros: no
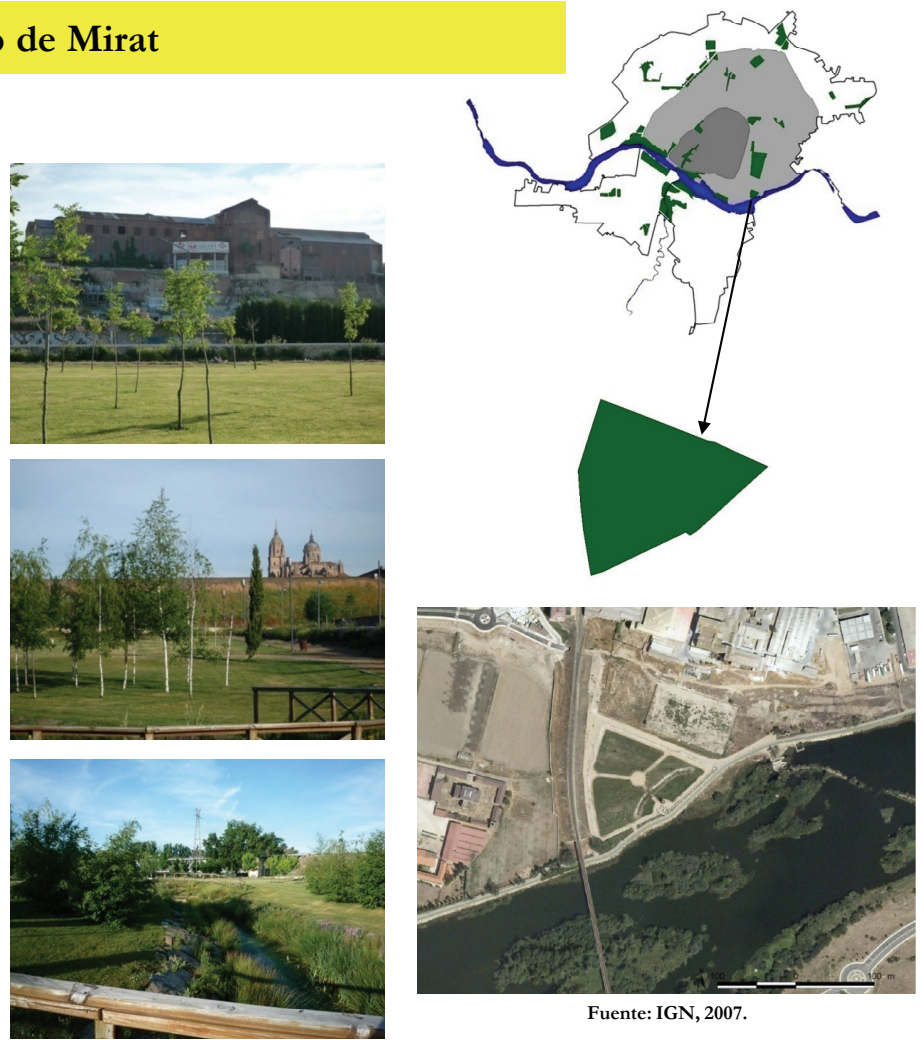

Fuente: Gómez, A. (01/06/2010)

\section{S-20 Parque de Ciudad Rodrigo}

Características generales

- Ciudad: Salamanca

- Barrio: Puente Ladrillo y Rollo

- Posición en la ciudad: segunda orla

- Identificador: S-20

- Unidades: 1

- Superficie: 2,7 ha

- Periodo de origen: entre 2002 y 2007

\section{Datos de la encuesta}

- Encuestas asignadas: 7

- Encuestas realizadas: 4

- Porcentaje de éxito: $57 \%$

- Índice de atracción: 1,08

- Tipo de uso mayoritario: estancia

Datos de calidad

- Calidad estimada: 6,5

- Aspectos positivos

- Zonas deportivas: no

- Zonas de sombra: no

- Bancos:si

- Zonas de juego infantil: si

- Aspectos negativos:

- Falta de usuarios: no

- Exceso de usuarios: no

- Inseguridad: no

- Deficiente mantenimiento o presencia de perros: no
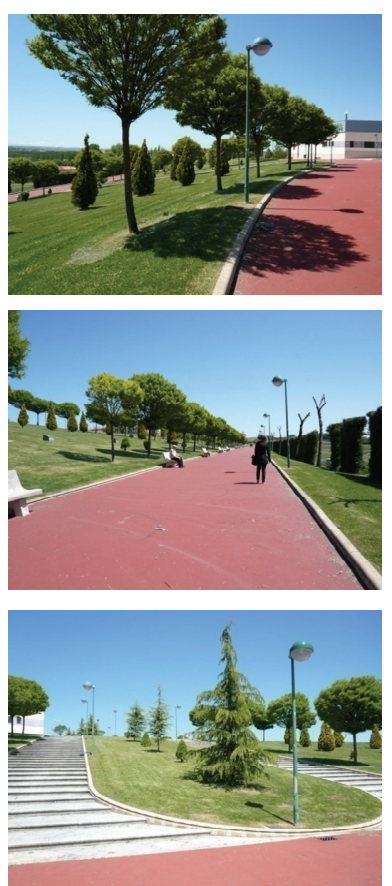

Fuente: Gómez, A. (16/05/2010)

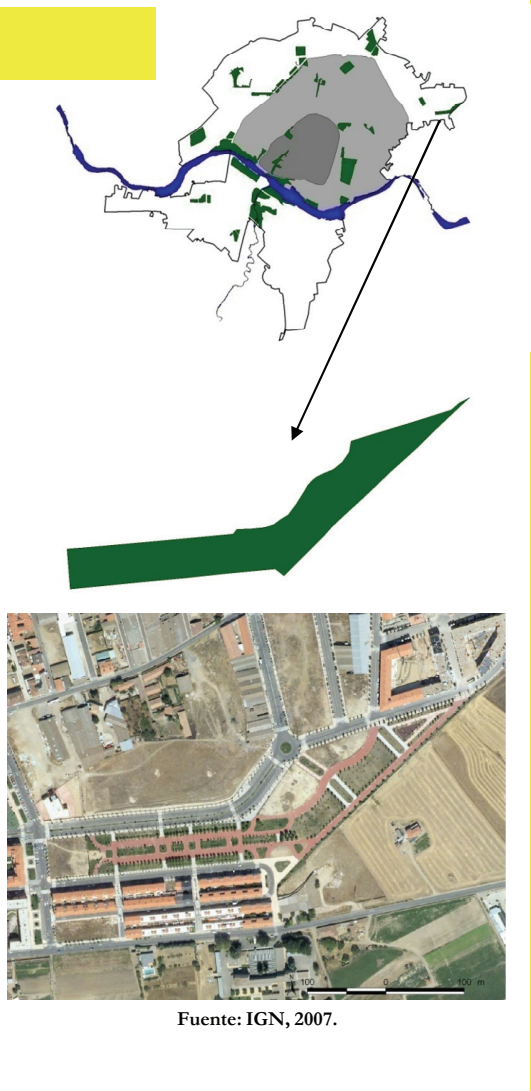




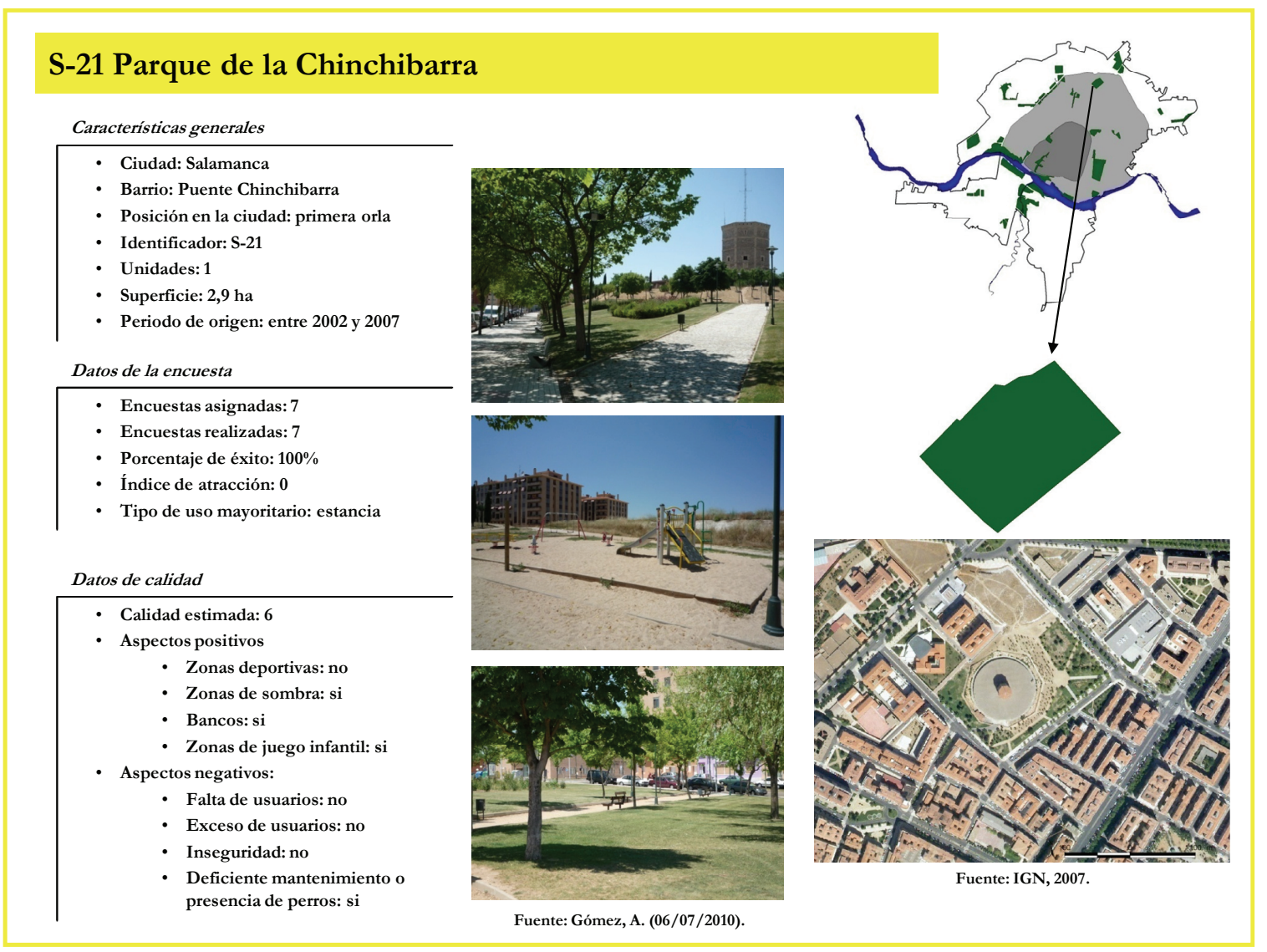

\section{S-22 Parque de Vistahermosa}

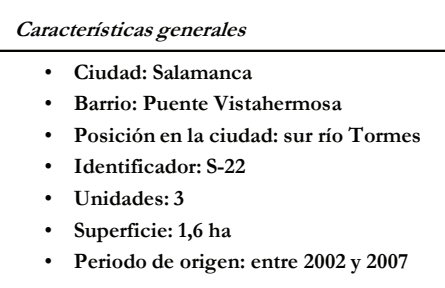

Datos de la encuesta

- Encuestas asignadas: 4

- Encuestas realizadas: 3

- Porcentaje de éxito: $75 \%$

- Índice de atracción: 0

- Tipo de uso mayoritario: actividad física y estancia

Datos de calidad

$$
\begin{aligned}
& \text { - Calidad estimada: } 6 \\
& \text { - Aspectos positivos } \\
& \text { • Zonas deportivas: si } \\
& \text { - Zonas de sombra: no } \\
& \text { - Bancos: si } \\
& \text { - Zonas de juego infantil: si } \\
& \text { - Fspectos negativos: } \\
& \text { - Ealta de usuarios: si } \\
& \text { - Inseguridad: no } \\
& \text { - Deficiente mantenimiento o } \\
& \text { presencia de perros: no }
\end{aligned}
$$
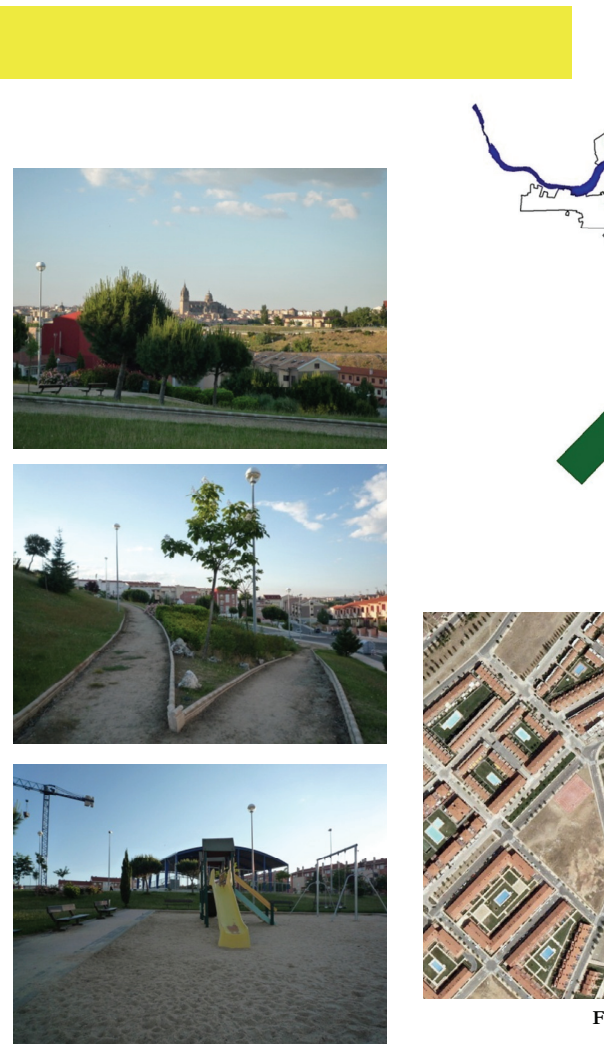

Fuente: Gómez, A. (17/06/2010).

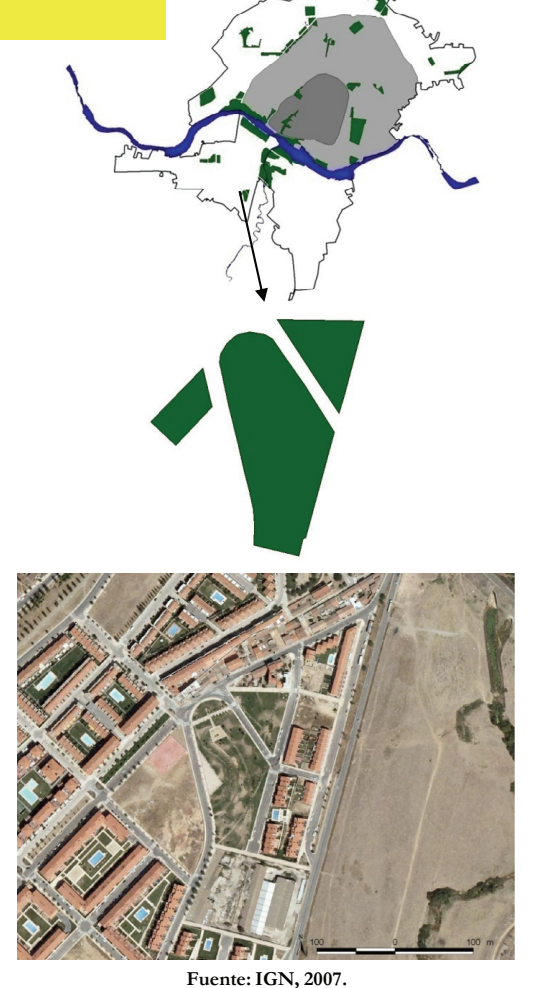

Fuente: IGN, 2007.

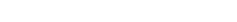




\section{S-23 Parque de Villar y Macías}

Características generales

- Ciudad: Salamanca

- Barrio: Puente San Bernard

- Posición en la ciudad: segunda orla

- Identificador: S-23

- Unidades: 1

- Superficie: 1,6 ha

- Periodo de origen: entre 1985 y 2002

Datos de la encuesta

- Encuestas asignadas: 4

- Encuestas realizadas: 4

- Porcentaje de éxito: $100 \%$

- Índice de atracción: 1,85

- Tipo de uso mayoritario: actividad física y estancia

Datos de calidad

- Calidad estimada: 6

- Aspectos positivos

- Zonas deportivas: si

- Zonas de sombra: si

- Bancos: si

- Zonas de juego infantil: si

- Aspectos negativos:

- Falta de usuarios: no

- Exceso de usuarios: $\mathrm{s}$

- Inseguridad: si

- Deficiente mantenimiento o presencia de perros: no
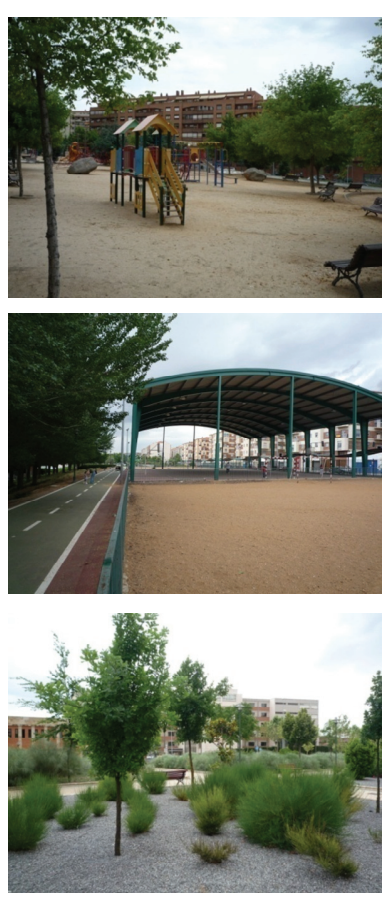

Fuente: Gómez, A. (25/06/2010)
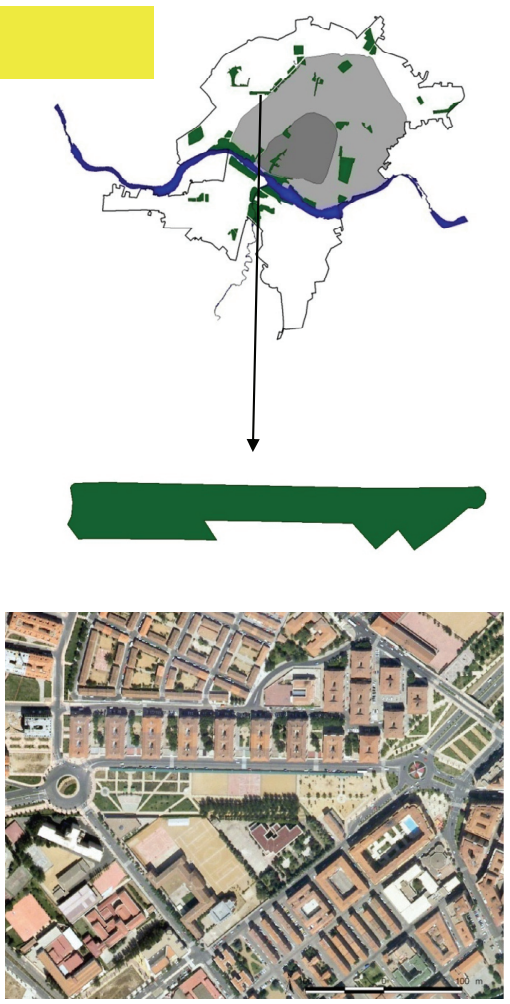

Fuente: IGN, 2007.

S-24 Verde urbano de La Salle

Características generales

- Ciudad: Salamanca

- Barrio: Tejares

- Posición en la ciudad: sur río Tormes

- Identificador: $\mathrm{S}-24$

- Unidades: 3

- Superficie: 1,9 ha

- Periodo de origen: entre 1956 y 1971

Datos de la encuesta

- Encuestas asignadas: 5

- Encuestas realizadas: 5

- Porcentaje de éxito: $100 \%$

- Índice de atracción: 0,37

- Tipo de uso mayoritario: estancia

Datos de calidad

- Calidad estimada: 6

- Aspectos positivos

- Zonas deportivas: no

- Zonas de sombra: si

- Bancos:si

- Zonas de juego infantil: si

- Aspectos negativos:

- Falta de usuarios: no

- Exceso de usuarios: no

- Inseguridad: no

- Deficiente mantenimiento o presencia de perros: si
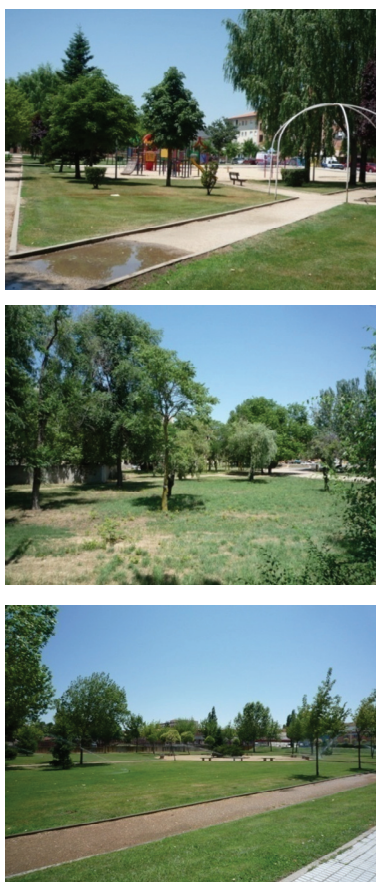

Fuente: Gómez, A. (06/07/2010).

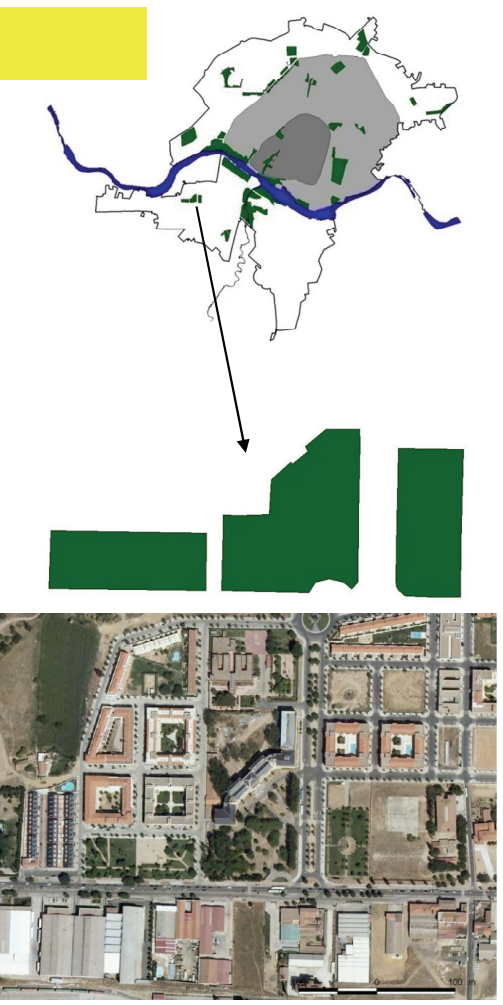

Fuente: IGN, 2007. 


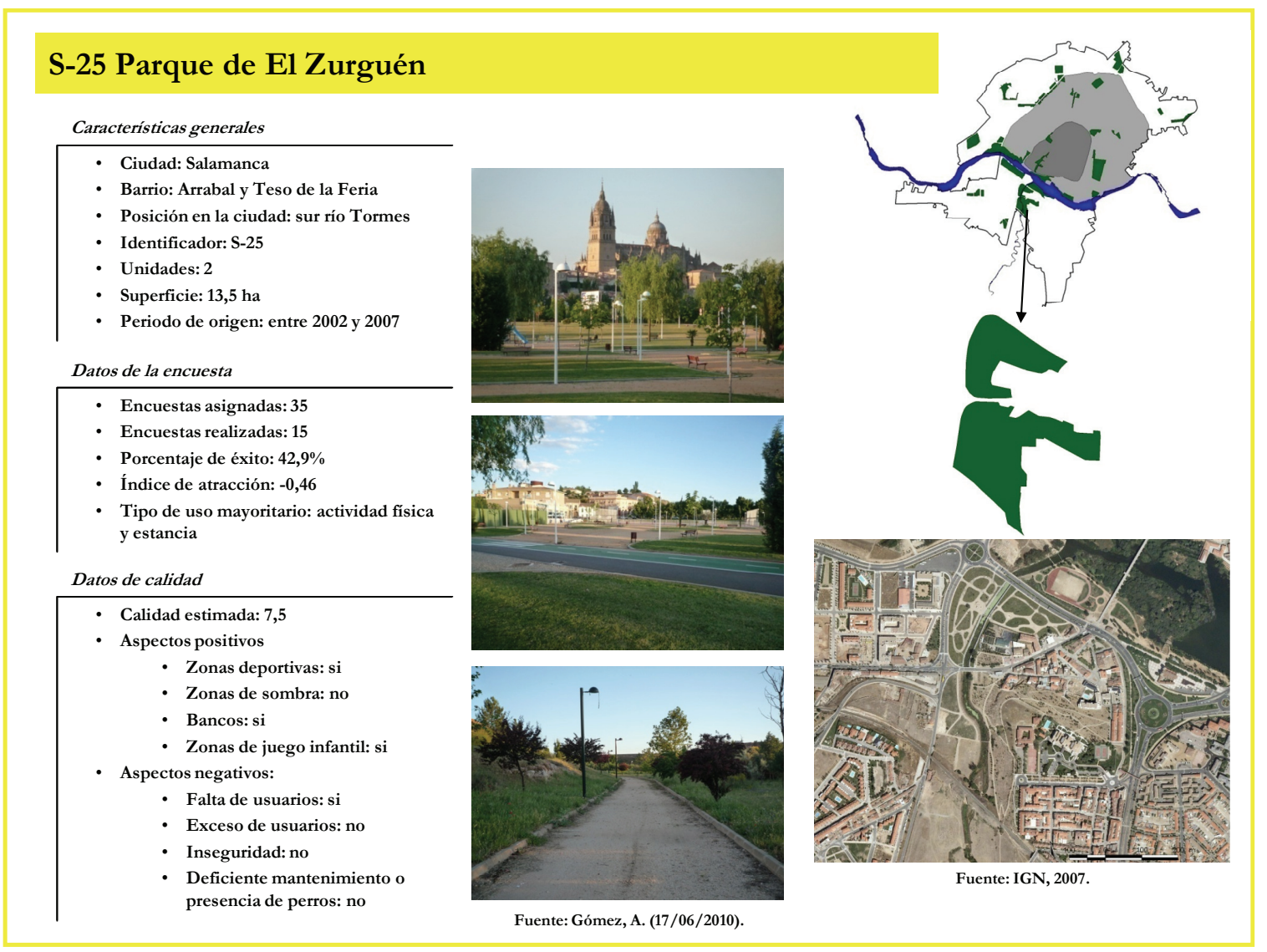

\section{S-26 Verde urbano Avenida de Salamanca}

Características generales

- Ciudad: Salamanca

- Barrio: Blanco, Vidal, Carmen y San Bernardo

- Posición en la ciudad: segunda orla

- Identificador: S-26

- Unidades: 10

- Superficie: 4,3 ha

- Periodo de origen: entre 2002 y 2007 Datos de la encuesta

- Encuestas asignadas: 11

- Encuestas realizadas: 13

- Porcentaje de éxito: $118,2 \%$

- Índice de atracción: 0,15

- Tipo de uso mayoritario: actividad física y estancia

Datos de calidad

- Calidad estimada: 7

- Aspectos positivos

- Zonas deportivas: si

- Zonas de sombra: si

- Bancos: si

- Zonas de juego infantil: si

- Aspectos negativos:

- Falta de usuarios: no

- Exceso de usuarios: no

- Inseguridad: no

- Deficiente mantenimiento o presencia de perros: si
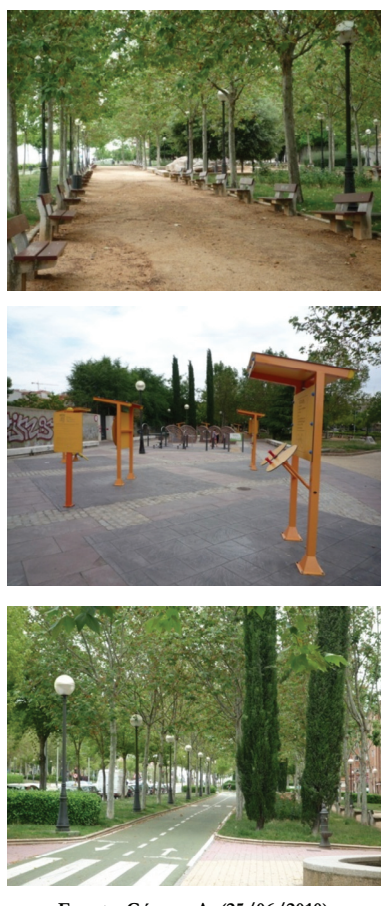

Fuente: Gómez, A. (25/06/2010).

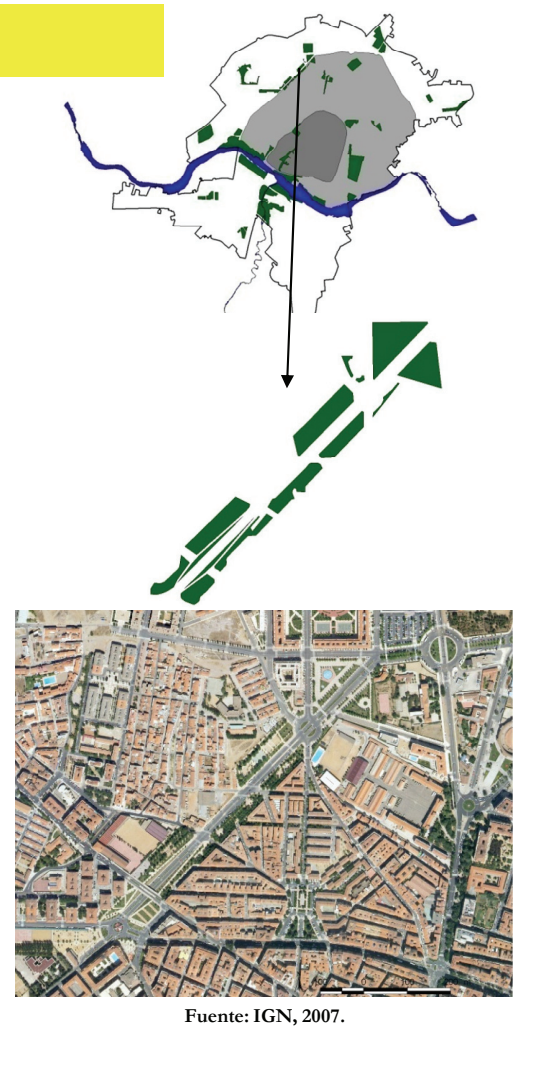




\section{S-27 Verde urbano de la Facultad de Comunicación}

Características generales

- Ciudad: Salamanca

- Barrio: Hospital

- Posición en la ciudad: segunda orla

- Identificador: S-27

- Unidades: 1

- Superficie: 1,2 ha

- Periodo de origen: entre 2002 y 2007

Datos de la encuesta

- Encuestas asignadas: 3

- Encuestas realizadas: 10

- Porcentaje de éxito: $333,3 \%$

- Índice de atracción: $-1,48$

- Tipo de uso mayoritario: zona de tránsito

Datos de calidad

- Calidad estimada: 4,

- Aspectos positivos

- Zonas deportivas: no

- Zonas de sombra: no

- Bancos: si

- Zonas de juego infantil: no

- Aspectos negativos:

- Falta de usuarios: si

- Exceso de usuarios: no

- Inseguridad: no

- Deficiente mantenimiento o presencia de perros: no
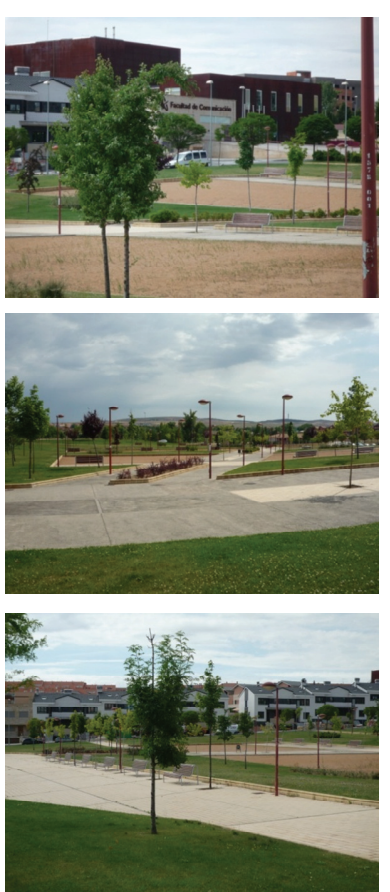

Fuente: Gómez, A. (25/06/2010).

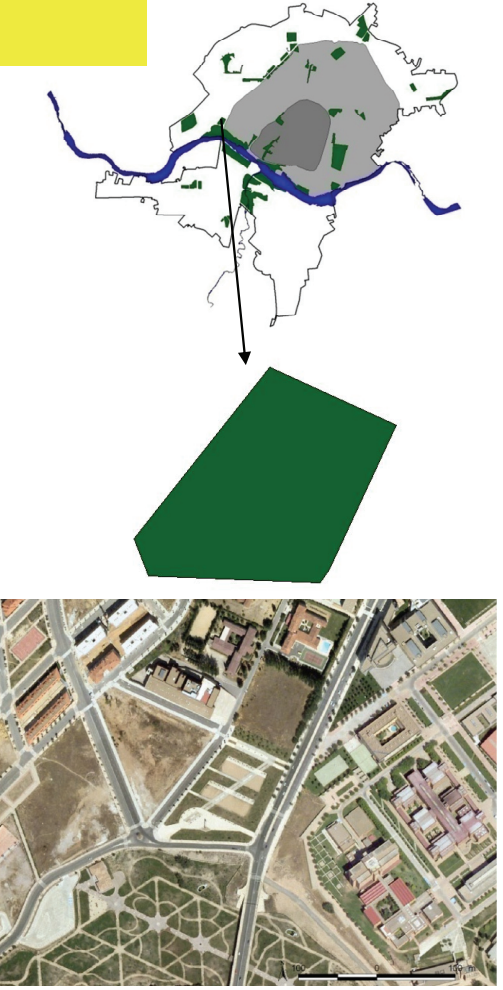

Fuente: IGN, 2007.

\section{S-28 Parque de Bretón}

Características generales

- Barrio: Puente Ladrillo

- Posición en la ciudad: segunda orla

- Identificador: S-28

- Unidades: 1

- Superficie: 1,7 ha

- Periodo de origen: entre 1984 y 2002

Datos de la encuesta

- Encuestas asignadas: 3

- Encuestas realizadas: 4

- Porcentaje de éxito: $333,3 \%$

- Índice de atracción: $-0,74$

- Tipo de uso mayoritario: estancia

Datos de calidad

- Calidad estimada: 5

- Aspectos positivos

- Zonas deportivas: no

- Zonas de sombra: si

- Bancos:si

- Zonas de juego infantil: si

- Aspectos negativos:

- Falta de usuarios: si

- Exceso de usuarios: no

- Inseguridad:si

- Deficiente mantenimiento o presencia de perros: no
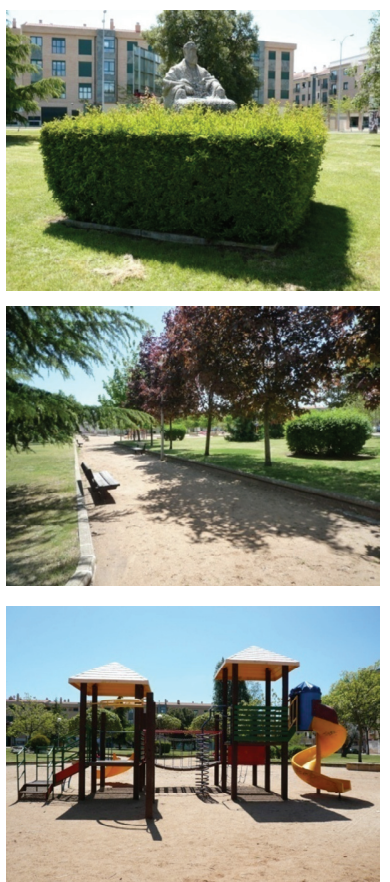

Fuente: Gómez, A. (16/05/2010)

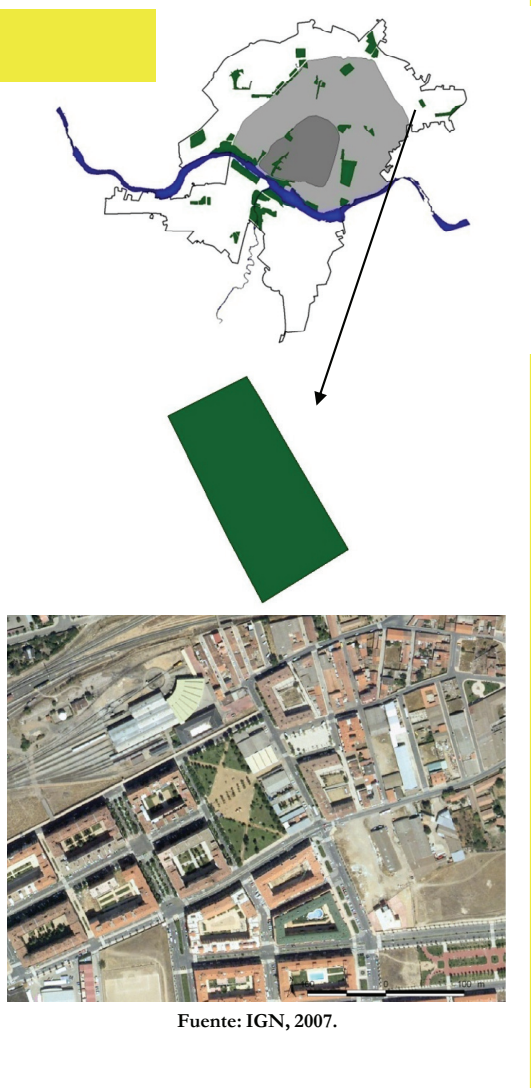




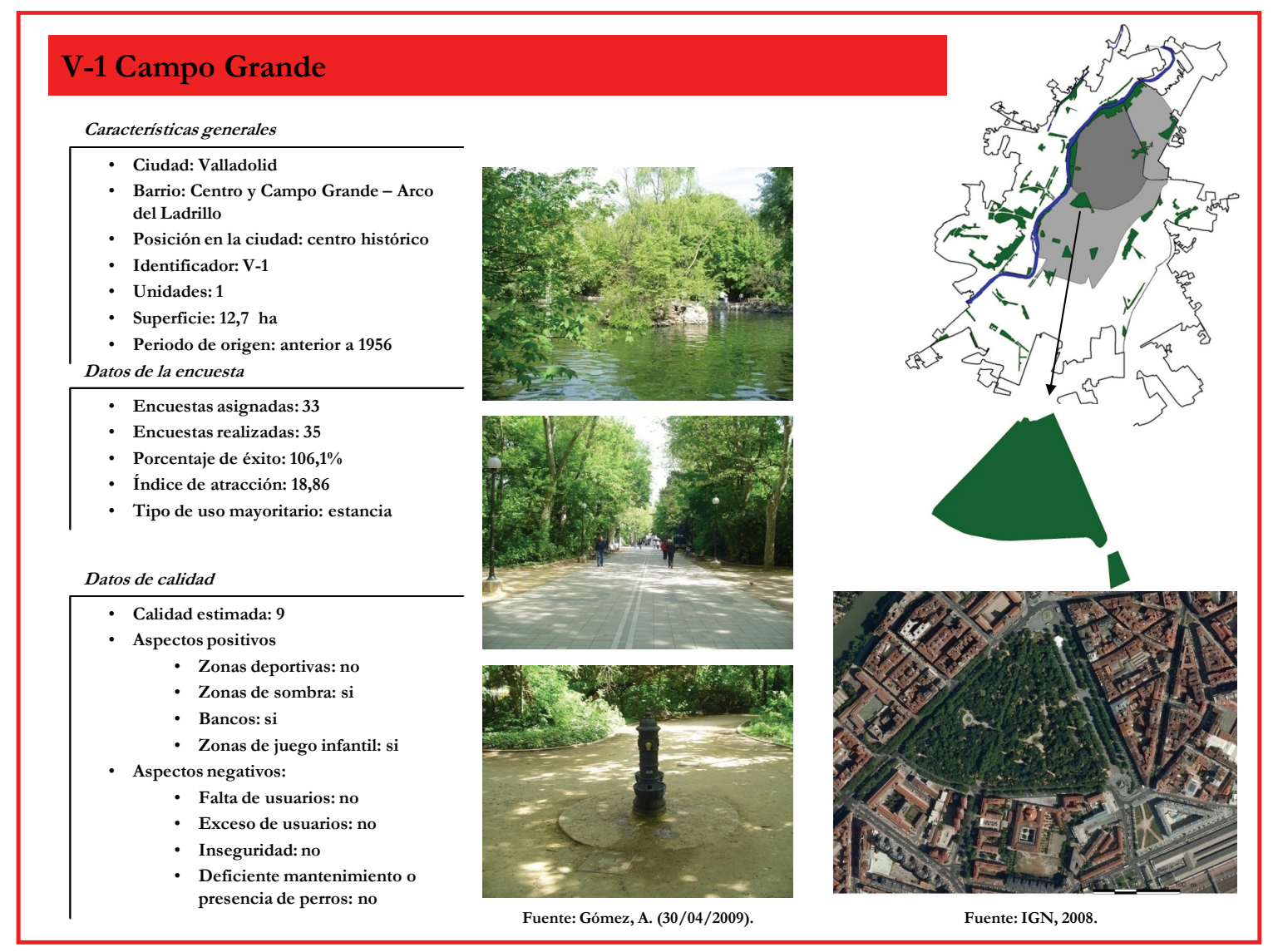

V-2 Rosaleda Francisco Sabadell y Parque de Poniente

Características generales
\begin{tabular}{|l} 
- Ciudad: Valladolid \\
- Barrio: Centro y Paseo Zorrilla \\
- Posición en la ciudad: centro histórico \\
- Identificador: V-2 \\
- Unidades: 2 \\
- Superficie: 4,6 ha \\
- Periodo de origen: anterior a 1956
\end{tabular}

Datos de la encuesta

$$
\begin{aligned}
& \text { - Encuestas asignadas: } 12 \\
& \text { - Encuestas realizadas: } 13 \\
& \text { - Porcentaje de éxito: } 108,3 \% \\
& \text { - Índice de atracción: } 7,57 \\
& \text { - Tipo de uso mayoritario: estancia }
\end{aligned}
$$

Datos de calidad

$$
\begin{aligned}
& \text { - Calidad estimada: } 8 \\
& \text { - Aspectos positivos } \\
& \text { • Zonas deportivas: no } \\
& \text { - Zonas de sombra: si } \\
& \text { - Bancos: si } \\
& \text { - Zonas de juego infantil: si } \\
& \text { - Aspectos negativos: } \\
& \text { - Ealta de usuarios: no } \\
& \text { - Inseguridad: no } \\
& \text { - Deficiente mantenimiento o } \\
& \text { presencia de perros: no }
\end{aligned}
$$
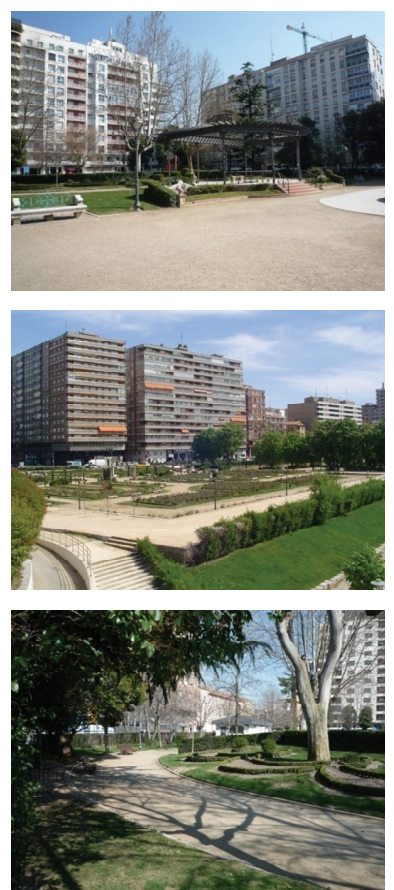

Fuente: Gómez, A. (30/04/2009 y 21/03/2011).
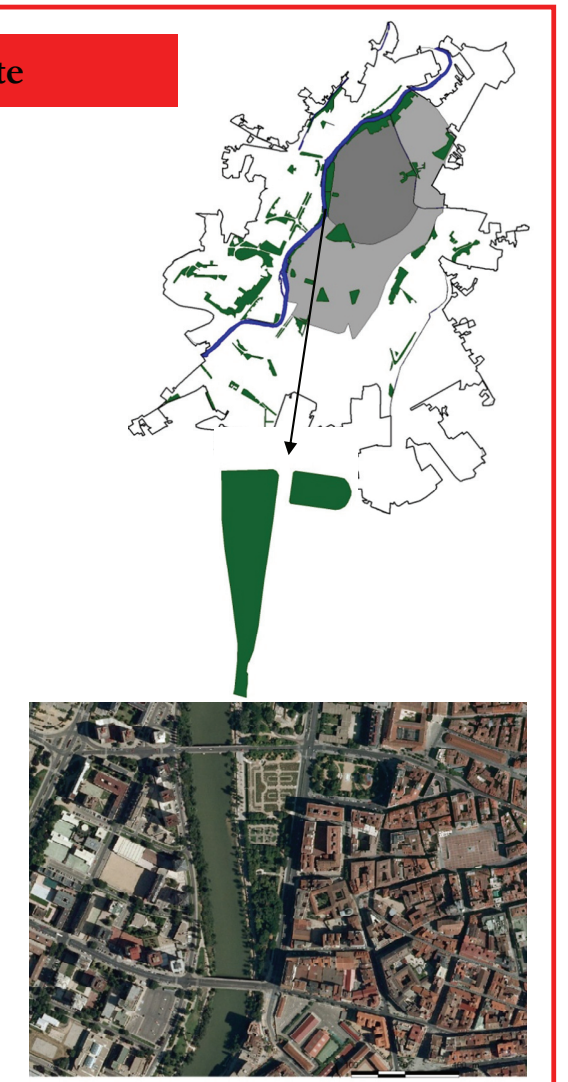

Fuente: IGN, 2008. 

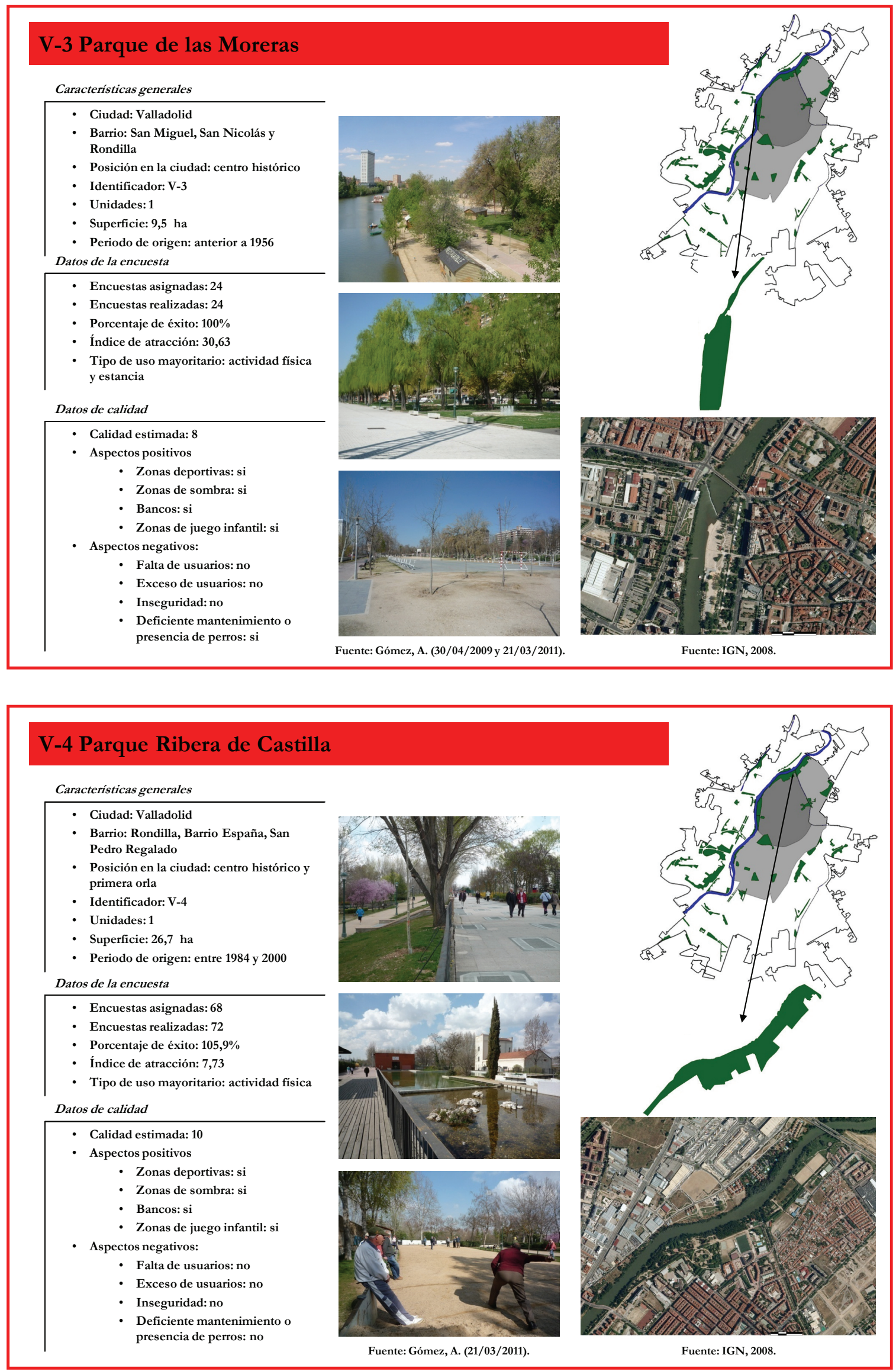


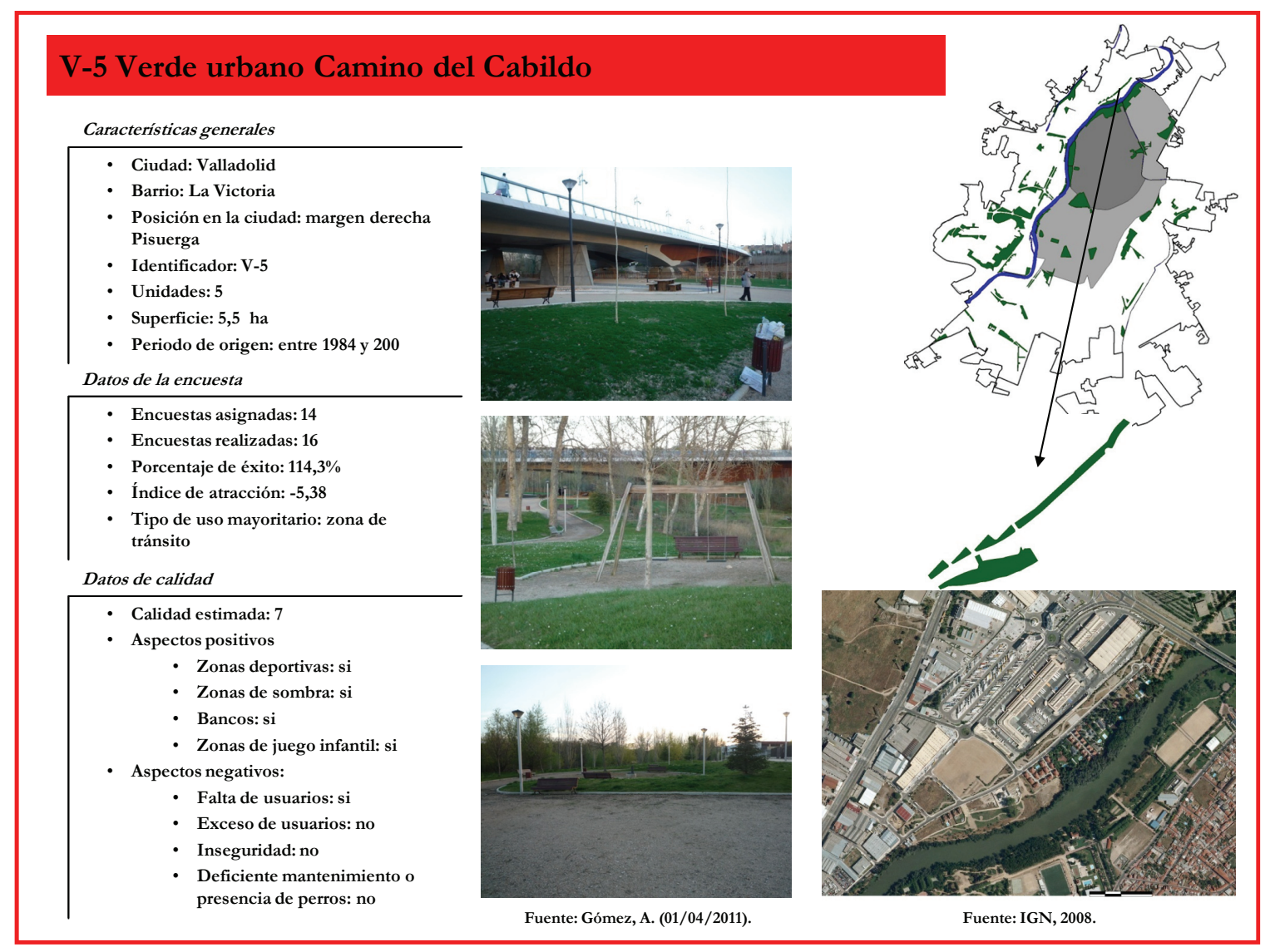

\section{V-6 Jardín Botánico}

\begin{tabular}{|l} 
Características generales \\
\hline - Ciudad: Valladolid \\
- Barrio: La Victoria y La Overuela - \\
Navabuena - El Berrocal \\
- Posición en la ciudad: margen derecha \\
Pisuerga \\
- Identificador: V-6 \\
- Unidades: 1 \\
- Superficie: 7 ha \\
- Periodo de origen: entre 1984 y 2000
\end{tabular}

Datos de la encuesta

- Encuestas asignadas: 18
- Encuestas realizadas: 22
- Porcentaje de éxito: $122,2 \%$
- Índice de atracción: 6,45
- Tipo de uso mayoritario: estancia
Datos de calidad

Datos de calidad

- Calidad estimada: 7

- Aspectos positivos

- Zonas deportivas: no

- Zonas de sombra: si

- Bancos: si

- Zonas de juego infantil: si

- Aspectos negativos:

- Falta de usuarios: no

- Exceso de usuarios: no

- Inseguridad: no

- Deficiente mantenimiento o presencia de perros: no
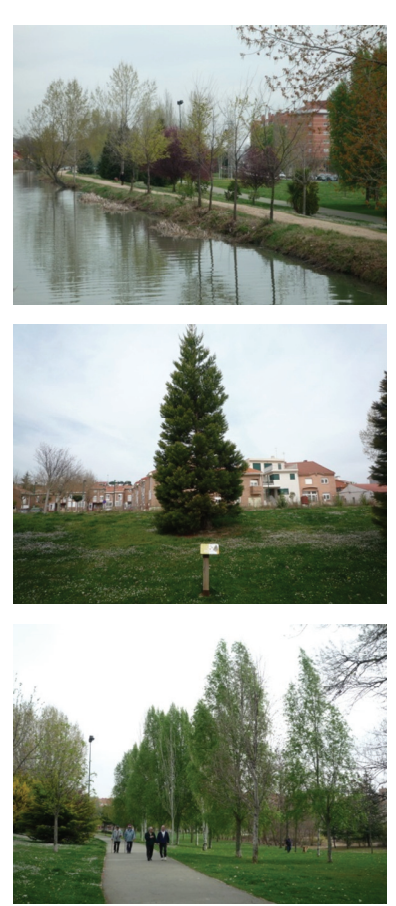

Fuente: Gómez, A. (02/04/2011).

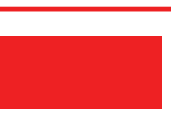

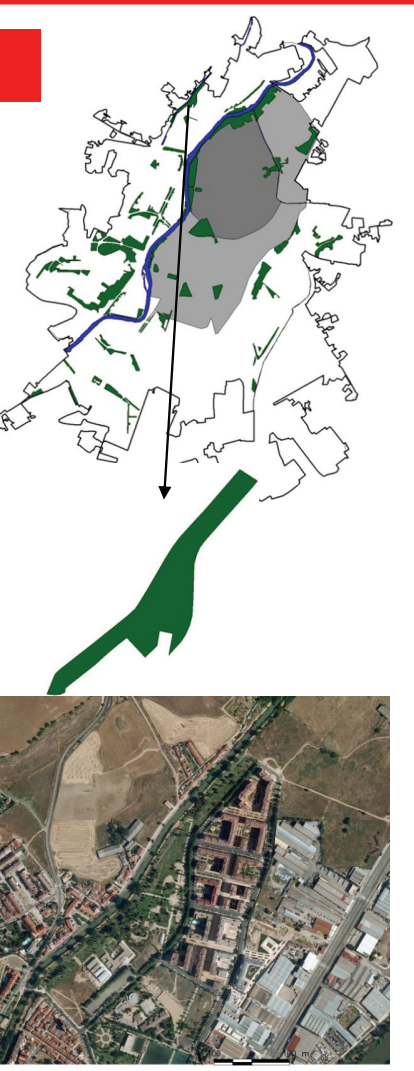

Fuente: IGN, 2008. 


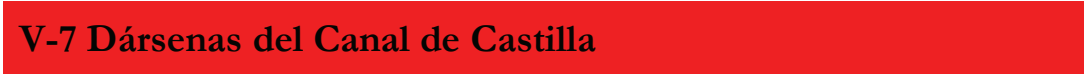

Características generales

- Ciudad: Valladolid

- Barrio: La Victoria

- Posición en la ciudad: margen derecha Pisuerga

- Identificador: V-7

- Unidades: 2

- Superficie: 1,2 ha

- Periodo de origen: entre 1984 y 2000 Datos de la encuesta

- Encuestas asignadas: 54

- Encuestas realizadas: 55

- Porcentaje de éxito: $101,9 \%$

- Índice de atracción: 6,96

- Tipo de uso mayoritario: actividad física

Datos de calidad

- Calidad estimada: 8

- Aspectos positivos

- Zonas deportivas: si

- Zonas de sombra: si

- Bancos:si

- Zonas de juego infantil: si

- Aspectos negativos:

- Falta de usuarios: no

- Exceso de usuarios: no

- Inseguridad: no

- Deficiente mantenimiento o presencia de perros: si
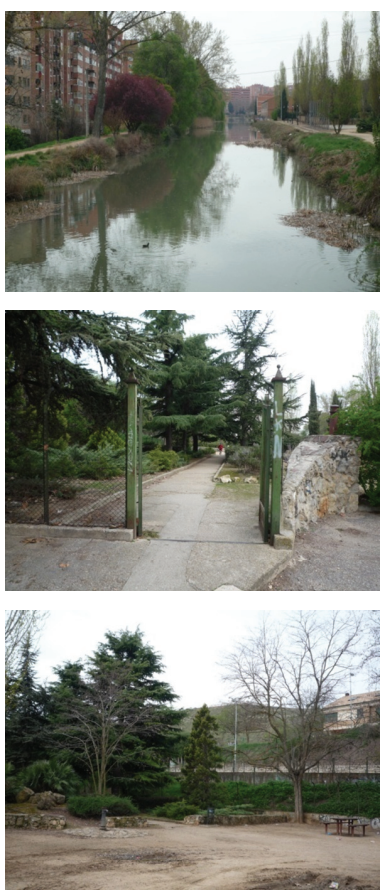

Fuente: Gómez, A. (02/04/2011).
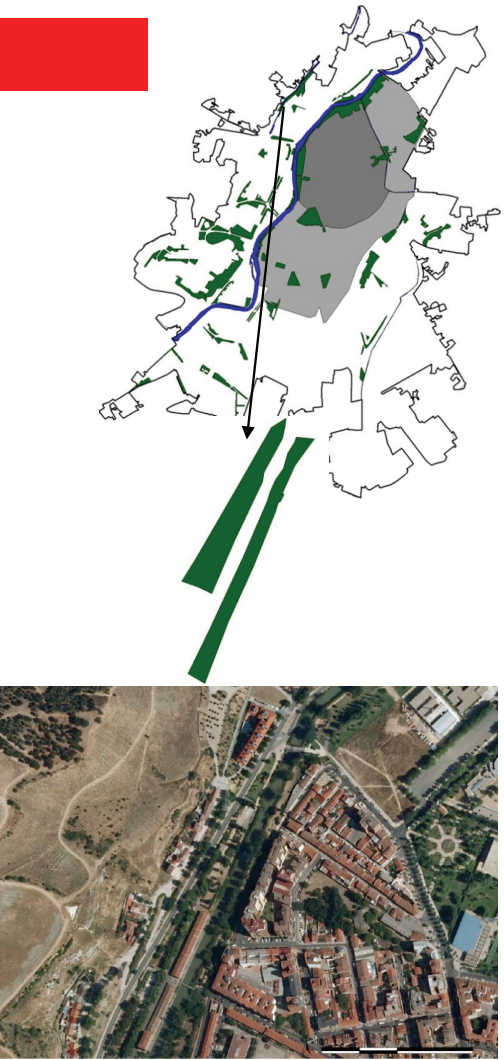

Fuente: IGN, 2008.

V-9 Parque del Mediodía

Características generales

- Ciudad: Valladolid

- Barrio: Parquesol

- Posición en la ciudad: margen derecha Pisuerga

- Identificador: V-9

- Unidades: 1

- Superficie: 21 ha

- Periodo de origen: anterior a 1956 Datos de la encuesta

- Encuestas asignadas: 12

- Encuestas realizadas: 13

- Porcentaje de éxito: $108,3 \%$

- Índice de atracción: 7,57

- Tipo de uso mayoritario: estancia

Datos de calidad

- Calidad estimada: 8

- Aspectos positivos

- Zonas deportivas: no

- Zonas de sombra: si

- Bancos:si

- Zonas de juego infantil: si

- Aspectos negativos:

- Falta de usuarios: no

- Exceso de usuarios: no

- Inseguridad: no

- Deficiente mantenimiento o presencia de perros: no
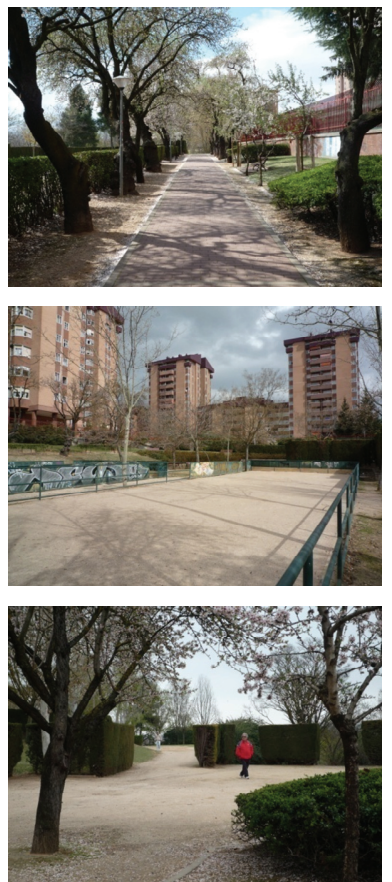

Fuente: Gómez, A. (23/03/2011)

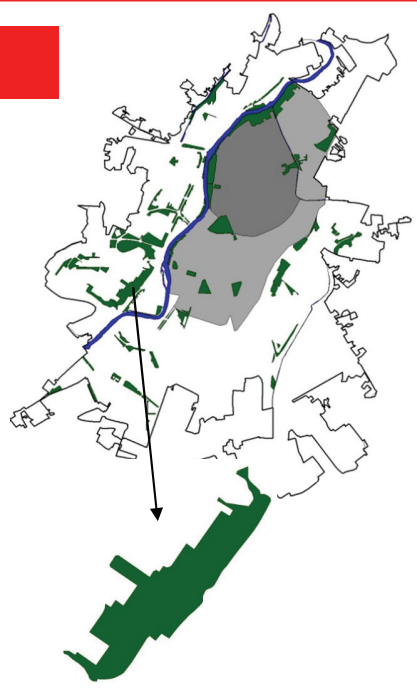

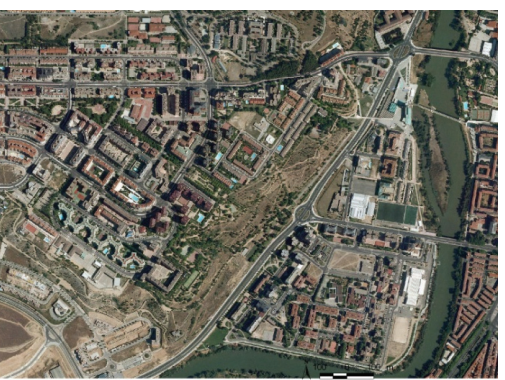

Fuente: IGN, 2008 


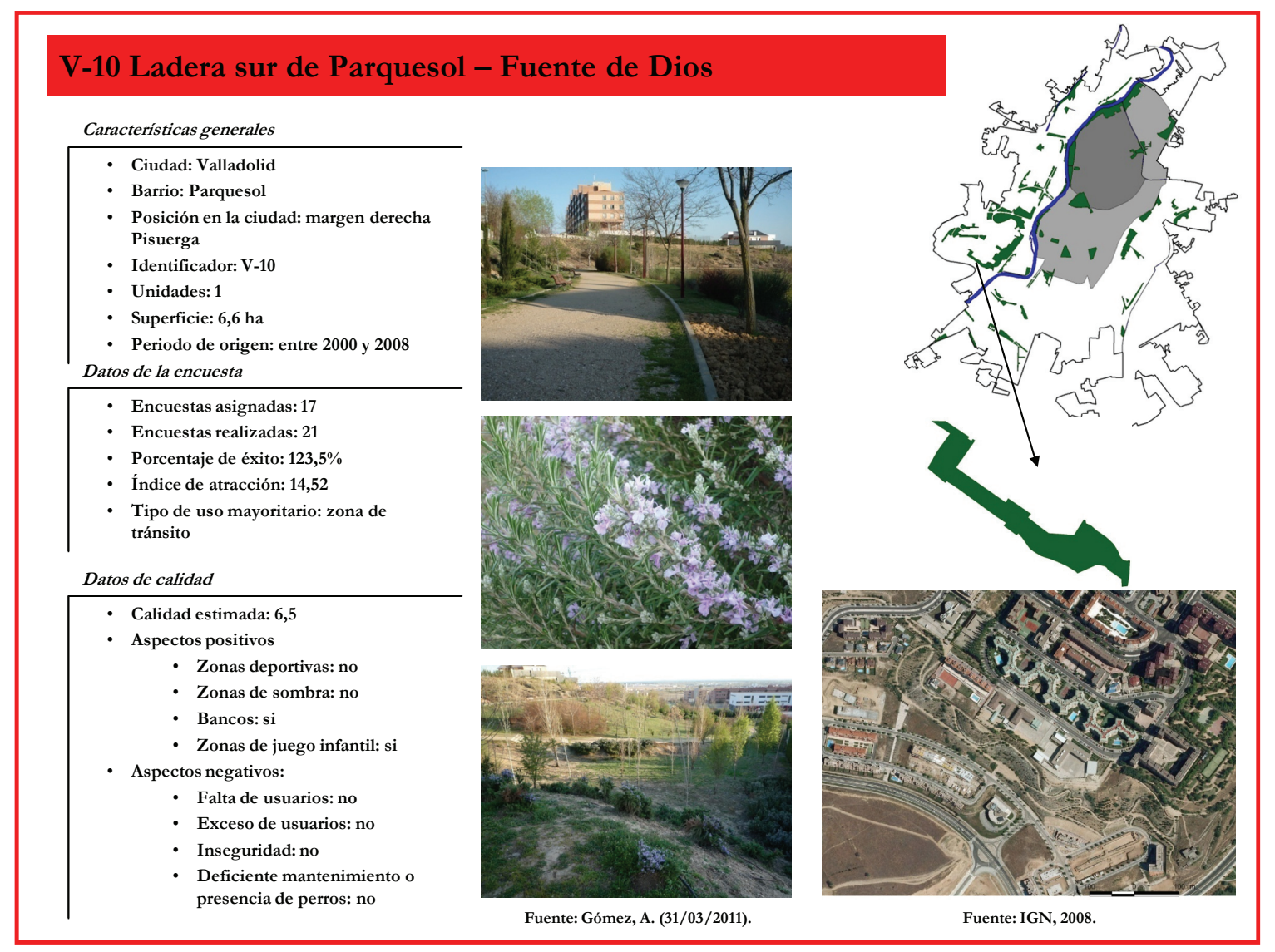

\section{V-11 Arturo Eyries}

Características generales

- Ciudad: Valladolid

- Barrio: Arturo Eyries

- Posición en la ciudad: margen derecha Pisuerga

- Identificador: V-11

- Unidades: 1

- Superficie: 4,7 ha

- Periodo de origen: entre 1984 y 2000 Datos de la encuesta

- Encuestas asignadas: 12

- Encuestas realizadas: 13

- Porcentaje de éxito: $108,3 \%$

- Índice de atracción: $-1,08$

- Tipo de uso mayoritario: zona de tránsito

Datos de calidad

- Calidad estimada: 5

- Aspectos positivos

- Zonas deportivas: no

- Zonas de sombra: si

- Bancos: si

- Zonas de juego infantil: no

- Aspectos negativos:

- Falta de usuarios: si

- Exceso de usuarios: no

- Inseguridad: no

- Deficiente mantenimiento o presencia de perros: no
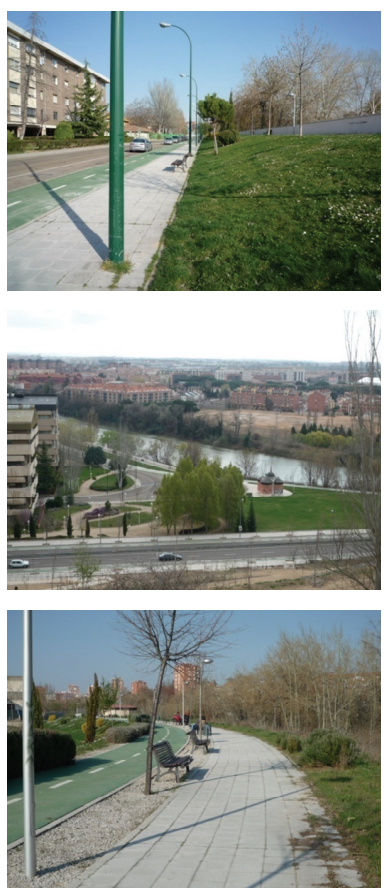

Fuente: Gómez, A. (21/03/2011).
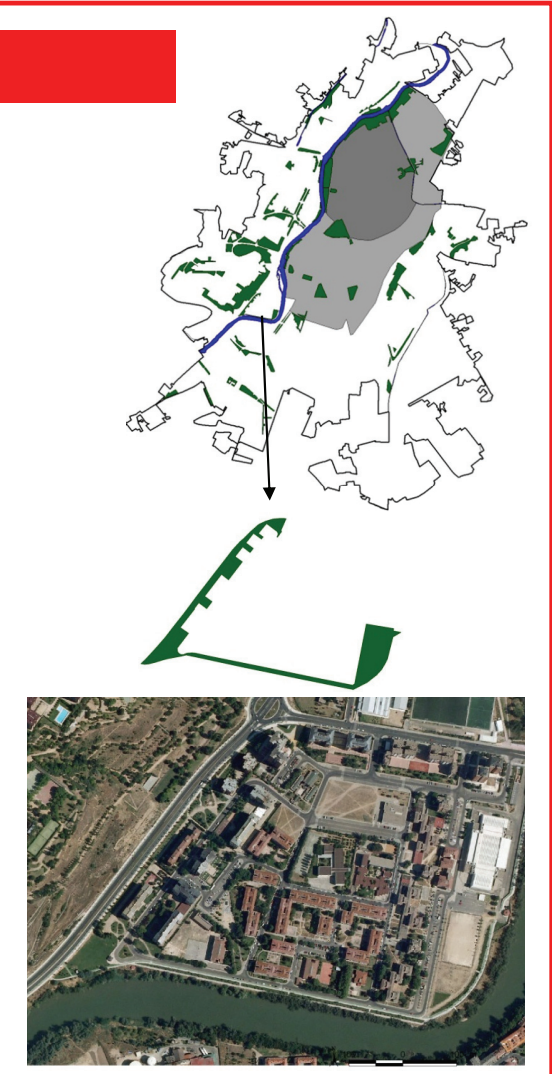

Fuente: IGN, 2008. 


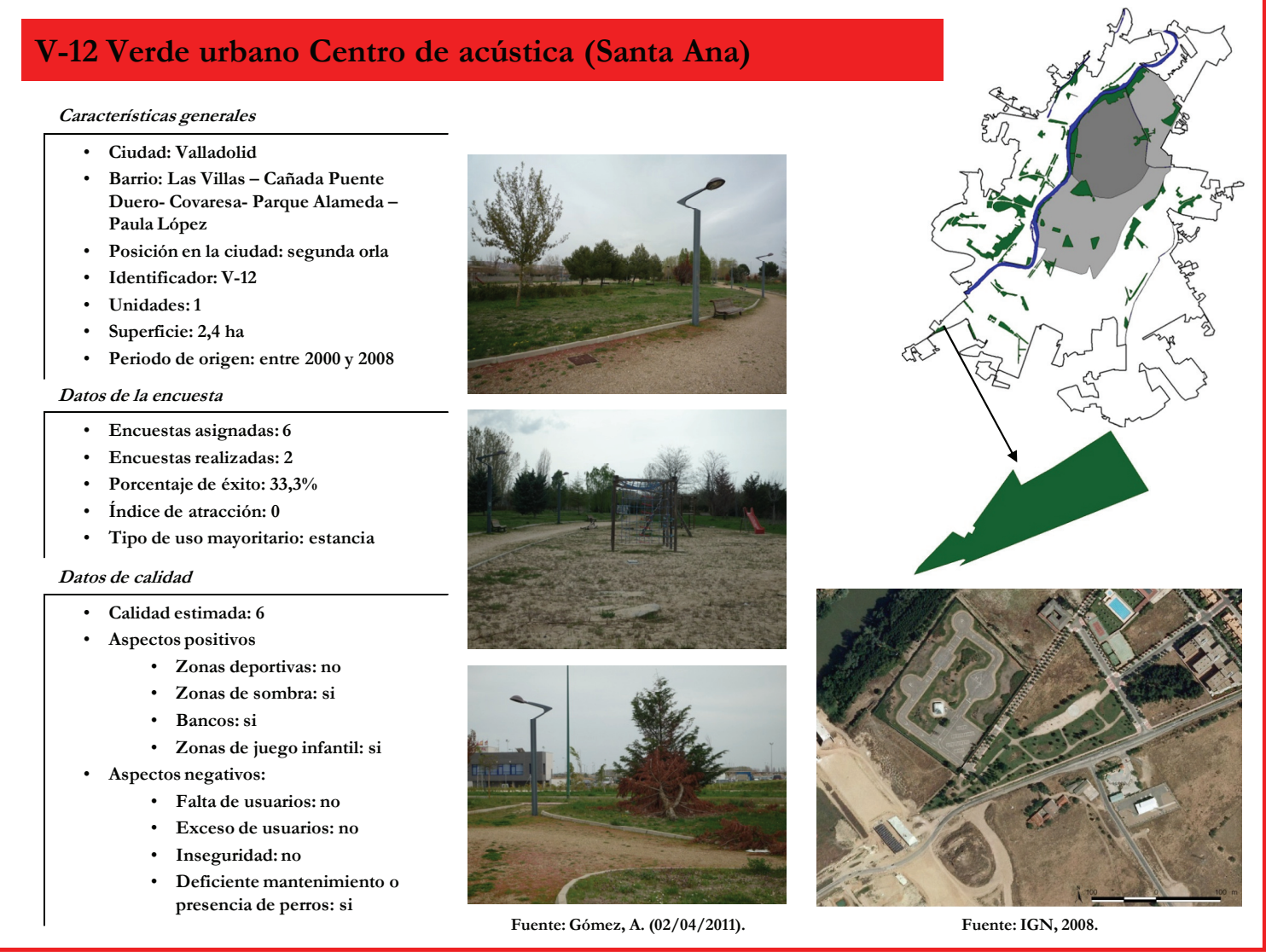

\section{V-14 Parque de Covaresa}

Características generales

Ciudad: Valladolid

Barrio: Las Villas - Cañada Puente Duero- Covaresa- Parque Alameda Paula López

- Posición en la ciudad: segunda orla

- Identificador: V-14

- Unidades: 3

- Superficie: 5,3 ha

- Periodo de origen: entre 1984 y 2000

Datos de la encuesta

- Encuestas asignadas: 14

- Encuestas realizadas: 17

- Porcentaje de éxito: $121,4 \%$

- Índice de atracción: 4,33

- Tipo de uso mayoritario: estancia

Datos de calidad

- Calidad estimada: 7

- Aspectos positivos

- Zonas deportivas: no

- Zonas de sombra: si

- Bancos:si

- Zonas de juego infantil: si

- Aspectos negativos:

- Falta de usuarios: no

- Exceso de usuarios: no

- Inseguridad: no

- Deficiente mantenimiento o presencia de perros: no
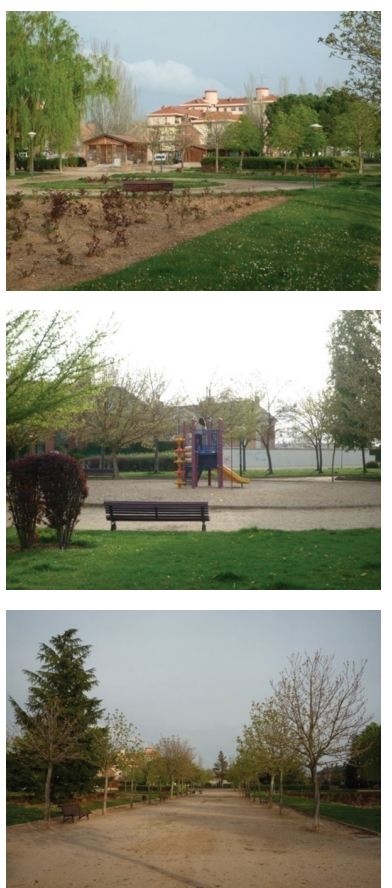

Fuente: Gómez, A. (02/04/2011).

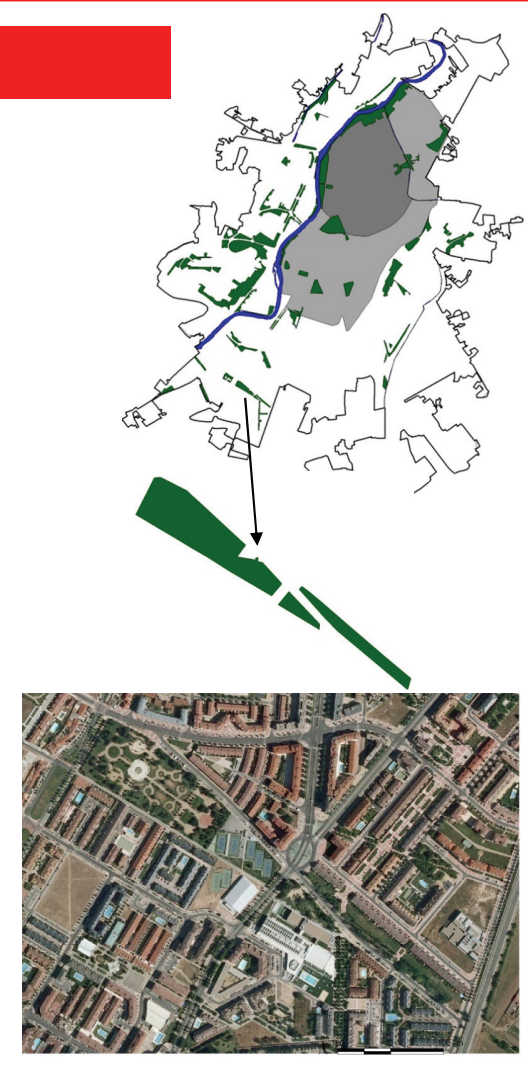

Fuente: IGN, 2008. 


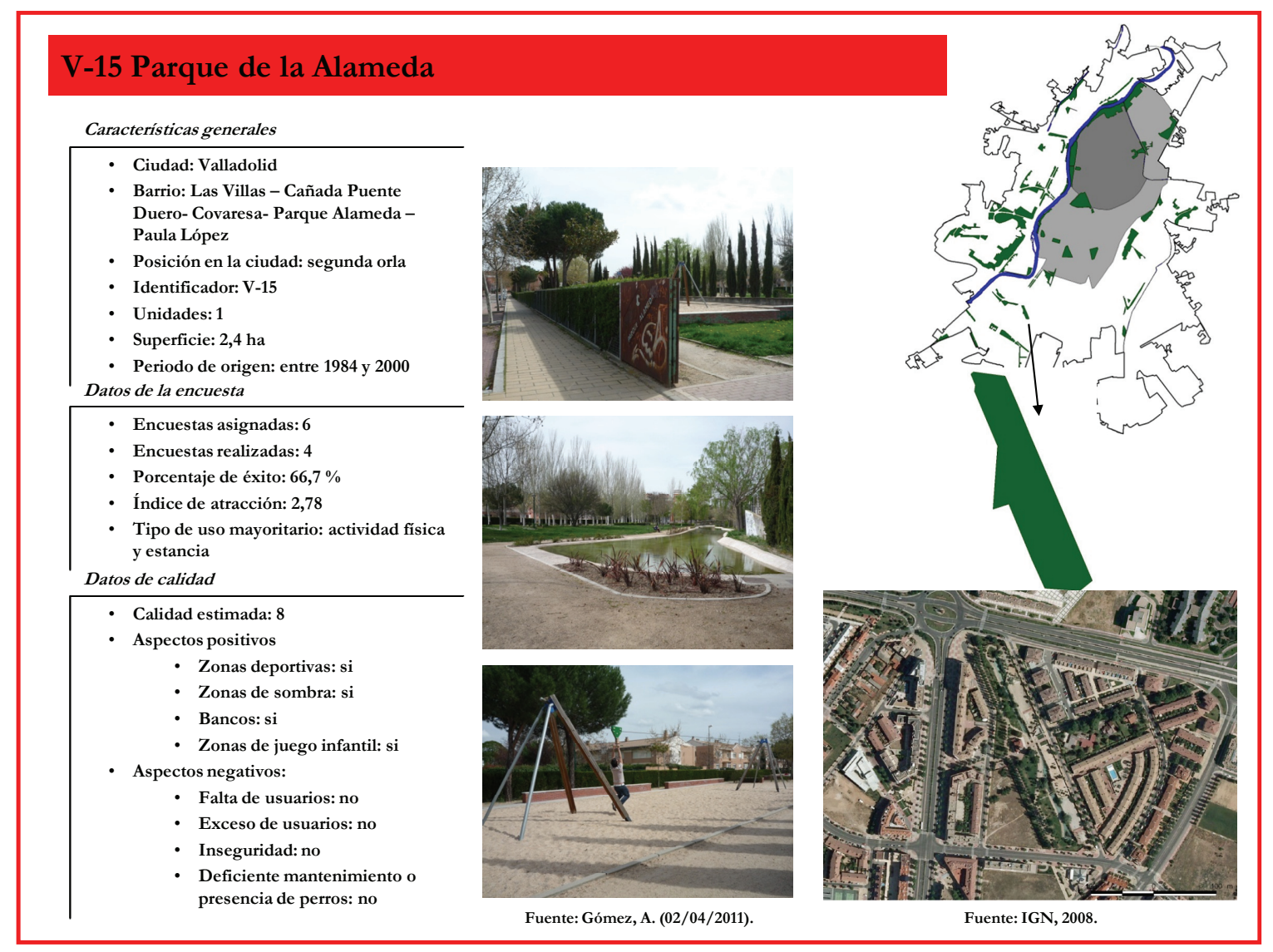

\section{V-16 Verde urbano Avenida de los Castaños}

Características generales

- Ciudad: Valladolid

- Barrio: Las Villas - Cañada Puente Duero- Covaresa- Parque Alameda Paula López

- Posición en la ciudad: segunda orla

- Identificador: V-16

- Unidades: 1

- Superficie: 1,8 ha

- Periodo de origen: entre 1984 y 2000

Datos de la encuesta

- Encuestas asignadas: 5

- Encuestas realizadas: 10

- Porcentaje de éxito: $200 \%$

- Índice de atracción: $-0,93$

- Tipo de uso mayoritario: estancia

Datos de calidad

\section{- Calidad estimada: 6}

- Aspectos positivos

- Zonas deportivas: no

- Zonas de sombra: si

- Bancos: si

- Zonas de juego infantil: si

- Aspectos negativos:

- Falta de usuarios: si

- Exceso de usuarios: no

- Inseguridad: no

- Deficiente mantenimiento o presencia de perros: no
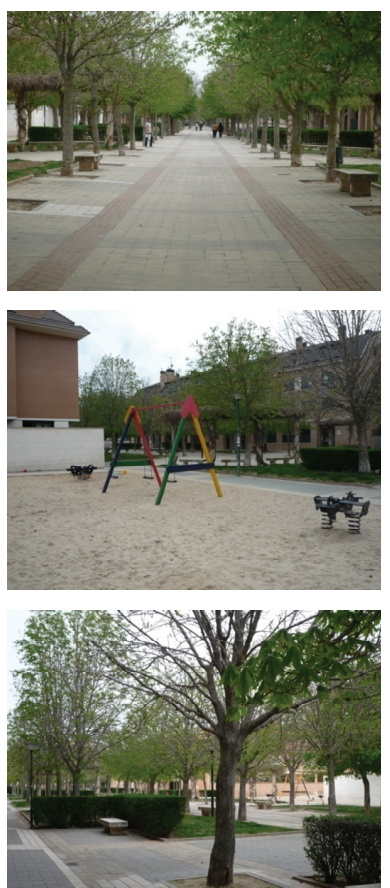

Fuente: Gómez, A. (02/04/2011).

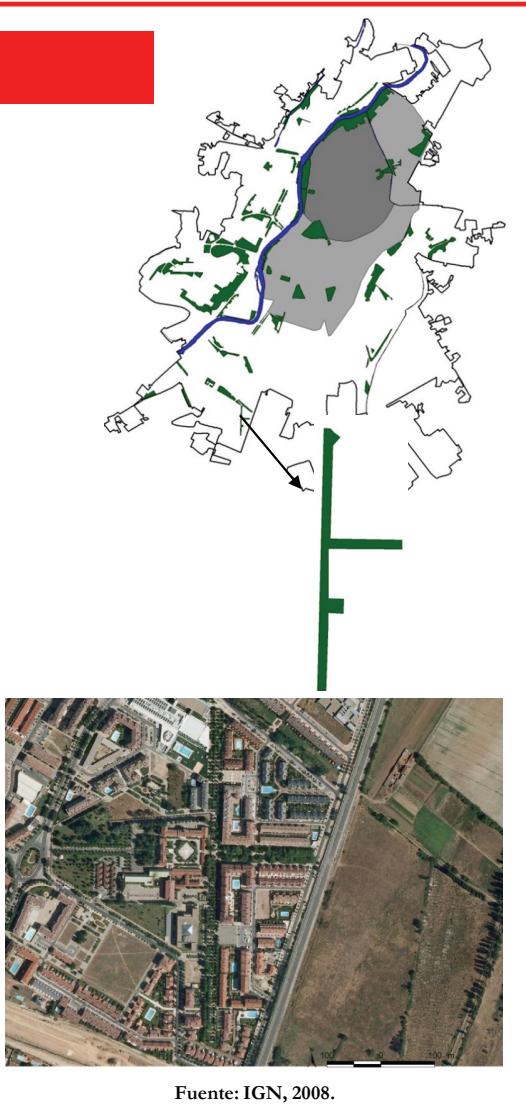




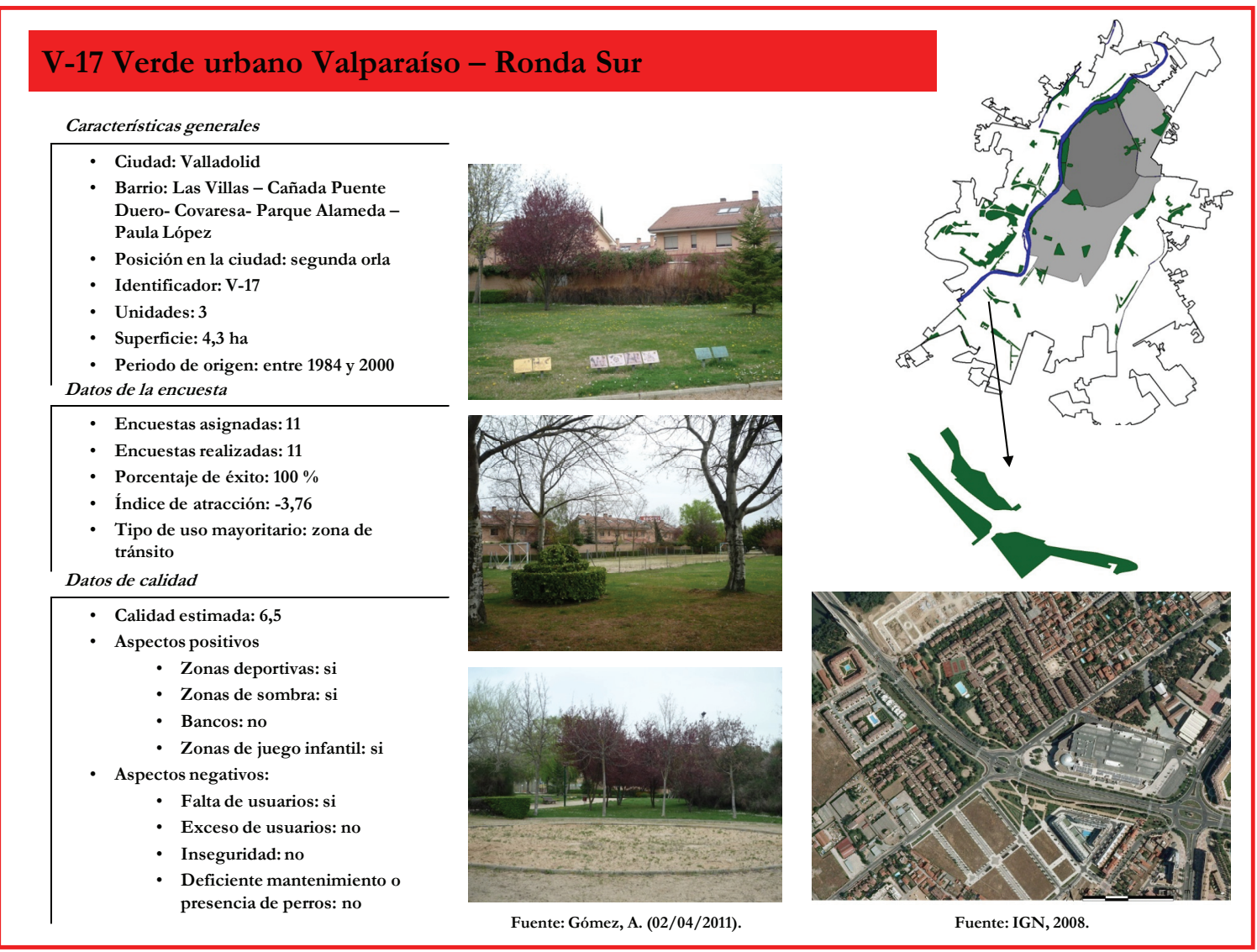

V-18 Parque Arturo León

Características generales
\begin{tabular}{|l} 
- Ciudad: Valladolid \\
- Barrio: Camino de la Esperanza \\
- Posición en la ciudad: primera y \\
segunda orlas \\
- Identificador: V-18 \\
- Unidades: 2 \\
- Superficie: 3,9 ha \\
- Periodo de origen: entre 1984 y 2000
\end{tabular}

Datos de la encuesta

- Encuestas asignadas: 10

- Encuestas realizadas: 10

- Porcentaje de éxito: $100 \%$

- Índice de atracción: 0

- Tipo de uso mayoritario: zona de tránsito

Datos de calidad

$$
\begin{aligned}
& \text { - Calidad estimada: 6,5 } \\
& \text { - Aspectos positivos } \\
& \text { • Zonas deportivas: no } \\
& \cdot \text { Zonas de sombra: si } \\
& \cdot \text { Bancos: no } \\
& \cdot \text { Zonas de juego infantil: si } \\
& \text { - Aspectos negativos: } \\
& \text { - Falta de usuarios: no } \\
& \text { - Inseguridad: no } \\
& \text { - Deficiente mantenimiento o } \\
& \text { presencia de perros: no }
\end{aligned}
$$

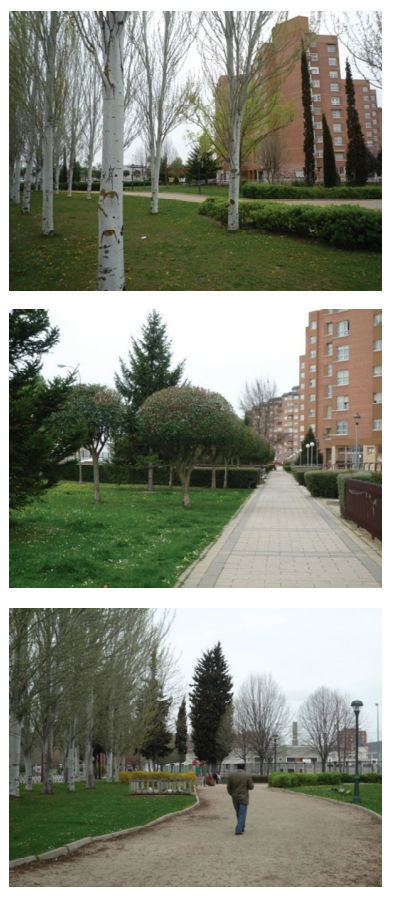

Fuente: Gómez, A. (02/04/2011).

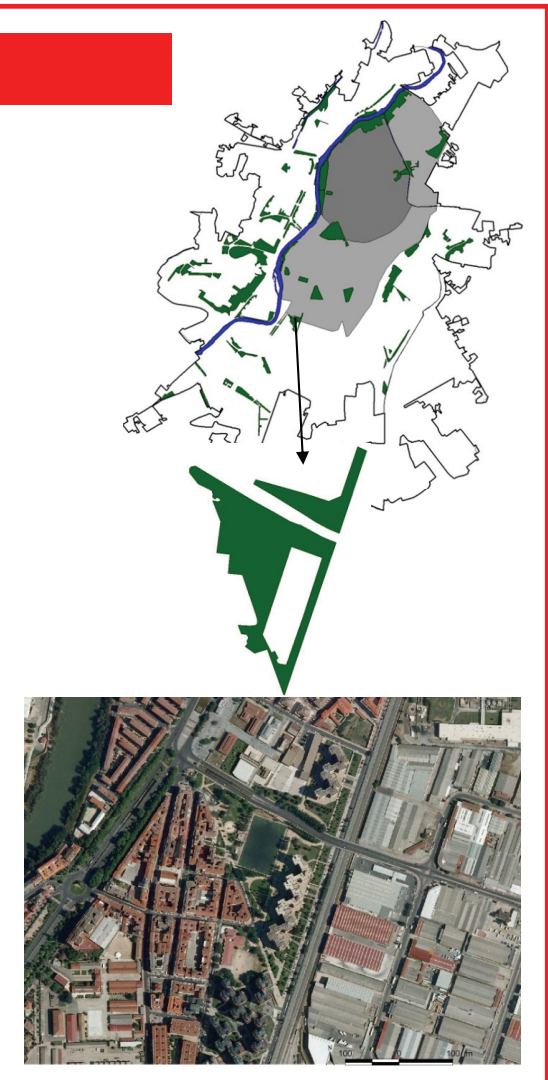

Fuente: IGN, 2008. 

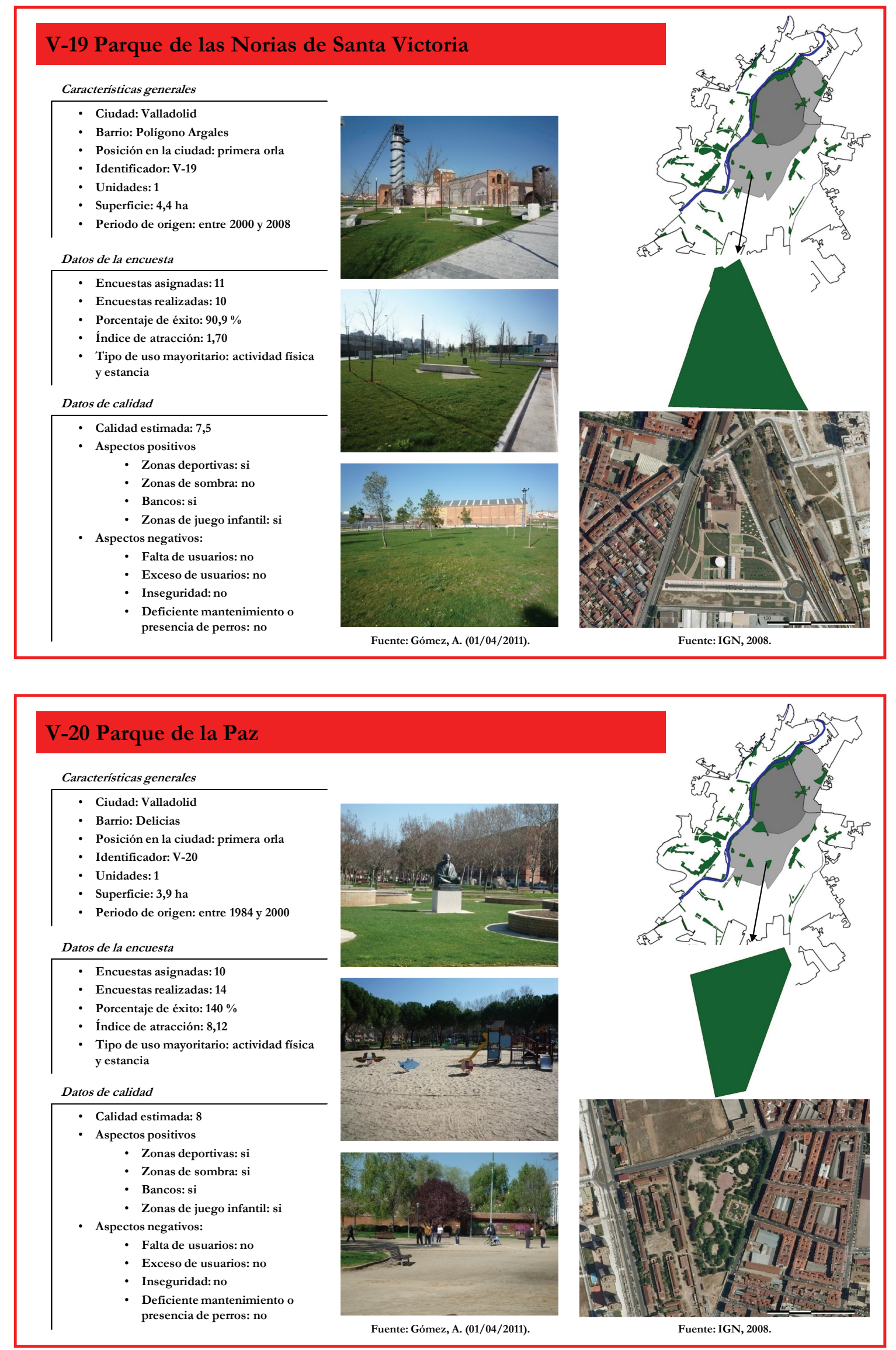


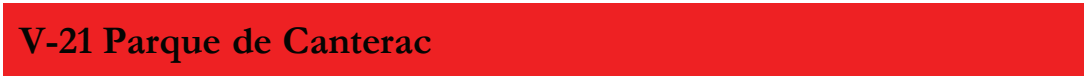

Características generales

- Ciudad: Valladolid

Barrio: Caamaño - Las Viudas Polígono San Cristóbal

- Posición en la ciudad: segunda orla

- Identificador: V-21

- Unidades: 1

- Superficie: $12,2 \mathrm{ha}$

- Periodo de origen: entre 1971 y 1984 Datos de la encuesta

- Encuestas asignadas: 31

- Encuestas realizadas: 35

- Porcentaje de éxito: $112,9 \%$

- Índice de atracción: 1,11

- Tipo de uso mayoritario: estancia

Datos de calidad

- Calidad estimada: 7

- Aspectos positivos

- Zonas deportivas: no

- Zonas de sombra: si

- Bancos:si

- Zonas de juego infantil: si

- Aspectos negativos:

- Falta de usuarios: no

- Exceso de usuarios: no

- Inseguridad: no

- Deficiente mantenimiento o presencia de perros: si
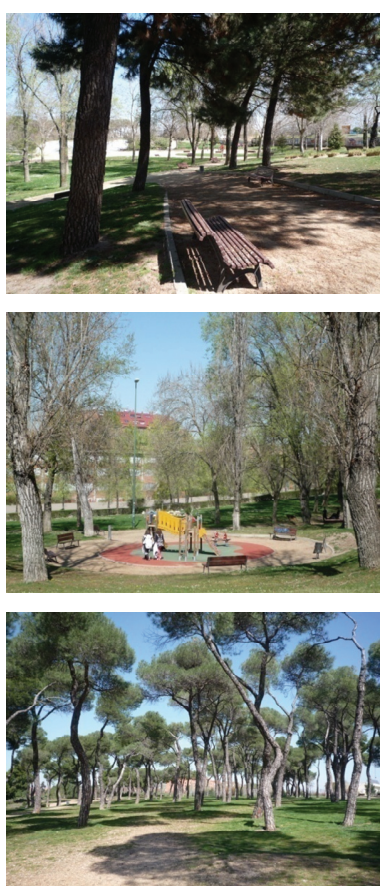

Fuente: Gómez, A. (01/04/2011)

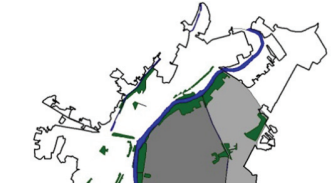

30

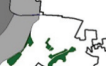

sen

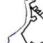

है
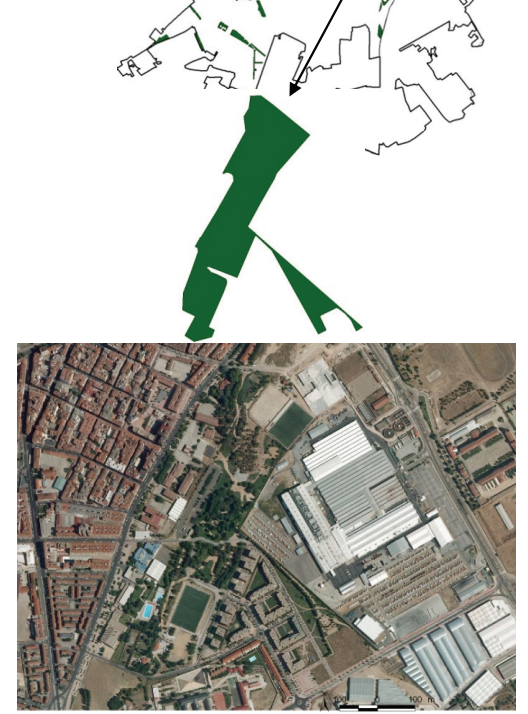

Fuente: IGN, 2008.

V-22 Parque de San Isidro - Fuente de la Salud

Características generales

- Ciudad: Valladolid

- Barrio: Páramos San Isidro - Campo de Tiro

- Posición en la ciudad: segunda orla

- Identificador: V-22

- Unidades: 2

- Superficie: 5,9 ha

- Periodo de origen: entre 1971 y 1984 Datos de la encuesta

- Encuestas asignadas: 15

- Encuestas realizadas: 15

- Porcentaje de éxito: $100 \%$

- Índice de atracción: 0,77

- Tipo de uso mayoritario: estancia

Datos de calidad

- Calidad estimada: 7

- Aspectos positivos

- Zonas deportivas: no

- Zonas de sombra: si

- Bancos:si

- Zonas de juego infantil: si

- Aspectos negativos:

- Falta de usuarios: no

- Exceso de usuarios: no

- Inseguridad: no

- Deficiente mantenimiento 0 presencia de perros: no
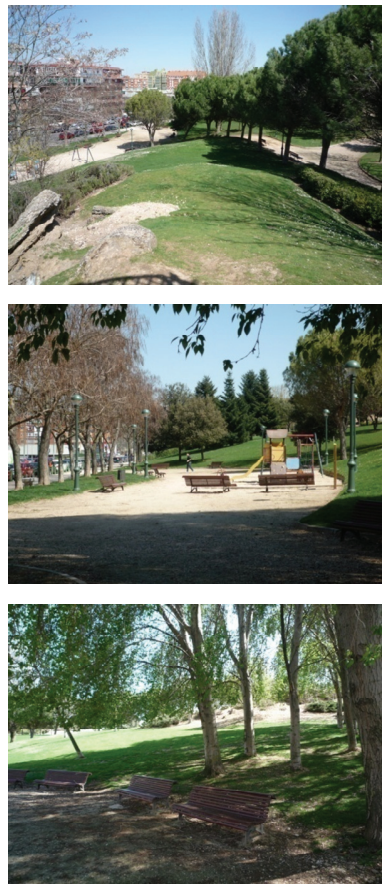

Fuente: Gómez, A. (01/04/2011).
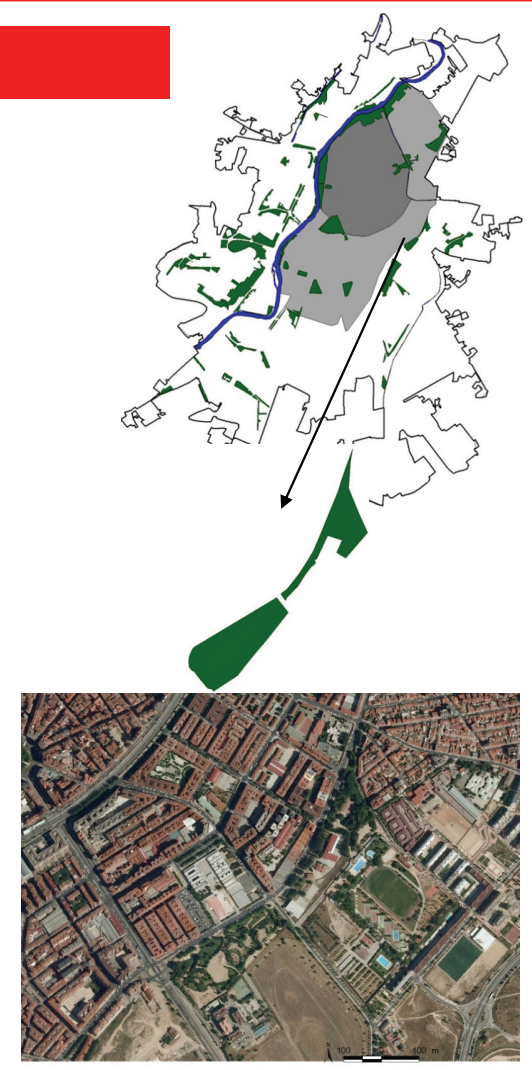

Fuente: IGN, 2008. 


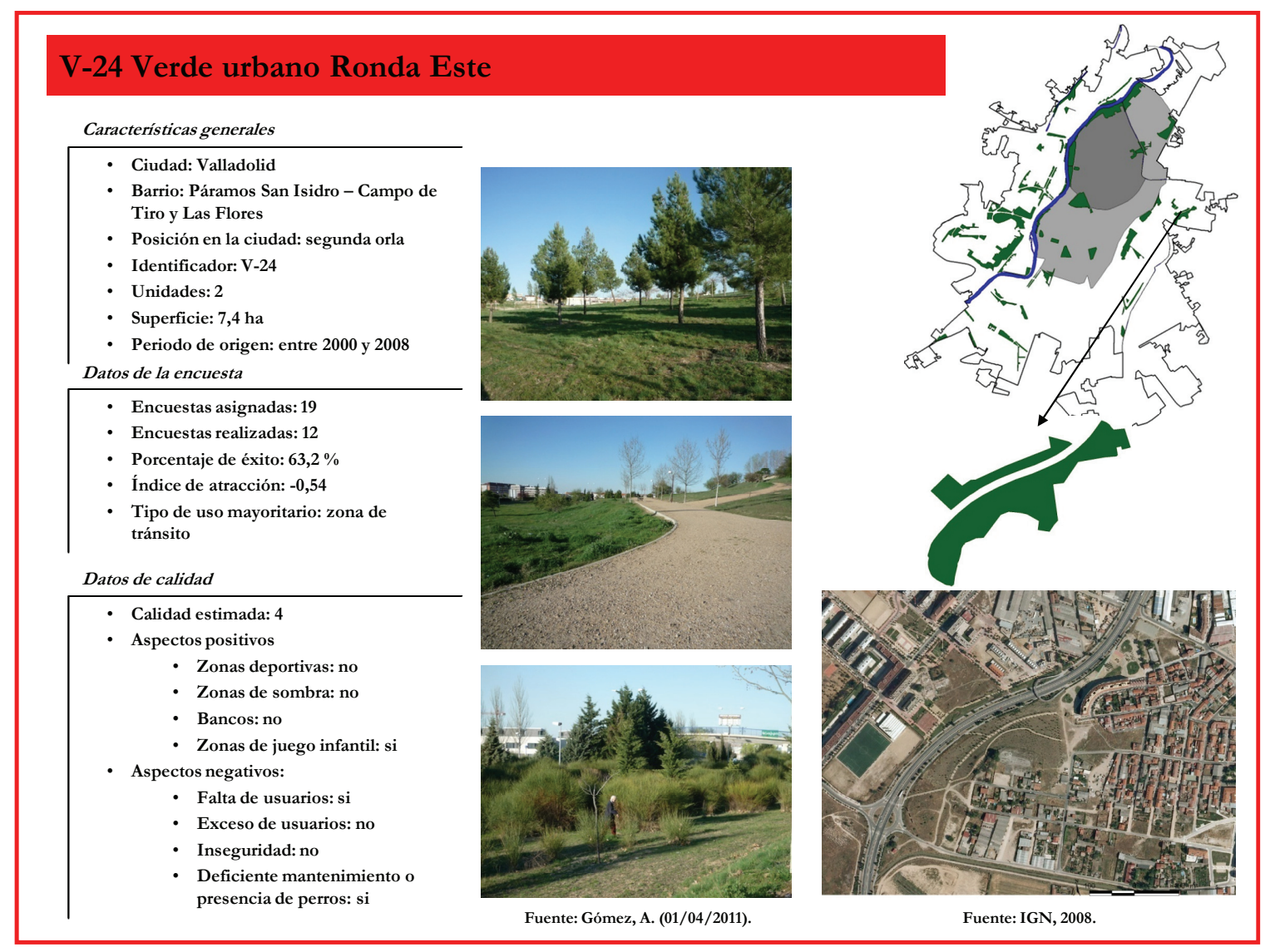

\section{V-25 Verde urbano Calle Arribes del Duero}

\begin{tabular}{|l} 
Características generales \\
\hline - Ciudad: Valladolid \\
- Barrio: Caamaño - Las Viudas - \\
Polígono San Cristóbal \\
- Posición en la ciudad: segunda orla \\
- Identificador: V-25 \\
- Unidades: 3 \\
- Superficie: 4 ha \\
- Periodo de origen: entre 2000 y 2008 \\
Datos de la encuesta
\end{tabular}

\begin{tabular}{|l}
\hline - Encuestas asignadas: 4 \\
- Encuestas realizadas: 4 \\
- Porcentaje de éxito: $100 \%$ \\
- Índice de atracción: $-0,62$ \\
Tipo de uso mayoritario: zona de \\
\end{tabular}

Datos de calidad

- Calidad estimada: 6
- Aspectos positivos
• Zonas deportivas: no
- Zonas de sombra: si
- Bancos: si
- Zonas de juego infantil: si
- Fspectos negativos:
- Exceso de usuarios: no
- Inseguridad: no
peficiente mantenimiento o
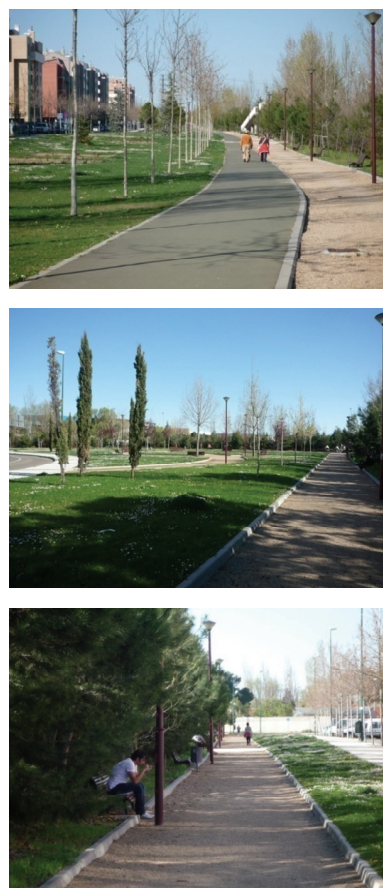

Fuente: Gómez, A. (01/04/2011).
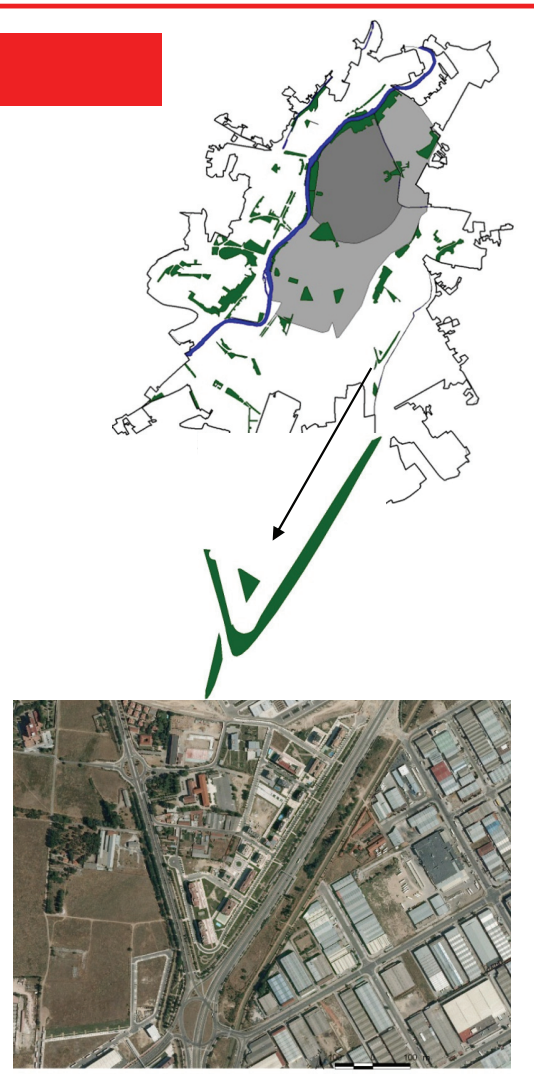

Fuente: IGN, 2008. 


\section{V-26 Campus Esgueva}

Características generales

- Ciudad: Valladolid

Barrio: Hospital y Belén

- Posición en la ciudad: centro histórico y primera orla

- Identificador: V-26

- Unidades: 3

- Superficie: 6,1 ha

- Periodo de origen: entre 1971 y 1984 Datos de la encuesta

- Encuestas asignadas: 16

- Encuestas realizadas: 16

- Porcentaje de éxito: $100 \%$

- Índice de atracción: $-\mathbf{0 , 6 2}$

- Tipo de uso mayoritario: actividad física y estancia

Datos de calidad

\section{- Calidad estimada: 8}

- Aspectos positivos

- Zonas deportivas: si

- Zonas de sombra: si

- Bancos: si

- Zonas de juego infantil: si

- Aspectos negativos:

- Falta de usuarios: si

- Exceso de usuarios: no

- Inseguridad: no

- Deficiente mantenimiento o presencia de perros: no
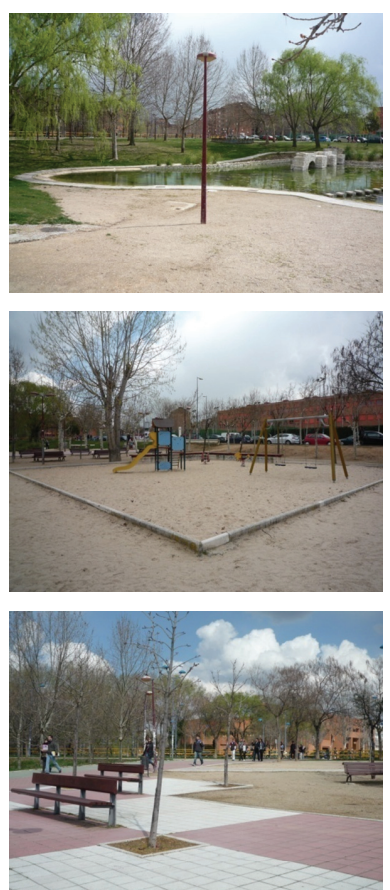

Fuente: Gómez, A. (22/03/2011).

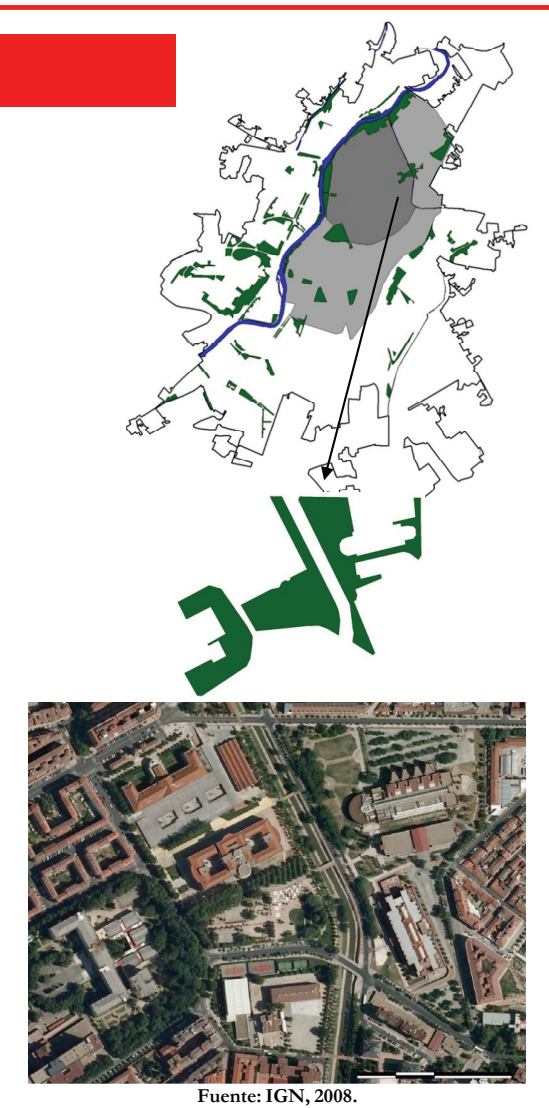

\section{V-27 Campus Miguel Delibes}

$$
\begin{aligned}
& \text { Características generales } \\
& \text { - Ciudad: Valladolid } \\
& \text { - Barrio: Belén } \\
& \text { - Posición en la ciudad: primera orla } \\
& \text { - Identificador: V-27 } \\
& \text { - Unidades: } 1 \\
& \text { - Superficie: } 8,8 \text { ha } \\
& \text { - Periodo de origen: entre } 1984 \text { y } 2000
\end{aligned}
$$

Datos de la encuesta

- Encuestas asignadas: 23

- Encuestas realizadas: 25

- Porcentaje de éxito: $108,7 \%$

- Índice de atracción: $-\mathbf{- 0 , 9 3}$

- Tipo de uso mayoritario: zona de tránsito

Datos de calidad

- Calidad estimada: 8

- Aspectos positivos

- Zonas deportivas: no

- Zonas de sombra: no

- Bancos: si

- Zonas de juego infantil: no

- Aspectos negativos:

- Falta de usuarios: si

- Exceso de usuarios: no

- Inseguridad: no

- Deficiente mantenimiento o presencia de perros: no
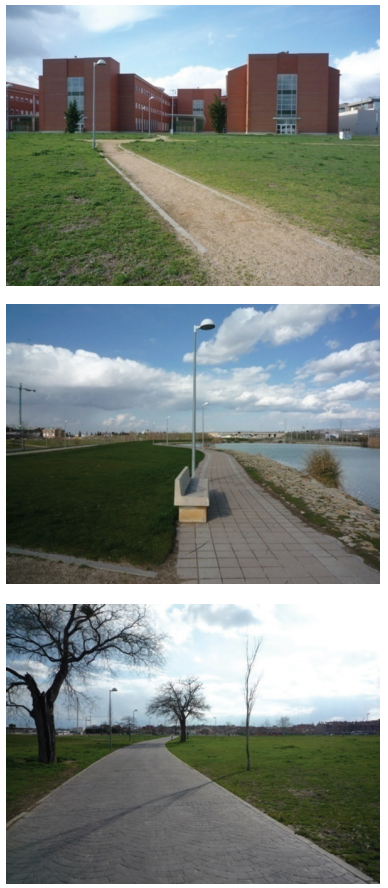

Fuente: Gómez, A. (22/03/2011).

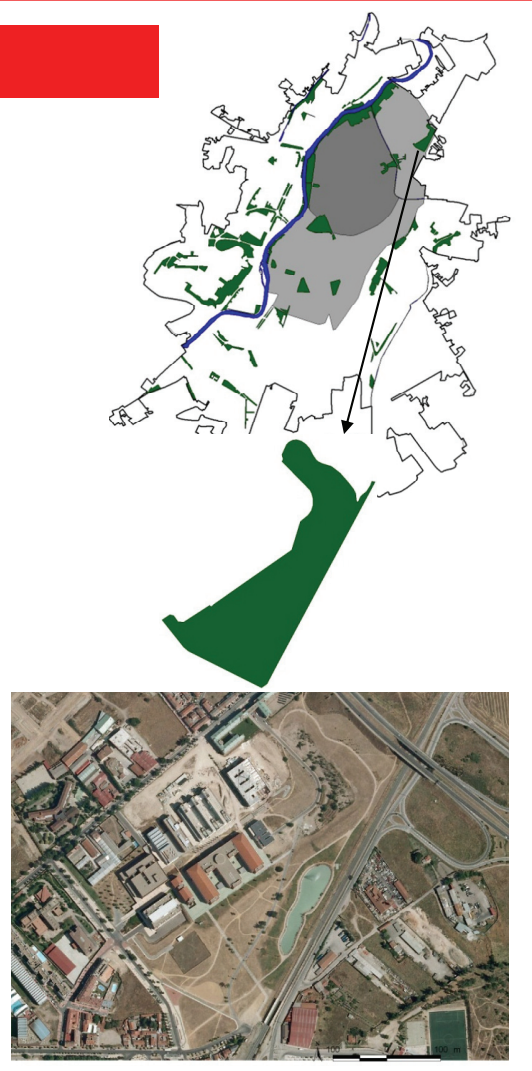

Fuente: IGN, 2008. 


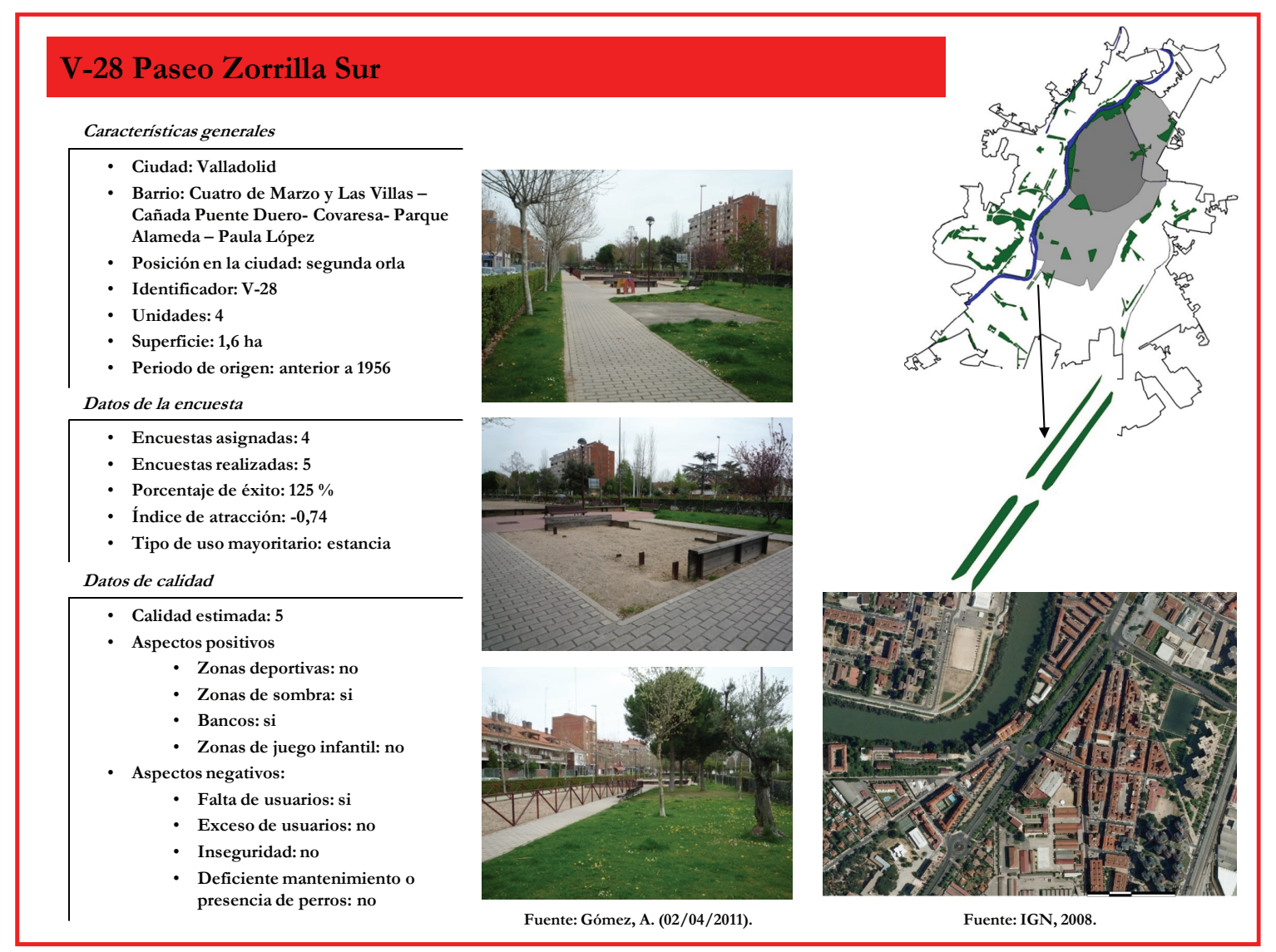

\section{V-29 Verde urbano Cortes de Castilla y León}

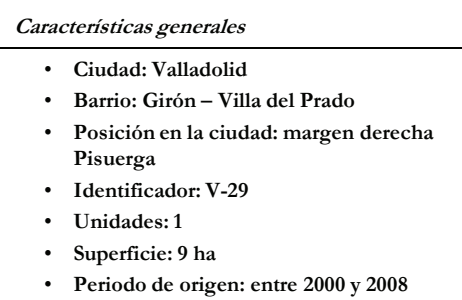
Datos de la encuesta

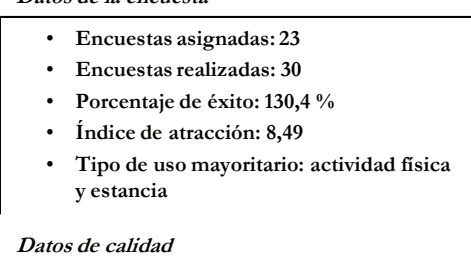
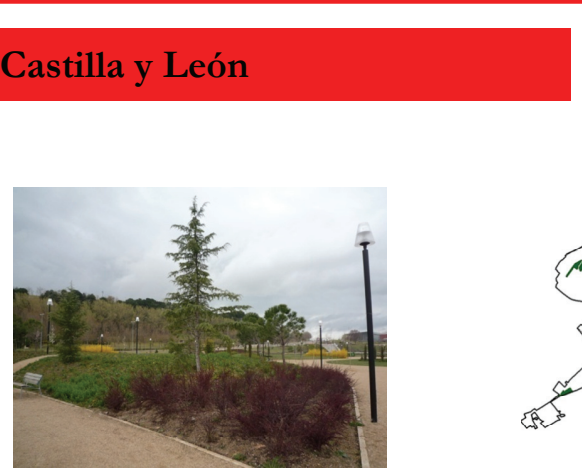

\footnotetext{
- Calidad estimada: 8

- Aspectos positivos

- Zonas deportivas: si

- Zonas de sombra: si

- Bancos: si

- Zonas de juego infantil: si

- Aspectos negativos:

- Falta de usuarios: no

- Exceso de usuarios: no

- Inseguridad: no

- Deficiente mantenimiento o presencia de perros: no
}

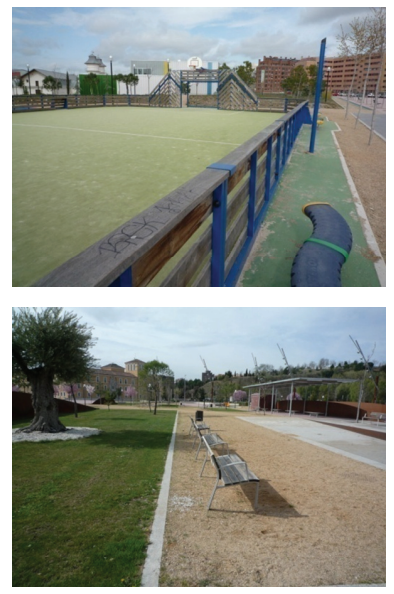

Fuente: Gómez, A. (25/03/2011).

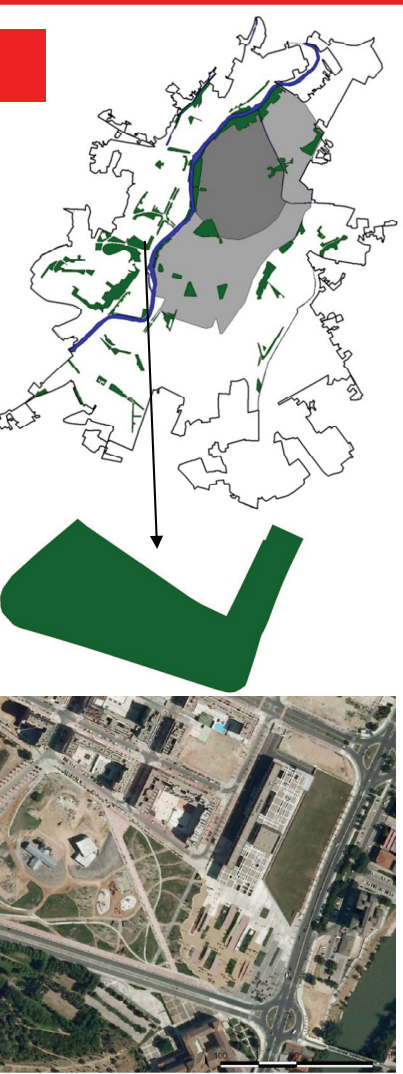

Fuente: IGN, 2008. 


\section{V-30 Verde urbano Auditorio Miguel Delibes}

Características generales

- Ciudad: Valladolid

Barrio: Girón - Villa del Prado

Posición en la ciudad: margen derecha Pisuerga

- Identificador: V-30

- Unidades: 2

- Superficie: 4,8 ha

- Periodo de origen: entre 2000 y 2008 Datos de la encuesta

- Encuestas asignadas: 12

- Encuestas realizadas: 8

- Porcentaje de éxito: $66,7 \%$

- Índice de atracción: 1,08

- Tipo de uso mayoritario: estancia

Datos de calidad

- Calidad estimada: 6

- Aspectos positivos

- Zonas deportivas: no

- Zonas de sombra: si

- Bancos: si

- Zonas de juego infantil: no

- Aspectos negativos:

- Falta de usuarios: no

- Exceso de usuarios: no

- Inseguridad: no

- Deficiente mantenimiento o presencia de perros: no
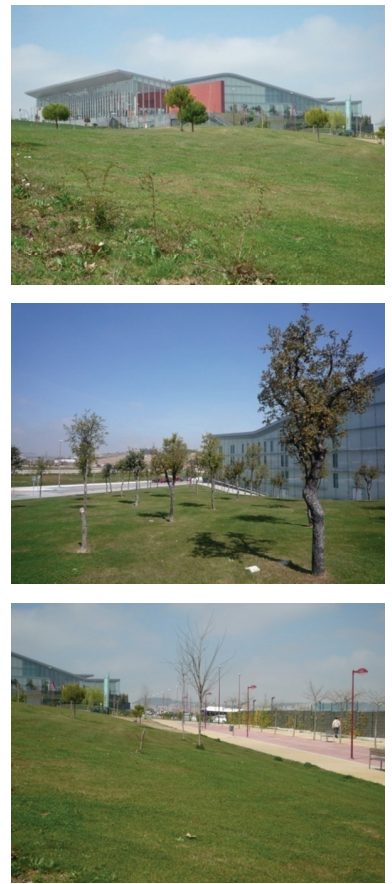

Fuente: Gómez, A. (31/03/2011).

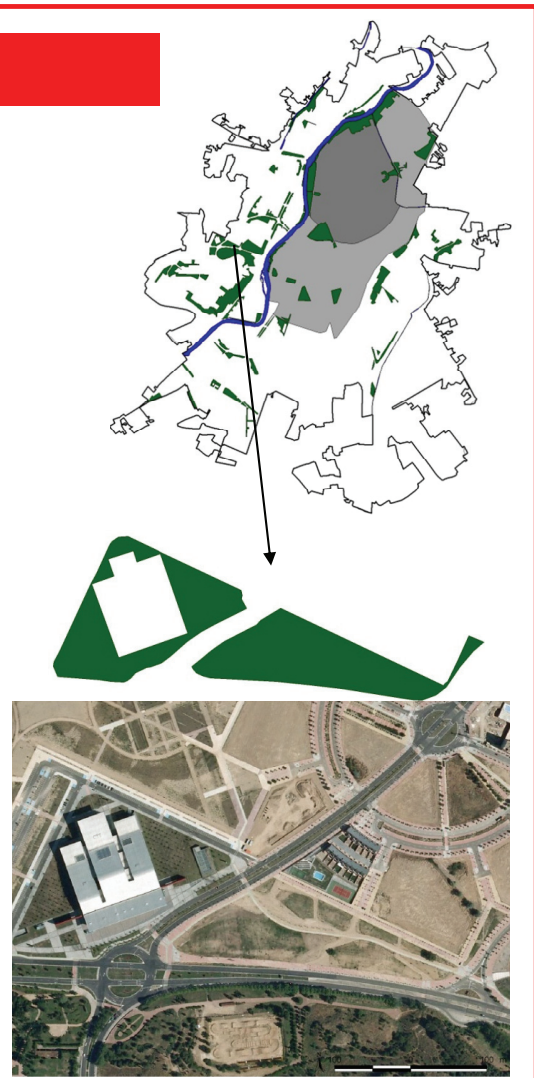

Fuente: IGN, 2008.

\section{V-31 Verde urbano Mirador de Parquesol}

Características generale

Ciudad: Valladolid

- Barrio: Parquesol

Posición en la ciudad: margen derecha Pisuerga

- Identificador: V-31

Unidades: 1

- Superficie: 15,4 ha

- Periodo de origen: entre 1971 y 1984 Datos de la encuesta

- Encuestas asignadas: 39

- Encuestas realizadas: 3

- Porcentaje de éxito: $7,7 \%$

Índice de atracción: 2,01

- Tipo de uso mayoritario: zona de tránsito

Datos de calidad

- Calidad estimada: 5

Aspectos positivos

- Zonas deportivas: no

- Zonas de sombra: si

- Bancos: si

- Zonas de juego infantil: no

- Aspectos negativos:

- Falta de usuarios: no

- Exceso de usuarios: no

- Inseguridad: si

- Deficiente mantenimiento o presencia de perros: si
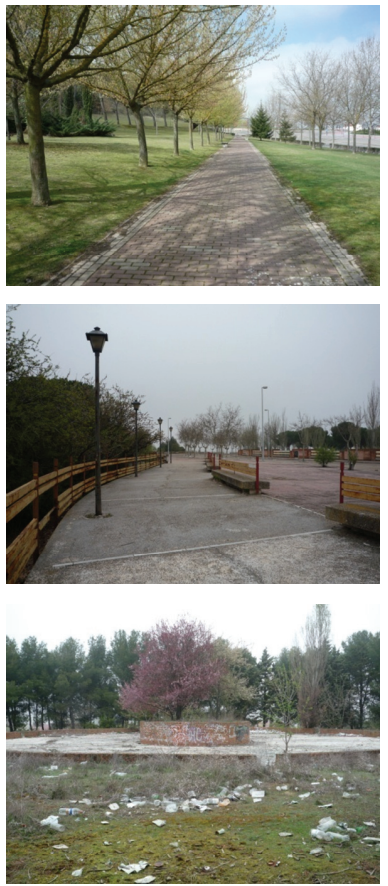

Fuente: Gómez, A. (31/03/2011).
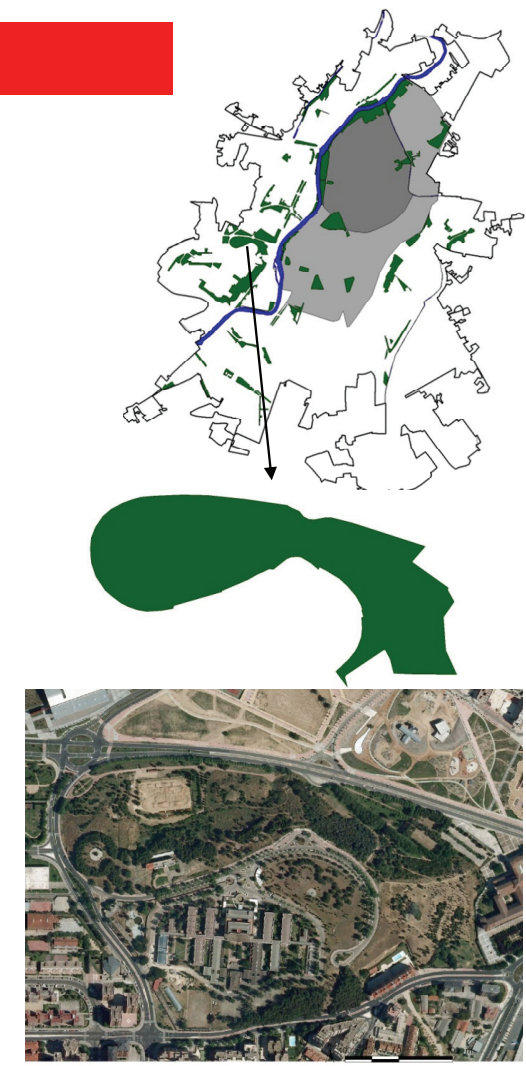

Fuente: IGN, 2008. 


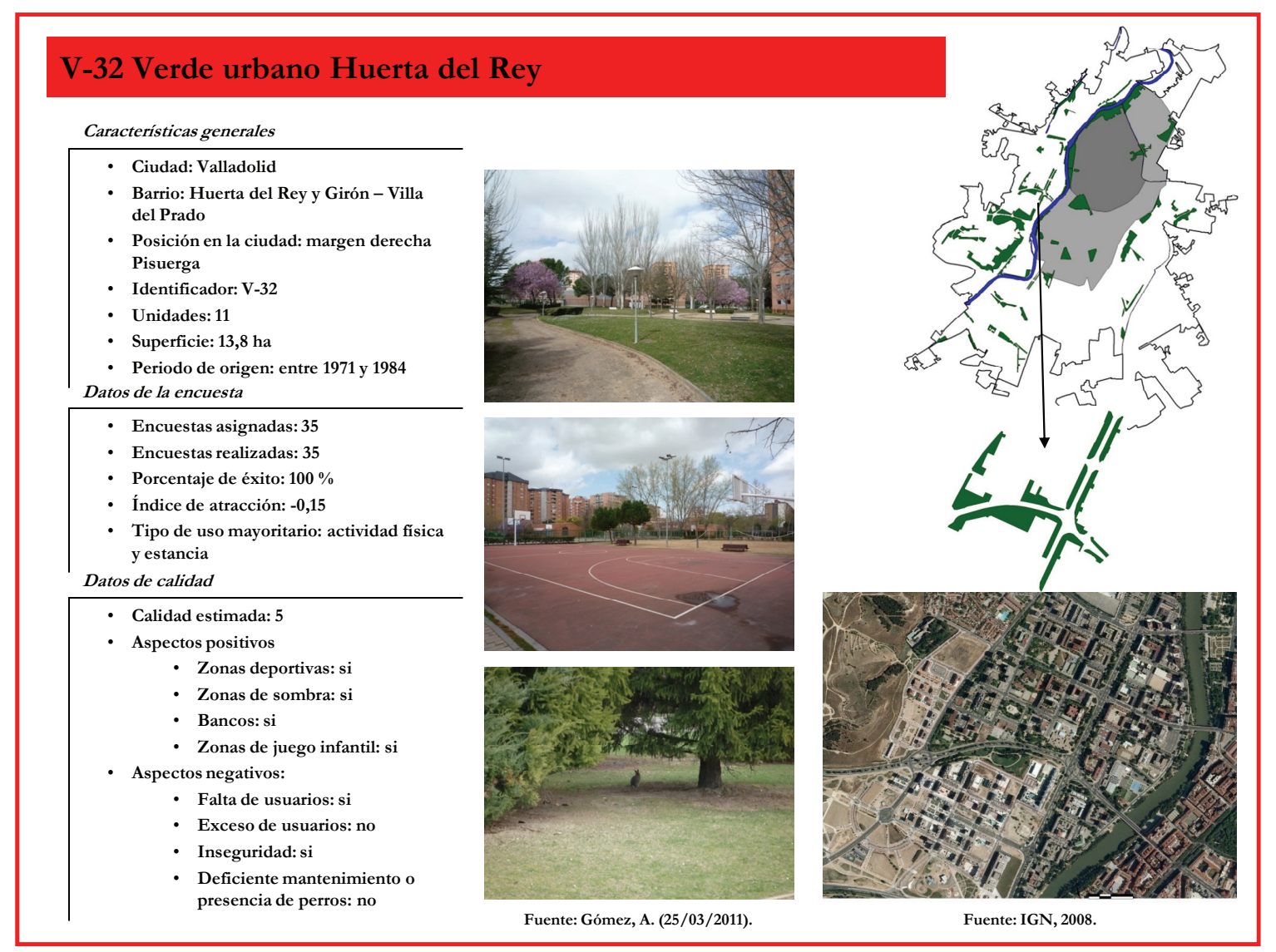

\section{V-33 Verde urbano Parquesol Calle Morelia}

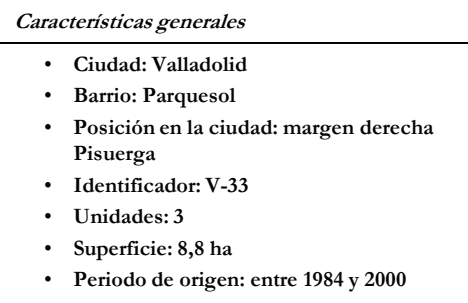

Datos de la encuesta

- Encuestas asignadas: 22
- Encuestas realizadas: 30
- Porcentaje de éxito: $136,4 \%$
- Índice de atracción: 0
- Tipo de uso mayoritario: estancia

\section{Datos de calidad}

\begin{aligned} \hline Calidad estimada: 7 \\ - Aspectos positivos \\ - Zonas deportivas: no \\ - Bonas de sombra: si \\ - Zonas de juego infantil: si \\ - Aspectos negativos: \\ - Ealta de usuarios: no \\ - Inseguridad: no \\ - Deficiente mantenimiento o \\ presencia de perros: no \end{aligned}
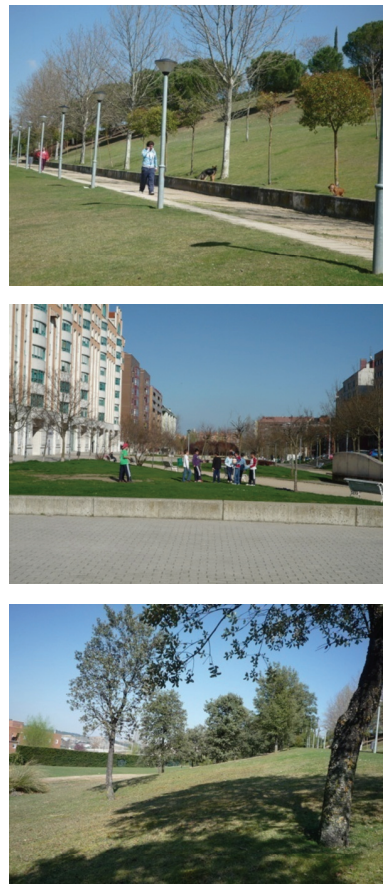

Fuente: Gómez, A. (31/03/2011).
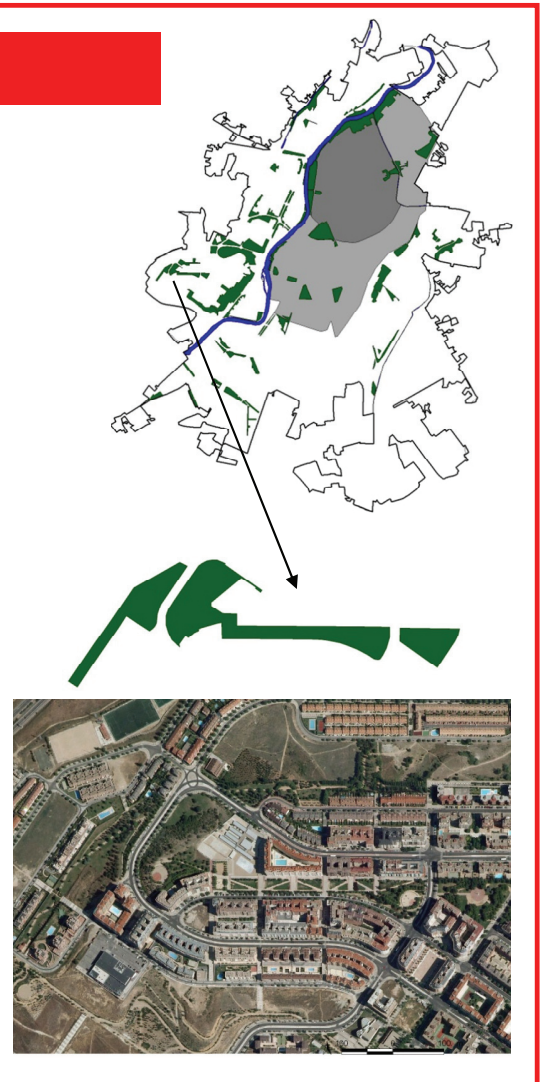

Fuente: IGN, 2008. 


\section{V-34 Verde urbano Parquesol Calle Juan de Valladolid}

Características generales

- Ciudad: Valladolid

- Barrio: Parquesol

Posición en la ciudad: margen derecha Pisuerga

- Identificador: V-34

- Unidades: 1

- Superficie: 2,5 ha

- Periodo de origen: entre 1984 y 2000 Datos de la encuesta

- Encuestas asignadas: 7

- Encuestas realizadas: 7

- Porcentaje de éxito: $100 \%$

- Índice de atracción: 2,58

- Tipo de uso mayoritario: estancia

Datos de calidad

- Calidad estimada: 5

- Aspectos positivos

- Zonas deportivas: no

- Zonas de sombra: si

- Bancos: si

- Zonas de juego infantil: no

- Aspectos negativos:

- Falta de usuarios: no

- Exceso de usuarios: si

- Inseguridad: no

- Deficiente mantenimiento o presencia de perros: no
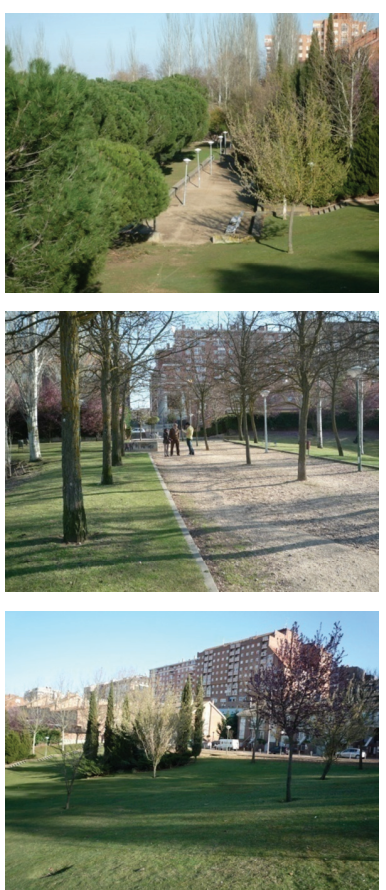

Fuente: Gómez, A. (31/03/2011).
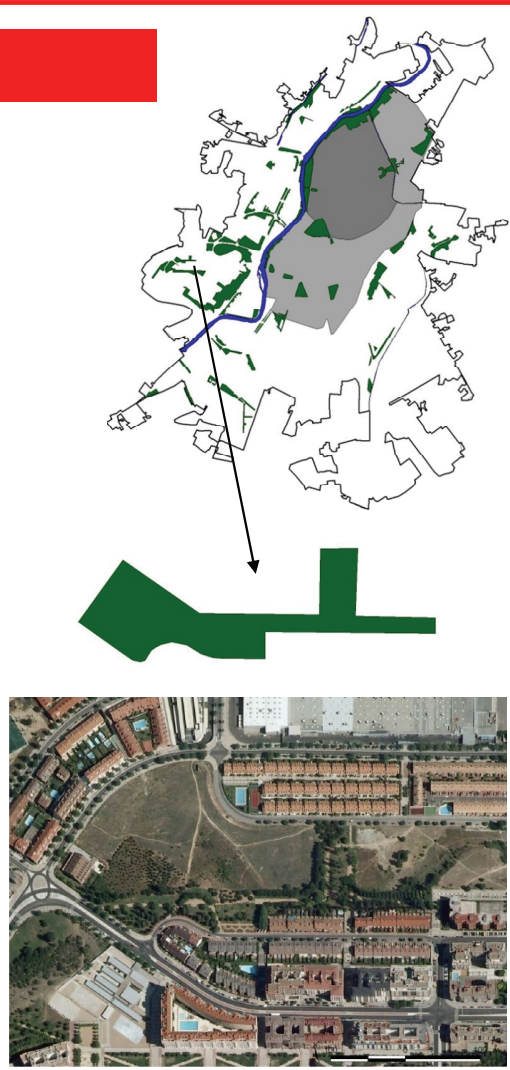

Fuente: IGN, 2008.

V-35 Parque del Reloj de Sol

Características generales

- Ciudad: Valladolid

- Barrio: Parquesol

Posición en la ciudad: margen derecha Pisuerga

- Identificador: V-35

- Unidades: 1

- Superficie: 2 ha

- Periodo de origen: entre 1984 y 2000 Datos de la encuesta

- Encuestas asignadas: 5

- Encuestas realizadas: 5

Porcentaje de éxito: $100 \%$

- Índice de atracción: 1,08

- Tipo de uso mayoritario: estancia

Datos de calidad

- Calidad estimada: 5

- Aspectos positivos

- Zonas deportivas: no

- Zonas de sombra: si

- Bancos: si

- Zonas de juego infantil: no

- Aspectos negativos:

- Falta de usuarios: no

- Exceso de usuarios: si

- Inseguridad: no

- Deficiente mantenimiento o presencia de perros: no
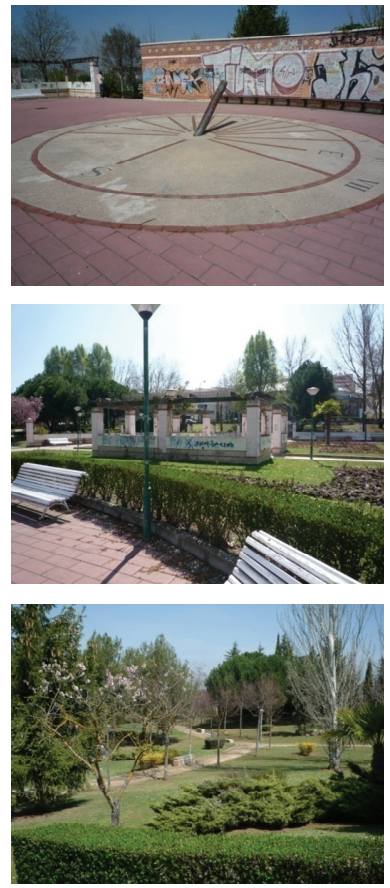

Fuente: Gómez, A. (31/03/2011).
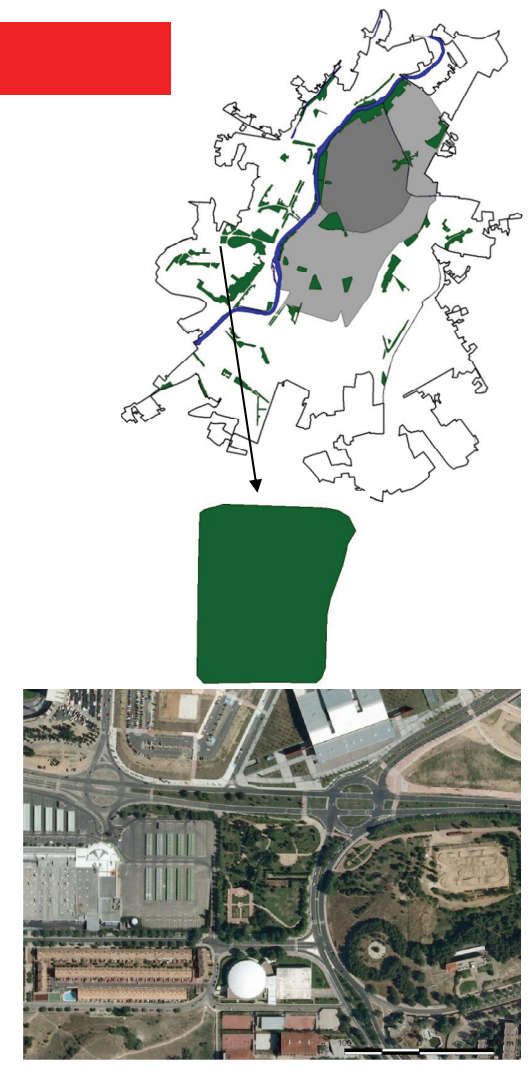

Fuente: IGN, 2008. 


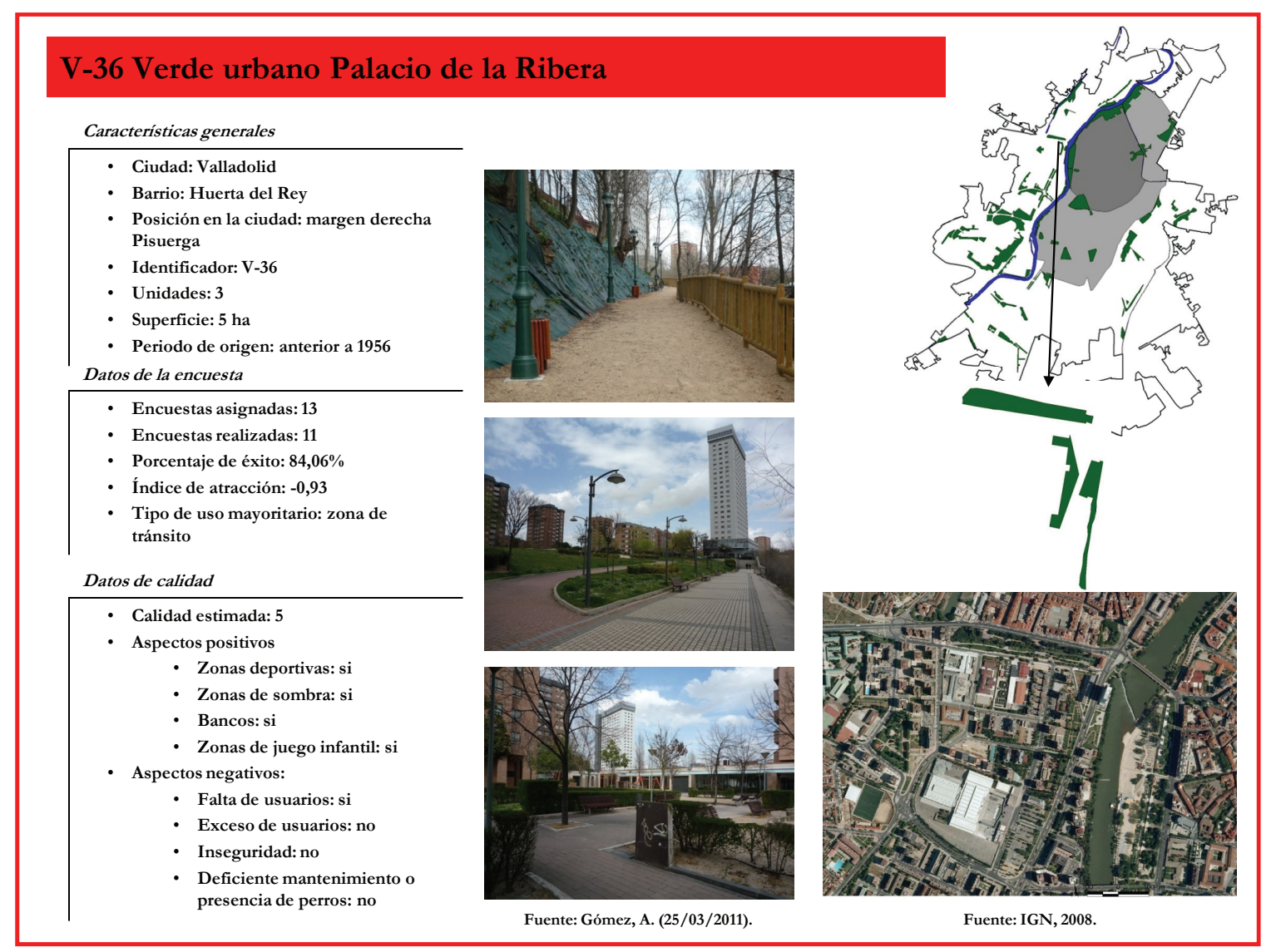

\section{V-37 Ribera Huerta del Rey}

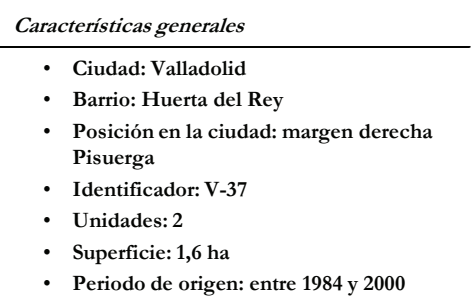

Datos de la encuesta

- Encuestas asignadas: 4
- Encuestas realizadas: 5
- Índice de atracción: $-\mathbf{- 0 , 1 5}$
- Tipo de uso mayoritario: zona de
tránsito
Datos de calidad

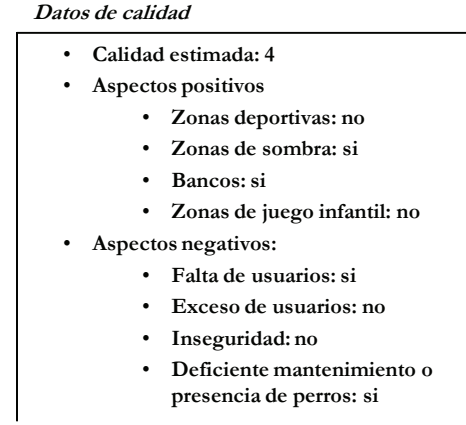

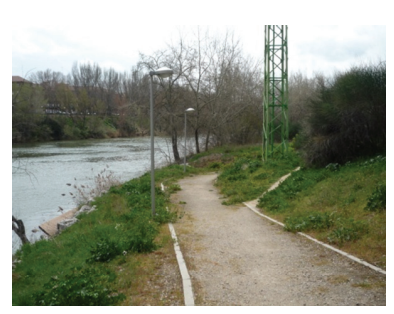
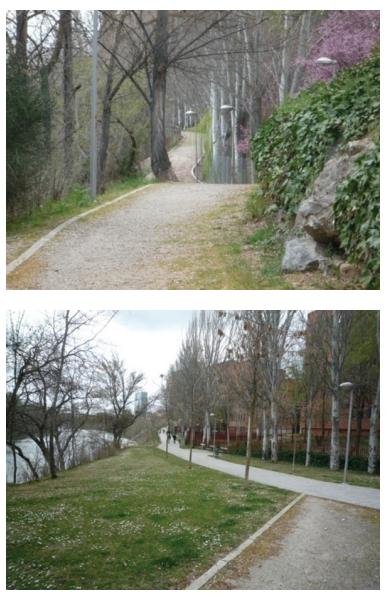

Fuente: Gómez, A. (25/03/2011).
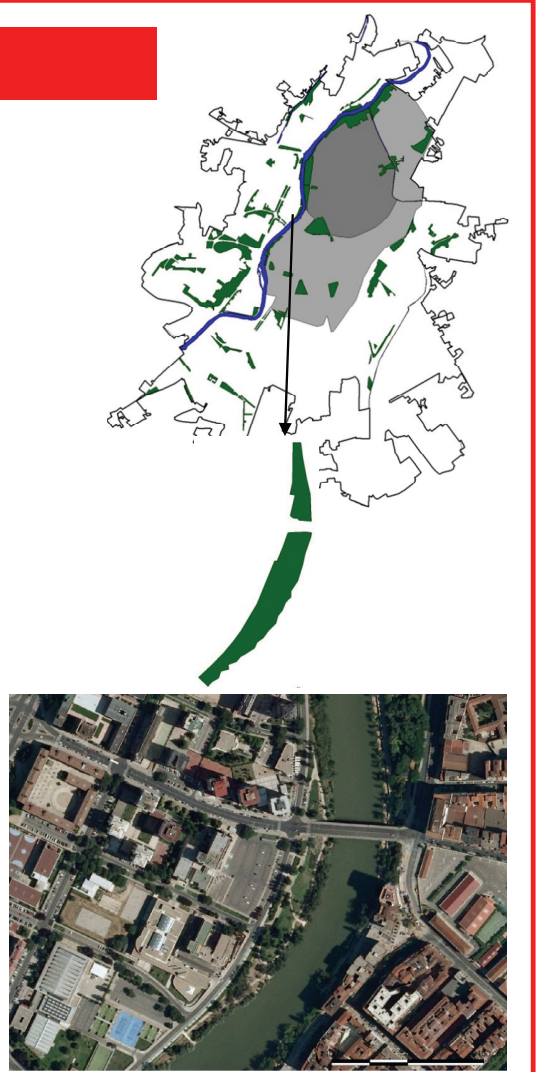

Fuente: IGN, 2008. 
V-38 Verde urbano Plaza Juan de Austria

Características generales

- Ciudad: Valladolid

- Barrio: Paseo Zorrilla

- Posición en la ciudad: primera orla

- Identificador: V-38

- Unidades: 1

- Superficie: 1,4 ha

- Periodo de origen: entre 1984 y 2000

Datos de la encuesta

- Encuestas asignadas: 3

- Encuestas realizadas: 0

- Porcentaje de éxito: $0 \%$

- Índice de atracción: 1,61

- Tipo de uso mayoritario: actividad física y estancia

Datos de calidad

- Calidad estimada: 7

- Aspectos positivos

- Zonas deportivas: si

- Zonas de sombra: si

- Bancos: si

- Zonas de juego infantil: si

- Aspectos negativos:

- Falta de usuarios: si

- Exceso de usuarios: no

- Inseguridad: no

- Deficiente mantenimiento o presencia de perros: no
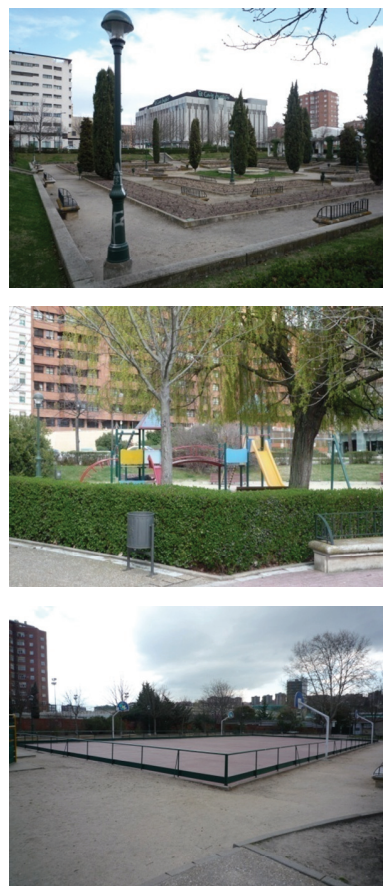

Fuente: Gómez, A. (25/03/2011).

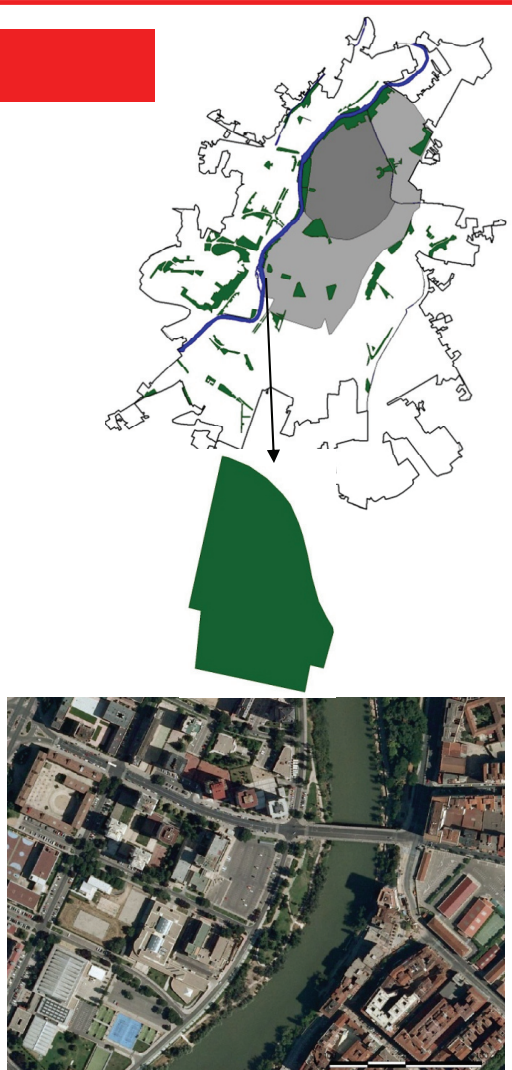

Fuente: IGN, 2008.

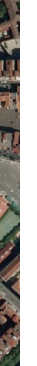

V-39 Verde urbano Calle Morena - Feria de Muestras

Características generales

- Ciudad: Valladolid

- Barrio: Huerta del Rey

- Posición en la ciudad: margen derecha Pisuerga

- Identificador: V-39

- Unidades: 1

- Superficie: 1,7 ha

- Periodo de origen: entre 1984 y 2000 Datos de la encuesta

- Encuestas asignadas: 4

- Encuestas realizadas: 4

Porcentaje de éxito: $100 \%$

- Índice de atracción: 2,15

- Tipo de uso mayoritario: actividad física y estancia

Datos de calidad

Calidad estimada: 7

Aspectos positivo

- Zonas deportivas: si

- Zonas de sombra: si

- Bancos: si

- Zonas de juego infantil: si

- Aspectos negativos:

- Falta de usuarios: no

- Exceso de usuarios:

- Inseguridad: no

- Deficiente mantenimiento o presencia de perros: no
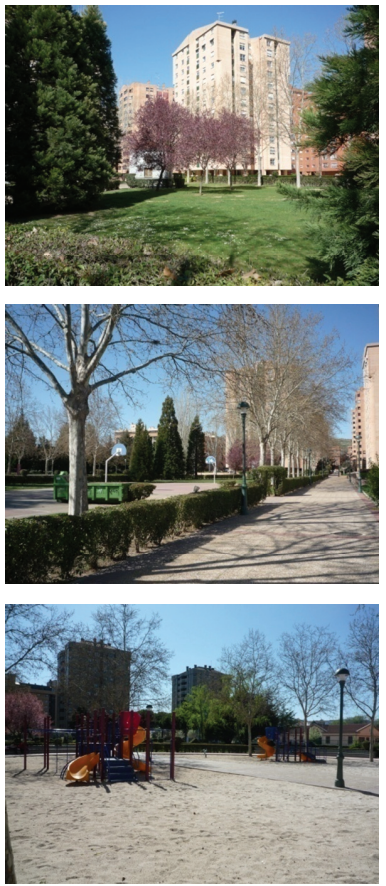

Fuente: Gómez, A. (01/04/2011). 


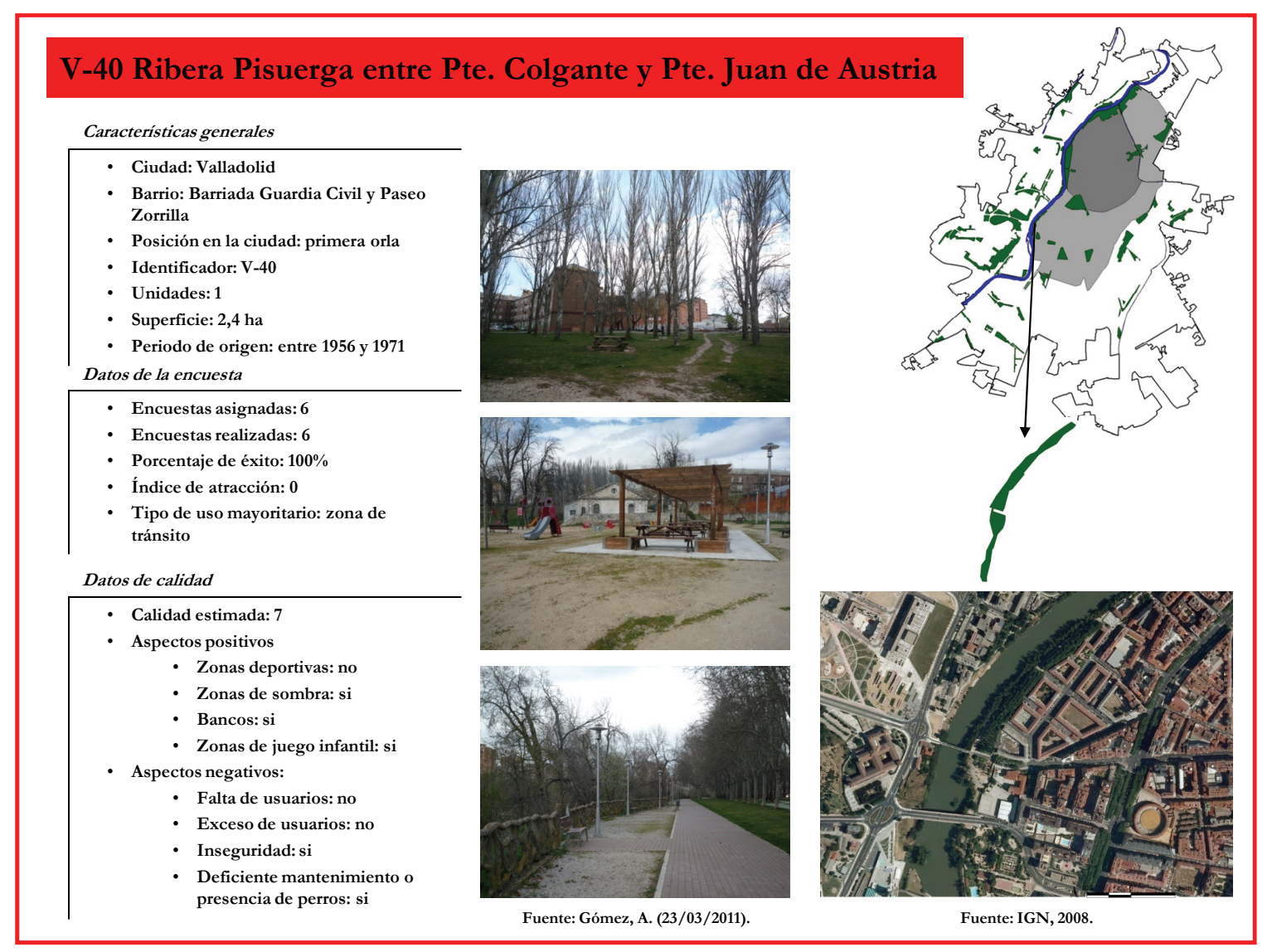

\section{V-42 Plaza del Ejército}

Características generales
$\begin{aligned} & \text { - Ciudad: Valladolid } \\ & \text { - Barrio: Paseo Zorrilla } \\ & \text { - Posición en la ciudad: primera orla } \\ & \text { - Identificador: V-42 } \\ & \text { - Unidades: } 1 \\ & \text { - Superficie: } 1,6 \text { ha } \\ & \text { - Periodo de origen: entre } 2000 \text { y } 2008\end{aligned}$

Datos de la encuesta

- Encuestas asignadas: 4
- Encuestas realizadas: 8
- Porcentaje de éxito: $200 \%$
- Índice de atracción: $-0,46$
- Tipo de uso mayoritario: actividad física

Datos de calidad

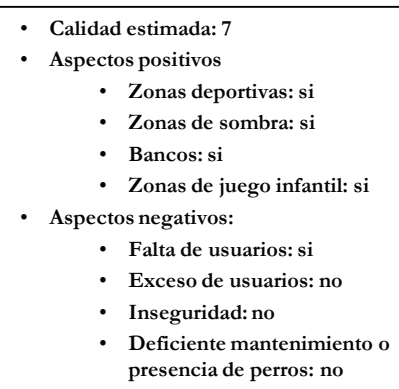
presencia de perros: no
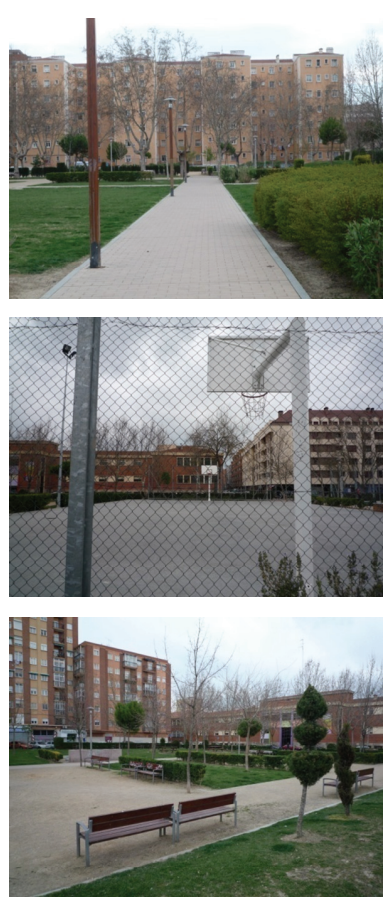

Fuente: Gómez, A. (23/03/2011).
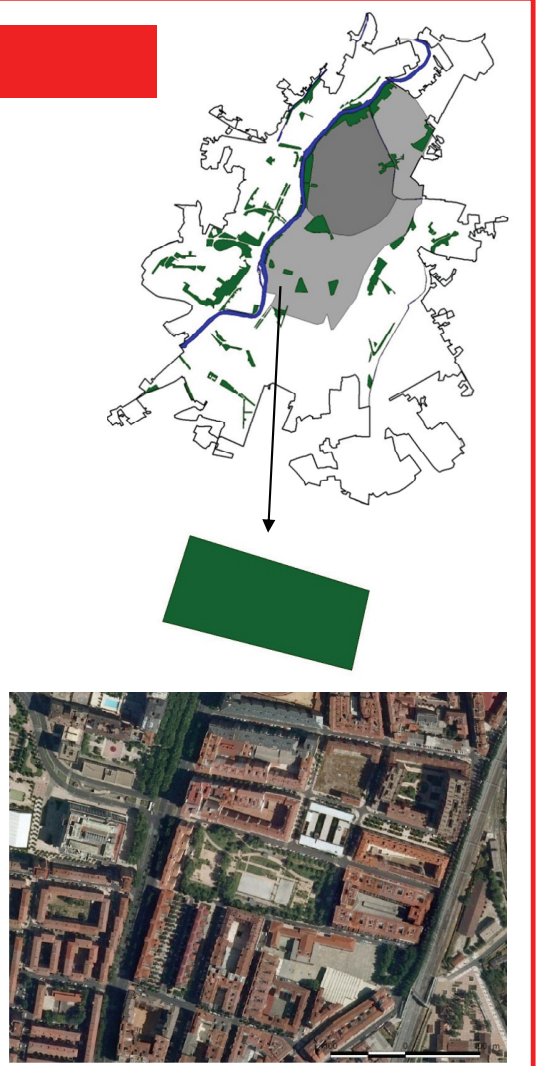

Fuente: IGN, 2008. 


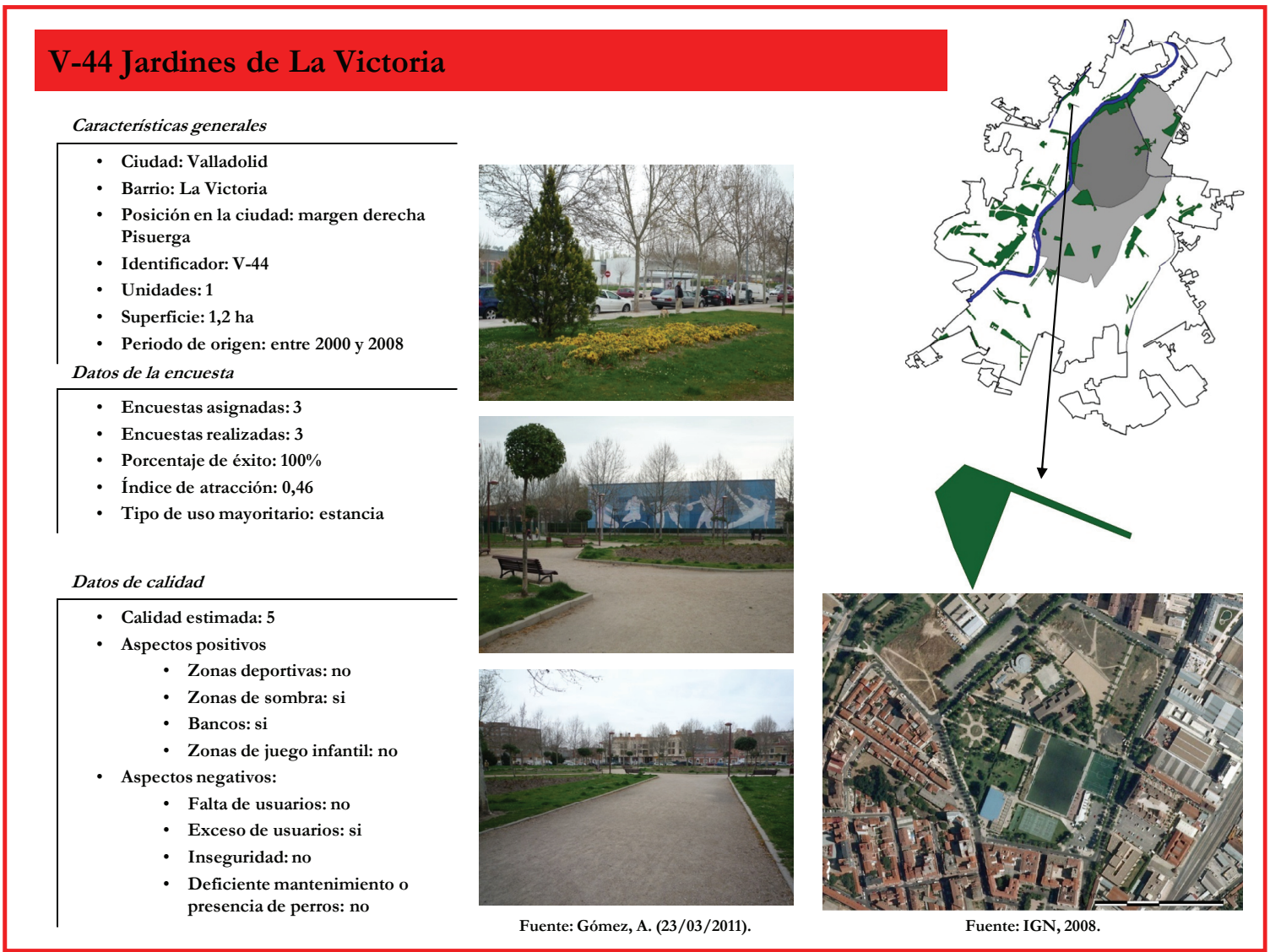

\section{V-45 Verde urbano Barrio de la Esperanza}

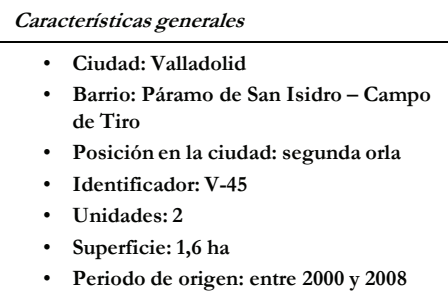
Datos de la encuesta

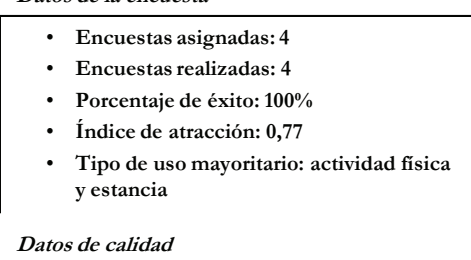

\footnotetext{
Datos de calidad
- Calidad estimada: 6,5

- Aspectos positivos

- Zonas deportivas: si

- Zonas de sombra: no

- Bancos: si

- Zonas de juego infantil: si

- Aspectos negativos:

- Falta de usuarios: no

- Exceso de usuarios: si

- Inseguridad: no

- Deficiente mantenimiento o presencia de perros: no
}
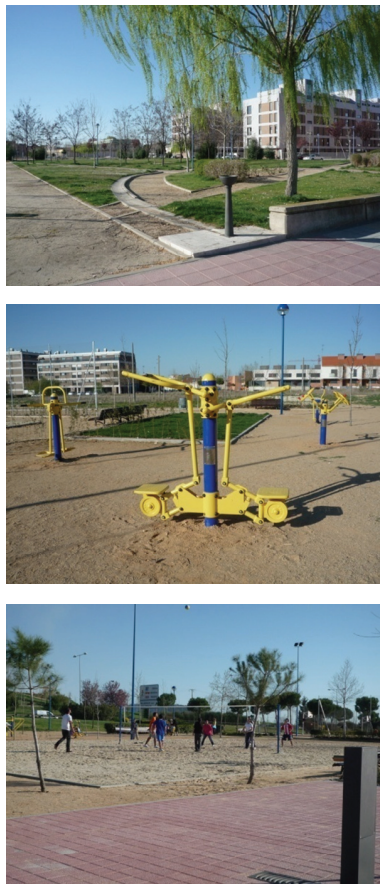

Fuente: Gómez, A. (01/04/2011).
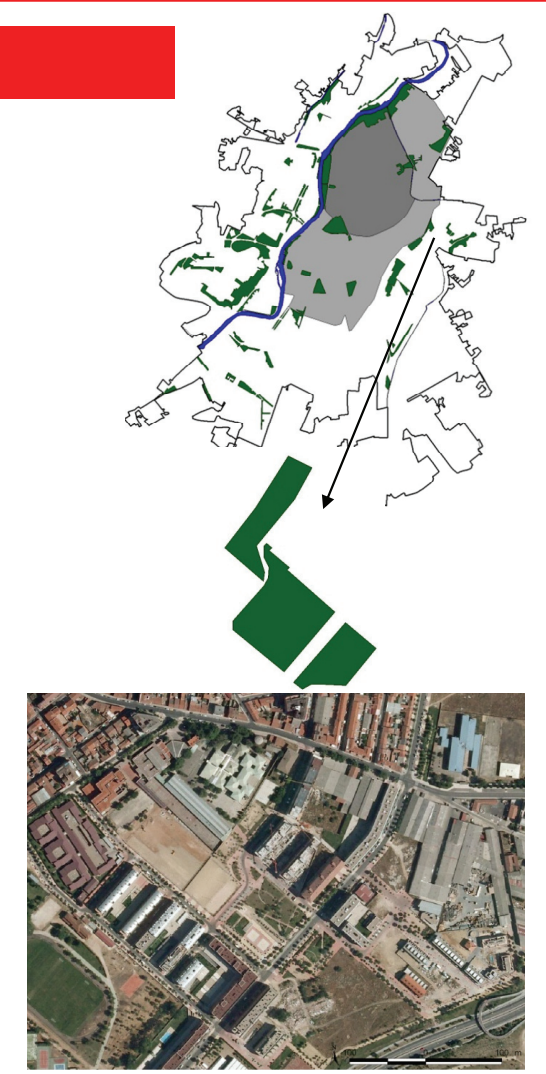

Fuente: IGN, 2008. 


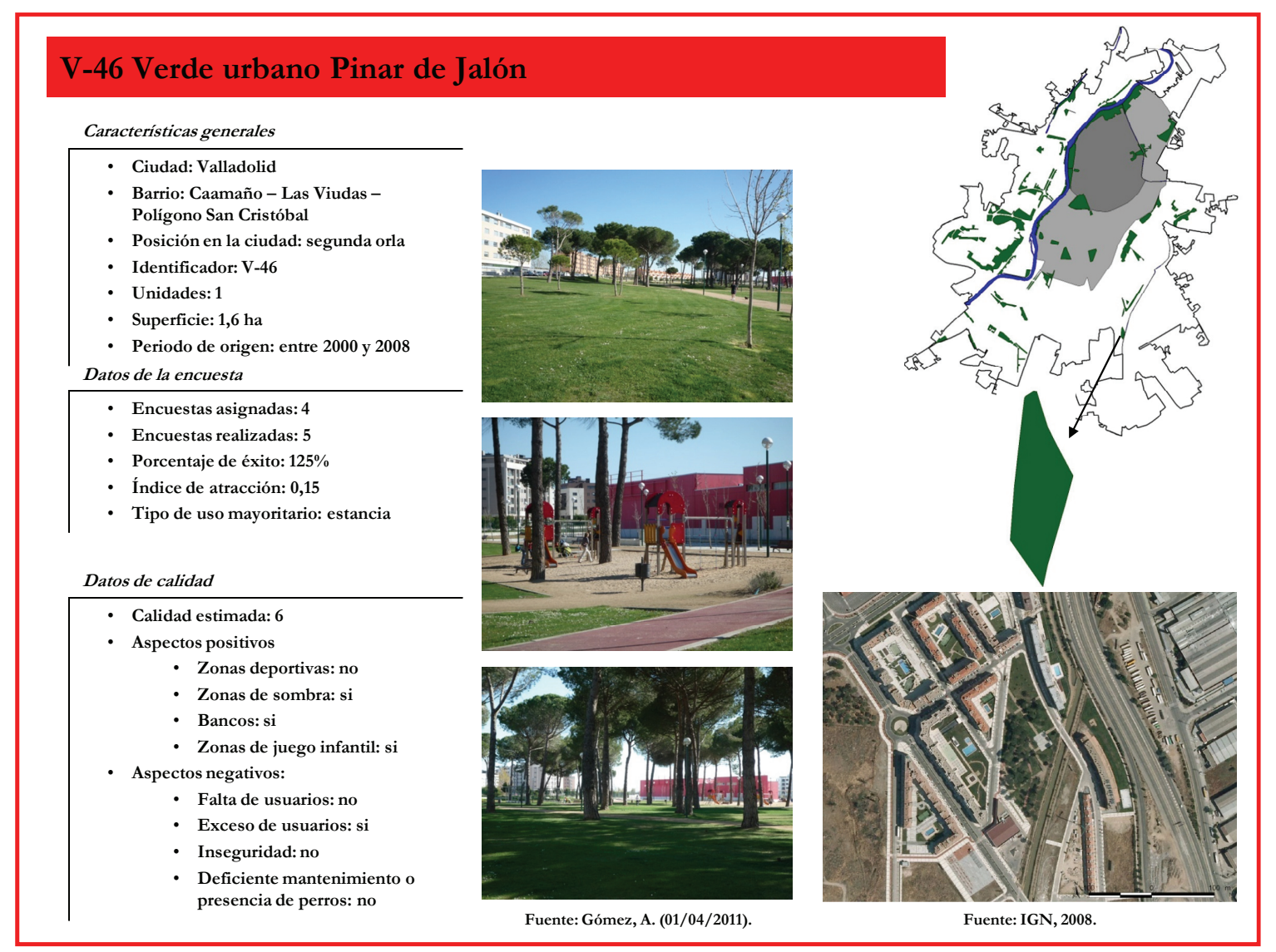

V-47 Verde urbano Calle de la Vega de Valdetronco - Villas Sur

\begin{tabular}{|l} 
Características generales \\
\hline - Ciudad: Valladolid \\
- Barrio: Las Villas - Cañada Puente \\
Duero - Covaresa - Parque Alameda - \\
Paula López \\
- Posición en la ciudad: segunda orla \\
- Identificador: V-47 \\
- Unidades: 2 \\
- Superficie: 1,5 ha \\
- Periodo de origen: entre 2000 y 2008 \\
Datos de la encuesta
\end{tabular}

- Encuestas asignadas: 4

- Encuestas realizadas: 4

- Porcentaje de éxito: $100 \%$

- Índice de atracción: 0,93

- Tipo de uso mayoritario: estancia

Datos de calidad

\begin{aligned} \hline Calidad estimada: 6 \\ - Aspectos positivos \\ $\cdot$ Zonas deportivas: no \\ - Zonas de sombra: si \\ - Zancos: si \\ - Aspectos negativos: \\ - Falta de usuarios: no \\ - Inseguridad: no \\ $\cdot$ Deficiente mantenimiento o \\ presencia de perros: no \end{aligned}
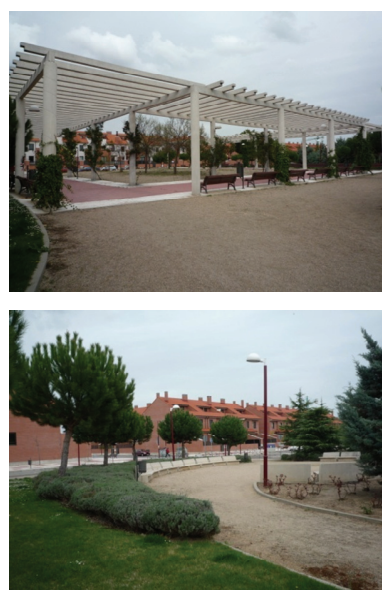

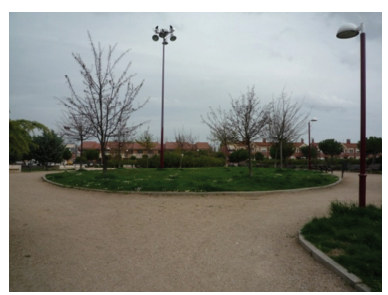

Fuente: Gómez, A. (01/04/2011).

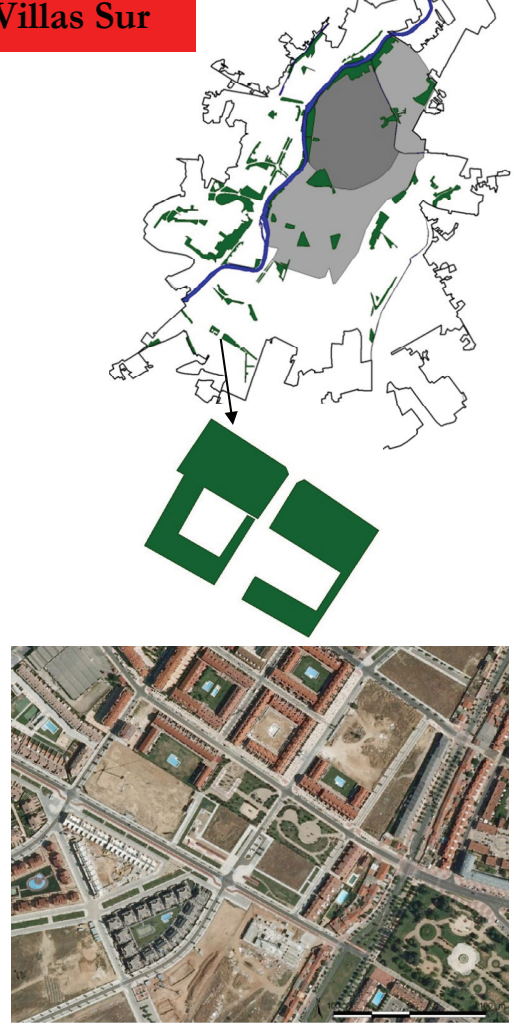

Fuente: IGN, 2008. 


\section{V-48 Verde urbano Escuela Deportiva Niara}

Características generales

- Ciudad: Valladolid

- Barrio: Las Villas - Cañada Puente Duero - Covaresa - Parque Alameda Paula López

- Posición en la ciudad: segunda orla

- Identificador: V-48

- Unidades: 2

- Superficie: 1,2 ha

- Periodo de origen: entre 1984 y 2000 Datos de la encuesta

- Encuestas asignadas: 3

- Encuestas realizadas: 3

- Porcentaje de éxito: $100 \%$

- Índice de atracción: 0,15

- Tipo de uso mayoritario: estancia

Datos de calidad

- Calidad estimada: 4,5

- Aspectos positivos

- Zonas deportivas: no

- Zonas de sombra: no

- Bancos: si

- Zonas de juego infantil: no

- Aspectos negativos:

- Falta de usuarios: no

- Exceso de usuarios: si

- Inseguridad: no

- Deficiente mantenimiento o presencia de perros: no
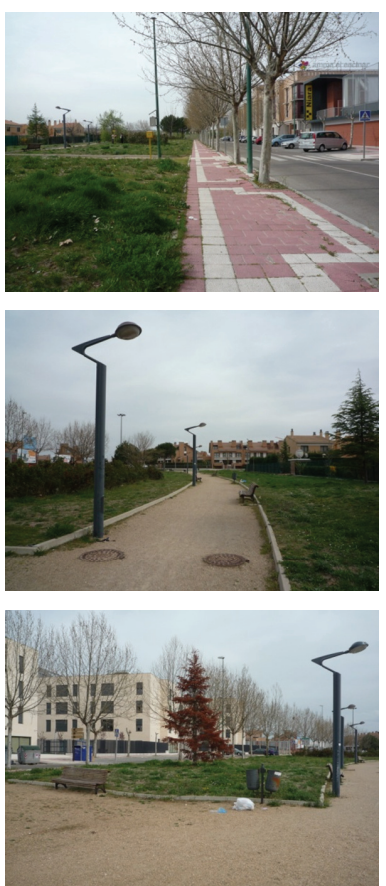

Fuente: Gómez, A. (01/04/2011).

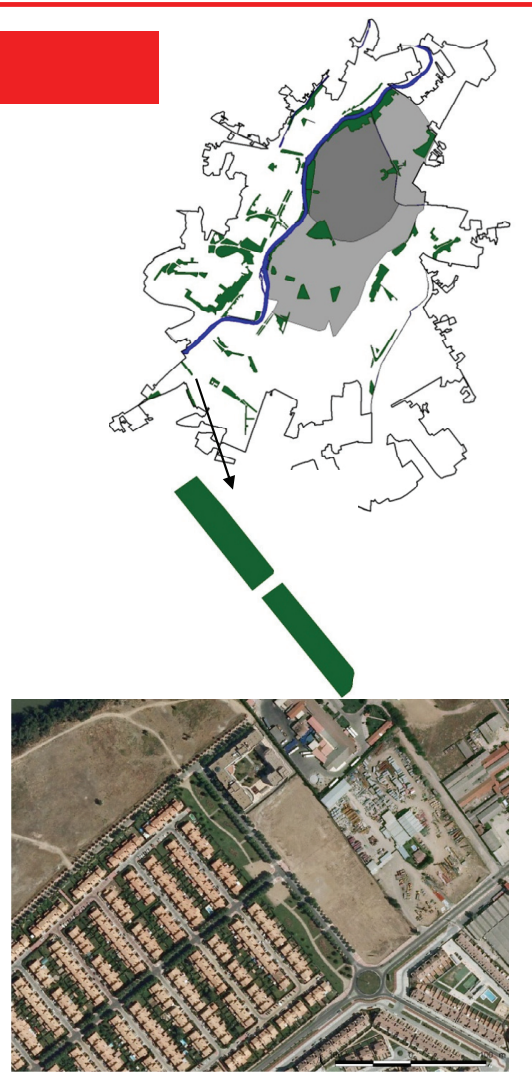

Fuente: IGN, 2008.

\section{V-49 Verde urbano Calle Alcaparra}

Características generales

- Ciudad: Valladolid

- Barrio: Las Villas - Cañada Puente

Duero - Covaresa - Parque Alameda Paula López

- Posición en la ciudad: segunda orla

- Identificador: V-49

- Unidades: 2

- Superficie: 1,8 ha

- Periodo de origen: entre 2000 y 2008 Datos de la encuesta

- Encuestas asignadas: 5

- Encuestas realizadas: 5

- Porcentaje de éxito: $100 \%$

- Índice de atracción: 0

- Tipo de uso mayoritario: estancia

Datos de calidad

- Calidad estimada: 6,5

- Aspectos positivos

- Zonas deportivas: no

- Zonas de sombra: no

- Bancos: si

- Zonas de juego infantil: si

- Aspectos negativos:

- Falta de usuarios: no

- Exceso de usuarios: no

- Inseguridad: no

- Deficiente mantenimiento o presencia de perros: no
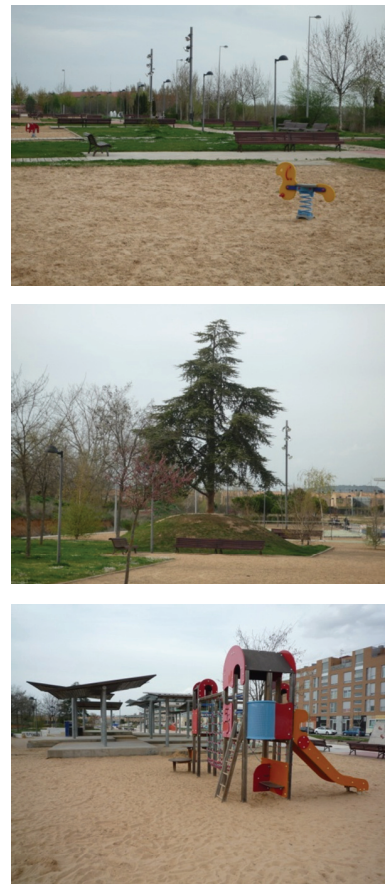

Fuente: Gómez, A. (01/04/2011).
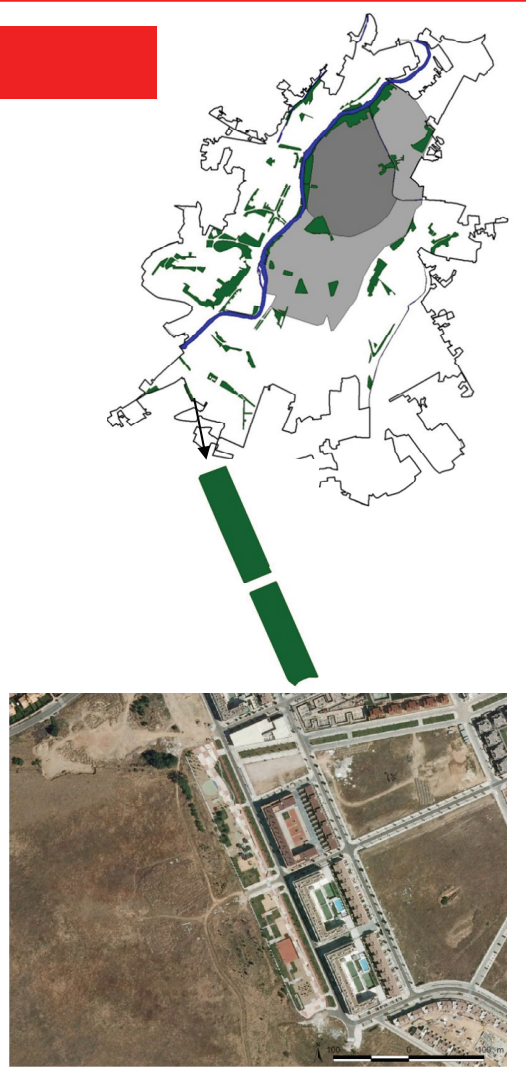

Fuente: IGN, 2008. 

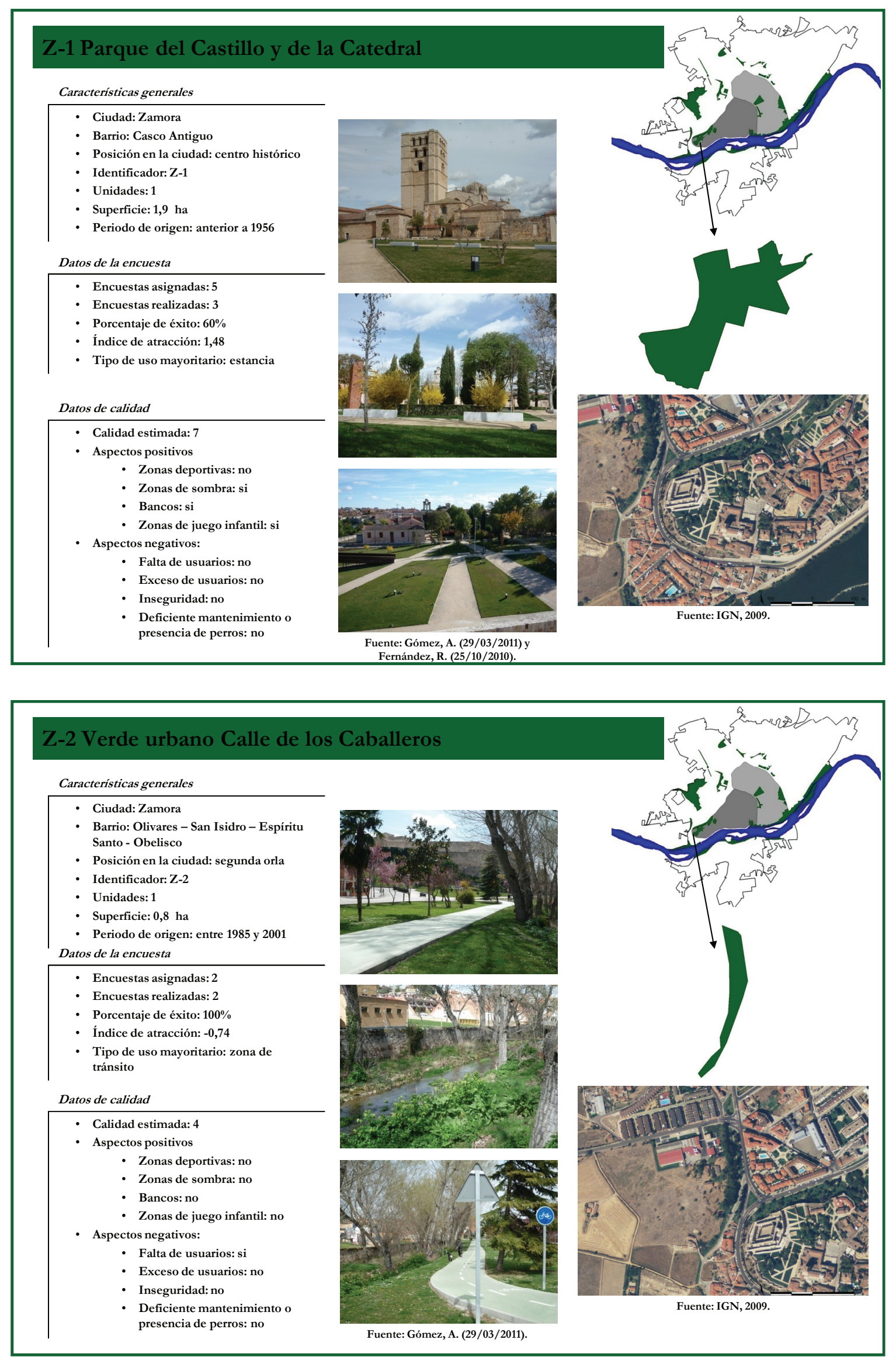

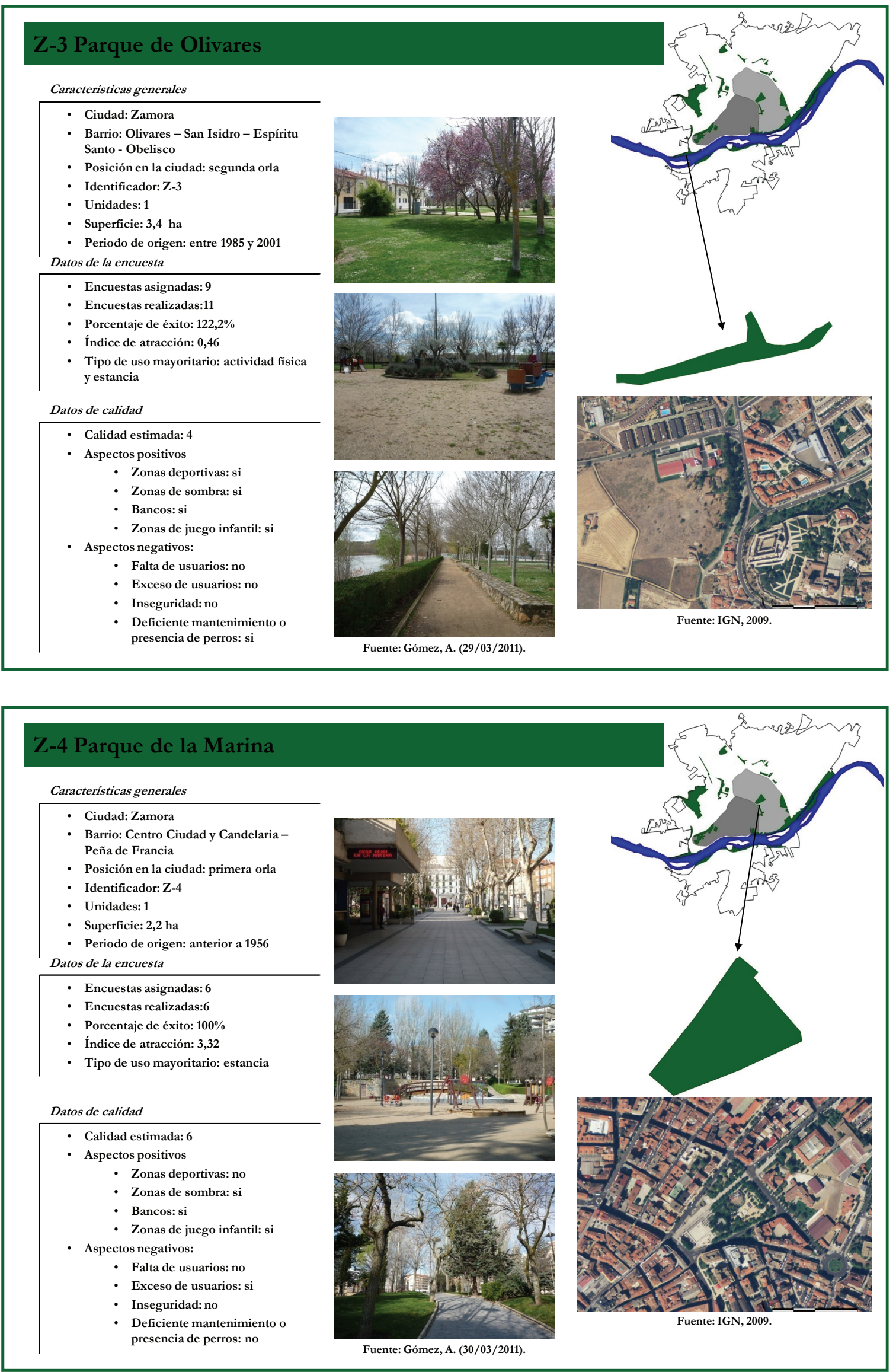

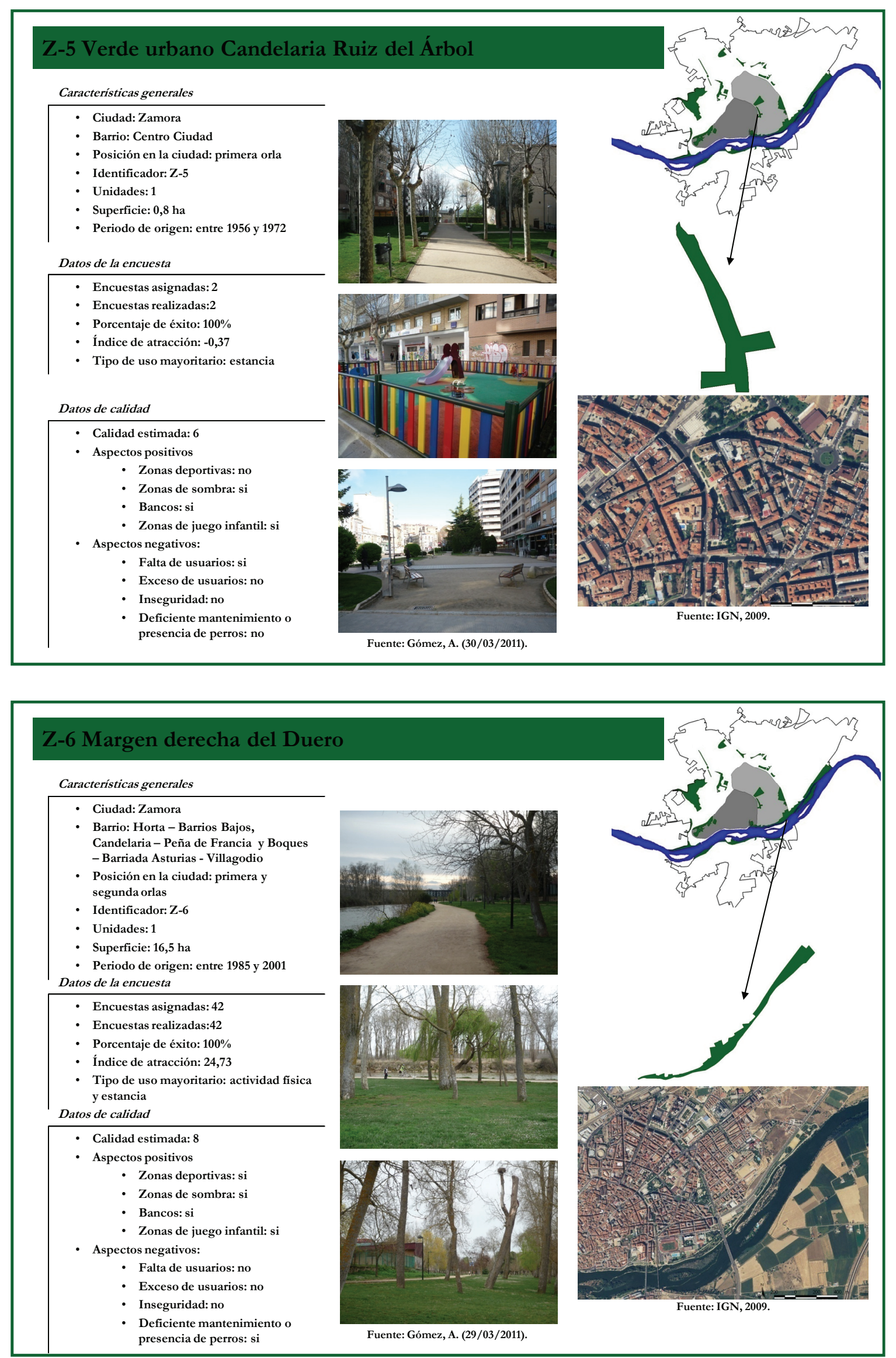

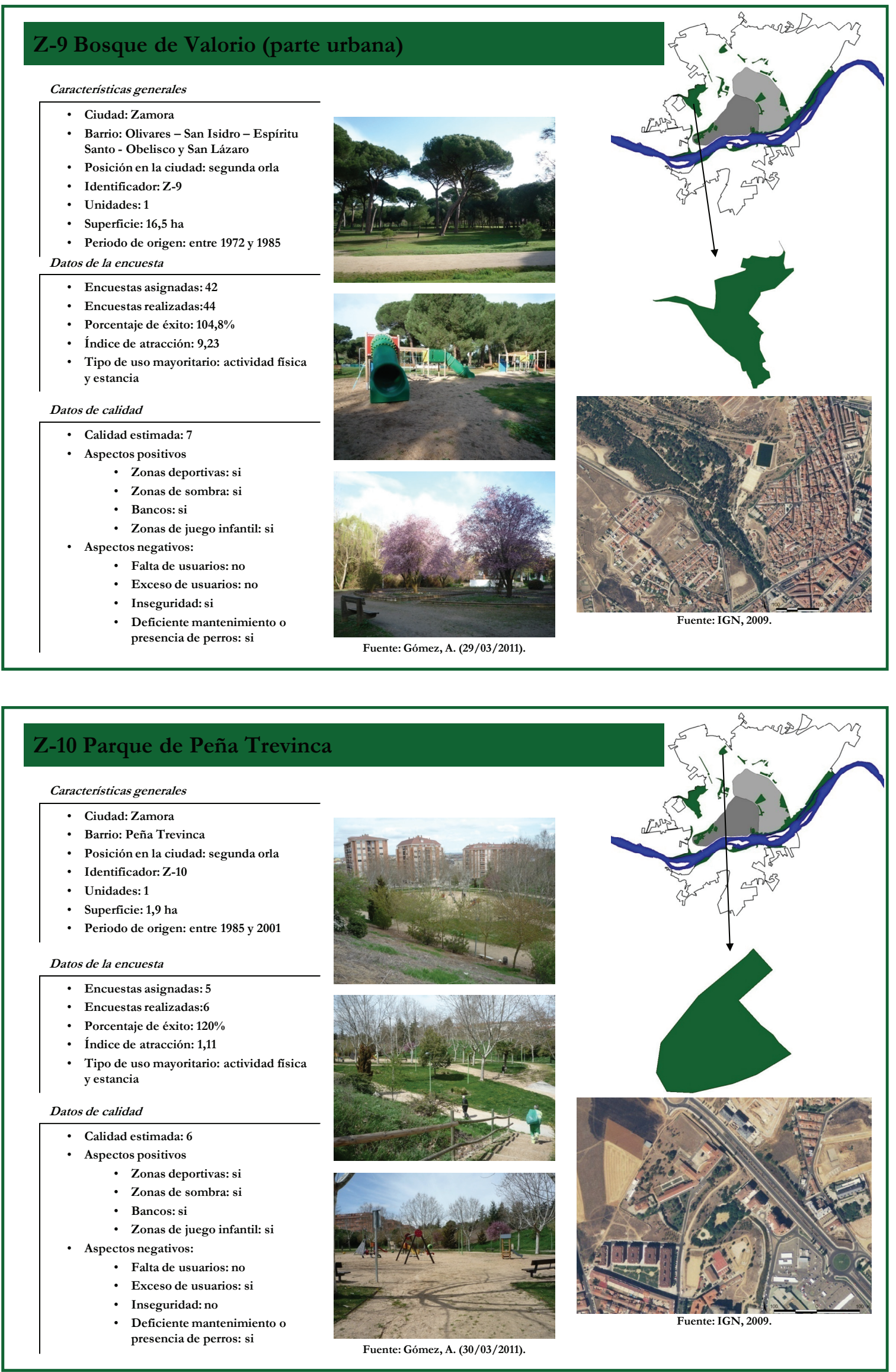

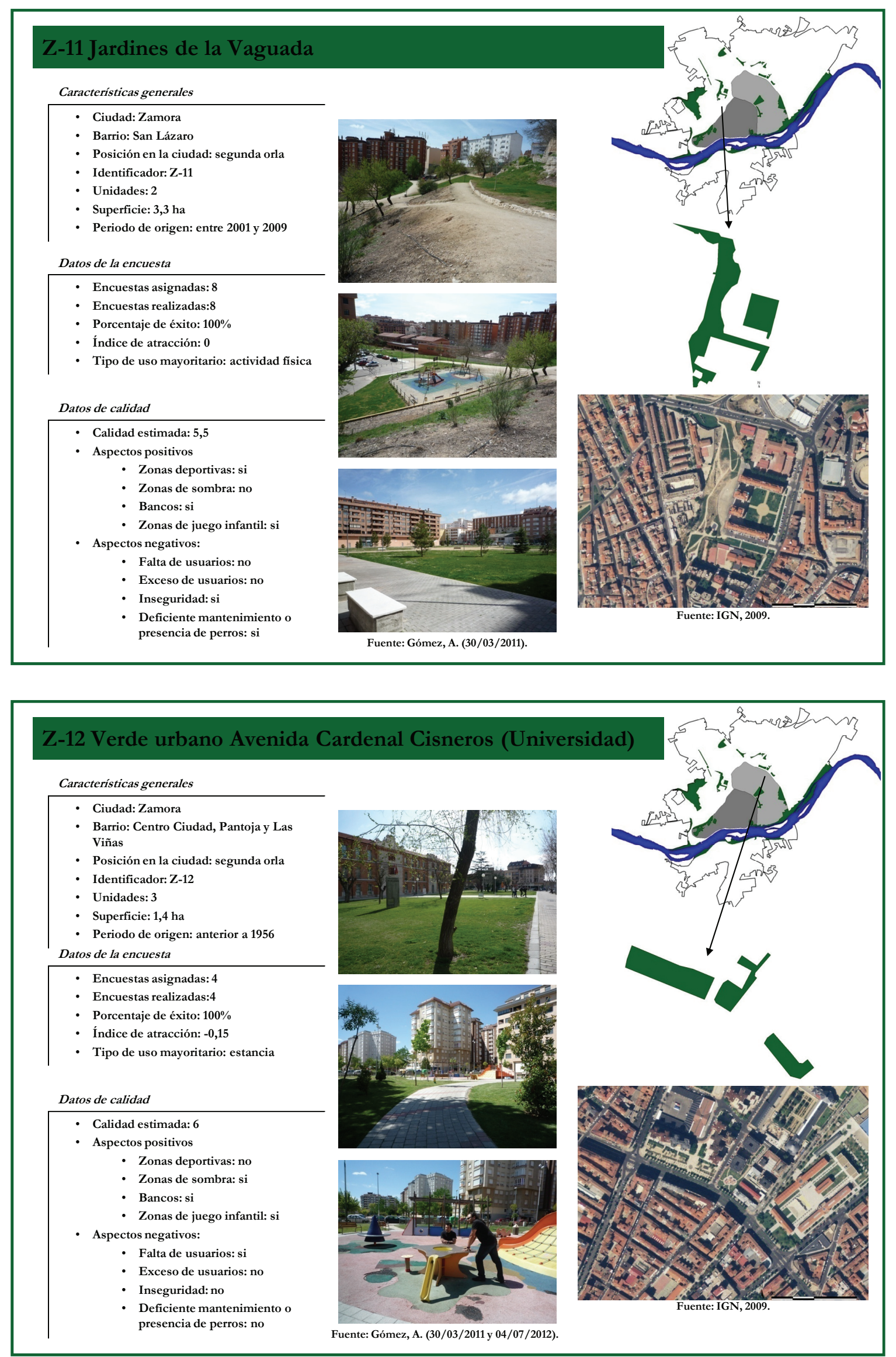

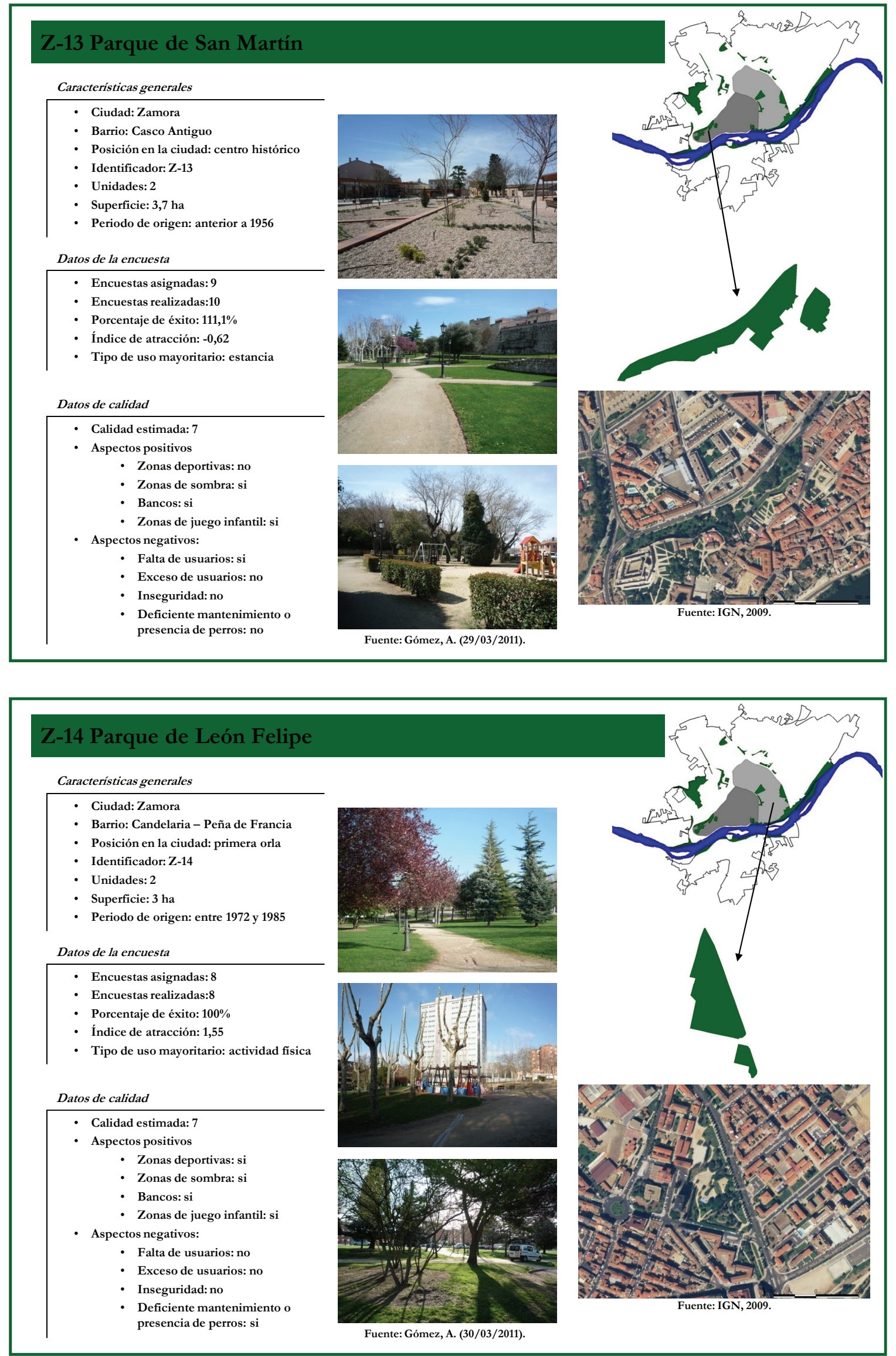

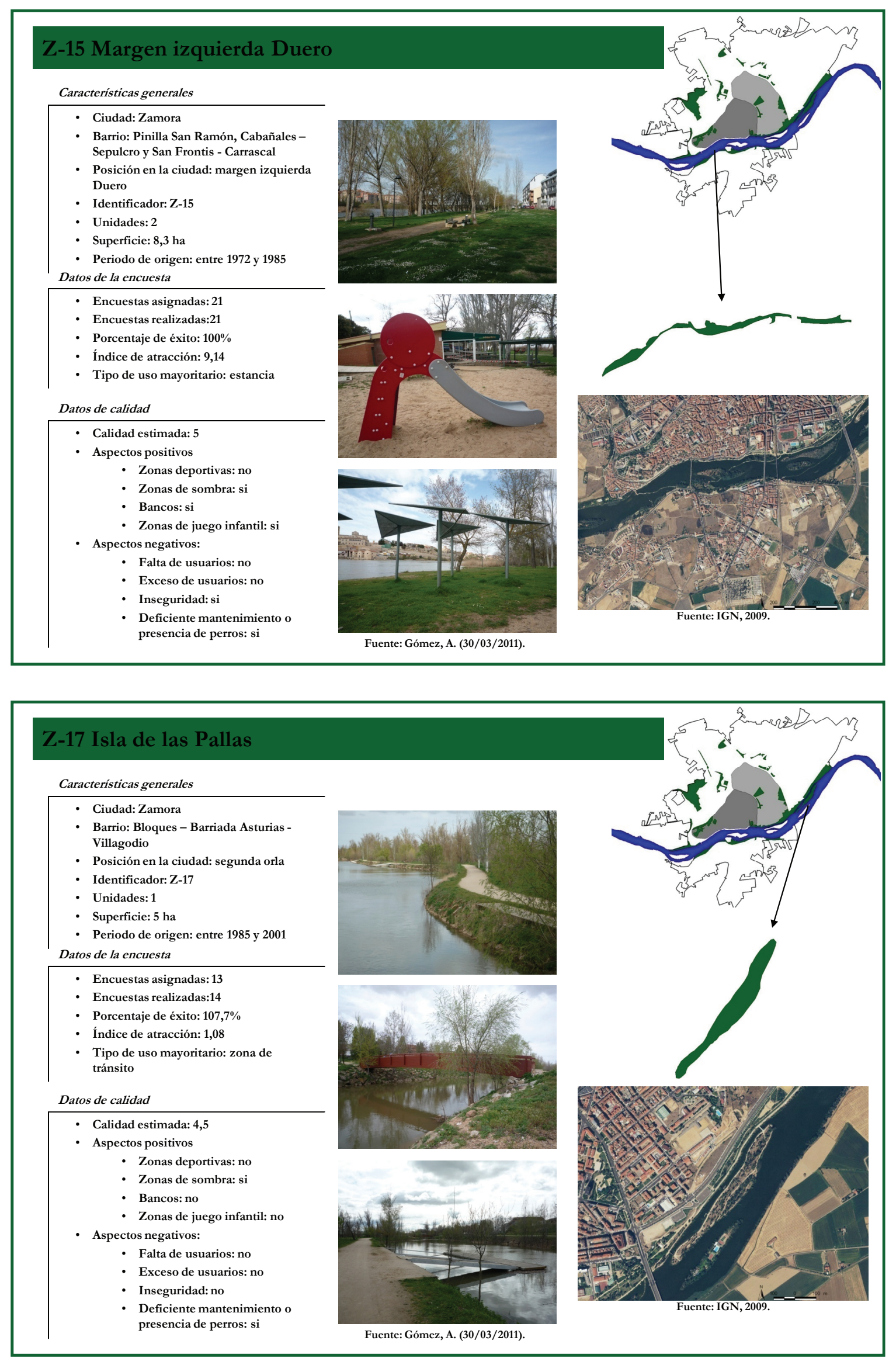

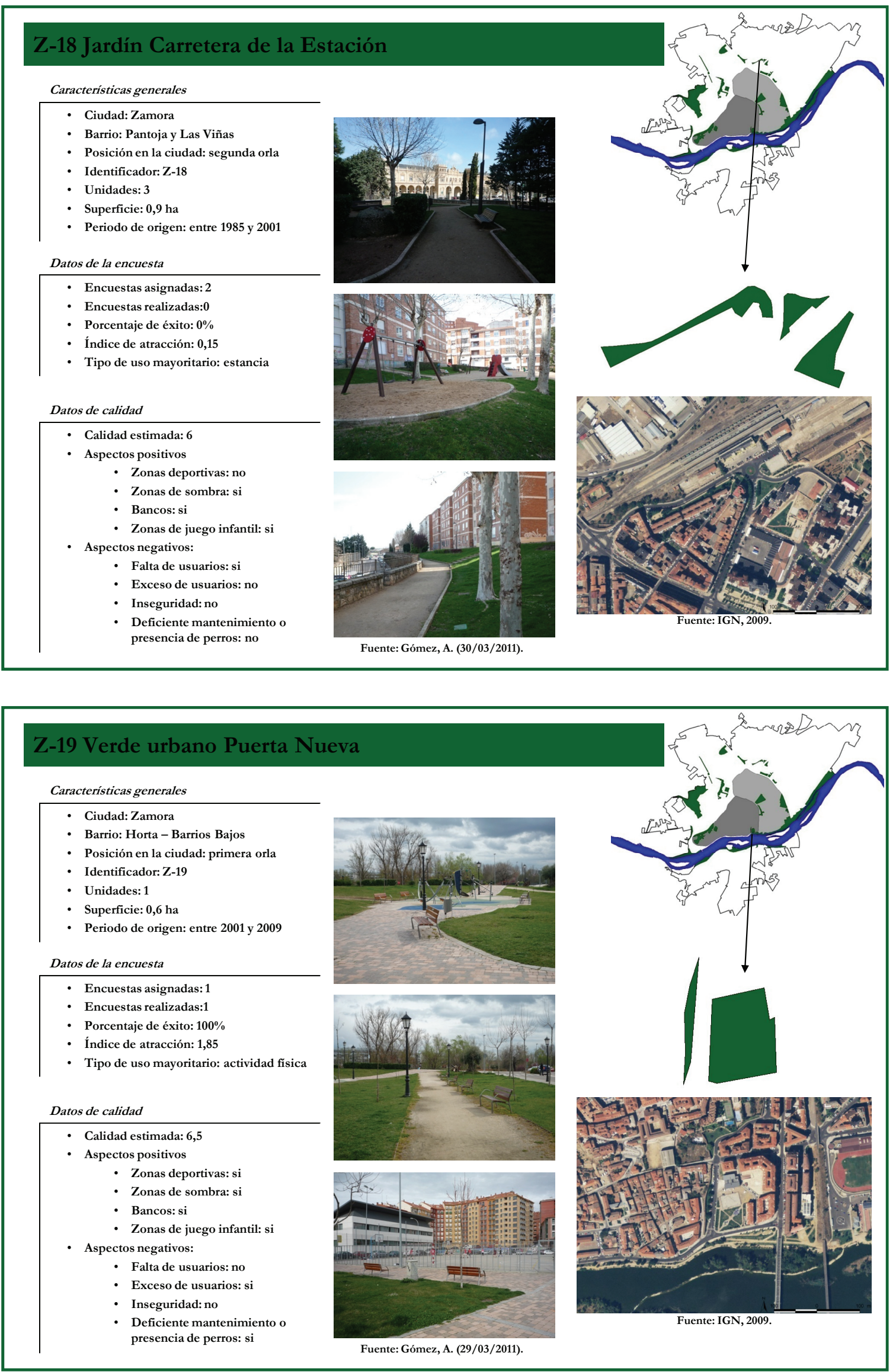

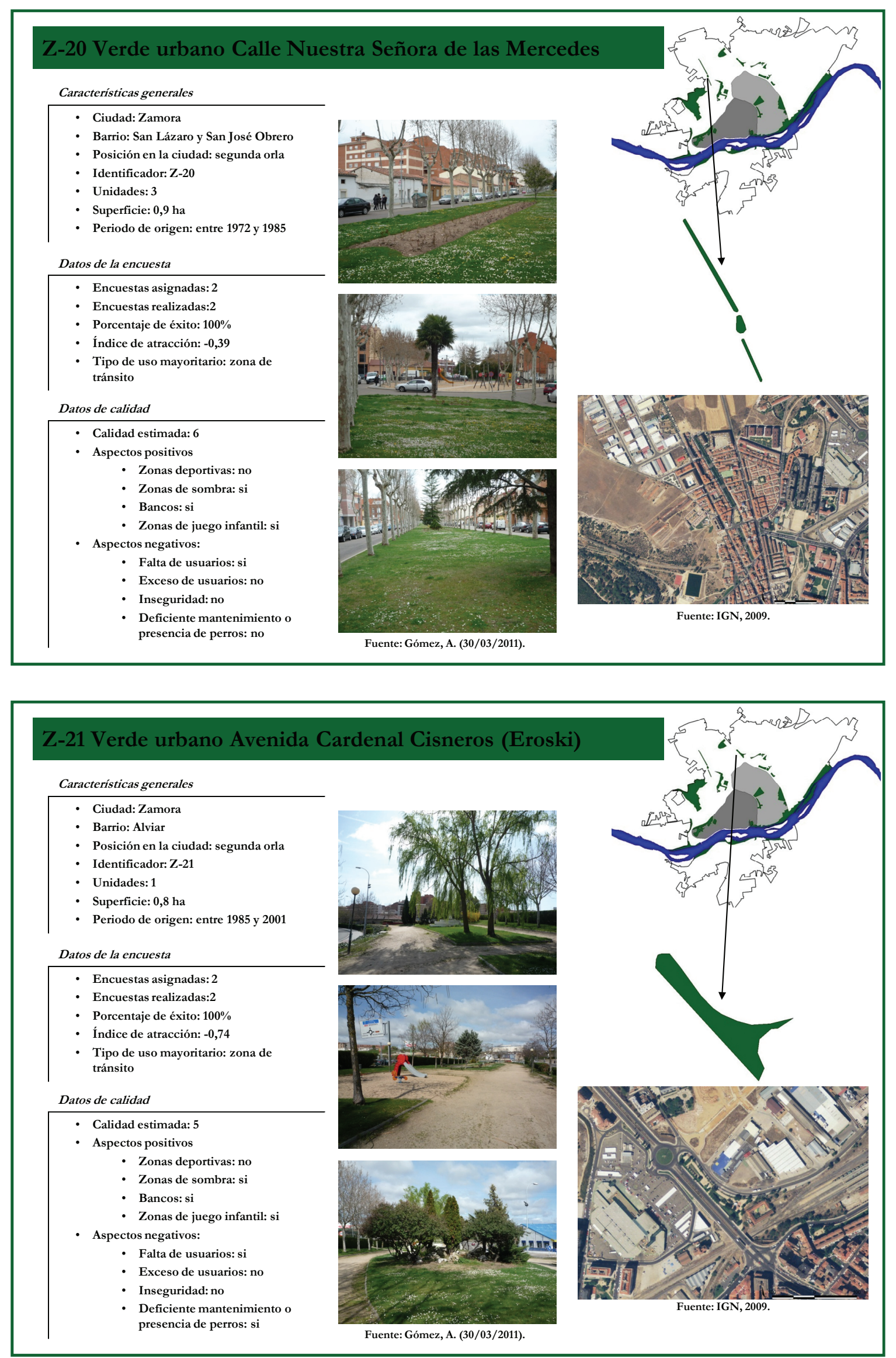